\title{
DISCLAIMER
}

\begin{abstract}
This repert was prepared as an account of work sponsored by an agency of the United States Government. Neither the United States Government nor any agency thereof, nor any of their employees, makes any warranty, express or implied, or assumes any legal liability or responsibility for the accuracy, completeness, or usefulness of any information, apparatus, product, or process disclosed, or represents that its use would not infringe privately owned rights. Reference herein to any specific commercial product, process, or service by trade name, trademark, manufacturer, or otherwise does not necessarily constitute or imply its endorsement, recommendation, or favoring by the United States Government or any agency thereof. The views and opinions of authors expressed herein do not necessarily state or reflect those of the United States Government or any agency thereof.
\end{abstract}

\section{ADIRONDACK LAKES SURVEY: \\ AN INTERPRETIVE ANALYSIS OF FISH COMMUNITIES AND WATER CHEMISTRY, 1984-87}

Project Coordinators

Joan P. Baker

Steven A. Gherini

Tetra Tech, Inc.

with

Sigurd W. Christensen

Oak Ridge National Laboratory

Charles T. Driscoll

Syracuse University

James Gallagher

Adirondack Lakes Survey Corporation
Ronald K. Munson

Tetra Tech, Inc.

Robert M. Newton

Smith College

Kenneth H. Reckhow

Duke University

Cari L. Schofield

Cornell University

A publication of Adirondack Lakes Survey Corporation " 


\section{LEGAL NOTICE}

This report was prepared by a team of experts identified on the title page as an account of work sponsored by the Adirondack Lakes Survey Corporation (ALSC). The report is an independent interpretation of data previously collected by the ALSC. The authors identified with each section support the scientific conclusions of that section. Overall, report coauthors make no such representation for sections of the report not specifically attributed to them. Neither ALSC, members of ALSC, nor any person acting on behalf of either

- makes any warranty or representation, express or implied, with respect to the accuracy, completeness, or usefulness of the information contained in this report, or that the use of any information, apparatus, method, or process disclosed in this report may not infringe upon privately owned rights; or

- assumes any liability with respect to the use of, or for damages resulting from the use of, any information, apparatus, method, or process disclosed in this report

It is anticipated that this evaluation of the ALSC data will lead to a thorough scientific evaluation of the analyses and conclusions proposed by individual authors.

\section{USE AND CITATION}

This report is a compilation of contributions from several authors. Please cite specific sections of this report with credit to the appropriate authors. If citing the entire report, either Baker, J.P., et al. or the fi"

Gallagher, J., and J. Baker. 1990. Current status of fish cornmunities in Adirondack Lakes. Pages 3-11 to 3-48. In: Adirondack Lakes Survey: An Interpretive Analysis of Fish Communities and Water Chemistry, 1984-87. Adirondack Lakes Survey Corporation, Ray Brook, NY.

\section{ORDERING INFORMATION}

Copies of Adirondack Lakes Survey: An Interpretive Analysis of Fish Communities and Water Chemistry, 1984.87, are avaitable from the Adirondack Lakes Survey Corporation, clo the New York State Department of Environmental Conservation, Ray Brook, NY 12977. 


\section{ADIRONDACK LAKES SURVEY CORPORATION}

\section{Board of Directors}

Thomas C. Jorling, Chairman

Paul j. Torpey

Carl D. Hobelman, Esq.
Commissioner, NYSDEC

Executive Director, ESEERCO

LeBoeuf, Lamb, Leiby \& MacRae

\section{Management Committee}

John M. Toennies (Chairman)

John G. Holsapple

William L. Kirk

Gerald Barnhart

Bruce D. Shupp

Italo G. Carcich

James R. Colquhoun
Manager, Environrnental Affairs and Engineering Technical Services, Niagara Mohowk Power Corp.

Administrator, Water Quality Programs ESEERCO

Director, Biological Studies and Evaluation, Consolidated Edison Company of New York, Inc.

Assistant Director, Division of Fish and Wildlife, NYSDEC

Chief, Bureau of Fisheries, NYSDEC

Chief, Bureau of Technical Services \& Research, NYSDEC

Chief, Bureau of Environmental Protection, NYSDEC
ALSC
= Adirondack Lakes Survey Corporation
NYSDEC $=$ New York State Department of Environmental Conservation
ESEERCO = Empire State Electric Energy Research Corporation 


\section{ACKNOWLEDGMENTS}

The authors of this report are deeply indebted to John Holsapple of the Empire State Electric Energy Research Corporation and Walter Kretser of the New York State Department of Environmental Conservation for their long-standing support and guidance as they developed and directed the research plan that made this report possible.

Besides the principal authors listed on the title page, the following individuals contributed significantly to this report: Dr. John J. Beauchamp, Engineering Physics and Mathematics Division, Oak Ridge National Laboratory; Jan M. Coe and Jean A. Shaakir-Ali, Computing and Telecommunications Division, Martin Marietta Energy Systems, Inc; Jill W. Newton, Smith College; Dr. Eric P. Smith, Virginia Polytechnic Iristitute and State University, and Dr. William Warren-Hicks, Kilkelly Environmental Associates.

The authors wish to thank Kilkelly Environmental Associates for producing this document. We especially thank Blanche Everett Brown and Debra Stare for their capable handling of the word processing and editors Lynn Moore and Susan Taylor for their efforts in making our individual manuscripts into a publishable document.

Oak Ridge National Laboratory's participation in this research was sponsored in part by the Adirondack Lakes Survey Corporation under contract ERD-88-778 with the U.S. Department of Energy, and in part by the U.S. Environmental Protection Agency (EPA) as a part of the National Acid Precipitation Assessment Program under Interagency Agreement DOE No. 1824-1808-A 1 (EPA No. DW89932112-01) with the U.S. Department of Energy, under contract No. DE-AC05-84OR21400 with Martin Marietta Energy Systems, Inc. Although is part of the research described in this report has been funded by the EPA, it has not been subjected to EPA review and therefore does not necessarily reflect the views of EPA, and no official endorsement should be inferred. This is Publication No. 3494, Environmental Siciences Division, Oak Ridge National Laboratory. 


\section{ACRONYMS}

$\begin{array}{ll}\text { ALSC } & \text { Adirondack Lakes Survey Corporation } \\ \text { ALTM } & \text { Adirondack Long-Term Monitoring Project } \\ \text { ANC } & \text { Acid neutralizing capacity } \\ \text { BP } & \text { Before present } \\ \text { CI } & \text { Condition index } \\ \text { CPUE } & \text { Catch per unit effort } \\ \text { DDRP } & \text { DirectDelayed Response Project } \\ \text { ELS-I } & \text { Eastern Lake Survey-Phase 1 } \\ \text { EPA } & \text { Environmental Protection Agency } \\ \text { EPRI } & \text { Electric Power Research Institute } \\ \text { ESEERCO } & \text { Empire State Eleriric Energy Research Corporation } \\ \text { FIN } & \text { Fish Information Network } \\ \text { ILWAS } & \text { Integrated Lake-Watershed Acidification Study } \\ \text { IML } & \text { Interactive Matrix Language } \\ \text { NADP } & \text { National Acid Deposition Program } \\ \text { NSA } & \text { Natural spawning adequate } \\ \text { NSWS } & \text { National Surface Water Survey } \\ \text { NYSDEC } & \text { New York State Department of Environmental Conservation } \\ \text { QA/QC } & \text { Quality assurance/quality control } \\ \text { RILWAS } & \text { Regional Integrated Lake-Watershed Acidification Study } \\ \text { SAS } & \text { Statistical Analysis System } \\ \text { UAPSF } & \text { Utilities Acid Precipitation Sampling Program } \\ \text { USGS } & \text { U.S. Geological Survey } \\ \text { VP } & \text { Variance-decomposition proportion } \\ \text { YOY } & \text { Young-of-the-year } \\ \end{array}$




\begin{tabular}{|c|c|c|c|}
\hline$A^{-}$ & Organic or weak acid anion & $\mathrm{OH}$ & Hydroxide \\
\hline Al & Aluminum & $\mathbf{P}$ & Phosphorus \\
\hline$A l_{d}$ & Dissolved aluminum & $\mathrm{P}_{\mathrm{CO}_{2}}$ & Partial pressure of carbon dioxide \\
\hline$A l_{i}$ & Inorganic aluminum & $\mathrm{Pb}$ & Lead \\
\hline$A I_{m}$ & Monomeric aluminum & pK & $\log$ of 1/equilibrium constant for a \\
\hline$A I_{0}$ & Organic aluminum & & specified reaction \\
\hline$\left.A\right|_{p}$ & Particulate aluminum & $\mathbf{S}_{\mathrm{o}}$ & Organic ligand-supported free $\mathrm{H}^{+}$ \\
\hline$A I_{t}$ & Total aluminum & $\mathrm{Si}$ & Silicon \\
\hline C & Carbon & $\mathrm{SiO}_{2}$ & Silica \\
\hline $\mathrm{Ca}$ & Calcium & $\mathrm{SO}_{4}{ }^{2}$ & Sulfate \\
\hline$C_{A}$ & Mineral acid anions & $\mathrm{Zn}$ & Zinc \\
\hline$C_{B}$ & Base cations & & \\
\hline $\mathrm{CaCO}_{3}$ & Calcium carbonate & & \\
\hline $\mathrm{Cl}$ & Chloride & & \\
\hline $\mathrm{CO}_{2}$ & Carbon dioxide & & \\
\hline $\mathrm{Cu}$ & Copper & & \\
\hline DIC & Dissolved inorganic carbon & & \\
\hline DO & Dissolved oxygen & & \\
\hline DOC & Dissolved organic carbon & & \\
\hline $\mathbf{F}$ & Fluoride & & \\
\hline $\mathrm{Fe}$ & iron & & \\
\hline $\mathrm{H}^{+}$ & Hydrogen ion & & \\
\hline HA & Weak acid & & \\
\hline $\mathrm{HCl}$ & Hydrochloric acid & & \\
\hline $\mathrm{HCO}_{3}$ & Bicarbonate & & \\
\hline $\mathrm{HNO}_{3}$ & Nitric acid & & \\
\hline $\mathrm{H}_{2} \mathrm{SO}_{4}$ & Sulfuric acid & & \\
\hline $\mathbf{K}$ & Potassium & & \\
\hline $\mathbf{M g}$ & Magnesium & & \\
\hline MN & Manganese & & \\
\hline $\mathbf{N}$ & Nitrogen & & \\
\hline $\mathrm{Na}$ & Sodium & & \\
\hline $\mathrm{NH}_{4}$ & Ammonium & & \\
\hline $\mathrm{NO}_{3}$ & Nitrate & & \\
\hline $\mathrm{O}_{2}$ & Oxygen & & \\
\hline
\end{tabular}




\section{CONTENTS}

\author{
List of Acronyms \\ List of Chemicals \\ List of Figures \\ List of Tables
}

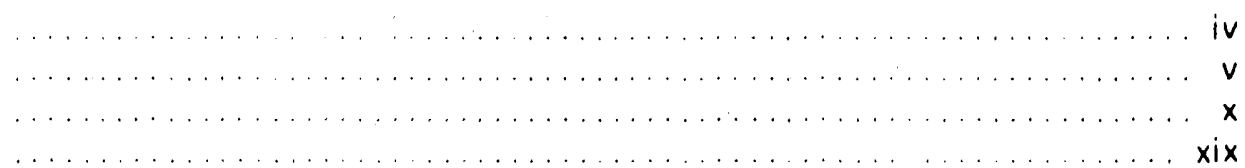

EXECUTIVE SUMMARY SURFACE WATER CHEMISTRY

FISH COMMUNITIES

ES-1

ES-3

ES-6

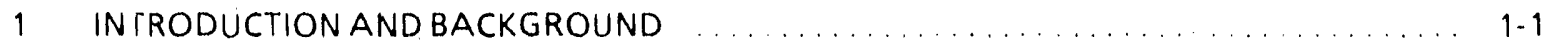

References

2 EVALUATION OF THE CHEMISTRY OF ALSC LAKES

2.1 INTRODUCTION

$2-1$

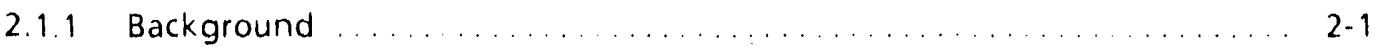

2.1 .2 Objectives and Approach ............................. 2-1

2.1 .3 Past Synoptic Surveys . . . . . . . . . . . . . . . . . . . . . . . 2. 2-2

2.1 .4 Adirondack Lakes Survey .......................... $2-5$

2.1.5 Comparison of ELS and ALSC Data Bases .................... 2-13

2.2 ADIRONDACKREGION .... .............................. 2.18

2.2 .1 Geology of the Adirondacks ............................ 2-18

2.2.2 Climate and Regional Precipitation Pattern ................ 2-22

2.2 .3 Land Use ........................................... $2-23$

2.2 .4 Major Drainage Basins ................................ 2-24

2.3 PHENOMENOLOGICAL ANALYSIS OF ALSC CHEMISTRY DATA $\ldots \ldots \ldots \ldots \ldots$
2.27

2.3.1 Mineral Acid-Base System ............................ 2-27

2.3 .2 Deposition .......................................... 2.52

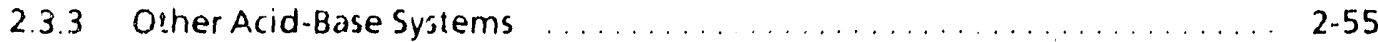

2.3.4 Summary ...................................... 2-68

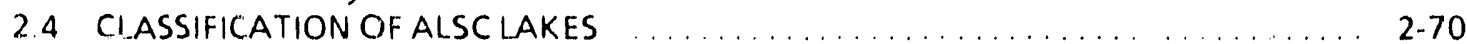

2.4.1 Physical Characteristics of the Lakes ....................... 2-70

2.4.2 Chemical Characteristics of the Lakes ..................... 2-72

2.4 .3 Flowpaths .................................... 2-74

2.4.4 Lake Classification Theory ........................... 2-76

2.4.5 Classification Based un Chemical Characterisics ............... 2-78

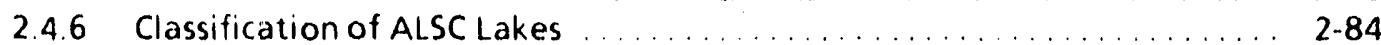

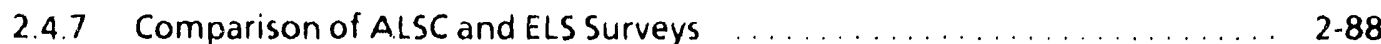

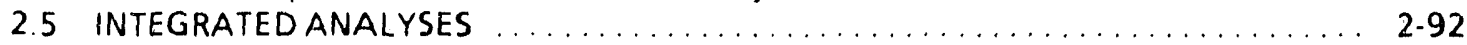

2.5.1 Support of Hydrogen lons in ALSC Waters ................... 2-92

2.5.2 Sensitivity Analyses ................................ 2-96

2.5.3 Influence of Organic Anions of Gran ANC ............... 2-102

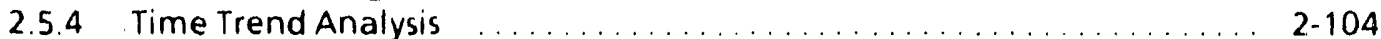

2.5.5 Summary ..................................... 2-109

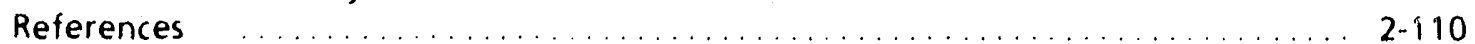




\section{CONTENTS}

FISH COMMUNITIES IN ADIRONDACK LAKES

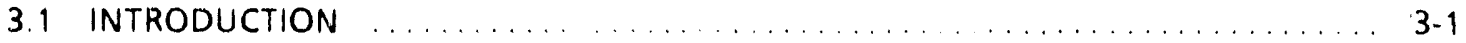

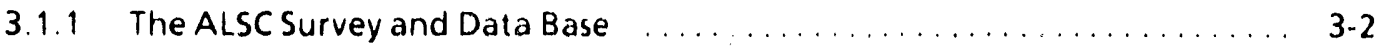

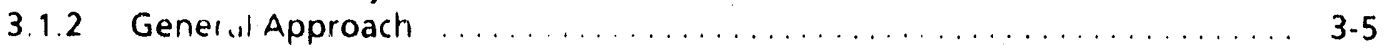

3.1.3 Factors Influencing Fish Habitat Suitability $\ldots \ldots \ldots \ldots \ldots \ldots \ldots \ldots \ldots \ldots$

3.2 CURRENT STATUS OF FISH COMMUNITIES IN ADIRONDACK LAKES $\ldots \ldots \ldots \ldots$

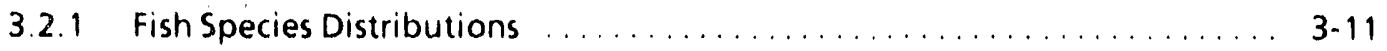

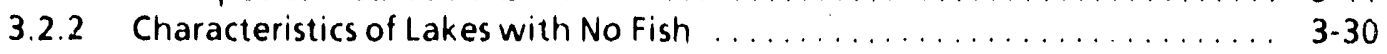

3.3 HABITAT SUITABILITY FOR BROOK TROUT NATURAL

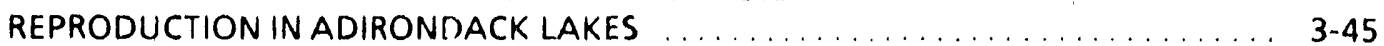

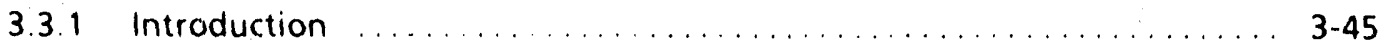

3.3.2 Methods ................................. 3-46

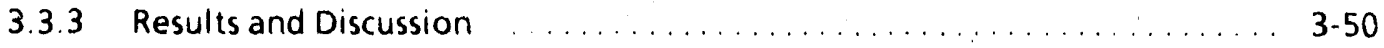

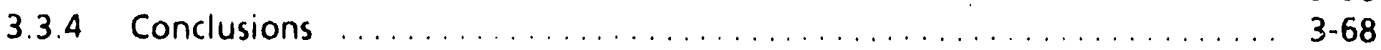

3.4 PATTERNS OF FISH SPECIES DISTRIBUTION IN RELATION

TO LAKENWATERSHED CHARACTERISTICS $\ldots \ldots \ldots \ldots \ldots \ldots \ldots \ldots \ldots \ldots \ldots$

3.5 FISH SPECIES D!STRIBUTION PATTERNS IN SELECTED

ADIRONDACK DRAINAGE SYSTEMS $\ldots \ldots \ldots \ldots \ldots \ldots \ldots \ldots \ldots \ldots \ldots \ldots \ldots$

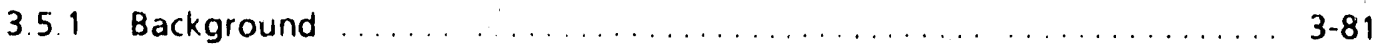

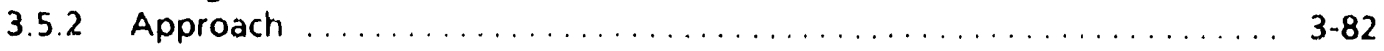

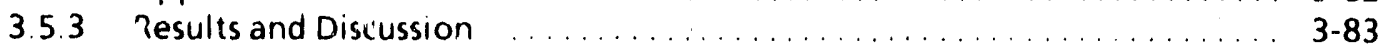

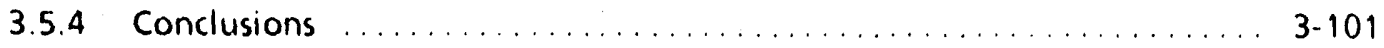

3.6 HISTORICAL CHANGES IN FISH COMMUNITIES IN
ADIRONDACK LAKES $\ldots \ldots \ldots \ldots \ldots \ldots \ldots \ldots \ldots \ldots \ldots \ldots \ldots \ldots \ldots \ldots \ldots \ldots \ldots$

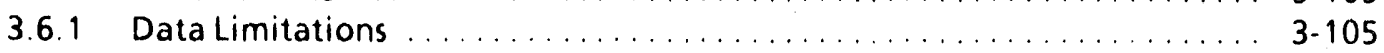

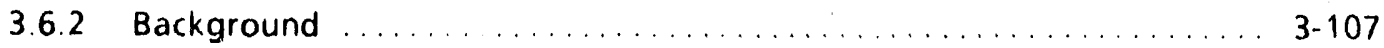

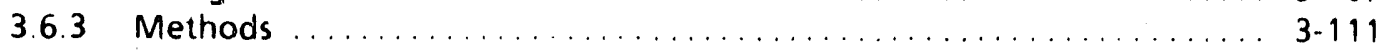

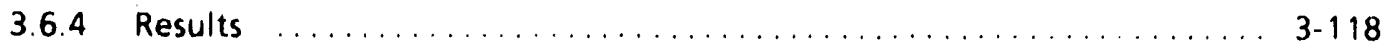

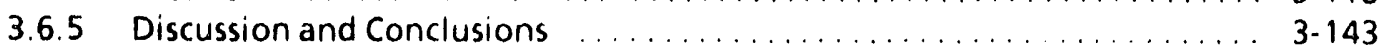

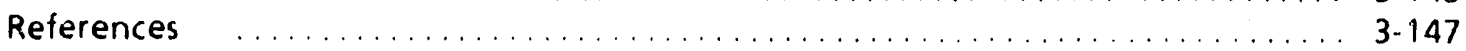

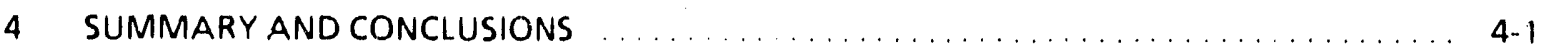

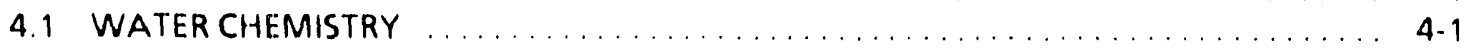

4.1.1 What is the Influence of Mineral Acids and Bases on Hydrogen Ion
Concentration? $\ldots \ldots \ldots \ldots \ldots \ldots \ldots \ldots \ldots \ldots \ldots \ldots \ldots \ldots \ldots \ldots \ldots \ldots$

4.1.2 What Is the Influence of Other Acids and Bases on Hydrogen Ion Concentration?

4.1.3 What is the influence of Geomorphic Characteristics

(e.g., Soil Thickness, Wetlands) on Lake Water Quality? . . . . . . . . . . 4-?

4.1.4 Can Lakes be Classified Based Upon Water Quality Measurements to Estimate Urımeasured yet Influential Geologic Characteristics? ...... 4-3

4.1.5 Can Estimates Be Made of the Change in pH Resulting from Changes in Acidic Deposition and/or DOC Concentration?

4.1.6 is There Evidence of Time Trends in the Water Quality of Adirondack Lakes? 


\section{CONTENTS}

4.2 FISH COMMUNITIES .................................... 4.6

4.2.1 Where Do Fish Occur? Where Do They Not Occur? . . . . . . . . . . . . 4-6

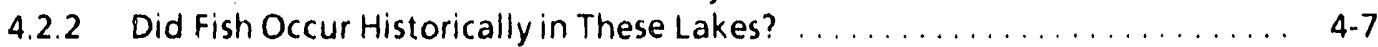

4.2.3 If Fish Do Not Occur in a Lake or Group of Lakes, Why Not? . . . . . . . . 4-8

4.2.4 W/hat Fish Could These Lakes Support if the Chemistry Were Suitable? . . 4-10

4:2.5 How Many of the Lakes with Fish Are at Risk from Acidic Deposition? ... 4-11

Appendix A Patterns of Fish Distribution in Relation to Lake/Watershed Characteristics:

Regression Analyses and Diagnostics

Appendix B Patterns of Fish Distribution in Relation to Lake/Watershed Characteristics: Robust Estimation

Appendix C Procedures for Evaluating Historical Trends in Fish Communities

Appendix D Comparison of Assessments of Historical Changes in Fish Communities 


\section{FIGURES}

1-1 Adirondack region showing both the Adirondack Park and Adirondack ecological zone boundaries

1-2 Locations of the lakes surveyed by the Adirondack Lakes Survey Corporation from 1984 to 1987 relative to the Adirondack Park boundary.

2. 1-1 Distribution of physical and chemical characteristics of lakes sampled during ELS-I for Subregion IA (the Adirondacks): (a) surface area; (b) $\mathrm{pH}$; (c) $A N C_{\text {; }}$ and (d) DOC

2.1-2 Replicate analysis for (a) field $\mathrm{FH}$, (b) calcium, (c) sulfate, and (d') chloricie. Points close to the one-to-one line indicate small variability in replicate values.

2.1-3 ANC replicates from (a) ALSC data, -50 to $250 \mu \mathrm{eq} / \mathrm{L}$, (b) ALSC data, -25 to $25 \mu \mathrm{eq} / \mathrm{L}$, (c) RILWAS data, .25 to $25 \mu \mathrm{eq} / \mathrm{L}$, and (d) ILWAS data, -25 to $25 \mu \mathrm{eq} / \mathrm{L}$

2.1-4 Total positive versus total negative charge. Most values fall below the one-to-one line, indicating a deficit of anions. This deficit is normally attributed to dissociated organic acids (unprotonated organic ligands).

2.1-5 Distr bution of the ratin of the partial pressure of carbon dioxide in ALSC waters to that in the atmosphere

2.1-6 Distribution of Gran ANC in ELS-I subregion 1 A lakes that are (a) inside, and

(b) outside the Adirondack ecological zone.

2.2-1 Bedrock types within the Adirondacks (after Wiener et al. 1984).

2.2-2 Typical Adirondack soil profile (after Cronan et al. 1984)

2.2-3 Average annual runoff in centimeters (after Knox et al. 1955)

2.2-4 Hydrogen ion and sulfate deposition isopleths for the northeastern United States (after Driscoll et al., in press)

2.3-1 Acid neutralizing capacity definition: ANC can be measured by titration or calculated.

2.3-2 $C_{B}-C_{A}$ versus Gran-titrated $A N C$ Over the full range of observations, (a), the values appear to be centered around the one-to-one line, but for smaller ranges, $(b)$ and $(C), C_{B}-C_{A}$ is often higher than Gran-titrated $A N C$, possibly due to the influence of organics.

2.3-3 Gran ANC versus the sum of base cation concentrations. As indicated, base cation concentrations largely determine ANC 


\section{FIGURES}

2.3-4 Mineral weathering: (a) idealized representation; (b) rate expressions. . . . . . . 2-35

2.3-5 Weathering stoichiometries for a hornblende, plagioclase, and

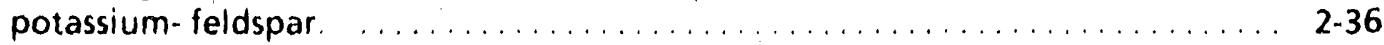

2.3.6 Silica concentration (a) in deep versus sha!low lake water samples and

(b) versus sodium for ALSC drainage lakes not impacted

by road sait (chloride concentrations less than $20 \mu \mathrm{eq} / \mathrm{L}$ ).

2.3-7 Competitive cation exchange: (a) idealized representation;

(b) heterovalent exchange equation; and (c) homovalent exchange equation.

2.3-8 Relationships between (a) calcium and magnesium, (b) calcium and sodium, (c) calcium and silica, and (d) sodium and silica in ALSC drainage lake samples with chloride concentrations less than $20 \mu \mathrm{eq} / \mathrm{L}$

2.3-9 Shallow versus deep concentrations of (a) iron, (b) manganese, and (c) ANC. The elevated concentrations of iron and manganese lead to increases in ANC.

2.3-10 Predicting the speciation of aluminum: $A I_{1}$ and $A I_{U}$ based upon measured $A I_{m}, A I_{d}$, and $A I_{1}$.

2.3-11 Total and dissolved alurninum in ALSC (a) drainage and (b) seepage lakes. $\ldots \ldots \ldots$

2.3-12 Speciation of monomeric aluminum in ALSC drainage lakes using ALSC data and ALCHEMI. Vertical distances between the curves represent mean concentration of the indicated species groups.

2.3-13 ANC versus the sum of mineral acid anions shows little relationship between these parameters in AL.SC cilemistry samples.

2.3-14 Concentrations of $\mathrm{pH}$ and nitrate at Panther Lake. $\mathrm{pH}$ depressions coincide with nitrate peaks.

2.3-15 Distribution of sulfiate concentrations in (a) drainage lakes and

(b) seepage lakes, based upon samples (excluding replicates) taken from

$\leq 1.5 \mathrm{~m}$ deptr, during the summer water chemistry surveys.

2.3-16 Anion adsorption: (a) idealized representation and (b) adsorption isotherm. . . . 2-52

2.3-17 pH versus ANC (a) theorevical relationship and (b) ALSC data. The influence of mineral acids and bases on $\mathrm{pH}$ depends upon the initial ANC of the solution. $\quad \ldots \quad 2.53$

2.3-18 The RILWAS sites for precipitation quantity and quality measurements. 
2.3-19 pH buffering provided by carbon dioxide and a second weak acid. Changes in $\mathrm{pH}$ in response to additions of strong acid or strong base (changes in ANC) are greatly reduced when weak acids are present in solution.

2.3-20 The influence of nonmineral acids on solution $\mathrm{pH},(\mathrm{a})$ observed field $\mathrm{pH}$ versus

$C_{B}-C_{A} A N C_{i}(b)$ the deviations are more easily visualized when plotted directly.

2.3-21 Influence of (a) volatile and (b) nonvolatile nonmineral acids on solution $\mathrm{pH} . \quad \ldots \quad 2-60$

2.3-22 The influence of nonmineral acids on solution hydrogen ion concentration:

(a) total, (b) volatile component, and (c) nonvolatile component.

2.3-23 Evaluation of the nonvolatile component of the influence of nonmineral acids on solution hydrogen ion concentration with (a) exclusion of DOC influence and (b) exclusion of aluminum influence.

2.3-24 Anion deficit versus $D O C$ over (a) the full range of data, (b) samples with $\mathrm{pH}$ from 4.0 to 4.5 , (c) samples with pH from 4.5 to 5.0 , and (d) samples with $\mathrm{pH}$ from 5.0 to 5.5 .

2.3-25 The $F_{1}$ Gran function plot. The upper right-most linear portion of the curve is extrapolated downward to determine the titrant volume at the equivalence point and thus ANC.

2.3-26 $\quad F_{1}$ Gran function versus titrant volume for (a) a high-DOC and (b) a low-DOC sample. The curvature in the high-DOC sample leads to the underestimation of ANC.

2.3-27 Deviation between $C_{B}-C_{A}$ and Gran $A N C$ as a function of DOC concentration.

2.4-1 Areal distributions of ALSC (a) drainage lakes and (b) seepage lakes. Lines within the park boundary delineate the major Adirondack drainage basins.

2.4-2 Surface areas of ALSC (a) drainage and (b) seepage lakes. The distributions are limited to $<30$-ha lakes to illustrate the fine structure in the distribution of smail lakes. This limitation excluded only $16 \%$ of the drainage lakes and $<1 \%$ of the seepage lakes

2.4-3 ALSC drainage lakes distributions of (a) pH, (b) Gran ANC, (c) sulfate, and (d) base cations

2.4-4 ALSC seepage lakes distributions of (a) pH, (b) Gran ANC, (c) sulfate, and (d) base cations 


\section{FIGURES}

2.4-5 Flowpathe through areas of thick versus thin till and associated chemical reactions

2.4-6 Seepage lakes can be subdivided into three basic types: Flow-through seepage lakes, msunded seepage lakes perctied above the local water table on low permeability sediments, and bog ponds.

2.4-7 Relaticiship between sodium and chloride concentrations in (a) all ALSC waters at higher chloride concentrations at (b) lower chloride concentrations.

$2-80$

2.4-8 Data . om ILWAS and RILWAS projects showing relationships between

(a) base-flow calcium and thick till, (b) base-flow calcium and ANC, and

(c) base-flow discharge and the $C_{B}$. Woodruff Pond (thin till) is rich

in carbonate minerals.

2.4-9 Distribution of calcium concentratior,s in ALSC seepage lakes.

$2 \cdot 83$

2.4-10 Flow chart showing the sequence in which classification criteria also were applied to the ALSClakes

Distribution of (a) silica concentrations and (b) ANC for the major ALSC lake classes

2.4-12 Flow chart showing classification of ELS-1 target population lakes in Subregion IA using the same criteria as for the ALSC lakes.

2.4-13 Flow chart showing classification of those ELS-I target population lakes in the Adirondack ecological zone using the same criteria as for the ALSC lakes.

2.4-14 Comparison of DOC measurements made on lakes sampled by both the ALSC and ELS-1. The DOC values for the ELS-I samples are somewhat lower.

2.5-1 Distribution of $C_{B} \cdot C_{A}$ values for all $A L S C$ samples with lab $p H \leq 5$.

2.5-2 Distribution of the fraction of hydrogen ion supported by organic acids in all ALSC samples with $\mathrm{pH} \leq 5$. As indicated, the samples commonly had either $>90 \%$ or $<10 \%$ organic-acid-supported $H^{\prime}$.

2.5-3 Influence of organics in summer index lake samples for drainage lakes with lab pH $\leq 5$. (a) Disiribution of $C_{B}-C_{A}$. (b) Distribution of the fraction of organic-supported $H^{\prime}$ 


\section{FIGURES}

2.5-4 Influence of organics in summer index lake samples in seepage lakes with lab pH $\leq 5$ : (a) distribution of $C_{B}-C_{A}$; (b) distribution of the fraction of organic-anion-supported $H^{*}$

2.5-5 The fraction of hudrogen ion supported by organic anions in lakes wit: $\mathrm{pH} \leq 5$ within (a) low-DOC thin-till drainage lakes, (b) low-DOC mounded seepage, lakes, (c) high-DOC thin-till drainage lakes, and (d) high-DOC mounded seepag lakes

2.5-6 Relationship between air-equilibrated hydrozen ion concentrations and DOC over $C_{B}-C_{A}$ ranges from (a) -25 to $-15 \mu \mathrm{eq} / \mathrm{L}$, (b) -15 to $-5 \mu \mathrm{eq} / \mathrm{L}$, (c) $-5105 \mu \mathrm{eq} / \mathrm{L}$, arid (d) 5 to $15 \mu \mathrm{eq} / \mathrm{L}$.

2.5-7 Air-equilibrated $H^{\prime}$ concentration versus $D O C$ over a range oi $C_{B}-C_{A}$ values. This plot can be used to determire the change in hydrogen ion concentration given change in $C_{B}-C_{A}$ and/or $D O C$

2.5.8 For samples with pH from 4.0 to 4.5, (a) anion deficit versus DOC and (b) $\left(C_{B}-C_{A}\right)$ - Gran ANC versus $D O C$, slopes of the regression lines indicate that $90 \%$ of the difference between $C_{B}-C_{A}$ and $G r a n A N C$ is due to the presence of strong organic acids while $10 \%$ is due to curvature in the $F_{1}$ Gran function

2.5-9 Locations of Adirondack long-term monitoring sites.

2.5-10 Precipitation quantity and quality at the UAPSP site at Big Moose Lake and the NADP site at Huntington Forest.

2.5-11 Wet deposition at the UAPSP site at Big Moose Lirke and the NADP site at Huntington Forest.

3.2-1 (a) Frequency histogram of species richness for ALSC lakes and (b) notched box and whisker plots of species richness by watershed

3.2-2 Brown bullhead (a) spatial distribution in relation to the Adirondack Park and (b) bar chart of occurrence by watershed

3.2-3 White sucker (a) spatial distribution in relation to the Adirondack Park and (b) bar chart of occurrence by watershed

3.2-4 Golden shiner (a) spatial distribution in relation to the Adirondack Park and (b) bar chart of occurrence by watershed

3.2.5 Yellow perch (a) spatial distribution in relation to the Adirondack Park and (b) bar chart of occurrence by watershed 


\section{FIGURES}

3.2-6 Brook trout (a) spatial distribution in relation to the Adirondack Park and (b) bar chart of occurrence by watershed

3.2-7 Sensitive minnows (a) spatial distribution in relation to the Adirondack

Park and (b) bar chart of orcurrence by watershed

3.2.8 (a) Frequency histograms of common sensitive minnows captured in ALSClakes and (b) the number of sensitive minnow species captured in lakes represented by this group

3.2-9 Notched box and whisker plots of field pH for selected fish species

3.2-10 Notched box and whisker plots of inorganic monomeric Al for fish species collected in A!sC surveys

3.2-11 Notched box and whisker plots of species richness in Adirondack lake classes

3.2-12 Spatial distribution of ALSC lakes with (a) fish present and (b) fish absent

(a) $\mathrm{pH} \leq 5.0$, (b) $5.0<\mathrm{pH} \leq 55$.

Notched box and whisker plots of (a) surface area, (b) elevation, (c) mean depth, and (d) watershed area by fish presence or absence for ALSC lakes

3.2-15 Cumulative frequeri.y distributions of (a) surface area, (b) elevation, (c) mean depth, and (d) watershed area for ALSC lakes with fish absent

3.2-16 Notched box and whisker plots of (a) field pH, (b) ANC, (c) calcium, and (d) inorganic monomeric $\mathrm{Al}$ by fish presence or absence for ALSC lakes

3.2-17 Cumulative frequency distributions of (a) field pH, (b) ANC, (c) calcium, and (d) inorganic monomeric Al for ALSC lakes with fish absent

3.2-18 Notched box and whisker plots of (a) field pH and (b) estimated inorganic Al by fish presence or absence for ALSC seepage and drainage lakes

3.2-19 Fish presence and absence for lake categories defined by (a) the ALSC based on field observable characteristics and (b) measured water chemistry and hydrology

3.2-20 Notched box and whisker plots of field pH for (a) lakes at $>600$ m elevation in the 5 major Adirondack watersheds and (b) lake elevation classes

3.2-21 Field pH and clevation for small ( $\leq 4 \mathrm{ha}$ ), high-elevation ( $>600 \mathrm{~m}$ ), nonbog drainage lakes with fish present or absent

3.2-22 Estimated fraction of hydrogen ion concentration supported by organics for (a) lakes with no fish caught and (b) lakes with $\mathrm{pH} \leq 5.0$ 


\section{FIGURES}

3.2-23 Estimated fraction of hydrogen ion concentration supported by organics (summer surface-water chemistry) for lakes with fish present and absent for (a) lakes with field $\mathrm{pH} \leq 5.0$ and (b) lakes with $\mathrm{pH}$ field $\leq 5.5$.

3.2-24 Numbers of lakes with fish present and absent by DOC classes $\ldots \ldots \ldots \ldots \ldots . . \ldots 3$

3.2-25 Estimated fraction of hydrogen ion concentration supported by organics (summer surface-water chemistry) for lakes with field $\mathrm{pH} \leq 5.0$ and fish present and absent in selected lake classes.

3.3-1 Screening criteria utilized in development of brook trout status classification for ALSC lakes

3.3-2 Length frequency distributions for brook trout captured during fall surveys in ALSC lakes (September - November, 1984-87)

3.3-3 Relationship between sample size and minimum length of brook trout captured in ALSC lakes during fall survey periods

3.3-4 Effect of minimum number of trout in sample on proportions of lakes surveyed with young-of-year present

3.3-5 Distribution of ALSC BKT lakes by STATUS category

3.3-6 Cumulative frequency distributions of summer surface silica for ALSC lakes of various brook trout (BKT) categories.

3.3-7 Comparison of summer surface silica with deep water silica for ALSC brook trout (BKT) lakes

3-3-8 Comparisons of summer surface silica with spring and fall levels in ALSC brook trout (BKT) lakes

3.3-9 Fall surface silica in ALSC thin-till lakes with outlet beaver dams as a function of dam head height

3.3-10 Logistic regressions of brook trout status in relation to silica and sodium.

3.3-11 Effect of seasonal variation on predicted probability of brook trout natural reproduction in relation to summer surface silica concentration.

3.3-12 Comparison of summer surface silica and pH for ALSC non-BKT lakes.

3.3-13 Distribution of 21 Al.SC lakes with summer surface air-equilibrated $\mathrm{pH} \leq 5$ and both summer and spring/fall surface silica $\geq 2.5 \mathrm{mg} / \mathrm{L}$

3.5-1 Location and areas of selected watersheds in the eastern and western 
FIGURES

3.5-2 Distribution of drainage lakes in the Beaver, Moose, Ausable, and Schroon River watersheds

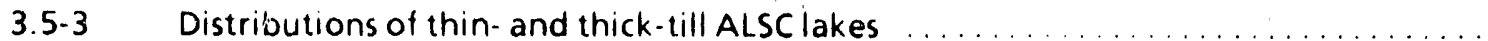

3.5-4 Predicted probabilities for fish species richness classes in a lake with 2-ha surface area at 400 m elevation

3.5-5 Predicted probabilities for fish species richness classes in a lake with 2-ha surface area at 700 m elevation.

3.5-6 Predicted probabilities for fish species richness classes for a 20-ha lake at $400 \mathrm{~m}$ elevation.

3.5-7 Predicted probabilities for fish species richness classes for a 20-ha lake at $700 \mathrm{~m}$ elevation.

3.5-8 Percent change in the number of fishless drainage lakes as a function of change in median $C_{B}-C_{A}$ and change in median $\mathrm{pH}$.

3.6-1 Numbers of lakes with historical survey data, by year of initial survey Lakes limed within 10 years preceding the ALSC survey or with flagged water chemistry data are noted.

3.6-2 Number of years in which lakes were surveyed prior to the ALSC survey: (a) all lakes with historical survey data and (b) only lakes first surveyed before 1970

3.6-3 Numbers of lakes with (a) historical reports or observations of fish occurrence but no pre-ALSC survey and (b) lakes with either historical survey data or reports/observations of fish occurrence, sorted by first year with historical information

3.6-4 Comparisons of the characteristics of four lake classes: (1) lakes surveyed by the ALSC, (2) ALSC lakes surveyed before 1970, (3) ALSC lakes surveyed in 1924-34, and (4) ALSC lakes surveyed in 1929.34 using both gill nets and seines

3.6-5 Percentage of lakes by ALSC species richriess class for (a) all lakes surveyed by the ALSC (lake class 1) and ALSC lakes surveyed before 1970 (class 2); and (b) ALSC lakes surveyed in 1924-39 (class 1) and in 1929-34 using both gill nets and seines (class 2 ) 
3.6-6 Comparisons of lake characteristics among four classes of fish presence/absence (1929-1934 versus 1984-1987).

3.6-7 Frequency histogram of difference in the number of species caught by the ALSC minus the number of species caught in the 1929-34 for the 128 lakes sampled in 1929-34 using both gill nets and seines.

3.6-8 Difference in the number of species caught in 1984-87 minus 1929-34, for the 128 lakes sampled in 1929-34 using gill nets and seines, plotted as a function of (a) ALSC summer surface field $\mathrm{pH}$, (b) elevation, (c) lake area, and (d) maximum depth.

3.6-9 Comparisons of the characteristics of four lake classes of brook trout presence/absence in historical and ALSC surveys

3.6-10 Comparison of ALSC summer surface field pH among four lake classes with historical and current fish species presence/absence.

3.6-11 Comparisons of ALSC summer surface field pH for lakes with fish community status 0.2 versus 3.5 for various fish community types

3.6-12 Comparisons of lake elevation for lakes with fish community status $0-2$ versus $3-5$ for various fish community types 


\section{TABLES}

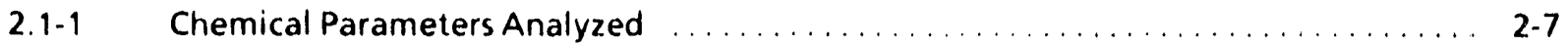

2.1-2 Summary Descriptors for the ALSC Data Base, Chemical and Physical Parameters ... 2-8

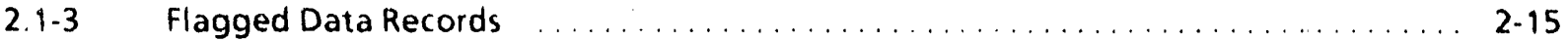

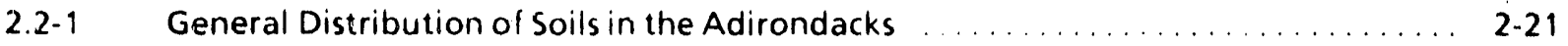

2.2-2 Major Rivers and Streams of the Adirondack Park $\quad \ldots \ldots \ldots \ldots \ldots \ldots \ldots$

2.3-1 Acid Neutralizing Capacity (a) Proton Reference Levels,

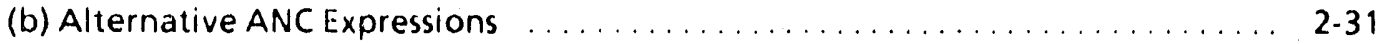

2.3-2 Empirical Aluminum Relationships Based on ' everal Different Data Sets $\ldots \ldots \ldots$. . .

2.3-3 Volume-weighted Mean lon Concentrations in Precipitation at the

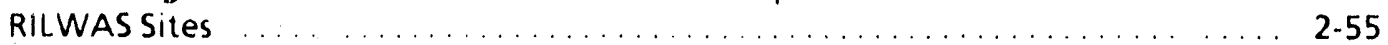

2.3-4 Expected Solute Concentrations in Adirondack Lakes in the Absence of

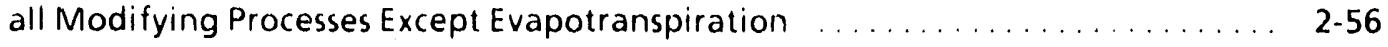

2.4-1 Mean Characteristics of ALSC Lake Classes $\ldots \ldots \ldots \ldots \ldots \ldots \ldots \ldots \ldots$

2.5-1 Changes in $\mathrm{pH}$ Given Changes in $\mathrm{C}_{B}-\mathrm{C}_{\mathrm{A}}$ and $\mathrm{DOC} \ldots \ldots \ldots \ldots \ldots \ldots$

2.5-2 Meta-Analysis and Probabilities .......................... 2-109

3.1-1 ALSC Netting Effort Based on Surface Area $\ldots \ldots \ldots \ldots \ldots \ldots \ldots \ldots$

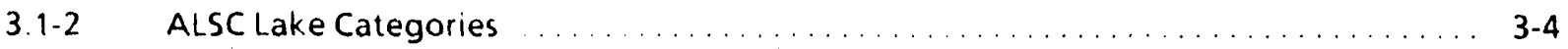

3.1-3 Candidate Explanatory Variables for Analyses of Fish Distributions in

3.2-1 Incidence of Fish Species Collected in ALSC Waters with

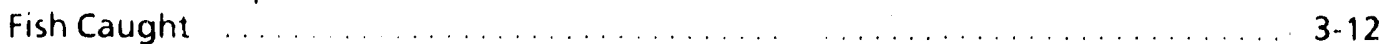

3.2-2 Distribution (Percent Occurrence) of Adirondack Fish Resources Among Lake Classes Reflecting ALSC Water Chemistry and Expected Susceptibility to Acidic Deposition

3.2-3 Fish Presence and Absence by Watershed 


\section{TABLES}

3.3-1 Comparison of Young-of-Year Presence/Absence in ALSC Lakes Surveyed before

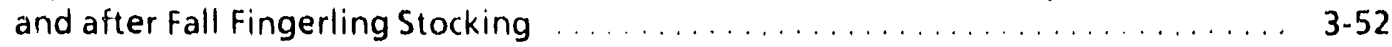

3.3-2 ALSC Lakes Classified by Stocking and Young of-Year Categories $\ldots \ldots \ldots \ldots$. $\ldots .54$

3.3-3 Summary Characteristics of ALSC BKT Status 1 (Unstocked, YOY Present) and Status 0 (Stocked, YOY Absent) Brook Trout Lakes .................... . 3-55

3.3-4 Comparison of F Values and Probability Levels for Selected Variables with Significant Differences Between Stocking and Young-of-Year Categories in

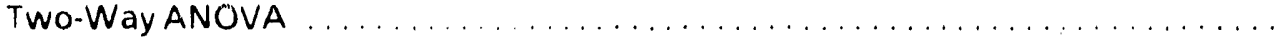

3.3-5 One-Factor ANOVA of Summer Surface Silica by Seepage/Drainage Lake Classification ...........................................

3.3-6 Summary Results of Paired Comparisons Between Lakes With and Without Natural Reproduction ................................. $3-58$

3.3-7 Comparison of Summer Surface Silica Concentrations in ALSC Drainage Lakes With (Group 1) and Without (Group 2) Beaver Dams on the Outlet

3.3-8 Comparison of Percent Sand and Muck in Littoral Zones of ALSC Drainage Lakes With (Group 1) and Without (Group 2) Beaver Dams on the Outlet

3.3-9 Logistic Regression Models of BKT STATUS as Functions of Summer Silica, Summer Sodium, arid Fall Silica

3.3-10 Verification Statistics for Logistic Regression Models of Probability of Brook Trout Natural Reproduction as Functions of Silica and Sodium Concentrations . . 3-67

3.3-11 Predicted Potential for Brook Trout Natural Reproduction in ALSC Lakes

Based on Summer Surface Silica Concentration

3.3-12 ALSC Non-BKT Lakes with Summer $\mathrm{pH} \leq 5$ and both Summer Surface and Spring or Fall Silica $\geq 2.5 \mathrm{mg} / \mathrm{L}$

3.4-1 Candidate Explanatory Variables and Summary of Results from Mann-Whitney and Contingency Table Analyses To Test for Differences Between Lakes with rish Present versus Absent

3.4-2. Greatest Level of Significance of Any Variable Within each of Six Explanatory Variable Groups for Brook Trout

3.4-3 Greatest Level of Significance of any Variable Within each of Six Explanatory Variable Groups for Creek Chub and Fish versus No Fish 
TABLES

3.4-4 Comp trison of Values of the Coefficients of the pH Term in Stepwise-Selected Loyistic Models of Brook Trout Presence/Absence in Adirondack Lakes

3.5-1 Characteristics of ALSC Drainage Lakes in Discrete Drainage Systems of the Western and Eastern Adirondack Regions

3.5-2 Comparison of Bog, Beaver Dam, and Stratification Categories for Draınage Lakes in We'stern and Eastern Adirondack Basins

3.5-? Comparison of ALSC Drainage Lake Type Frequencies Between Eastern and Western Watersheds

3.5-4 Characteristics of Fish Communities in ALSC Drainage Lakes in Western and Eastern Adirondack Drainage Systems

3.5.5 Parameters for Multinomial Logistic Regression Model of Species Richness Class as a Function of Summer Surface $\mathrm{pH}, \log _{10}(1+A$ rea $)$ and $\log _{10}(1+$ Elevation $)$

3.5-6 Observed and Predicted Species Richness Class Distributions for Lakes in Selected Adirondack Watersheds

3.5.7 Stepwise Multiple Linear Regression Analyses for Species Richness for the Beaver Rivcr and Moose River (North and South Branch) Watersheds

3.5-8 Regression Equations Used to Estimate $\mathrm{pH}$ from $C_{B}-C_{A}$ and $D O C$

3.5-9 Predirted Species Richness Class Distributions for Lakes in Selected Adirondack Watersheds Based on Observed $\mathrm{pH}$ With $\mathrm{pH}$ Levels Increased to a Minimum pH of 6.5

3.5-10 Predicted Species Richness Class Distributions for Lakes in Selected Adirondack Watersheds Based on Observed $\mathrm{pH}$ and at a $\mathrm{pH}$ Associated with a $15 \mu \mathrm{eq} / \mathrm{L}$ Increase in $\mathrm{C}_{B}-\mathrm{C}_{\mathrm{A}}$ )

3.5-11 Comparisons of Fish Presence/Absence within Western and Eastern Drainage Systems in Relation to Habitat Characteristics

3.5-12 Comparisons of Brook Trout Presence/Absence within Western and Eastern Drainage Systems in Relation to Other Fish Presence and Habitat Characteristics

3.5-13 Comparisons of Yellow Perch Presence/Absence within Western and Eastern Drainag. Systems in Relation to Habitat Characteristics 


\section{TABLES}

3.5-14 Comparisons of Acid-Tolerant Fish Species Presence/Absence within Western and Eastern Drainage Sysiems in Relation to Habitat Characteristics

3.5-15 Comparisons of Acid-Sensitive Cyprinid Species Presence/Absence within Western and Eastern Drainage Systems in Relation to Habitat Characteristics

3.5-16 Comparisons of Percentages of ALSC Lakes Containing Different Fish Associations in Thin-Ti!l Basins and all Other Drainage Basin Types

3.6-1 Available Data on Factors That May Influence Fish Population Status in Fish Communities Over Time in Adirondack Lakes

3.6-2 Rankings of the Evidence for Historical Occurrence of the Species (PAST)

3.6.3 Rankings of the Evidence that the Fish Species is Currently Absent from the Lake (ABSENT)

3 6-4 Examples of Codes and Conditions Considered in Identifying Possible Explanations for Apparent Fish Population Losses

3.6.5 Ratings of Probable Causes for Apparent Fish Population Losses (CAUSE)

3.6.6 Ratings of Changes in the Fish Community Status as a Whole

3.6-7 Comparisons of the Characteristics of Lakes Surveyed by the ALSC to ALSC Lakes With Historical Survey Data

3.6-8 Numbers (and Percentages) of lakes With and Without Fish Caught in 1929-34 versus $1984-87$

3.6-9 Numbers (and Percentages) of lakes With and Without Fish Caught or reported in 1929-34 versus $1984-87$

3.6-10 Numbers (and Percentages) of Lakes With and Without Fish Caught in 1929-34 versus 1984-87, for 128 Lakes Sampled in 1929-34 Using Both Gill Nets und Seines

3.6-11 Percentage of Lakes in Each Lake Class (Defined by Fish Presence/Absence in 1929-34 and 1984-87) for Selected Lake Characteristics

3.6-12 Percentage of Lakes with Individual Fish Species in 1929-34 versus 1984-87, Using Two Data Subsets

3.6-13 Apparent Fish Population Losses and Losses Apparently due to Acidification in Lakes with Confirmed or Reported Historical Fish Species Occurrence 


\section{TABLES}

3.6-14 Apparent Fish Population Losses and Losses Apparently due to Acidification in Lakes with Confirmed Historical Presence of Fish

3.6-15 Alternative Explanations for Observed Fish Population Losses: Numbers of Lakes Coded for Selected Possible Causes for Decline Other than Acidification.

3.6-16 l.ake Characteristics Associated with the Loss of Fish Populations (all Possible Causes), Compared to Lakes That Still Support the Species

3.6-17 Lake Characteristics Associated with Fish Population Losses Rated as Apparently Resulting from Acidification, Compared to Lakes That Still Support the Species

336-18 Percentage of Lakes with Confirmed Presence of the Species Before 1970, Percentage per Lake Characteristic That (1) Still Support the Species, (2) Have Lost the Species, and (3) for Which the Observed Fish Population Loss is Probably Due to Acidification

3.6-19 Percentage of Lakes That (a) Have Lost Fish Species Apparently as a Result of Acidification and (b) That Still Support Fish Which Are Classified as Mounded Seepage or Thin-Till Drainage Lakes

3.6-20 Percentage of Lakes that have Lost Fish Populations Apparently as a Result of Acidification and that Still Support the Fish Species with $\leq 50 \%$ of the Hydrogen Ion Concentration Supported by Organics

3.6-21 Numbers of Lakes by Rating of Fish Community Status and Fish Community Type

3.6-22 Lake Characteristics Associated with Fish Community Changes Rated as Apparently Resulting from Acidification, by Fish Community Type 


\section{ADIRONDACK LAKES STUDY: \\ AN INTERPRETIVE ANALYSIS OF \\ FISH COMMUNITIES AND WATER CHEMISTRY - 1984-1987}

\section{EXECUTIVE SUMMARY}

\section{INTRODUCTION}

The Adirondacks is a large, forested upland and mountainous region in northern New York. The majority of surface waters in the region are dilute, with low levels of acid neutralizing capacity (ANC). At the same time, the region receives relatively large inputs of precipitation ( $100.150 \mathrm{~cm}$ annually) and acidic deposition (e.g., typical pH is about 4.1 to 4.2 ). As a result, much of the debate regarding the effects of acidic deposition on aquatic ecosystems has focused on the Adirondacks.

The Adirondark Lakes Survey Corporation (ALSC) was formed as a cooperative effort of the New York State Department of Environmental Conservation (NYSDEC) and the Empire State Electric Energy Research Corporation (ESEERCO) to better characterize the chemical and biological status of Adirondack lakes. Between 1984 and 1987, the ALSC surveyed 1469 lakes within the Adirondack ecological zone (Figure 1). This unique cooperative effort resulted in the acquisition of an unparalleled, extensive physical, chemical, and biological data base on $52 \%$ of the porided waters in the Adirondack region. The results from this survey are described in the ALSC summary report, Adirondack Lakes Study 1984-1987: An Evaluation of Fish Communities and Water Chemistry.

As a follow-up to the survey, the ALSC sponsored a series of interpretive analyses of the ALSC data base. The primary objectives of these analyses were as follows:

- evaluate the influence of mineral acids (e.g., from acidic deposition) and nonmineral acids (e.g., natural organic acids) on lake $\mathrm{pH}$ levels

- classify Adirondack lakes according to lake and watershed features expected to influence their responsiveness to changes in acidic deposition

- evaluate the sensitivity of Adirondack lakes to changes in environmental conditions, such as changes in mineral acids or dissolved organic carbon (DOC) concentrations

- identify lake characteristics important in explaining the observed present-day status of fish communities in Adirondack lakes, in particular the relative importance of lake acidity 


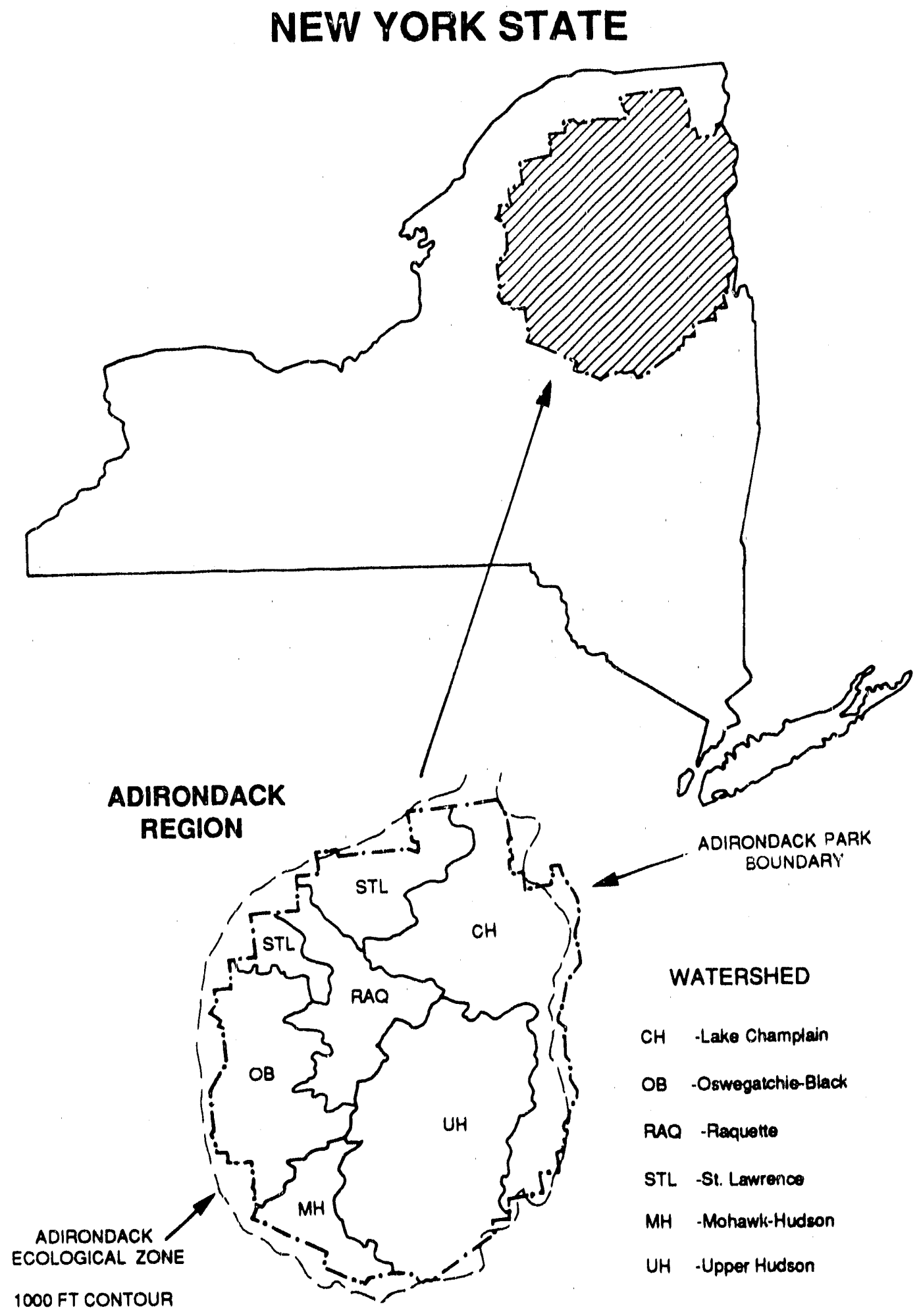

Figure 1 Adirondack region showing both Adirondack Park and Adirondack ecological zone boundaries. 
- evaluate changes that have occurred over time in Adirondack fish communities and probable causes for these trends by using the available historical data on fish communities in the Adirondacks and the ALSC data base

- determine the degree to which the existing fish resource might be at risk from continued acidic deposition, or might recover if acidity levels were reduced

The basic approach examined relationships observed in the ALSC data base amon 7 watershed characteristics, lake chemistry, and fish status. These analyses built upon the understanding of important processes influencing lake chemistry and fish communities derived from earlier, mechanistic research projects in the Adirondacks, such as the Integrated Lake/Watershed Acidification Study (ILWAS) and the Regional Integrated Lake/Watershed Acidification Study (RILWAS). Key advantages of the ALSC data base include its size, which allows for in-depth analyses for particular lake types or data subsets, and the associated regional perspective provided by the survey.

\section{SURFACE WATER CHEMISTRY}

Lakes with low $\mathrm{pH}$ and low ANC are prevalent in the Adirondacks. For example, $26 \%$ of the waters surveyed by the ALSC had air-equilibrated $\mathrm{pH}<5.0$, representing $8 \%$ of the lake surface area. Negative ANC values (indicating the occurrence of strong acids in the system) were measured in $26 \%$ of the lakes sampled, $11 \%$ of the lake area. Waters with low pH and ANC were found throughout the region, but were concentrated in the western and southwest $\epsilon$ " $n$ Adirondacks, in particular in the Oswegatchie-Black and Mohawk-Hudson watersheds (see Figure 1). This area is characterized by large numbers of small, high elevation lakes and receives the highest levels of precipitation in the region.

\section{Influence of Mineral Acids}

Acid neutralizing capacity is a measure of the net strong base in solution, or net strong acid if its value is negative. As a result, additions of strong acids or bases to surface waters have a direct effect on ANC. Depending on the initial ANC of the solution, this addition may also significantly influence $\mathrm{pH}$.

Sulfate is the dominant mineral acid anion in ALSC lakes, indicating that sulfuric acid is the major source of mineral acidity. Some portion of this sulfate is attributable to acidic deposition. In the absence of all modifying processes other than evaporation, current levels of sulfate deposition in the Adirondacks would produce concentrations of sulfate from about $10010150 \mu \mathrm{eq} / \mathrm{L}$ in the surface waters. Most drainage lakes (that is, lakes with an outlet) in the Adirondacks have sulfate concentrations between about 80 and $140 \mu \mathrm{eq} / \mathrm{L}$. The retention of sulfate in Adirondack soils is 
minimal, and thus sulfate retention would have little effect on lake sulfate concentrations. In-lake and wetland processes, however, may modify sulfate concentrations substantially, especially in systems with longer water residence times. Seepage systems (lakes with no outlet), for example, even with more evaporation, commonly have sulfate concentrations that are about $40 \mu \mathrm{eq} / \mathrm{L}$ lower than those in drainage lakes, most likely as a result of in-lake processes

In contrast to sulfate, nitrate and chloride concentrations measured by the ALSC were generally low (except for chloride concentrations iri lakes impacted by road salt). Other siudies, however, have shown that higher concentrations of nitrate occur during hydrologic events, such as snowmelt, and result in periodic decieases in $A N C$ and $\mathrm{pH}$

The relative contributions of mineral and nonmineral acids to hydrogen ion $\left(\mathrm{H}^{+}\right)$concentration in Adirondack lakes with low pH were estimated based on the concentrations of mineral acid anions, base cations, and DOC as measured by the ALSC. Of the 256 drainage lakes sampled by the ALSC with $\mathrm{pH} \leq 5.0$, mineral acids were estimat : $\mathrm{d}$ to support more than half the $\mathrm{H}^{+}$present in $48 \%$ of the lakes, and over $90 \%$ of the $\mathrm{H}^{*}$ present in $83(32 \%)$ of these lakes. In seepage lakes, on the other hand, mineral acids are apparently less important. Cf the 92 seepaga lakes sampled by the ALSC with pH $\leq 5.0$, mineral acids were estimated to support more than ha!f of the $H^{*}$ present in $33 \%$ of the sample, and over $90 \%$ of $H^{+}$in $13 \%$ of these lakes.

\section{Influence of Nonmineral Acids}

Other important acid-base systems in Adirondack waters include organic acids (products of the decay of plant and animal matter) and carbon dioxide. These acids can have a significant effect on lake pH levels. Results from the ALSC survey indicate that volatile acids (largely carbon dioxide) ha ve the greatest effect on $\mathrm{pH}$ levels in waters with $\mathrm{ANC}>50 \mu \mathrm{eq} / \mathrm{L}$, depressing the lake $\mathrm{pH}$ by 0.3 to $1 \mathrm{pH}$ units below the levels expected for air equilibration. Nonvolatile acids (primarily organic acids) have the greatest effect on $\mathrm{pH}$ levels in waters with ANC between about zero and $50 \mu \mathrm{eq} / \mathrm{L}$, where $\mathrm{pH}$ depressions attributed to organic acids range from about 0.5 to $2.5 \mathrm{pH}$ units

In the past, organic acids were generally thought to act as weak acids capable of decreasing pH but not ANC. The ALSC data, however, indicate that in Adirondack waters dissolved organics also have strong acid compor.ents, as evidenced by the strong relationship between DOC and the anion deficit (i.e., the charge imbalance) in lakes with very high $\mathrm{H}^{+}$concentrations $(\mathrm{pH} 40-4.5)$. Analysis of the

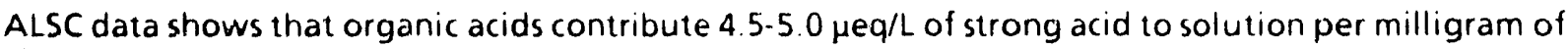
DOC. The implication of this finding is most important. As a result of their strong acid component, organic acids, by themselves, can produce negative values for ANC. Thus, the common assumption 
that negative ANC values are necessarily indicative of acidification from mineral acids is incorrect. These observations were based on empirical data collected during extensive field investigations and nors ifirming laboratory experiments were conducted.

Finally, as a corollary to the statements regarding the importance of mineral acids, organic acids were estimated to support more than half the $\mathrm{H}^{+}$present in $52 \%$ of the drainage lakes sampled with $\mathrm{pH}$ $\leq 5.0$, and over $90 \%$ of the $H^{+}$in $41 \%$ of these lakes. In seepage lakes with $\mathrm{pH} \leq 5.0$, organic acids were estimated to support more than half of the $\mathrm{H}^{+}$present in $67 \%$ of the 92 lakes sampled and more than $90 \%$ in $43 \%$ of these lakes.

\section{Lake Classification}

The acid-base status of surface waters is ultimately a function of the relative contributions of acids and bases. The acids are derived from both atmospheric deposition and natural processes, such as organic matter decay and the oxidation of organic nitrogen. The bases result from reactions occurring within the watershed soils (e.g., weathering and cation exchange reactions) and from atmospheric deposition. The degree to which the incoming precipitation interacts with the watershed soils and the routing of the water through these soils, are major determinants of the base supply rate. In watersheds with thick soils, acids -- whether natural or from acidic deposition -- will be largely neutralized by bases within the soils. In contrast, in watersheds with thin soils, much of the incoming precipitation passes only through the shallow organic horizons and on into the lakes and streams. Such systems would generally be expected, therefore, to be more responsive to increases or decreases in atmospheric acid inputs. Some seepage lakes, in particular "mounded" seepage lakes that are separated by relatively impermeable soil layers from the groundwater system, receive almost all of their water as direct precipitation, with little to no interaction with the soil Mounded seepage lakes, therefore, might be expected to be quite responsive to changes in atmospheric inputs.

A classification scheme was developed to group the ALSC lakes according to these influential watershed features based on their chemical and hydrological characteristics measured during the ALSC survey. Thirty-nine percent of the lakes classified fell within the four classes expected to have the smallest amount of neutralization by the watershed: (1) mounded seepage lakes with low levels of DOC $(3 \%)$; (2) mounded seepage lakes with high DOCs (3\%); (3) drainage lakes in watersheds with thin till and with low DOC (19\%); and (4) drainage lakes in thin-tilled watersheds with righ DOC $(14 \%)$. 


\section{Predicted Changes in pH}

One of the objectives of the analysis of the ALSC water chemistry data was to determine how the $\mathrm{H}^{+}$ concentration (or $\mathrm{pH}$ ) might change in response to changes in mineral acid inputs or $\mathrm{DOC}$ Because of the large size of the ALSC data base, it was possible to conduct these sensitivity analyses based solely on the ALSC data.

The U.S. Environmental Protection Agency's Direct'Delayed Response Project (DDRP) involved the application of three dynamic simulation models to predict changes in ANC as a result of a $30 \%$ decrease in atmospheric deposition. All three models predicted increases of about 5 to $15 \mu \mathrm{eq} / \mathrm{L}$ for Adirondack lakes. Analyses were conducted, therefore, to determine the response of selected representative ALSC lakes from the four lowest ANC classes (high-and low-DOC thin-tilled drainage lakes and high-and low-DOC mounded seepage lakes) to a $15 \mu \mathrm{eq} / \mathrm{L}$ increase in ANC. The predicted increases in $\mathrm{pH}$, assuming no change in $D O C$, ranged from 0.17 to $0.38 \mathrm{pH}$ units. If increases in $D O C$ occur simultaneously, as a limited number of field observations indicate, the changes in $\mathrm{pH}$ would be smaller. For example, an increase in DOC of about $2-4 \mathrm{mg} / \mathrm{L}$ would be sufficient to entirely offset the increase $\mathrm{n} \mathrm{pH}$ resulting from the $15 \mu \mathrm{eq} / \mathrm{L}$ increase in ANC. Whether or not a DOC increase might occur in the Adirondacks with a decrease in deposition is not known. Some additional research is needed to answer this question

\section{FISH COMMUNITIES}

Fish were caught in $76 \%$ of the lakes surveyed by the ALSC. No fish were caught in $24 \%$, representing $7 \%$ of the lake area. Lakes with fish occurred throughout the Adirondacks, while fishless lakes were concentrated in the western and southwestern watersheds (Oswegatchie-Black and Mohawk-

Hudson) Fifty-three fish species were collected in total. The number of species caught per lake (i.e., species richness) ranged from zero (fishless) to 13, with a median of one species per lake in the Oswegatchie-Black and Mohawk-Hudson watersheds, as compared to median values of 4-5 species per lake in the other three major Adirondack watersheds

\section{Characteristics of Lakes Without Fish}

Lakes without fish have a diversity of characteristics, reflecting the large number of factors that determine the suitability of a lake for fish survival and reproduction. Many of the fishless lakes were small (nearly $70 \%$ were $<4 \mathrm{ha}$ ) and shallow ( $60 \%$ had a mean depth $<2 \mathrm{~m}$ ). Fishless lakes were also prevalent at high elevations, no fish were caught in $65 \%$ of the lakes surveyed at $>600 \mathrm{~m}$. The 
majority of lakes without fish had relatively low pH and ANC levels: $77 \%$ had $\mathrm{pH}<5.0 ; 92 \%$ had $\mathrm{pH}$ $<5.5 ;$ and $77 \%$ had ANC $<0 \mu$ eq/L.

The factors responsible for the absence of fish vary among lakes. Forty-six of the lakes surveyed by the ALSC were classified as bogs. No fish were caught in any of these lakes. The absence of fish from bogs probably reflects the combined effects of low concentrations of dissolved oxygen, poor spawning substrate, and naturally low pH levels Of the remaining 300 fishless lakes, 270 had pH levels below 5.5 and thus may potentially be fishless as a result of high levels of acidity. About half of these lakes $(54 \%)$ had a high estimated fraction (> 50\%) of the $\mathrm{H}^{*}$ supported by organics, while the rest had less than half of the $\mathrm{H}^{+}$supported by organics and appear to be dominated instead by mineral acids. Not all of the low-pH fishless lakes, however, would necessarily be able to support fish in the absence of high acidity. For example, 31 of the low $\mathrm{pH}$ lakes that were dominated by mineral acids were small ( $<4 \mathrm{ha}$ ) and occurred at elevations above $600 \mathrm{~m}$. Some portion of these small, high elevation lakes would be expected to lack fish regardless of the lake $\mathrm{pH}$ (perhaps about $40 \%$ based on comparison to similar lakes with $\mathrm{pH}>5.5$ that were fishless) because of low levels of dissolved oxygen during winter, freezing, or inaccessibility to fish. Thus, based on these analyses, the estimated number of surveyed waters for which mineral acids (and acidic deposition) appear to be the primary cause for the lack of fish is $100-113$, or about $30 \%$ of the fishless lakes sampled by the ALSC.

Lake Characteristics Associated with Patterns of Fish Species Distribution

Changes in fish species composition and lower species richness may occur at more moderate environmental conditions than those that result in the total absence of fish from a lake. Factors associated with the presence and absence of selected fish species and with among-lake variations in species richness were examined using bivariate and multivariate regression, both for the Adirondack region as a whole and for individual drainage systems.

As expected, a large number of factors were significantly associated with fish status for example, stocking, biological variables (e.g., the occurrence of potential predators or competitors), and silica (an index of groundwater inflow) were of particular importance in explaining patterns of brook trout presence/absence similar analyses for creek chub identified lake characteristics such as the presence of predators, small lake size, the absence of inlets and outlets, and lower flushing rates as significantly associated with the absence of creek chub. In each analysis, however, one or more variables related to surface water acid-base chemistry, generally lake $\mathrm{pH}$, was also selected as a significant predictor of the occurrence of brook trout and creek chub. Thus, even after accounting as much as possible for the effects of the many other factors that influence fish, lakes without these fish species had lower $\mathrm{pH}$ than did lakes with fish present Likewise, within individual drainage systems in the western 
Adirondacks, where low pH lakes are common, all of the fish species and groups of species examined exhibited uniformly lower frequencies of occurrence in waters with lower $\mathrm{pH}$. These results support the conclusion that lake $\mathrm{pH}$ (and/or other acidity-related variables) plays an important role in restricting the distribution of fish species from at least some Adirondack lakes that would otherwije be suitable habitat.

In nonacidic lakes, species richness is highly correlated with lake area; larger lakes provide more diverse habitat and generally support more fish species. Lakes with higher $\mathrm{pH}$ also tend to support more fish species than do lakes with lower $\mathrm{pH}$. The relative effects of lake area and $\mathrm{pH}$ on species richness were quantified using a regression model and applying it to selected drainage systems in the western and eastern Adirondacks. In general, lakes in the western Adirondacks support fewer species than do lakes in the eastern Adirondacks. These differences appear to be largely attributable to differences in lake pH. Model applications suggest that the species-impoverished, acidic lakes prevalent in the western Adirondacks have the potential (based on the surface area/species richness relationship) to support more diverse fish communities, comparable to those present in the eastern Adirondacks, if $\mathrm{pH}$ levels in these western lakes were to increase significantly. Although other factors (e.g., productivity, access for fish immigration, disturbance) may locally modify the potential species richness for individual lakes, these other variables were not four $d$ to be strongly influential on a regional scale

\section{Historical Changes in Fish Communities}

Changes in fish communities over time also provide insight into the potential effects of acid base chemistry on fish resources. Survey data collected since the late 1920 s by the NYSDEC were examined to assess the historical occurrence of fish in lakes sampled by the ALSC, and probable causes for observed fish community and population trends.

Only 17 of the lakes that are now fishless were surveyed in the initial statewide biological surveys in 1929-34. At that time, about half of these lakes (9 lakes) had one or more fish species caught or reported to occur. The other half have apparently always been fishless, although it is possible that some lakes lost fish communities prior to these earliest surveys.

Most of the lakes sampled in 1929-34 were larger lakes at lower elevations, which today have relatively high $\mathrm{pH}$. Fish communities in these lakes would be less likely to have been impacted by acidic deposition, compared to Adirondack lakes as a whole. To partially compensate for this bias, historical surveys conducted after 1929-34 but before 1970 were also considered in evaluating fish trends. Unfortunately, many of these surveys were not intended to comprehensively sample the fish 
community. Therefore, trends through time were assessed only for the subset of lakes with confirmed occurrence of a species in the past ( $i$ e., caught in a survey prior to 1970). This expanded data set is also somewhat biased towards larger, lower-elevation lakes with higher $\mathrm{pH}$, but to a lesser degree than for the subset of lakes surveyed in 1929-34. For this reason, results from these analyses provide evidence for fish population losses but are not suitable for regional estimates of the extent of such losses.

All available data, except for information on acid-base chemistry, were reviewed for each lake to identify apparent fish population losses and probable causes for observed losses. The numbers of lakes classified as having lost fish populations apparently as a result of acidification varied between zero (for rainbow trout, brown trout, largemouth bass, and northern pike) to 44 (for brook trout, representing $11 \%$ of the lakes surveyed by the ALSC in which brook trout were caught prior to 1970) Acid-sensitive minnow species had apparently disappeared as a result of acidification from 19\% of the lakes with evidence for historical occurrence; common shiner from $15 \%$ of the lakes; creek chub and lake trout from $10 \%$; and white sucker from $6 \%$ of the lakes with confirmed historical occurrence. Among-species variations in the proportion of fish populations lost are a function of several factors: (1) the sensitivity of the species to acidic waters; (2) the degree to which the species tends to naturally occur in those lakes more susceptible to acidification; and (3) the susceptibility of the species to capture during the historical and ALSC surveys. Of the 858 lakes evaluated for historical trends ( $i$ e , all lakes with at least some historical information), $140(16 \%)$ had lost one or more fish populations apparently as a result of acidification. Lakes considered to have lost fish populations as a result of acidification consistently had lower present-day levels of $\mathrm{pH}$ than did lakes still supporting the fish species.

Acidification is not the only factor, however, nor necessarily the dominant factor influencing Adirondack fish communities. The numbers of lakes for which fish population losses were attributed to factors other than acidification actually exceeded those for which acidification was rated as the primary cause. Common alternative explanations that could be identified with the available datia include lake reclamation with rotenone, changes in stocking policy, and the introduction of potential competitors or predators. In contrast to acidification, however, these other factors often affected only some fish species within the fish community (resulting in species replacements rather than a net decline in species richness) or resulted directly from fishery management practices design to improve fishing opportunities in the region. 


\section{Fisheries Resource at Risk}

As noted above, lakes classified as mounded seepage lakes or thin-tilled drainage lakes (for both high and low DOC) would be expected to be more responsive to changes in atmospheric inputs of sirong acids. Thirty-nine percent of the lakes sampled by the ALSC were classified into these groups. Of the lakes in which the ALSC caught fish, on the other hand, only $27 \%$ were mounded seepage or thintilled drainage lakes. Twenty-five percent of the lakes with brook trout fall within these two lake classes. Other sport fish species, however occur relatively infrequently in these lake classes: 10\% of the lakes with lake trout caught by the ALSC; $6 \%$ of the lakes with smallmouth bass or largemouth bass; $3 \%$ of the lakes with rainbow trout or brown trout; and $3 \%$ of the lakes with northern pike. Thus, the majority of lakes currently supporting sport fish would appear to be relatively insensitive to further acidification, i.e., they were classified as drainage lakes in watersheds with intermediate or thick till or influenced by carbonate minerals, or as flow-through seepage lakes.

With a reduction in lake acidity, some portion of these lakes would gradually recover fish populations. Quantitative regional analyses of fish recovery were outside of the scope of this project. However, the historical trend analyses provide an index of the types of species likely to be recovered with improvements in water quality. Of the fish populations rated as having been lost apparently as a result of acidification, brook trout accounted for $28 \%$, white sucker for $14 \%$, creek chub $13 \%$, common shiner $11 \%$, brown bullhead $9 \%$, pumpkinseed $7 \%$, northern redbelly dace $6 \%$, golden shiner $5 \%$, and lake trout, smallmouth bass, yellow perch, and lake whitefish, $<5 \%$ each. The majority of lakes affected tend to be smaller lakes at higher elevations, which historically supported fairly simple fish communities.

Brook trout is the most important indigenous sport fish in Adirondack waters and was the second most common species caught by the ALSC (occurring in $52 \%$ of the lakes with fish present). Anecdotal accounts of brook trout occurrence in the 1800 s indicate that the species was also widespread historically. Although native to the Adirondacks, brook trout have been introduced into many waters where they must currently be maintained by stocking because of insufficient spawning substrate. Brook trout typically spawn in tributaries and over areas of groundwater upwelling, and high levels of silica were found to be associated with the potential for self-sustaining brook trout populations. Concentracions of silica measured by the ALSC were used, therefore, to estimate the potential for brook trut natural reproduction within waters that currently have low $\mathrm{pH}(<5.0)$ and no brook trout. Rsiatively few of these lakes (10-15\%) were classified, based on their silica conceritration, as having the potential to support lake-spawning populations of brook trout. Thus, 
even if acidity levels were reduced, it would appear that under present-day conditions (e.g., of fishing pressure) many of these lakes would require supplement stocking to support brook trout.

Finally, perhaps 50-70\% of the lakes that are currently fishless appear to always have been fishless, or are fishless primarily for reasons other than mineral acidity, and thus would likely remain fishless even with reductions in acidic deposition. 


\section{SECTION 1}

\section{INTRODUCTION AND BACKGROUND}

\section{- J. Baker, S. Gherini, and R. Munson}

Much of the debate in the United States concerning the effects of acidic deposition on surface water chemistry and fish communities has focused on the Adirondack Region of New York State

(Figure 1-1). To better characterize the chemical and biological status of Adirondack lakes, the Adirondack Lakes Survey Corporation (ALSC) was formed as a cooperative effort of the New York State Department of Environmental Conservation (NYSDEC) and the Empire State Electric Energy Research Corporation (ESEERCO). Between 1984 and 198\%, the ALSC surveyed 1469 lakes within the Adirondack ecological zone. The results from this survey are described in the ALSC summary report, Adirondack Lakes Study 1984 1987: An Evaluation of Fish Communities and Water Chemistry (Kretser et al. 1989). The summary report details the survey objectives, design, and techniques, and provides extensive summary statistics for all measured parameters.

As a follow-up to this effort, the ALSC sponsored a series of interpretive analyses of the ALSC data set The results from these analyses are presented in this report, which is organized in two parts: one dealing with the acid-base chemistry of Adirondack lakes, the other with fish communities and factors that influence them in Adirondack lakes. To guide these analyses, the ALSC. Management Committee, which is comprised of members from the NYSDEC and ESEERCO (and its member utilities), identified a set of key questions of interest:

\section{Water Chemistry}

- What is the influence of mineral acids and bases on hydrogen ion $\left(H^{\prime}\right)$ concentrations in Adirondack lakes?

- What is the influence of other acids and bases on $\mathrm{H}^{+}$concentrations?

- What is the influence of geomorphic characteristics (e.g., soil thickness, wetlands) on lake water quality?

- Can lakes be classified based upon water quality measurements to estimate unmeasured yet influential geologic characteristics? 


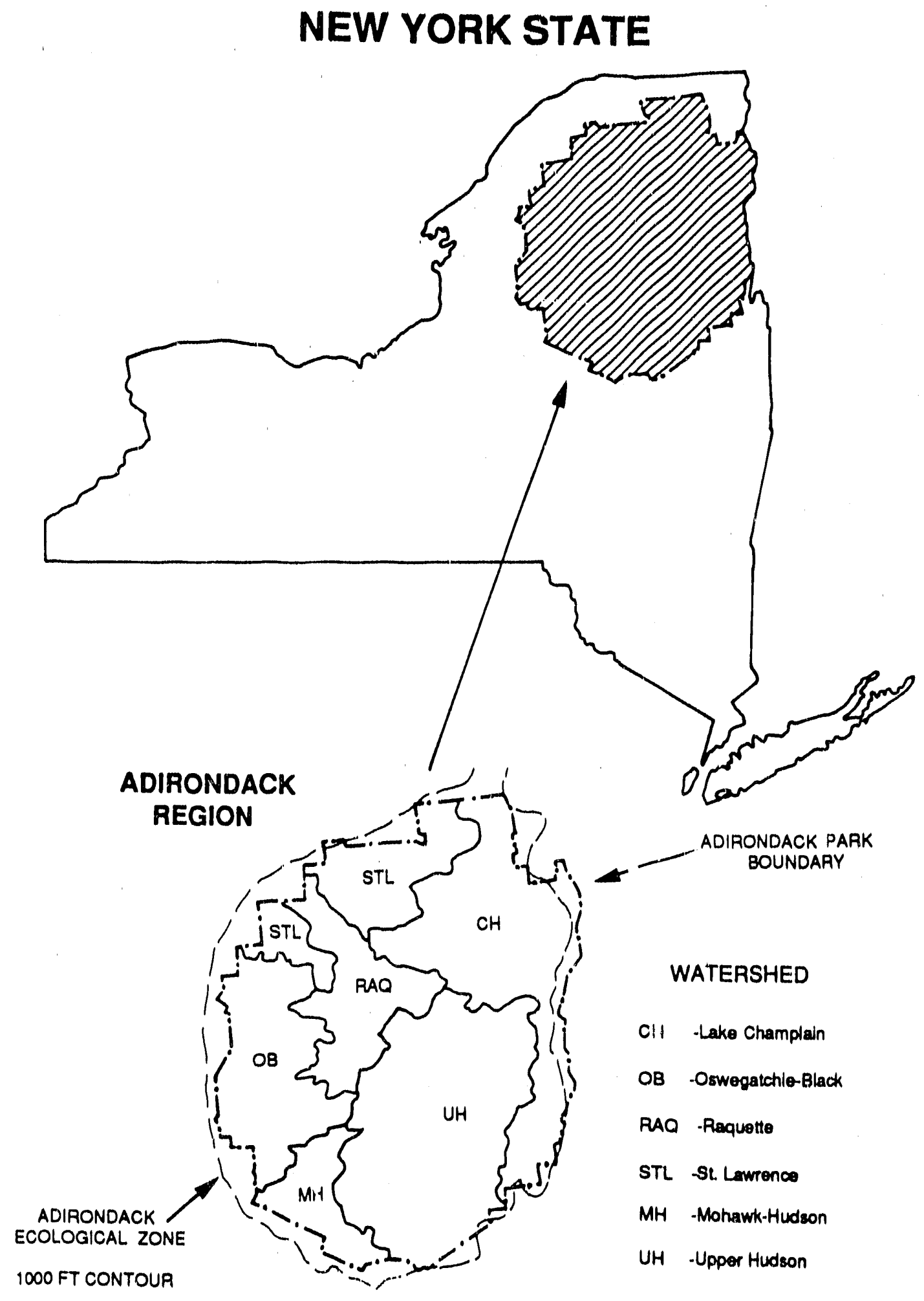

Figure 1.1 Adirondack region showing both the Adirondack Park and Adirondack ecological zone boundaries. 
- Can the change in $\mathrm{pH}$ resulting from ch inges in acidic deposition or dissolved organic carbon concentrations be estimated?

- Is there evidence of time trends in the water quality of Adirondack lakes?

\section{Fish Communities}

- Where do fish occur? Where do they not occur?

- Did fish occur historically in these lakes?

- If fish do not occur in a lake or group of lakes, why not?

- What fish could these lakes support if the chemistry was suitable?

- How many of the lakes with fish are at risk frum acidic deposition?

These questions are primarily addressed using the ALSC survey results. As appropriate, other data sets and tools developed during related research projects conducted in the Adirondack region, such as the Regional Integrated Lake.Watershed Acidification Study (RILWAS) sponsored by the llectric Power Research Institute (EPRI) and ESEERCO (Project 82-4), are used. Sections 2 and 3 of this report describe the results of interpretative analyses on water chemistry and fish, respectively. In Section 4, Summary and Conclusions, the results from these analyses are then reorganized specifically to answer each question above

The ALSC survey provides an extremely comprehensive overview of the current status of water chemistry and fish communities in Adirondack lakes. Several features of the ALSC survey design deserve note as they may influence interpretation of the study results. The lakes sampled are distributed within the five major watersheds originating in the Adirondack ecological zone: Lake Champlain, Oswegatchie-Black, St.Lawrence-Raquette, Upper Hudson, and Mohawk-Hudson (Figures $1-1$ and 1-2). The ecological zone is defined as the area generally lying within the $305 \mathrm{~m}$ $(1000 \mathrm{ft})$ elevation contour surrounding the Adirondack uplands and mountain region, with minor deviations from the elevation perimeter to accommodate waters such as Lake George and Sacandaga Reservoir. Lakes located within the Adirondack ecological zone at elevations below $305 \mathrm{~m}$ were also included in the target population for the ALSC survey. The ecological zone covers approximately 2.6 million ha (10,000 square miles); 2759 individual lakes and ponds $>0.2$ ha in size (more than 99,000 ha of lake area) have been identified on U.S. Geological Survey (USGS) 15 -minute and 7.5-minute maps within the zone boundary (Colquhoun et al. 1984). The ALSC surveyed 1469 or $53 \%$ of these waters.

Lakes were selected for sampling to provide a nonbiased, representative sample of lakes in the region based on size and elevation, but constrained by the logistical requirements of surveying a large number of remote lakes within the available field seasons. Several types of lakes were excluded from 


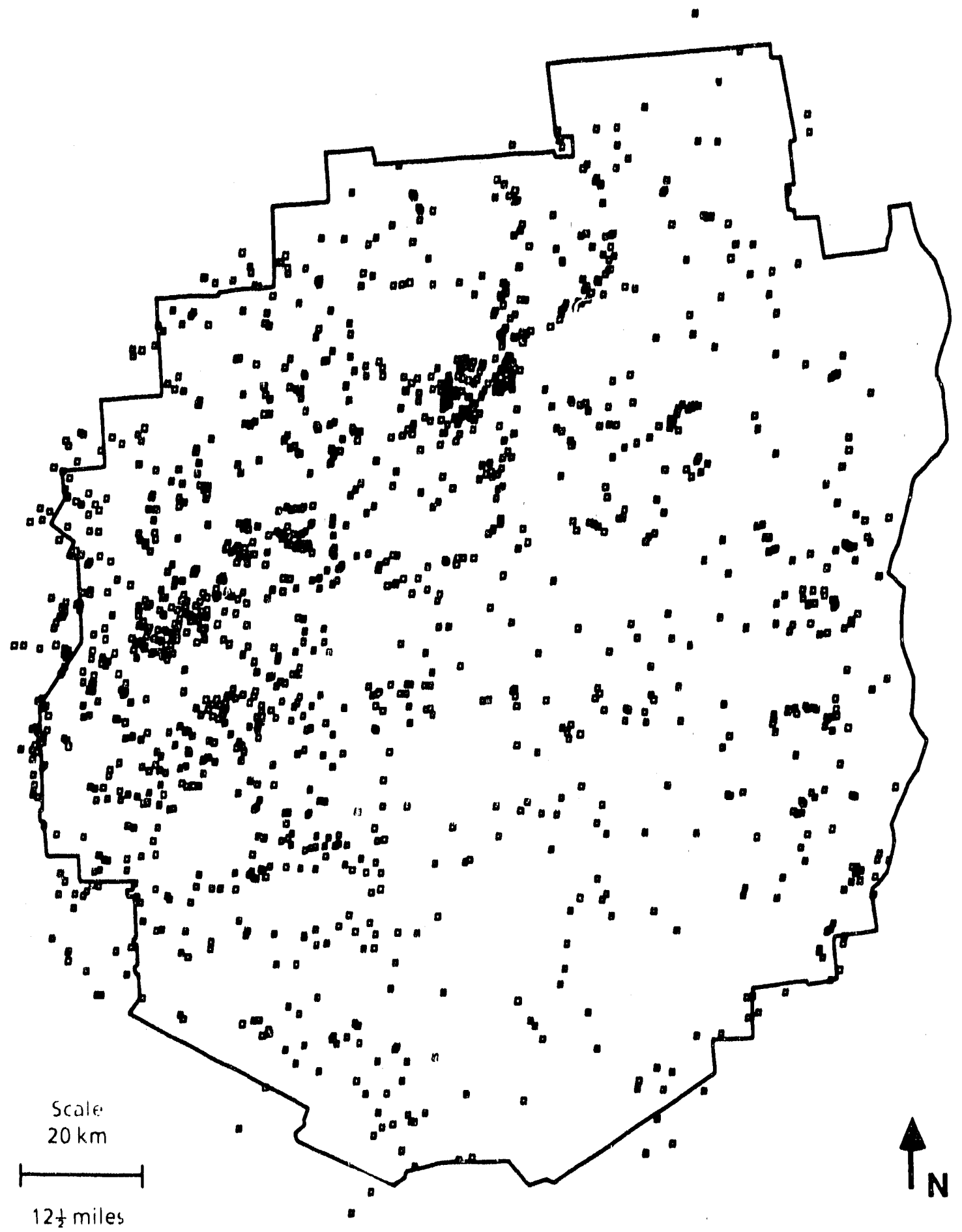

Figure 1-2 Locations of the lakes surveyed by the Adirondack Lakes Survey Corporation from 198 / to 1987 relative to the Adirondack Park boundary. 
consideration: lakes limed, reclaimed, or sampled for fish within 3 years prior to the scheduled sampling season; lakes less than 0.5 ha in size that were identified as being too shallow or dry, weed choked, or filled with trees or stumps; and lakes greater than 203 ha surface area A minimum lake size of 0.2 ha was established.

To accommodate the intensive level of sampling during the first 3 years of the survey (1984-86), sampling efforts were restricted to three of the five Adirondar.k watersheds: Lake Champlain, St. Lawrence-Raquette, and the Oswegatchie-Black. These watersheds represent approximately twothirds of the physical landmass of the Adirondack ecological zone. About 400 lakes per year were selected for surveying using a modified randoin sampling process. Each year (1984-86), at least 60\% of the lakes to be sampled were selected randomly and identified on the ALSC Adirondack regional planning map. The randomly selected waters were then supplemented with nearby ponded waters that met qualifying criteria and were located within a distance of approximately $2.0 \mathrm{~km}$ of the randomly selected lakes. Some final adjustments to the list of lakes to be sampled were made after comparing the size and elevation of the stuciy lakes to those on the candidate list Over the 3-year period, 1247 lakes $(67 \%$ ) of the 1862 lakes in the three watersheds with surface areas greater than 0.2 ha were sampled.

During 1987, only lakes in the Upper Hudson and Mohawk-Hudson watersheds were sampled. Lakes were selected for sampling using a completely random process. Two-hundred and twenty-two (222) lakes were surveyed, comprising $25 \%$ of the 897 lakes larger than 0.2 ha in these two watersheds within the Adirondack ecological zone.

The distributions of lake area and elevation for the 1469 lakes surveyed by the ALSC are quite similar to those for all lakes (larger than 0.2 ha in size; $n=2759$ ) in the Adirondack ecological zone (see Kretser et al. 1989). Thus, the results from the ALSC survey are summarized as the percentage of lakes sampled; it is presumed that this sample of lakes is reasonably representative of all lakes in the Adirondack ecological zone

The specific procedures and variables measured for surveys of water chemistry and fish communities are described in Sections 2 and 3, respectively. Further details on the survey design can be found in Kretser et al. (1989) 


\section{SECTION 1 - REFERENCES}

Colquhoun, J., W. Kretser, and M. Pfelffer. 1984. Acidity Status Update on Lakes and Streams in New York State. New York State Department of Environmental Conservation, Albany.

Kretser, W.J., J. Gallagher, and J. Nicolette. 1989. Adirondack Lakes Survey, 1984-87: An Evaluation of Fish Communities and Water Chemistry. Adirondack Lakes Survey Corporation, Ray Brook, NY. 


\section{SECTION 2}

\section{EVALUATION OF THE CHEMISTRY OF ALSC LAKES}

\subsection{INTRODUCTION}

\section{- C.T. Driscall, J. Gallagher, and R.K. Munson}

\subsubsection{Background}

Interpretation of the ALSC chemical data was undertaken after all of the data had been collected; the results of these analyses are presented in this report. It is not our intent, however, to duplicate the summary statistics presented in Kretser et al. (1989). Sections 2.1 and 2.2 present background information on the study and a description of the Adirondack region. Section 2.3 contains analyses of the inter relationships of water quality parameters and also provides a framework for understanding the subsequent interpretive analyses presented in Section 2.4 on lake classification and Section 2.5 on the integrated analyses.

The remlainder of this section describes the objectives and the approach used in the interpretive analyses. This is followed by descriptions of past synoptic lake acidification studies conducted in the Adirondacks and a brief overview of the Adirondack Lakes Survey. Finally, a discussion of the ALSC data base and the quality of the data it contains is also presented.

\subsubsection{Objectives and Approach}

The objective of the interpretive analyses of the ALSC water quality data was to provide as thorough an understanding as possible of the acid-base characteristics of Adirondack lakes This effort was guided by the project Management Committee, comprised of members from the New York State Department of Environmental Conservation (NYSDEC) and Empire State Electric Energy Research Corporation (ESEERCO), and its member utilities. The committee developed the following series of questions to be addressed:

- What is the influence of mineral acids and bases on hydrogen ion $\left(H^{*}\right)$ concentration?

- What is the influence of nonmineral acids and bases on $\mathrm{H}^{*}$ concentration? 
- What is the influence of geomorphic characteristics (e.g., till thickness, wetlands) on lake water quality?

- Can lakes be classified based upon water quality measurements to estimate unmeasured yet influential geologic characteristics?

- Can estimates be made of the change in $\mathrm{pH}$ resulting from changes in acidic deposition and/or dissolved organic carbon (DOC) concentration?

- Is there evidence of time trends in the water quality of Adirondack lakes?

Attempts to answer these questions involved full use of the ALSC data and, whenever possible, avoided sole reliance on the use of algorithms for describing water quality behavior. Instead, knowledge derived from mechanistic investigations such as the Integrated Lake-Watershed Acidification Study (ILWAS) and the Regional Integrated Lake-Watershed Acidification Study (RILWAS) (Goldstein et al. 1984, 1987) was used to guide the analyses of the ALSC data. Basing an analysis on data alone has the advantage of avoiding disputes regarding the proper values of equilibrium constants and other calculated parameters. The size and depth of the ALSC data base made these types of analyses possible. It was hoped that restricting analyses to the data would lead to much more rigorous and defensible conclusions. There were, however, a few instances whien equilibrium expressions were used to conduct analyses (e.g., speciation of aluminum), but the bulk of the analyses presented rely solely and directly on the ALSC data.

To address the question regarding time trends, the analysis had to go beyond the ALSC data. The ALSC survey, being synoptic in nature, did not lend itself to the analysis of trends in lake water quality. Therefore time series data from lakes sampled during RILWAS and the Adirondack LongTerm Monitoring Project (ALTM) were used in this analysis, as described in Section 2.5.

\subsubsection{Past Synoptic Surveys}

A number of synoptic surveys have been conducted to assess the quality of surface waters in the Adirondack region. Several of these are described below.

\subsubsection{Early NYSDEC Biological Surveys}

A series of biological surveys of ponded waters in the Adirondacks were conducted by New York State from 1929 through 1934 (N'YSDEC, 1930; 1931; 1932; 1933; 1934; 1935). In the early surveys, pH was measured using a Hellige color comparitor, and acid neutralizing capacity (ANC) was determined by strong acid titration using a methyl orange end point indicator. Unfortunately, these techniques do 
not provide accurate analyses of dilute waters (Pfeiffer and Festa 1980; Kramer and Tessier 1982). Moreover, only a fraction of the waters surveyed were actually measured for $\mathrm{pH}$ and ANC.

\subsubsection{The Schofield Survey}

Schofield surveyed the chemical chararteristics of 214 high-elevation lakes $(>610 \mathrm{~m})$ in 1975 . He conducted a detailed analysis to elucidate factors responsible for regional variations in water chemistry. Schofield (1976a) reported that $55 \%$ of the high-elevation lakes had negative titrated ANC values. The distribution of $\mathrm{pH}$ in these waters was skewed, with $52 \%$ of the lakes having values less than 5, 24\% having values bctween 5 and 6 , and $24 \%$ having values greater than 6 .

Concentrations of sulfate $\left(\mathrm{SO}_{4}\right)$ were relatively uniform across the region.

Variations in ANC were largely explained $(77 \%)$ by variations in base cation concentration. Schofield concluded that lake-to-lake differences in ANC were due to the heterogeneity in the geological characteristics of the Adirondacks (Schofield 1976a,b).

Schofield (1976a) also showed that ANC is generally lowest in high-elevation lakes in the western Adirondacks, which are typically situated in basins derived from granitic gneiss and receive large amounts of precipitation. He suggested that these watersheds are characterized by minimal inputs of base cations. Most of the lakes with $\mathrm{pH}$ values $>6$ were situated near Grenville marble outcrops or within lower elevation surficial deposits and drift, which were presumably high in exchangeable bases. As part of this survey, samples were measured for aluminum (Al), manganese (Mn), iron (Fe), Zinc $(\mathrm{Zn})$, and copper $(\mathrm{Cu})$. Concentrations of $\mathrm{Al}, \mathrm{Mn}$, and $\mathrm{Zn}$ were found to be highest at low $\mathrm{pH}$ values.

\subsubsection{The Wood Survey}

Wood (1978) surveyed 57 lakes in the Adirondacks in 1975; he found that $53 \%$ of the lakes had pH below $5,45 \%$ had $\mathrm{pH}$ values between 5 and 6 , and $2 \%$ had $\mathrm{pH}$ above 6 . Unfortunately, ANC was not measured in this survey. Regional patternis reported were similar to the findings of Schofield $(1976 a, b)$. An additional observation was that concentrations of lead $(\mathrm{Pb})$ were higher in the lower $\mathrm{pH}$ waters.

\subsubsection{Later NYSDEC Surveys}

NYSDEC conducted a series of surveys to assess the acid-base status of selected ponded waters and streams in the 1970s and 1980s. The results of these studies are summarized in two reports (Pfeiffer and Festa 1980; Colquhoun et al 1984). From 1975 to 1982,980 ponds were surveyed: $6 \%$ had 
negative ANC; $18 \%$ had ANC between 0 and $40 \mu \mathrm{eq} / \mathrm{L} ; 52 \%$ had $A N C$ between 40 and $200 \mu \mathrm{eq} / \mathrm{L}$; and $25 \%$ had ANC above $200 \mu \mathrm{eq} / \mathrm{L}$ (Colquhoun et al. 1984). The regional patterns of $\mathrm{pH}$ and ANC summarized in these studies were similar to those reported by Schofield $(1976 a, b)$.

\subsubsection{U.S. EPA Eastern Lake Survey}

In 1984, the U.S. Environmental Protection Agency (EPA) initiated Phase I of the Eastern Lake Survey (ELS-1), as a part of the National Surface Water Survey (NSWS) (Linthurst et al. 1986a; Landers et al. 1988). The objective of the ELS-I was to determine the physical and chemical characteristics of lakes within regions thought to be susceptible to acidic deposition and to estimate the number, percentage, and location of acidic lakes. The lakes surveyed were selected using a stratified random design to allow extrapolation of results to the entire population of lakes. The target population was generally defined as lakes with a surface area greater than 4 ha. In addition to the randomly selected lakes, several lakes of special interest were sampled as part of this survey.

In the ELS-1, lakes were sampled during fall turnover in 1984. The resulting values were considered to be an index of annual water chemistry (Linthurst et al. 1986a). Twenty- six water chemistry parameters were measured. In addition, information was collected on the physical characteristics of the lake/watershed systems surveyed, including lake elevation, depth, surface area, volume, hydrologic type, annual runoff, watershed area, and land use. A detailed description of the ELS-I is provided in linthurst et al. (1986a).

As part of the ELS-I, 155 lakes in the Adirondack region of New York (NSWS Subregion 1A) were sampled in order to make population estimates (Brakke et al. 1988). These lakes were thought to represent a target population of 1290 lakes, with a total surface area of 119,000 ha. An additional 49 special-interest lakes were also sampled in the Adirondacks.

Lakes sampled as part of the ELS-I in Subregion IA were generally small, with a median surface area of 20.9 ha (Figure 2.1-1a). Adirondack lakes of the ELS-I were predominantly drainage lakes (78\%). Other lake hydrologic types defined for ELS-I included seepage lakes, 8\%; closed lakes, 7\%; and reservoirs, $7 \%$.

The Adirondacks, Subregion 1A, ranked second in the number and percentage of low-pH and negative Gran ANC lakes among ELS-I subregions (Florida was first) (Linthurst et al. 1985a). Ten percent of the Adirondack lakes had $\mathrm{pH}$ values $<5$ (Figure 2.1-1b). Fourteen percent of the lakes had negative Gran ANC values, and 50\% had Gran ANC values, $<100 \mu \mathrm{eq} / \mathrm{L}$ (Figure 2.1 - $\mathrm{C}$ ) 

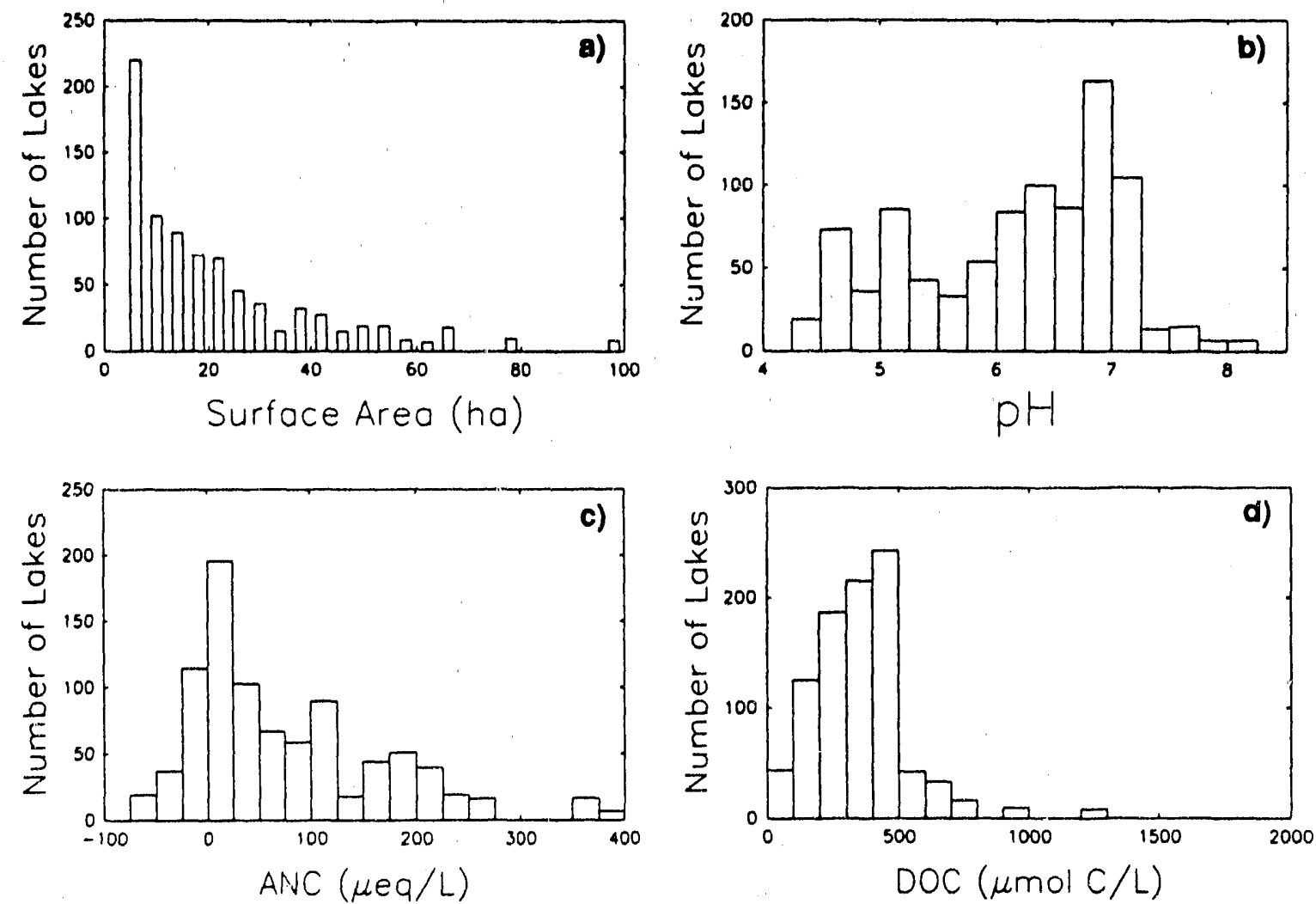

Figure 2.1-1 Distribution of physical and chemical characteristics of lakes sampled during ELS-I for Subregion IA (the Adirondacks): (a) surface area; (b) pH; (c) ANC; and (d) DOC.

Adirondack lakes were generally characterized by low DOC concentrations (median $347 \mu \mathrm{mol} C / \mathrm{L}$, or $4.2 \mathrm{mg} \mathrm{C/L}$ ) (Figure 2.1-1d). Estimates of dissociated organic anion concentrations, by discrepancy in charge balance, yielded a median value of $34 \mu \mathrm{eq} / \mathrm{L}$ (Driscoll et al. 1990). Few waters (less than $1 \%$ ) had DOC values above $1000 \mu \mathrm{mol} \mathrm{C/L} \mathrm{(1} \mathrm{mg} \mathrm{C/L)} \mathrm{or} \mathrm{dissociated} \mathrm{organic} \mathrm{anion} \mathrm{concentrations} \mathrm{above}$ $50 \mu \mathrm{eq} / \mathrm{L}$.

\subsubsection{Adirondack Lakes Survey}

Recognizing the need for a much expanded and standardized data base compared to those available from previous studies, the ALSC was formed to conduct the necessary field sampling and laboratory analyses. The study design, sampling and analytical methods, and objectives of the Adirondack Lakes Survey are described in detail by Kretser et al. (1989). A brief summary of the survey is given below. 


\subsubsection{Field Efforts}

As indicated in Section 1, field sampling efforts focused on the five major watersheds in the Adirondack ecological zone (see Figure 1-1). The water quality sampling and analysis of physical characteristics are described briefly below.

Water Chemistry. Samples from each of the 1469 ALSC lakes were collected for chemical analysis twice during the study; once during the spring (April through June) or fall (September through October) biological survey, and once during the midsummer chemistry survey (July and August). This resulted in at least two samples for each lake surveyed, with all lakes having a $1.5-\mathrm{m}$ midsummer sample and either a spring or fall sample. During the biological survey, a single water sample was collected $1.5 \mathrm{~m}$ below the water surface. During the midsummer survey, a $1.5-\mathrm{m}$ sample was also collected and, if the lake was deep enough, an additional sample was collected $1.5 \mathrm{~m}$ above the lake bottom. When lake depth was $<1.5 \mathrm{~m}$, the shallow sample was collected at mid-depth or occasionally near the surface to avoid suspended particulate matter or dense aquatic macrophyte growth. Each water sample was analyzed for 30 chemical parameters (Table 2.1-1). During the 4-year study, more than 200,000 analyses were made by the ALSC laboratory.

All water samples were collected at the deepest area of the lake or pond based on bathymetric data or at the approximate middle of the lake beyond the direct influence of inlets or surface runoff.

Helicopters were used to gain access to approximately $80 \%$ of the lakes. By using aircraft, the greatest number of waters could be sampled within the shortest time period. Water color, Secchi depth, and lake surface conditions were not recorded during aircraft operations because of rotor disturbance of lake surface water.

In addition to routine water samples, field triplicates and blanks were collected and analyzed for quality assurance and quality control ( $(2 \mathrm{AQQ})$ purposes. Five percent of the samples were collected as field triplicates. Field blanks were collected on a daily basis and processed with each batch of routine samples.

Chain-of-custody records were submitted to the laboratory with each sample batch to document sample handling, storage, and transport from time of collection to receipt at the laboratory. These documents were also used to identify holding time violations or other problems that may have occurred during sample collection or transportation.

Physical Characteristics. Morphometric data for ALSC lakes were accumulated from various sources including U.S. Geological Survey (USGS) maps, aerial photographs, NYSDEC watershed files, private 
Table 2.1-1 Chemical Parameters Analyzed

\begin{tabular}{|c|c|c|}
\hline Parameter & Method & Site \\
\hline Air-equilibrated pH & $\mathrm{pH}$ Meter & Lab \\
\hline Al & $A A^{1}$ - Furnace & Lab \\
\hline $\mathrm{NH}_{4}$ & $I C^{2}$ & Lab \\
\hline ANC & Titration-Gran Plot & Lab \\
\hline $\mathrm{Ca}$ & AA - Direct Aspiration & Lab \\
\hline $\mathrm{Cl}$ & IC & Lab \\
\hline $\mathrm{Cu}$ & AA - Furnace & Lab \\
\hline DIC & $\mathbb{R}^{3}$ Detection & Lab \\
\hline DO. & DO Probe & Field \\
\hline DOC & Oxidation - IR Detection & Lab \\
\hline Lab pH & pHMeter & Lab \\
\hline Field $\mathrm{pH}$ & $\mathrm{pH}$ Meter & Field \\
\hline $\mathrm{FI}$ & Ion Specific Electrode & Lab \\
\hline $\mathrm{Fe}$ & $A A$ - Furnace & Lab \\
\hline $\mathrm{Pb}$ & AA - Furnace & Lab \\
\hline $\mathrm{Mg}$ & AA-Direct Aspiration & Lab \\
\hline $\mathrm{Mn}$ & AA - Furnace & Lab \\
\hline $\mathrm{NO}_{3}$ & IC & Lab \\
\hline$k$ & AA - Direct Aspiration & Lab \\
\hline Secchi Depth & Secchi Disc & Field \\
\hline $\mathrm{SiO}_{2}$ & Colorimetric Molybolate Reactive & Lab \\
\hline $\mathrm{Na}$ & AA-Direct Aspiration & Lab \\
\hline S. Conductance & Wheatstone Bridge & Lab \\
\hline $\mathrm{SO}_{4}$ & IC & Lab \\
\hline Temperature & Thermometer & Field \\
\hline$P$ & Colorimetric-Ascorbic Acid & Lab \\
\hline Pt-Co Color & Hach Colorimetric Kit & Field \\
\hline True Color & Nessler Tubes/Visual & Lab \\
\hline Water Color & Visual Observation & Field \\
\hline$Z n$ & AA - Furnace & Lab \\
\hline
\end{tabular}

$1 A A=$ Atomic Adsorption

2 IC = Ion Chromatography

I IR $=$ Infrared Gas Chromatographic Detection 
landowner information, and bathymetric surveys conducted by the ALSC field teams. Prior to field investigations, each lake was identified on a topographic map, and surface area and watershed size were calculated. Surface area data along with any previous bathymetric map sounding data were verified during field studies. Lake volume, mean depth, maximum depth, littoral zone area, and shoreline length were all derived from ALSC bathymetric maps, whereas watershed area was calculated from USGS topographic maps. National Oceanic and Atmospheric Administration (NOAA) mean annual runoff data were used in making flushing rate calculations.

\subsubsection{Data Base}

The ALSC data base was designed and implemented in 1984 for the purpose of organizing and storing data collected during the comprehensive lake surveys. The data base consists of biological, chemical, and physical data organized into 16 record types that reflect data forms used during field surveys. This data base is extensive, containing synoptic survey data from the large number of lakes sampled during the 4-year survey. The accumulation of information resulted in a data base with more than 170,000 records and 242 variables. In 1988, the data base was expanded to include lake categorizations based on drainage, thermal stratification, bog habitat, beaver activity, fish presence or absence, and natural spawning brook trout populations.

Specifically, the data base contains physical data such as location information (latitude/longitude), lake morphometric data, and characteristics of the surrounding watershed. Inlet and outlet data were collected, and stream flow estimates were made when possible. Lake shoreline substrate and slope characteristics were described qualitatively on a percentage basis. Table 2.1-2 briefly summarizes the major descriptors for the physical and chemical parameters in the ALSC data base.

Table 2.1-2 Summary Descriptors for the ALSC Data Base, Chemical and Physical Parameters

\begin{tabular}{ll}
\hline Descriptor & Totals \\
\hline & \\
Lakes surveyed & 1,469 \\
Water quality parameters & 30 \\
Physical parameters & 10 \\
Total number of analyses & $>200,000$ \\
Average number of chemical analyses per lake & 150 \\
QAVC analyses & 80,000 \\
\hline
\end{tabular}




\subsubsection{Data Certification}

The data certification task was undertaken early within this interpretive study to ensure that the data used in subsequent analyses were of high quality and internally consistent. Certification procedures involved the analysis of field replicate data, charge balance, and other interrelationships indicative of data quality. The certification process resulted in a list of flagged data (about $1 \%$ ), which were not used in subsequent analyses. Several of the QAVQC analyses conducted and their results are described below.

Replicate Analysis. A total of 108 triplicate field samples was collected during the water chemistry and fisheries surveys. The analysis of these samples quantified field plus laboratory variability. The data can be plotted against one another (i.e., Replicate 1 versus Replicate 2 ) on one-to-one plots. Points falling close to the diagonal one-to-one line indicate that the sum of the field and laboratory variability is small. Large deviations from the one-to-one line indicate that the data are suspect. If the data fall consistently above the one-to-one line, this indicates that the vertical axis parameter has a consistently higher value than the horizontal axis parameter. One-to-one plots are also used for several other types of analyses throughout this report.

The ALSC field replicates for $\mathrm{pH}$, calcium ( $\mathrm{Ca})$, sulfate $\left(\mathrm{SO}_{4}\right)$ and chloride $(\mathrm{Cl})$ are plotted in Figure 2.1-2. As indicated, the data generally fall very close to the one-to-one line. Replicate data for ANC are plotted in Figure 2.1-3. If the scale is expanded for the ANC measurements to encompass the range from -25 to $+25 \mu \mathrm{eq} / \mathrm{L}$ (a range in which $A N C$ is very difficult to measure), the deviations from the one-to-one line are small, indicating that the measurements are of acceptable precision. As a point of comparison, ANC data from the ILWAS and RILWAS projects are also plotted in Figure 2.1-3 The variability in the ALSC measurements is as small or smaller than that observed in the earlier studies.

Charge Balance. Another test of data quality involved calculating the charge balance for each sample. This was done by comparing the concentration of the sum of all positively charged ions to that of the negatively charged ions. Hydrogen ion $\left(\mathrm{H}^{+}\right)$concentrations were calculated directly from $\mathrm{pH}$ values. Bicarbonate ion $\left(\mathrm{HCO}_{3}{ }^{-}\right)$concentrations were calculated as a function of $\mathrm{H}^{+}$and dissolved inorganic carbon (DIC) concentrations using the thermodynamic constants and expressions shown below (Lowenthal 1978):

$$
\left.\left|I C O_{3}^{-}\right|=\mid I\right)|C|\left(\frac{\left|I^{+}\right|}{K_{C_{1}}}+1+\frac{K_{C_{2}}}{\left|I^{+}\right|}\right)^{-1}
$$




$$
\begin{gathered}
p K_{c_{1}}=\frac{17052}{T^{\prime}}+215.21 \log T^{\prime}-0.12675-545.56 \\
p K_{c_{2}}=\frac{2902.39}{T}+0.02379 T^{\prime}-6.498
\end{gathered}
$$

Where:

$$
\begin{array}{ll}
T ' & =\text { temperature (Kelvin) } \\
p K C_{1}, p K_{2} & =-\log \text { (first and second equilibrium constants for the carbonate system) } \\
l / & =\text { molar concentrations. }
\end{array}
$$

The sum of the total positive charge versus total negative charge is plotted in Figure 2.1-4. As indicated, the values typically fall below the one-to-one line, indicating that more cations have been accounted for than anions. The difference between total cation and total anion concentrations is commonly referred to as the anion deficit. The anion deficit is thought to be due, in large part, to the presence of dissociated organic acids (unprotonated organic ligands) in solution. However, there were a small number of samples in which the anion deficit was so large that the data were considered suspect. Thus, a criterion was established such that any samples with anion deficit values of greater than $400 \mu \mathrm{eq} / \mathrm{L}$ wers flagged. In addition, three samples were also flagged for which anion deficit could not be calculated because some constituent values were missing. Here anomalously high concentrations of the missing constituents would have been required to bring the anion deficit values into an acceptable range.

Special Analyses. A special test of data consistency involved calculating the partial pressure of carbon dioxide $\left(\mathrm{PCO}_{2}\right)$ in each sample based on measured $\mathrm{pH}$ and $\mathrm{DIC}$. This value was then compared to the $\mathrm{PCO}_{2}$ in the atmosphere.

Surface waters typically have $\mathrm{PCO}_{2}$ levels ranging from about 0.2 up to 10 times atmospheric values. Soil solution generally has higher $\mathrm{PCO}_{2}$ levels than surface water (e.g. 10 to 200 times atmospheric values). Soil microbial activity and root respiration produce $\mathrm{CO}_{2}$ and the solid phase and moisture occlude its diffusion from the soil.

The $\mathrm{PCO}_{2}$ ratios calculated using the $\mathrm{A}^{\prime}$ ' $\mathrm{C}$ surface water data largely clustered in the range from 1 to 10 times atmospheric levels (see Figure 2.1.5) However, there were a substantial number of samples with higher values. Data records were flagged when the calculated ratios were greater than 50 times the atmospheric value.

Data Certification Summary. A total of 44 records in the data base were flagged as being suspect (see Table 2.1-3). These were all based upon the analyses described above. The 44 records represent 

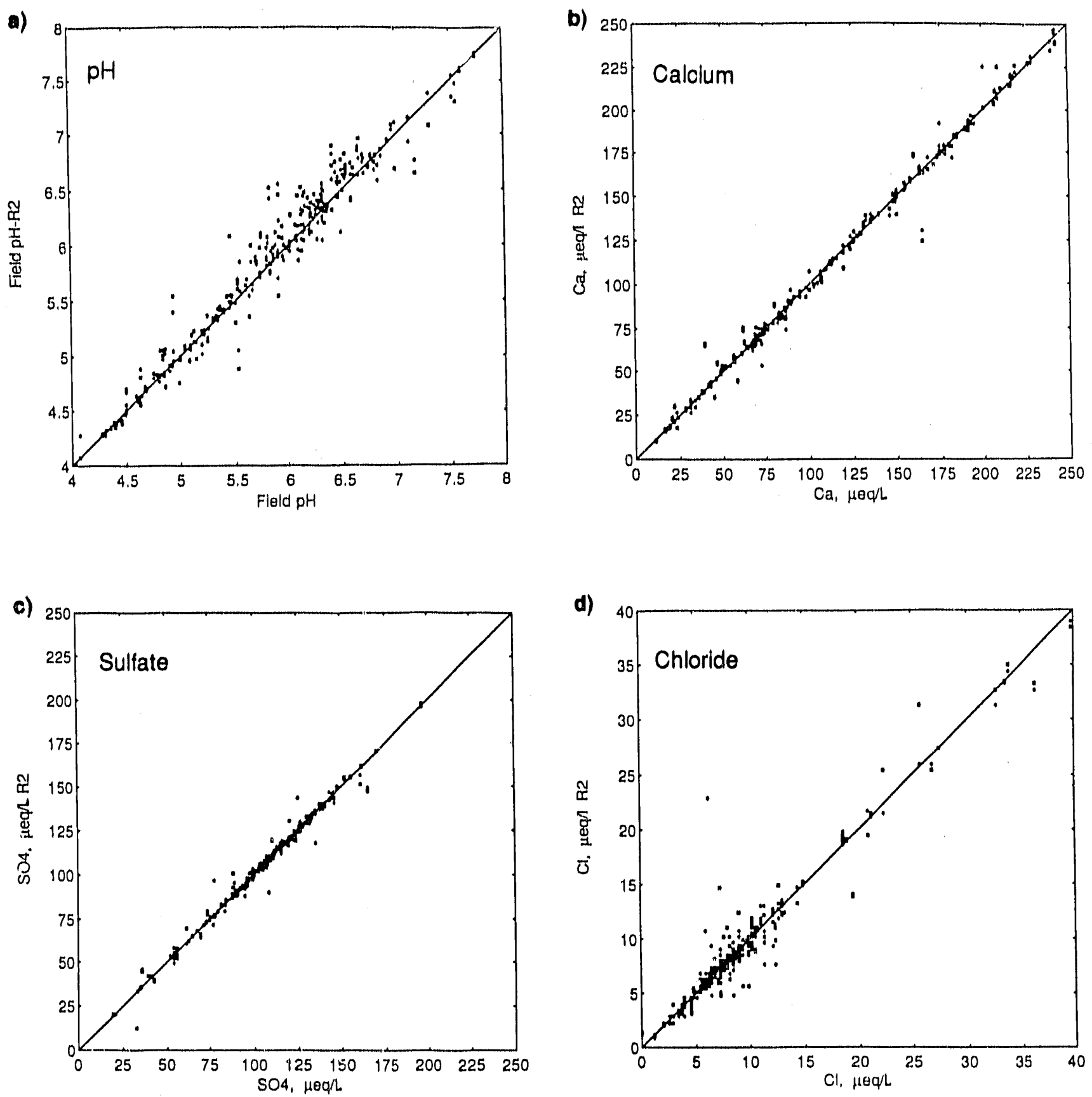

Figure 2.1-2 Replicate analysis for (a) field pH, (b) calcium, (c) sulfate, and (d) chloride. Points close to the one-to-one line indicate small variability in replicate values. 
a)

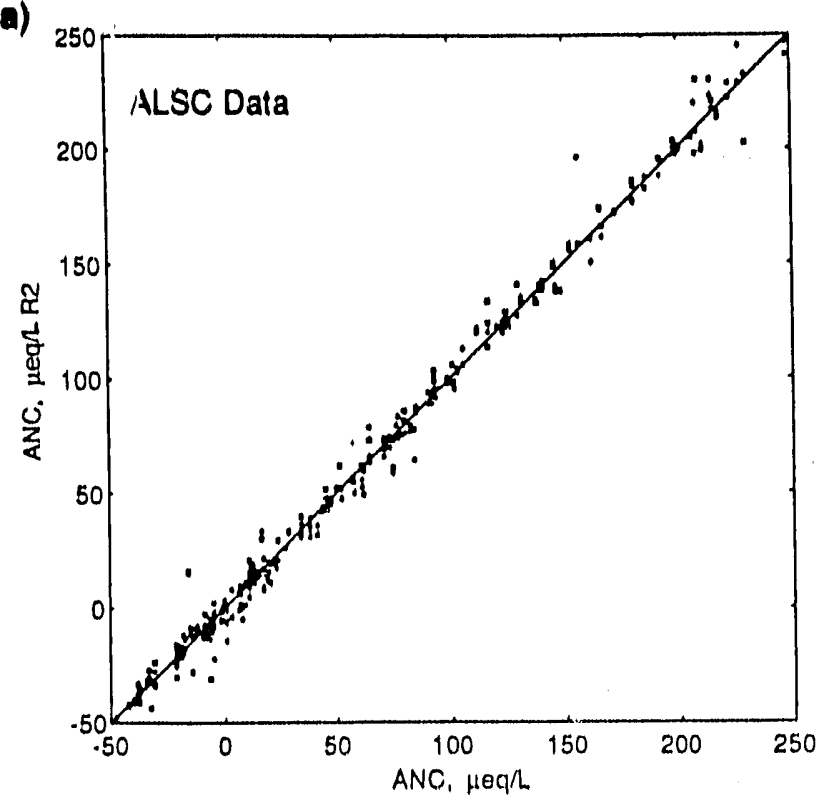

c)

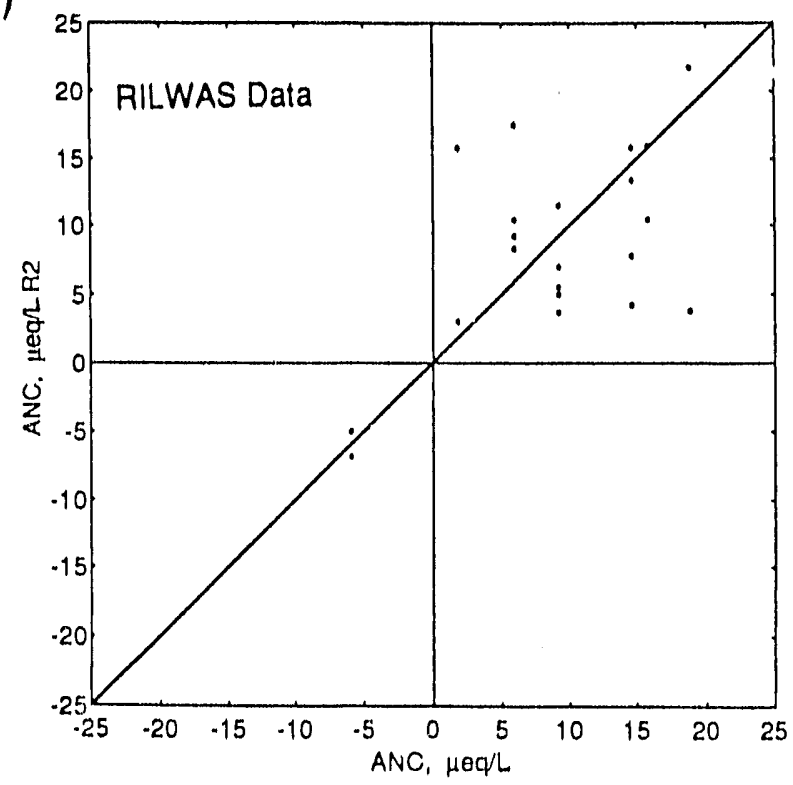

b)

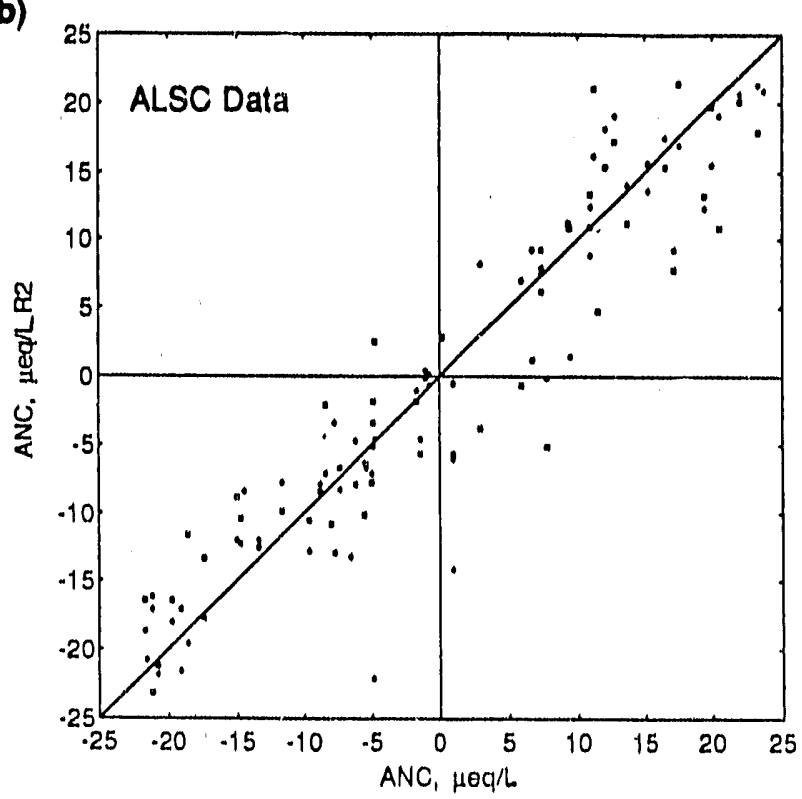

d)

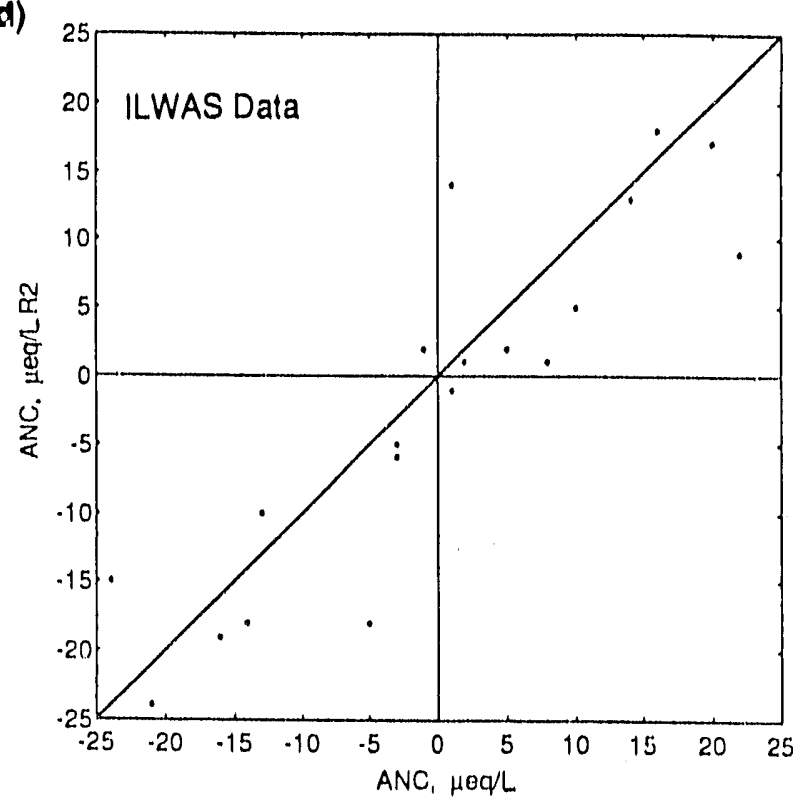

Figure 2.1-3 ANC replicates from (a) ALSC data, -50 to $250 \mu \mathrm{eq} / \mathrm{L}$, (b) ALSC data, -25 to $25 \mu \mathrm{eq} / \mathrm{L}$, (c) RILWAS data, -25 to $25 \mu \mathrm{eq} / \mathrm{L}$, and (d) ILWAS data, -25 to $25 \mu \mathrm{eq} / \mathrm{L}$. 


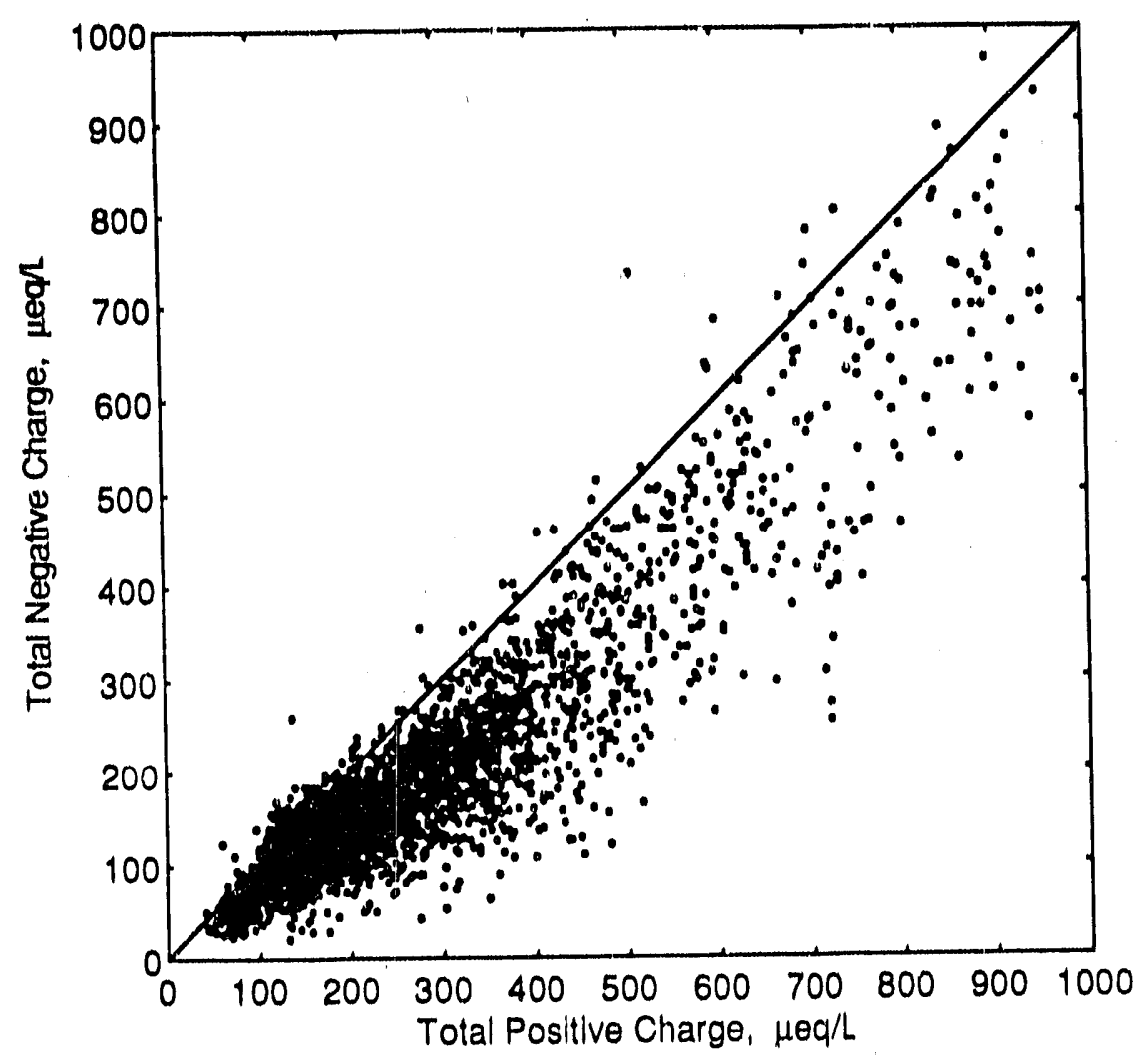

Figure 2.1.4 Total positive versus total negative charge. Most values fall below the one-to-one line, indicating a deficit of anions. This deficit is normally attributed to dissociated organic acids (unprotonated organic ligands).

just over $1 \%$ of the total data records. The flagged data were retained within the data base, but were not used in the analyses that follow.

\subsubsection{Comparison of ELS and ALSC Data Bases}

The ELS Adirondack region encompasses a much larger geographic area than that defined by the boundary of the Adirondack Park or the Adirondack ecological zone As a result, many of the lakes sampled in ELS-I Subregion 1A would not generally be considered "Adirondack" lakes Of the target population of lakes in the ELS-I Subregion 1-A, 17\% are located outside the ecological zone.

There are two aspects of the ELS-I design that warrant consideration with respect to their influence on the representation of the characteristics of Adirondack lakes. The first issue is associated with the 4-ha surface area minimum size used to select the lakes sampled. Baker and Harvey (1984) found that the frequency of lakes in the Adirondacks with negative Gran ANC values increased with decreasing surface area. In the ALSC survey, $36 \%$ of the drainage lakes and $74 \%$ of the seepage lakes had surface areas less than 4 ha (Kretser et al. 1989). Johnson et al. (1989) estimated that the Adirondack 


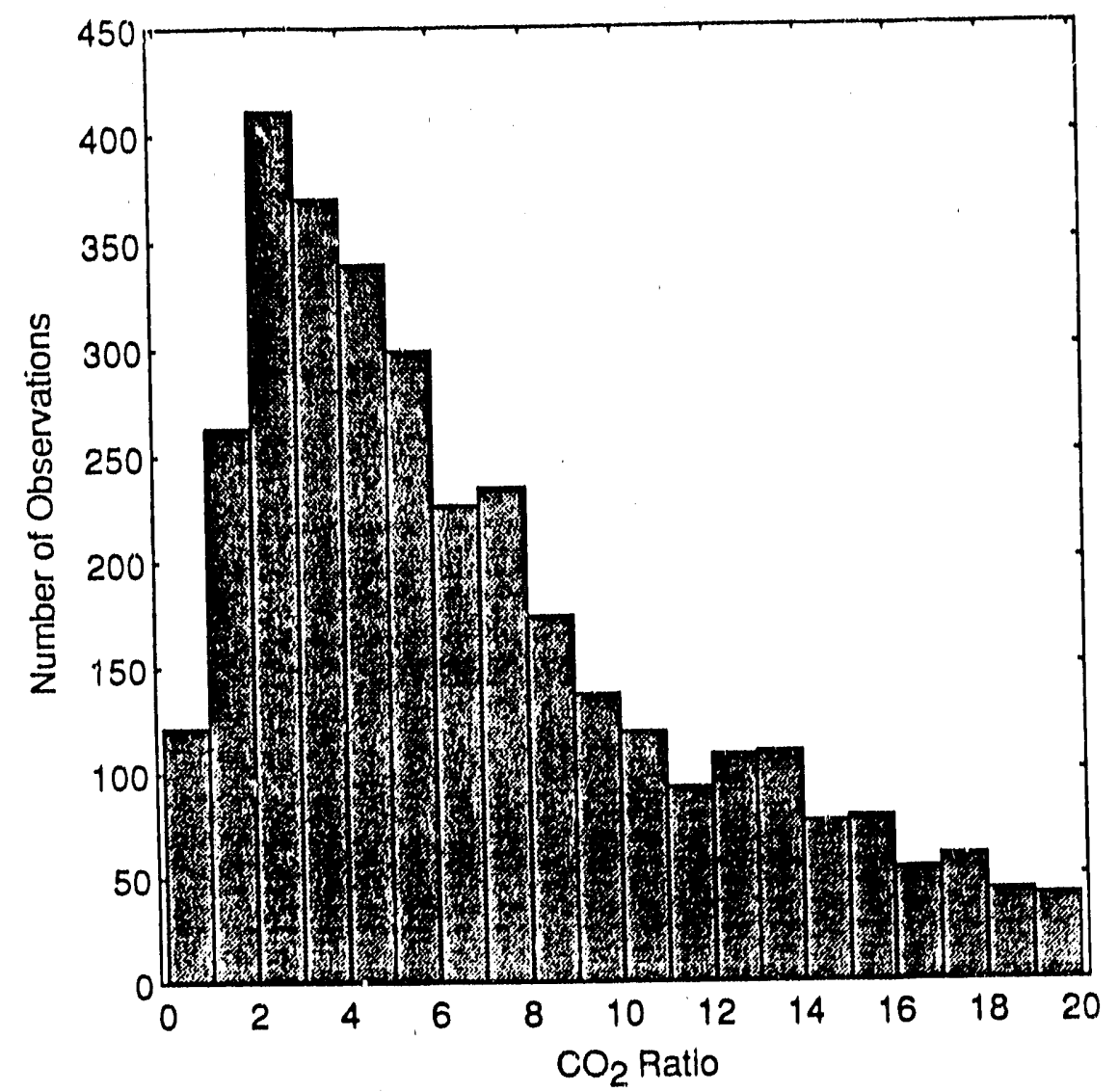

Figure 2.1-5 Distribution of the ratio of the partial pressure of carbon dioxide in ALSC waters to that in the atmosphere.

subregion of ELS-I contains 5657 lakes with surface areas greater than 1 ha and that 3130 of these are between 1 and 4 ha

Sullivan et al. (1989) attempted to evaluate the influence of the 4-ha surface area cutoff imposed in the design of the ELS-I on estimates of the number of negative Gran ANC lakes in the Adirondacks. Their assessment was accomplished by comparing ELS-I data with data available from the ALSC survey for lakes in the Adirondack ecological zone. The ALSC generally sampled ponded waters greater than $0.5 \mathrm{ha}$, but 151 smaller lakes, identified as having viable fish populations, were also sampled. While these small lakes were not sampled randomly and may not be representative of small lakes in the region, Sullivan et al. (in press) reported that the chemical characteristics of lakes with surface areas less than 1 ha were similar to lakes of the size class $1.4 \mathrm{ha}$. Sullivan et al. (in press) also indicated that generally there was little difference in the chemical characteristics of ELS-I lakes and ALSC lakes with surface areas greater than 4 ha. However, an important exception to this conclusion occurs with DOC. ALSC lakes had considerably higher concentrations of DOC (median value about $6 \mathrm{mg} / \mathrm{L}$ ) than ELS.1 lakes (about $4 \mathrm{mg} / \mathrm{L}$ ). 
Table 2.1-3 Flagged Data Records

\begin{tabular}{|c|c|c|c|c|}
\hline Pond ID & Date & Station & Depth (m) & Flags \\
\hline 20351 & $07 / 09 / 86$ & 1 & 10 & Anion def. \\
\hline 20425 & $09 / 16 / 86$ & 7 & 1.5 & Anion def. \\
\hline 50573 & $08 / 19 / 87$ & 1 & 1.5 & Anion def. \\
\hline 50402 & $10 / 06 / 87$ & 92 & 1.5 & Anion def. \\
\hline 40937 & $09 / 18 / 86$ & 5 & 1.5 & Anion def. \\
\hline 50452 & $08 / 24 / 87$ & 1 & 1 & Anion def. \\
\hline $20272 \mathrm{~A}$ & $10 / 28 / 86$ & 3 & 1.5 & Anion def. \\
\hline 50402 & $10 / 06 / 87$ & 91 & 1.5 & Anion def. \\
\hline 50573 & $08 / 19 / 87$ & 1 & 4.5 & Anion def. \\
\hline 40935 & $07 / 08 / 86$ & 1 & 3 & Anion def. \\
\hline 20139 & $07 / 19 / 84$ & 1 & 5 & Anion def. \\
\hline 50452 & $10 / 29 / 87$ & 4 & 1 & Anion def \\
\hline $40664 \mathrm{~A}$ & $08 / 23 / 84$ & 1 & 8 & Anion def. \\
\hline 20370 & $09 / 23 / 86$ & 4 & 1 & Anion def. \\
\hline 50429 & $08 / 20 / 87$ & 1 & 7 & Anion def \\
\hline 40935 & $07 / 0 B / 86$ & 1 & 1.5 & Anion def \\
\hline $5 C 573$ & $10 / 07 / 87$ & 4 & 1.5 & Anion def \\
\hline 70681 B & $09 / 02 / 87$ & 4 & 1.5 & Anion def \\
\hline 20365 & $10 / 01 / 85$ & 6 & 1.5 & Anion def \\
\hline 30083 & $08 / 15 / 85$ & 91 & 0.1 & Anion def \\
\hline 60188 & $10 / 23 / 86$ & 6 & 1.5 & $\mathrm{SO}_{4}$ \\
\hline $40303 \mathrm{~A}$ & $07 / 15 / 86$ & 1 & 1.5 & $\mathrm{Ca}$ \\
\hline $40303 \mathrm{~A}$ & $06 / 17 / 86$ & 5 & 1.5 & $\mathrm{Ca}$ \\
\hline 20373 & $08 / 13 / 84$ & 1 & 2 & $\mathrm{pH}, \mathrm{DIC}$ \\
\hline 40667 & $07 / 25 / 85$ & 1 & 2 & $\mathrm{pH}, \mathrm{DIC}$ \\
\hline 50425 & $08 / 20 / 87$ & 1 & 5 & $\mathrm{pH}, \mathrm{DIC}$ \\
\hline 50649 & $08 / 11 / 87$ & 1 & 3 & $\mathrm{pH}, \mathrm{DIC}$ \\
\hline 20105 & $07 / 25 / 84$ & 1 & 3 & $\mathrm{pH}, \mathrm{DIC}$ \\
\hline 30376 & $08 / 13 / 85$ & 1 & 4 & $\mathrm{pH}, \mathrm{DIC}$ \\
\hline $2038 ?$ & $07 / 08 / 86$ & 1 & 3 & $\mathrm{pH}, \mathrm{DIC}$ \\
\hline $600 \vdots 35 \mathrm{D}$ & $08 / 05 / 86$ & 1 & 0.5 & $\mathrm{pH}, \mathrm{DIC}$ \\
\hline 50249 & $08 / 17 / 87$ & 1 & 35 & $\mathrm{pH}, \mathrm{DIC}$ \\
\hline 20298 & $07 / 23 / 85$ & 1 & 11.5 & $\mathrm{pH}, \mathrm{DIC}$ \\
\hline 20145 & $08 / 09 / 85$ & 1 & 5 & $\mathrm{pH}, \mathrm{DIC}$ \\
\hline 30342 & $08 / 16 / 85$ & 1 & 4 & $\mathrm{pH}, \mathrm{DIC}$ \\
\hline 60169 & $08 / 07 / 85$ & 1 & 4 & $\mathrm{pH}, \mathrm{DIC}$ \\
\hline 50399 & $08 / 20 / 87$ & 1 & 1.5 & $\mathrm{pH}, \mathrm{DIC}$ \\
\hline 40439 & $08 / 22 / 84$ & 1 & 6 & $\mathrm{pH}, \mathrm{DIC}$ \\
\hline 30055 & $08 / 15 / 85$ & 1 & 6 & $\mathrm{pH}, \mathrm{DIC}$ \\
\hline 60079 & $08 / 14 / 85$ & 1 & 3.5 & $\mathrm{pH}, \mathrm{DIC}$ \\
\hline $40303 \mathrm{~A}$ & $06 / 17 / 86$ & 5 & 1.5 & $\mathrm{pH}, \mathrm{DIC}$ \\
\hline 30358 & $08 / 19 / 85$ & 1 & 6 & $\mathrm{pH}, \mathrm{DIC}$ \\
\hline 60059 & $08 / 14 / 85$ & 1 & 15 & $\mathrm{pH}, \mathrm{DIC}$ \\
\hline 50486 & $08 / 18 / 87$ & 1 & 7 & $\mathrm{pH}, \mathrm{DIC}$ \\
\hline
\end{tabular}


Distinct differences in chemical characteristics are evident between ALSC lakes with surface area $<4$ ha and either ALSC or ELS-I lakes with surface area > 4 ha. The smaller lakes (tended to have lower $\mathrm{pH}, \mathrm{Gran} \mathrm{ANC}$, and $\mathrm{Ca}$ values and higher DOC than larger lakes.

A second concern with the design of the ELS-I is the geographic definition of the Adirondack region. Although the boundary of the Adirondack Park closely coincides with the Adirondack ecological zone, Subregion 1A of the ELS-I encompasses a much larger area, including much of northern New York State. Sullivan et al. (1989) suggest that there is little difference in the chemical characteristics of ALSC lakes (within the Adirondack ecological zone) and ELS-l lakes with surface areas $>4 \mathrm{ha}$. However, closer examination of the data shows that solute concentrations in the ELS-I lakes of the Adirondack ecological zone were distinctly different from ELS-I lakes outside this zone. A.S an example of the differences, compare the distribution of Gran ANC values for waters within and outside of the ecological zone shown in Figure 2.1-6. Lakes in the ELS-1 Subregion 1A, but outside the Adirondack ecological zone, generally had higher $\mathrm{ANC}, \mathrm{Ca}$, and base cations and slightly higher $\mathrm{SO}_{4}$ than lakes within the zone
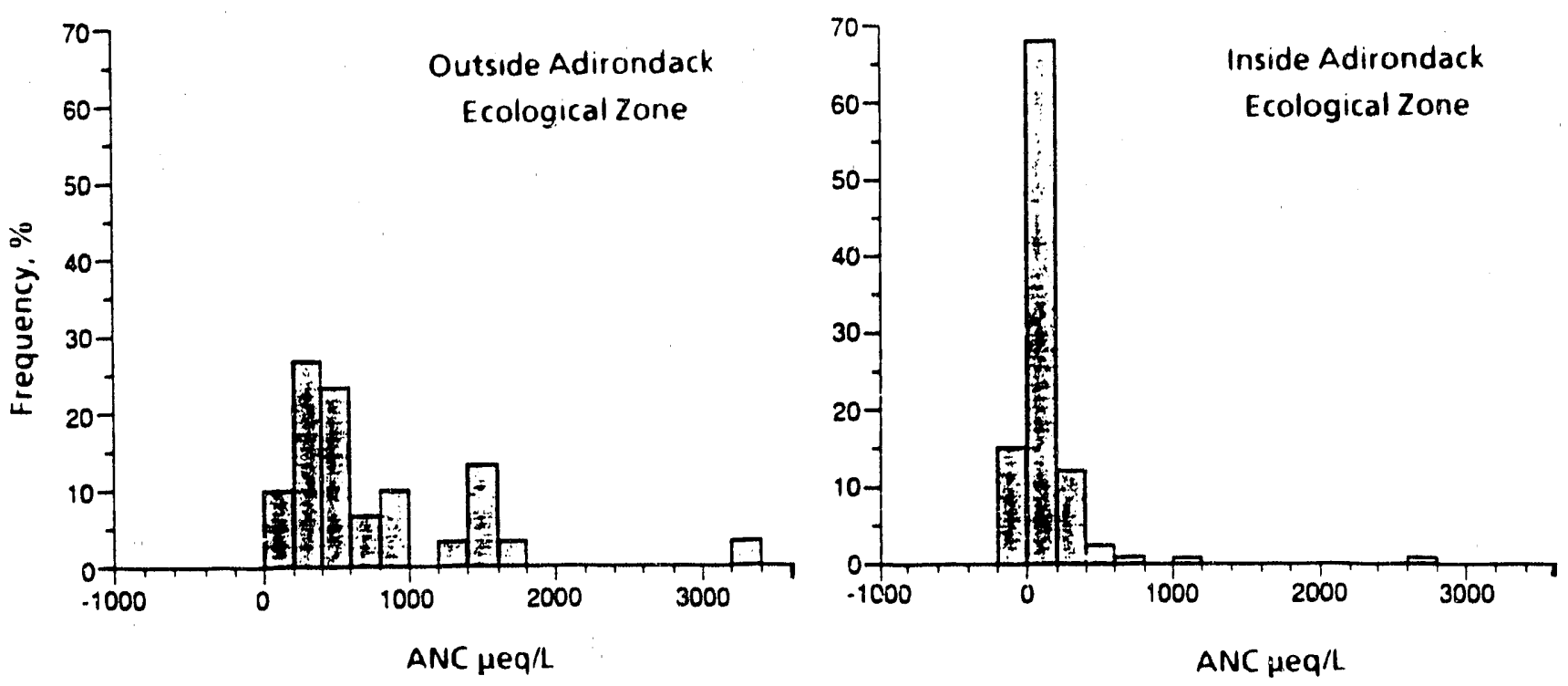

Figure 2.1-6 Distribution of Gran ANC in ELS-I subregion 1A lakes that are (a) inside, and (b) outside the Adirondack ecological zone. 
The differences are consistent with differences in the geological characteristics within and outside the Adirondacks (Driscoll et al., in press). The boundary for the Adirondacks as used by ELS-I

Subregion $1 \mathrm{~A}$ is beyond the border of the Adirondack Park and the Adirondack ecological zone. This influences the interpretation of the physical and chemical characteristics of the lakes as well as population estimates of low-pH and low-ANC lakes in the "Adirondacks." For example, if the ELS-I boundary only included the Adirondack ecological zone, the percentage estimate of lakes with negative Gran ANC values would increase by about 20\% (Driscoll et al., in press) 


\subsection{ADIRONDACK REGION}

\section{J.W. Newton}

\subsubsection{Geology of the Adirondacks}

\subsubsection{Physiography}

The Adirondack region is a dome feature of the North American plate (Figure 2.2-1). Surface elevations range from approximately $30 \mathrm{~m}$ near Lake Champlain to $1630 \mathrm{~m}$ at Mt Marcy, allowing the area to be divided into two physiographic regions; the High Peaks and the Adirondack Highlands. The High Peaks region in the northeastern portion of the park is characterized by mountains ranging in elevation from 1200 to $1600 \mathrm{~m}$ above sea level with up to $1200 \mathrm{~m}$ of vertical relief Forty-six of the high peaks have elevations greater than $1200 \mathrm{~m}$. To the north, south, and west of the High Peaks region, surface elevation decreases gradually. This less rugged terrain is the Adirondack Highlands with relief of generally less than $600-700 \mathrm{~m}$. To the east of the High Peaks, surface elevation changes sharply as a result of block faulting in the Lake Champlain area

The Adirondack dome is extensively fractured by north northeast-trending block faults on its eastern and southeastern flanks. Glacial erosion along these faults has produced deep, linear valleys, many of which are occupied by long narrow lakes (Van Diver 1985)

\subsubsection{Bedrock Geology}

The bedrock of the Adırondack Mountains is part of the Grenville Province of the Canadian Shield and is some of the oldest rock in North America. These Precambrian rocks were intensely metamorphosed and deformed approximately 1.1 billion years ago. Occupying the center of the region is the Anorthosite Massif; a large igneous intrusion (Figure 2.2-1). The intrusion is composed of up to $90 \%$ Ca-rich feldspar and has undergone extensive metamorphism since its initial emplacement.

Surrounding the anorthosite are igneous and high temperature-high pressure metamorphic rocks of three general categories: metasediments, quartz syenites, and granite/granitic gneiss (Figure 2.2-1) All have undergone extensive metamorphism The metasediments comprise $30 \%$ of the Adirondack region, and compositions range from amphibolite and gneiss to marble. Marble occurs mostly in the eastern Adirondacks. The quartz syenite series defines a variety of gneisses of mafic syenitic composition (more than 20-25\% heavy minerals; primarily pyroxenes, Buddington 1968) The granite 


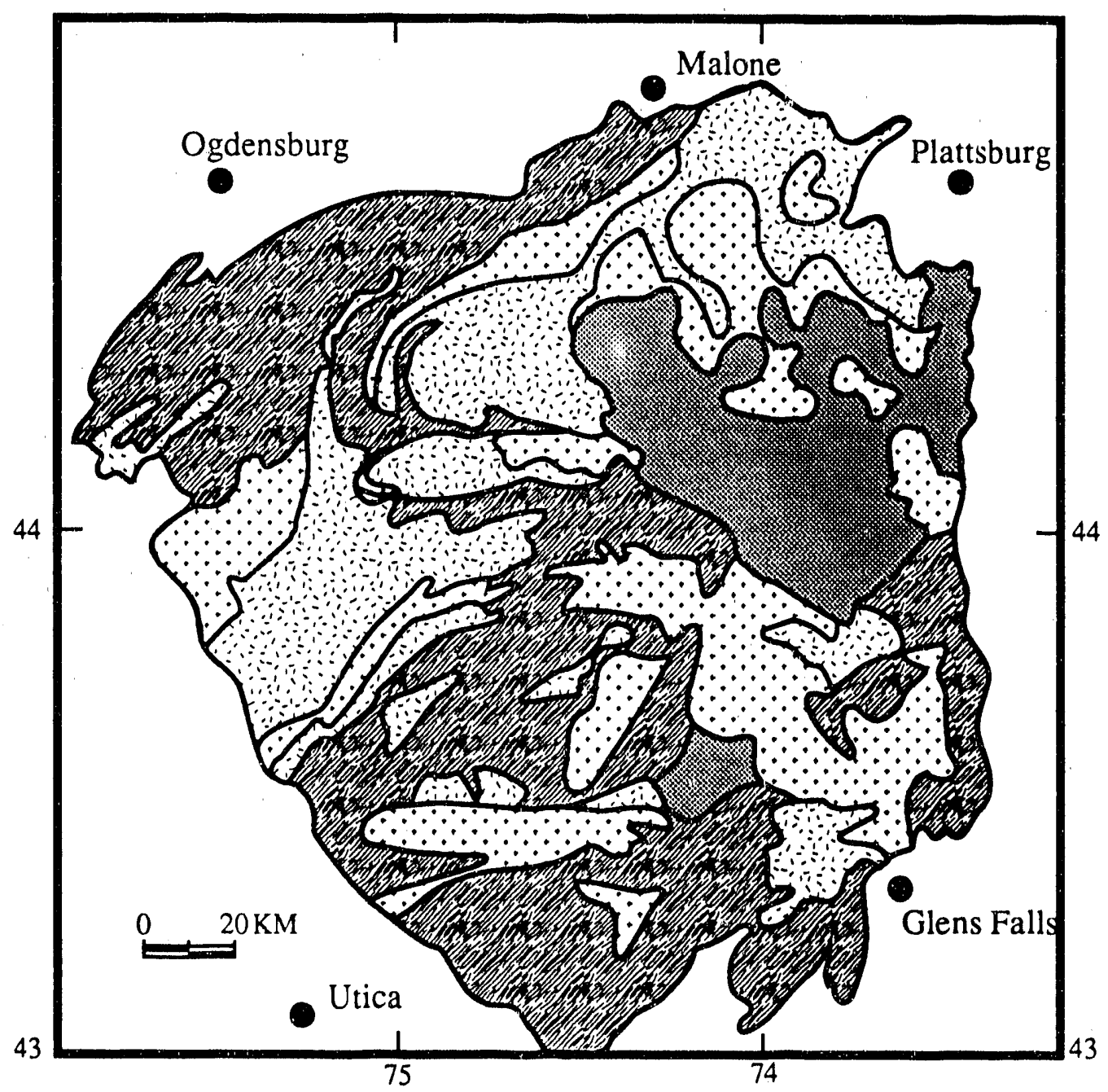

Granite and granitic gneiss includes layers of amphibolite

Anorthosite $\because \quad$ Quartz Syenite

DIII Metasediments, may include marble in isolated areas especially in the east.

Figure 2.2-1 Bedrock types within the Adirondacks (after Wiener et al. 1984). 
and granitic gneisses cover approximately $25 \%$ of the region, and compositions are generally granitic and rich in hornblende (Wiener et al. 1984). On the margin of the Adirondack region, overlying the Precambrian rocks are sedimentary deposits (lower Paleozoic age), primarily sandstones, limestones, and shales.

\subsubsection{Surficial Geology}

As early as 2 million years ago the first of several continental glaciers covered the Adirondacks. Subsequent glaciation removed and reworked initial deposits preserving only the features of the most recent Pleistocene glaciation (Wisconsin). The timing of the retreat of this last glaciation is unclear. Craft (1976) speculated that the continental ice had left the Adirondack region as early as 15,500 years before present (BP), but thought local alpine glaciers may have remained in the High Peaks region until $11,000 \mathrm{BP}$. The oldest radiocarbon date from the Adirondacks is just over 12,000 BP (Overpeck 1985). The last glaciation peaked approximately 20,000 BP and left behind substantial sediment deposits. These sediments include ablation and basal till as well as extensive deposits of stratified sand and gravel laid down by the meltwater streams of retreating glaciers.

Glacial till is an unsorted, unstratified sediment deposited directly by glacial ice. The till of the Adirondacks has a high sand content, numerous cobbles and boulders, and generally averages less than 30\% silt-and clay-sized material. Ablation till consists of material accumulated on the surface of glacial ice and deposited as the ice melts Basal till, deposited directly beneath the glacial ice, has higher concentrations of silt and clay (up to $50 \%$ )

The meltwater deposits are well-sorted and stratified sediments of sand to gravel-sized material. Most of the till and stratified drift deposits are mantled by a thin layer of aeolian silt. The mineral composition of this material is identical to that of the sediment underlying it

Since the most recent glaciation, soils have developed on the glacial sediment, the soils are generally thin and quite acidic in the upper organic-rich horizons. They are classified as varieties of Spodosols. Over 130 different soil series have been used to map the entire Adirondack region. The general distribution of soil types in the Adirondacks is summarized in Table 2.2-1

A typical Spodosol profile has a thick organic horizon overlying a well-developed leached $E$ horizon (Figure 2.2-2). Intense leaching of the E horizon by mineral and organic acids depletes base cations, $\mathrm{Al}$, and $\mathrm{Fe}$, leaving this horizon enriched in silicon (Si). The upper part of the underlying $\mathrm{B}$ horizon typically contains organic matter, together with $\mathrm{Al}$ and Fe, illuviated from the E horizon. 
Table 2.2-1 General Distribution of Soils in the Adirondacks

\begin{tabular}{lc}
\hline Description & Percent of Area \\
\hline Organic soils & 4.4 \\
Alluvial soils & 13 \\
Lacustrine soils & 1.3 \\
Acidic glacial outwash soils & 13.4 \\
Calcareous glacial till soils & 1.1 \\
Acidic glacial till soils & 48.7 \\
Shallow bedrock control soils & 24.4 \\
Water & 5.4 \\
\hline
\end{tabular}

Source: Adirondack Park Agency files

\section{Typical Adirondack Soil Profile}

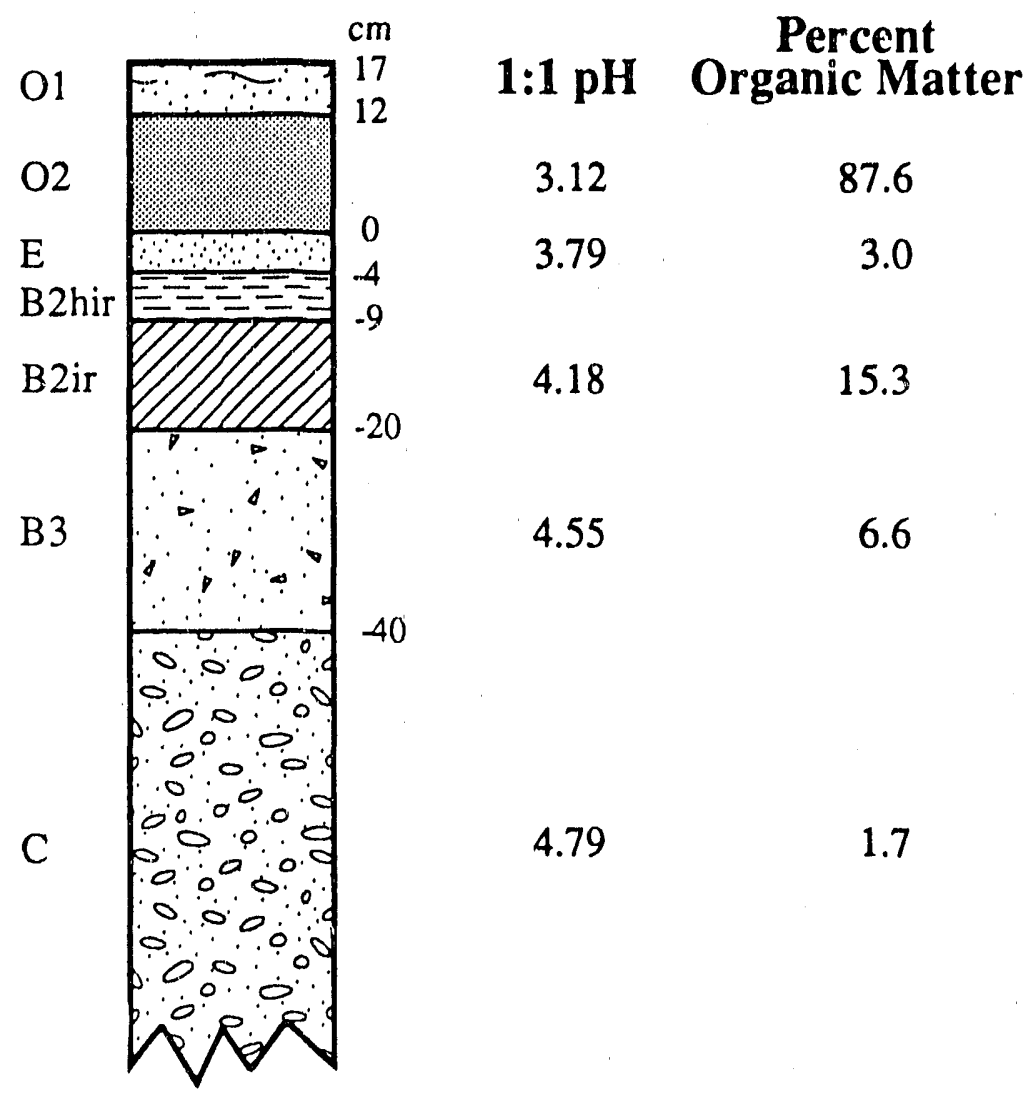

Figure 2.2.2 Typical Adirondack soil profile (after Cronan et al. 1984). 
The $B$ horizon gives way gradually to a relatively unaltered $C$ horizon, which in most cases represents the original glacial material The dominant clay mineral in Adirondack soils is vermiculite.

\subsubsection{Climate and Regional Precipitation Pattern}

The Adirondack region climate is characterized as Humid Continental (Trewartha 1954) with short, cool summers and long, cold winters. Elevation differences produce considerable variation in climate and wide ranges in both daily and annual temperature. The 30-year mean air temperature ranges from - $10^{\circ} \mathrm{C}$ in January to $18^{\circ} \mathrm{C}$ in July (U.S Environmental Data Service, 1987). The Adirondacks are located in the middle latitudes, so air is continental in origin and flows from west to east

As prevailing winds travel west to east across low-lying areas in the midwestern United States, moisture from the Great Lakes and southern Ontario accumulates. When moisture-bearing air masses intercept the higher elevations of the western Adirondacks, a large quantity of precipitation falls, producing considerable runoff (Figure 2.2-3). The Adirondack region generally receives $100-150 \mathrm{~cm}$ of precipitation annually with approximately $35 \%$ of the total falling as mixed precipitation (snow, sleet, rain, and freezing rain). The amount of precipitation at any location is influenced by the

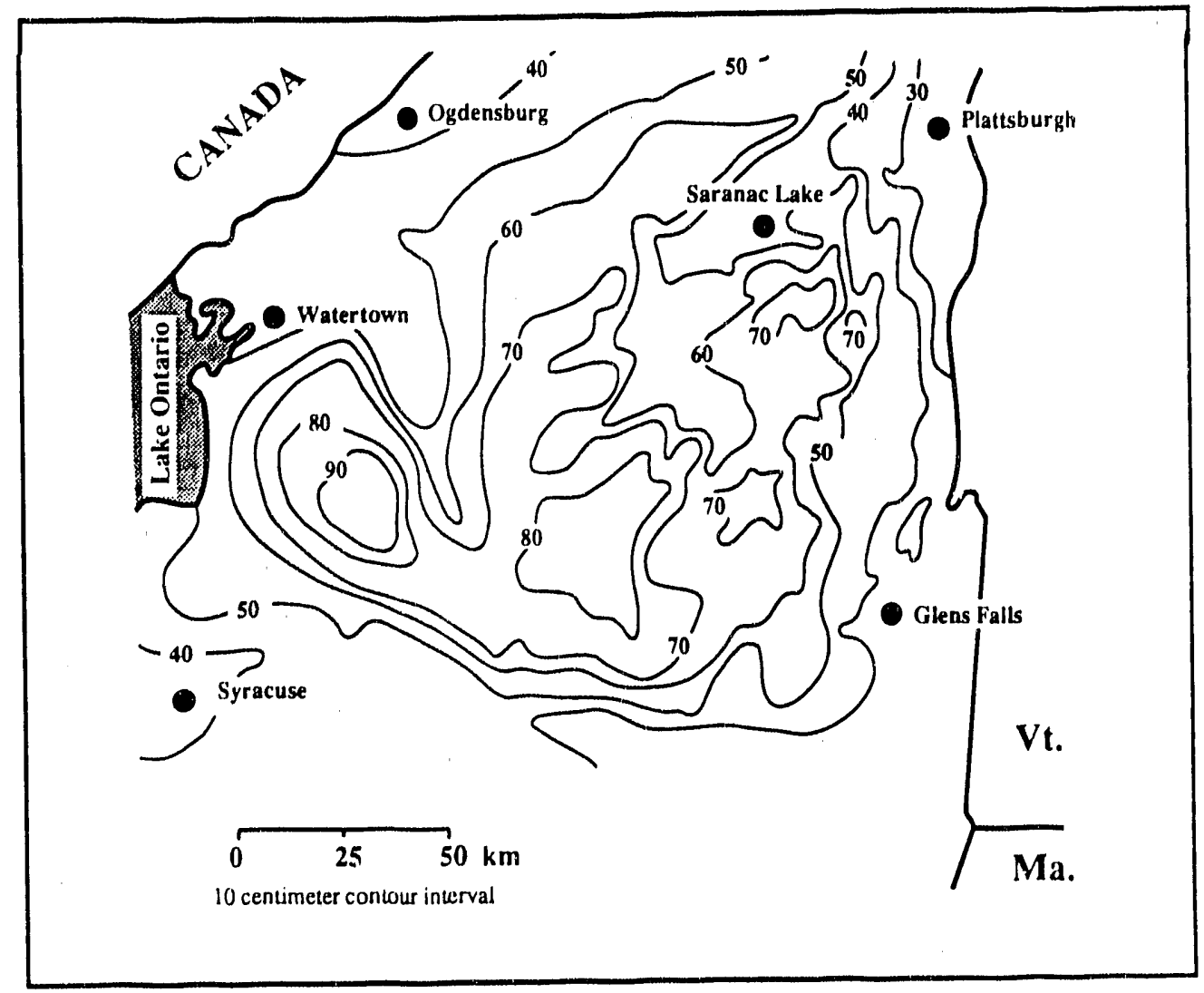

Figure 2.2-3 Average annual runoff in centimeters (after Knox et al. 1955). 
topography, with higher elevations receiving greater amounts. The dominant storm path is from southwest to northeast. Orographic lifting as storms move along this track cause more precipitation in the southwest with a large area risceiving $>125 \mathrm{~cm}$. Orographic lifting also explains the small isolated areas of the High Peaks region that receive $>125 \mathrm{~cm}$ of annual precipitation.

The RILWAS project derrionstrated that the concentrations of solutes in precipitation show little variation across the Adirondacks (, lohannes et al. 1986). Wet deposition is calculated as the product of precipitation amount and precipitation solute concentration, and thus observed variation in the wet deposition is due to the variation in precipitation amount. Since the southwest Adirondacks receive the highest amounts of precipitation, this area also receives the highest deposition Figure 22.4 shows deposition isopleths for $\mathrm{H}^{+}$and $\mathrm{SO}_{4}$ for the entire Northeast to provide a regional perspective on Adirondack deposition.

\subsubsection{Land Use}

The Adirondack region was not settled by Native Americans but served as a border between the Iroquois Nations of central New York and the Algonquins who settled the St. Lawrence River valley.
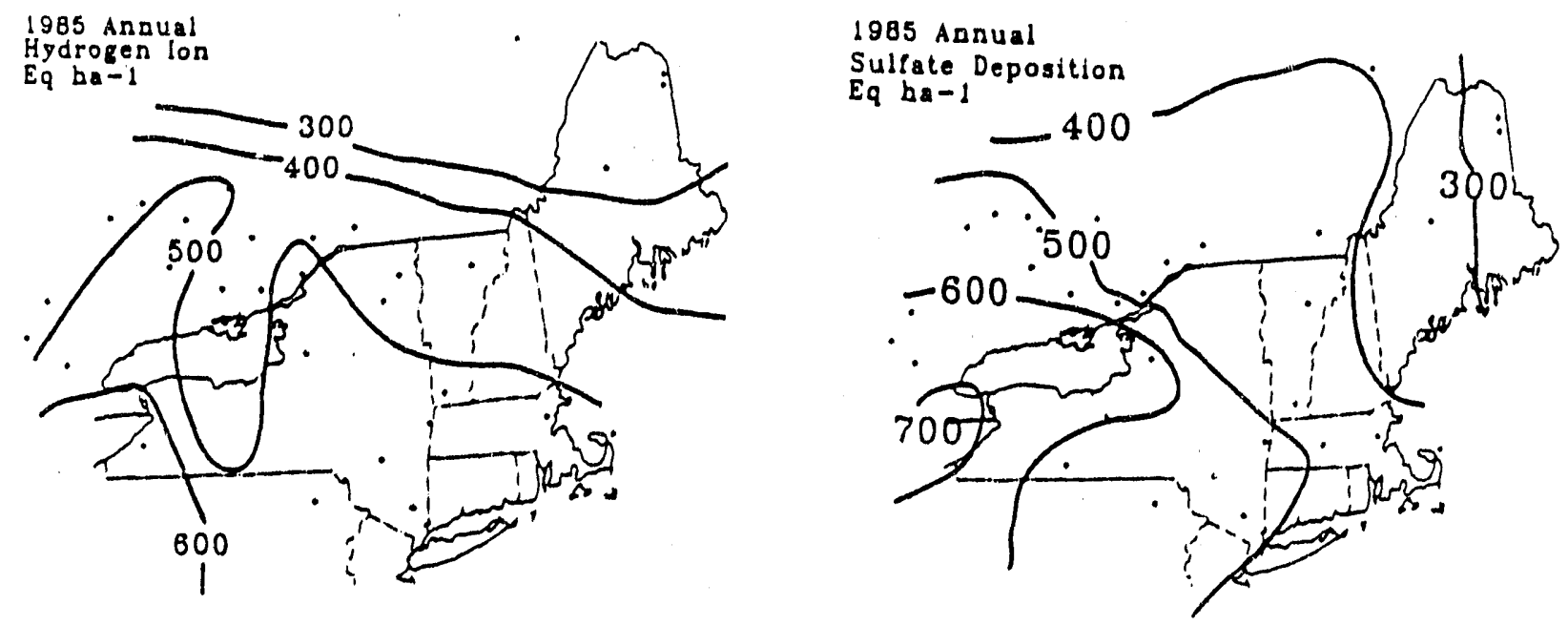

Figure 2.2-4 Hydrogen ion and sulfate deposition isopleths for the northeastern United States (after Driscoll et al., in press). 
First visited by Europearis in 1609, the region remain uninhabited for the next 150 years. During that time the border area was logged, and infrequent trapping and hunting occurred in the interior. The State of New York began selling land to private investors after the Revolutionary War, and during the following 60 years logging, pulp processing, tanning, an t charcoal production proliferated. By the end of the 19th Century, widespread clear-cutting and numerous large fires had occurred in most of the Adirondacks.

Since the 1880 s the State has exerted increasing control over land use and development. These activities included formation of the Adirondack Park in 1892 (which includes both public and private holdings) and a constitutional amendment in 1894, which requires all State land within the Park tr remain wild and not be sold or leased.

The Adirondack Preserve (public lands) has been managed by the NYSDEC since 1972. The use and development of private land is overseen by the Adirondack Park Agency. The Adirondack Park encompasses approximately 2.4 million ha and is the largest park in the lower 48 states. Of the total park acreage $41 \%$ ( 1 million ha) is State forest preserve.

Current land use in the Adirondack Park. is regulated by the Adirondack Park Master Plan. Most of the State lands are classified as wilderness or wild forest areas and protected from any development. The remaining state land is used for purposes ranging from campgrounds and ski areas to administrative facilities (including $1780 \mathrm{~km}$ of highway). Private lands have been classified to protect the environment and to preserve open space whenever possible. Most of the private land has been classified for rural use or resource management

\subsubsection{Major Drainage Basins}

The abundance of lakes in the Adirondacks is the direct result of Pleistocene glaciations. Most lakes occur at elevations below $650 \mathrm{~m}$, although a few very small lakes occur at elevations up to $1200 \mathrm{~m}$. The lakes were created in a variety of ways Some lie in deeply eroded bedrock. troughs, while others are found in bedrock basins dammed by glacial till. In addition, lakes occupy depiessions within glacial sediments created by the melting of buried ice blocks (kettle holes; seepage lakes).

The Adirondacks are subdivided into five large drainage basins (see Figure 1-1). The Lake Champlain vatershed contains 393 lakes and encompasses a drainage area of 777,328 ha Major rivers within the watershed are the Chazy, Saranac, Ausable, Bouquet, and the Mettawee. These generally drain to the east toward Lake Champlain (Table 2 2-2). 
Table 2.2-2 Major Rivers and Streams of the Adirondack Park (after Brown 1985)

\begin{tabular}{|c|c|c|}
\hline Name of Stream & $\begin{array}{c}\text { Drainage Area } \\
\text { (ha) }\end{array}$ & $\begin{array}{l}\text { Length } \\
(\mathrm{km})\end{array}$ \\
\hline \multicolumn{3}{|l|}{ Upper Hudson River Rasin } \\
\hline Hudson River & $1,198,000$ & 251 \\
\hline Scanandaga River & 274,000 & 129 \\
\hline Schroon River & 147,000 & 85 \\
\hline West Branch, Scanandaga River & 59,000 & 40 \\
\hline East Branch, Scanandaga River & 32,000 & 35 \\
\hline Indian Rlver & 52,000 & 24 \\
\hline Cedar River & 42,000 & 63 \\
\hline Boreas River & -. & $\cdots$ \\
\hline \multicolumn{3}{|l|}{ Mohawk-Hudson River Basin } \\
\hline Mohawk River & 987,000 & 248 \\
\hline West Canada Creek & 146,000 & 111 \\
\hline East Canada Creek & 75,000 & 48 \\
\hline Black Creek & 27,000 & 39 \\
\hline \multicolumn{3}{|l|}{ Oswegatchie-Black River Basin } \\
\hline Oswegatchie River & 415,000 & 201 \\
\hline East Branch, Oswegatchie River & 86,000 & 82 \\
\hline West Branch, Oswegatchie River & 76,000 & 42 \\
\hline Black River & 496,000 & 203 \\
\hline Moose River & 112,000 & 84 \\
\hline South Branch, Moose River & 55,000 & 56 \\
\hline Beaver River & 87,000 & 87 \\
\hline Woodhull Creek & 39,000 & 26 \\
\hline \multicolumn{3}{|l|}{ St Lawrence River Basin } \\
\hline St. Regis River & 221,000 & 135 \\
\hline Grasse River & 175,000 & 175 \\
\hline Indian River & 145,000 & 180 \\
\hline Salmon River & 106,000 & 87 \\
\hline Chateguay River (NY portion only) & 42,000 & 45 \\
\hline \multicolumn{3}{|l|}{ Lake Champlain Basin } \\
\hline Saranac River & 159,000 & 121 \\
\hline Ausable River & 134,000 & 92 \\
\hline Great Chazy River & 78,000 & 71 \\
\hline Boquet River & 72,000 & 89 \\
\hline \multicolumn{3}{|l|}{ Raquette River Basin } \\
\hline Raquette River & 325,000 & 245 \\
\hline
\end{tabular}


The St. Lawrence-Raquette Rlver watershed covers an area of $1,390,000$ ha and includes a total of 678 lakes. Rivers within the watershed generally flow north. The Raquette River subwatershed $(329,000$ ha) splits the $S t$. Lawrence subwatershed $(1,062,000$ ha) in half and contains a total of 336 lakes (Flgure 1-1). The major rivers of the St. Lawrence subwatershed include the Chateaugay, Salmon, St. Regis, and Grass Rivers (Table 2.2-2). The St. Lawrence subwatershed contains 342 lakes.

The Oswegatchie-Black River watershed, in the west-central Adirondacks, encompasses 1,114,000 ha, which are heavily forested and mountainous. This watershed includes 807 lakes, and drainage is generally to the west.

The Upper Hudson watershed occupies a drainage area of 910,000 ha. Tributaries flow to the south and include the Hudson, Scanandaga, Schroon, Indian, and Cedar Rivers (Table 2.2-2). The MohawkHudson watershed encompasses an area of 1,554,000 ha and includes the Mohawk River, East and West Canada Creeks, and Black Creek. 


\subsection{PHENOMENOLOGICAL ANALYSIS OF ALSC CHEMISTRY DATA}

\section{R.K. Munson, C.T. Driscoll, and S.A. Gherini}

The richness of the AL.SC data base allows for the analysis of relationships among variables. These relationships indicute the importance of various processes occurring within the terrestrial and surface water systems that influence observed water quality. The analyses described below focus first on the mineral acid-base system and the components that make it up. This is followed by a section on atmospheric deposition and then by a discussion on the influence of organic and inorganic carbon (C). The concepts discussed in this section are used in the analysis of the ALSC data throughout this report. The analyses presented in this section, unless explicitly stated otherwise, use the ALSC water chemistry sample data ( 3984 samples), including replicates and samples taken during the blological surveys.

\subsubsection{Mineral Acid-Base System}

Mineral acids and bases play an important role in determining lakewater quality. Ir the past, they have often been referred to as strong acids and bases to help distinguish them from carbon-based acids (organic acids and aqueous $\mathrm{CO}_{2}$ ), which were treated as weak acids. However, analysis of the ALSC data indicates that characterizing all organic acids as weak may be inappropriate. 'The nomenclature used in this section reflects the results of the ALSC analyses.

Addition of mineral acids or bases to solution has a direct effect on ANC. Depending on the initial ANC of the solution, this addition may also significantly influence $\mathrm{pH}$. The concept of ANC is described below along with its components, base cations and mineral acid anions.

\subsubsection{Theory of Acid Neutralizing Capacity}

The concept of ANC, or alkalinity, was developed to overcome difficulties associated with massbalance calculations of free $H^{*}$ concentration. The analytical procedure for determining $\mathrm{H}^{+}$concentration (the $\mathrm{pH}$ meter and electrodes) measures only those ions free in solution. Hydrogen ions associated with other species (e.g, R-COOH) are not measured. Thus, mass balance calculations based on free $\mathrm{H}^{+}$measurements alone would not account for $\mathrm{H}^{\prime}$ associated with other species, which can enter solution if conditions change. 
ANC is a measurable parameter which indicates the net strong base in solution or net mineral acid if its value is negative. It is routinely measured by titration with mineral acid or base to an equivalence point (inflection point). The higher the ANC of a water, the more mineral acid is required to reduce the $\mathrm{pH}$ to a given equivalence point.

The ANC of a water can be defined as the concentration. of $H^{\prime}$ acceptors in solution minus the concentration of $H^{+}$donors (Stumm and Morgan 1981) as indicated below:

$$
A N C=\left|H C O_{3}^{-}\right|+2\left|C O_{3}^{2-}\right|+\left|O H^{-}\right|+\mid 0 t h e r H^{+} \text {acxeplors }|-| H^{+} \text {donors } \mid
$$

Where:

$$
\begin{aligned}
& \mathrm{HCO}_{3}{ }^{\circ}=\text { bicarbonate ion, } \\
& \mathrm{CO}_{32^{2}}=\text { carbonate ion, } \\
& \mathrm{OH}^{-}=\text {hydroxide ion, and } \\
& {[1=\text { molar concentrations }}
\end{aligned}
$$

For most lakes and streams, all of the terms on the right-hand side of the Equation 4 except the first $\left(\left[\mathrm{HCO}_{3}{ }^{-}\right]\right)$are negligible and can be set equal to zero. In low-ANC waters, however, the concentration of the "other $\mathrm{H}^{+}$acceptors" becomes quantitatively important. The "other $\mathrm{H}^{\text {* acceptors" include }}$ organic suiustances with functional groups that can accept $\mathrm{H}^{+}$(e.g., carboxyl and phenolic or enolic hydroxyl groups), for example:

$$
R-C O)^{-}+H^{+} \Leftrightarrow R-C O O H
$$

and the monomeric Al species and their complexes, for example:

$$
\begin{aligned}
& A I(O H)_{2}^{+}+2 U^{+} \Leftrightarrow A l^{3+}+2 H_{2}() \\
& A I-R_{3}+3 I^{+} \Leftrightarrow A l^{3+}+3 H I R
\end{aligned}
$$


An alternazive representation of solution-phase ANC, which is mathematically equivalent to that above (See Gherini et ai. 1985 for derivation), equates $A N C$ with the sum of base cation $\left(C_{B}\right)$ concentrations (in equivalents), minus the sum of mineral acid anion $\left(C_{A}\right)$ concentrations (in equivalents), as shown below:

$$
A N C=\Sigma C_{B}-\Sigma C_{A}
$$

Where

$$
\left.\Sigma C_{B}=2\left|C a_{T}\right|+2\left|M g_{T}\right|+\left|N a_{T}\right|+\left|K_{T}\right|+\left|N h_{4 T}\right|+2\left|A l_{T}\right|+2\left|M n_{T}\right|+2 \mid F e_{T}\right\}
$$

and

$$
\Sigma C_{A}=2\left|S O_{4 T^{\prime}}\right|+\left|N O_{3 T^{\prime}}\right|+\left|C l_{T}\right|+\left|F_{T^{\prime}}\right|
$$

The multipliers in Equations 9 and 10 correspond to the charge of the predominant species at the equivalence point. The " $T$ " subscripts in these equations stand for the analytical total concentrations of each constituent, all of which are readily and commonly measured. Figure 2.3-1 summarizes the definition of ANC. As shown in Equation (C) in the figure, changes in ANC result from changes in the components of $2 C_{B}$ and/or $\Sigma C_{A}$

Proton Reference Level. ANC is defined in Equations 8 through 10 relative to a proton $\left(\mathrm{H}^{+}\right)$reference level. The proton reference level is defined as a group of species which, upon addition to solution either individualiy or together, can influence $\mathrm{pH}$, but by definition do not change ANC (Stumm and Morgan 1981).

In mineral acid-base-aqueous $\mathrm{CO}_{2}$ systems (i.e., the carbonate system), the proton reference level for ANC is taken to include water and aqueous $\mathrm{CO}_{2}\left(\mathrm{CO}_{2}(\mathrm{aq})+\mathrm{H}_{2} \mathrm{CO}_{3}\right.$ or $\left.\mathrm{H}_{2} \mathrm{CO}_{3}{ }^{\circ}\right)$. For ANC calculations in more complex systems, which contain proton acceptors other than $\mathrm{HCO}_{3}{ }^{\circ}, \mathrm{CO}_{3} 2^{-}$, and $\mathrm{OH}^{-}$, the proton reference level must be clearly defined. The proton reference level that coincides with the ANC definition presented in Equations 8 through 10 and in Figure 2.3-1 consists of water, aqueous $\mathrm{CO}_{2}$, HR (fully protonated organic acid), and $\mathrm{Al}(\mathrm{OH})^{2+}$ (See Table 2.3-1). ANC calculated in this manner is compared to the Gran-titrated ANC for the ALSC data in Figure 2.3-2. Deviations from the one-to-one line are discussed in Section 2.3.3 


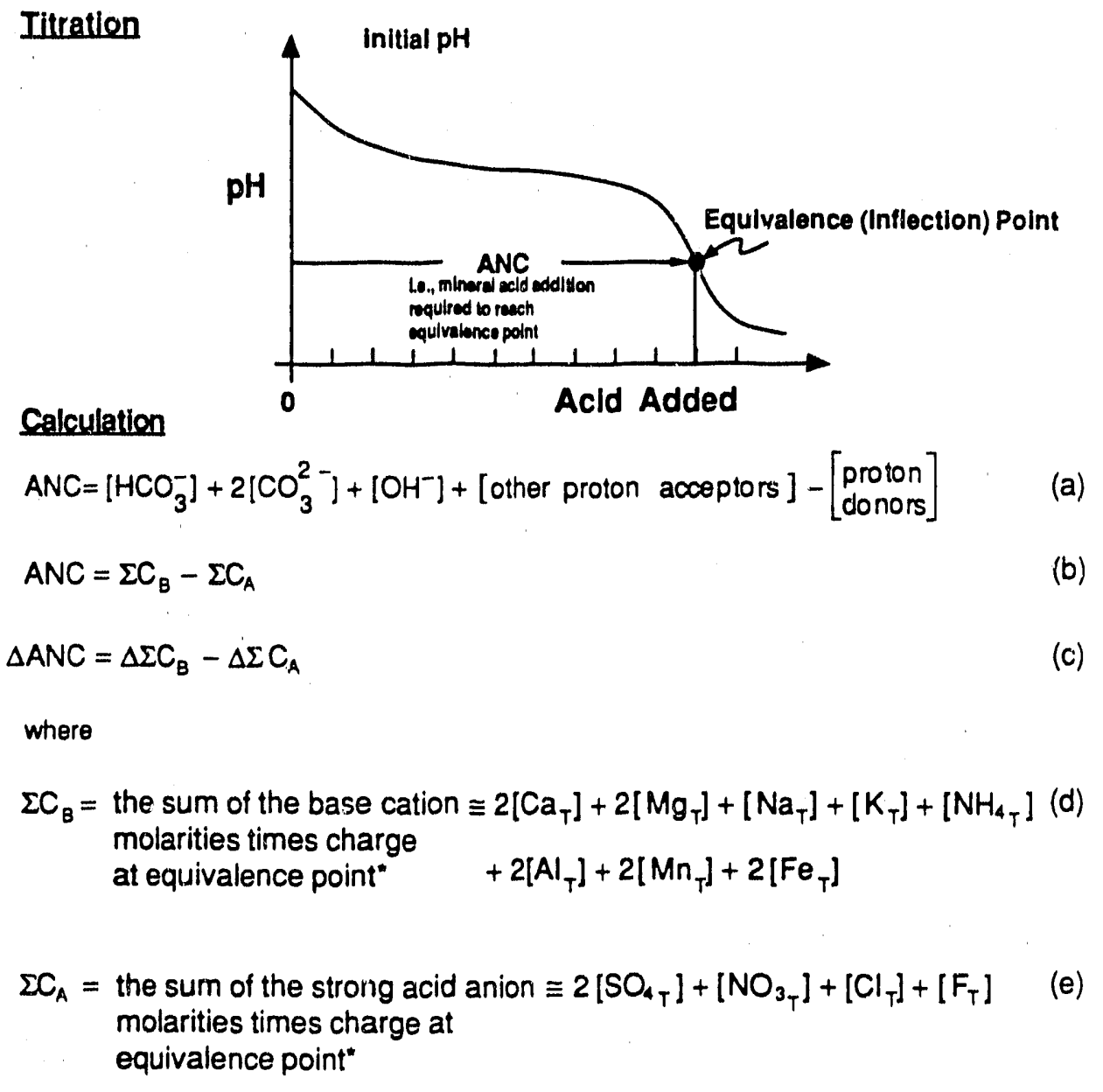

* Proton reference level includes $\mathrm{CO}_{2}(\mathrm{aq}), \mathrm{AL}(\mathrm{OH})^{2+}$, HR (fully protonated organic acid)

Addition of base cations, $C_{B}$, and removal of Mineral acid anions, $C_{A}$, both increase the ANC of a solution. Concentrations shown above are in moles/liter.

Figure 2.3-1 Acid neutralizing capacity (ANC) Definition: ANC can be measured by titration or calculated as shown above (Equation B). 
a) Proton Surplus/Deficit Table

\begin{tabular}{|c|c|c|c|c|c|}
\hline+1 & $\begin{array}{c}\text { Proton } \\
\text { Reference } \\
\text { Level } \\
0\end{array}$ & -1 & -2 & -3 & -4 \\
\hline \multirow[t]{3}{*}{$\mathrm{H}_{+}$} & $\mathrm{H}_{2} \mathrm{O}$ & $\mathrm{OH}^{-}$ & & & \\
\hline & $\mathrm{H}_{2} \mathrm{CO}_{3}^{\star}$ & $\mathrm{HCO}_{3}^{-}$ & $\mathrm{CO}_{3}^{2-}$ & & \\
\hline & HR & $\mathrm{R}^{-}$ & & & \\
\hline \multirow[t]{2}{*}{$\mathrm{Al}^{3+}$} & $\mathrm{Al}(\mathrm{OH})^{2+}$ & $\mathrm{Al}(\mathrm{OH})_{2}^{+}$ & $\mathrm{Al}(\mathrm{OH})_{3}^{0}$ & $\mathrm{Al}(\mathrm{OH})_{4}^{-}$ & \\
\hline & & AlR $^{2+}$ & $\mathrm{AlR}^{+}$ & $\mathrm{AlR}_{3}^{0}$ & \\
\hline
\end{tabular}

b) ANC Expressions

$$
\begin{aligned}
& \mathrm{ANC}_{W}=\left[\mathrm{OH}^{-}\right]-\left[\mathrm{H}^{+}\right] \\
& \mathrm{ANC}_{C}=\left[\mathrm{HCO}_{3}^{-}\right]+2\left[\mathrm{CO}_{3}^{2-}\right] \\
& \mathrm{ANC}_{\mathrm{R}}=\left[\mathrm{R}^{-}\right] \\
& \mathrm{ANC}_{A \mathrm{l}}=\left[\mathrm{Al}(\mathrm{OH})_{2}^{+}\right]+2\left[\mathrm{Al}(\mathrm{OH})_{3}^{0}\right]+3\left[\mathrm{Al}(\mathrm{OH})_{4}^{-}\right]-\left[\mathrm{Al}^{3+}\right] \\
& \mathrm{ANC}_{\mathrm{Al}-0}=\left[\mathrm{AlR}^{2+}\right]+2\left[\mathrm{AlR}_{2}^{+}\right]+3\left[\mathrm{Al}(\mathrm{R})_{3}^{0}\right] \\
& \mathrm{ANC}_{\mathrm{T}}=\mathrm{ANC}_{\mathrm{W}}+\mathrm{ANC}_{\mathrm{C}}+\mathrm{ANC}_{\mathrm{R}}+\mathrm{ANC}_{\mathrm{Al}}+\mathrm{ANC}_{\mathrm{Al}-0}
\end{aligned}
$$



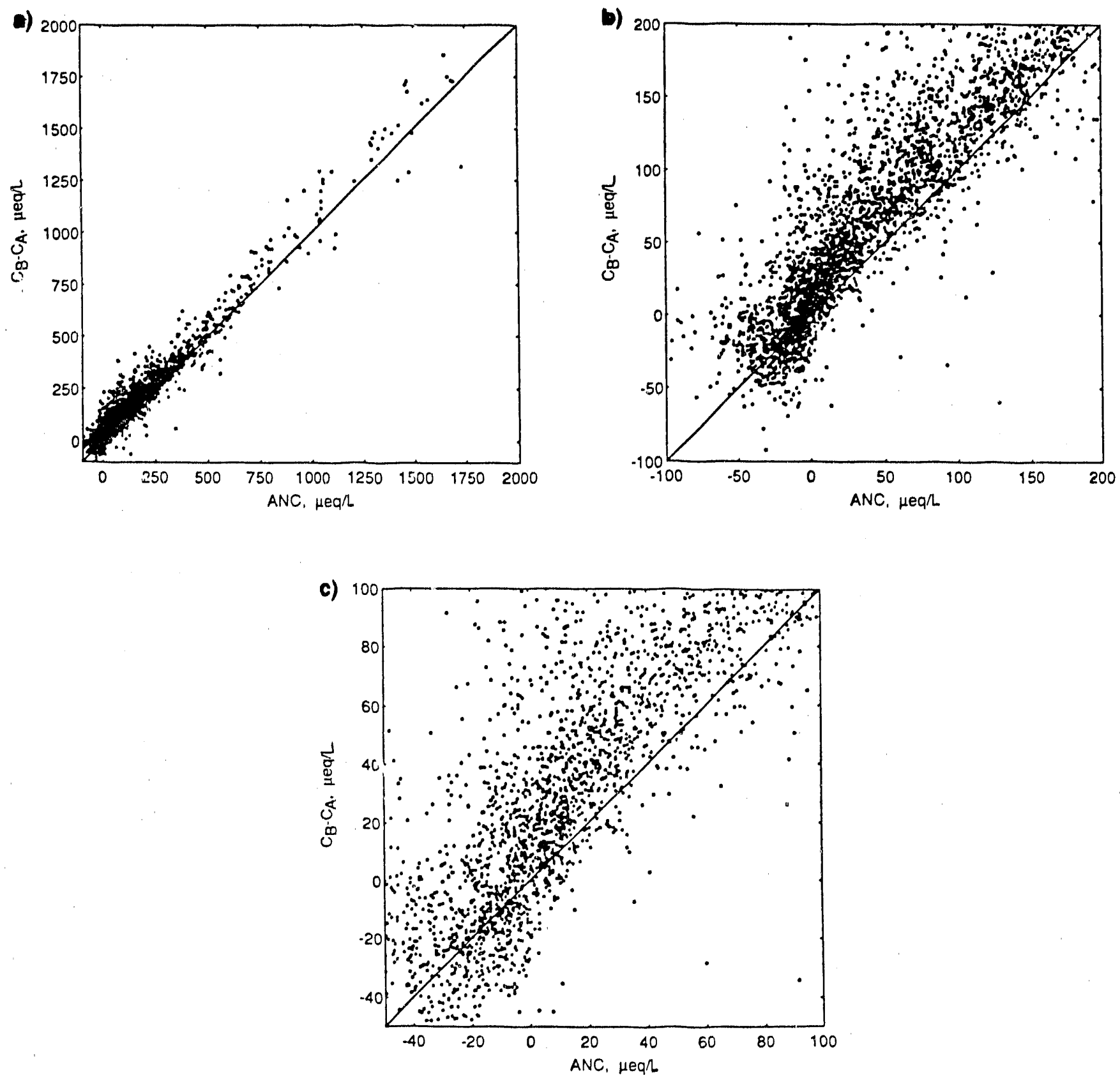

Figure 2.3-2 $C_{B}-C_{A}$ versus Gran-titrated $A N C$. Over the full range of observations, (a), the values appear to be centered around the one-to-one line, but for smaller ranges, (b) and $(c), C_{B}-C_{A}$ is often higher than Gran-titrated $A N C$, possibly due to the influence of organics. 
In summary, ANC is a conservative parameter, independent of temperature and $\mathrm{PCO}_{2}$ (for a solution not reacting with the solid phase). Although these factors change the relative sizes of the terms in Equation 4, they do not change the sum. For example, increasing the $\mathrm{P}_{\mathrm{CO}_{2}}$ increases the $\mathrm{H}^{+}$ concentration but also increases the concentration of $\mathrm{HCO}_{3}{ }^{-}$and $\mathrm{CO}_{3}{ }^{2-}$ in a directly offsetting manner and thereby yields no net change in ANC.

$$
\mathrm{CO}_{2}+\mathrm{H}_{2} \mathrm{O} \Leftrightarrow \mathrm{H}^{+}+\mathrm{HCO}_{3}^{-} \Leftrightarrow 2 \mathrm{I}^{+}+\mathrm{CO}_{3}^{2-}
$$

Mass balance equations can be readily written for ANC, which can then be used together with DIC, DOC, and total monomeric aluminum $\left(A I_{m}\right)$ to implicitly determine the $\mathrm{H}^{+}$concentration and $\mathrm{pH}$ (Munson and Gherini in press).

Summary of ANC Theory. Equations 8 through 10 provide a basis for evaluating the contributions of mineral acids and bases to ANC. As Equation (C) in Figure 2.3-1 indicates, changes in ANC result from changes in $\Sigma C_{B}$ and/or changes in $\Sigma C_{A}$. Thus, tracking the individual components of $\Sigma C_{B}$ and $\Sigma C_{A}$ will allow for evaluation of their mineral acid-base consequences.

\subsubsection{Base Cations}

As indicated in Equation 8, base cations make a positive contribution to ANC. For the ALSC data, $2 C_{B}$ is strongly correlated with the observed ANC, as shown in Figure 2.3-3. Thus, variations in the $C_{B}$ appear to be a major determinant of the variations in ANC in Adirondack lakes.

There are a wide variety of basin processes that influence base cation concentrations. These include mineral weathering, ion exchange, and oxidation/reduction reactions. Using the ALSC data, the relative importance of these processes can be determined as discussed below.

Mineral Weathering. Primary mineral weathering is a slow process which adds base cations, and thus ANC, in specific stoichiometric ratios to soil solution (April and Newton 1984). The process is represented schematically in Figure 2.3-4, and stoichiometries of three weatherable minerals commonly encountered in the Adirondacks are presented in Figure 2.3-5. Since the total content of minerals in most systems is very large, the potential supply of base cations from mineral weathering is 
nearly infinite. However, the rate of supply can be quite slow. The rate of weathering is commonly represented mathematically as follows (Gherini et al. 1985; Schnoor and Stumm 1984):

$$
R=k M\left|H^{+}\right|^{\alpha}
$$

Where:
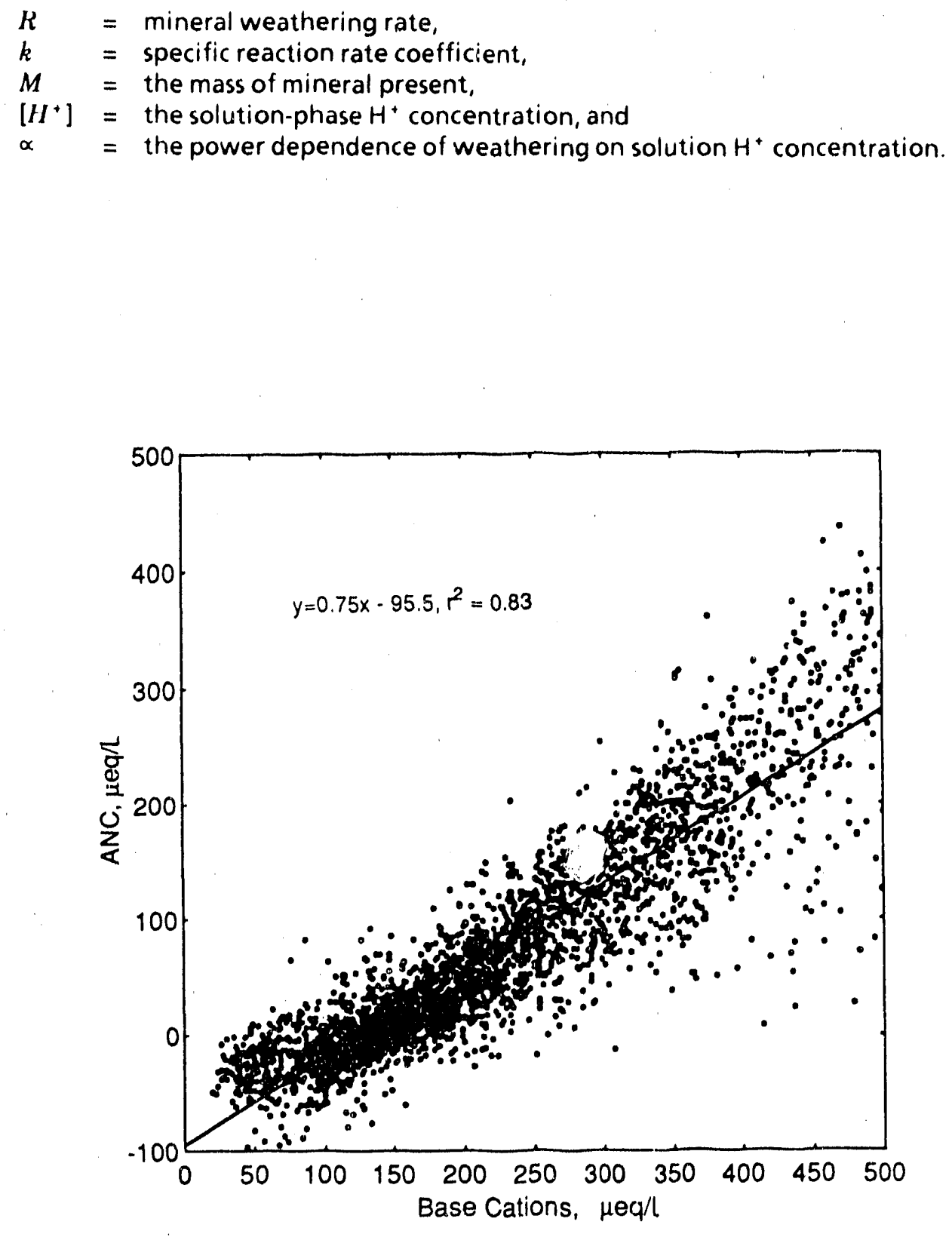

Figure 2.3-3 Gran ANC versus the sum of base cation concentrations. As indicated, base cation concentrations largely determine ANC. 


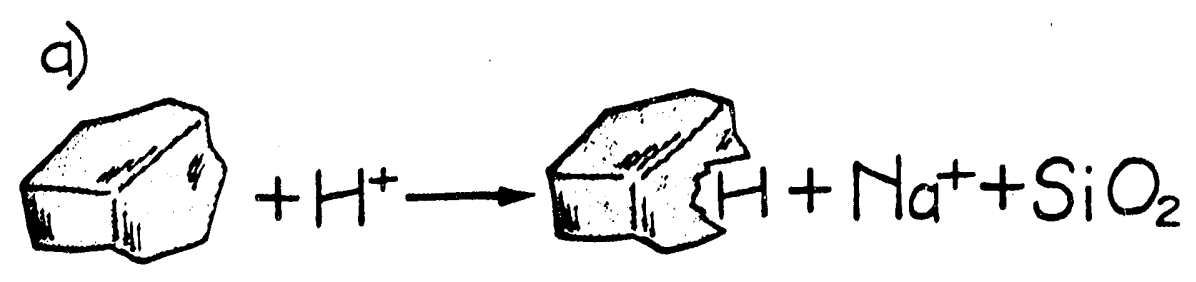

b) Rate Expressions

$$
R_{1}=K_{1} M_{1}\left[H^{+}\right]^{\alpha} \quad R_{2}=K_{2} M_{2}\left(C^{*}-C\right)
$$

Figure 2.3-4 Mineral weathering: (a) idealized representation, and (b) rate expressions. $C^{\star}=$ equilibrium concentration of reaction product (from Munson and Gherini, in press).

The value of $a$ is reported to range from 0.0 to 0.8 (Chen et al. 1983; Schnoor and Stumm 1984; Drever and Hurcomb 1986; Bloom 1988). Thus, the weathering rate is weakly dependent on $H^{+}$ concentration, and the response to any change in soil solution $\mathrm{H}^{+}$would be less than proportional. In addition, cation exchange, another process capable of supplying base cations to solution (described below), responds rapidly to limit any change in solution $\mathrm{H}^{+}$concentration. Therefore, short-term changes in weathering rate in response to changes in deposition acidity would be expected to be small.

Two solutes whose presence is indicative of the degree of mineral weathering in a watershed are sodium ( $\mathrm{Na}$ ) and silica $\left(\mathrm{SiO}_{2}\right)$. As indicated in Figure 2.3-5, both are common products of weathering reactions. In addition, the influence of other processes on these solutes is small. Cation exchange reactions can release $\mathrm{Na}$, but $\mathrm{Na}$ exchange is minimal compared with the exchange of other ions. 
1. Hornblende $(M W=928)$

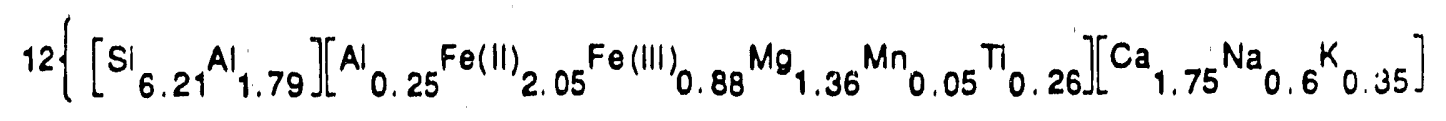

$$
\begin{aligned}
& \left.\left[(\mathrm{OH})_{1.6} \mathrm{~F}_{0.27} \mathrm{Cl}_{0.13}\right]^{\circ}{ }_{22}\right\}+79.96 \mathrm{H}^{+}+9.6 \mathrm{O}_{2} \rightarrow \\
& 2\left\{\left[\mathrm{Fe}(\mathrm{II})_{2.36} \mathrm{Fe}(\mathrm{III})_{0.48} \mathrm{Al} 0.16\right]\left[\mathrm{Al}{ }_{1.28} \mathrm{Si}_{2.72}\right]_{10}^{\mathrm{O}}{ }_{10}(\mathrm{OH})_{2} \cdot\left(4.3 \mathrm{H}_{2} \mathrm{O}\right) \mathrm{Ca}_{0.32}\right\} \text { (vermiculite) } \\
& +14.74 \mathrm{Fe}_{2} \mathrm{O}_{3}+21.6 \mathrm{Al}(\mathrm{OH})_{3}+3.12 \mathrm{TIO}_{2}+69.08 \mathrm{SiO}_{2}+20.36 \mathrm{Ca}^{2+} \\
& +16.32 \mathrm{Mg}^{2+}+4.2 \mathrm{~K}^{+}+7.2 \mathrm{Na}^{+}+3.24 \mathrm{~F}^{-}+1.56 \mathrm{Cl}^{-} \\
& +0.6 \mathrm{MnO}_{2}+6.58 \mathrm{H}_{2} \mathrm{O}
\end{aligned}
$$

2. Plagioclase $(M W=266)$

$$
\begin{aligned}
& \left\{\mathrm{Fe}(I I)_{0.01} \mathrm{~K}_{0.01}{ }^{\mathrm{Na}} 0.84{ }^{\mathrm{Ca}} 0.17^{\mathrm{Al}}{ }_{1.17} \mathrm{Si}_{2.82} \mathrm{O}_{8}\right\}+1.19 \mathrm{H}^{+}+0.575 \mathrm{H}_{2} \mathrm{O} \\
& +0.0025 \mathrm{O}_{2} \rightarrow 0.005 \mathrm{Fe}_{2} \mathrm{O}_{3}+0.01 \mathrm{~K}^{+}+0.84 \mathrm{Na}^{+}+0.17 \mathrm{Ca}^{2+} \\
& +0.585 \mathrm{H}_{4} \mathrm{Al}_{2} \mathrm{Si}_{2} \mathrm{O}_{9}+1.65 \mathrm{SiO}_{2} \\
& \text { (kaolinite) }
\end{aligned}
$$

3. K.Foldspar (MW $=278)$

$$
2 \mathrm{KAISI}{ }_{3} \mathrm{O}_{8}+2 \mathrm{H}^{+}+\mathrm{H}_{2} \mathrm{O} \rightarrow \underset{\text { (kaolinite) }}{\mathrm{H}_{4} \mathrm{Al}_{2} \mathrm{Si}_{2} \mathrm{O}_{9}+2 \mathrm{~K}^{+}+4 \mathrm{SiO}_{2}}
$$

Figure 2.3-5 Weathering stoichiometries for a hornblende, plagioclase, and potassium-feldspar (April and Newton 1984). 
Sodium's role as a nutrient is also quite small, thus its concentration is not significantly influenced by plant uptake.

Silica is produced solely by weathering. The only significant confounding factor in its use as an indicator of weathering is the role it plays as a nutrient for diatoms in lakes. As indicated in Figure 2.3-6a, the concentration of $\mathrm{SiO}_{2}$ in surface samples, where diatoms are active, is generally lower than at depth. This indicates that, while $\mathrm{SiO}_{2}$ can be used as an indicator of mineral weathering, it should be regarded as an indicator of the lower limit of weathering actually occurring in the watershed.

Despite the confounding factors described above, there is a relationship between $\mathrm{Na}$ and $\mathrm{SiO}_{2}$ concentrations in ALSC drainage waters not impacted by road salt (samples with Cl concentrations less than $20 \mu \mathrm{eq} / \mathrm{L}$; Section 2.4) as indicated in Figure 2.3-6b. This implies that both $\mathrm{Na}$ and $\mathrm{SiO}_{2}$ are derived from a common source

a)

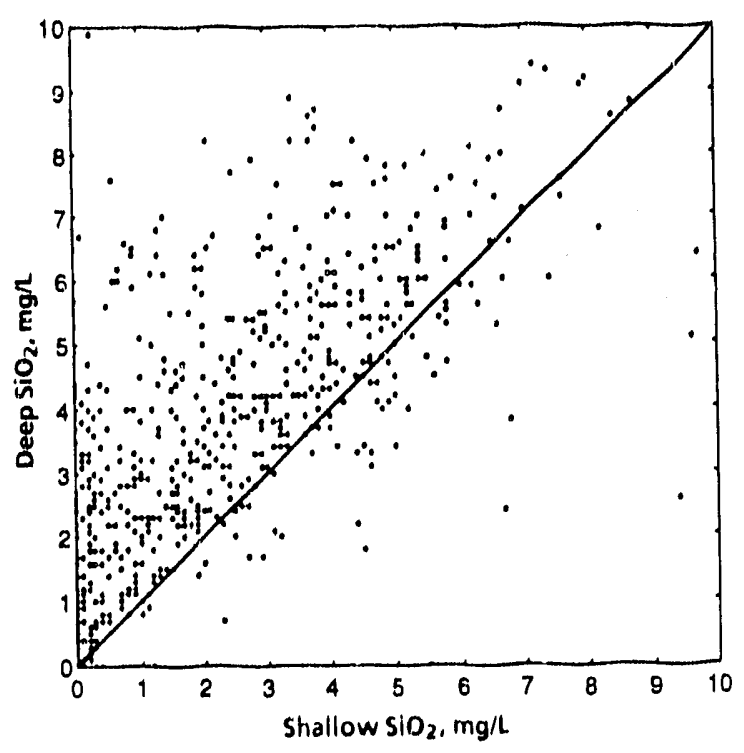

b)

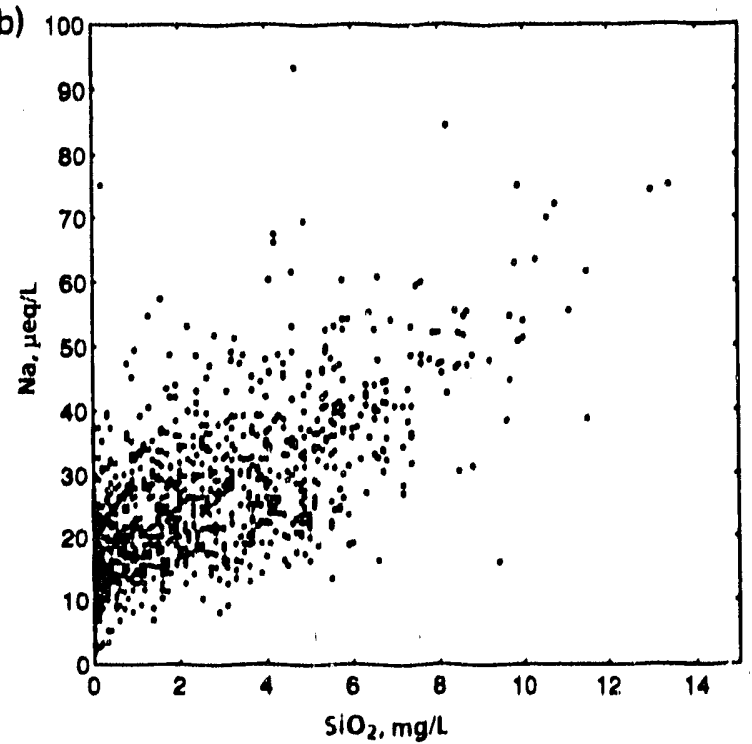

Figure 2.3-6 Silica concentration (a) in deep versus shallow lake water samples and (b) versus sodium for ALSC drainage lakes not impacted by road salt (chloride concentrations less than $20 \mu \mathrm{eq} / \mathrm{L}$ ). 
Cation Exchange. Cation exchange is a fast process that minimizes changes in cation concentrations in solution. Figure 2.3-7 depicts the cation exchange process. A soll's cation exchange sites include functional groups on immobile organic matter and the surfaces and edges of fine particles. The exchange sites are occupied by base cations (including $\mathrm{Al}$ ) and $\mathrm{H}^{+}$. Solution-phase $\mathrm{H}^{\prime}$ concentrations are maintained at fairly constant levels because when $\mathrm{H}^{+}$enters a soil, these ions are replaced by base cations, which desorb from the exchange sites. This produces $A N C$ in solution (by increasing $2 C_{B B}$ ). If for some reason a strong base were added to a soll, consuming soil solution $\mathrm{H}^{\prime}$, sorbed $\mathrm{H}^{+}$would be released from the exchange sites and enter solution, as the cations associated with the base were adsorbed. In this manner, cation exchange serves as an effective buffering process that minimizes changes in soil solution $\mathrm{H}^{+}$concentration.

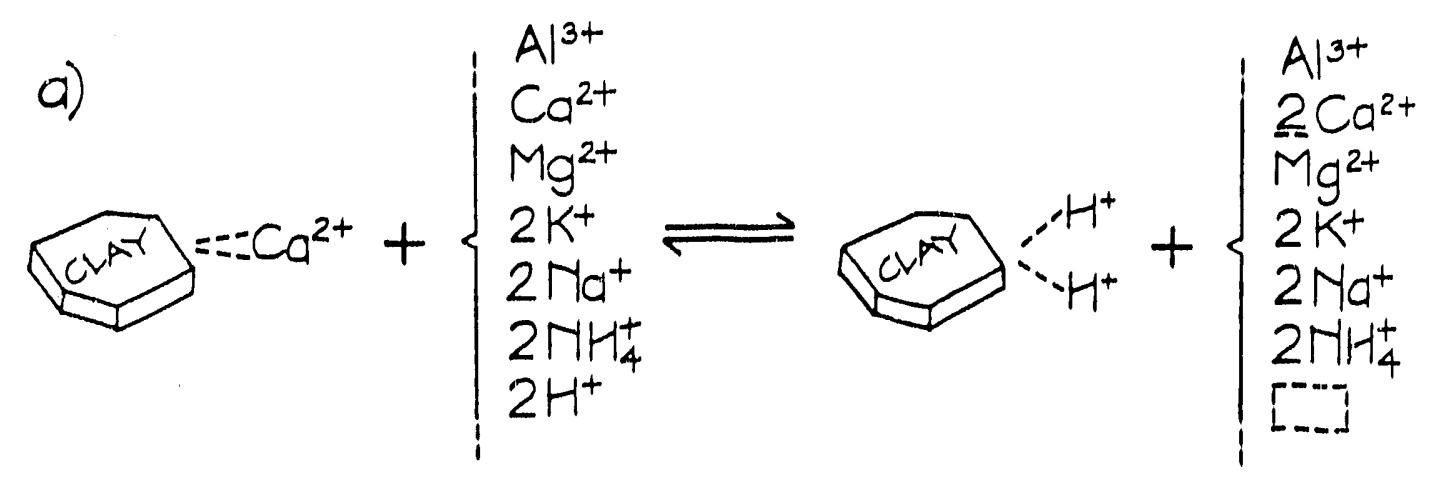

b)

c)
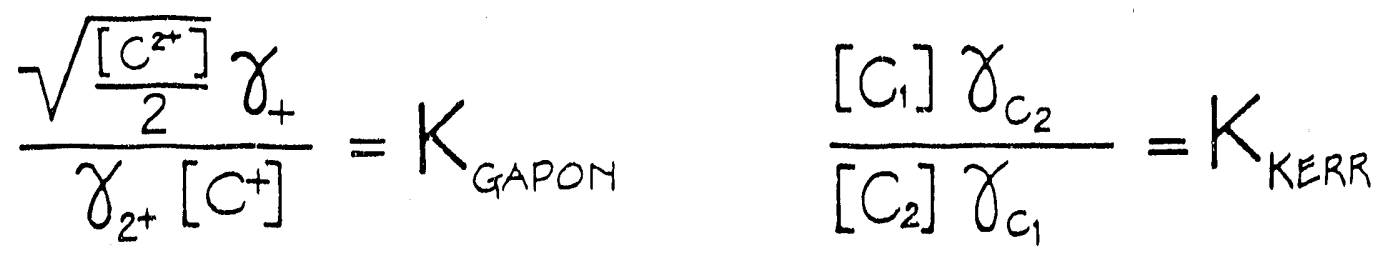

Figure 2.3-7 Competitive cation exchange: (a) idealized representation; (b) heterovalent exchange equation; and (c) homovalent exchange equation. [C] represents solution-phase inn concentration, and y represents solid-phase ion concentration (Munson and Gherini, in press). 
The cation exchange complex of a soil has a finite capacity. Studies indicate that solls in the northeastern United States have adequate sorbed base cations to buffer acid inputs for anywhere from 50 to 200 years (Schnoor and Stumm 1984) to as many as several hundred years (Gherini et al. 1985) If exchange alone were to supply base cations to solution (i.e., in the abserice of weathering).

Since cation exchange does represent a finite source of base supply, distinguishing whether mineral weathering or cation exchange is the major source of base cations in a particular basin can have important Implications regarding future acidification. While surveys such as the ALSC's were not designed for process-level analysis (as, for example, ILWAS and RIL.WAS were), the resulting data do allow for general interpretations regarding base supply in the region.

For example, the relationship depicted in Figure 2.3-6b indicates that $\mathrm{Na}$ and $\mathrm{SlO}_{2}$ have a common source -- mineral weathering. A similar plot of Ca versus magnesium $(\mathrm{Mg})$ also shows a good relationship, again indicating a common source (see Figure 2.3-8a). However, the relationship between $\mathrm{Ca}$ and $\mathrm{Na}$ is weaker (Figure 2.3-8b). The correlation coefficient ( $\left.\mathrm{r}^{2}\right)$ derived from a linear regression analysis is 0.68 for Ca versus $\mathrm{Mg}$, but only 0.24 for Ca versus $\mathrm{Na}$. The relationshio between $\mathrm{Ca}$ and $\mathrm{SiO}_{2}$ is alsu much weaker than the relationship between $\mathrm{Na}$ and $\mathrm{SiO}_{2}$, as shown in Figure 2.3.8C and $d$. Taken together, it can be inferred that a significant portion of the $\mathrm{Ca}$ and $\mathrm{Mg}$ present in ALSC drainage lakes is derived from a common source. While weathering does supply divalent cations to solution, in the absence of carbonate minerals, cation exchange appears to be an important source of these ions on a quantitative basis.

Oxidation/Reduction Reactions. Oxidation/reduction (radox) reactions can serve as sources and sinks of base cations. For example, Fe and $\mathrm{Mn}$ can exist in solution under reducing conditions. In the presence of oxygen $\left(\mathrm{O}_{2}\right)$, however they largely precipitate. Reducing conditions most often occur in the lower portion of the water column near the sediment/water interface. As indicated in Figure 2.39, Fe and $\mathrm{Mn}$ concentrations are usually highest in deep lake samples, where reducing conditions favor their presence. These compounds contribute to the ANC when they are present (see Figure 2.39c), but the contribution is typically ephemeral because upon mixing with oxic waters the Fe and $\mathrm{Mn}$ largely precipitate.

Redox reactions can also serve as a sink for base cations in the case of ammonium. Ammonium $\left(\mathrm{NH}_{4}\right)$ is produced by the decay of organic matter in both terrestrial and surface-water systems. However, much of the ammonium is converted to nitrate $\left(\mathrm{NO}_{3}\right)$ fairly rapidly in the presence of oxygen. This oxidation, along with uptake by biota, helps to explain the low concentration of $\mathrm{NH}_{4}$ typically observed in Adirondack lake samples (mean concentration $=2.5 \mu \mathrm{eq} / \mathrm{L}$ ). 

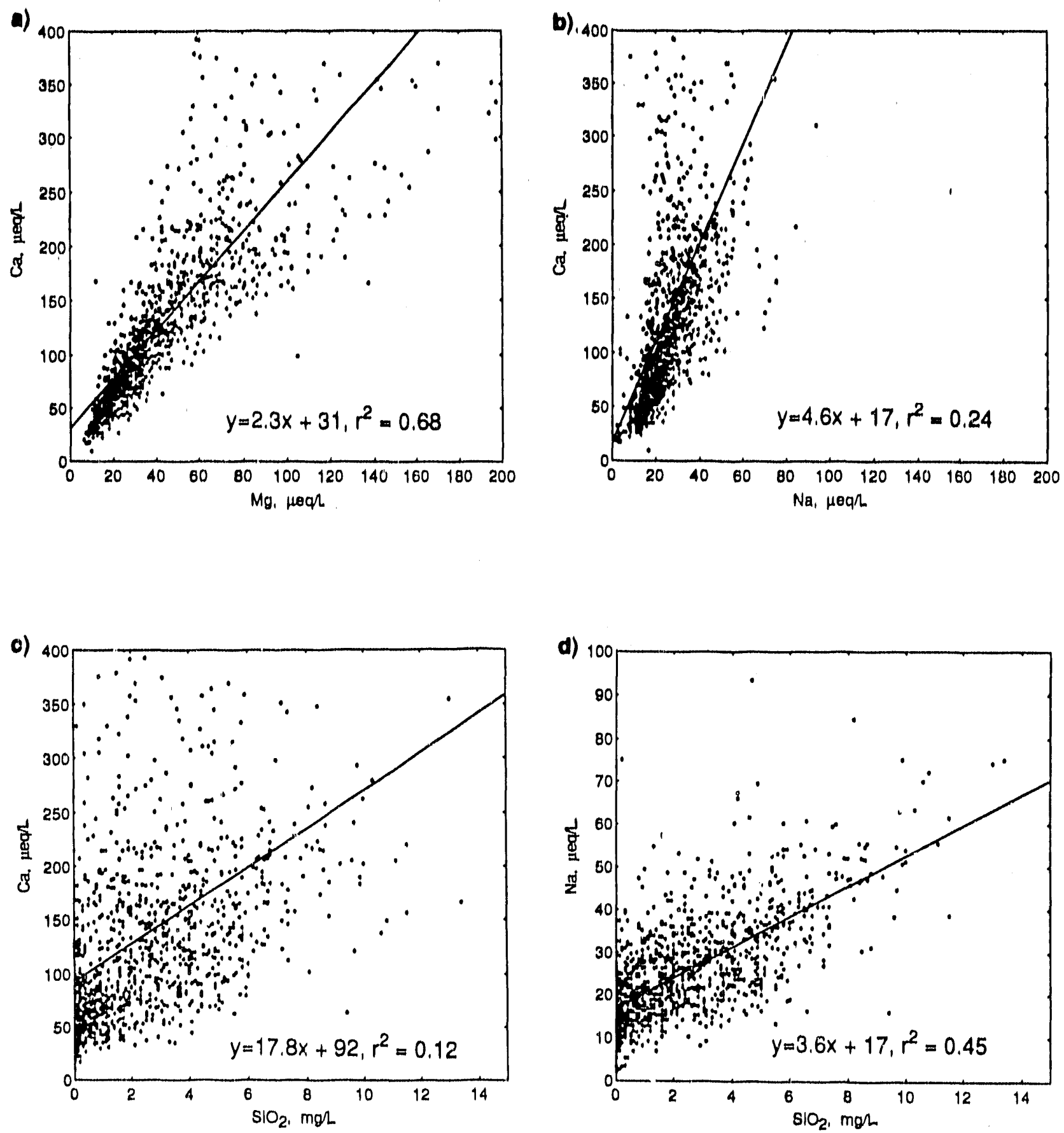

Figure 2.3-8 Relationships between (a) calclum and magnesium, (b) caicium and sodium, (c) calcium and silica, and (d) sodium and silica in ALSC drainage lake samples with chloride concentrations less than $20 \mu \mathrm{eq} / \mathrm{L}$. 

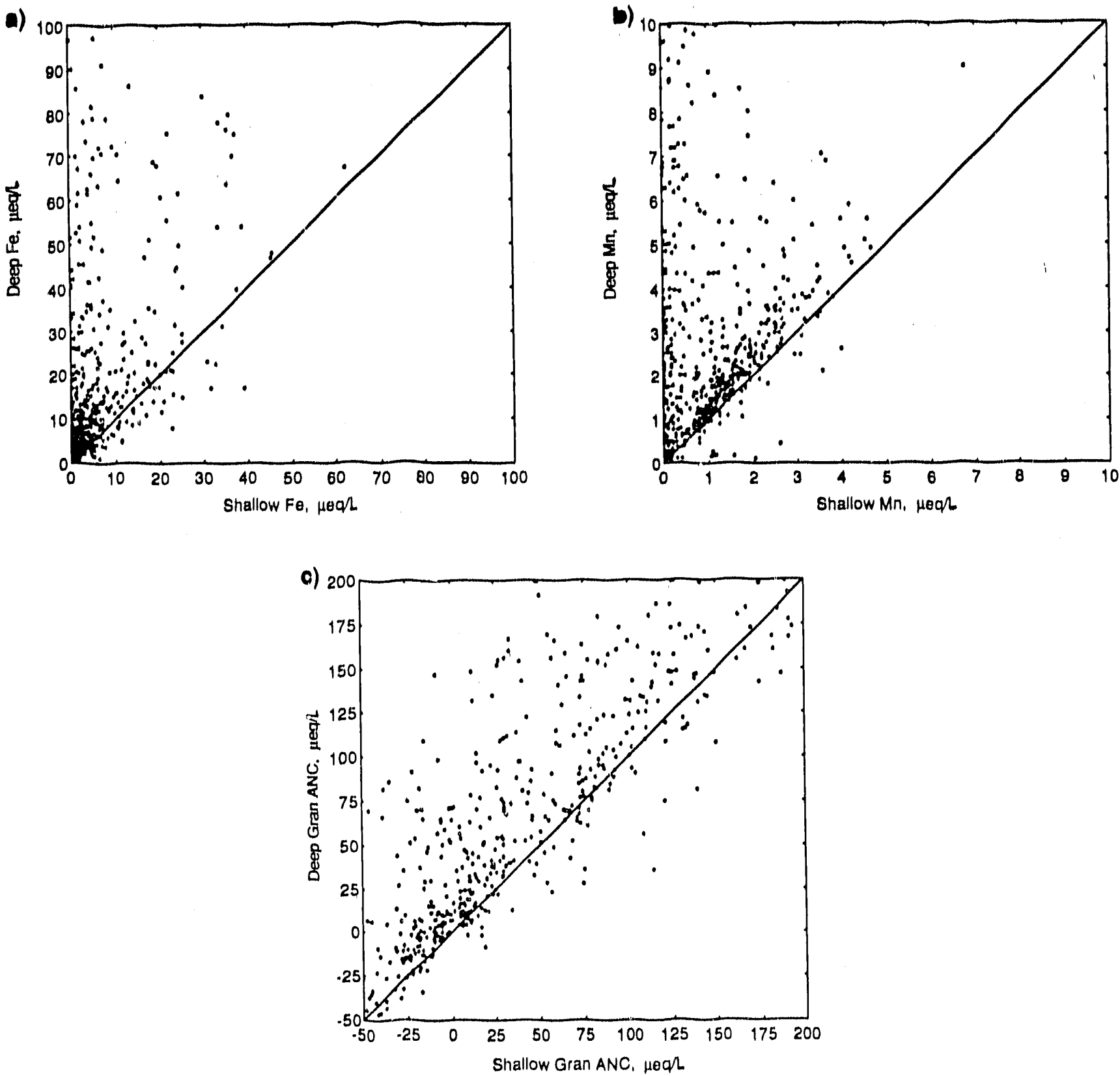

Figure 2.3.9 Shallow versus deep concentrations of (a) iron, (b) manganese, and (c) ANC. The elevated concentrations of iron and manganese lead to increases in ANC. 


\subsubsection{Aluminum}

An increase in concentrations of aqueous $\mathrm{Al}$ is evident in drainage lakes as $\mathrm{pH}$ decreases below 6.0 (Galloway et al. 1983; Driscoll et al. 1984). In the aquatic environment Al is found in a variety of forms, including: (1) particulate aluminum, $A l_{p}$, which may represent primary or secondary minerals or Al assoclated with organic particles; (2) inorganic dissolved aluminum, $A l_{1}$, which occurs as aquo $\left(\mathrm{A} \mid 3^{+}\right), \mathrm{OH}(\mathrm{Al}-\mathrm{OH})$, fluoride (Al-F), $\mathrm{SO}_{4}\left(\mathrm{Al}-\mathrm{SO}_{4}\right)$, and dissolved $\mathrm{Si}$ (Al-Si) complexes; or (3) as complexes with organic matter.

Acidic lake waters in the Adirondacks show seasonal varlations in Al concentration. In general, concentrations of the alkali and alkali earth cations $\left(\mathrm{C}_{B}^{\prime}=\mathrm{Ca}+\mathrm{Mg}+\mathrm{Na}+\right.$ potassium $(\mathrm{K})$ and $\mathrm{SO}_{4}$ change little over the annual cycle in low pH waters. Concentrations of $\mathrm{Al}$ increase during the fall and typically peak during spring snowmelt when they are assoclated with high nitrate $\left(\mathrm{NO}_{3}\right)$ concentrations and low pH. During the summer, lake $\mathrm{pH}$ is generally highest, and $\mathrm{Al}$ concentrations are lowest (Schofield et al. 1985; Schafran and Driscoll 1987).

The reasons for concern over elevated concentrations of $A$ l are closely linked to its spiciation. It appears that elevated concentrations of $A l_{1}$ are toxic to aquatic organisms (Baker and Schofield 1982). Aluminum-induced coagulation of organic solutes or particles can increase the transparency and alter the thermal structure of acidic lakes (Effler et al. 1985). Finally, Al species may be important pH buffers in dilute acidic waters (Driscoll and Bisogni 1984).

Speciation. As part of the ALSC survey, dissolved aluminum ( $\left.\left.A\right|_{d}\right)$ was measured, except in 1985 when total aluminum $\left(\left.A\right|_{t}\right)$ was analyzed because of contamination of the $A l_{d}$ samples. Because of interest in the aqueous chemistry and toxicity of $A l$, fractionation procedures have been developed to quantify the various forms of aluminum (e.g. $A l_{1}$, organic aluminum $\left(A I_{0}\right)$ and $A I_{p}$ ) present in natural waters (Driscoll 1984). Fractionation methods, though, have not generally been applied in large synoptic surveys. Recently, however, these procedures have been autcmated (MCAvoy et al in press), and their application may increase in the future.

The analytical procedure for $A l_{t}$ uses a strong acid digestion followed by a spectrophotometric analysis. The results are thought to include both particulate and aqueous forms of $A l$. In the $A l_{d}$ procedure, the samples are filtered through an $0.4-\mu \mathrm{m}$ polycarbonate filter, and the filtrate is acid digested. This $\mathrm{Al}_{d}$ fraction includes aqueous and fine particulate $\mathrm{Al}$ not retained by the filter. These measurements were used by ALSC to quantify the concentration of Al in Adirondack lakes.

To obtain a better estimate of reactive $A \mid$, or monomeric aluminum $\left.(A)_{m}\right)$, the field sample is extracted with a chelating agent, such as 8 -hydroxyquinoline or pyrocatechol violet, and then 
an 'zed for Al by atomic absorption spectrophotometry or by using colorimetric methods. The difference between $A I_{t}$ and $A I_{m}$ is particulate aluminum, $A . I_{p}$. In order to differentiate between inorganic and organic forms of $A I_{m}$, solutions are fractionated using a cation exchange resin (Driscoll 1984). It is not possible to analytically distinguish between individual species (e.g., $\mathrm{Al}^{+}{ }^{+}$, $\left.\mathrm{Al}(\mathrm{OH})^{2+}, \mathrm{AlF}^{2+}\right)$ that comprise $\mathrm{Al}_{1}$, but using measured values of $\mathrm{Al}_{1}, \mathrm{pH}_{1}, \mathrm{~F}_{1} \mathrm{SO}_{4}$ and dissolved $\mathrm{Si}$, the speciation of $A l_{1}$ can be estimated using a chemical equilibrium model (Gherini et al. 1985; Schecher and Driscoll 1987)

To p:.. e data for chemical calculations and to assess the poteritial toxicity of Al in ALSC waters, it was necessary to determine the speciation of Al through model calculations. In order to develop an approach for predicting the speciation of Al, 40 samples were collected from low-pH lakes during August 1988. These samples were measured for $A I_{t}$ and $A I_{d}$ using $A L S C$ procedures, as well as for $A I_{m}$ $A l_{1}$, and $A l_{0}$ using the procedure described by MCAvoy et al: (in press). Empirical relationships were developed (Table 2.3-2) to obtain estimates of $A I_{m}$ from measured values of $A I_{d}$ or $A I_{1}$. In general, the agreement between $A i_{d}$ and $A I_{t}$ values was close, which suggests that most of the $A l$ in Adirondack lakes is dissolved or associated with fine particles. In this survey, strong lincar relationships were fourd between $A I_{m}$ and both $A I_{d}$ and $A I_{t}$ (Table 2.3-2). The slope of the empirical relationship between $A I_{m}$ and $A I_{t}(0.54)$ is between the values obtained for Phase I $(0.46)$ and Phase $I 1(0.62-0.68)$ of the Eastern Lake Survey (Linthurst et al. 1986a).

To obtain estimates of $A_{1} I_{1}$ and $A I_{0}$, as well as the speciation of $A I_{1}$, the chemical equilibrium model ALCHEMI was used. The speciation of Al can be calculated with this model from inputs of $A I_{m}, p H, F$, $\mathrm{SO}_{4}$, dissolved Si, DOC, and other major solutes. A description of the model, including thermodynamic data and a detailed uncertainty analysis, is available in the literature (Schecher and Driscoll 1987, 1988).

In order to verify this ap . oach, values of $A I_{1}$ and $A I_{0}$ measured during the 1988 survey of low-pH lakes were compared to predicted values using ALCHEMI (Figure 2.3-10). The predictions were made using measured values of $A I_{m}$, as well as $A I_{m}$ concentrations determined using the empirical relationships based upon $A l_{d}$ ar. $A l_{t}$ (see Table 2.3-2). Using measured values of $A l_{m}$, thr agreement between measured and predicteu $A I_{1}$ and $A I_{U}$ was generally good. The agreement between measured and predicted values was not quite as good when empirical relationships were used to determine $A I_{m}$. For most observati ins, however, measured and predic* a! ises were within $1 \mu \mathrm{mol} / \mathrm{L}(27 \mu \mathrm{g} / \mathrm{L})$. 
Table 2.3-2 Empirical Aluminum Relationships Based on Several Different Data Sets

\begin{tabular}{|c|c|c|}
\hline EQUATION NO. & DATA SET/EQUATION & $r^{2}$ \\
\hline \multicolumn{3}{|c|}{ Survey of low-pH and low-ANC waters $(n=40)$} \\
\hline 1 & $A l_{d}=0.29(1.5)+0.95(0.033) \times A l_{t}$ & 0.96 \\
\hline 2 & $A I_{m}=0.67(1.4)+0.54(0.032) \times A I_{t}$ & 0.88 \\
\hline 3 & $A I_{m}=0.67(1.4)+0.55(0.032) \times A I_{d}$ & 0.88 \\
\hline \multicolumn{3}{|c|}{ ELS - \|Fall data-a\|data $(n=144)$} \\
\hline \multirow[t]{2}{*}{4} & $A I_{m}=-0.026(1.46)+0.62(0.027) \times A I_{t}$ & 0.79 \\
\hline & ELS-\|l Fall data-Adirondack data $(n=36)$ & \\
\hline \multirow{2}{*}{5} & $A l_{m}=-0.022(2.32)+0.68(0.056) \times A l_{t}$ & 0.81 \\
\hline & ELS-1 Adirondack data $(n=211)$ & \\
\hline 6 & $A I_{m}=-0.071(1.21)+0.46(0.017) \times A I_{t}$ & 0.79 \\
\hline \multirow[t]{4}{*}{ Where } & $A I_{m}=$ extractable $A l$ & \\
\hline & $A l_{d}=$ dissolved total $A l$ & \\
\hline & $A I_{t}=$ total $\mathbf{A l}$ & \\
\hline & () = standard error & \\
\hline
\end{tabular}

Aluminum in ALSC Waters. ALSC drainage lakes showed an increase in Al concentration with decreasing pH (Figure 2.3-11a). Seepage lakes generally had low Al concentrations even at low pH values (Figure 2.3-11b). The differences in Al concentration between drainage and seepage lakes reflect differences in hydrologic flowpaths. In both drainage and seepage lakes, if the lake water is primarily derived from deep soils, $\mathrm{pH}$ is high, and concentrations of $\mathrm{Al}$ are low (Goldstein et al. 1984) In acidic drainage lakes, however, tributary water largely flows through shallow deposits and may contain high concentrations of Al. Acidic seepage lakes are generally isolated from groundwater inputs, and lake water largely originates from direct presipitation (Driscoll and Newton 1985). As a result there is limited contact of lake water with soil, and thus little opportunity for Al mobilization from the terrestrial environment. 

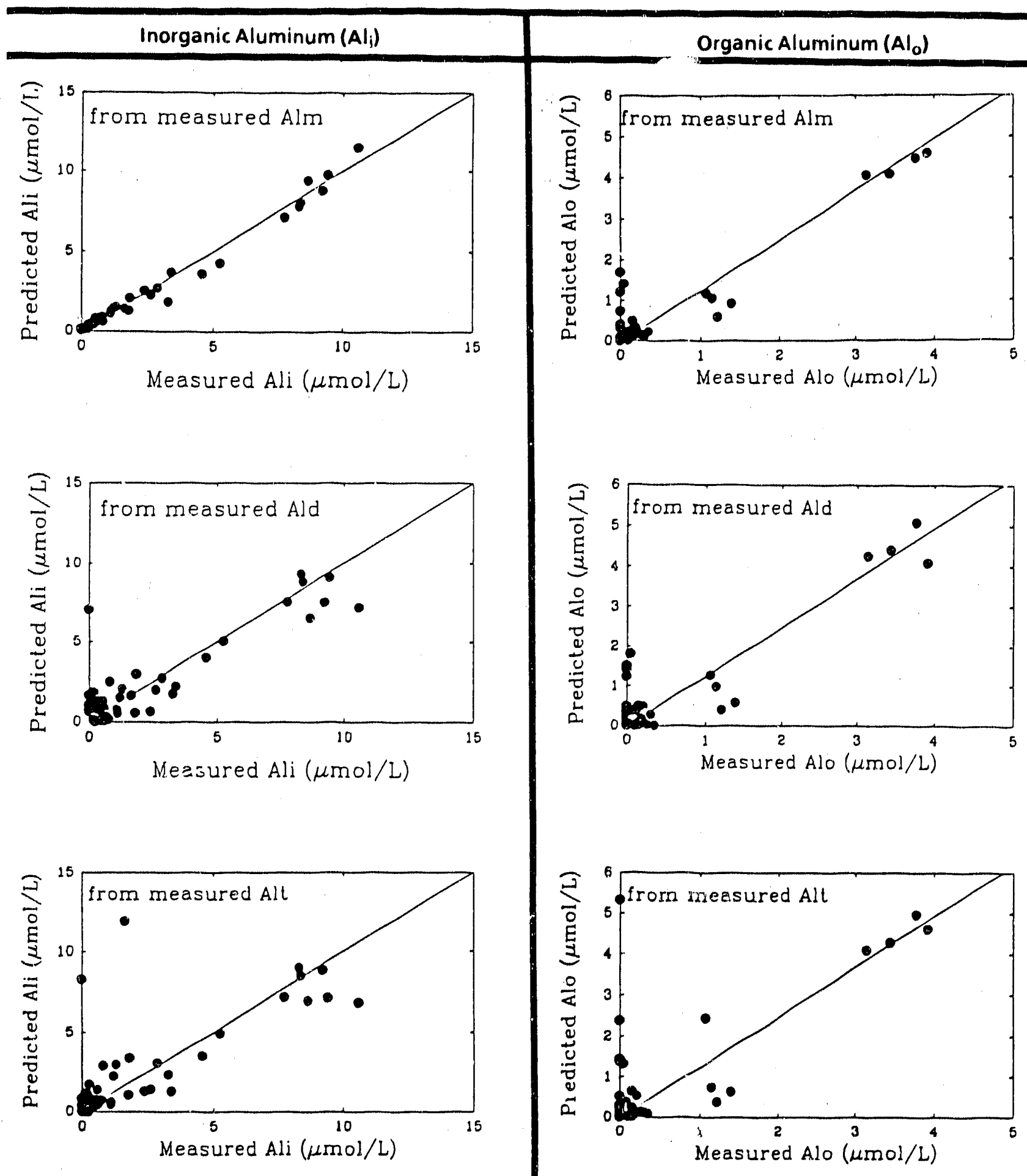

Figure 2.3-10 Predicting the speciation of aluminum: $A I_{i}$ and $A I_{0}$ based upon measured $A I_{m}$.
$A I_{d}$, and $A I_{t}$. 

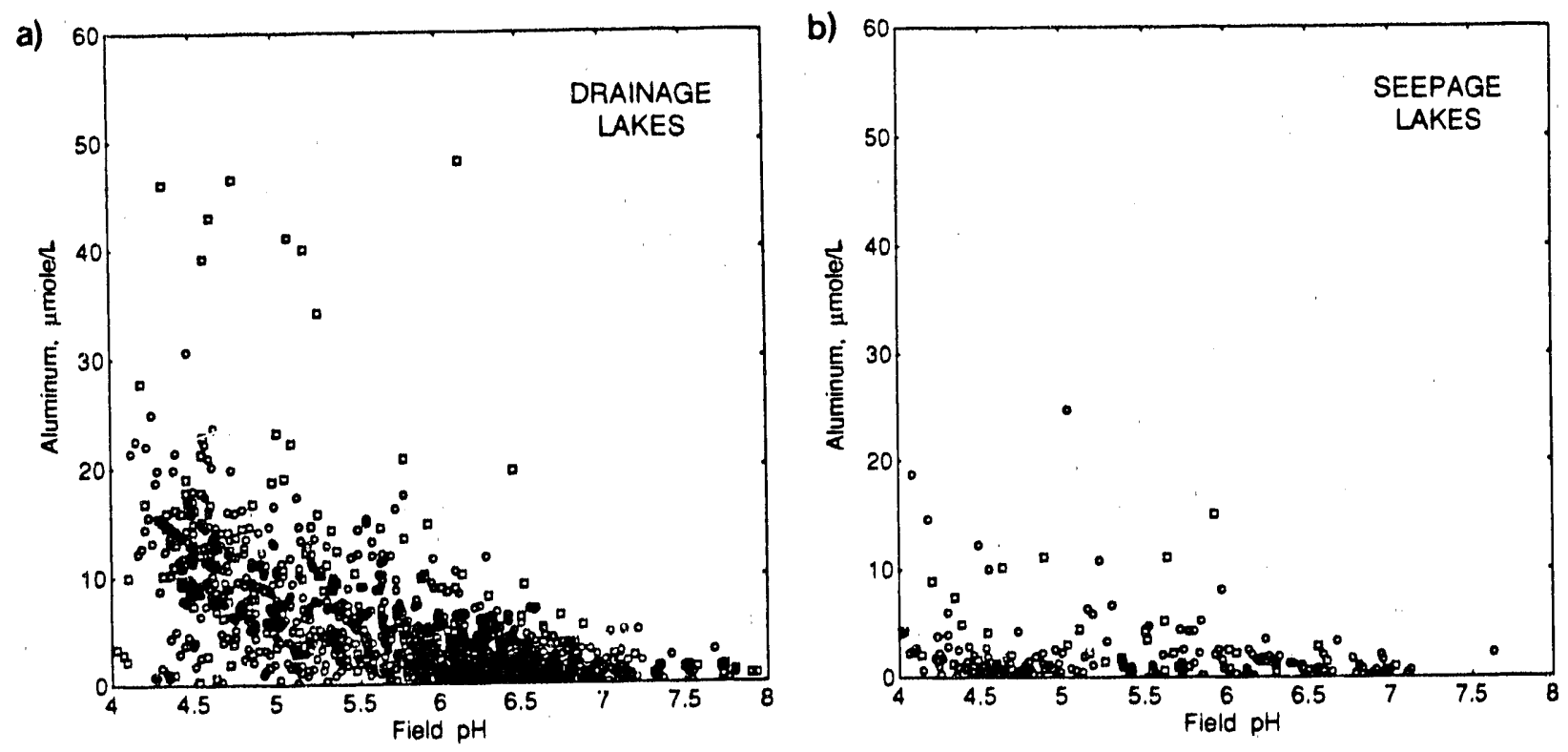

O Al-d. Hmole/l.

口Al-t, $\mu$ mole/L

Figure 2.3-11 Total and dissolved aluminum in (a) ALSC drainage and (b) seepage lakes.

Using the chemical equilibrium model, various fractions of $A l$, were calculated for the ALSC drainage lakes (Figure 2.3-12) using summer samples. Although Al concentrations are generally low during the summer, samples were available for all of the lakes during this period. There was considerable variability in $\mathrm{Al}$ speciation among the lakes due to differences in $\mathrm{pH}$ and the concentrations of complexing ligands. At pH values above 7.0, hydroxides $(\mathrm{OH})$ of $\mathrm{Al}$ (largely $\mathrm{Al}(\mathrm{OH})_{4}$ ) were the dominant forms of $A I_{m}$. Estimates of $A I_{m}$ concentrations were generally low at neutral $p H$ values. As lake $\mathrm{pH}$ decreased below 7.0, $\mathrm{Al}-\mathrm{OH}$ decreased, and organic monomeric and $\mathrm{Al}-\mathrm{OH}-\mathrm{F}$ complexes became more significant. At pH values below 6.0 these forms of $A \mathrm{l}$ declined, and $\mathrm{Al}-\mathrm{F}$ increased in significance. Below pH 5.0, the concentration of $\mathrm{Al}^{3}{ }^{*}$ increased markedly and became the dominant specie of inorganic monomeric $\mathrm{Al}$ in the more acidic lakes.

ALSC drainage waters generally were close to saturation with respect to the solubility of gibbsite $\left(\mathrm{pK}_{\mathrm{sp}}=33.88\right)$. This suggests that Al concentrations in Adirondack 'akes may be regulated by the solubility of this mineral. 

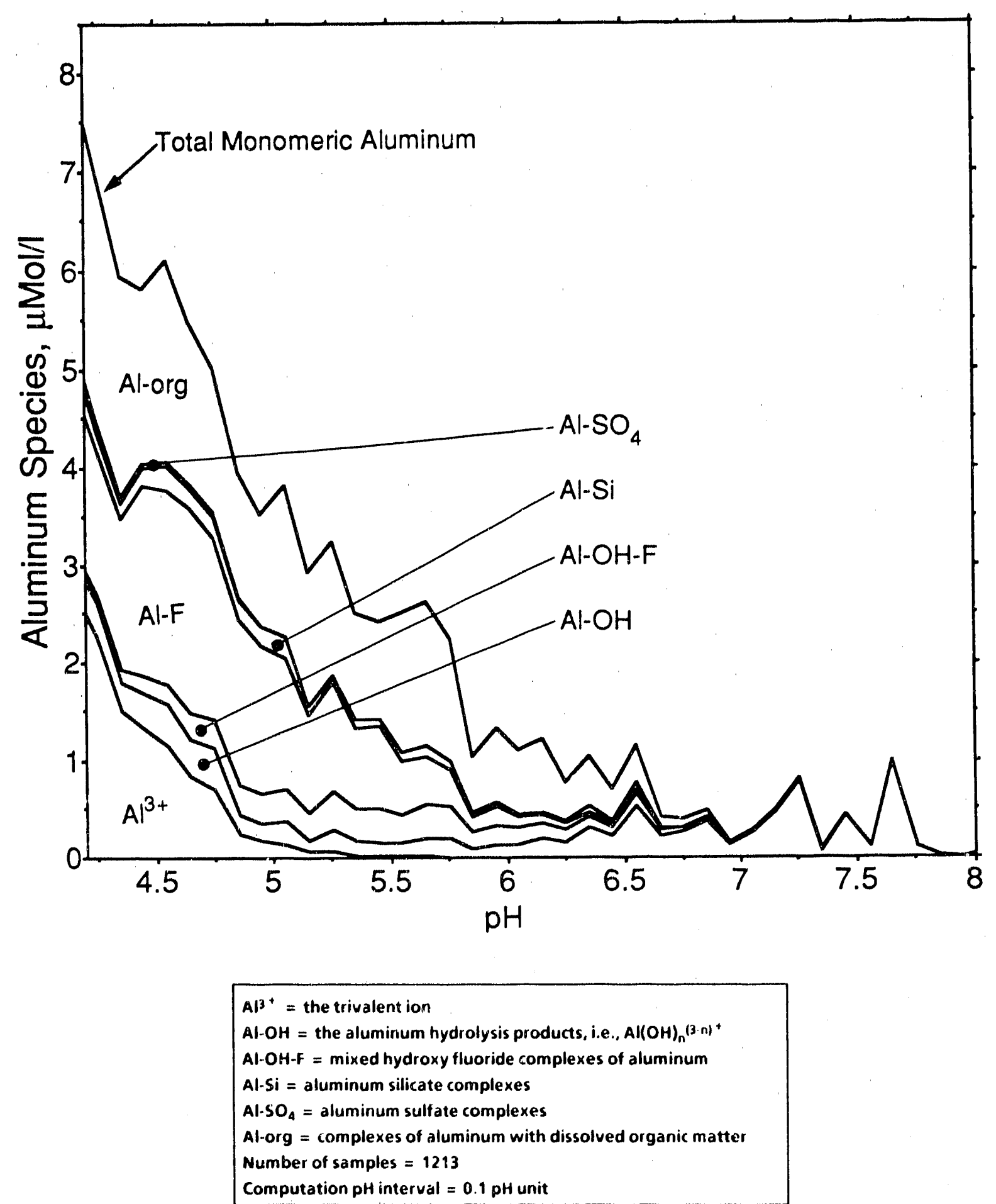

Figure 2.3-12 Speciation of monomeric aluminum in ALSC drainage lakes using ALSC data and ALCHEMI. Vertical distances between the curves represent mean concentration of the indicated species groups. 


\subsubsection{Mineral Acid Anions}

As noted above, mineral acid anions $\left(\mathrm{SO}_{4}, \mathrm{NO}_{3}, \mathrm{CL}, \mathrm{F}\right)$ make a negative contribution to $\mathrm{ANC}$ (Figure 2.3.1 and Section 2.3.1.1) The relationship between mineral acid anions and ANC in ALSC waters (see Figure 2.3-13) is much whe relationship to base cations demonstrated in Figure 2.3-3. The lack of a relationship watwen ANC and mineral acid anions and the strong relationship in Figure 2.33 indicate that the ANC of Adirondack lakes depends largely on the supply of base cations.

(Exceptions to this do occur during spring snowmelt; see figure 2.3-14.) This is because there is much greater variability in total $C_{B}$ than in total $C_{A}$. Thus the variation in $A N C$ throughout the $A d$ dirondacks is determined by base cation concentration.

A variety of basin processes influence mineral acid anion concentrations in surface waters, including biological cycling, redox reactions, and anion adsorption. These processes and their relevance in ALSC waters are discussed below.

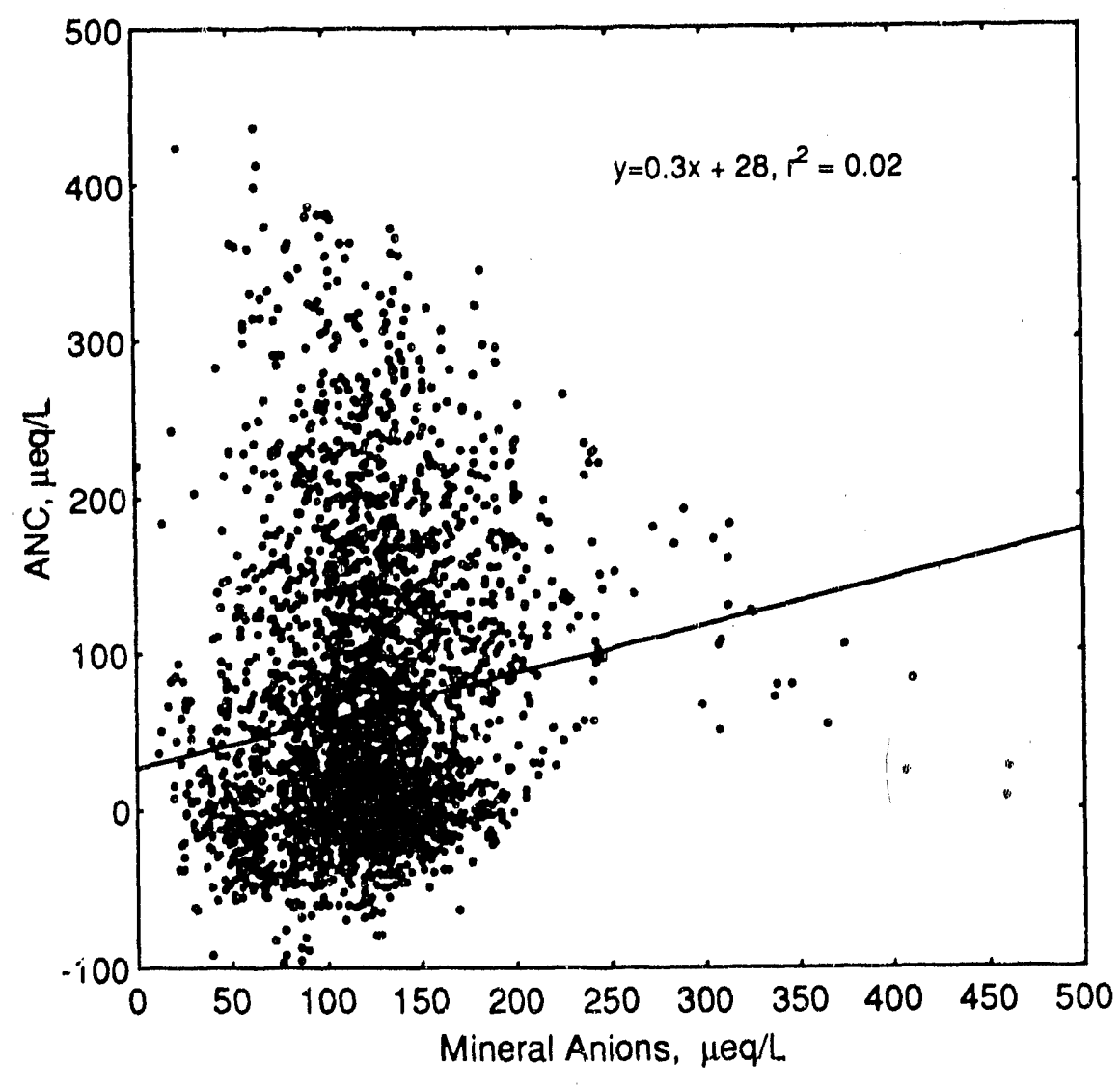

Figure 2.3-13 ANC versus the sum of mineral acid anions shows little relationship between these parameters in ALSC chemistry samples. 
Biological Cycling. The biological processes that influence $\mathrm{NO}_{3}$ concentration include uptake by terrestrial vegetation, organic matter decay, and nitrification. Nitrate also serves as a nutrient for aquatic plants and algae. Thus, in many forested lake-watershed systems, the $\mathrm{NO}_{3}$ from deposition and that produced by nitrification is largely removed from solution (Reuss and Johnson, 1986). However, organic matter decay and nitrification processes continue during the winter dormant season, and $\mathrm{NO}_{3}$ concentrations can accumulate under the snowpack (Strayer et al. 1981). During snowmelt, this $\mathrm{NO}_{3}$ along with $\mathrm{NO}_{3}$ that accumulates in the snowpack as a result of atmospheric deposition, can be flushed into surface waters where it contributes to the spring pulses of acidity observed in many western Adirondack lakes (Goldstein and Gherini 1984; Driscoll et al. 1987;

Gherini et al., 1989). This spring pulse of $\mathrm{NO}_{3}$ and acidity is illustrated using data from Panther Lake, NY (Figure 2.3-14).
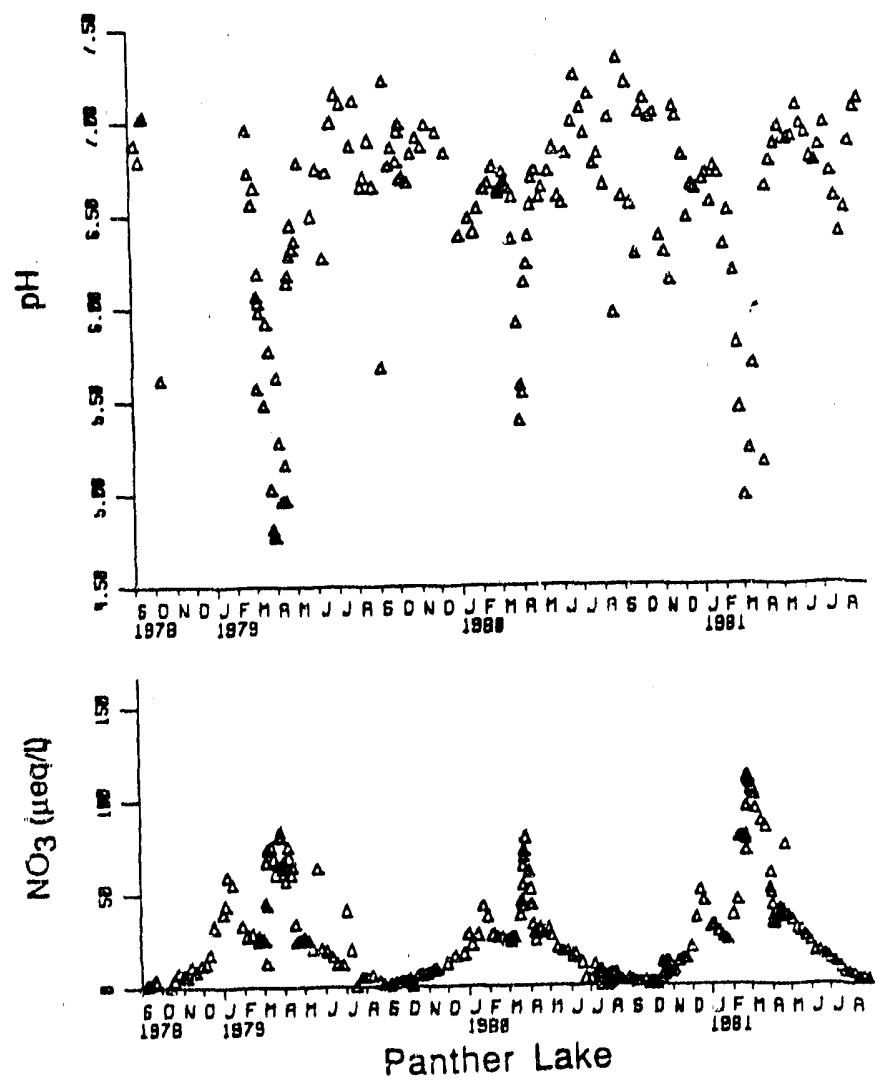

Figure 2.3-14 Concentrations of $\mathrm{pH}$ and nitrate at Panther Lake. $\mathrm{pH}$ depressions coincide with nitrate peaks (Munson and Gherini, in press). 
Redox. Nitrate and $\mathrm{SO}_{4}$ reduction reactions take place in the sediments of lakes, but they are relatively slow processes (in particular $\mathrm{SO}_{4}$ reduction) and have their greatest impact on anion concentrations in lakes with longer hydraulic detention times (Kelly et al. 1987). For example in Dart's Lake in the Adirondacks, in-situ measurements indicate that $\mathrm{SO}_{4}$ reduction is occurring at a rate of about $130 \mu \mathrm{eq} / \mathrm{m}^{2}$ of sediment/day (Kelly et al. 1987). However, applying a mass balance for $\mathrm{SO}_{4}$ in the lake indicates that $\mathrm{SO}_{4}$ loss by sediment reduction does not appreciably alter the lake water $\mathrm{SO}_{4}$ concentration. At Crystal Lake, Wisconsin, in-situ measurements indicate that the loss rate to sediment is nearly the same as in Dart's Lake (i.e., $100 \mu \mathrm{eq} / \mathrm{m}^{2} /$ day). However, mass balance calculations indicate that the lake $\mathrm{SO}_{4}$ concentration without loss to sediments would be $140 \mu \mathrm{eq} / \mathrm{L}$, while the observed concentration is near $75 \mu \mathrm{eq} / \mathrm{L}$ (Greb et al. 1988). The major difference in the two systems is that the hydraulic detention time at Crystal lake is about 10 years while at Dart's Lake the mean detention time is about 1 month. The water does not remain in Dart's long enough for an appreciable loss of solution $\mathrm{SO}_{4}$ to occur.

Recent studies indicate that $\mathrm{SO}_{4}$ reduction can be represented mathematically as a rate-limited reaction that is first order with respect to the $\mathrm{SO}_{4}$ concentration. The reaction also appears to be temperature-dependent. Arrhenius activation energy analysis indicates that at low temperatures $\left(\leq 20^{\circ} \mathrm{C}\right)$ the process is chemical-reaction-limited while at higher temperatures $\left(-20^{\circ} \mathrm{C}\right)$, the reaction is diffusion-limited (Munson and Gherini 1986)

For the $\mathrm{ALSC}$ lakes, the impact of $\mathrm{SO}_{4}$ reduction can be illustrated by examining the distribution of summer surface $\mathrm{SO}_{4}$ concentrations in seepage lakes versus drainage lakes. Seepage lakes generally have longer hydraulic detention times than drainage lakes and thus would be expected to exhibit more influence from $\mathrm{SO}_{4}$ reduction reactions. Figure 2.3-15 illustrates that this is indeed the case. The median $\mathrm{SO}_{4}$ concentration in drainage lakes was $106 \mu \mathrm{eq} / \mathrm{L}$, while in seepage lakes it was $67 \mu \mathrm{eq} / \mathrm{L}$. If evapotranspiration were the only factor influencing $\mathrm{SO}_{4}$ concentrations, the seepage lakes, with longer hydraulic detention times, wou!d be expected to have higher concentrations than drainage lakes. However, there are other ronfounding factors, such as the ability of a drainage basin's vegetation to enhance the collection of dry deposition $\mathrm{SO}_{4}$.

Adsorption. Adsorption of heterovalent anions can be an important process, particularly in old, highly weathered soils containing high concentrations of $\mathrm{Fe}$ and $\mathrm{Al}$ oxides and $\mathrm{OH}$ solids. In such systems anion adsorption effectively maintains constant solution arion concentrations, at least over short periods. For example, if $\mathrm{SO}_{4}$ is added to a sorbing soil, the added ions are largely adsorbed, and thereby $A N C$ is increased in solution (decrease in $2 C_{A}$ ). Conversely, if a solution with a very low $\mathrm{SO}_{4}$ 

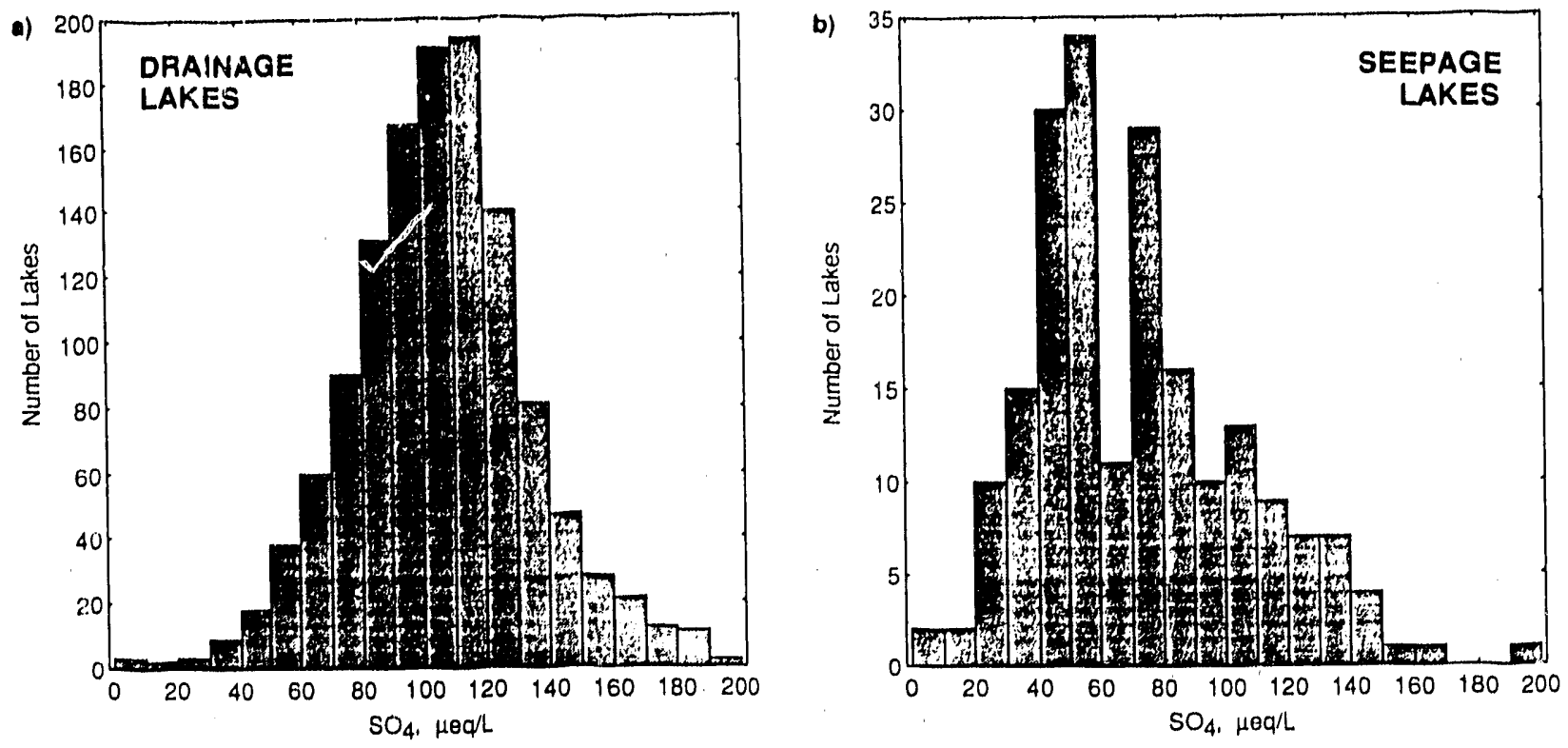

Figure 2.3-15 Distribution of sulfate concentrations in (a) drainage lakes and (b) seepage lakes, based upon samples (excluding replirates) taken from $\leq 1.5 \mathrm{~m}$ depth during the summer water chemistry surveys.

concentration is added to a sorbing suil, anions are desorbed in an attempt to maintain constant solution $\mathrm{SO}_{4}$ concentration. The anion adsorption process is depicted schematically in Figure 2.3-16.

The Adirondacks lie within a zone which was glaciated within the past 12,000 to 14,000 years. The soils are young and not highly weathered. Thus anion adsorption plays only a minor role in determining the acid-base characteristics of Adirondack surface waters (Cronan 1985).

\subsubsection{Influence on $\mathrm{pH}$}

The influence that mineral acids and bases have on $\mathrm{pH}$ depends on the ANC of the solution.

Figure 2.3-17a illustrates the $\mathrm{t}$ leoretical relationship between $\mathrm{pH}$ and $\mathrm{ANC}$ for a water in equilibrium with atmospheric $\mathrm{CO}_{2}$ and free from the influence of other weak acid species. As indicated, the addition of $50 \mu \mathrm{eq} / \mathrm{L}$ of mineral acidity 10 a water with an initial ANC of $25 \mu \mathrm{eq} / \mathrm{L}$ will lead to a decrease in pH of over 2 units. The same addition to a water with an initial ANC of $200 \mu \mathrm{eq} / \mathrm{L}$ will lead to a decease in $\mathrm{pH}$ about 0.1 units. 


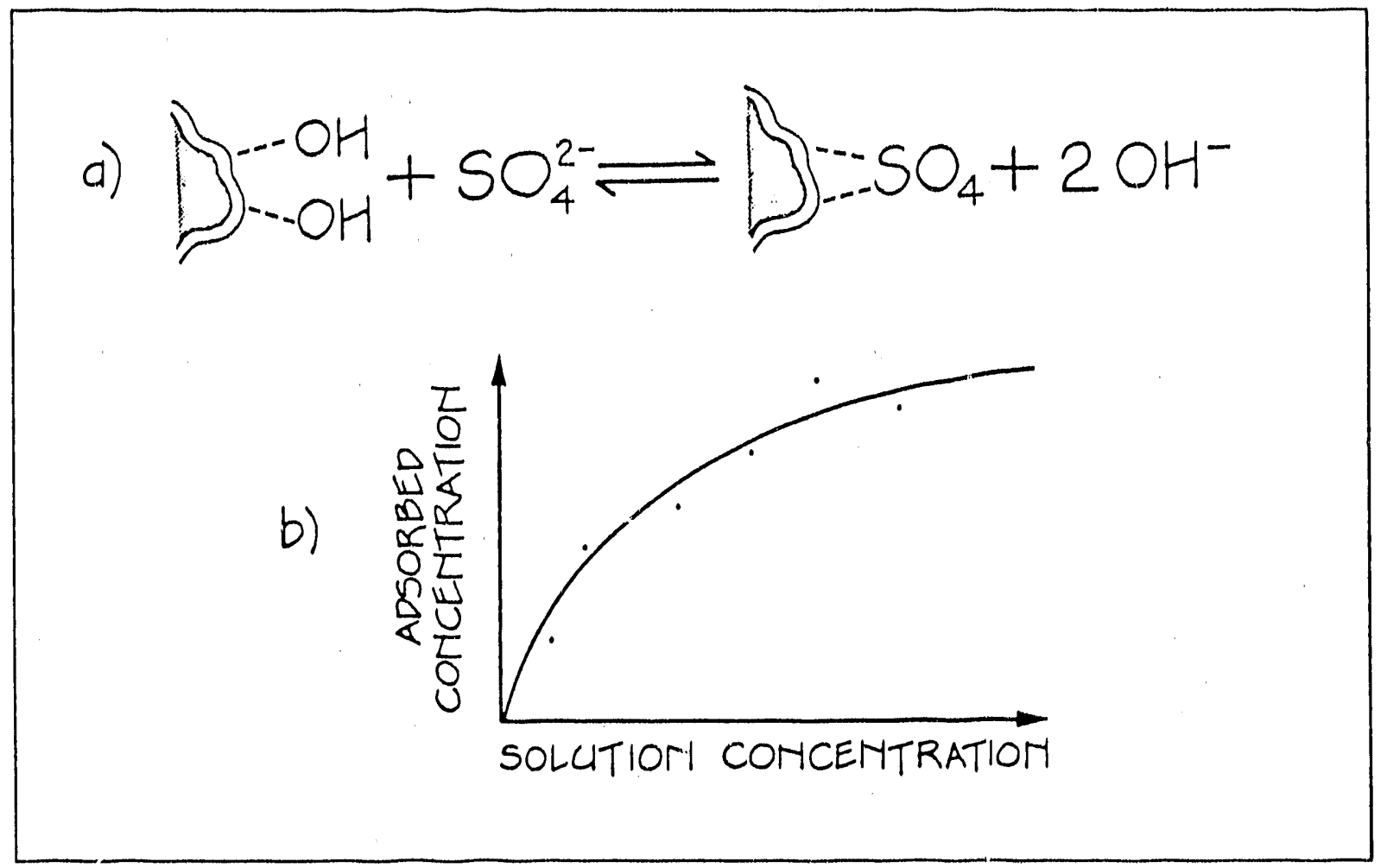

rigure 2.3-16 Anion adsorption: (a) idealized representation and (b) adsorption isotherm.

The' ALSC data follow the same general curve as the theoretical line shown in Figute 2.3-17a, as indicated by the plot of measured air-equilibrated $\mathrm{pH}$ versus Gran-titrated ANC in Figure $2.3-17 \mathrm{~b}$. The scatter in this curve is due to the effects of nonmineral acids and bases such as those associated with $D O C$ and to the influence of $\mathrm{Al}$ at lower $\mathrm{pH}$ values.

\subsubsection{Deposition}

The atmospheric acids and bases reaching lake-watershed and stream-watershed systems enter in both wet and dry forms. Wet deposition, by definition, enters the basin directly with precipitation. Wet deposition flux is quantified by multiplying the measured precipitation amount by the observed precipitatiun solute concentrations. There are many stations at which precipitation amount is measured, but relatively few where solution composition is also determined. As part of the RILWA; project, precipitation quality was measured at four sites within the Adirondacks (see Figure 2.3-18). The volume-weighted mean concentrations from these analyses are very similar. These data would indicate that variation in deposition across the Adirondacks results mostly from variation in precipitation amount (Johannes et al. 1986). Thus, reasonable estimates of deposition can be made for a particular basin even if precipitation concentration values are not available from directly within or adjacent to the basin. 

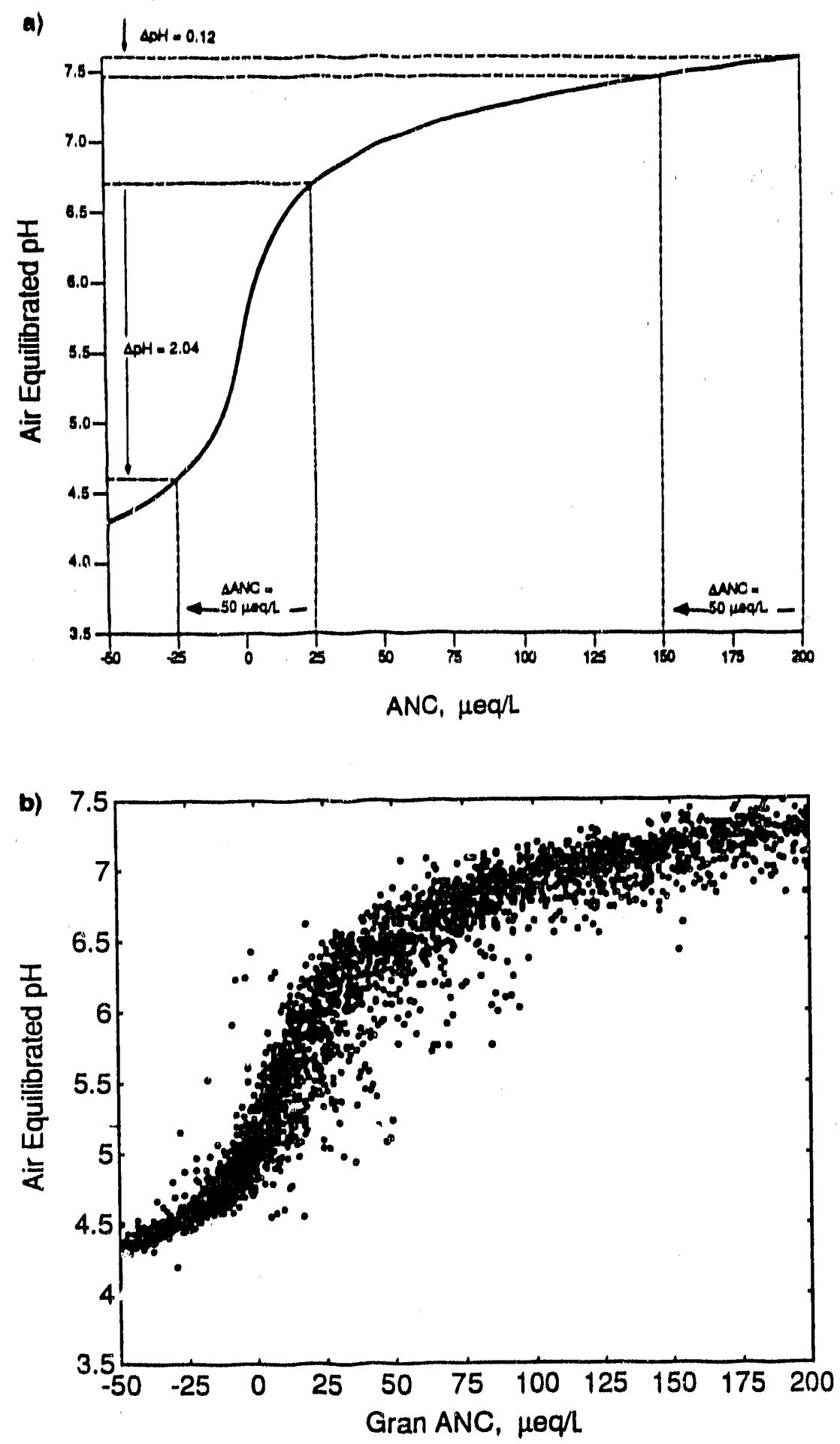

Figure 2.3-17 pH versus ANC (a) theoretical relationship and (b) ALSC data. The influence of mineral acids and bases on pH depends upon the initial ANC of the solution. 


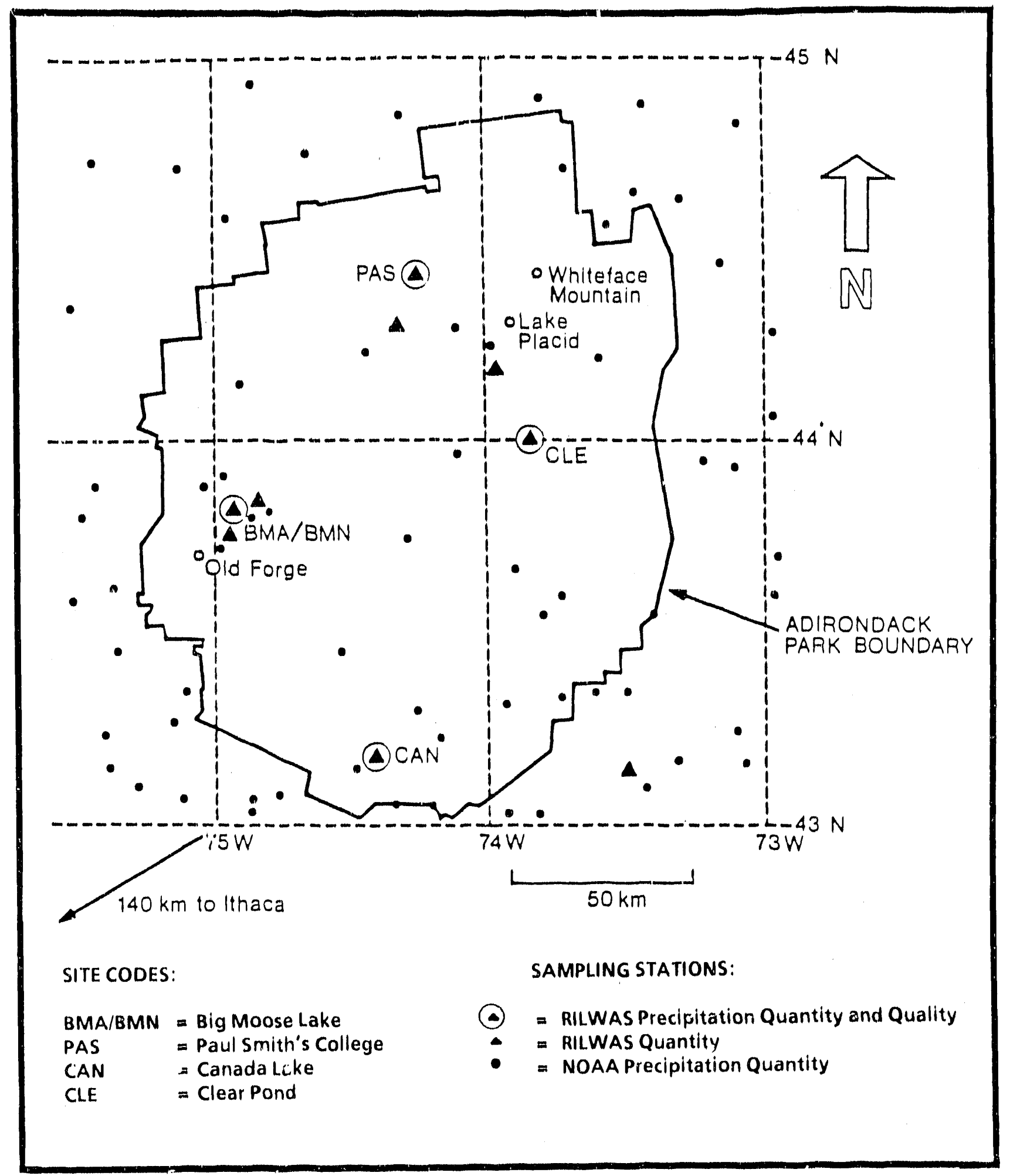

Figure 2.3-18 The RILWAS sites for precipitation quantity and quality measurements (Johannes et al. 1986). 
An estimate of wet deposition throughout the Adirondacks can be made based on the concentrations in Table 2.3-3 and the long.term precipitatlon record. This, in conjunctlon with the long-term runoff

Table 2.3.3 Volume-weighted Mean Ion Concentrations in Precipltation at the RILWAS Sitesa

\begin{tabular}{lrrrr}
\hline & BMA/BMN & CAN & CLE & PAS \\
\hline & & & & \\
$\mathrm{SO}_{4}, \mu \mathrm{eq} / \mathrm{L}$ & 49.6 & 47.4 & 43.1 & 53.3 \\
$\mathrm{NO}, \mu \mathrm{eq} / \mathrm{L}$ & 26.3 & 29.0 & 22.9 & 26.7 \\
$\mathrm{CL}, \mu \mathrm{eq} / \mathrm{L}$ & 4.7 & 4.7 & 4.2 & 5.2 \\
$\mathrm{Lab} \mathrm{pH}$ & 4.2 & 4.2 & 4.3 & 4.2 \\
$\mathrm{NH} \mathrm{H}_{4} \mu \mathrm{eq} / \mathrm{L}$ & 14.0 & 13.4 & 11.7 & 16.6 \\
$\mathrm{Ca}, \mu \mathrm{eq} / \mathrm{L}$ & 8.5 & 8.8 & 6.0 & 8.2 \\
$\mathrm{Mg}, \mu \mathrm{eq} / \mathrm{L}$ & 2.8 & 3.0 & 2.1 & 2.7 \\
$\mathrm{Na}, \mu \mathrm{eq} / \mathrm{L}$ & 3.2 & 3.6 & 3.5 & 4.0 \\
$\mathrm{~K}, \mu \mathrm{eq} / \mathrm{L}$ & 1.8 & 1.2 & 1.3 & 1.5 \\
& & & & \\
\hline
\end{tabular}

a Data are for the RlLWAS stations for the two-year period from August 1982 to July 1984, except for the Canada Lake station (CAN), which is for the 12-month period from August 1983 to July 1989: BMA/BMN = Big Moose Lake;

CAN = Canada Lake; CLE - Clear Pond; PAS - Paul Smith's College.

record and estimates of dry deposition flux into the region, can be used to estimate what lakewater quality throughout the Adirondacks would be in the absence of all processes other than evapoconcentration. Using the concentration data from the Big Moose Lake station, runoff estimates ranging from 30 to $70 \%$, and dry deposition at one-half wet, the expected concentrations would be those listed in Table 2.3-4. Deviations from these concentrations in the observed lakewater quality data indicate that other processes aie occurring that produce or consume the various constituents (Munson and Gherini, in press).

\subsubsection{Other Acid-Base Systems}

The other acid-base systems include DIC and DOC. In the past, these compounds were generally thought to act as weak acids in surface waters. The ALSC data, however, indicate that DOC has strong acid components. This section will first describe weak acid-buse theory. This will be followed by a

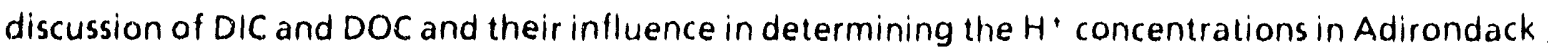
lakes. 
Table 2.3-4 Expected Solute Concentrations in Adirondack Lakes in the Absence of all Modifying Processes Except Evapotranspirationa

\begin{tabular}{lrrrrr}
\hline & $\begin{array}{c}30 \% \\
\text { runuff }\end{array}$ & $\begin{array}{c}\mathbf{4 0 \%} \\
\text { runoff }\end{array}$ & $\begin{array}{c}\mathbf{5 0 \%} \\
\text { runoff }\end{array}$ & $\begin{array}{c}\mathbf{6 0 \%} \\
\text { runoff }\end{array}$ & $\begin{array}{c}\mathbf{7 0 \%} \\
\text { runoff }\end{array}$ \\
\hline $\mathrm{SO}_{4}$ & 248.0 & 186.0 & 148.8 & 124.8 & 106.3 \\
$\mathrm{NO}_{3}$ & 131.5 & 98.6 & 78.9 & 65.8 & 56.4 \\
$\mathrm{Cl}$ & 23.5 & 17.6 & 14.1 & 11.8 & 10.7 \\
$\mathrm{NH}_{4}$ & 70.0 & 52.5 & 42.0 & 35.0 & 30.0 \\
$\mathrm{Ca}$ & 42.5 & 31.9 & 25.5 & 21.3 & 18.2 \\
$\mathrm{Mg}$ & 14.0 & 10.5 & 8.4 & 7.0 & 6.0 \\
$\mathrm{Na}$ & 16.0 & 12.0 & 9.6 & 8.0 & 6.9 \\
$\mathrm{~K}$ & 9.0 & 6.8 & 5.4 & 4.5 & 3.9 \\
\hline
\end{tabular}

- Concentrations in peq/h, precipitation concentrations given in Table 2.3-3, dry deposition assumed to equal ont-half wet. Note: $30 \%$ runoff is equivalent to a concentration factor of 5, (i.e., Precip + Dry Dep./runoff $=$ concentration factor).

\subsubsection{Weak Acids}

Water with only strong acid and strong base componerits can change from a high to a low $\mathrm{pH}$ with a small addition of strong acid (e.g., adding $40 \mu \mathrm{eq} / \mathrm{L}$ of strong acid to such a solution with an initial ANC of $20 \mu \mathrm{eq} / \mathrm{L}$ [all as $\mathrm{OH}^{-}$], will decrease the $\mathrm{pH}$ from 9.3 to 4.7). If small amounts of weak acids are added to a solution, they will serve as buffers and resist drastic changes in $\mathrm{pH}$. For example, in Figure 2 3-19, theoretical titration curves are shown for a pure strong acid-base system $\left(\mathrm{H}_{2} \mathrm{O}_{1} \mathrm{H}^{*}\right.$, $\mathrm{OH}^{\prime \prime)}$, a strong acid"base system that is kept in equilibrium with atmospheric $\mathrm{CO}_{2}$ levels (and thus includes $\mathrm{CO}_{2}, \mathrm{H}_{2} \mathrm{CO}_{3}{ }^{*}, \mathrm{HCO}_{3}$, and $\mathrm{CO}_{3}{ }^{2}$ ) , and a strong acid-base-atmospheric $\mathrm{CO}_{2}$ system that includes another weak acid in solution (HA plus $A$; as indicated by $20 \mu \mathrm{eq} / \mathrm{L}$ of total charge; $\mathrm{pK}_{\mathrm{A}}=4.5$ ). Note the much more gradual change in $\mathrm{pH}$ for the latter systems upon the addition of strong acid or strong base. This results from the amphoteric behavior of the weak acid species, i.e., they can act both as acids and bases and thereby minimize changes in $\mathrm{pH}$ upon addition of strong acid or strong base. For example, upon addition of strong acid, $\mathrm{HCO}_{3}{ }^{-}$undergoes the following reaction:

$$
\left.\mathrm{HCO}_{3}+\mathrm{HI}^{+} \rightarrow \mathrm{CO}_{2}+\mathrm{H}_{2} \mathrm{O}\right)
$$


Upon addition of strong base, $\mathrm{HCO}_{3}^{-}$reacts as follows:

$$
\mathrm{HCO}_{3}^{-}+\mathrm{OHI}^{-} \rightarrow \mathrm{CO}_{3}^{2-}+\mathrm{H}_{2} \mathrm{O}
$$

\subsubsection{Influence of Other Acids on pH}

The influence of other (nonmineral) acids and bases on solution $\mathrm{pH}$ can be illustrated by examining the difference between the $\mathrm{pH}$ expected in the presence of only mineral acids and bases and atmospheric $\mathrm{CO}_{2}$ and the actual measured $\mathrm{pH}$ values for ALSC waters. This difference is illustrated in Figure 2.3-20a where field $\mathrm{pH}$ is plotted versus $C_{B}-C_{A}$. The solid line on the plot indicates the theoretically expected $\mathrm{pH}$ for a water in equilibrium with the atmosphere. The vertical deviation of each point from the solid line represents the influence of other acids and bases in each sample. The deviation is more easily visualized if the difference between measured field $\mathrm{pH}$ and the theoretical $\mathrm{pH}$ is plotted versus $C_{B}-C_{A}$, as in Figure 2.3-20b. As indicated, the majority of the deviations are negative (i.e., the other acids and bases gerierally depress $\mathrm{pH}$ ), and they vary from zero to three $\mathrm{pH}$ : :

The deviations can be evaluated further by examining the volatile and nonvolatile solution components. The volatile component (mostly $\mathrm{CO}_{2}$ ) can be examined by plotting field $\mathrm{pH}$ minus measured air-equilibrated $\mathrm{pH}$ versus $C_{B}-C_{A} A N C$, as shown in Figure 2.3-21a. The depression ranges frorn zero to more than two $\mathrm{pH}$ units. The nonvolatile component (mostly organics) can be illustrated by plotting the difference between measured and theoretical air-equilibrated $\mathrm{pH}$, as shown in Figure 2.3-21b. As indicated, the deviations vary from zero to three $\mathrm{pH}$ units, with the majority of the large deviations occurring between 0 and $50 \mu \mathrm{eq} / L C_{B}-C_{A}$.

A similar analysis can be performed by examining the differences between theoretical and observed values in terms of $\mathrm{H}^{+}$concentration rather than $\mathrm{pH}$. Figure 2.3-22a shows the difference between measured field and theoretical air-equilibrated $\mathrm{H}^{+}$concentration. This plot corresponds to Figure 2.3-20b in terms of $\mathrm{pH}$. As indicated, at positive $C_{B}-C_{A}$, field samples had higher $H^{*}$ concentrations than the theoretically expected values over most of the $C_{B}-C_{A}$ range. Positive deviations ranged from 0 to over $100 \mu \mathrm{eq} / \mathrm{L}$ and were highest near $C_{B}-C_{A}=0 \mu \mathrm{eq} / \mathrm{L}$. There were a significant number of negative deviations at negative $C_{B}-C_{A}$ values. The sources of both positive and negative deviations are discussed below.

The influence of the volatile component of the nonmineral acid-base system is depicted in Figure 2.3-22b (analogous to Figure 2.3-21a). Deviations from theoretically expected values are 


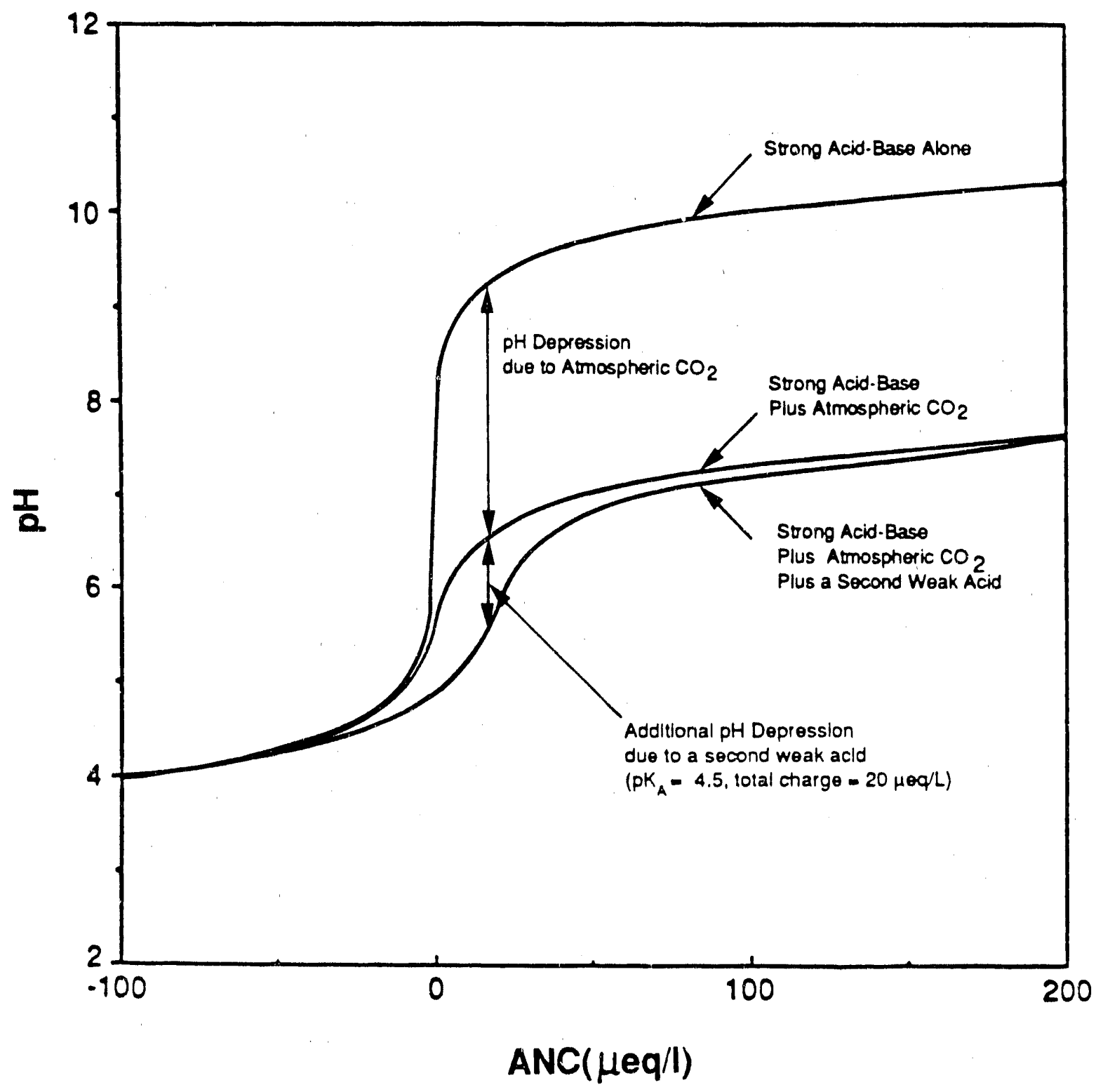

Addition of Strong Base Addition of Strong Acid

Figure 2.3-19 pH buffering provided by carbon dioxide and a second weak acid. Changes in pH in response to additions of strnng acid or strong base (changes in ANC) are greatly reduced when weak acids are present in solution. 
a)

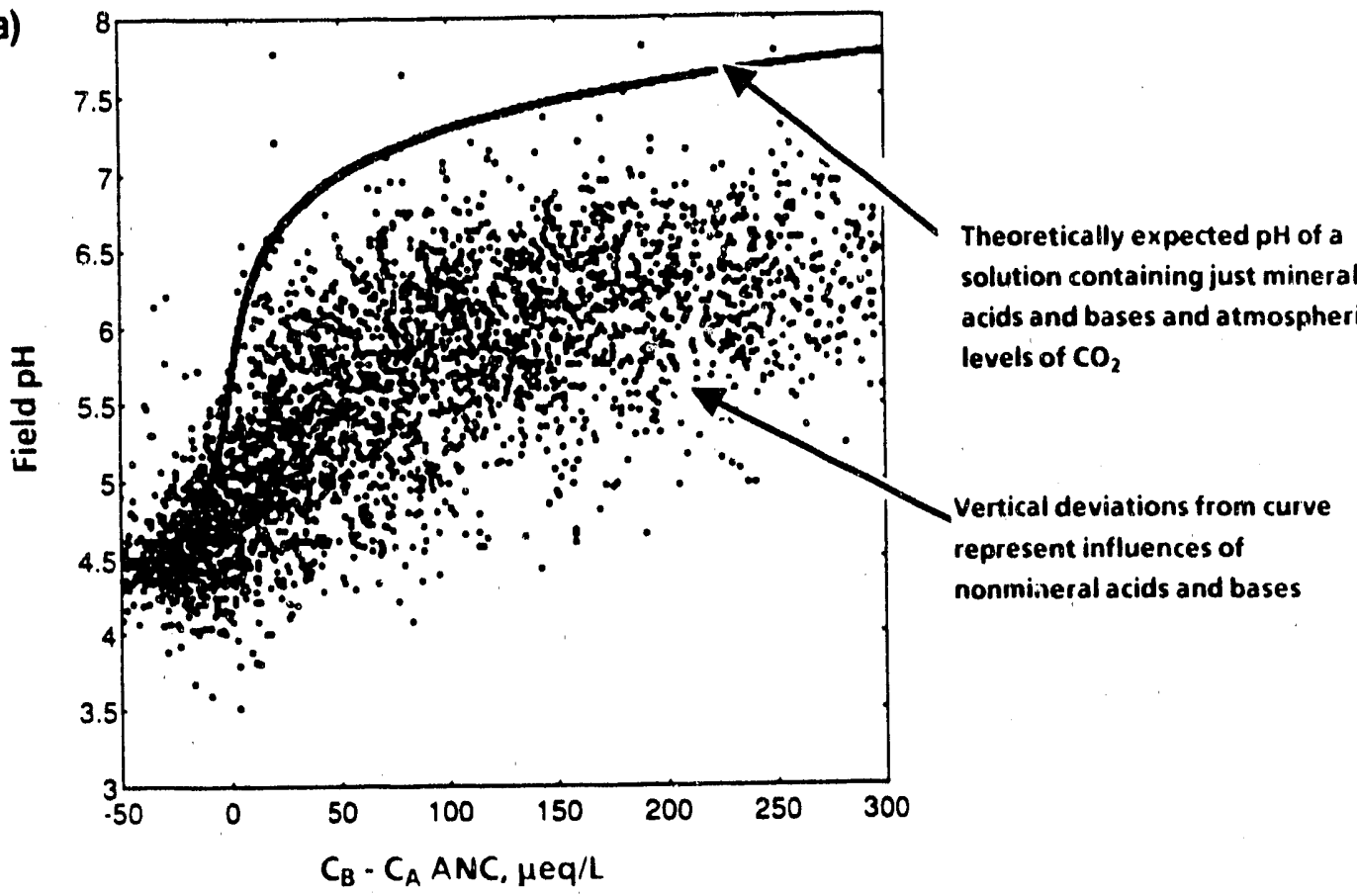

b)

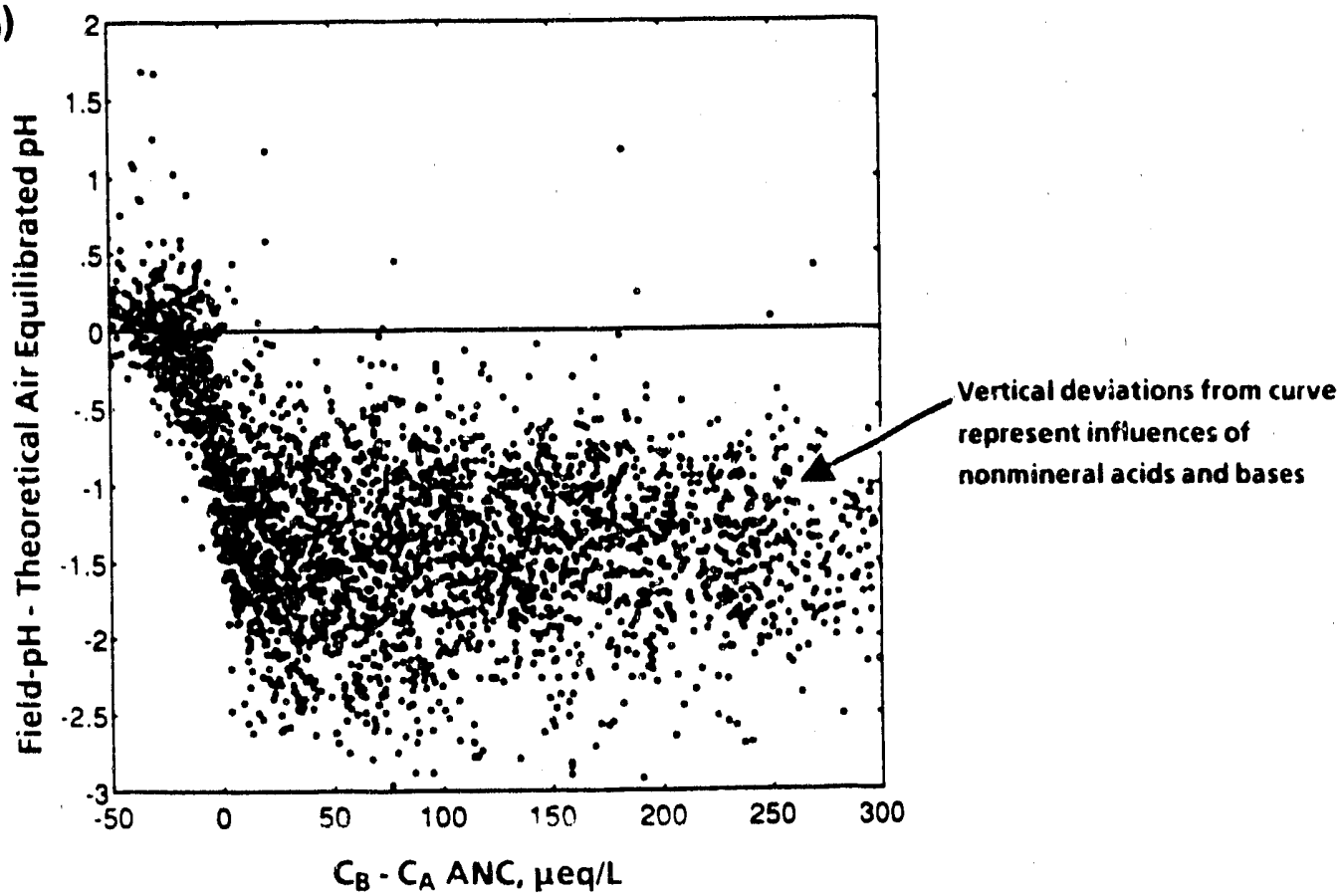

Figure 2.3-20 The influence of nonmineral acids on solution $\mathrm{pH}$, (a) observed field $\mathrm{pH}$ versus $C_{B}-C_{A} A N C_{;}(b)$ the deviations are more easily visualized when plotted directly. 
a)

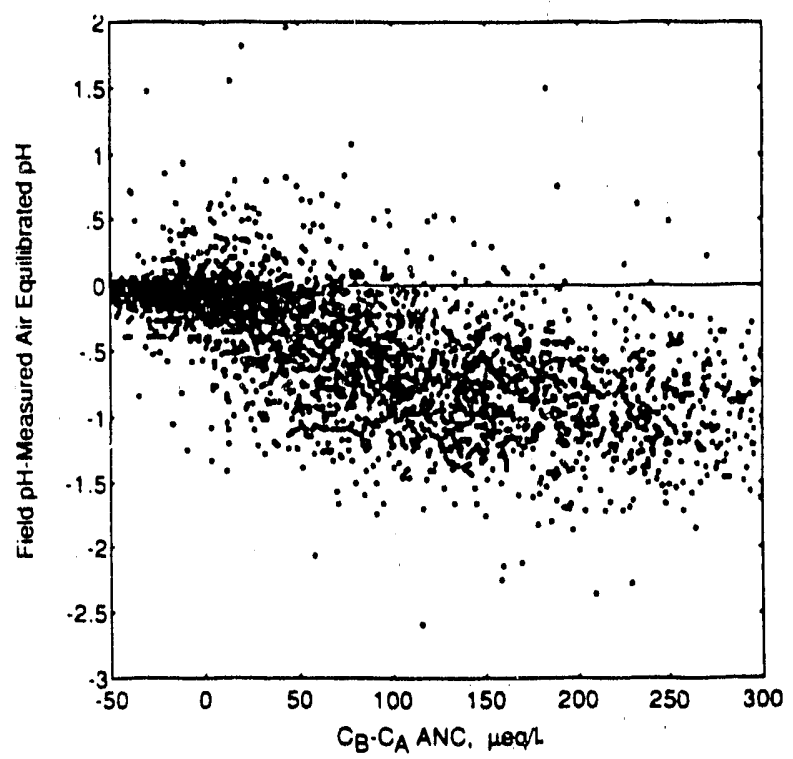

b)

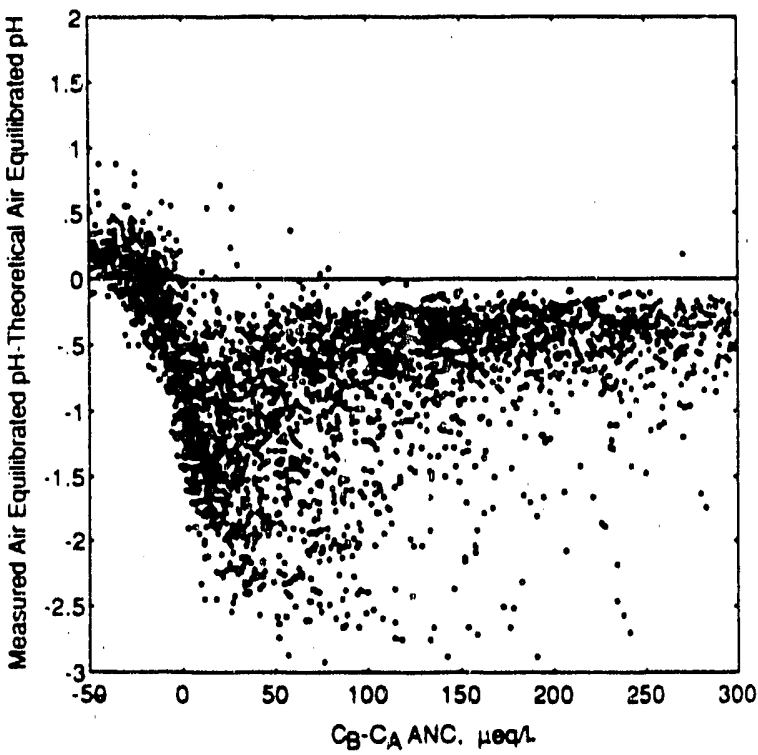

Figure 2.3-21 Influence of (a) volatile and (b) nonvolatile nonmineral acids on solution pH.

typically less extreme than those in Figure 2.3-22a. The largest positive and negative deviations are both near zero $C_{B}-C_{A}$

The nonvolatile component is shown in Figure 2.3-22c (analogous to Figure 2.3-20b). As with the total nonmineral influence (Figure 2.3-22a), the nonvolatile component shows the laryest positive devia!ions near $C_{B}-C_{A}=0$ and significant negative deviations at negative $C_{B}-C_{A}$ values.

The sources of the positive and negative deviations of the nonvolatile component can be determined by examining Figure 2.3-23. If DOC concentrations are limited to $2 \mathrm{mg} / \mathrm{L}$ or less and the nonvolatile component is examined, the plot in Figure 2.3-23a is produced As indicated, most of the points not excluded by limiting the $D O C$ are found within the cluster of negative deviations at $C_{B} \cdot C_{A}$ values less than zero. If the restriction on $D O C$ is lifted and instead a restriction is placed on total $\mathrm{Al}_{\mathrm{m}}$ at $\mathrm{a}$ maximum concentration of $0.5 \mu \mathrm{eq} / \mathrm{L}$, Figure 2.3-23b results. As indicated, the majority of the deviations remaining after the imposition of the $A I_{m}$ restriction are positive and near zero $C_{B}-C_{A}$.

Taken together these two plots indicate that the positive deviations in Figure $2.3 .22 \mathrm{c}$ are a result of the influence of DOC, and the negative deviations result from the presence of Al Limiting DOC 

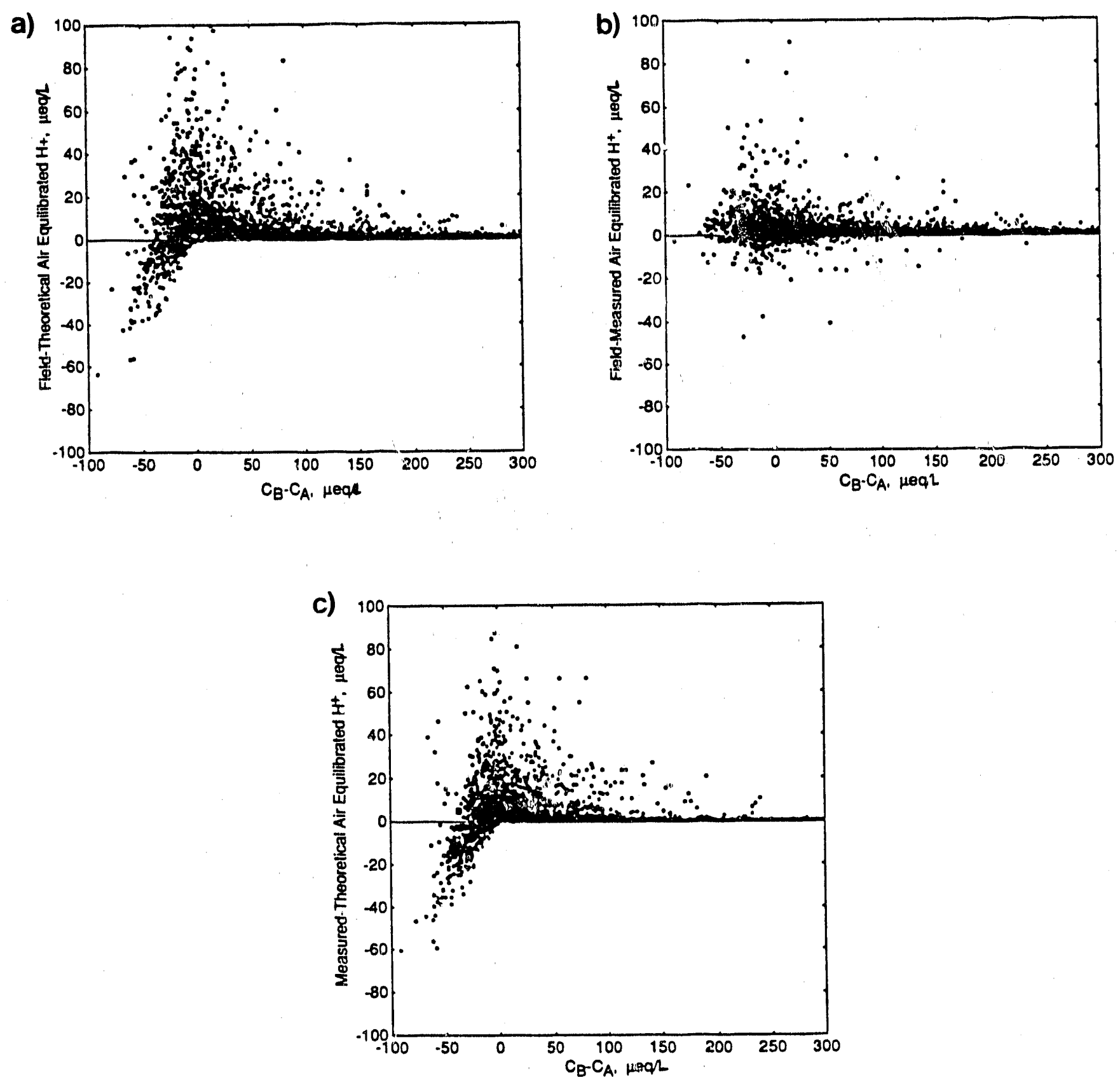

Higure 2.3-22 The influence of nonmineral acids on solution hydrogen ion concentration: (a) total, (b) volatile component, and (c) nonvolatile component. 

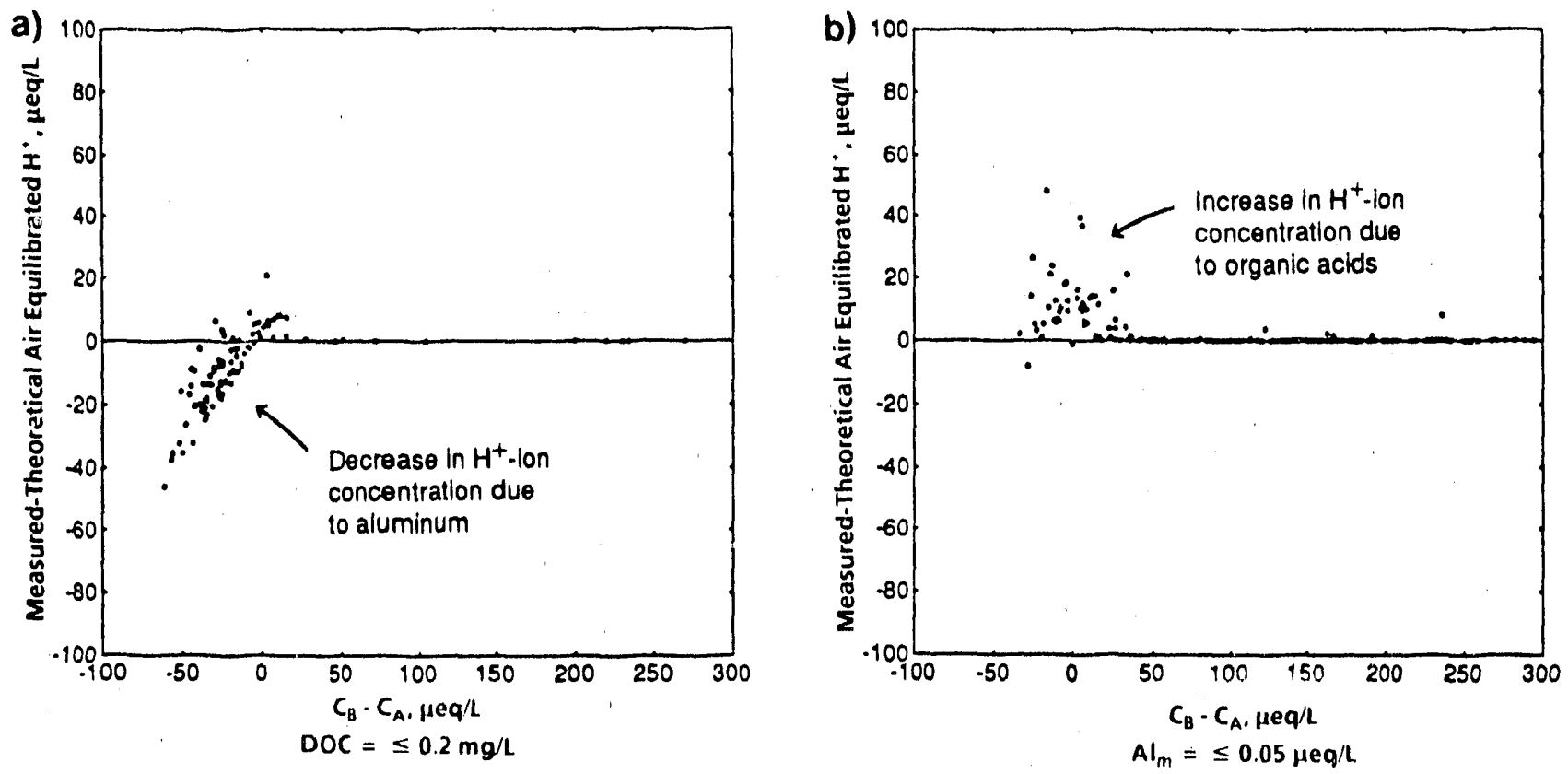

Figure 2.3-23 Evaluation of the nonvolatile component of the influence of nonmineral acids on solution hydrogen ion concentration with (a) exclusion of DOC influence and (b) exclusion of aluminum influence. Scales are same as figure 2.3-22.

concentration, as was done in Figure 23-23a, effectively removes its influence and shows that $\mathrm{Al}$ species react with protons in the negative $C_{B}-C_{A}$ range and thus remove protons from solution. In other words, in these waters, $A$ l is acting as a base. Removing the influence of $A l$, as in Figure 2.3-23b, shows that DOC predominantly elevates $\mathrm{H}^{+}$concentrations in solution. In other words, DOC acts as an acid.

\subsubsection{Further Analysis of Dissolved Organic Carbon}

DOC is a product of the decay of organic matter. Included within the degradation products are substances containing acid-base functional groups, or organic acids. As shown above, these organic acids contribute to the observed acid-base characteristics of the waters in which they are found. The precise role that they play in determining lake and stream acid-base behavior is an area of ongoing research (e.g., Kramer and Davies 1988) Several empirical approaches have been used to quantify the effect of organic acids on solution $\mathrm{pH}$. These include the Oliver model (Oliver et al. 1983) in which an equivalent acid dissociation constant for organic acid $\left(K_{A}\right)$ is represented as a function of the solution $\mathrm{H}^{+}$concentration. Several organic acid analogue approaches have been developed using monoprotic 
representations (e.g., Schecher and Driscoll 1987; $K_{A}=4.5$ ) and polyprotic acids with several functional groups (e.g., Gherini et al. 1985; $\mathrm{pK}_{\mathrm{A} 1}=4.0, \mathrm{pK}_{\mathrm{A} 2}=6.1, \mathrm{pK}_{\mathrm{A} 3}=9.25$ ).

The behavior of organic acids in ALSC waters can be investigated by examining the relationship of charge imbalance, or anion deficit, to DOC. As indicated in Figure 2.3-24a, the relationship over the full range of observations is weak. However, if the data are examined over discrete $\mathrm{pH}$ intervals, much stronger relationships are observed (Figure 2.3-24b, $c$, and d). This is thought to occur because the organic acids are made up of multiple functional groups with varying acid-base strength. The degree of dissociation of each of these functional groups depends on solution $\mathrm{pH}$. Over a wide range of $\mathrm{pH}$, the degree of dissociation varies widely, whereas over small $\mathrm{pH}$ intervals the percent that is dissociated is more nearly constant.

Figures 2.3-24b, $c$, and d also show that the slope of the relationship between anion deficit and DOC increases as the interval $\mathrm{pH}$ increases. This reflects a larger extent of dissociation of the functional groups as the concentration of $\mathrm{H}^{+}$in solution decreases.

The fact that there is a good relationship between anion deficit and DOC, even at high $\mathrm{H}^{\text {* }}$ concentrations ( $\mathrm{pH}=4.0$ to 4.5), suggests that a portion of the organic acids should be considered "strong" acids. If the organic acids were all weak, they would be protonated at low pH, uncharged, and thus would not contribute to the anion deficit. This observation runs counter to many of the past representations of organic acids, in which they were treated as weak acids.

Influence of DOC on Gran-Titrated ANC. In addition to its influence on $\mathrm{pH}, \mathrm{DCC}$ also influences the measurement of Gran ANC. As indicated in Figure 2.3-2, the $C_{B}-C_{A} A N C$ is generally higher than the Gran-titrated ANC. It has been suggested that this may be due to the systematic underestimation of titrated ANC as a result of curvature in the Gran F, function induced by DOC (Butler 1982; Sullivan et al. 1989). Another hypothesis suggests that some fraction of the organic ligand should be included in $\Sigma C_{A}$ (Davis et al. 1987). A brief description of the Gran procedure is presented below, along with analyses of ALSC data related to the influence of DOC on Gran ANC 

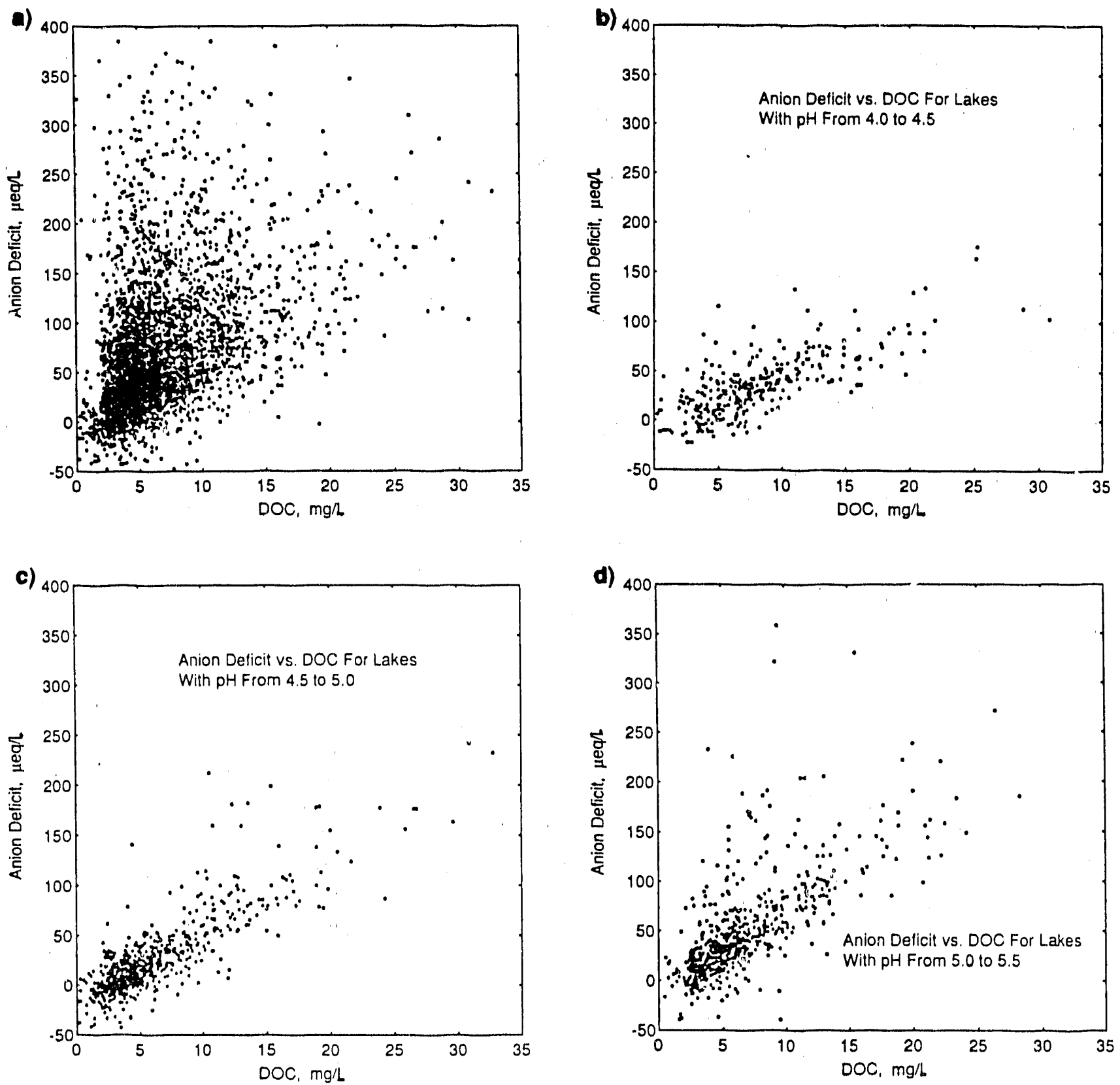

Figure 2.3-24 Anion deficit versus DOC over (a) the full range of data, (b) sainples with pH from 4.0 to $4.5, i c$ ) samples with pH from 4.5 to 5.0 , and (d) samples with pH from 5.0 to 5.5 . 


\section{Gran Titration Analysis}

As stated in Section 2.3.1.1, ANC is measured by titrating a solution with mineral acid to an equivalence point. In dilute water, the equivalence point is difficult to determine. The Gran (1952) procedure is typically ssed to identify the equivalence point volume. The Gran analysis requires plotting the function $F_{1}$ versus titrant volume. $F_{1}$ is calculated as follows:

$$
F_{1}=\left(V+V_{0}\right) 10^{-p H t}=\left(V+V_{0}\right)\left|H^{+}\right|
$$

Where:

$V=$ added titrant volume

$V_{u}=$ original sample volume.

This produces a curve like that shown in Figure 2.3-25. The upper right-most "linear" portion of the curve is extrapolated downward to determine the equivalent volume $\left(V_{e}\right)$ of titrant. The slope of this extrapolated line should be identical to the titrant normality. The ANC is then calculated as follows:

$$
A N C^{\circ}=\frac{V_{e} C_{t}}{V_{0}}
$$

Where:

$c_{1}=$ normality of titrant.

\section{DOC Effects}

The organic acids associated with DOC exhibit a wide range of acid-base characteristics, as was previously shown. Organic functional groups are protonated throughout the ANC titration procedure. This becomes problematic in the low-pH range of the titration because the buffering provided by the organic ligands leads to curvature in the $F_{1} G$ ran function.

Sullivan et al. (1989) noted the increasing curvature of the $F_{1}$ function with increasing organic acid concentrations. This has the effect of making the curve nonlinear at much lower $\mathrm{pH}$ values as DOC increases. If the curve is extrapolated using data from a nonlinear portion of the curve, $V_{e}$ and thus ANC will be systematically underestimated. It has been reccimmended (Sullivan et al. 1989) that ANC titrations be carried out to $\mathrm{pH} 3.0$ to minimize problems with curvature. Below pH 3.0, the error associated with the precise measurement of $\mathrm{H}^{+}$concentration becomes too large to further improve Gran estimates

ANC was measured for ALSC waters using a standard EPA method in which samples were first acidified to $\mathrm{pH} 4$.0. Then six 20- $\mu \mathrm{L}$ increments of hydrochloric acid (HCl) were added to the solution, 


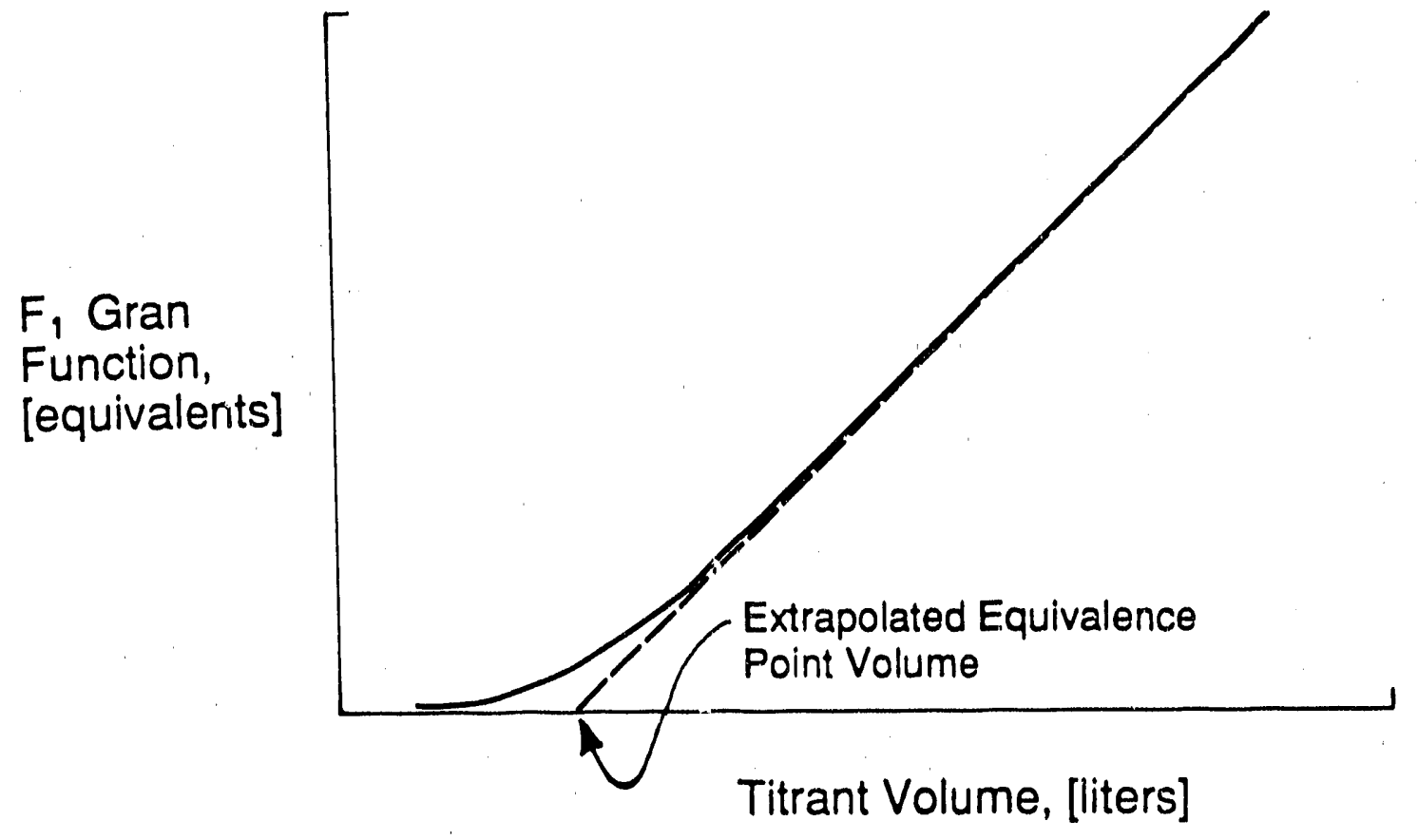

Figure 2.3-25 The $F_{1}$ Gran function plot. The upper right-most linear portion of the curve is extrapolated downward to determine the titrant volume at the equivalence poirit and thus ANC.

and the $\mathrm{pH}$ was recorded following each addition. These six measurements were used to calculate $F_{1}$ values, which served as the basis for extrapolation to $\mathrm{V}_{\mathrm{e}}$. The final $\mathrm{pH}$ in these titrations was typically around 35 .

Figure 2.3-26 presents Gran plots for a high- and a low-DOC water from the ALSC data. A $45^{\circ}$ line ha'; been added to each plot to serve as a visual guide to highlight the curvature in the data points. The data from the high-DOC water in Figure 23 -26a show a visually obvious deviation from lirearity with decreasing $F_{1}$ values. In addition, the slope of linear regression curve derived from the six points was 0.0876 as compared to the titrant normality, which was 0.1004 . The data in Figure $2.3-26 \mathrm{~b}$, for the low-DOC water, show smaller visual deviations from the $45^{\circ}$ line. Here the slope of the regression line, 0.0955, was much closer to the titrant normality, 0.0998 . The regression coefficients, $r 2$ for both plots were greater than 0.999 , in spite of the obvious curvature in plot a, particularly in the lower left corner. This illustrates the danger of the common practice of relying on regression coefficients to 
a)

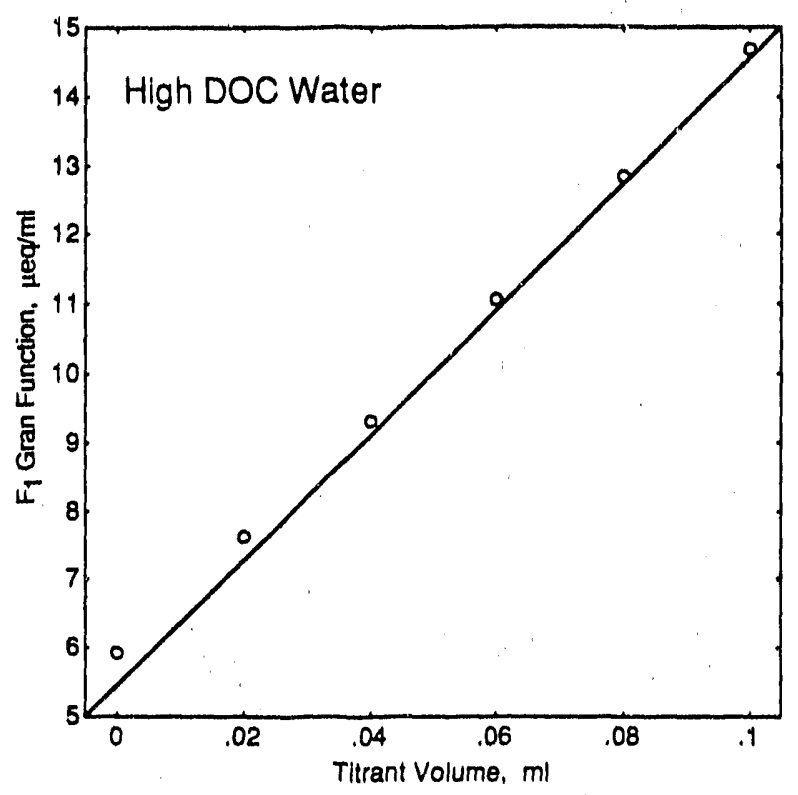

b)

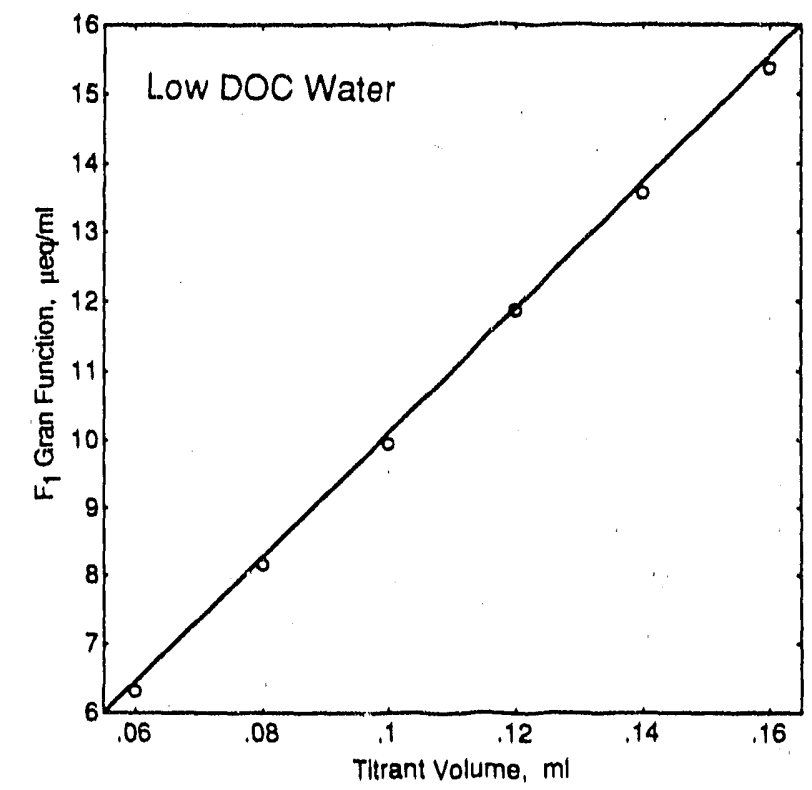

Figure 2.3-26 F, Gran function versus titrant volume for a (a) high-DOC and a (b) low-DOC sample. The curvature in the high-DOC sample leads to the underestimation of ANC.

indicate that the titration has entered the linear range (where each addition of mineral acid creates an equivalent increment in solution $\mathrm{H}^{+}$concentration; i.e., where there are no more unprotonated sites on the ligands).

The curvature of the $F_{1}$ Gran function due to the presence of organic acids does lead to the underestimation of Gran ANC, especially if the titration is not carried out to $\mathrm{pH} 30$. A significant part of the deviation between $C_{B}-C_{A} A N C$ and Gran ANC (See Figure 2.3-27) might be explained by the underestimation due to curvature. The alternative hypothesis stated at the beginning of this section, that part of the organic ligand should be included in $\Sigma C_{A}$, also accounts for some of the observed deviation. An accepted means for quantifying this contribution has not been available prior to this study. 


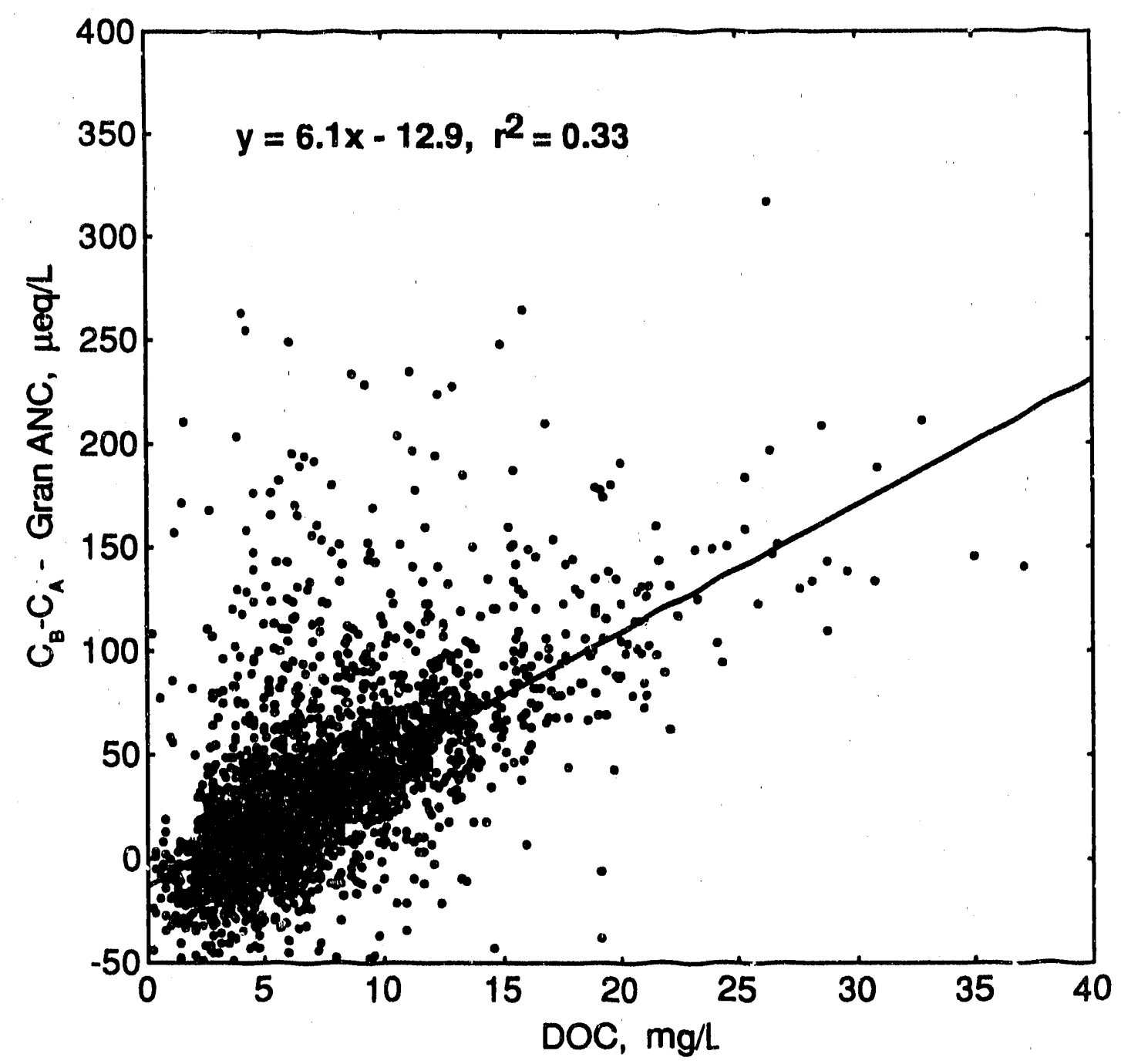

Figure 2.3-27 Deviation between $C_{B}-C_{A}$ and $G r a n A N C$ as a function of DOC concentration.

\subsubsection{Summary}

Relationships between variables for 3,984 ALSC water chemistry samples were assessed. Mineral acids and bases influenced $\mathrm{pH}$ largely through their effects on ANC. The influence beromes particularly significant as ANC values approached zero. Differences in ANC values (and thus differences in the relative amounts of mineral acids, $C_{A}$, and bases, $C_{B}$ ) among the surveyed waters resulted from varying concentrations of base cations rather than acid anions. Dissolved Fe and Mn ephemeraliy incremented the ANC of lake bottom waters. Sodium and $\mathrm{SiO}_{2}$ covaried in concentration indicating a common source -- the weathering of primary aluminum silicate minerals. Vertical gradients in lake $\mathrm{SiO}_{2}$ concentrations reflected active $\mathrm{SiO}_{2}$ uptake by diatoms. Silica concentrations thus should only be 
considered an indication of the minimum amount of primary mineral weathering occurring within a basin. It appears that ion exchange is currently a major source of $\mathrm{Ca}$ and $\mathrm{Mg}$ in the ALSC surface waters.

A significant fraction of the organic acids were shown to be strong acids. Gran-titrated ANC values were generally less than $A N C$ calculated from $C_{B} \cdot C_{A}$. The differences tvere demonstrated to result in part from the effects of DOC on the linearity of the Gran $F_{1}$ function and from the fraction of the organic acids that were strons. Organic acids in general depressed $\mathrm{pH}$, particularly at ANC values between $n$ and $50 \mu$ eq/ $\mathrm{L}$. At negat:ye ANC values, Al species consumed $H^{+}$and thereby increased $\mathrm{pH}$.

The relationships developed in this section are consistent with Bronsted-Lowry acid-base theory. This theory was particularly helpful in elucidating both the mineral acid-base system $\left(C_{B}-C_{A}\right)$ and the other acid-base systems active in ALSC waters. Both the theory and the relationships developed in this section will be used in subsequent analyses. 


\subsection{CLASSIFICATION OF ALSC LAKES}

\section{- R.M. Newton and C.T. Driscoll}

The classification of Adirondack lakes provides a means for describing the chemical status of this diverse group of waters. It alco provides a basis for regionally assessing the effects of changes in atmospheric deposition on surface water quality. Classification schemes may be based on chemical or watershed characteristics. Wầershed-sased classifications cons,der the physical characteristics within the basin to be most important in determining both the currunt chemical status and the susceptibility of the lakes to change. Previous watershed cilassifications range from the discrimination of drainage and seepage lakes (Goldstein, et al. 1987) to detailed classifications based largely upon flowpath analysis (RILWAS project; Gherini, et al. 1989). Chemical classification schemes generally group lakes according to some ANC criteria such as that used by Colquhoun et al. (IS84). They classified Adirondack waters in terms of their perceived sensitivity to acidification as follows; acidified

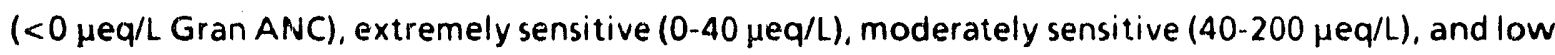
sensitivity (200-500 $\mu \mathrm{eq} / \mathrm{L})$

This section presents a water-quality-based classification for the ALSClakes. The classification is preceded by a brief overview of the general physical and chemical characteristics of the ALSC lakes and of flowpath theory (Goldstein et al. 1984). This is followed by a discussion of the theory and application of lake classification. Finally, ine ALSC and ELS data bases are compared in light of the classification scheme developed.

\subsubsection{Physical Characteristics of the Lakes}

Two general types of lakes were sampled in the ALSC survey, drainage lakes and seepage lakes. Drainage lakes by definition have a surface outlet, whereas seepage lakes do not. These two types of lakes are formed by different geologic processes and have differing chemical characteristics.

Seepage lakes are generally found in areas with stratified sand and gravel deposits. These lakes were created during deglaciation when isolated blocks of stagnant ice were buried by meltwater stream deposits. The subsequent melting of these blocks led to surface collapse and the formation of closed depressions (kettle lakes).

Drainage lakes, in contrast, form in several ways, including glacial erosion, which creates basins in the bedrock, or behind deposits of till, which dam drainage systems. As a result of these basic differences 
and the differences they create in water quality, the discussion of lake physical characteristics has been subdivided between drainage and seepage lakes.

Most of the lakes sampled by the ALSC are drainage lakes (86\%). These lakt: are located throughout the Adirondack Park (Figure 2.4-1a). Fourteen percent of the waters sampled by the ALSC were seenpage lakes. The latter are principally located along the western border of the Adirondack Park znd in the northcentral Adirondacks (Figure 2 4-1b).

ALSC lakes are generally small (Figure 2.4-2). Surface areas ranged from 0.2 to $287 \mathrm{ha}$. The mean surface area of the drainage lakes surveyed was $18 \mathrm{ha}$; mean depth was $2.5 \mathrm{~m}$. Mean surface area of the seepage lakes was $5 \mathrm{ha}$, mean depth $2.9 \mathrm{~m}$. The mean watershed area of the drainage lakes is 501 ha. Small lake volumes, coupled with moderately sized watersheds, cause Adirondack drainage lakes to generally have short h;draulic residence times (median value $=45$ days)

Lakes sampled in the ALSC survey are located over a wide elevation range, from $137 \mathrm{~m}$ to $1129 \mathrm{~m}$. Drainage lakes are generally located at higher elevations (mean elevation $=510 \mathrm{~m}$ ) than seepage lakes (mean $=464 \mathrm{~m}$ ). Two hundred thirty-five of the ALSC drainage lakes and 9 of the seepage lakes
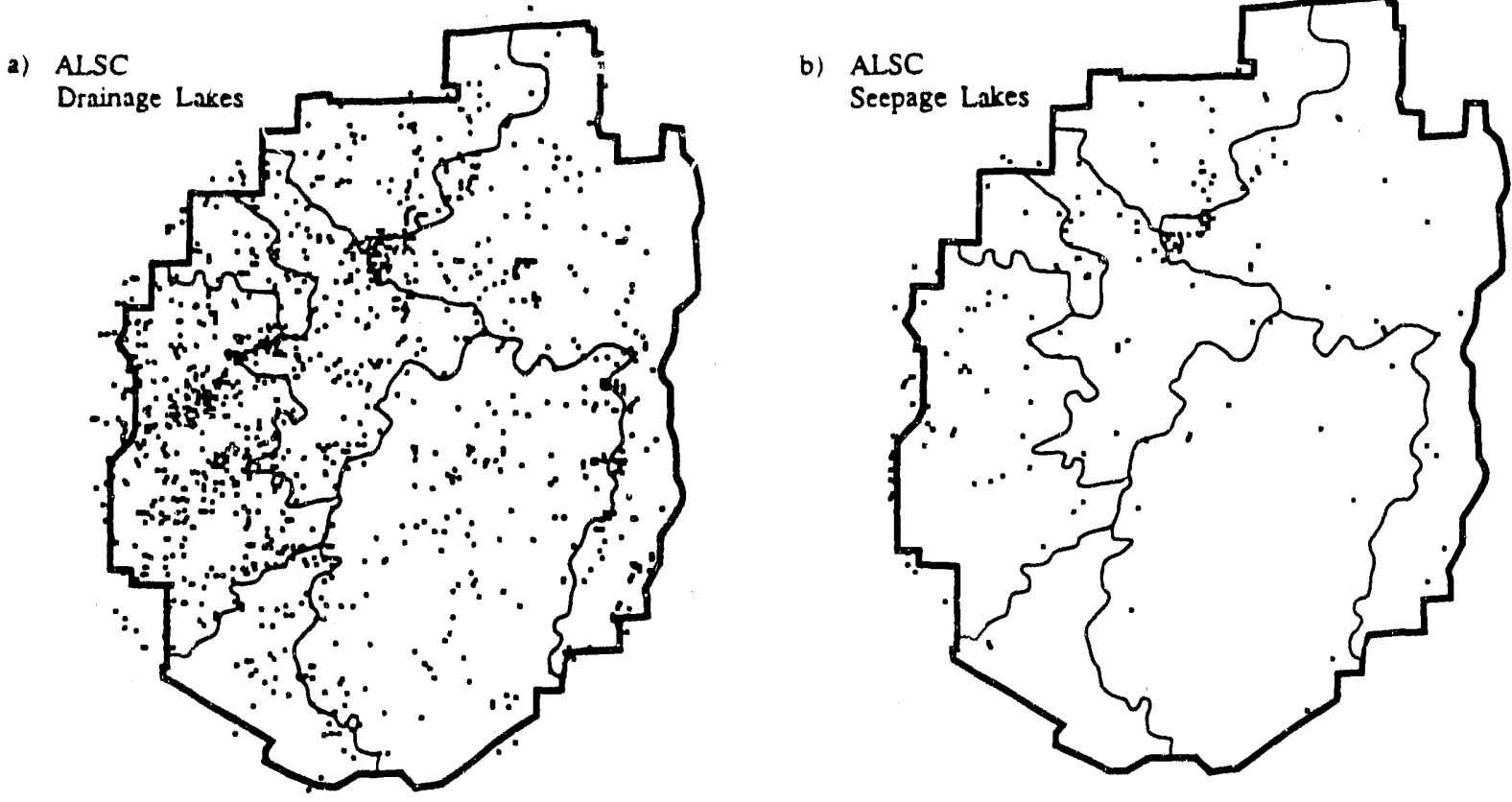

Figure 2.4-1 Areal distributions of ALSC (a) drainage lakes and (b) seepage lakes. Lines within the park boundary delineate the major Adirondack drainage basins. 

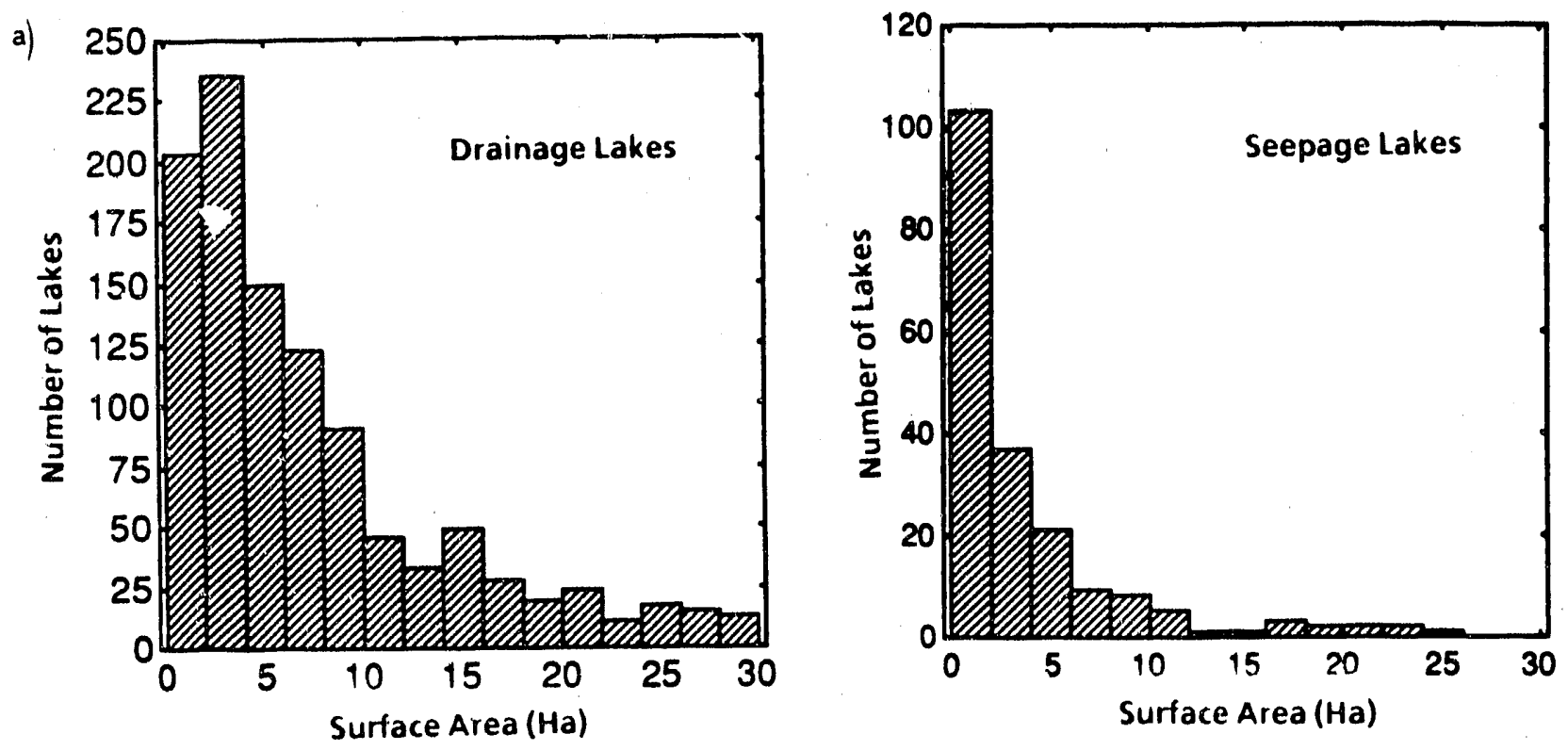

Figure 2.4-2 Surface areas of ALSC (a) drainage and (b) seepage lakes. The distributions are limited to $<30$-ha lakes to illustrate the fine structure in the distribution of small lakes. This limitation exciuded only $16 \%$ of the drainage lakes and $<1 \%$ of the seepage lakes.

are above $600 \mathrm{~m}$. Low-elevation $(<400 \mathrm{~m}$ ) seepage lakes are generally located along the western boundary of the Adirondack Park, with a few lakes occurring within the vicinity of Lake Champlain. Low-elevation drainage lakes are also located near the border of the Park. High-elevation ( $>600 \mathrm{~m}$ ) lakes are generally found in the southwestern Adirondacks. A few high-elevation lakes are located in the central Adirondacks and in the High Peaks region.

\subsubsection{Chemical Characteristics of the Lakes}

Owing in part to their differing physical characteristics, drainage and seepage lakes' chemical characteristics can be quite different as well. Thus, the distributions of chemical characteristics described below were also evaluated by lake type.

The distributions of $\mathrm{pH}, \mathrm{ANC}, \mathrm{SO}_{4}$ and total $\mathrm{C}_{B}$ concentrations in the drainage lakes are shown in Figure 2.4-3. As indicated, $\mathrm{pH}$ has a bimodal distribution with peaks between 6.25 ard 6.5 and between 4.5 and 4.75 . There are more drainage lakes with $\mathrm{pH}$ values $>5.5$ than with values $<5.5$. The Gran ANC distribution is skewed toward low values, with the most commonly occurring concentrations being between -25 and $+25 \mu \mathrm{eq} / \mathrm{L}$. Sulfate, as indicated in Section 2.3 , is more 

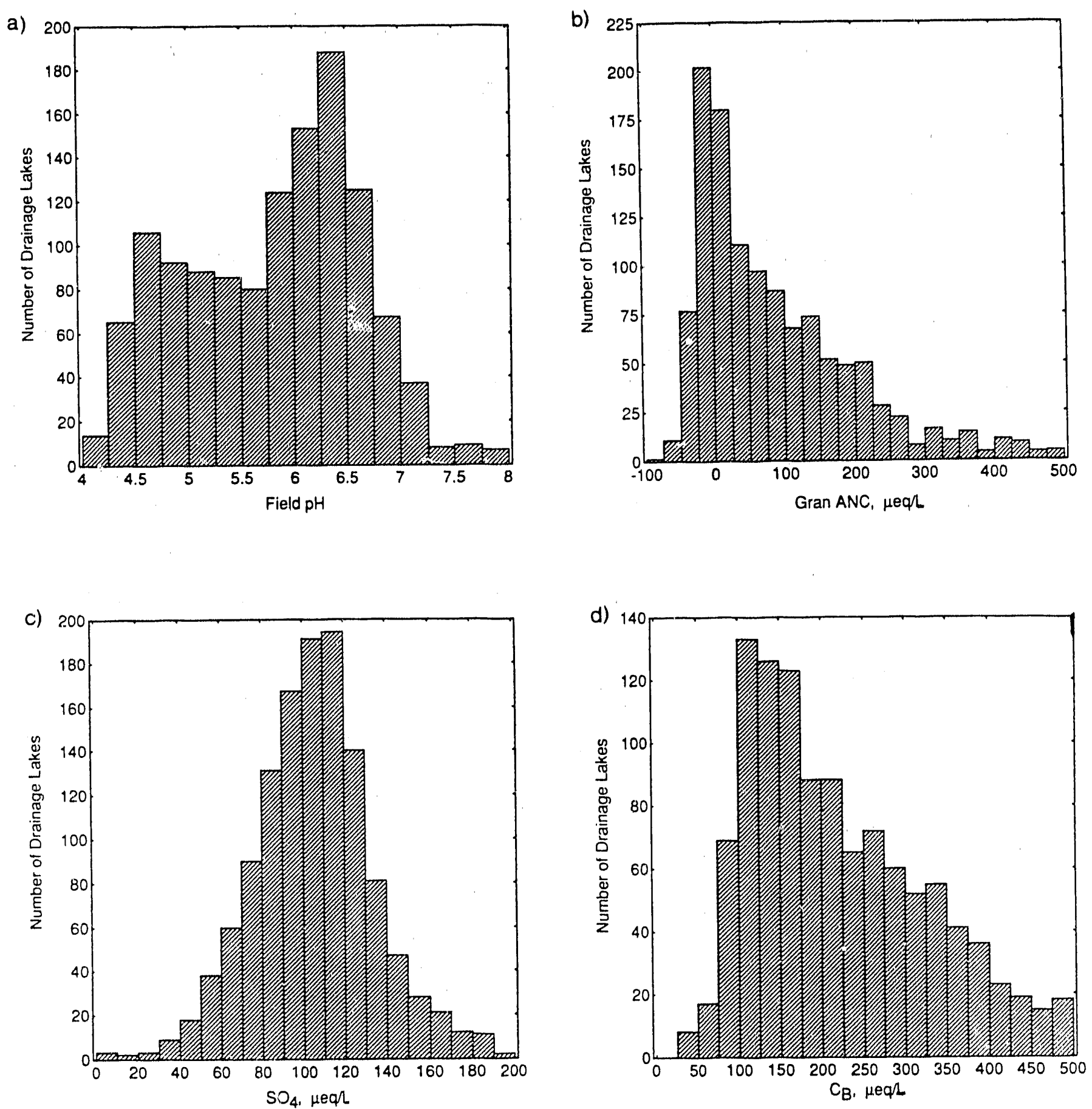

Figure 2.4-3 ALSC drainage lakes distributions of (a) pH, (b) Gran ANC, (c) sulfate, and (d) base cations. 
normally distributed with the most commonly occurring values between 90 and $120 \mu \mathrm{eq} / \mathrm{L}$. Finally, $\mathrm{C}_{B}$ concentrations are skewed toward low concentrations with the peak of the distribution between $10 \mathrm{U}$ and $175 \mu \mathrm{eq} / \mathrm{L}$.

The distributions for the same parameters for the seepage lakes are shown in Figure 2.4-4. The $\mathrm{pH}$ distribution is skewed toward low values. The most commonly occurring Gran ANC values are between -50 and $+50 \mu \mathrm{eq} / \mathrm{L}$. Both the $\mathrm{C}_{\mathrm{B}}$ and the $\mathrm{SO}_{4}$ concentrations are considerably lower than in the drainage lakes. As indicated in Section 2.3, the lower $\mathrm{SO}_{4}$ concentrations in part result from the longer hydraulic residence time in the seepage lakes, which allows slow reduction reactions enough time to decrease $\mathrm{SO}_{4}$ concentrations. Base cation concentrations are typically much lower in seepage lakes than in drainage lakes, reflecting their differing sources of water. Seepage lakes receive larger proportions of their total inflow as direct precipitation onto their surfaces and thus have lower concentrations of terrestrially derived base cations.

\subsubsection{Flowpaths}

The acid-base status of surface waters is ultimately a function of the relative contribution of acids and bases. The acids are primarily derived from atmospheric deposition of sulfuric $\left(\mathrm{H}_{2} \mathrm{SO}_{4}\right)$ and nitric $\left(\mathrm{HNO}_{3}\right)$ acids, from the oxidation of organic nitrogen $(\mathrm{N})$, and from the production of soluble organic acids through the decay of plant and animal matter. Other potential sources include the oxidation of sulfide (S) minerals and plant uptake of base cations. The bases are primarily derived from exchange and weathering reactions occurring within the watershed soils. Much of the deposited and internally produced $\mathrm{NO}_{3}$ is taken up to support plant growth. Since $\mathrm{SO}_{4}$ is only a minor plant nutrient, and Adirondack soils have little $\mathrm{SO}_{4}$ retention capability, this anion largely passes through watershed soils and on into surface waters. If an equivalent amount of base is not released from the watershed soils, $\mathrm{H}^{+}$and $\mathrm{Al}$ are transported from the soil to the surface water as well (Driscoll and Newton 1985).

For most watersheds in the Adirondack region, the relative routing of water through the soils is the major determinant of the base supply rate. The relative routing, or flowpath, is important as it determines the material the precipitation comes in contact with and conlinls the time for reaction

with the solid phase. The material may range from very acid, aluminum-rich upper soil horizons to relatively alkaline unweathered till and stratified drift. Occasionally, the wate:r may come in contact with carbonate minerals.

The flowpath of water moving through a watershed is a function of a number of lake-watershed characteristics including thickness and hydraulic conductivity of the permeable media, and land slope (Chen et al. 1984). For most Adirondack watersheds, the dominant flowpath is determined by the 

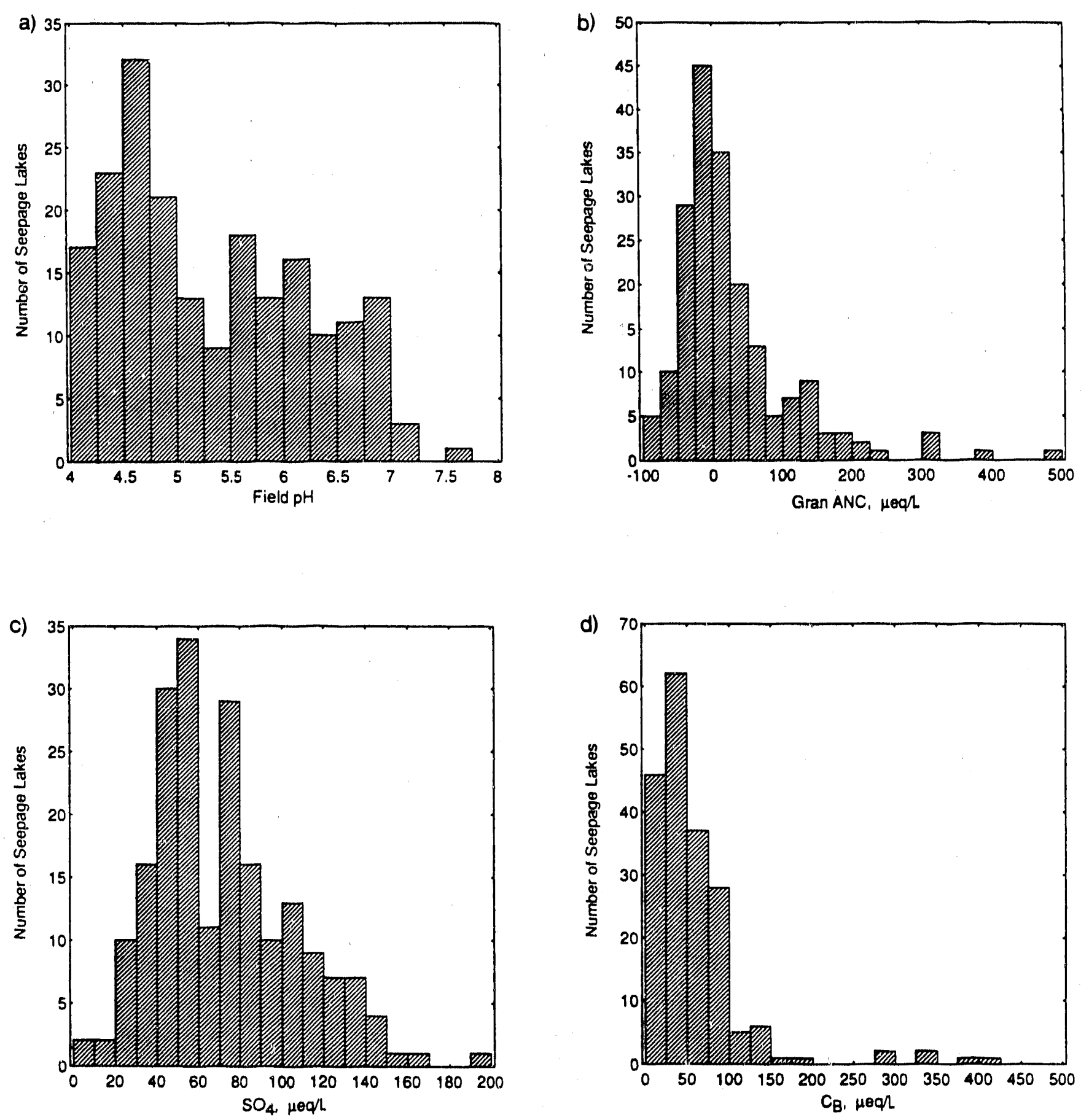

Figure 2.4-4 ALSC seepage lakes distributions of (a) pH, (b) Gran ANC, (c) sulfate, and (d) base cations. 
depth of the unconsolidated glacial deposits overlying the bedrock surface. This depth determines the capacity for lateral groundwater flow in the deeper, more alkaline soils and the size of the potential groundwater reservoir. In watersheds with thick soils, precipitation infiltrates downward into the mineral horizons where weathering and exchange reactions neutralize acidity. In contrast, those watersheds with thin surficial deposits have only small groundwater reservoirs and a limited capacity to route water through the more alkaline soil horizons. Consequently, much of the incident precipitation is forced to move rapidly to the lakes as shallow interflow through the upper more acidic, soil layers.

\subsubsection{Lake Classification Theory}

Lake watersheds can be classified according to lake type (drainage or seepage) and dominant flowpath. Drainage lakes receive water from a variety of flowpaths including surface runoff, tributary streams, direct precipitation, and groundwater inseepage. Water is lost primarily by surface outflow (lake outlet) but also through evaporation and in some cases groundwater outseepage. The relative importance of these flowpaths may differ markedly from lake to lake.

Seepage lakes receive water from the same types of flowpaths as drainage lakes but in different relative proportions. For example, while many drainage lakes receive most of their water from surface runoff and tributary streams, most seepage lakes have no surface inflow streams and receive only minor amounts of water as surface runoff. Instead, direct precipitation and groundwater inseepage most often dominate. Since seepage lakes are defined as having no surface outflow, groundwater outseepage and evaporation are the only ways in which water is lost from these systems.

These two lake types can be further divided on the basis of dominant input flowpath. Drainage lakes can be subdivided on the basis of the relative amount of groundwater inseepage Groundwater inseepage will be important in watersheds with significant quantities of thick surficial deposits. In the Adirondacks this will be primarily thick till $(>3 \mathrm{~m})$. Since water flowing through thick till has time to react with the associated minerals, these watersheds will generally produce higher $\mathrm{pH}$ lakes (Figure 2.4-5). Lakes in basins lacking such thick deposits will have little groundwater inseepage and will therefore be dominated by water moving as overland flow or along shallow flowpaths (interflow). Since this water moves lateralyy through shallow organic-rich acid soils, the associated lakes will likely be more acidic (Figure 2.4-5). The importance of flowpaths is reduced in watersheds with carbonate minerals. Here, even water moving rapidly along shallow flowpaths may be neutralized by reactions with carbonates (primarily calcite and dolomite). In many Adirondack basins there are significant areas of wetlands, usually adjacent to stream channels or lakes. The organic 


\section{Flow Path}

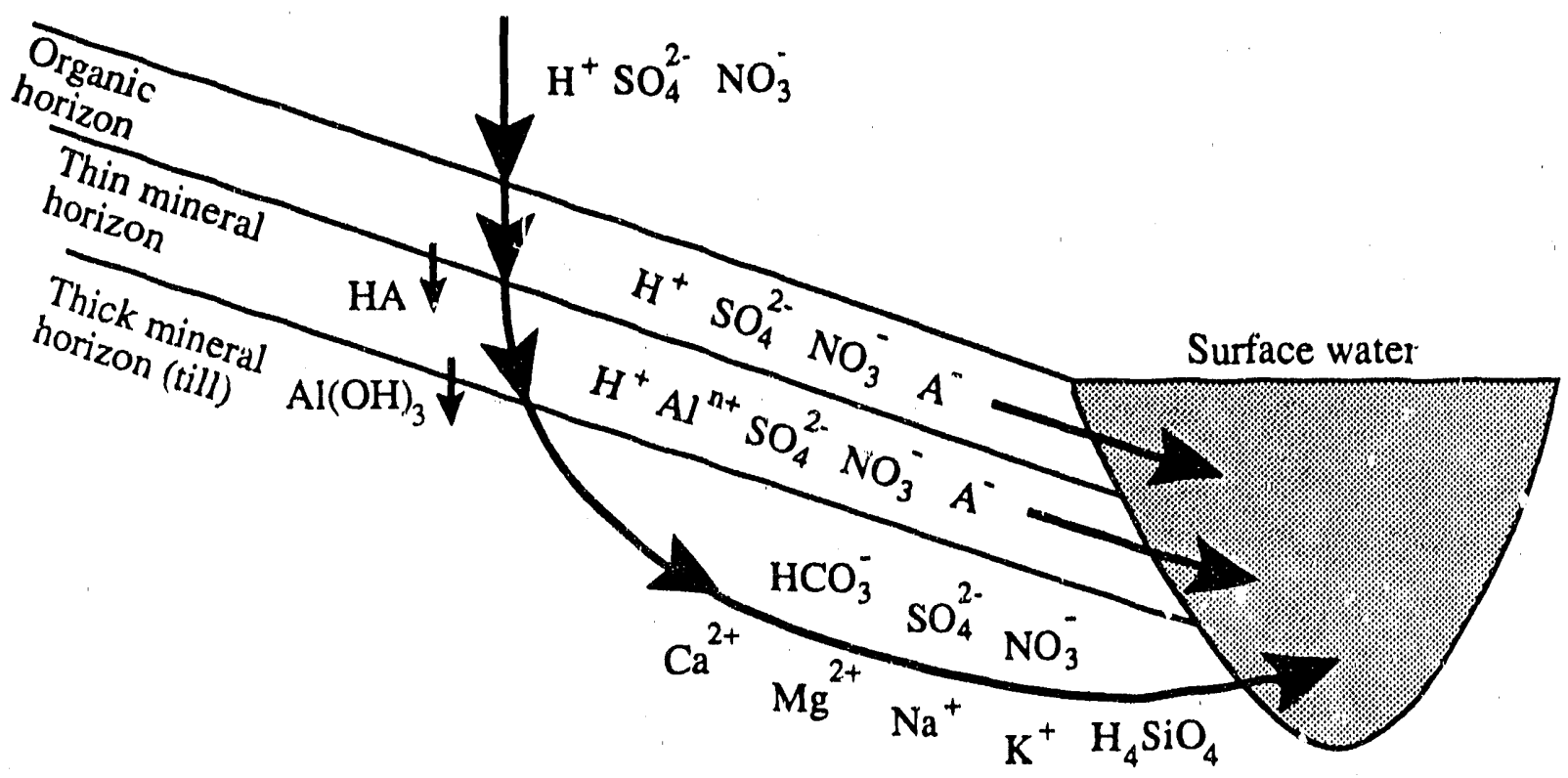

In areas of thin till, infiltrating water quickly fills the available ground water reservoir forcing precipitation and meltwater to move laterally through the upper organic and mineral horizons. In areas of deeper till, most of the infiltrating water percolates into the more alkaline mineral horizons where $H^{+}$ is retained, and base cations and silica are released $(A=$ organic acid anion).

Figure 2.4-5 Flowpaths through areas of thick versus thin till and associated chemical reactions.

acids produced in these wetlands (including marginal bogs) are carried with the surface flow laterally into the lakes. Because of the flatness of wetlands, little hydraulic gradient exists to force water downward through underlying mineral horizons where normally such organic matter would be removed from solution.

Seepage lakes can be subdivided according tu their relationship to the water table. A "flowthrough" seepage lake can be considered a windovs into the groundwater system fa large diameter 
well). In some parts of the lake, water enters as groundwater inseepage, while in others water is returned to the groundwater system by outseepage (Figure 2.4-6). These lakes, like the thick-1ill drainage lakes, can have relatively high ANC depending on how much water enters the lake us groundwater versus the amount entering as direct precipitation. It might be expected that this would be the dominant type of seepage lake in the Adirondacks, as most of the seepage lakes are found in kettle holes surrounded by highly permeable stratified drift. However, it has been found that many of these kettle hole seepage lakes are actually perched or mounded above the local water table because of accumulations of low permeability bottom sediments. In these mounded lakes, most of the water derives directly from precipitation with only minor amounts from surface runoff or groundwater (Figure 2.4-6). Since little of the water comes in contact with soll, ANC production in these waters is largely a result of in-lake processes (e.g., $\mathrm{SO}_{4}$ reduction). In some cases, seepage lakes may become completely isolated from the surrounding aquifers because of iniringement by peat bogs. These lakes are commonly rimmed by floating mats of sedge and sphagnum which in time slowly fill the lake with peat Water enters these lakes primarily as direct precipitation and as surface runoff through the uppermost active zone (acrotelm) of the peat. Thus, the water tends to be acidic and rich in DOC.

The lake classification theory described above uses a number of watershed characteristics that determine the groundwater flowpath and thus the chemistry of the surface water. Although watersheds may be classified as either thin-till-dominated or thick-till-dominated, there is obviously a complete continuum between these two end members. Essentially, drainage lakes are classified on the basis of the presence or absence of thick $(>3 \mathrm{~m})$ deposits of glacial till, with a category for watersheds containing carbonate minerals and a category for watersheds with wellands. Seepage lakes are classified according to their relationship with the surrounding groundwater, with the "flowthrough" type receiving some groundwater input, the mounded type receiving little groundwater input, and the bog type being surrounded by peat deposits (Figure 2.4-6)

\subsubsection{Classification Based on Chemical Characteristics}

To apply the above classification theory to the ALSC lakes would require extensive watershed data, which are not available. Insteaa, the ILWAS and RILWAS data bases have been used to establish a set of chemical criteria to differentiate lakes with varying physical characteristics. 

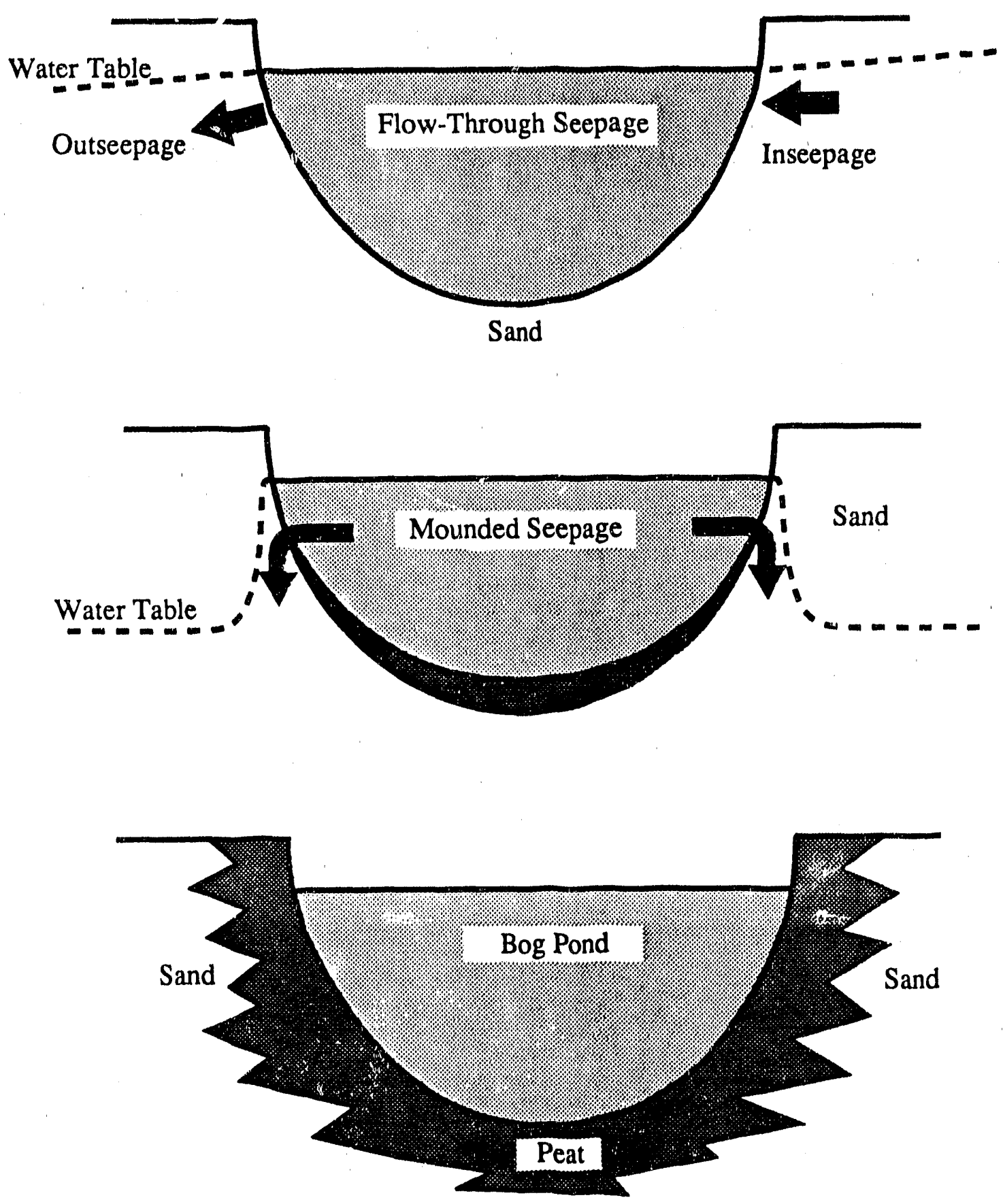

Figure 2.4-6 Seepage lakes can be subdivided into three basic types: Flow-through seepage lakes, mounded seepage lakes perched above the local water table on low permeability sediments, and bog ponds, which receive both direct precipitation and runoff through peat. 


\subsubsection{Salt-In pacted Lakes}

An initial analysis of the ALSC data showed that a number of lakes had very high $\mathrm{Cl}$ concentrations suggesting impacts by road salt. Plots of Na versus $\mathrm{Cl}$ (Figure 2.4-7) show that lakes with les; than about $20 \mu \mathrm{mol} / \mathrm{L} \mathrm{Cl}$ fall in a distinct cluster. Those having higher $\mathrm{Cl}$ levels also have $\mathrm{Na} / \mathrm{Cl}$ ratios that are very close to that of sea salt and thus have been designated salt impacted
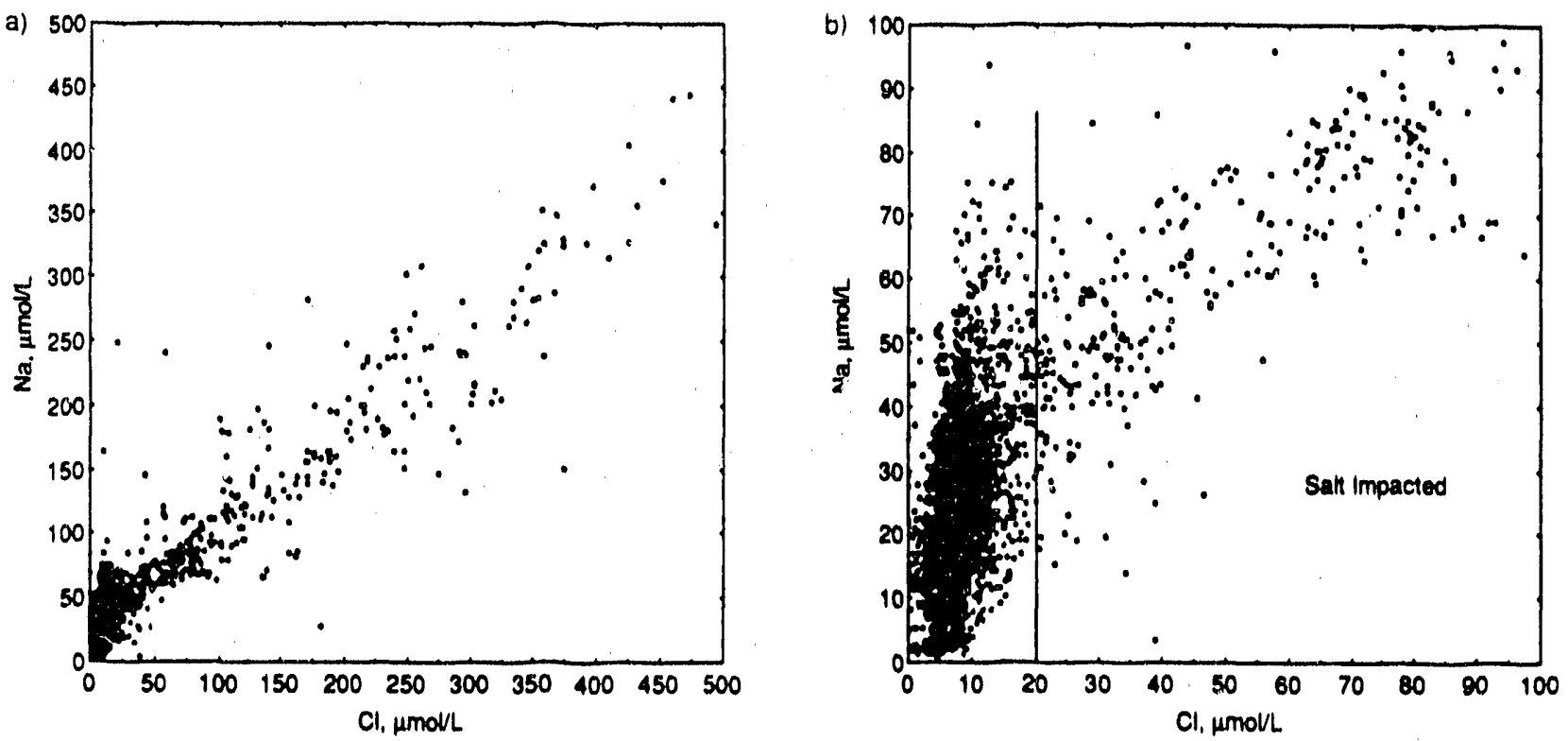

Figure 2.4-7 Relationship between sodium and chloride concentrations in (a) all ALSC waters: at higher chloride concentrations the sodium to chloride molar ratio is similar to sea salt and represents road salt contamination. At (b) lower chloride concentrations, the difference between salt-impacted and non-salt-impacted waters becomes obvious.

\subsubsection{Drainage Lakes}

The RILWAS project examined 23 hydrologic basins of varying size throughout the Adirondacks. The results of this study showed that, in lakes whose water quality is flowpath controlled, there is a statistically significant relationship between base-flow (low flow) Ca concentration and percentage of watershed covered by thick till and stratified drift (Figure 2.4-8a). RILWAS base-flow Ca is ured because this mostly closely corresponds with the ALSC summer sampling period. Base-flow Ca is in turn closely correlated with ANC (Figure 2.4-8b). Based on these relationships, approximately $10 \%$ of a watershed must be covered with thick surficial material to create a base-flow Ca concentration of $100 \mu \mathrm{eq} / \mathrm{L}(50 \mu \mathrm{M})$, which in turn corresponds to an ANC of approximately $10 \mu \mathrm{eq} / \mathrm{L}$ at current 
a)

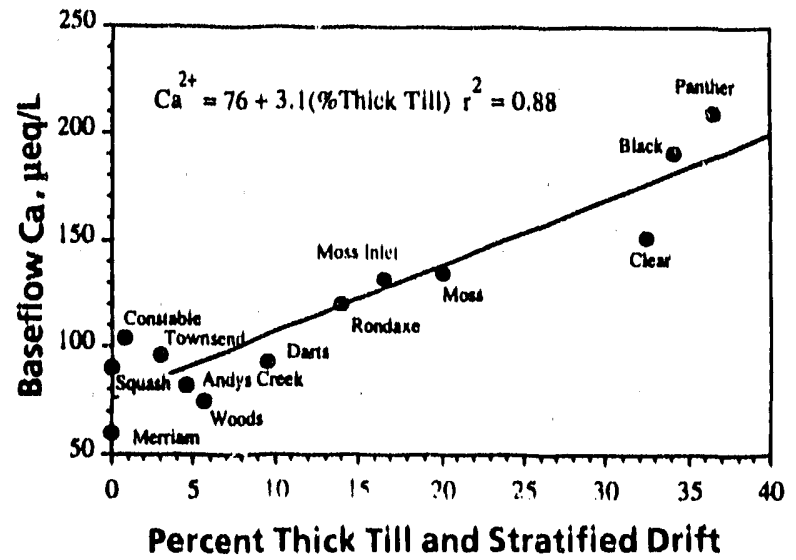

b)

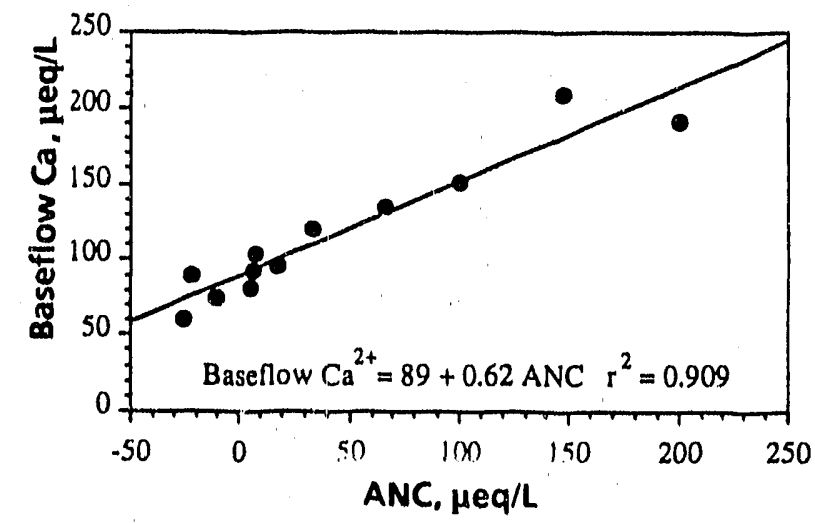

c)

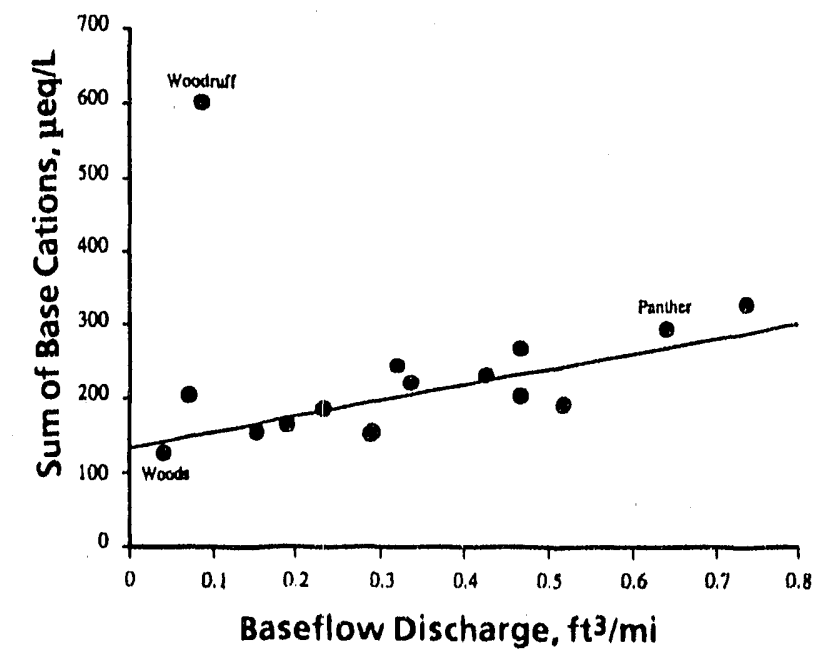

Figure 2.4-8 Data from ILWAS and RILWAS projects showing relationships between (a) baseflow calcium and thick till, (b) base-flow calcium and ANC, and (c) base-flow discharge and the $C_{B}^{\prime}$. Woodruff Pond (thin till) is rich in carbonate minerals. 
deposition loadings. Lakes with ANC values in excess of $100 \mu \mathrm{eq} / \mathrm{L}$ would normally be expected to show little response to acidifying episodes such as spring snowmeit. These relationships can be used to establish the criteria to differentiate, on a chemical basis, watersheds dominated by thick till deposits from those dominated by thin till.

\subsubsection{Carbonate-Influenced Lakes}

The thickness of surficial deposits did not explain the chemistry of all the RILWAS drainage lakes. For example, Woodruff Pond has a higher base cation concentration than can be explained by soil

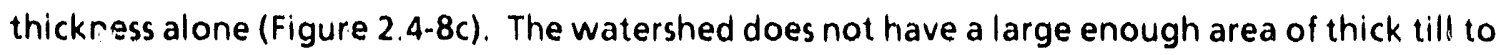
explain the lake's high ANC, the highest ANC ( $480 \mu \mathrm{eq} / \mathrm{L})$ observed during the RILWAS project, nor its high Ca concentration. A study of the pond's location, however, reveals that it is bordered to the north by one of the Adirondack marble belts. A detailed geological investigation found that the boulders in the glacial till covering the watershed contain varying amounts of calcium carbonate $\left(\mathrm{CaCO}_{3}\right)$. This dramatically influenced surface water quality. Even though the water moves rapidly along shallow flow paths, there is sufficient time for carbonate minerals to react with $\mathrm{H}^{+}$3ccording to the following general stoichiometry:

$$
\mathrm{CaCO}_{3}+\mathrm{H}^{+} \rightarrow \mathrm{Ca}^{2}+\mathrm{HCO}_{3}^{-}
$$

The amount of reaction is apparently enough so that the till thickness is no longer the dominant factor in determining ANC. Watersheds overlain by thin till can have high. ANC surface waters when carbonate minerals are present in either the till or are exposed on the bedrock surface.

Carbonate-influenced waters can be identified by the molar ratio of dissolved $\mathrm{Ca}$ to $\mathrm{SiO}_{2}$. For the RILWAS lake-watershed systems, the $\mathrm{Ca} / \mathrm{SiO}_{2}$ values ranged from approximately 0.65 for watersheds underlain by granitic gneiss to about 1.15 for watersheds underlain by anorthosite or calcsilicate rocks to $\mathbf{2 . 3 6}$ for the carbonate-influericed Woodruff Pond. Although these ratios may be influenced by variations in the activity of diatoms between lakes, it is probably safe to say that the ANC of waters with molar $\mathrm{Ca} / \mathrm{SiO}_{2}$ ratios greater than 2 are controlled by $\mathrm{CaCO}_{3}$ dissolution processes.

\subsubsection{Seepage Lakes}

The RILWAS watersheds included only two seepage lakes. Both were isolated from the local water table, one being hydrologically mounded and the other isolated by thick peat deposits. The available RILWAS chemical and watershed data are not sufficient for differentiating mounded and flowthrough seepage systems. Since by definition the flow-through type receives groundwater input, it would be expected to have higher concentrations of base cations and $\mathrm{SiO}_{2}$ than the mounded type. 
In reality there is probably a continuum of seepage lakes between the mounded and the flowthrough types.

Initially, it was thought that $\mathrm{SiO}_{2}$ concentration might be a good criterion for determining the amount of groundwater entering a lake. However, as noted in Section 2.3 (Figure 2.3-6a), a comparison of the $\mathrm{SiO}_{2}$ concentrations in near-surface samples with deeper samples shows the surface samples to be depleted in $\mathrm{SiO}_{2}$. This depletion is probably due to diatom uptake. Since the classification of ALSC lakes is based on surface samples taken during summer, a period of high diatom activity, the use of $\mathrm{SiO}_{2}$ concentration alone as the criterion for groundwater inflow was not advisable. Instead, a Ca concentration of $25 \mu \mathrm{mol} / \mathrm{L}$ was used as the basis for classifying seepage lakes as mounded or flow-through baseu upon a water/solute balance for a seepage lake with typical priysical characteristics. The $25 \mu \mathrm{mol} / \mathrm{L}$. concentration ( $1 \mathrm{mg} \mathrm{Ca} / \mathrm{L}$ ) also has fisheries significance (Brown 1983) (see Figure 2.4-9 for distribution of calcium).

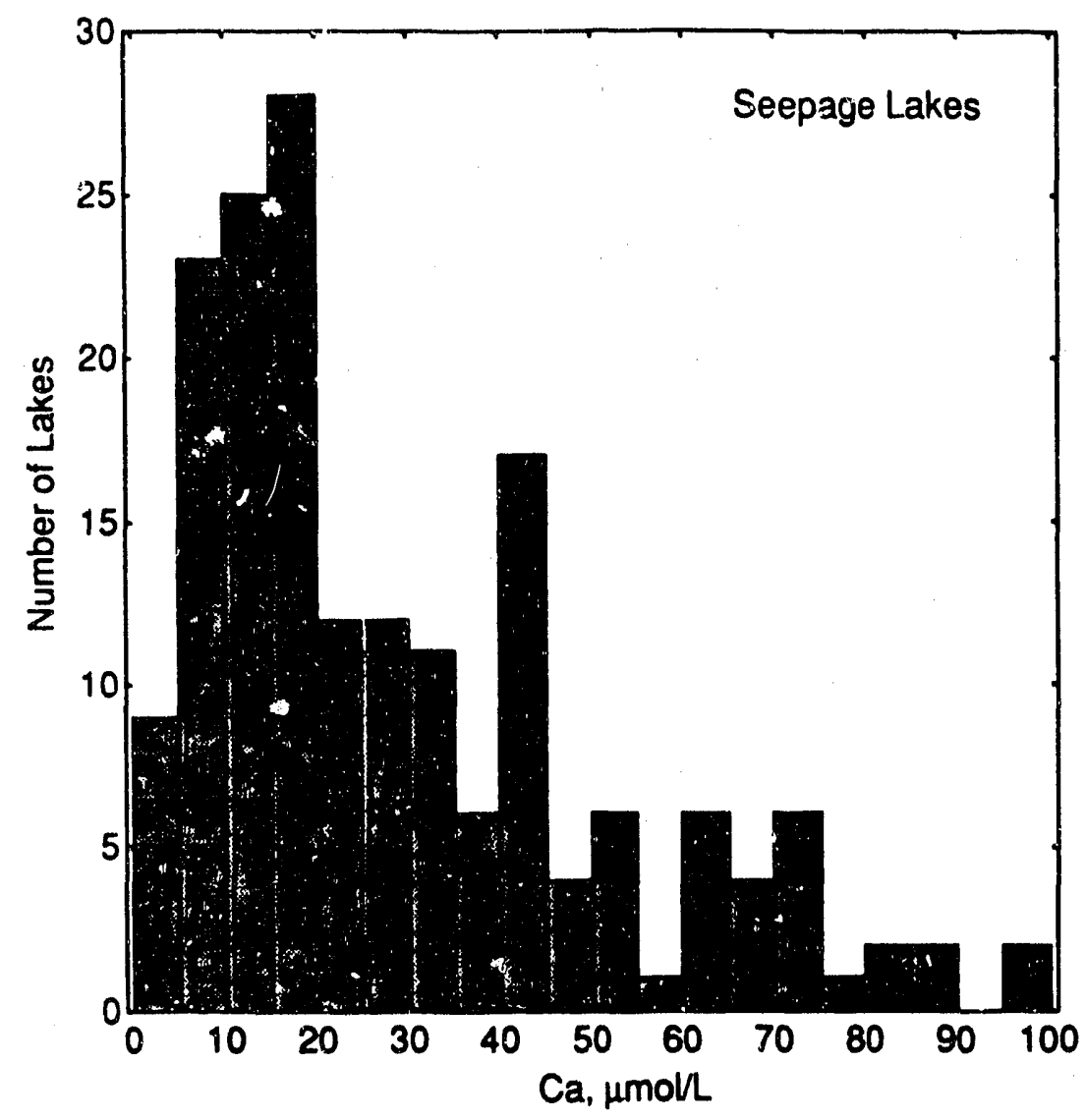

Figure 2.4-9 Distribution of calcium concentrations in ALSC seepage lakes. 


\subsubsection{High-and Low-DOC Laikes}

DOC conrertrations vary widely in all types of Adirondack lakes. Since DOC is an important indicator of the amount of organic acid present in solution and since it may influence the toxicity of aqueous $A l$, it is useful to include a DOC subdivision in the classification scheme. A value of $500 \mu \mathrm{mol} / \mathrm{L}$ was chosen because this corresponds to approximately the median DOC concentration in ALSC lakes. Waters with DOC values $<500 \mu \mathrm{mol} / \mathrm{L}$ are classified as low-DOC waters, while those with larger concentrations are classified as high-DOC waters.

\subsubsection{Classification of ALSC Lakes}

The classification of the ALSC lakes was done by applying the criteria described above to the nonflagged summer surface samples. Five drainage lakes and two seepage lakes were not classified because of QAVQC concerns (see Section 2.1). The remaining lakes $(1,462)$ were classified according to the following scheme (Figure 2.4-10). If any constituent concentration that was used as a classification criterion was missing for a particular lake, that lake was not included in the subsequent classifications. Chloride concentration was first checked. Lakes with more than $20 \mu \mathrm{mol} / \mathrm{L} \mathrm{Cl}$ were classed as salt-impacted (192 lakes). Salt-impacted lakes included both drainage and seepage lakes, although most were of the drainage type $(>90 \%)$. After identification of the salt-impacted class, the presence or absence of a lake outlet was used to separate drainage lakes (1085) from the seepage lakes (185). The seepage lakes were then separated into flow-through and mounded types. Using the $25 \mu \mathrm{mol} / \mathrm{L}$ Ca criterion, 88 lakes fell into the flow-through category, and 97 lakes were mounded. Each of these categories were subdivided into high-DOC and low-DOC groups. Using the $500 \mu \mathrm{mol} / \mathrm{L}$ criterion, 38 of the flow-through seepage lakes were classified as low-DOC types, whereas 47 fell into the high-DOC class. The mounded seepage lakes were similarly split about equally between the low-DOC class ( 45 lakes) and the high-DOC class (50). The high-DOC mounded class corresponds fairly closely with the lakes that were classified as bog types according to the ALSC field designation.

The drainage lakes were first differentiated using the $<50 \mu \mathrm{mol} / \mathrm{L}$ Ca criterion to yield 509 thin-till drainage lakes. Another 224 lakes had summer Ca concentrations between 50 and $75 \mu \mathrm{mol} / \mathrm{L}$ and were thus classified as intermediate systems. The $>75 \mu \mathrm{mol} / \mathrm{L}$ Ca criterion was used to identify the thick-till and carbonate-irifluenced lakes, which were then subdivided on the basis of the Ca/Si molar ratio. Those with $\mathrm{Ca} / \mathrm{Si}$ ratios greater than 2 were put into the carbonate-influenced class ( 169 lakes). Another 179 fell into the thick-till class, and 4 were unclassed due to the lack of Si or Ca values. 


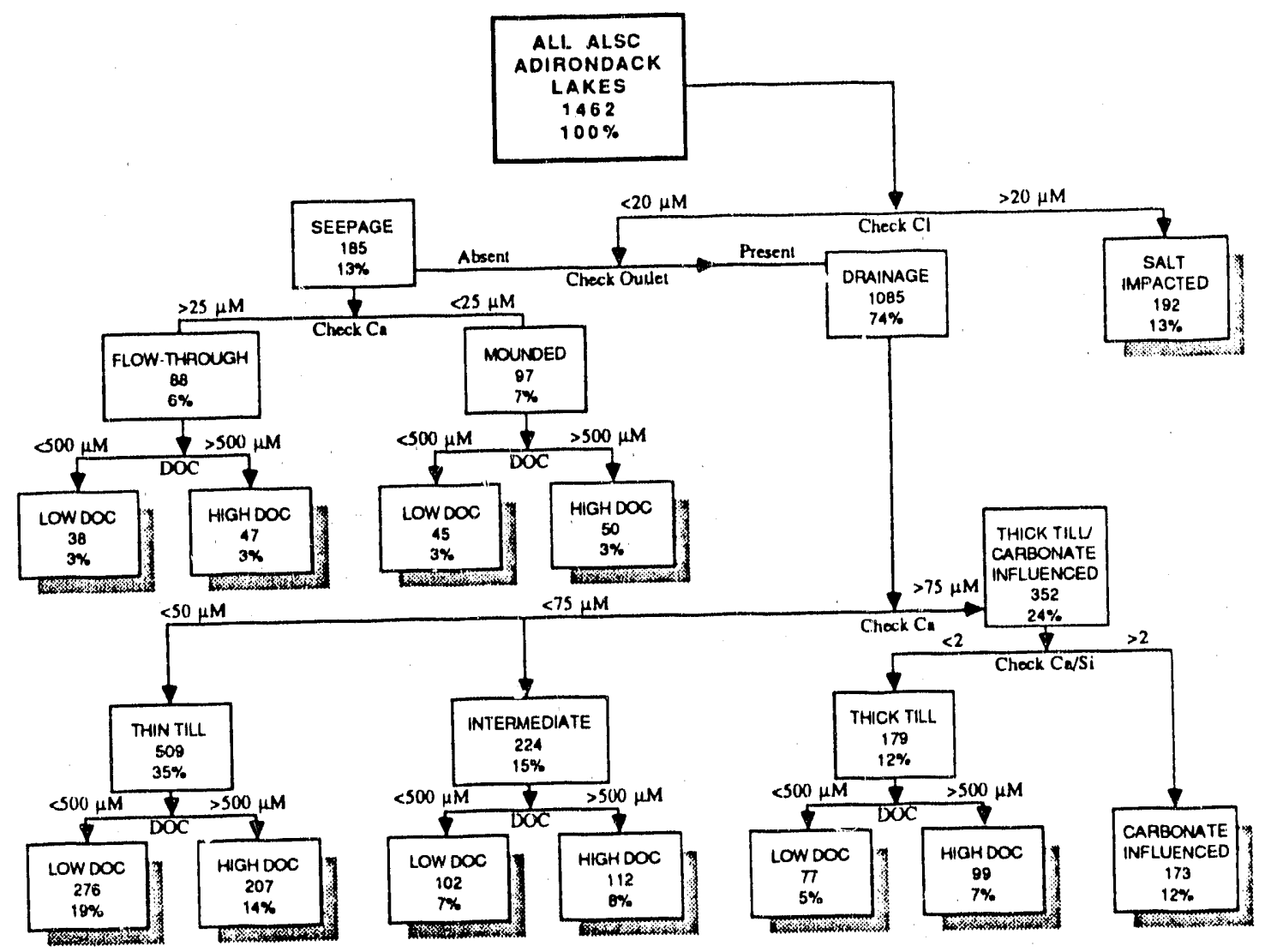

Figure 2.4-10 Flow chart of the sequence in which classification criteria were applied to the ALSC lakes. Each box shows the total number of lakes in that class and the percent of all lakes. Seven lakes were not classified as they did not meet the quality assurance criteria. (Lakes also were not subclassified when parameters were missing.)

Finally, each of the drainage lake classes were subdivided into high-DOC and low-DOC subclasses using the same $500 \mu \mathrm{mol} / \mathrm{L}$ criterion that was applied to seepage lakes. As with seepage lakes, this analysis generally split each drainage lake class into approximately equal numbers (Figure 2.4-10)

\subsubsection{Characteristics of the Lake Classes}

The mean values of selected parameters for each of the lake classes are shown in Table 2.4-1. The saltimpacted lakes are chemically distinct from the other classes. These lakes generally had high pH and ANC and were found in large, low-elevation basins.

The distribution of mean $\mathrm{SiO}_{2}$ concentrations and ANC for each of the major lake classes is shown in Figure 2 4-11. As predicted by flowpath theory, $\mathrm{SiO}_{2}$ concentrations increase from the thin-till class to the thick-till class. This is expected, as the thick-till class should have the most groundwater inflow, 


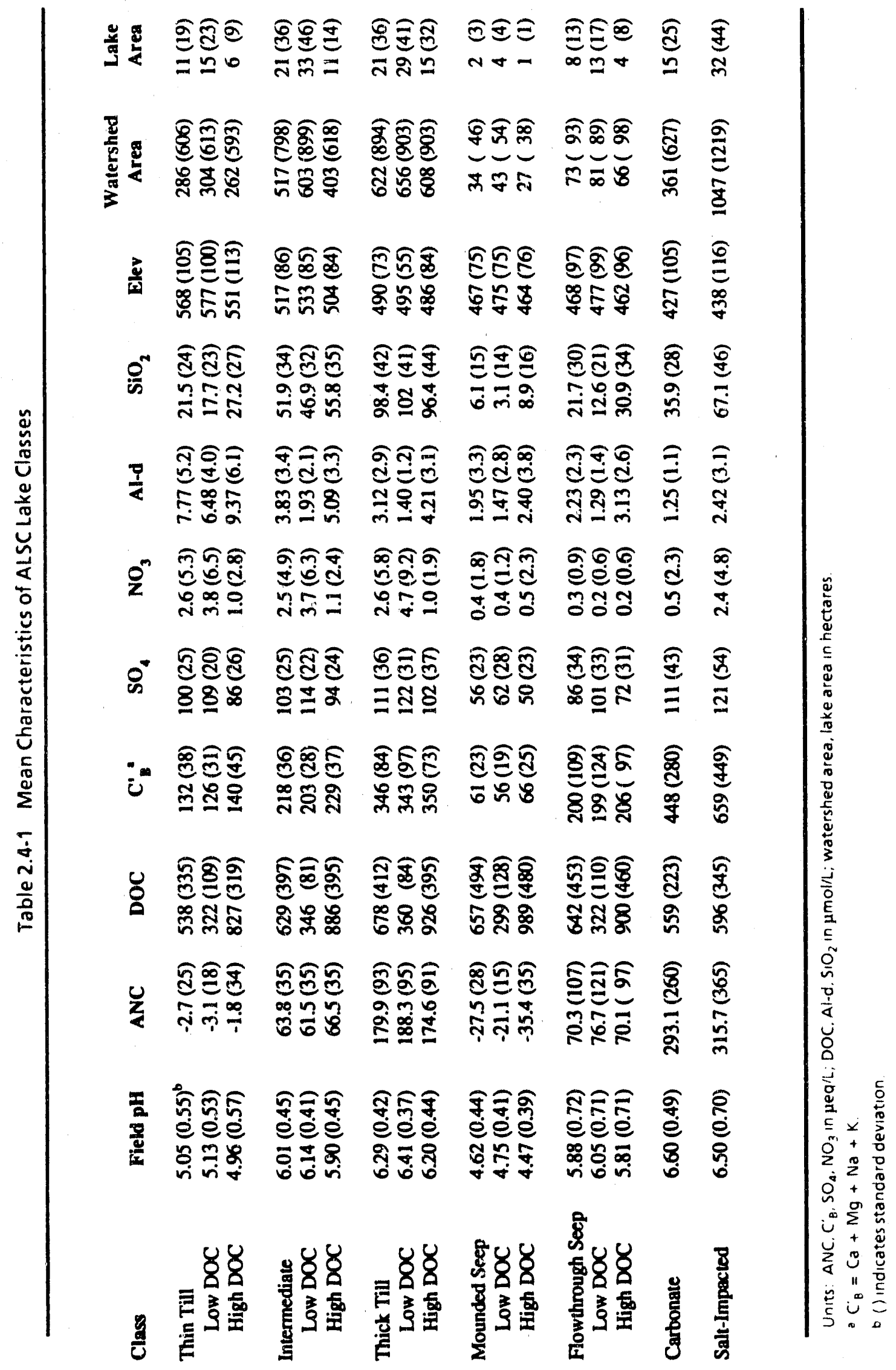



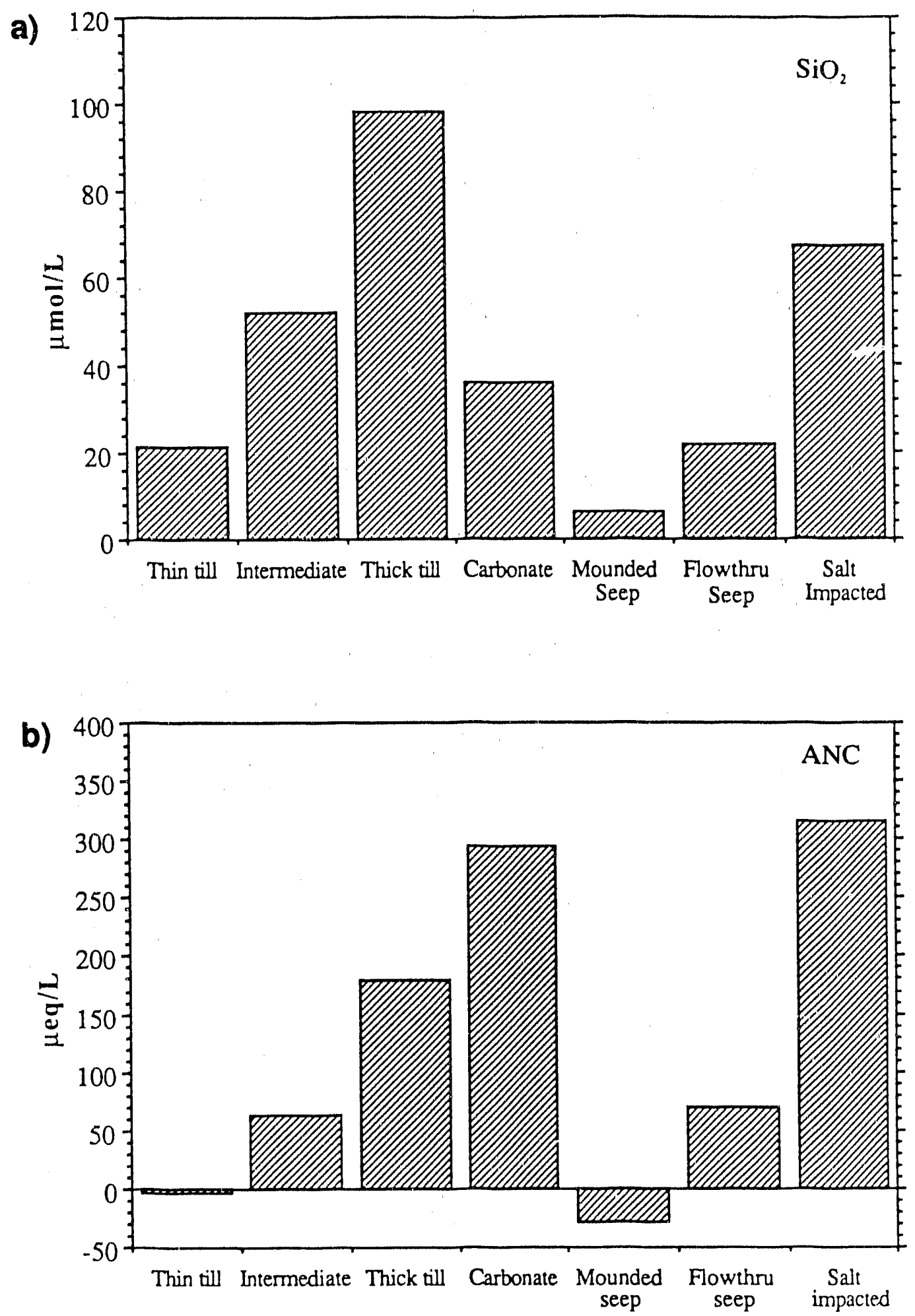

Figure 2.4-11 Distribution of (a) silica concentrations and (b) ANC for the major ALSC lake classes. 
the most mineral weathering, and hence the highest $\mathrm{SiO}_{2}$ concentrations. It is interesting to note that the flow-through seepage lakes have $\mathrm{SiO}_{2}$ concentrations as low as the thin-till class. This might be taken to indicate similar small amounts of groundwater input. However, $C_{B}$ concentrations are almost twice as large in the flow-through systems, and thus the groundwater input is most likely also larger. The lower $\mathrm{SiO}_{2}$ concentration may result from the longer detention times in these seepage lakes which allow for greater removal of $\mathrm{SiO}_{2}$ by diatom activity. Although the carbonate-influenced class has the highest nonsalt-impacted ANC, it has only intermediate $\mathrm{SiO}_{2}$ concentrations. This is to be expected, because the carbonate weathering reactions that contribute to the ANC do not release $\mathrm{SiO}_{2}$.

\subsubsection{Comparison of ALSC and ELS Surveys}

The most comprehensive synoptic survey of lake chemistry in the Adirondack region prior to the completion of the ALSC survey was Phase I of the U.S. EPA Eastern Lake Survey (see Section 2.1.3.5). In ELS-I, a total of 155 lakes was sampled to represent a target population of 1290 lakes. The measurements for the 155 lakes were scaled up vith weighting factors to the target population. The resulting ELS-I survey numbers have been used by several groups to quantify the status of ponded waters in the Adirondacks (e.g., Brakke et al. 1988), including the National Acid Precipitation Assessment Program (NAPAP) (Kulp 1987). As a result, it is instructive to compare the distribution of the inferred ELS-I lake water qualities with the distribution of the ALSC lakes according to the classification system developed above and depicted in figure 2.4-10.

Marked differences in the results of the two surveys become evident upon comparison of Figures 2.4-10 and 2.4-12. First, the percentage of salt-impacted lakes was much greater for the ELS-I survey. This discrepancy can largely be attributed to the differences in the boundaries of the two surveys. As discussed previously, the ELS-I boundary encompassed much of northern New ' York and included a large area beyond the boundaries of the Adirondack ecological zone. Lakes outside the Adirondack ecological zone were distinctly different in chemical composition (Figure 2.1-6), having higher $\mathrm{pH}, \mathrm{ANC}, \mathrm{SO}_{4}$ and $\mathrm{C}_{\mathrm{B}}$. In fact $86 \%$ of the ELS-I target population lakes outside the Adirondack ecological zone were salt impacted. If the above classification system is applied just to ELS-I lakes within the Adirondack ecological zone (Figure 2.4-13), the percentage of salt-impacted lakes is greatly reduced. However, the ELS-I lakes within the Adirondack ecological zone still show a significantly higher percentage of salt-impacted lakes than those sampled by ALSC 


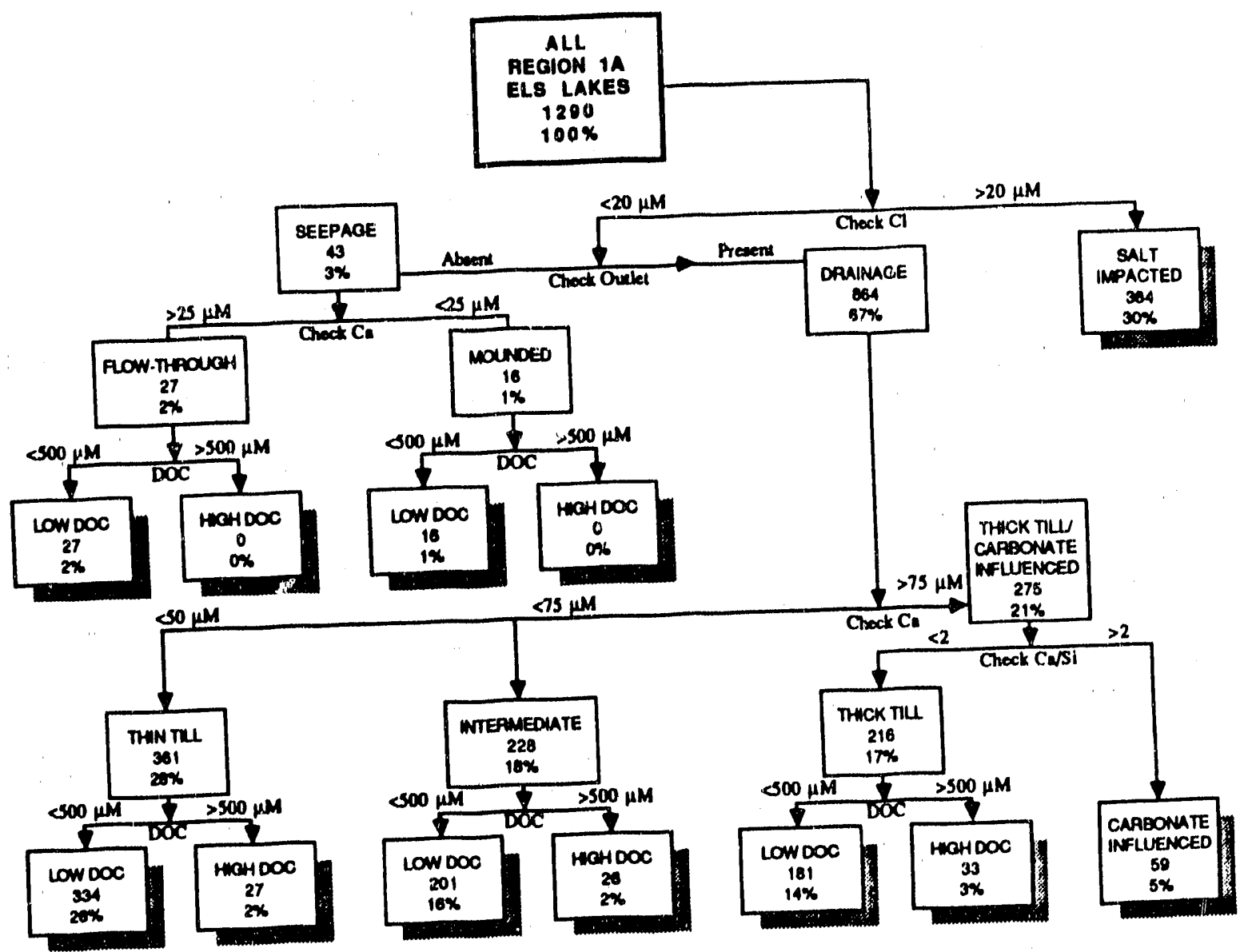

Figure 2.4-12 Flow chart showing classification of ELS-I target population lakes in Subregion $1 \mathrm{~A}$ using the same criteria as for the ALSC lakes. (When a parameter was missing from the data set, classification using the associated criterion was not done.)

The second major discrepancy in the distribution of lakes within lake classes is the number and percentage of seepage lakes. In the ALSC survey the nonsalt-impacted seepage lakes were $13 \%$ of the total lakes. The ELS-I results would indicate that nonsalt-impacted seepage lakes represent only $4 \%$ of the Adirondack ecological zone lakes. Adirondack seepage lakes are small. Sixty-nine percent of the ALSC seepage lakes have surface areas of $<4$ ha (Figure 2.4-2b). The difference in the number of seepage lakes between the two surveys appears to be an artifact of the sampling design for ELS-I, as only lakes with surface areas $>4$ ha were studied. This suggests that seepage lakes were not adequately represented in the ELS-I survey.

Finally, the percentage of high-DC,C lakes was much larger in the ALSC survey than in ELS-I

(Figure 2.4-13). This discrepansy is, again, due in part to differences in the minimum lake size surveyed. Sma" "lakes typica!'iy have higher DOC than larger lakes for all lake types. In addition, there appear to be difterences in the analysis of DOC by the two surveys. In paired observations of DOC concentrations analyzed during summer surface ALSC collections and ELS-I (fall collections) 


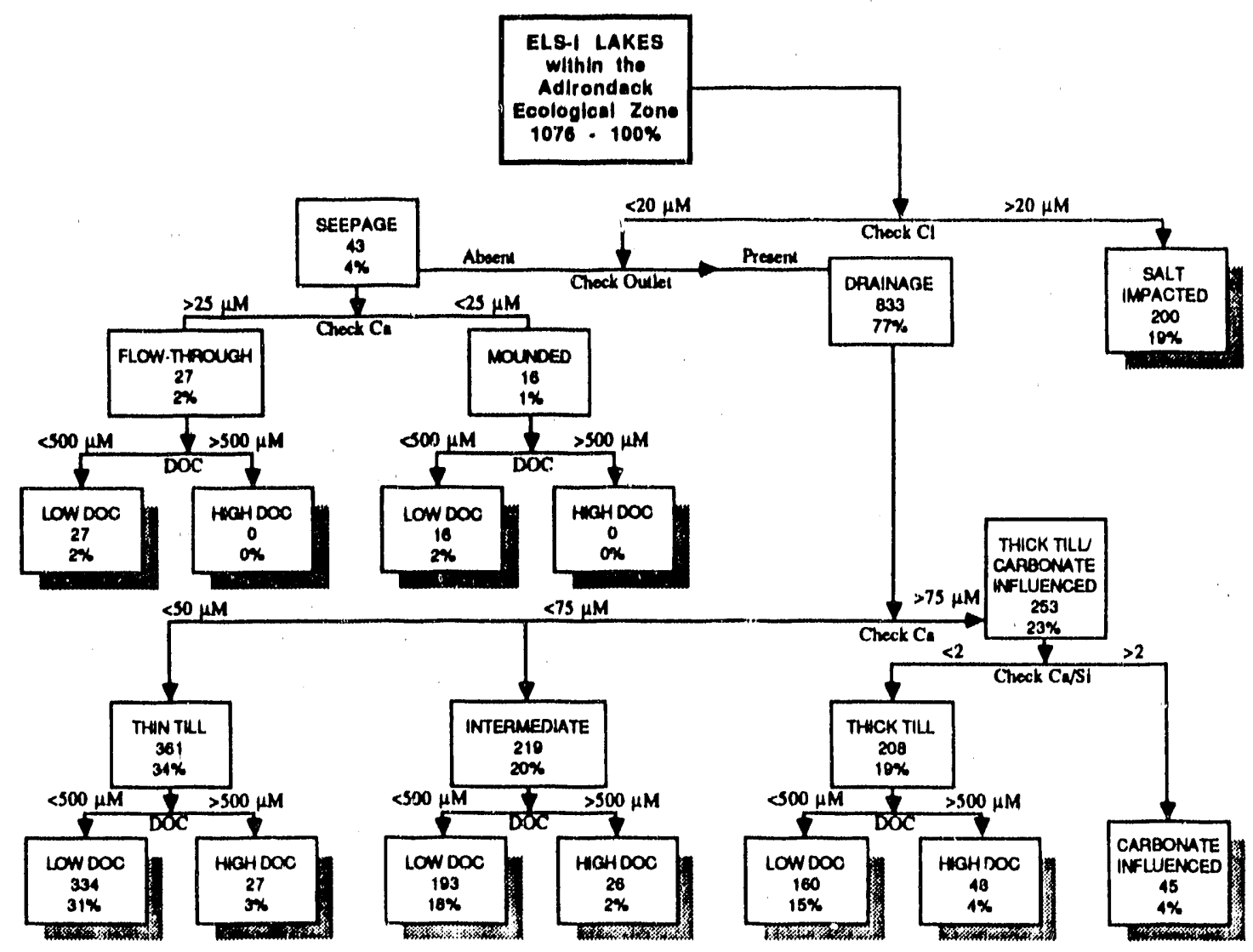

Figure 2.4-13 Flow chart showing classification of those ELS-I target population lakes in the Adirondack ecological zone using the same criteria as for the ALSC lakes. (When a parameter was missing from the data set, classification using the associated criterion was not done.)

(Figure 2.4-14), ELS-I values were generally lower than those measured by ALSC. This is confirmed by comparing the limited number of paired observations for fall DOC from both ALSC and ELS-I. Some of the differences depicted in Figure 2.4-14 might be attributed to seasonal variations in DOC concentration. However, detailed analysis of DOC variations in Adirondack lakes indicates that concentrations are at minimum during the summer, increase in the autumn, and reach maximum concentrations during the winter or spring (Effler et al. 1985; Driscoll et al. 1987; Schafran and Driscoll 1987). Given this, the ELS-I values in Figure 2.4-14 should have been greater than or at least equal to the ALSC values. 


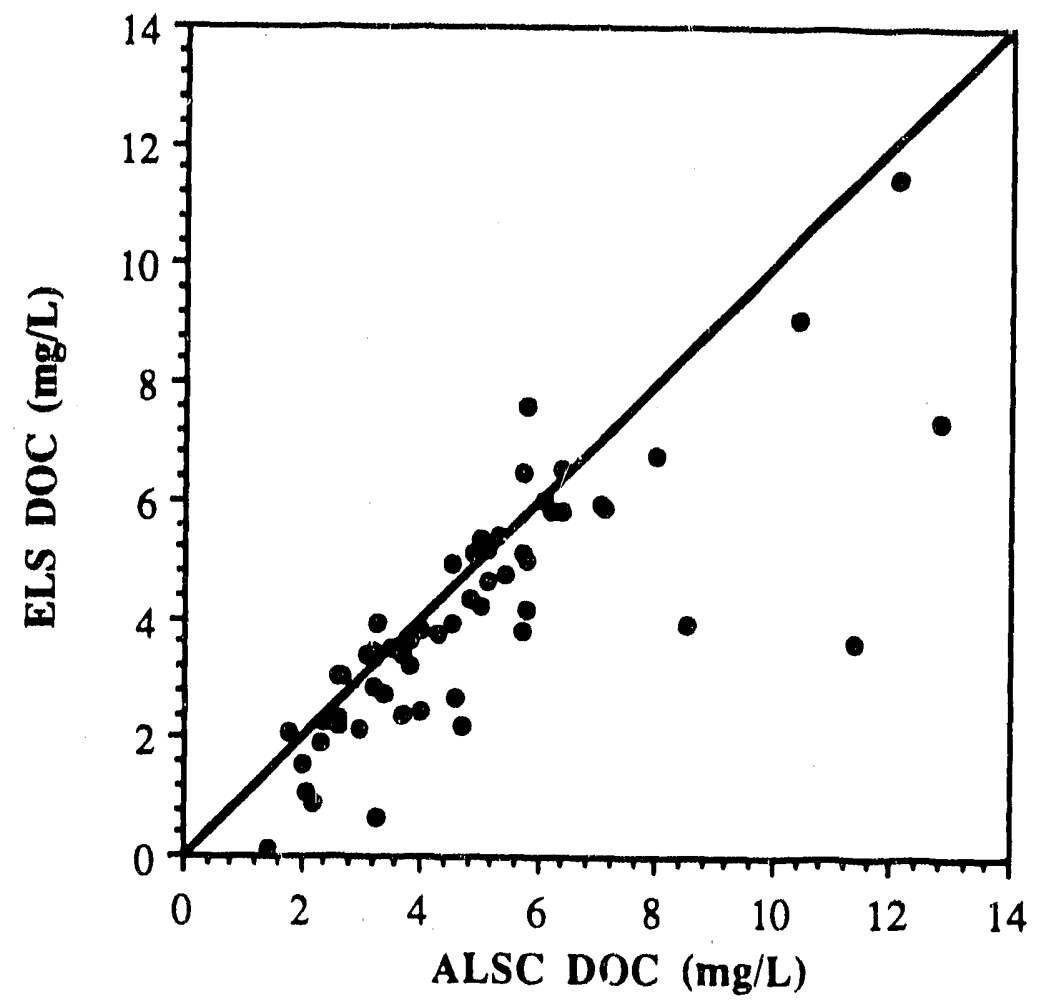

Figure 2.4-14 Comparison of DOC measurements made on lakes sampled by both the ALSC and ELS-I. The DOC values for the ELS-I samples are somewhat lower. 


\subsection{INTEGRATED ANALYSES}

\section{- R.K. Munson, S.A. Gherini, K.H. Reckhow, arıd C.T. Driscoll}

The phenomenological analyses presented in Section 2.3 are expanded upon here. Parametric sensitivity analyses are presented which quantify changes in $\mathrm{H}^{+}$concentration $(\mathrm{pH})$ given changes in deposition acidity. An analysis of recent trends in surface water quality is presented, and the role of organics in supporting $\mathrm{H}^{+}$in solution is examined.

\subsubsection{Support of Hydrogen Ions in ALSC Waters}

As was noted in Section 2.3, there is a strong relationship between anion deficit and DOC in low-pH waters. The existence of this relationship prompted an investigation to evaluate which anions were supporting $\mathrm{H}^{+}$in low-pH waters. The investigation involved the analysis of waters with lab $\mathrm{pH}$ values $\leq 5$. This value was chosen because dissolved $\mathrm{CO}_{2}$, at levels commonly encountered in surface waters, has minimal influence on $\mathrm{H}^{+}$concentration at and below this $\mathrm{pH}$ value. $\mathrm{ApH}$ of 5 is indicative of a free $\mathrm{H}^{+}$concentration of $10 \mu \mathrm{eq} / \mathrm{L}$. In a pure mineral acid-base atmospheric $\mathrm{CO}_{2}$ system, a $\mathrm{C}_{H}-\mathrm{C}_{A}$ of $-10 \mu \mathrm{eq} / \mathrm{L}$ would correspond to a $\mathrm{pH} 5$ solution. If $\mathrm{C}_{\mathrm{B}}-\mathrm{C}_{\mathrm{A}}$ is more positive than $-10 \mu \mathrm{eq} / \mathrm{L}$ and the $\mathrm{pH}$ is $\leq 5$, this would indicate that something other than mineral acid is depressing the $\mathrm{pH}$. Figure 2.5-1 presents the distribution of $C_{B}-C_{A}$ values for all $A L S C$ samples (including spring, summer, and fall samples as well as replicates) with lab $\mathrm{pH}$ values $\leq 5.0$. As indicated, the $C_{B}-C_{A}$ values are centered around $-10 \mu \mathrm{eq} / \mathrm{L}$. There are, however, a large number of samples with $C_{B}-C_{A}>-10 \mu \mathrm{eq} / \mathrm{L}$. In fact, over $37 \%$ of the samples with $\mathrm{pH} \leq 5$ have more mineral base than mineral acid $\left(C_{B}-C_{A}-0\right)$, and the $H^{+}$ present is supported exclusively by organic acids.

For an individual sample with $\mathrm{pH} 5$ (and $\mathrm{CO}_{2}$ partial pressures less than 30 times atmospheric level), the contribution of organic acid to the observed $\mathrm{H}^{+}$concentration can be calculated as the difference between the $H^{+}$concentration and positive values of net mineral acidity, or $C_{A} \cdot C_{B}$. This difference, divided by the $H^{+}$concentration, represents the fraction of organic-ligarid-supported free $H^{*}, S_{0,}$ in the sample:

$$
s_{u}=\frac{\left|H^{+}\right|-\left(C_{A}-C_{B}\right)}{\left|I^{+}\right|} \text {for }\left(C_{A}-C_{B}\right)>0
$$




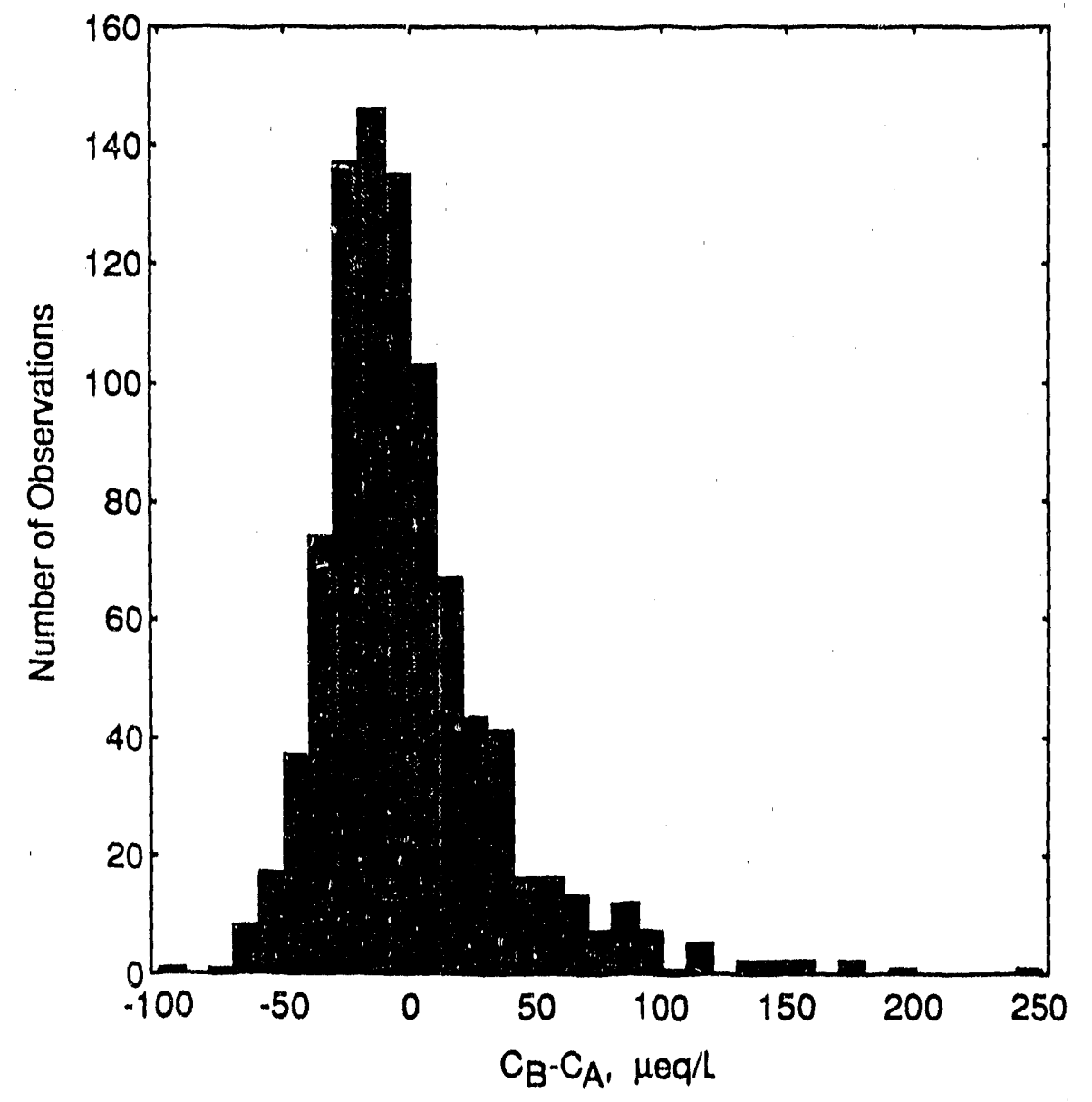

Figure 2.5-1 Distribution of $C_{B} \cdot C_{A}$ values for all ALSC samples with lab $\mathrm{pH} \leq 5$.

If there is net mineral base in solution, and yet there is free $\mathrm{H}^{+}$in solution then all of the $\mathrm{H}^{+}$is supported by organic anions, i.e.,

$$
S_{u}=1,0 \quad \text { for }\left(C_{A}^{\prime}-C_{B}\right) \leq 0
$$

Where:

$S_{0}=$ the fraction of organic-ligand-supported free $H^{*}$ in solution,

$C_{A}-C_{B}=$ net mineral acidity (the same as negative $C_{B}-C_{A}$, stumm and Morgan 1987), and

$\left[I^{+}\right]=$free $\mathrm{H}^{+}$concentration in solution.

The distribution of organic-supported $\mathrm{H}^{*}$ in all ALSC samples with lab $\mathrm{pH} \leq 5$ is shown in Figure 2.5-2. As indicated, the samples most commonly have either $>90 \%$ organic-supported $\mathrm{H}^{+}$( 374 samples out of a total of 897 ) or $<10 \%$ (243 samples).

An alternative method for performing this analysis would involve a variation in the way that $A l$ is handled. Because of its low solubility at high pH, Al is present in apprecialsle concentrations only in low-pH water. There its presence is induced by $\mathrm{H}^{*}$, which is consumed in dissolution reactions. Thus 


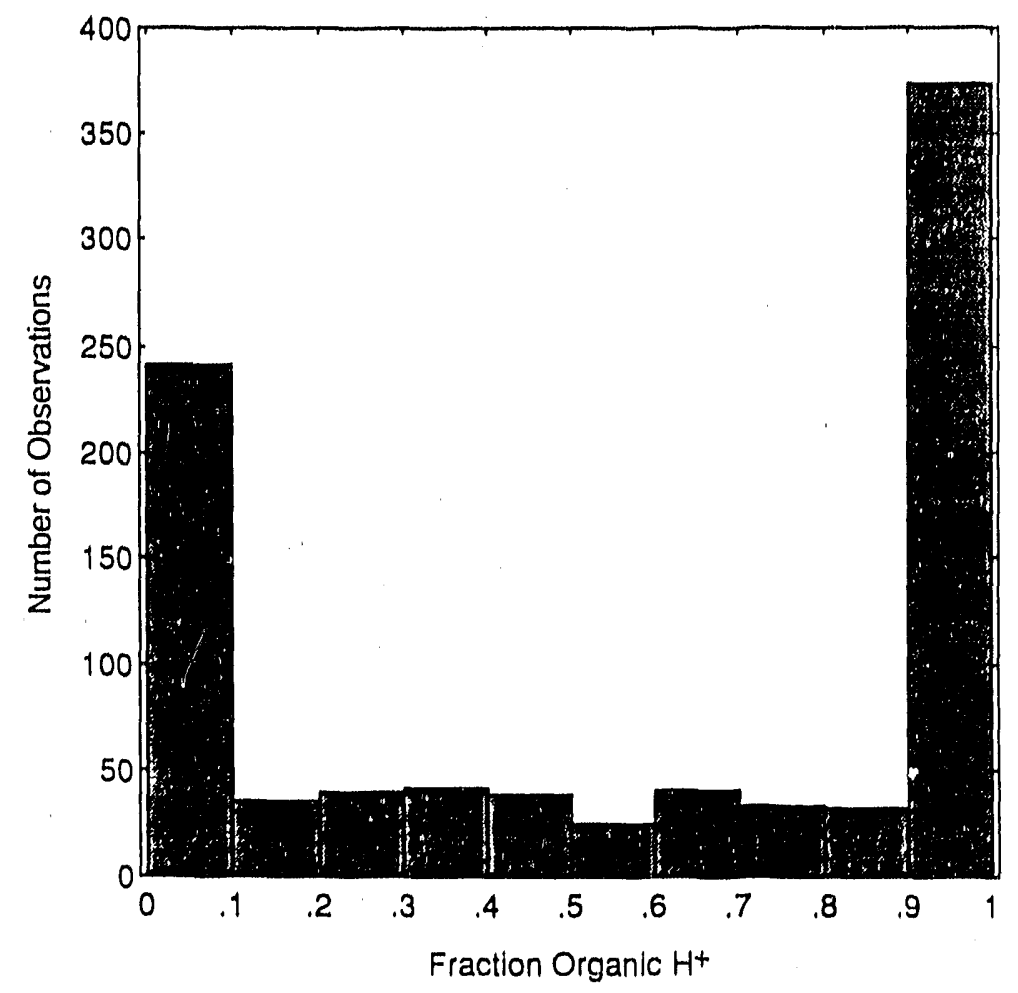

Figure 2.5-2 Distribution of the fraction of hydrogen ion supported by organic acids in all ALSC samples with $\mathrm{pH} \leq 5$. As indicated, the samples commonly had either $>90 \%$ or $<$ $10 \%$ organic-acid-supported $H^{+}$.

Al might be thought of as a surrogate for $\mathrm{H}^{+}$. Given this type of behavior, it may be inappropriate to include it in $\Sigma C_{B}$ for this analysis. If instead the ratio of mineral acidity (calculated as $C_{A}-C_{B}-A l$ ) to total acidity $\left(H^{+}+A l\right)$ is evaluated, a different measure of the fraction of mineral supported acidity can be evaluated. This was done and compared to the values calculated when $A l$ is included in $C_{B}$ to provide an estimate of the error involved in the calculation of the fraction of mineral-and organic-supported acidity. The results were very similar for extreme values (i.e., $<10 \%$ or $>90 \%$ ), which includes most of the samples. The largest variations occur in the 0.2 to 0.4 fraction mineral acid ranges, where the fraction of mineral-supported acidity may be as much as 0.18 higher when $C_{B}$ includes $A l$ than when it does not.

\subsubsection{Drainage Lakes}

This type of analysis can also be applied to subsets of the data. For drainage lakes with pti $\leq 5$ (one sample per lake) the $C_{H}-C_{A}$ values are centered around -10 $\mu \mathrm{eq} / \mathrm{L}$ (see figure 2.5-3a), just as they were in the analysis of all samples. As with the above analysis, many drainage lakes, however, have net mineral base (i.e., $C_{B}>C_{A}$ ), with more than $38 \%$ of the lakes with $p H \leq 5$ having positive $C_{B}-C_{A}$ values 

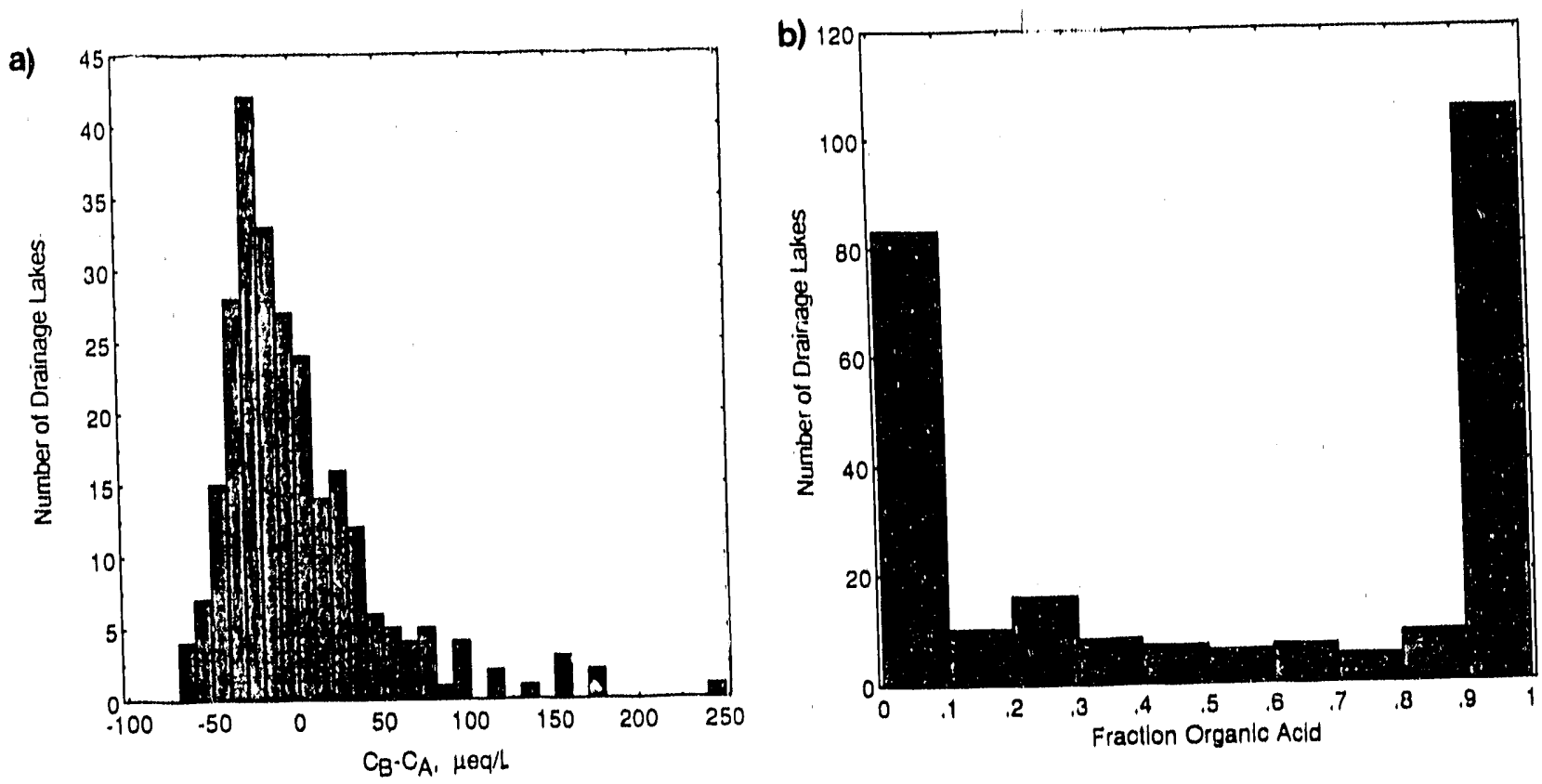

Figure 2.5-3 Influence of organics in summer index lake samples for drainage lakes with lab pH $\leq 5$. (a) Distribution of $C_{B}-C_{A}$. Many lakes have net mineral base indicating that the $\mathrm{H}^{+}$present must be supported by organic ligands. (b) Distribution of the fraction of organic-supported $\mathrm{H}^{+}$.

Examining the fraction of organic-ligand-supported $\mathrm{H}^{+}$in drainage lakes, 83 had $10 \%$ or less of their $\mathrm{H}^{+}$supported by organic ligands, and 105 had $90 \%$ or more supported by organic acids (see

Figure 2.5-3b).

\subsubsection{Seepage Lakes}

For seepage lakes, the $C_{B}-C_{A}$ values are again centered around $-10 \mu \mathrm{eq} / \mathrm{L}$ (see Figure 2.5-4a). As with drainage lakes, more than $39 \%$ of the seepage lakes with $\mathrm{pH} \leq 5$ have net mineral base. The $H^{+}$ present in these lakes are supported exclusively by organic acids. Here, examination of the fraction of organic-ligand-supported $\mathrm{H}^{+}$indicates that 12 of the seepage lakes out of a total of 92 had $10 \%$ or less of their $\mathrm{H}^{+}$supported by organic ligands and 40 had $90 \%$ or more supported by organic acids.

\subsubsection{Within Lake Classes}

As might be expected, the degree of organic ligand support of solution $H^{*}$ is related to the lake DOC concentration. This is illustrated in Figure 2.5-5 using data from the four lowest ANC classes of lakes described in Section 2.4. Figures 2.5-5a and $b$ indicate that mineral acids support the majority of the 

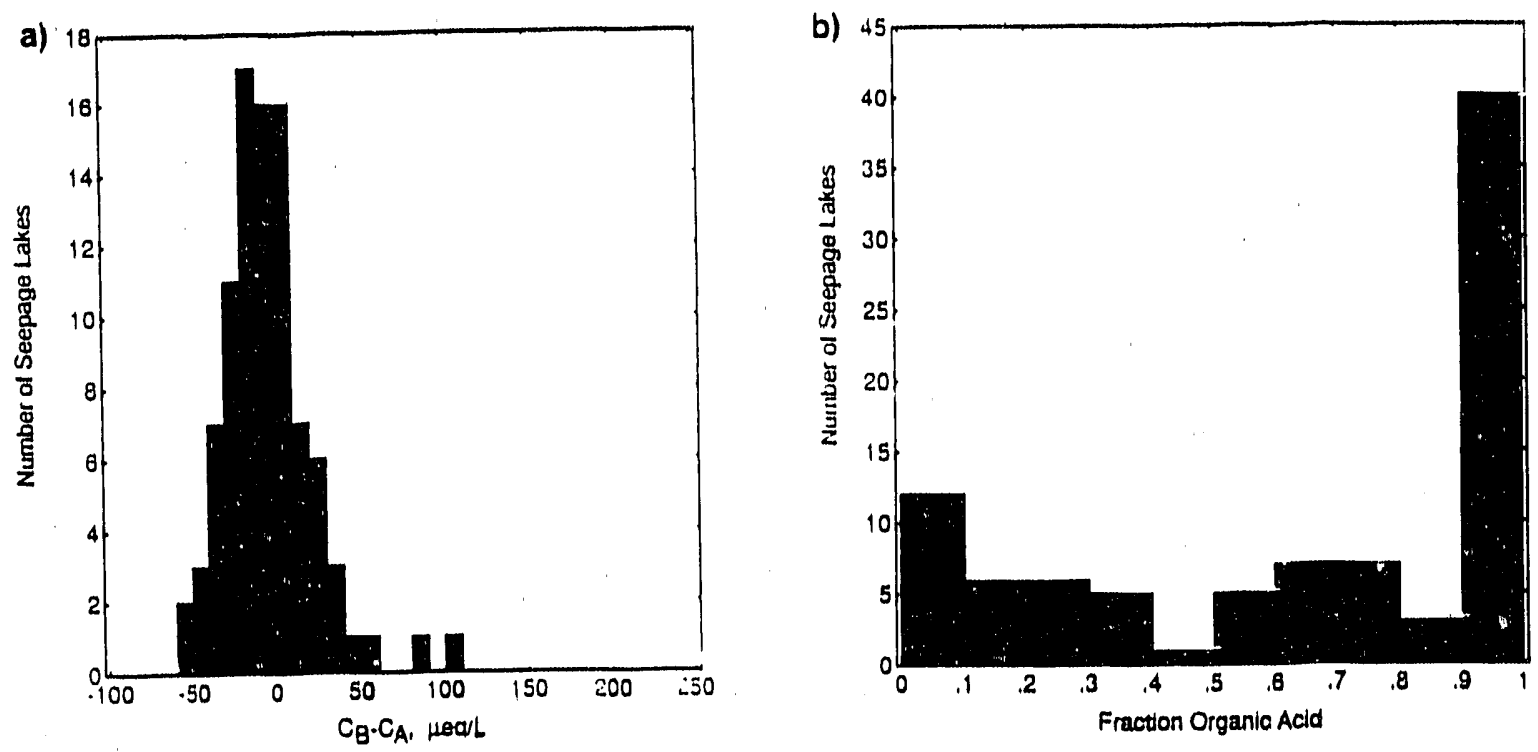

Figure 2.5-4 Influence of organics in summer index lake samples in seepage lakes with lab $\mathrm{pH} \leq 5$ : (a) distribution of $\mathrm{C}_{B}-\mathrm{C}_{\mathrm{A}}$ (b) distribution of the fraction of organic-anionsupported $H^{+}$.

$\mathrm{H}^{+}$in solution in most low-DOC $(<6 \mathrm{mg} \mathrm{C/L})$, thin-till drainage lakes and mounded seepage lakes with $\mathrm{pH} \leq 5$. The fact that some low-DOC lakes have $\mathrm{H}^{+}$supported largely by organic acids results from $\mathrm{C}_{B}$ being approximately equal to $C_{A}$ in those waters. In such waters the mineral bases have offset the mineral acids in high-DOC, thin-till drainage lakes, and mounded seepage lakes, organic ligands support the majority of $\mathrm{H}^{+}$in solution as indicated in Figures $2.5 .5 \mathrm{C}$ and $\mathrm{d}$.

\subsubsection{Sensitivity Analyses}

One of the objectives of the water chemistry analyses of the ALSC data was to provide an indication of hovs $\mathrm{H}^{+}$concentration (or $\mathrm{pH}$ ) might change in response to changing environmental conditions. As noted in Section 2.3, $\mathrm{pH}$ can be calculated as a function of ANC, DIC, DOC, and Al T. Formulations to calculate $\mathrm{pH}$ as a function of these four parameters are embedded in several equilibrium models, such as PHCALC (Gherini et al. 1985) and ALCHEMI (Schecher and Driscoll 1987). Initially, models like these were going to be used to perform parametric sensitivity analyses. As the analyses of the data proceeded, however, it was decided that the equilibrium constants used in these models would have to be reparameterized to match the ALSC data. This proved to be unnecessary, however, because of 
a)

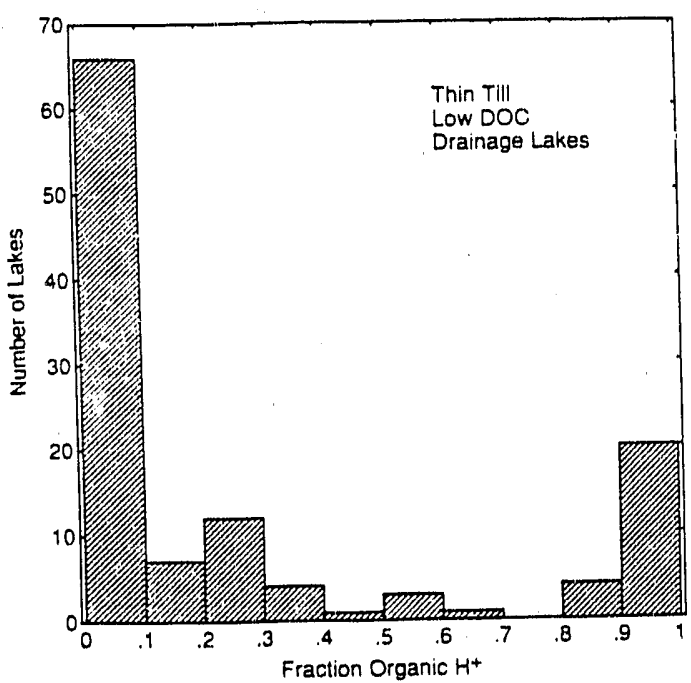

c)

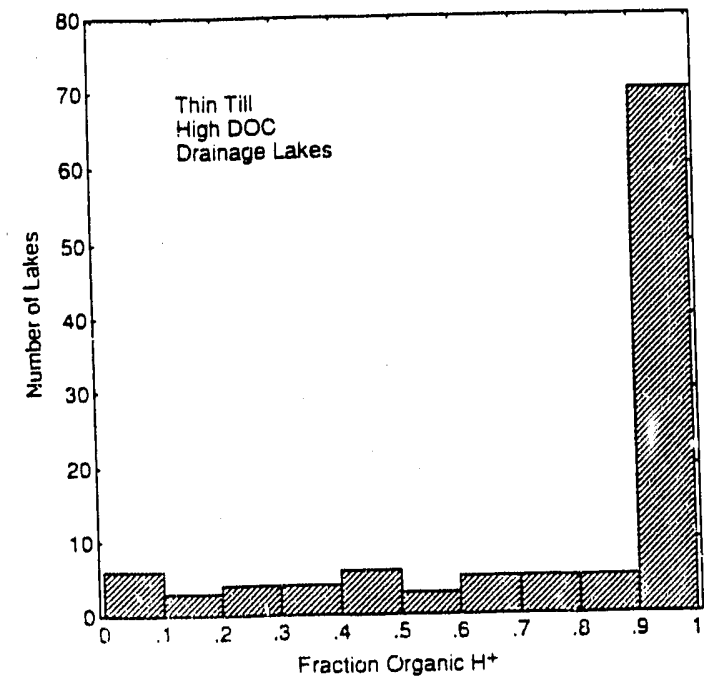

b)

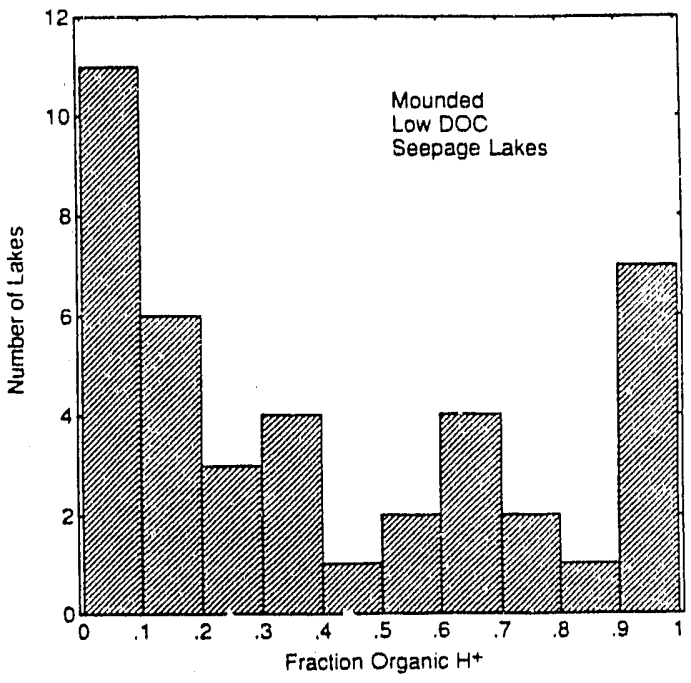

d)

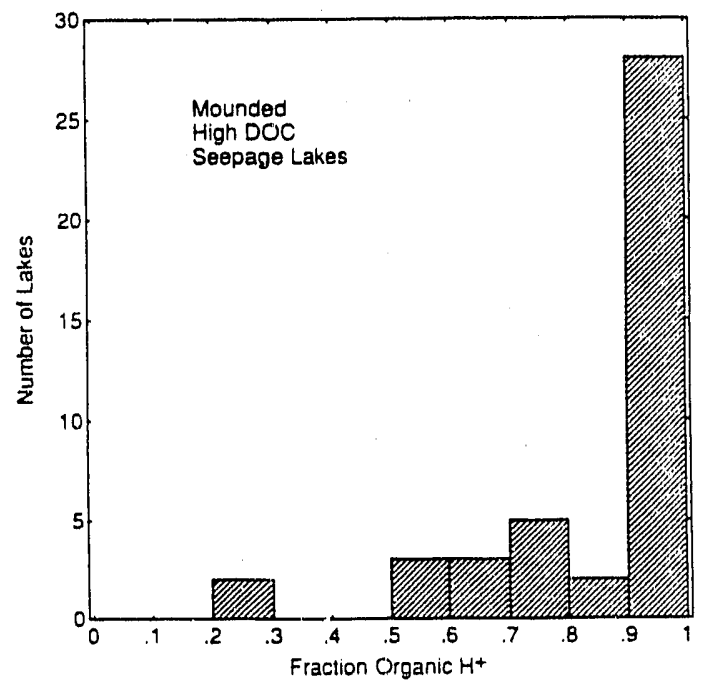

Figure 2.5-5 The fraction of hydrogen ion supported by organic anions in lakes with $\mathrm{pH} \leq \mathbf{5}$ within (a) low-DOC thin-till drainage lakes, (b) low-DOC mounded seepage lakes, (c) high-DOC thin-till drainage lakes, and (d) high-DOC mounded seepage lakes. 
the large quantity of data available. With such an abundance of data, sensitivity analyses could be performed using the data directly.

\subsubsection{Approach}

The first step in developing a sensitivity analysis scheme was to examine the relationship between air-equilibrated $\mathrm{H}^{+}$concentration and $D O C$ over several small ranges in $C_{B}-C_{A}$. As indicated in Figure 2.5-6, the relationships were linear. Plots like those in Figure 2.5-6 were developed for $C_{B}-C_{A}$ intervals of $10 \mu \mathrm{eq} / \mathrm{L}$ ranging from -50 to $100 \mu \mathrm{eq} / \mathrm{L}$. Regression equations were developed for each plot. If all of the regression lines are plotted on a single figure, a plot like that shown in Figure 2.5-7 is produced.

\subsubsection{Change in ANC}

As noted in Saction 2.3, $C_{B}-C_{A}$ is a measure of the net mineral base in solution. If the value is negative, the solution has more mineral acid than mineral base, i.e., it has net mineral acidity. Using Figure 2.5$7 a$, sensitivity analyses can be performed making vectorial movements on the graph. For example, if the water being analyzed had an initial $C_{B}-C_{A}$ of $-20 \mu e q / L$ and $D O C$ of $4 \mathrm{mg} / \mathrm{L}$, a vertical line can be drawn at $D O C=A$ on the plot to see the effect of adding mineral acid or mineral base (i.e., changing $C_{B}-C_{A}$ ) while maintaining constant $D O C$ concentrations. If the $C_{B}-C_{A}$ increased by $20 \mu \mathrm{eq} / \mathrm{L}$ to $0 \mu \mathrm{eq} / \mathrm{L}$ (i.e., the mineral acidity was reduced by $20 \mu \mathrm{eq} / \mathrm{L}$, the vertical line at $D O C=4$ would be followed downward to its intersection with the $C_{B}-C_{A}=0$ line. The $H^{*}$ concentration as noted on the vertical axis would decrease from about $22 \mu \mathrm{eq} / \mathrm{L}(\mathrm{pH}=4.66)$ to about $12 \mu \mathrm{eq} / \mathrm{L}(\mathrm{pH}=4.92)$.

\subsubsection{Change in $D O C$}

Another analysis that could be made using Figure 2.5-7 is the evaluation of the influence of DOC on lake $\mathrm{H}^{+}$concentration. For example, to determine the effect of adding $2 \mathrm{mg} / \mathrm{L} \mathrm{DOC}$ to the solution first described in the example above $\left(C_{B}-C_{A}=-20 \mu \mathrm{eq} / \mathrm{L} ; D O C=4 \mathrm{mg} / \mathrm{L}\right)$, you could simply follow the $C_{B}-C_{A}=-20$ line upward to where it intercepts a vertical line from $D O C=6$. The effect of this addition as noted on the vertical axis would be an increase in the $H^{+}$concentration to about $30 \mu \mathrm{eq} / \mathrm{L}$ (new $\mathrm{pH}=4.52$ )

\subsubsection{Combined Analysis}

Still another test would involve a combined analysis in which both the $C_{B}-C_{A}$ and $D O C$ change. This type of test takes on added significance in light of a recent hypothesis, posed by Krug (1985) and others, which states that the $\mathrm{H}^{+}$concentration of lakes has not changed significantly as a result of 
a)

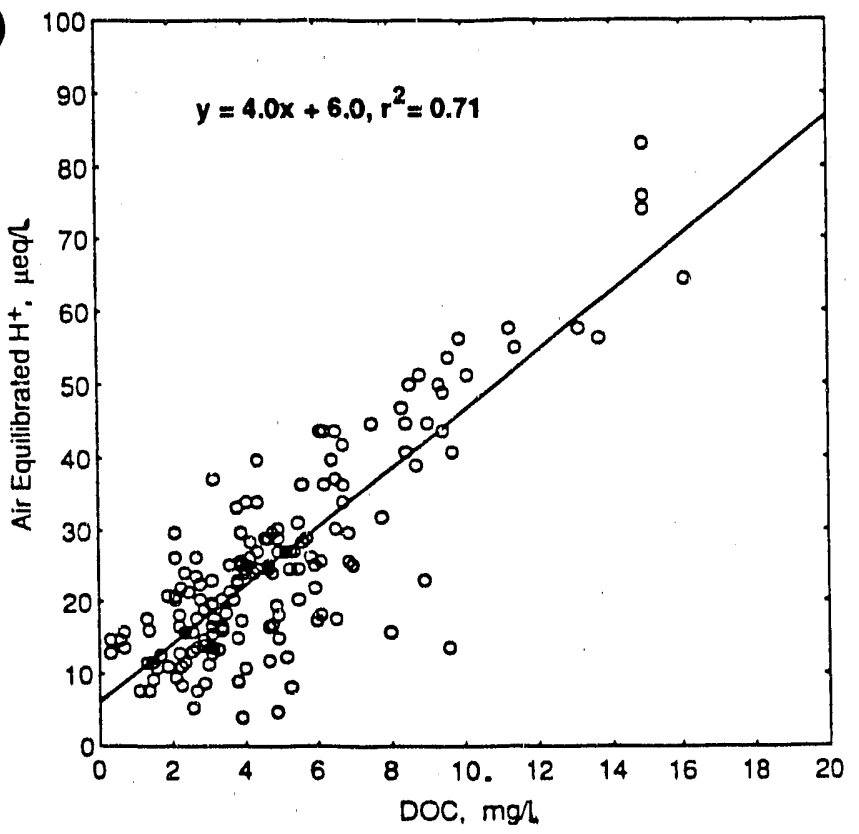

c)

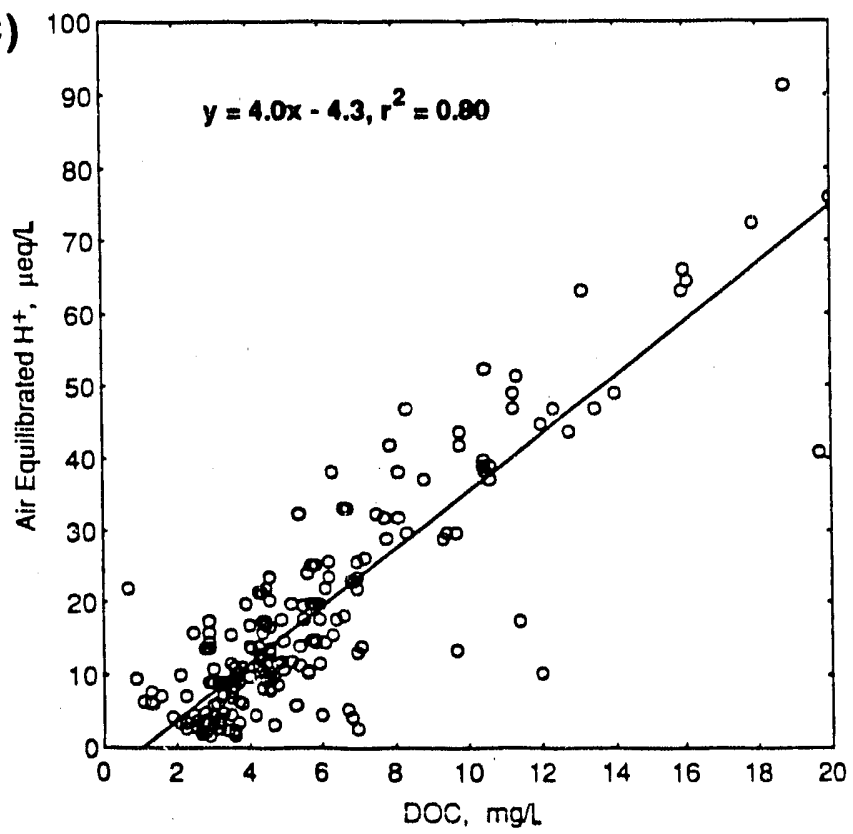

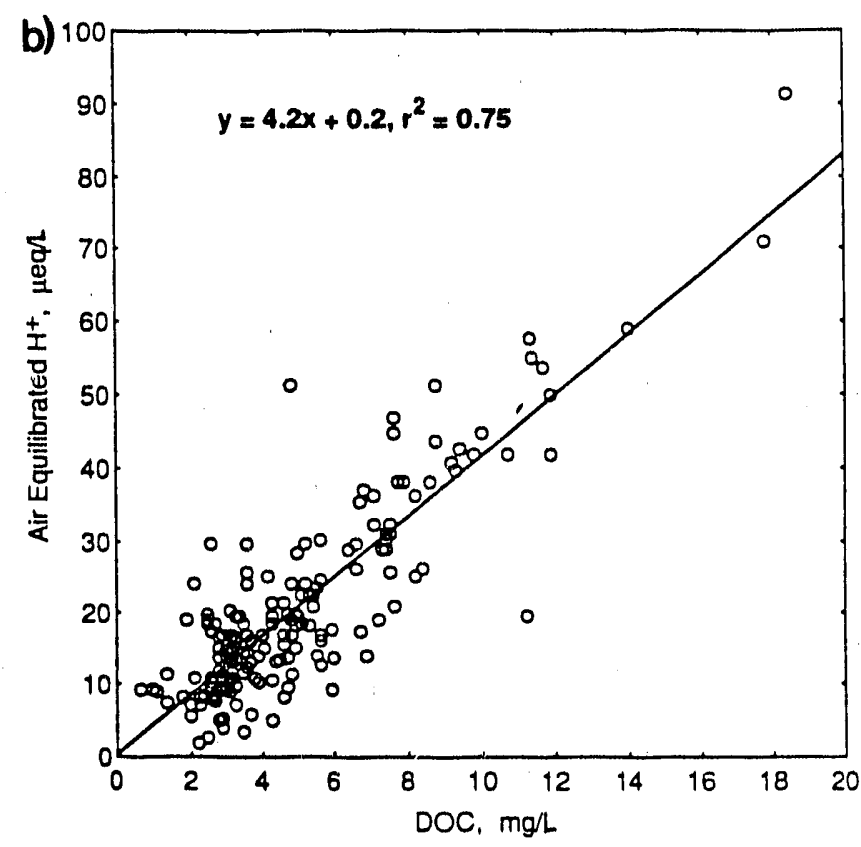

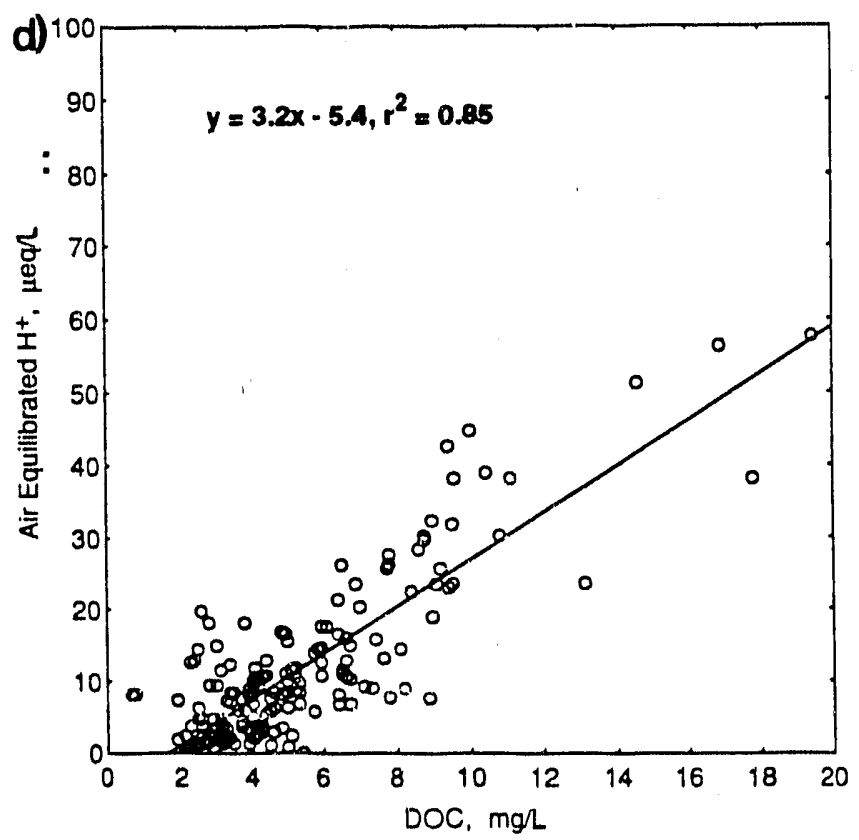

Figure 2.5-6 Relationship between air-equilibrated hydrogen ion concentrations and DOC over $C_{B}-C_{A}$ ranges from (a) -25 to $-15 \mu \mathrm{eq} / \mathrm{L}$, (b) -15 to $-5 \mu \mathrm{eq} / \mathrm{L}$. (c) -5 to $5 \mu \mathrm{eq} / \mathrm{L}$, and (d) 5 to $15 \mu \mathrm{eq} / \mathrm{L}$. 


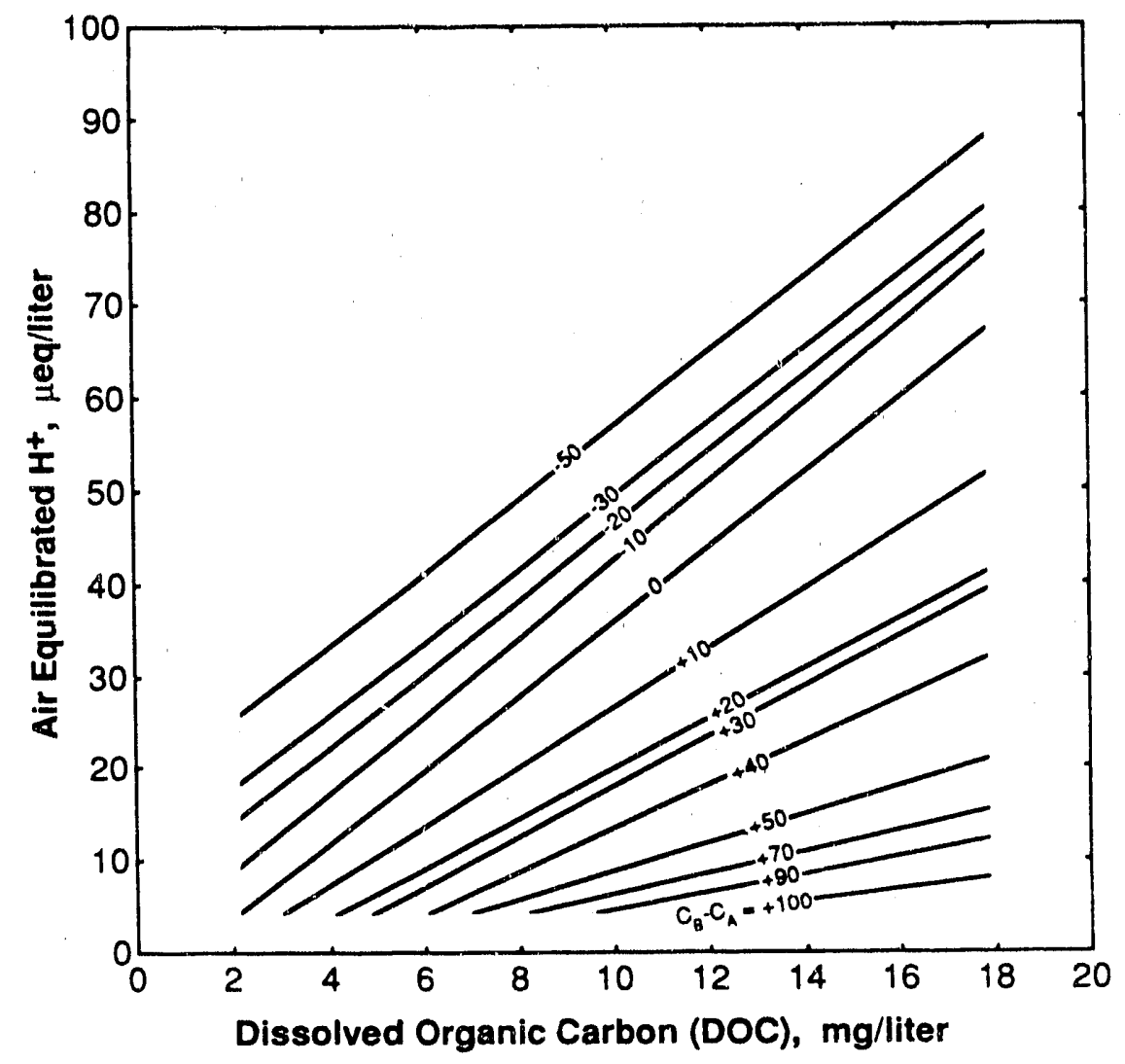

Figure 2.5-7 Air-equilibrated hydrogen ion concentration versus $D O C$ over a range of $C_{B}-C_{A}$ values. This plot can be used to determine the change in $H^{\prime}$ concentration given a change in $C_{B}-C_{A}$ and/or DOC.

acidic deposition, but rather that the form of the acidity has changed from organic acidity to mineral acidity. This hypothesis is supported by the observation that Woods Lake, the acidic Adirondack lake studied during the ILWAS project, experienced an increase in DOC concentration when it was limed as part of the Lake Acidification Mitigation Project (Porcella 1989). There the DOC increased by about $35 \%$ when the lake ANC was increased to $400 \mu \mathrm{eq} / \mathrm{L}$ and remained at that level even when the ANC decreased to about $40 \mu \mathrm{eq} / \mathrm{L}$. If the two sensitivity tests described above are combined (i.e, a water with $-20 \mu \mathrm{eq} / \mathrm{L} C_{B}-C_{A}$ and $4 \mathrm{mg} / \mathrm{L} \mathrm{DOC}$ is changed to a water with $0 \mu \mathrm{eq} / \mathrm{L} C_{B}-C_{A}$ and $6 \mathrm{mg} / \mathrm{L} \mathrm{DOC}$ ), the resulting $\mathrm{H}^{+}$concentration is about $20 \mu \mathrm{eq} / \mathrm{L}(\mathrm{pH}=4.70)$, a change of only about $2 \mu \mathrm{eq} / \mathrm{L}$ (or $0.04 \mathrm{pH}$ units) from the original solution.

An analysis can be performed in which it is determined how much additional DOC would be required to offset the increase in $\mathrm{pH}$ resulting from an increase in $\mathrm{C}_{B}-\mathrm{C}_{A}$. This is done by selecting an initial $C_{B}-C_{A}$ and $D O C$, plotting that point on the graph, and then drawing a horizontal line from this initial point to an intersection with the $C_{B}-C_{A}$ line that corresponds to desired change in $C_{B}-C_{A}$. The difference between the $D O C$ at the intersection and the initial DOC corresponds to the amount of additional $D O C$ needed to offset the change in $H^{*}$ concentration given the increase in $C_{B}-C_{A}$ alone 
For example, using the same initial conditions as above $\left(C_{B}-C_{A}=-20 \mu \mathrm{eq} / \mathrm{L} ; D O C=4 \mathrm{mg} / \mathrm{L}\right)$ and assuming a $20 \mu \mathrm{eq} / \mathrm{L}$ increase in $C_{B}-C_{A}$, a horizontal line would intersect the $0 \mu \mathrm{eg} / \mathrm{L} C_{B}-C_{A}$ line at a DOC value of approximately $6.5 \mathrm{mg} / \mathrm{L}$. In other words, an increase of about $2.5 \mathrm{mg} / \mathrm{L} \mathrm{DOC} \mathrm{(6.5-4)}$ would offset a $20 \mu \mathrm{eq} / \mathrm{L}$ increase in $C_{B}-C_{A}$ for this water. In fact, over the $C_{B}-C_{A}$ range of about -50 to $+100 \mu \mathrm{eq} / \mathrm{L}$ the necessary increase in $\mathrm{DOC}$ to hold $\mathrm{pH}$ constant given a $20 \mu \mathrm{eq} / \mathrm{L}$ increase in $\mathrm{C}_{B}-\mathrm{C}_{\mathrm{A}}$ would range from about 2 to $5 \mathrm{mg} / \mathrm{L} \mathrm{DOC}$.

\subsubsection{Analyses for Lake Classes}

The analyses described above can be applied to representative lakes from the lake classes described in Section 2.4. If the same classes used in Section 2.5.1.4 are again used here (high-and low-DOC, thintill drainage lakes and high- and low-DOC, mounded seepage lakes), the results shown in Table 2.5-1 are derived. Table 2.5-1 lists the measured $C_{B}-C_{A}$ and $D O C$ from the representative lakes along with median concentrations for each class. The representative lake was that lake in each class which had characteristics $\left(C_{B} \cdot C_{A}\right.$ and $\left.D O C\right)$ closest to the median values for the class. Also included are the observed air-equilibrated $\mathrm{pH}$ as well as that derived using Figure 2.5-7 and the measured $C_{B}-C_{A}$ and DOC of the lake. It should be noted that the DDRP lakes were a subset of the Eastern Lakes Survey and may not be representative of the much larger sample studied by the ALSC (see Section 2.4.7)

Changes in $\mathrm{pH}$ are then presented for a $15 \mu \mathrm{eq} / \mathrm{L}$ increase in $\mathrm{C}_{B}-C_{A}$ alone (equivalent to a $15 \mu \mathrm{eq} / \mathrm{L}$ decrease in mineral acidity) as well as $15 \mu \mathrm{eq} / \mathrm{L}$ increases in $C_{B}-C_{A}$ coupled with increases in DOC of 1 and $3 \mathrm{mg} / \mathrm{L}$. Finally, a column is included that shows the change in DOC required to totally offset the change in pH resulting from the $15 \mu \mathrm{eq} / \mathrm{L}$ increase in $C_{B}-C_{A}$. The $15 \mu \mathrm{eq} / \mathrm{L}$ increase in $C_{B}-C_{A}$ was used in these analyses because modeling results from U S. EPA's Direct/Delayed Response Project (DDRP) indicated that the response to a nominal 30\% decrease in total sulfur deposition. (EPA's northeast scenario) would produce a 10 to $15 \mu \mathrm{eq} / \mathrm{h}$. increase in $C_{B}-C_{A}$ (Church et al. 1989).

As indicated, the response to changes in mineral acidity alone ranges from 0.17 to $0.38 \mathrm{pH}$ units. If concurrent increases in DOC are considered, the changes in $\mathrm{pH}$ are smaller, and in one case the $\mathrm{pH}$ after a $15 \mu \mathrm{eq} / \mathrm{L}$ increase in $C_{B}-C_{A}$ and a $3 \mathrm{mg} / \mathrm{L}$ increase in $D O C$ is lower than the initial value. The final column indicates that increases of 2 to $4 \mathrm{mg} / \mathrm{L} \mathrm{DOC}$ would negate any increases in $\mathrm{H}^{*}$ due to the $15 \mu \mathrm{eq} / \mathrm{L}$ increase in $C_{B}-C_{A}$. It is unclear at this time, however, if or how much $D O C$ concentration would change in response to changes in $C_{B}-C_{A}$. This is an important area needing further research.

\subsubsection{Summary of Sensitivity Analyses}

In summary, the ALSC data have provided a means of performing parametric sensitivity analyses without having to rely on equilibrium models and the uncertainties in the equilibrium constants 
Table 2.5-1 Changes in PH Given Changes in $C_{B}-C_{A}$ and DOC

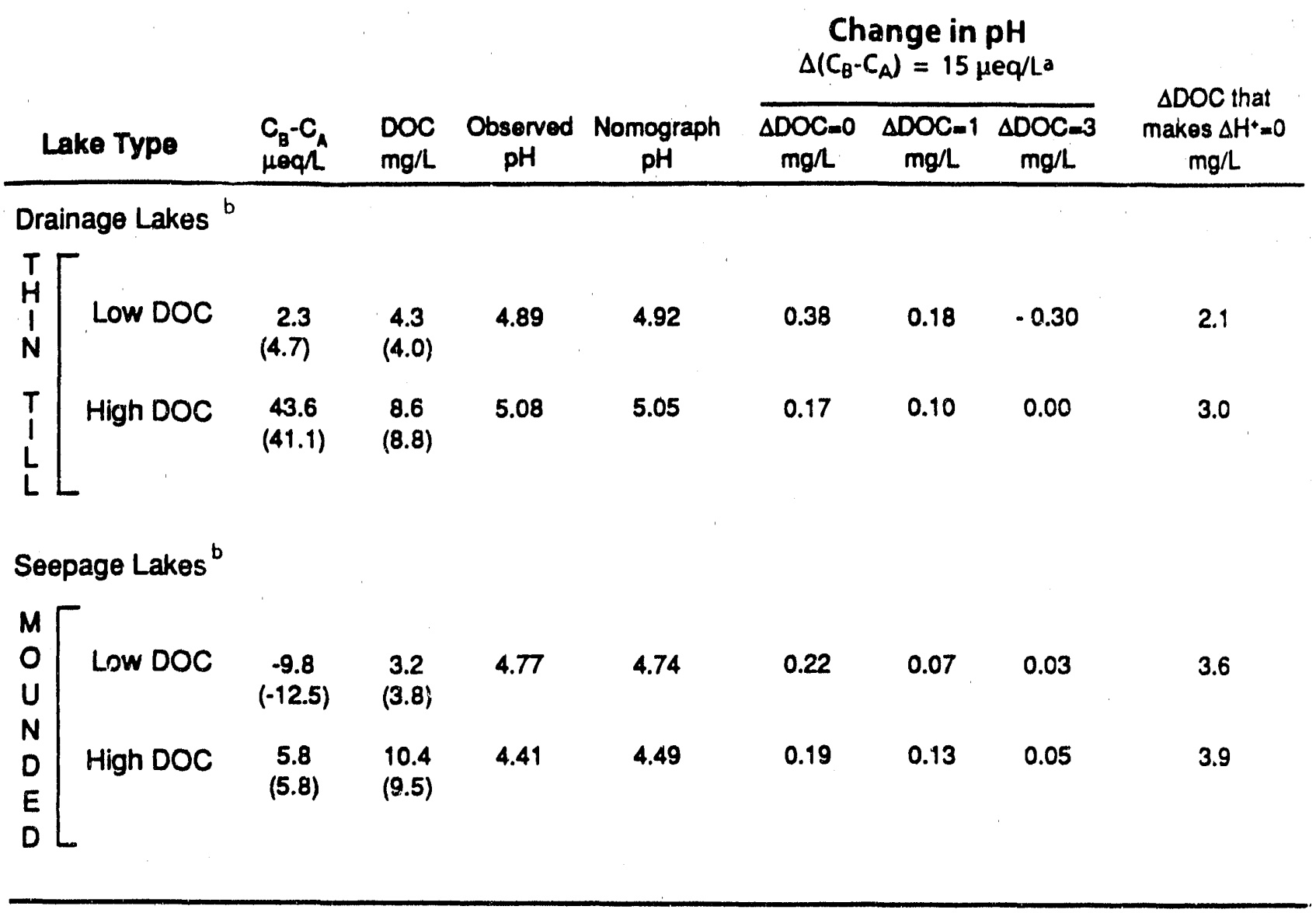

a U.S. EPA DDRP's projected $C_{B}-C_{A}$ increase for a $30 \%$ decrease in sulfur deposition.

b () indicate median values for the specific lake class.

embedded in such codes. Instead, the sensitivity analyses were based solely on the data. Using Figure 2.5-7, changes in $\mathrm{H}^{*}$ concentration as a result of changes in mineral acidity, DOC, or both can be determined. In addition, changes in DOC required to offset any changes in $\mathrm{H}^{*}$ concentration as a result of changes in mineral acidity can be evaluated This provides a powerful and direct means of determining the response of lake $\mathrm{pH}$ to a variety of environmental changes.

\subsubsection{Influence of Organic Anions on Gran ANC}

In Section 2.3 it was noted that $C_{B}-C_{A}$ ANC is often higher than Gran ANC. Part of the difference was attributed to the systematic underestimation of Gran ANC due to curvature in the $F_{1}$ Gran function The difference not due to curvature was attributed to the presence of "strong" organic acids. These strong organics are simply those that remain unprotonated in the titration procedure Some strong 
organic acids are similar to $F^{-}$in that they do not have enough affinity for $\mathrm{H}^{+}$to remove them from solution during the titration. Although in a classical chemical sense HF would not be considered a strong acid $\left(p K_{A}=3.2\right)$, for the purposes of evaluating the acid-base characteristics of dilute lake waters, it should be treated as strong. The strong organics fit in the same category.

Perhaps the most compelling evidence that a portion of the organic acids is strong is the relationship observed between anion deficit and $\mathrm{DOC}$ in low pH waters $(\mathrm{pH}=4.0$ to 4.5 , see figure 2.5-8a). At

a)

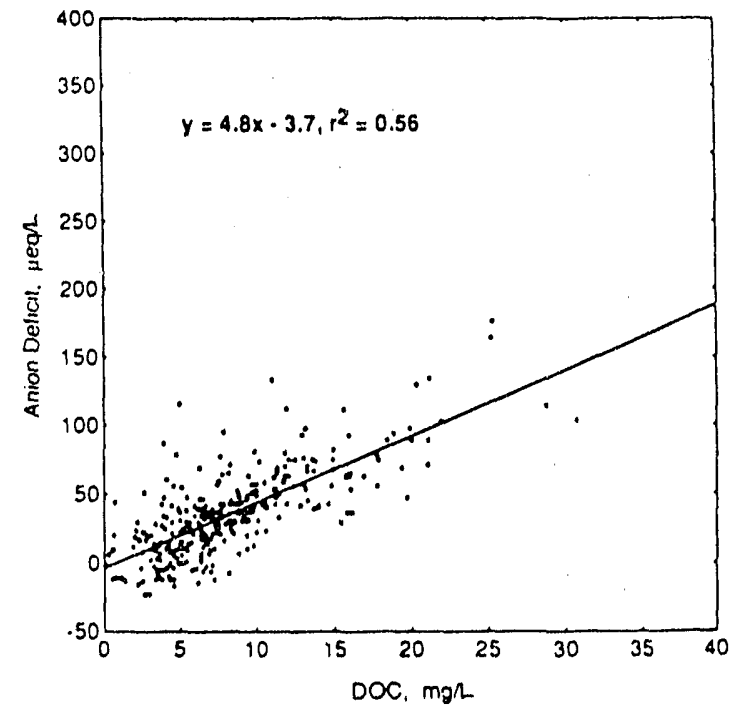

b)

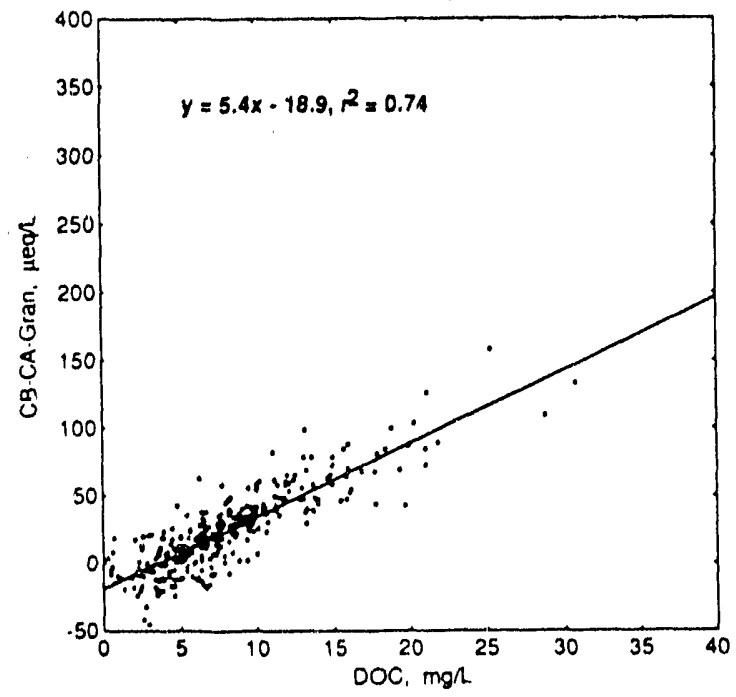

Figure 2.5-8 For samples with pH from 4.0 to 4.5, (a) Anion deficit versus $D O C$ and $(b)\left(C_{B}-C_{A}\right)$ Gran ANC versus DOC. Slopes of the regression lines indicate that $90 \%$ of the difference between $C_{B}-C_{A}$ and Gran $A N C$ is due to the presence of strong organic acids while $10 \%$ is due to curvature in the $F_{1}$ Gran function.

such low $\mathrm{pH}$ values, weak acids are protonated and thus do not contribute to the anion deficit. That the deficit increases with increasing $D O C$ even at these low $\mathrm{pH}$ values indicates that there are strong organic acids in solution

The relative contribution of strong organic anions and curvature in the $F_{1}$ Gran function to the difference between $C_{B}-C_{A}$ and $G$ ran $A N C$ can be estimated by examining the relationship between anion deficit and $D O C$ at low $\mathrm{pH}$ and the relationship between $\left[\left(C_{B}-C_{A}\right)\right.$ - Gran $]$ and DOC also at low $\mathrm{pH}$ as illustrated in Figure 2.5.8a and b Theoretically, the slopes of these two curves should be identical because the weak organic species will be protonated at these low $\mathrm{pH}$ values As the 
regression equations on the plots illustrate, however, the slope for the $\left[\left(C_{B}-C_{A}\right) \cdot G\right.$ ran $]$ versus $D O C$ curve is $5.4 \mu \mathrm{eq} / \mathrm{mg} \mathrm{DOC}$, while the slope of the anion deficit versus $D O C$ curve is $48 \mu \mathrm{eq} / \mathrm{mg} D O C$. This is because the difference between $C_{B}-C_{A}$ and $G$ ran results from both the presence of strong organics and from curvature in the $F_{1}$ Gran function. The ratios of the two slopes indicate that $90 \%$ of the deviation between $C_{B}-C_{A}$ and $G r a n A N C$ is due iu the presence of strong organics, whereas $10 \%$ is due to curvature in the $F_{1}$ Gran function.

These analyses also indicate that DOC contributes 4.5 to $5 \mu \mathrm{eq} / \mathrm{mg}$ DOC of strong acid to solution. The associated anions make a negative contribution to $\mathrm{Gran} \mathrm{ANC}$ just as $\mathrm{F}, \mathrm{Cl}, \mathrm{NO}_{3}$, and $\mathrm{SO}_{4}$ do. Given this, it is possible (and does, in fact, quite often occur) to have positive $C_{B}-C_{A}$ in solution and a negative Gran ANC. Because organic anions can produce negative Gran ANC values, the common practice of considering negative values of Gran ANC evidence of acidification solely by mineral acids is not supported by the ALSC data.

\subsubsection{Time Trend Analysis}

Although Adirondack lake water quality data are available from a number of synoptic surveys conducted from the 1920s through the present, comparisons of paired historical and contemporary observations suffer from two major limitations. First, there have been changes in the procedures used to analyze dilute waters, which has raised concerns over the precision and accuracy of historical data, and second, in most synoptic surveys, only a single surface sample was collected from each lake. Natural spatial and seasonal variations are not easily resolved in comparisons of synoptic surveys. Any changes in water quality must be large in order to be distinguished from normal ranges of variation. For these reasons, time series data (consistently measured parameters at fixed locations with frequent. measurements) are needed to best perform trend analysis.

Time series data for precipitation and lake water quality in the Adirondacks have only become available within the past decade (Volentini and Gherini 1986, Hirsch and Peters1988, Raynal et al. 1987. Driscoll and van Dreason 1988). For this analysis, precipitation data from two monitoring

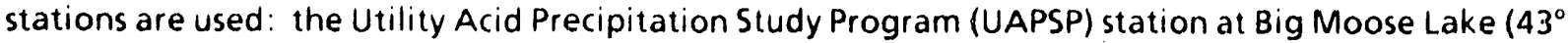
$49^{\prime} \mathrm{N}, 74^{\circ} 54^{\prime} \mathrm{W}$ ) in the west-central Adirondacks and the National Acid Deposition Program (NADP) site at Huntington Forest $\left(43^{\circ} 58^{\prime} \mathrm{N}, 74^{\circ} 14^{\prime} \mathrm{W}\right.$. Arbutus Lake) in the central Adirondacks. The longest record of dilute lake water quality is available from Adirondack Long-Term Monitoring (ALTM) program (Driscoll and van Dreason 1989). This program involves monthly sampling of 17 Adirondack lakes (see Figure 2.5-9) that were originally sampled over a 2-year period as part of the RILWAS (Goldstein et al. 1987, Driscoll and Newton 1985) The data records for these lakes cover the period 
from 1982 to the present. The analyses conducted to identify the existence of trends in these data are described below.

\subsubsection{Precipitation Trends}

The annual volume-weighted concentrations of $\mathrm{SO}_{4}, \mathrm{NO}_{3}$, and $\mathrm{NH}_{4}$ from the UAPSP station at Big Moose Lake and the NADP station at Huntington Forest do not exhibit discernible long-term trends (Figure 2.5-10). Sulfate and $\mathrm{NO}_{3}$ concentrations have remained steady at about 45 and $23 \mu \mathrm{eq} / \mathrm{L}$, respectively, since 1979. The concentrations of $\mathrm{NH}_{4}{ }^{+}$varied irregularly between sites and years, from 10 to $20 \mu \mathrm{eq} / \mathrm{L}$. The concentrations of $\mathrm{H}^{\prime}$ at both sites and the sum of alkali and alkali earth cation concentrations $\left(C^{\prime}{ }_{B}\right)$ at the NADP site appear to have declined approximately $25 \%$ from 1979 to 1982 , and have remained relatively constant since 1982 . Whether the decline in these two parameters is statistically significant is currently unresolved (Raynal et al 1987)

Mean annual deposition at the UAPSP and the NADP stations is controlled primarily by the precipitation quantity (Figure 2.5-11). The highest recorded deposition of $\mathrm{H}^{*}(1400 \mu \mathrm{eq} / \mathrm{ha} / \mathrm{yr})$ occurred at Big Moose Lake during 1986, when the precipitation volume $(275 \mathrm{~cm})$ was nearly double

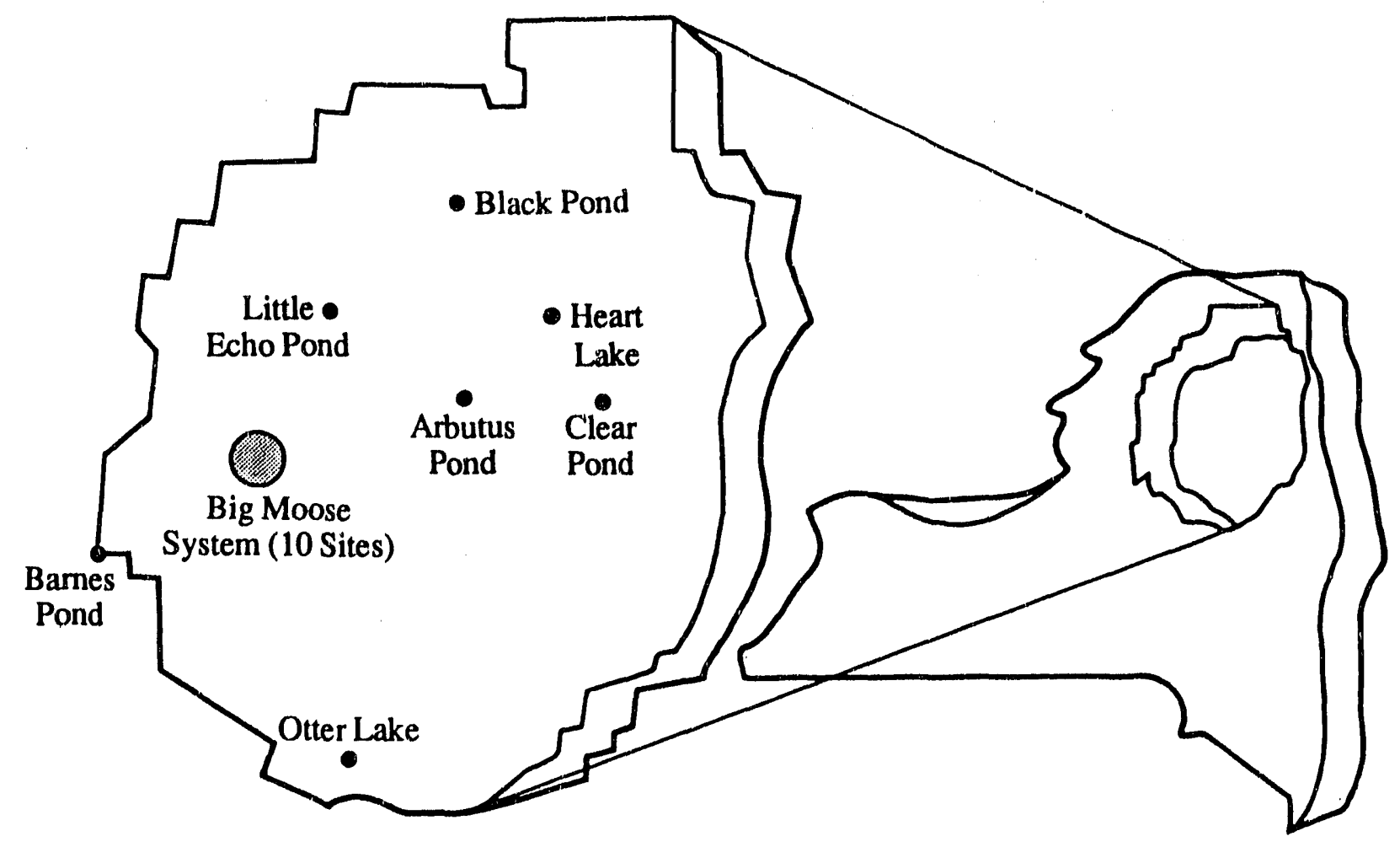

Figure 2.5-9 Locations of Adirondack long-term monitoring sites. 

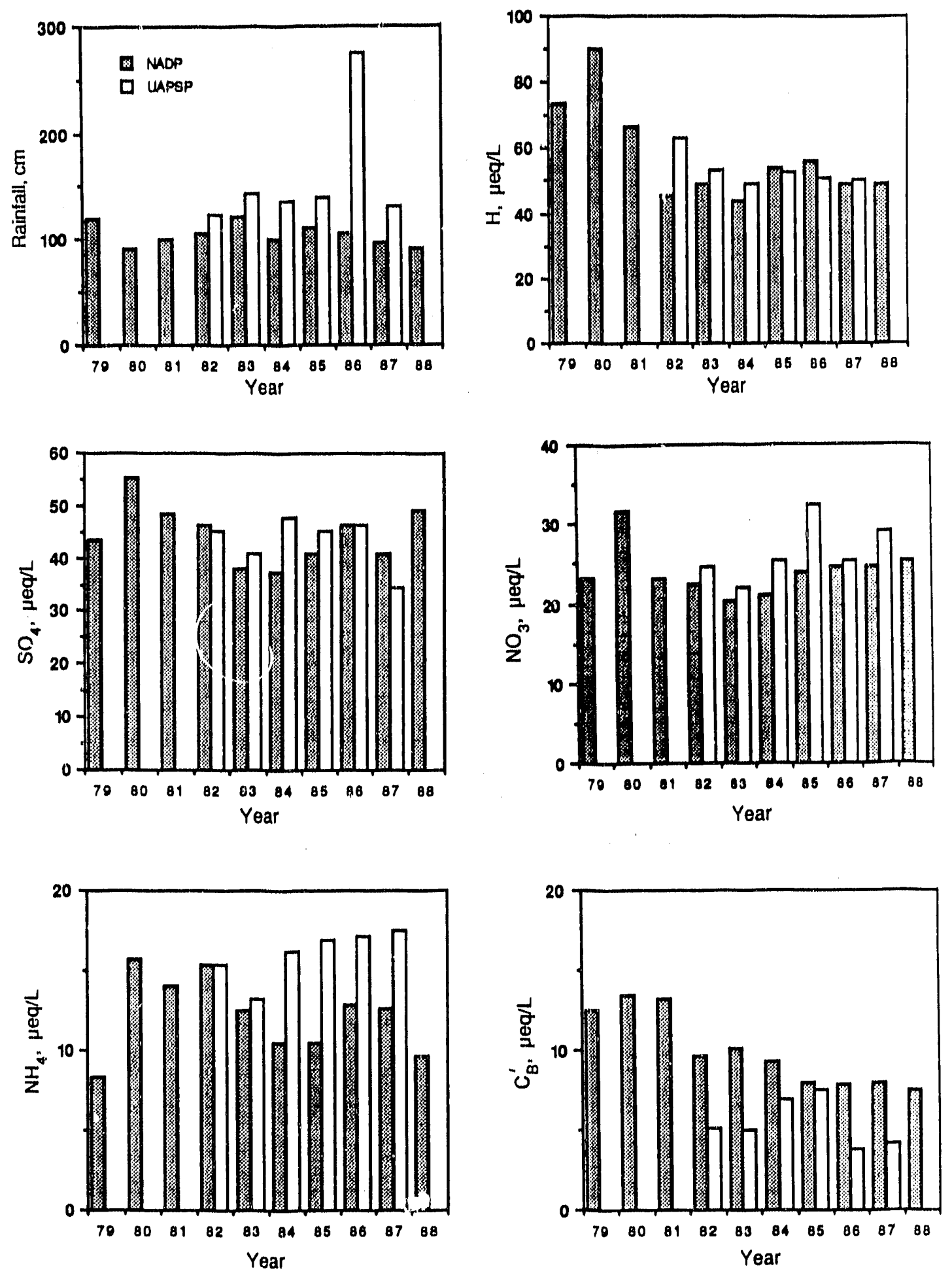

Figure 2.5-10 Precipitation quantity and quality at the UAPSP site at Big Moose Lake and the NADP site at Huntington Forest. 

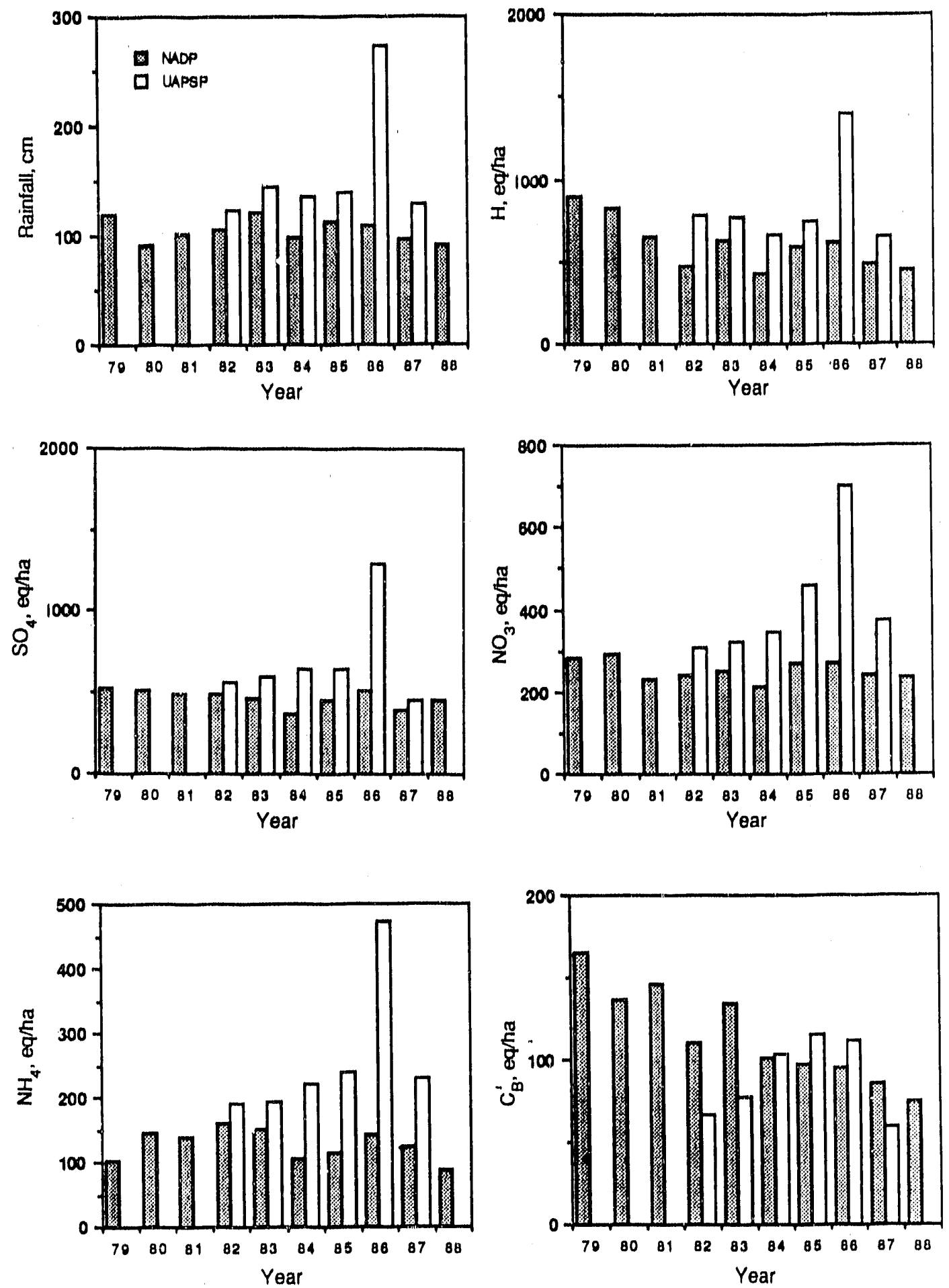

Figure 2.5-11 Wet deposition at the UAPSP site at Big Moose Lake and the NADP site at Huntington Forest. 
that of other years. The deposition of $\mathrm{H}^{\prime}$ appears to be declining at both sltes from values of approximately $900 \mu \mathrm{eq} / \mathrm{ha} / \mathrm{yr}$ in 1979 to $500 \mu \mathrm{eq} / \mathrm{ha} / \mathrm{yr}$ in 1988. The $\mathrm{C}_{\mathrm{H}}$ flux also declined at the NADP site from $170 \mu \mathrm{eq} / \mathrm{ha} / \mathrm{yr}$ in 1979 to $80 \mu \mathrm{eq} / \mathrm{ha} / \mathrm{yr}$ in 1988. At the UAPSP station, $\mathrm{C}_{B}{ }_{B}$ deposition trends differed from those at the NADP site, ranging from 60 to $120 \mu \mathrm{eq} / \mathrm{ha} / \mathrm{yr}$. As would be "xpected from the invariant temporal concentrations of $\mathrm{SO}_{4}{ }^{2 \cdot}$ and $\mathrm{NO}_{3}{ }^{\circ}$, their deposition rates varied linearly with the quantity of precipitation (Figure 2.5-11).

\subsubsection{Lake Water Quality Trends}

Trends in lake water quality for the ALTM lakes were analyzed using nonparametric statistical methods. Although parametric procedures are more powerful, these methods require the assumption of a particular model, or distribution, for the trends. If the model does not hold, as is the case for the ALTM data, nonparametric or distribution-free methods have to be used.

Kendall's Tau or the seasonal Kendall's Tau test (Hirsch et al. 1982; Hirsch and Slack 1984) are often good choices for distribution-free tests. The Keridall's Tau test is used to determine whether a time series is moving upward, downward, or remaining relatively level. This is accomplished by computing a statistic, based on all possible data pairs, that represents the net direction of movement of the series. The seasonal Kendall's Tau test yields the same analysis on a seasonal basis. With monthly data, we may define a "season" as one month in length. If there is distinct seasonal behavior, then the seasonal Kendall's Tau test is appropriate. Berryman et al. (1988) and Gilbert (1987) provide useful guidance on the selection and application of such tests.

The Kendall's Tau statistic provides a nonparametric assessment of the presence or absence of a trend. The Sen or seasonal Kendall slope estimator (Gilbert 1987) provides a nonparametric estimate of the magnitude of any trend. These estimators are based on the median slope from the set of slope estimates for the lines connecting all possible pairs of data.

Given the variability of ALTM data, trends for individual lakes could not be discerned Instead, metaanalysis (Hedges and Olkin 1985) was used to determine the statistical significance of seasonal Kendall slope estimates for all of the lakes to draw collective conclusions. The Sen slope was chosen over the seasonal Kendall's Tau statistic for the meta-analysis because the Sen slope estimator is expected to be nearly unbiased in the presence of autocorrelation. The analyses were performed on the monthly ALTM measurements, after the more frequent (weekly) spring observations were removed from the data set.

The meta-analysis presented in Tab!e 2.5 -2 yields a p-value for each of the five water chemistry variables examined. For the smaller (more statistically significant) p-values, Bayes Theorem was used 
as in Berger and Sellke (1987) to estimate a (posterior) probability for the null hypothesis (of no trend in each water chemistry variable). This probability is appropriate if we can say that, prior to seeing the data, we believed (expressed as a normal distribution) that there was a 50:50 chance of trend:notrend.

Table 2.5-2 Meta-Analysis and Probabilities

\begin{tabular}{llc}
\hline Variable & p-Value & Null Hypothesis Probability \\
\hline Field pH & 0.142 & 0.55 \\
$\mathrm{C}_{\mathrm{B}}$ & 0.054 & 0.40 \\
$\mathrm{ANC}$ & 0.055 & 0.40 \\
$\mathrm{SO}_{4}$ & 0.00005 & 0.01 \\
$\mathrm{NO}_{3}$ & 0.825 & $-\cdot$ \\
\hline
\end{tabular}

The meta-analysis and the probabilities for the null hypothesis indicate that we can be confident of a trend in $\mathrm{SO}_{4}$ only. The trend here is a downward one (meta average $\mathrm{SO}_{4}$ concentration change: $-2.1 \mu \mathrm{eq} / \mathrm{L} / \mathrm{yr}$ ). The analysis is inconclusive for $\mathrm{C}_{\mathrm{B}}, \mathrm{ANC}$, and field $\mathrm{pH}$, whereas it indicates no trend for $\mathrm{NO}_{3}$

\subsubsection{Summary}

Information presented in Section 2.5 integrates the results of al alyses presented earlier. A method was developed using the ALSC data alone whereby changes in $\mathrm{H}^{*}$ concentration, and thus $\mathrm{pH}$, can be predicted given changes in mineral acid-base concentrations and/or DOC. Using this method, $\mathrm{pH}$ changes of 0.17 and $0.38 \mathrm{pH}$ units were predicted in response to a $30 \%$ reduction in sulfur deposition for 4 specific lakes from the lowest ANC classes described in Section 2.4.

The role of inorganic ligands in supporting $\mathrm{H}^{+}$in solution was also investigated. Most lakes had either more than $90 \%$ or less than $10 \%$ of their hydrogen ions supported by organic ligands The distribution of organic support of $\mathrm{H}^{*}$ varied among lake classes, with high-DOC lakes lakes showing higher organic support.

The strength of organic acids was also quantified. Dissolved organic carbon contributes 4.5 to 5 $\mu \mathrm{eq} / \mathrm{mg}$ DOC of strong acid to solution. These strong organics decrease both $\mathrm{pH}$ and $A N C$, and thus the common practice of considering negative values of Gran ANC evidence of acidification solely by mineral acids is not supported by the ALSC data. 
A more quantitative summary of the analyses presented in Section 2.5 and throughout Section 2 is presented in Section 4 . The relevance of the findings in the chemistry section to fish communities is described in Section 3. 


\section{SECTION 2 - REFERENCES}

April, R.H., and R.M. Newton. 1984. The Geology and Geochemistry of the ILWAS Lake-Watersheds. Pages 41-420. In: The Integrated Lake Watershed Acidification Study, Vol. 4

Asbury, C.E., F.A. Vertucci, M.D. Mattson, and G.E. Likens. 1989. Acidification of Adirondack Lakes. Environ. Sci. Technol. 23:362-368

Baker, J. 1984. The Acidic Deposition Phenomenon and its Effects on Aquatic Biology. Pages 5-74 to 5-129. In: A.P. Altshuller and R.A. Linthurst, eds. The Acidic Deposition Phenomenon and Its Effects: Critical Assessment and Review Papers. EPA-600/8-83/016BF. U.S. Environmental Protection Agency, Washington, DC.

Baker, J.P., and T.B. Harvey. 1984. Critique of Acid Lakes and Fish Population Status in the Adirondack Region of New York State. Final Report. EPA 600/3-86/046. U.S. Environmental Protection Agency, Corvallis, OR

Baker, J.P., and C.L. Schofield. 1982. Aluminum Toxicity to Fish in Acidic Waters Water, Air, Soil Pollut. 18:289-309

Baker, L.A., T.E. Perry, and P.L. Brezonik. 1985. Neutralization of Acid Precipitation in Softwater Lakes. Pages 356-360 In: J. Taggart and L. Moore, eds. Lake and Reservoir Management. Vol. 1. North American Lake Management Society, Washington, DC

Berger, J.O., and T. Sellke. 1987. Testing a Point Null Hypothesis: The Irreconcilability of $p$ Values and Evidence. J. Am. Stat. Assoc. 82:112-139

Berryman, D., B. Bobee, D. Cluis, and J. Haemmerli. 1988. Nonparametric Tests for Trend Detection in Water Quality Time Series. Water Resour. Bull. 24:545-556.

Bloom, P.R. 1988. Annual Report io Electric Power Research Institute ALBIOS: Dissolution Kinetics of Minerals. (Unpublished). Electric Power Research Institute, Palo Alto, CA.

Brakke, D.F., D.H. L.anders, and J.M. Eilers. 1988. Chemical and Physical Characteristics of Lakes in the Northeastern United States. Environ. Sci. Technol. 22:155-163

Brown, D.J.A. 1983. Effect of Calcium and Aluminum Concentrations on the Survival of Brown Trout (Salmo trutta) at low pH. Bull. Environ. Contam. Toxicol. 30:582-587.

Buddington, A.F. 1968. Adirondack Anorthositic Series. Pages 215-231. In: Y.W. Isachsen, ed. Origin of Anorthosite and Related Rocks. Memoir 18. New York State Museum and Science Service, Albany.

Butler, J.N. 1982. Carbon Dioxide Equilibria and their Applications. Addison-Wesley Publishing Co., Reading, Mass. $259 \mathrm{pp}$

Chen, C.W., S.A. Gherini, R.J.M. Hudson, and J.D. Dean. 1983. The Integrated Lake-Watershed Acidification Study - Vol. 1: Model Principles and Application Procedures. EA-3221. Electric Power Research Institute, Palo Alto, CA. $214 \mathrm{pp}$

Chen, C.W., S.A. Gherini, N.E. Peters, P.S. Murdoch, R.M. Newton, and R.A. Goldstein. 1984 Hydrologic Analyses of Acidic and Alkaline Lakes. Water Resour. Res 20:1875-1882. 
Church, M.R., K.W. Thornton, P.W. Shaffer, D.L. Stevens, B.P. Rochelle, G.R. Holdren, M.G. Johnson, J.J. Lee, R.S. Turner, D.L. Cassell, D.A. Lammers, W.G. Campbell, C.I. Liff, C.C. Brandt, L.H. Liegel, G.D. Bishop, D.C. Mortenson, S.M. Pierson, and D.D. Schmoyer. 1989. Direct/Delayed Response Project: Executive Summary - Future Effects of Long-Term Sulfur Deposition on Surface Water Chemistry in the Northeast and Southern Blue Ridge Province. EPA-600/3-89/061a. U.S. EPA Office of Research and Development, Washington, DC., and Environmental Research Laboratory, Corvallis, OR.

Colquhoun, J., W. Kretser, and M. Pfeiffer. 1984. Acidity Status Update of Lakes and Streams in New York State. Report WM P-83. New York Department of Environmental Conservation, Albany 49 pp

Craft, J.T. 1976. Pleistocene Local Glaciation in the Adirondack Mountains, New York. Ph.D. Thesis. University of Western Ontario, London [Canada]. 220 pp

Cronan, C.S. 1984. Vegetation and soil chemistry of the ILWAS Watersheds. Page 3-1. In: The Integrated Lake-Watershed Acidification Study. Vol. 4. Summary of Major Results. EPRIEA-3221, Palo Alto, CA. 1:3-31.

Cronan, C.S. 1985. Biogeochemical influence of Vegetation and Soils in the ILVWAS Watersheds. Water, Air, Soil Pollut. 26:354-371.

Davis, G.F., J.J. Whipple, S.A. Gherini, C.W. Chen, R.A. Goldstein, R.W.H. Chan, and R.K. Munson. i987. Big Moose Basin: Simulation of Response to Acidic Deposition. Biogeochemistry 3:141-161.

Drever, J.I., and D.R. Hurcomb. 1986. Neutralization of Atmospheric Acidity in the North Cascade Mountains. Geology 14:221-224

Driscoll, C.T., and J.J. Bisogni. 1984. A procedure for the fractionation of aqueous aluminum in dilute acidic waters. Int. S. Anal. Chem 16:267-283.

Driscoll, C.T., and J.J. Bisogni. 1984. Weak Acid/Base Systems in Dilute Acidified Lakes and Streams of the Adirondack Region of New York State. Pages 53-82. In: J.L. Schnoor, ed Modeling of Total Acidification Impacts. Butterworth Publishers, New York.

Driscoll, C.T., and R.M. Newton. 1985. Chemical Characteristics of Adirondack Lakes. Environ. Sci. Technol. 19: 1018-1024.

Driscoll, C.T., and R. Van Dreason. 1989. A Program to Evaluate Long-Term Changes in the Chemistry of Adirondack Lakes. Final Report to the U.S. EPA Environmental Research Laboratory, Corvallis, OR. $43 \mathrm{pp}$.

Driscoll, C.T., W.A. Ayling, G.F. Fordham, and L.M. Oliver. 1989. Chemical Response of Lakes Treated with $\mathrm{CaCO}_{3}$ to Reacidification. Can. J. Fish. Aquat. Sci. 46:258-267.

Driscoll, C.T., L.P. Baker, J.J. Bisogni, and C.L. Schofield. 1984. Pages 55-75 in: Geological Aspects of Acid Deposition. Butterworth Publishers, Boston.

Driscoll, C.T., J.P. Baker, J.J. Bisogni, and C.L. Schofield. 1980. Effect of Aluminum Speciation on Fish in Dilute Acidified Waters. Nature 284:161-164.

Driscoll, C.T., R.M. Newton, C.P. Gubala, J.P. Baker, and S.W. Christensen. In press. Adirondack Mountains: Regional Analysis of Surface Water Acidification. In: D.F. Charles, ed. Acid Deposition and Aquatic Ecosystems: Regional Case Studies. Springer-Verlag, New York. 
Driscoll, C.T., B.J. Wyskowski, C.C. Cosentini, and M.E. Smith. 1987. Processes Regulating Temporal and Longitudinal Variations in Chemistry of a Low-order Woodland Stream in the Adirondack Region of New York. Biogeochemistry 3:225-241.

Effler, S., G. Schafran, and C. Driscoll. 1985. Partitioning Light Attenuation in an Acidic Lake. 'Can. J. Fish. Aquat. Sci. 42:1707-1711.

Galloway, J.J., C.L. Schofield, N.E. Peters, G.R. Hiendrey, and E.R. Altwicker. 1983. Effect of Atmospheric Sulfur on the Composition of Three Adirondack Lakes. Can. J. Fish. Aquat Sci 40:799806.

Gherini, S., R. Munson, E. Altwicker, R. April, C. Chen, N. Clesceri, C. Cronan, C. Driscoll, A. Johannes, R. Newton, N. Peters, and C. Schofield. 1989. Regional Integrated Lake-Watershed Acidification Study (RILWAS): Summary of Major Findings. RP2174-1. Electric Power Research Institute, Palo Alto, CA.

Gherini, S.A., C.W. Chen, L. Mok, R.A. Goldstein, R.J.M. Hudson, and G.F. Davis. 1985 The ILWAS Model: Formulation and Application. Water, Air, Soil Pollut. 26:425-459.

Gilbert, R.O. 1987. Statistical Methods for Environmental Pollution Monitoring. Van Nostrand Reinhold, New York.

Goldstein, R.A., and S.A. Gherini. 1984. The Integrated Lake Watershed Acidification Study - Vol. 4: Summary of Major Results. EA-3221. Electric Power Research Institute, Palo Alto, CA. 222 pp.

Goldstein, R.A., S.A. Gherini, C.W. Chen, L. Mok, and R.J.M. Hudson. 1984. Integrated LakeWatershed Acidification Study (ILWAS): A Mechanistic Ecosystem Analysis. Trans. R. Soc. London B 305:409-425.

Goldstein, R.A., S.A. Gherini, C.T. Driscoll, R. April, C.L. Schofield, and C.W. Chen. 1987. LakeWatershed Acidification in the North Branch of the Moose River: Introduction. Biogeochemistry 3:520.

Gran, G. 1952. Determination of the Equivalence Point in Potentiometric Titrations. ANALYST: Internat. Congress Analyt. Chem. 77:661-671.

Greb, S., R. Munson, S. Gherini, L. Gomez, C. Chen, P. Garrison, and D. Knauer. 1988 RILWASWisconsin: Simulation of the Effects of Acid Deposition on Crystal, Vandercook, and Little Rock Lakes. Wisconsin Department of Natural Resources

Hedges, L.V., and I. Olkin. 1985. Statistical Methods for Meta-Analysis. Academic Press. Orlando, FL.

Hirsch, R.M., and J.R. Slack. 1984. A Nonparametric Trend Test for Seasonal Data with Serial Dependence. Water Resour. Res. 20:727-732

Hirsch, R.M., and N.E. Peters. 1988. Short-term Trends in Sulfate Deposition of Selected Bulk Precipitation Stations in New York. Atmos. El viron. 22:1175-1178.

Hirsch, R.M., J.R. Slack, and R.A. Smith. 1982. Techniques of Trend Analysis for Monthly Water Quality Data. Water Resour. Res. 18:107-121.

Johannes, A.H., E.R. Altwicker, and M. Garrity. 1986 Use of Existing Network Data to Determine Wet Deposition. Trans Air Pollut. Control Assoc. (March):381-392 
Johnson, D.W. J. Colquhoun, F. Flack, and H. Simonin. 1987. In Situ Toxicity Test of Fishes in Acid Waters. Biogeochemistry 3:181-208.

Johnson, C.B., T.J. Sullivan, and D.J. Blick. 1989. Defining Regional Populations of Lakes for the Assessment of Surface Water Quality. Water Resour. Bull. 25:1-8.

Kelly, C.A., J.W.M. Rudd, R.H. Hesslein, D.W. Schindler, P.J. Dillon, C.T. Driscoll, S.A. Gherini, and R.E. Hecky. 1987. Prediction of Biological Acid-sensitive Lakes. Biogeochemistry 3:129-140.

Knox, C.E., and T.J. Nordenson. 1955. Average annual runoff and precipitation in the New EnglandNew York Area. U.S. Geological Survey Hydrologic Investigations Atlas HA 7, 6 pp.

Kramer, J.R. and S.S. Davies. 1988. Estimation of non-carbonate protolytes for selected lakes in the Eastern Lake Survey. Environ. Sci Technol. 22:182-184.

Kramer, J., and A. Tessier. 1982. Acidification of Aquatic Systems: A Critique of Chemical Approaches. Environ. Sci. Technol. 16:606-615

Kretser, W.J., J. Gallagher, and J. Nicolette. 1989. An Evaluation of Fish Communities and Water Cnemistry. Adirondack Lakes Survey Corporation, Ray Brook, NY.

Krug. E.C., P.J. Isaacson, and C.R. Frink. 1985. Appraisal of Some Current Hypotheses Describing Acidification of Watersheds. J. Air Pollut. Control Assoc. 35: 109.114.

Kulp, J.L. 1987. Interim Assessment: The Causes and Effects of Acidic Deposition. National Acid Precipitation Assessment Program. Washington, DC.

Landers, D.H., W.S. Overton, R.A. Linthurst, and D.F. Brakke. 1988. The Chemistry of Lakes in New England and New York State is of Special Interest. Environ. Sci. Technol. 22:128-135.

Linthurst, R.A., D.H. Landers, J.M. Eilers, D.F. Brakke, W.S. Overton, E.P. Meier, and R.E. Crowe. 1986a. Characieristics of Lakes in the Eastern United States - Vol. 1. Population Descriptions and Physico-Chemical Relationships. EPA-600/4-86/007a. U.S. Environmental Protection Agency,

Washington, DC.

Linthurst, R.A., D.H. Landers, J.M. Eilers, P.E. Kellar, D. F. Brakke, W.S. Overton, R. Crowe, E.P. Meier, P. Kanciruk, and D.S. Jeffries. 1986b. Regional Chemical Characteristics of Lakes in North America. 2. Eastern United States. Water, Air, Soil Pollut 31:577-591

Lowenthal, R.E, and G.V.R. Marais. 1978. Carbonate Chemistry of Aquatic Systems: Theory and Application - Vol. 1. Ann Arbor Science, Butterworth Publishers, Boston. 433 pp.

McAvoy. C.D., R.C. Santore, J.D. Shosa, and C.T. Driscoll. In press. A Comparison Between Pyrocatechol Violet and 8-Hydroxyquinoline Procedures for the Measurement of Monomeric Aluminum Fractions. J. Soil Sci. Soc. Am.

Munson, R.K., and S.A. Gherini. 1986. Simulation of Pancake-Hall Creek Electric Power Research Institute, Palo Alto, CA.

Munson, R.K., and S.A. Gherini. In press Processes Influencing Surface Water Acidification. In: D.F Charles, ed. Acid Deposition and Aquatic Ecosystems: Regional Case Studies. Springer-Verlag, New York. 
Newton, R.M., J. Weintraub, and R. April. 1987. The Relationship Between Surface Water Chemistry and Geology in the North Branch of the Moose River. Biogeochemistry 3:21-35.

New York State Conservation Department. 1935. A Biological Survey of the Mohawk-Hudson Watershed. Supplement to the 24th Annual Report [1934]. L.B. Lyon Company Printers, Albany,

New York State Conservation Department. 1934. A Biological Survey of the Raquette Watershed. Supplement to the 23rd Annual Report [1933]. L. B. Lyon Company Printers, Albany, NY.

New York State Conservation Department. 1933. A Biological Survey of the Upper Hudson Watershed. Supplement to the 22nd Annual Report [1932]. L.B. Lyon Company Printers, Albany, NY.

New York State Conservation Department. 1932. A Biological Surey of the Oswegatchie and Black Watersheds. Supplement to the 21st Annual Report [1931]. J.B. Lyon Company Printers, Albany, NY.

New York State Conservation Department. 1931. A Biological Survey of the St. Lawrence Watershed. Supplement to the 20th Annual Report [1930]. J.B. Lyon Company Printers, Albany, NY.

New York State Conservation Department. 1930. A Biological Survey of the Champlain Watershed. Supplement to the 19th Annual Report [1929]. J.B. Lyon Company Printers, Albany, NY.

Oliver, B.G., E.M. Thurman, and R.L. Malcolm. 1983. The contribution of humic substances to the acidity of colored natural waters. Geochim. Cosmochim. Acta 47:2031-2035.

Overpeck, J.T. 1985. A pollen study of a Late Quaternary Peat Bog, South-Central Adirondack Mountains, New York. Geol Soc. Am. Bull. 96:145-154.

Pfeiffer, M., and P. Festa. 1980. Acidity Status of Lakes in the Adirondack Region of New York in Relation to Fish Resources Page 168. In: NYSDEC Publication FW. New York State Department of Environmental Conservation, Albany.

Porcella, D.B. 1989. Lake Acidification Mitigation Project (LAMP); An Overview of an Ecosystem Perturbation Experiment. Can. J. Fish. Aquat. Sci. 46:246-248.

Raynal, D.J., B.T. Fitzgerald, and R.D. Masters. 1987. Characterization of Atmospheric Deposition at Huntington Forest, Adirondack Mountains, New York, 1987-1985. State University of New York, College of Environmental Science and Forestry, Syracuse

Reuss, J.O., and D.W. Johnson. 1986. Acid Deposition and the Acidification of Soils and Waters. No. 59. Ecological Studies Series, Springer-Verlag, New York.

Schafran, G.C., and C.T. Driscoll. 1987. Spatial and Temporal Variations in Aluminum Chemistry of a Dilute Acidic Lake. Biogeochemistry 3:105-119

Schecher, W.D., and C.T. Driscoll. 1988. An evaluation of equilibrium calculations within acidification models: The effect of uncertainty in measured chemical components. Water Resour. Res. 24:533-540.

Schecher, W.D., and C.T. Driscoll. 1987. An Evaluation of Uncertainty Associated with Aluminum Equilibrium Calculations. Water Resour. Res. 23:525-534.

Schnoor, J.L., and W. Stumm. 1984. Acidification of Aquatic and Terrestrial Systems. Pages 311-338. In: W. Stumm, ed. Chemical Processes in Lakes. Wiley-Interscience, New York 
Schofield, C.L., J.N. Galloway, and G.R. Hendry. 1985. Surface Water Chemistry in the ILWAS Basins. Water, Air, Soil Pollut.n 26:403-424

Schofield, C.L. 1976a. Acid Precipitation: Effects on Fish. Ambio 5:228-230

Schofield, C.L. 1976b. Dyriamics and Management of Adirondack Fish Populations; Project Report April 1, 1975 - March 31, 1976. No. F-28-R-4. New York State Department of Environmental Conservation, Albany.

Spry, E.J., C.M. Wood, and P.V. Hodson. 1981. The Effects of Environmental Acid on Freshwater Fish with Particular Reference to Softwater Lakes in Ontario and the Modifying Effects of Heavy Metals: A Literature Review. Canadian Technical Report of Fisheries and Aquatic Science. No. 999. Fisheries and Oceans, Government of Canada. $144 \mathrm{pp}$

Strayer, R., C-J. Lin, and M. Alexander. 1981. Effects of Simulated Acid Rain on Nitrification and Nitrogen Mineralization in Forest Soils. J. Environ. Qual. 10:(4).

Stumm, W., and J.J. Morgan. 1981. Aquatic Chemistry. 2nd. Wiley-Interscience, New York.

Sullivan, T.J., C.T. Driscoll, S.A. Gherini, R.K. Munson, R.B. Cook, D.F. Charles, and C.P. Yatsko. 1989 The influence of organic anions and aqueous aluminum on measurements of acid neutralizing capacity in surface waters. Nature 338:408-410.

Sullivan, T.J., D.L. Kugler, M.J. Smith, C.B. Johnson, D.H. Landers, B.J. Rosenbaum, W.S. Overton, W.A. Kretser, and J. Gallager. In press. Variation in Adirondack, New York, Lake Water Chemistry as Function of Surface Area. Water Resour. Bull

Trewartha, G.T. 1954 An Introduction to Climate McGraw-Hill, NY. 402 pp

U.S. Environmental Data Service: Climatological Data, 1987. 99:(13)

Valentini, J.L., and S.A. Gherini, eds. 1986. The Integrated Lake-Watershed Acidification Study: Database Documentation. EA3221, Volume 5. Electric Power Research institute, Palo Alto, CA.

Van Diver, 8 1985. Roadside Geology of New York. Mountain Press, Missoula, MT. 397 pp.

Wetzel, R.G. 1975. Limnology. Saunders, Philadelphia. 743 pp

Wiener, R.W., J.M. McLelland, Y.W. Isachsen, and L.M. Hall. 1984. Stratigraphy and Structural Geology of the Adirondack Mountains, New York: Review and Synthesis. Spec. Paper 194. Geol. Soc. Am. $55 \mathrm{pp}$.

Wood, L.W. 1978 Limnology of Remote Lakes in the Adirondack Region of New York State with Emphasis on Acidification Problems. New York State Department of Health. Albany 


\section{SECTION 3}

\section{FISH COMMUNITIES IN ADIRONDACK LAKES}

\subsection{INTRODUCTION}

\section{- J. Baker and J. Gallagher}

Numerous studies have been conducted on the effects of acid-base chemistry and acidification on fish communities in Adirondack lakes. The evidence for the importance of these processes includes the following:

- field bioassays -- demonstrating that acidic surface waters with low $\mathrm{pH}$ and high levels of inorganic aluminum (Al) are toxic to fish and that toxic responses increase during acidic episodes (Johnson et al. 1987, Schofield and Driscoll 1987, Parkhurst 1987)

- field experiments -- such as those monitoring fish population responses to lake liming and subsequent reacidification, with associated declines in fish population survival and density (Schofield et al. 1986, Gloss et al. 1989, Schofield et al. 1989)

- historical trend analyses -- identifying the association between the loss of fish populations and current levels of $\mathrm{pH}$ and other acid-base chemistry variables (Schofield 1976, Baker and Harvey 1984)

- field surveys -- confirming the absence of fish (or fish species) from lakes with lower $\mathrm{pH}$ and higher levels of Al (Schofield 1976, Schofield and Trojnar 1980, Colquhoun et al. 1984, Kretser et al. 1989)

However, many factors influence the suitability of lakes for fish population survival and reproduction and may also cause changes in fish communities over time. To ensure that the effects from acid-base chemistry are accurately assessed, it is essential to account for these other factors and activities. Thus, the underlying objectives of this analysis of the ALSC survey data are to (1) improve our understanding of the processes that affect fish distributions and trends in Adirondack lakes and (2) use this improved understanding to estimate the potential effects and future risks from changes in acid-base chemistry that may result from acidic deposition with greater confidence. 


\subsubsection{The ALSC Survey and Data Base}

Interpretation of the ALSC fish survey results requires both data on the current status of fish communities and associated information on lake chemical, physical, and biological characteristics that may influence the suitability of the lake as fish habitat. This section briefly describes the methods used by the ALSC to sample fish and other biota in Adirondack lakes and also outlines the types of data on fishery management activities, such as stocking, that are compiled in the ALSC data base. Measures of lake chemical and physical attributes are discussed in Section 2.1. For further details on the ALSC survey and sampling protocols, see Kretser et al. (1989).

Fish communities, macroinvertebrates, and aquatic macrophytes were studied as part of the Al.SC biological survey. Each lake was sampled once, either in the spring (April through June) or fall (September through October), corresponding to ALSC operational phases one and three. Nearly equal numbers of lakes were surveyed during the two phases. The midsummer months (July and August) were reserved for water chemistry sampling, lake ternperature profiles, and bathymetric surveys.

The greatest amount of time and effort was expended in sampling fish populations. The primary sampling gear was the 45.7-m experimental Swedish gill net with five panels and mesh sizes ranging from 38 to $90 \mathrm{~mm}$ (stretch mesh). The number of nets set per lake varied as a function of lake surface area (Table 3.1-1).

Table 3.1-1 ALSC Netting Effort Based on Surface Area

\begin{tabular}{cc}
\hline Surface Area (ha) & Number of Swedish Gill Nets \\
\hline$<4.0$ & 1 \\
$4.1-10.1$ & 2 \\
$10.2-20.2$ & 3 \\
$20.3-40.5$ & 4 \\
$>40.5$ & 1 additional net per 40 hà \\
\hline
\end{tabular}

Experimental gill nets were set on the lake bottom in a variety of habitats including littoral zone areas and deep water habitat where dissolved oxygen (DO) was adequate for fish survival. Most often, gill nets were set perpendicular from the shore and stretched across several bottom contours, with either the largest or smallest mesh size near shore. Deep water habitats were sampled with one of two methods: (1) by setting the net perpendicular to the shore down to or near the lake 
maximum depth, if DO levels were adequate for fish: srvival in these deeper waters, or (2) by setting the net parallel to the shore at a constant depth, but above areas of inadequate DO.

In lakes where minimal fish mortality was requested or lakes with special fish populations (such as heritage strain brook trout), modified Alaska style and Oneida style trap nets were used along with the experimental gill nets or in place of them. In these cases, at least one more than the required number of nets was set to compensate for differences in the catch efficiency and species selectivity of the two gear types.

In addition to the primary gear, minnow traps and 9.2-m monofilament or multifilament gill nets with 1.9-mm stretch mesh were used to sample juvenile fish and small minnow species in the littoral zone. At least one minnow trap and one small-mesh gill net were set in each lake.

Nets were generally set overnight for time periods ranging from 15 to 24 hours. On occasion, gill nets were retrieved sooner to reduce fish mortality, to avoid predation of captured fish, or because large numbers of fish had al ready filled the net, reducing the gear effectiveness.

Captured fish were sorted by species and then processed Length and weight measurements were obtained for a representative subsample (based on total length) of up to 20 individuals for each species caught. Scale samples were taken from sport fish including salmonids (trout and salmon), largemouth bass, smallmouth bass, and esocids (pike and pickerel). The reproductive condition of sport fish as well as diseases, wounds, or deformities observed on any fish were recorded.

A qualitative sample of macroinvertebrates was collected from the littoral zone of each lake using a modified D-frame net. All major littoral habitats (e.g., sand and gravel beaches, muck/silt areas, and shallow areas with emergent vegetation) were sampled for a minimum of 15 minutes and for approximately equal periods of time per habitat type. Macroinvertebrates specimens were preserved in the field and then identified in the laboratory to order or, when possible, family.

Aquatic macrophyte taxa observed during fish, summer chemistry, and bathymetric surveys were identified to genera. In addition, qualitative estimates were made of the percent open water, percent cover of floating and emergent vegetation, and percent cover of submerged vegetation.

The ALSC categorized the sampled lakes into several groups based on field observable physical and biological lake characteristics (Table 3.1-2): (1) seepage versus drainage lakes, depending on the presence or absence of a lake outlet; (2) bogs, marginal bogs, and nonbogs, depending on the lake type and the occurrence of Sphagnum spp. along the shoreline; and (3) the presence or absence of a beaver dam at the lake outlet. The analyses of fish distributions in the following sections use both 
Table 3.1-2 ALSC Lake Categories

\begin{tabular}{ll}
\hline Lake Category & \multicolumn{1}{c}{ Description } \\
\hline Fish Present & A minimum of one fishi captured in ALSC sampling gear. \\
Fish Absent & No fish captured in ALSC sampling gear. \\
\hline Seepage & $\begin{array}{l}\text { Lakes with no outlets observed. Inlets not considered. } \\
\text { Lakes with one or more outlets observed. }\end{array}$ \\
\hline Brainage & $\begin{array}{l}\text { Seepage lakes with 90\% of the shorellne surrounded by Sphagnum spp. } \\
\text { Seepage or drainage lakes with } 50 \% \text { to } 90 \% \text { of the shoreline } \\
\text { Marginal Bog }\end{array}$ \\
Surrounded by Sphagnum spp. \\
$\begin{array}{l}\text { Seepage or drainage lakes with less than } 50 \% \text { of the shoreline } \\
\text { surrounded by Sphagnum spp. }\end{array}$ \\
\hline Beaver Dam Present & $\begin{array}{l}\text { Drainage lakes with a beaver dam present on the outlet or on at least } \\
\text { one outlet if there are several. Seepage lakes not considered since they } \\
\text { do not have outlets. } \\
\text { Drainage lakes with no beaver dams present on any outlets. Seepage } \\
\text { lakes not considered since they do not have outlets. }\end{array}$ \\
\hline
\end{tabular}

these observation-based categories and the lake classification scheme based on midsummer surface chemistry and hydrology described in Section 2.4 .

In addition to the results from these survey activities, the ALSC data base also contains information on major fishery management activities. Stocking records for each lake dating back to the late $1920 \mathrm{~s}$ have been compiled from the New York State Department of Environmental Conservation (NYSDEC). Note, however, that these records include only official State-sponsored stocking; no records exist of private stockings or unofficial introductions. Thus, for privately owned waters, the available information on stocking cannot be considered a reliable index of the absence of fish stocking. Historical records of lake liming and reclamation are also provided. Again, these records may be somewhat incomplete for privately owned lakes, even though permits are generally required for both activities in all Adirondack waters.

In Section 2.1, procedures for flagging suspect water chemistry data were defined. Overall, a very small percentage of the total data base was flagged: For the most part, these flagged data have been excluded from analyses relating fish community status to lake characteristics. As a result, this report is at times working with slightly smaller numbers of lakes and fewer measures of water chemistry than those presented in Kretser et al. (1989). 


\subsubsection{General Approach}

As noted in Section 1, the ALSC Management Committee identified a series of five questions of primary interest relative to fish:

1. Where do fish occur? Where do they not occur?

2. Did fish occur historically in these lakes?

3. If fish da not occur in a lake or group of lakes, why not?

4. What fish could these lakes support if the chemistry were sultable?

5. How many of the lakes with fish are at risk from acidic deposition?

The following analyses attempt to address these questions as thoroughly as possible within the limitations of the available data and schedule. The focus is on analysis and interpretation of the results from the ALSC surveys of fish communitles in 1469 Adirondack lakes. Other data bases, particularly historical survey data (see Section 3.6), are used to supplement the ALSC data when appropriate. Our primary interest is in interpreting regional patterns of fish community status and identifying processes that are important on a regional scale, rather than on detailed assessments for individual lakes.

Analyses of survey data principally involve examining correlations between fish status and various lake features or management activities. Such correlative analyses, by themselves, can neither prove cause and effect nor definitively identify causal relationships. They do, however, provide a basis for evaluating alternative hypotheses about processes that affect fish and the consistency of the survey results with these various hypotheses. On the other hand, because of the large number of factors that may influence fish and because many of these factors are themselves highly interrelated, it often becomes quite difficult to distinguish specific key factors or primary causes for observed patterns or trends. To compensate for these complexities, multiple methods and analyses have been used to address the above questions and to identify major factors affecting fish in Adirondack lakes. Consistency of the results across these different approaches increases our confidence that we have correctly interpreted the ALSC survey data.

Since a single question may be addressed by several different analyses, and one analysis may contribute to addressing more than one question, the sections that follow are organized by approach rather than by question. The results from these analyses are then summarized by question in Section 4.

Section 3.2, Current Status of Fish Communities in Adirondar.k Lakes, presents an overview of the major results from the ALSC survey including a discussion of thie general distribution of fish species in 
Adirondack lakes. In particular, fish distributions among the lake classes defined in Section 2.4 are presented as a preliminary basis for evaluating the degree to which selected Adirondack fish resources may be "at risk" from acidic deposition. Finally, the types of lakes and classes of lakes that currently do not support any fish species are described.

Section 3.3, Habitat Sultability for Brook Trout Natural Reproduction in Adirondack Lakes, evaluates lake and watershed characteristics that may be useful for identifying waters with the potential for natural brook trout reproduction. The selected lake/watershed features are then used in subsequent analyses of factors affecting brook trout distributions and trends in Adirondack lakes (see Sections 3.4 to 3.6).

Sectlon 3.4, Multivariate Analyses of Patterns of Fish Distributions in Adirondack Lakes, uses multivariate regression techniques to identify lake characteristics significantly associated with the occurrence of fish and with the presence/absence of selected fish species in Adirondack lakes. Given that a number of factors, acting together, are probably responsible for the distribution of fish in Adirondack lakes, the simultaneous evaluation of all possible explanatory variables, using multivariate regression, is particularly appropriate. Bivariate relationships are also of interest, but may be misleading when candidate explanatory variables co-vary. For example, if lakes without fish have significantly lower $\mathrm{pH}$, on average, than do lakes with fish, this result is consistent with the hypothesis that low levels of $\mathrm{pH}$ adversely affect fish. On the other hand, it is possible that many low $\mathrm{pH}$ lakes are bogs, with low levels of DO and poor substrate for fish reproduction In this case, the general absence of fish from low-pH lakes may be unrelated to $\mathrm{pH}$, indicating instead that fish cannot live in bogs. Multivariate analyses provide additional insight that may help us to distinguish these confounding effects and the relative importance of these two factors. If fish are absent from nonbog low-pH lakes as well as bogs, then both $\mathrm{pH}$ and the bog index would be identified as significantly associated with fish status in multivariate analyses, suggesting that low $\mathrm{pH}$ adversely affects fish even after accounting for the effect of bogs on fish presence/absence. The outputs from these multivariate analyses provide the primary basis for identifying major factors that appear to be responsible for the absence of fish (and individual fish species) from some lakes. In addition, the final multivariate regression equations can be used as a tool for addressing what-if questions, e.g, what fish species could these lakes support if the water chemistry was suitable?

Section 3.5, Fish Species Distribution Patterns In Selected Adirondack Drainage Systems, addresses issues similar to those in Section 3.4, but focuses on individual drainage systems rather than the Adirondack region as a whole. Because fish can move relatively freely among drainage lakes within a given drainage system, we would expect an even clearer relationship in these analyses between fish status and lake characteristics that determine the suitability of the lake for fish survival and 
reproduction. Comparisons between drainage systems in the western and eastern Adirondacks are also of interest. Acidic, low-pH lakes are more prevalent in the western Adirondacks. Thus, acid-base chemistry may play a greater role in the distribution of fish species in these systems than in drainage systems in the eastern Adirondacks.

Finally, Section 3.6, Historical Changes in Fish Communities in Adirondack Lakes, uses historical survey data to evaluate trends in fish communitles through time. The results identify not only whether fish occurred historically in lakes that now have no fish, but also probable causes for observed fish declines. Information on historical patterns of fish distribution also assists in interpreting the current status of fish communities in Adirondack lakes.

Terms such as fishless, fish absent, and without fish are used in this document to describe ALSC waters in which no fish were caught. This does not preclude the possibility that fish occurred in these lakes but were not captured. However, glven the amount of sampling effort per lake, the likelihood that all species were missed is low. Nevertheless, it is likely that individual fish species, particularly fish species present in small numbers or less susceptible to the sampling techniques and gear (e.g., small minnow species), were occasionally missed even though they were present in the lake. While these sampling errors cannot be quantified, we belleve that they were reasonably small and do not introduce any systematic bias into the analyses that follow.

\subsubsection{Factors Influencing Fish Habitat Suitability}

At the start of the project, a comprehensive listing was developed of all variables, available in the ALSC data base, that were of potential importance in explaining the distribution of fish in Adirondack lakes. Approximately 50 candidate explanatory variables were identified and grouped into six broad categories (see Table 3.1-3):

1. acidification response variables

2. baseline habitat suitability variables

3. productivity-related variables

4. natural reproduction and access variables

5. anthropogenic control variables

6. biological variables

All of these candidate explanatory variables were considered in multivariate regression analyses; analyses in other sections generally involved only selected variables. The estimated fraction of the 
Table 3.1.3 Candidate Explanatory Variables for Analyses of Fish Distributions in Adirondack Lakes

\begin{tabular}{|c|c|c|}
\hline Category & Varlablea & Reason for Including \\
\hline \multirow[t]{11}{*}{ Acidification Response } & Fiteld pH & Direct causal effect \\
\hline & ANC & $\begin{array}{l}\text { With } p H \text {, a surrogate for weak acids including } \\
\text { aluminum }\end{array}$ \\
\hline & Measured total/dissolved Al & Direct causal effect \\
\hline & Estimated inorganic Alb & Direct causal effect \\
\hline & $\mathrm{Ca}$ & Mitigating effect on pil and aluminum \\
\hline & Ca plus Mg & Mitigating effect on $\mathrm{pH}$ and aluminum \\
\hline & Sum of base cations & Mitigating effect on pH and alımınum \\
\hline & $\mathrm{Na}$ & Mitıgatıng effect on $\mathrm{pH}$ and alumınum \\
\hline & Ratio of $\rho \mathrm{Ca}$ to $\rho \mathrm{H}$ & Direct causal effect \\
\hline & DOC & $\begin{array}{l}\text { May have direct causal effect; also surrogate for } \\
\text { bioavailability of aluminum }\end{array}$ \\
\hline & Flushing idte & Index of potential for episodic acidification \\
\hline Baseline Habitat & Mınımum DO & Direct causal effect \\
\hline \multirow[t]{10}{*}{ Sultability } & Maximum temperatuie & Direct causal effect \\
\hline & Summer minımum temperature & Occurrence of coldwater habitat \\
\hline & Thermalstratification & Occurrence of coldwater habitat \\
\hline & Maximum depth & Surrogate fur theimal stratification \\
\hline & Elevation & $\begin{array}{l}\text { Surrogate for winter oxygen deficits or freezing; } \\
\text { access problems }\end{array}$ \\
\hline & $\begin{array}{l}\text { Full bog (bogs vs marginal and noribog } \\
\text { lakes) }\end{array}$ & $\begin{array}{l}\text { Surrogate for oxygen deficits and poor spawning } \\
\text { substrate }\end{array}$ \\
\hline & $\begin{array}{l}\text { Marginal bog (bogs and marginal bogs } \\
\text { vs nonbugs) }\end{array}$ & $\begin{array}{l}\text { Surrogate for uxygen deficits and poor spawning } \\
\text { surstrate }\end{array}$ \\
\hline & $\begin{array}{l}\text { Beaver dam at outlet with height }>75 \% \\
\text { of lake depth }\end{array}$ & Surrogate for a variety of habitat disruptions \\
\hline & $\begin{array}{l}\text { Macrophyte richness (number of taxa } \\
\text { nbserved) }\end{array}$ & $\begin{array}{l}\text { Index of habitat avaliability and diversity for sinall } \\
\text { fish }\end{array}$ \\
\hline & Minımum percent spetel water & $\begin{array}{l}\text { Index of habitat availabinty and diversity for small } \\
\text { fish }\end{array}$ \\
\hline \multirow[t]{10}{*}{ Productivity-Related } & Total P & Limiting nutrient \\
\hline & Conductivity $\left(H^{+} \cdot\right.$ corlected $)$ & Common index of potential fish production \\
\hline & Surface area & $\begin{array}{l}\text { Surrogate for habitat diversity and total fish } \\
\text { abundance }\end{array}$ \\
\hline & Volume & $\begin{array}{l}\text { Surrogate for habitat diversity and potential for } \\
\text { thermal stratification }\end{array}$ \\
\hline & Meandepth & Common index of potential fish production \\
\hline & Conductivity $\left\langle H^{+}\right.$-corrected $\rangle /$miean depth & $\begin{array}{l}\text { Similar to cummon index of potential fish } \\
\text { production: pseudo-morpho-edaphic index }\end{array}$ \\
\hline & Mean Secchidepth & Common index of productivity \\
\hline & Ratlo of watershed to lake area & Surrogate far nutrient supplies \\
\hline & Littoral area & $\begin{array}{l}\text { Index of the contribution of littoral zone } \\
\text { production }\end{array}$ \\
\hline & Shoreline develupment index & $\begin{array}{l}\text { Index of habitat diversity and importance of } \\
\text { littoral zone }\end{array}$ \\
\hline
\end{tabular}


Table 3.1-3 Continued

\begin{tabular}{|c|c|c|}
\hline Category & Variablea & Reason for Including \\
\hline \multirow[t]{6}{*}{$\begin{array}{l}\text { Natural Reproduction and } \\
\text { Access }\end{array}$} & Lake typi & $\begin{array}{l}\text { Avallability of outlets for spawning and movement } \\
\text { of fist o the lake }\end{array}$ \\
\hline & Number of inlets & Avallability of inlets for sfrawning \\
\hline & Number of outlets & $\begin{array}{l}\text { Avallability of outlets for spawning and fish } \\
\text { movement }\end{array}$ \\
\hline & $\mathrm{S}_{1} \mathrm{O}_{2}$ & $\begin{array}{l}\text { Index of groundwater upwelling for brook tiout } \\
\text { spawning }\end{array}$ \\
\hline & $\begin{array}{l}\text { Presence of dams }>05 \mathrm{~m} \text { in height } \\
\text { (or absence of outlet) }\end{array}$ & Impacts ability of fish to move upstream into lake \\
\hline & $\begin{array}{l}\text { Shoalwater substrate of muck, silt, clay, } \\
\text { or organics }\end{array}$ & Rough index of spawning substrate avallability \\
\hline \multirow[t]{6}{*}{ Anthropogenic Control } & Distance to nearest road & Rough index of potential fishing pressure \\
\hline & Road type & $\begin{array}{l}\text { Lake accessibility to public and associated pótential } \\
\text { fishing pressure }\end{array}$ \\
\hline & Stocking of species of interest & Direct causal effect \\
\hline & Stocking of potential competitors & Direct causal effect \\
\hline & Ownership & Index of potential fishing pressure \\
\hline & Most recent year reclaimed & Direct causal effect \\
\hline \multirow[t]{3}{*}{ Biological } & Occurrence of potential competitors & Direct causal effect \\
\hline & $\begin{array}{l}\text { Occurrence of commonly associated } \\
\text { species }\end{array}$ & Surrogate for habitat sultability \\
\hline & Occurrence of potential predators & Direct causal effect \\
\hline
\end{tabular}

a All chemistry variables, except minimum dissolved sxygen, were measured during summer (July .August) at the lake surface $(\leq 1.5 \mathrm{~m})$.

b See Section 2.3.1.3 for procedures for estimating inorganic Al concentrations. 
hydrogen ion $\left(\mathrm{H}^{+}\right)$supported by organics, calculated as described in Section 2.5.1, was also used in some analyses.

Although the ALSC survey was extremely comprehensive, it is not possible in a survey to measure or assess all factors and activities that may influence fish. As a result, some potc. itially important factors are represented in the data base only by surrogate indices or imperfect measurements. Surrogate indices are noted in Table 3.1-3. Examples of variables that are poorly measured in surveys include (1) minimum levels of $D O$ and the potential for periodic $\mathrm{O}_{2}$ deficits; (2) maximum summer temperatures, and thus the suitability of the habitat for coldwater fish species; and (3) the availability of suitable spawning substrate, e.g., the occurrence of areas of groundwater upwelling for brook trout spawnirig. These data limitations affect, to some degree, our ability to interpret the Al.SC survey results. 


\subsection{CURRENT STATUS OF FISH COMMUNITIES IN ADIRONDACK LAKES}

\section{- J. Gallagher and J. Baker}

A total of 202,207 individual fish representing 53 species (including three hybrids) were caught in lakes surveyed by the ALSC (Table 3.2-1). The number of species caught per lake (i.e., species richness) ranged from 0 (fish absent) to 13, with a mean value of 3.7 and median of 3.0 (Figure 3.2-1). Among the five watersheds, the median species richness varied from 1.0 for the Oswegatchie-Black and Mohawk-Hudson watersheds to 5.0 for the Lake Champlain watershed.

Four fish species were caught in over half of the lakes surveyed by the ALSC with fish present: brown bullhead (/ctalurus nebulosus) (caught in $75 \%$ of the lakes with fish), brook trout (Salvelinus fontinalis) (52\%), white sucker (Catostomus commersoni) (51\%), and golden shiner (Notemigonus crysoleucas) (50\%). In addition, five species accounted for approximately $70 \%$ of the total catch: brown bullhead, golden shiner, white sucker, yellow perch (Perca flavescens), and pumpkinseed (Lepomis gibbosus).

\subsubsection{Fish Species Distributions}

Brown bullhead was the most common and most abundant species caught in ALSC lakes. A total of 49,394 brown bullhead were captureci in 841 lakes (Figure 3.2-2). Brown bullhead are indigenous to the region, reported in Lake George and other large Adirondack lakes as early as 1884 (Mather 1884). The widespread distribution of the species may be a result of its tolerance of a wide range of environmental conditions including high acidity (low $\mathrm{pH}$ ), low oxygen levels, and environmental pollutants, as well as its resistance to toxicants used in lake reclamation (George 1980). Brown bullhead was the only species caught in 67 lakes. The mean length $(136 \mathrm{~mm})$ of fish in lakes where brown bullhead occurred alone was considerably less than the mean length $(175 \mathrm{~mm})$ of brown bullhead pcpulations in other lakes.

White sucker was the third most common and abundant species in ALSC lakes; it was captured in 570 lakes and occurred in all five watersheds sampled (Figure 3.2-3). Mather (1884) reported its occurrence in many Adirondack waters in the late 1880 1 , and the species is considered native to

\footnotetext{
1 Early reports of fish distribution prior to the comprehensive surveys conducted between 1929 and 1934 are anecdotal in nature, consisting primarily of corresporidence between New York Fish Conmission representatives such as Fred Mathei and fishing guides, landowners, and sportsmen in the Adiroridack. region diuring the late 1880s These repurts do not contain reliable estimates of the abundance of fish species but rather provide a general sense of the species composition of Ad:rondac! ! atese and some of the t!stimanangmant prartures of that time porod
} 
Table 3.2-1 Incidence of Fish Species Collected in ALSC Waters with Fish Caught ( $n=1123$ lakes)

\begin{tabular}{|c|c|c|c|c|}
\hline Species & $\begin{array}{c}\text { Number of } \\
\text { Waters }\end{array}$ & $\begin{array}{c}\text { Total Number } \\
\text { Caught }\end{array}$ & Mean Catch & $\begin{array}{c}\text { Percent } \\
\text { Occurrence }\end{array}$ \\
\hline $\begin{array}{l}\text { Brown bullhead } \\
\text { Brook trout } \\
\text { White sucker } \\
\text { Golden shiner } \\
\text { Pumpkinseed } \\
\text { Creek chub } \\
\text { Yellow perch } \\
\text { N. Redbelly dace } \\
\text { Common shiner } \\
\text { Largemouth bass } \\
\text { Northern pike } \\
\text { Rock bass } \\
\text { Smallmouth bass } \\
\text { Brnwn trout } \\
\text { Pearl dace } \\
\text { Central mudminnow } \\
\text { Lake trout } \\
\text { Chain pickerel } \\
\text { Blacknose dace } \\
\text { Bluntriose minnow } \\
\text { Banded killifish } \\
\text { Fathead minnow } \\
\text { Redbreast sunfish } \\
\text { Rainbow trout } \\
\text { Splake } \\
\text { Rainbow smelt } \\
\text { Fallfish } \\
\text { Lake chub } \\
\text { Creek chubsucker } \\
\text { Lake whitefish } \\
\text { Atlantic salmon } \\
\text { Walleye } \\
\text { Black crappie } \\
\text { Cutlips minnow } \\
\text { Kokanee } \\
\text { Longnose sucker } \\
\text { Yellow bullhead } \\
\text { Brook stickleback } \\
\text { Longnose dace } \\
\text { Tiger trout } \\
\text { Cisco } \\
\text { Round whitefish } \\
\text { Slimy sculpin } \\
\text { Bluegill } \\
\text { Brassy minnow } \\
\text { Bridle shiner } \\
\text { Finescale dace } \\
\text { Tiger musky } \\
\text { Mimic shiner } \\
\text { Alewife } \\
\text { Eastern silvery minnow } \\
\text { American eel } \\
\text { Common carp } \\
\text { Commong }\end{array}$ & $\begin{array}{r}841 \\
579 \\
570 \\
566 \\
502 \\
438 \\
346 \\
218 \\
156 \\
112 \\
105 \\
102 \\
98 \\
59 \\
58 \\
54 \\
53 \\
49 \\
47 \\
46 \\
45 \\
40 \\
32 \\
32 \\
30 \\
29 \\
29 \\
19 \\
17 \\
14 \\
13 \\
12 \\
11 \\
11 \\
10 \\
9 \\
9 \\
8 \\
6 \\
5 \\
4 \\
4 \\
4 \\
4 \\
3 \\
3 \\
2 \\
2 \\
1 \\
1 \\
1 \\
1 \\
1\end{array}$ & $\begin{array}{r}49,394 \\
8,002 \\
26,066 \\
34,232 \\
13,048 \\
11,744 \\
22,479 \\
11,163 \\
7,120 \\
760 \\
723 \\
3,380 \\
996 \\
394 \\
1,526 \\
495 \\
330 \\
326 \\
416 \\
1,376 \\
720 \\
2,592 \\
996 \\
175 \\
303 \\
789 \\
247 \\
449 \\
277 \\
181 \\
596 \\
53 \\
105 \\
85 \\
342 \\
74 \\
259 \\
43 \\
37 \\
24 \\
3\end{array}$ & $\begin{array}{r}58.7 \\
13.8 \\
45.7 \\
60.5 \\
26.0 \\
26.8 \\
65.7 \\
51.2 \\
45.6 \\
6.8 \\
6.9 \\
33.1 \\
10.2 \\
7.7 \\
26.3 \\
9.2 \\
6.2 \\
6.6 \\
9.8 \\
29.7 \\
16.0 \\
64.8 \\
31.1 \\
5.5 \\
10.1 \\
27.2 \\
8.5 \\
23.7 \\
16.3 \\
12.9 \\
45.8 \\
4.4 \\
9.5 \\
7.7 \\
34.2 \\
8.2 \\
28.8 \\
5.4 \\
6.2 \\
4.8 \\
6.2 \\
3.2 \\
1.5 \\
11.0 \\
15.7 \\
4.0 \\
34.0 \\
2.0 \\
34.0 \\
1.0 \\
7.0 \\
3.0 \\
3\end{array}$ & $\begin{array}{l}74.9 \\
51.6 \\
50.8 \\
50.4 \\
44.7 \\
39.0 \\
30.8 \\
19.4 \\
13.9 \\
10.0 \\
9.3 \\
9.1 \\
8.7 \\
5.5 \\
5.2 \\
4.8 \\
4.7 \\
4.4 \\
4.2 \\
4.1 \\
4.0 \\
3.6 \\
2.8 \\
2.8 \\
2.7 \\
2.6 \\
2.6 \\
1.7 \\
1.5 \\
1.2 \\
1.2 \\
1.1 \\
1.0 \\
1.0 \\
0.9 \\
0.8 \\
0.8 \\
0.7 \\
0.5 \\
0.4 \\
0.4 \\
0.4 \\
0.4 \\
0.4 \\
0.3 \\
0.3 \\
0.2 \\
0.2 \\
0.1 \\
0.1 \\
0.1 \\
0.1 \\
0.1\end{array}$ \\
\hline
\end{tabular}


a)

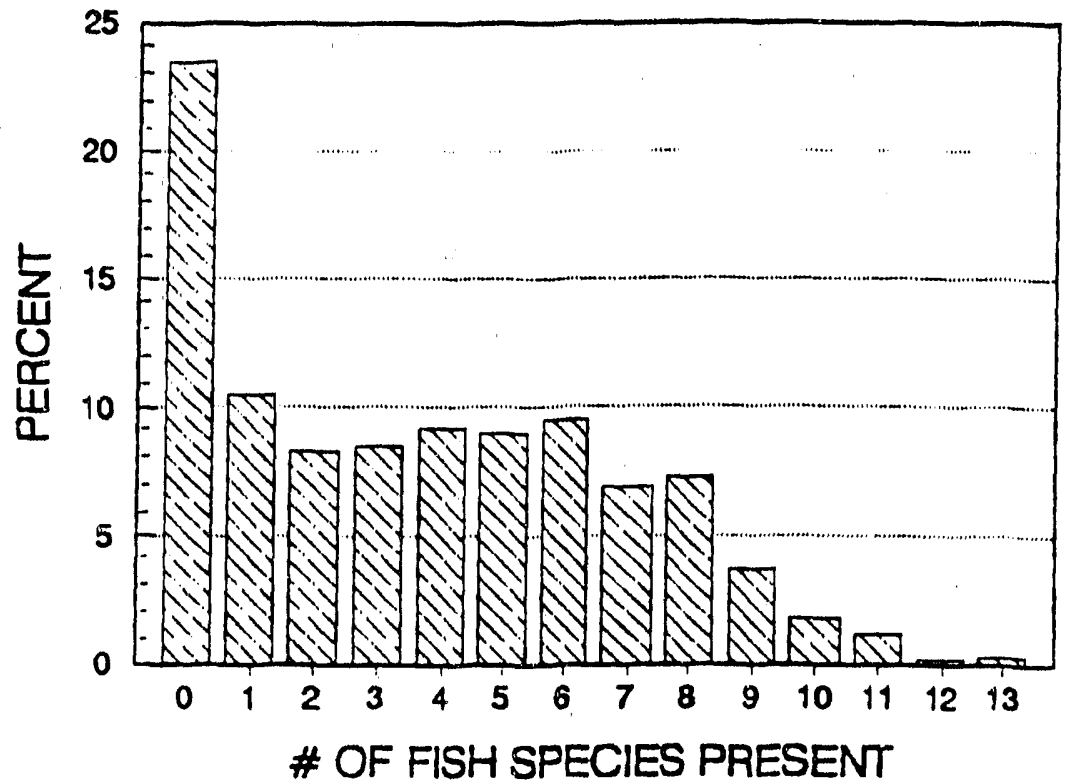

b)
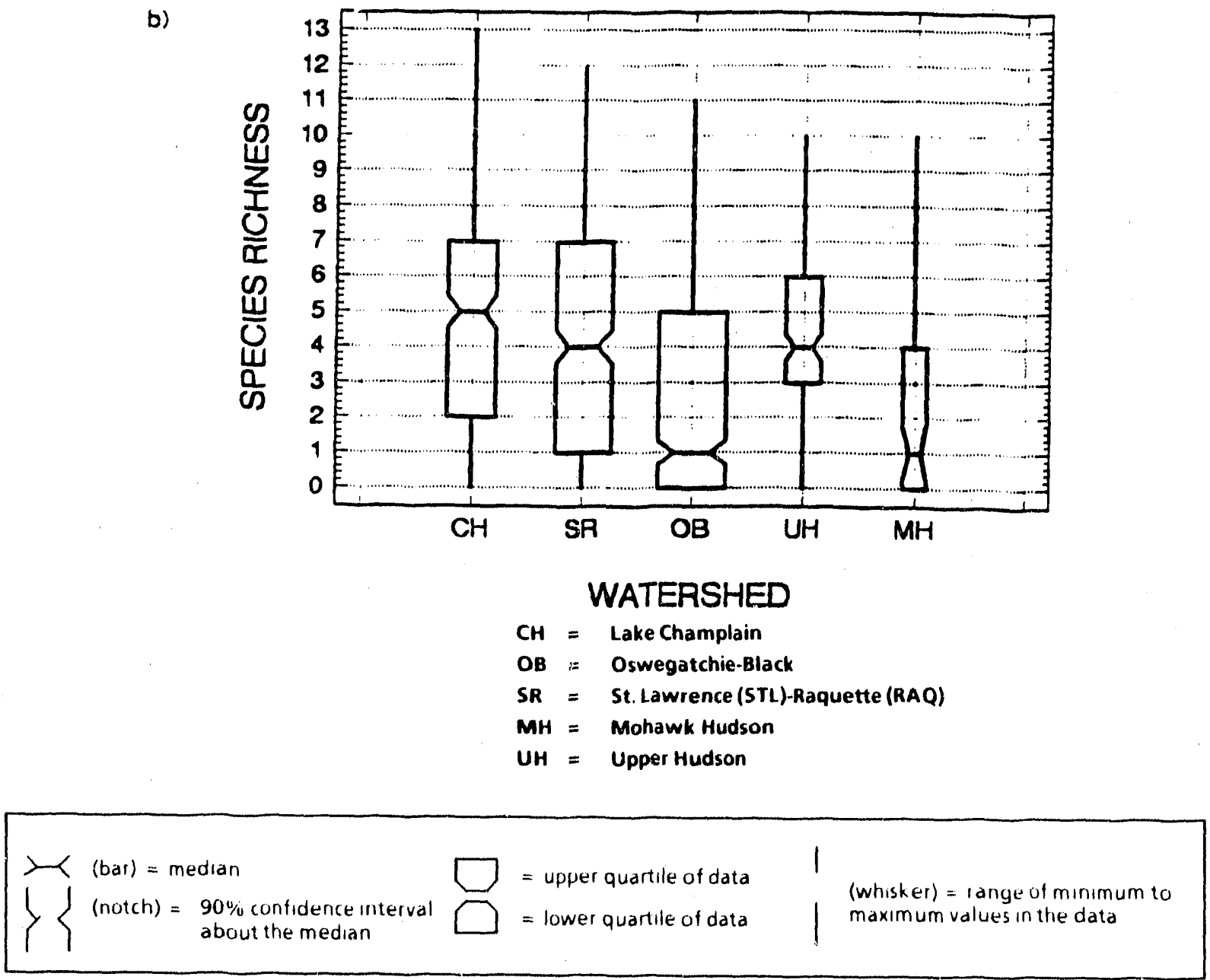

Figure 3.2-1 (a) Frequency histogram of species richness for ALSC lakes and (b) notched box and whisker plots of species richness by watershed. 
WATERSHED KEY

$\mathrm{CH}=$ Lake Champlain

$\mathrm{OB}=$ Oswegatchie-Black

$S R=$ St. Lawrence (STL)-Raquette (RAQ)

MH = Mohawk Hudson

UH $=$ Upper Hudson

a)
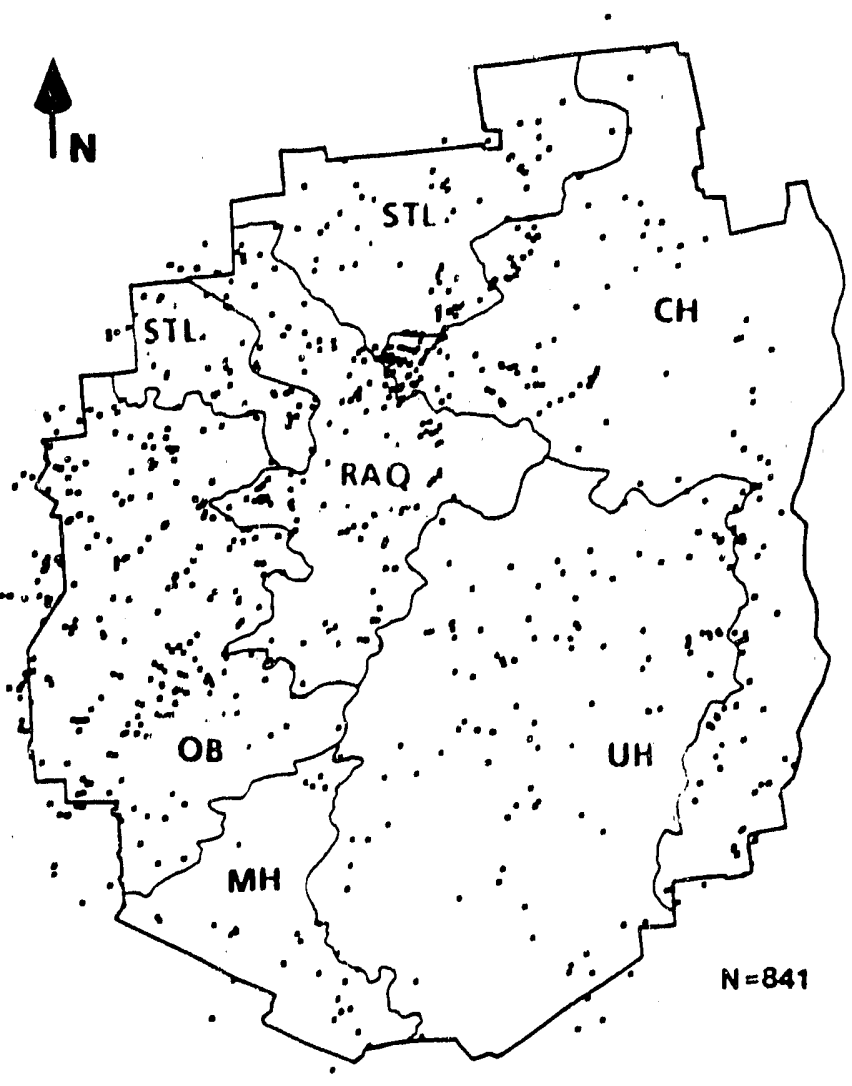

b)

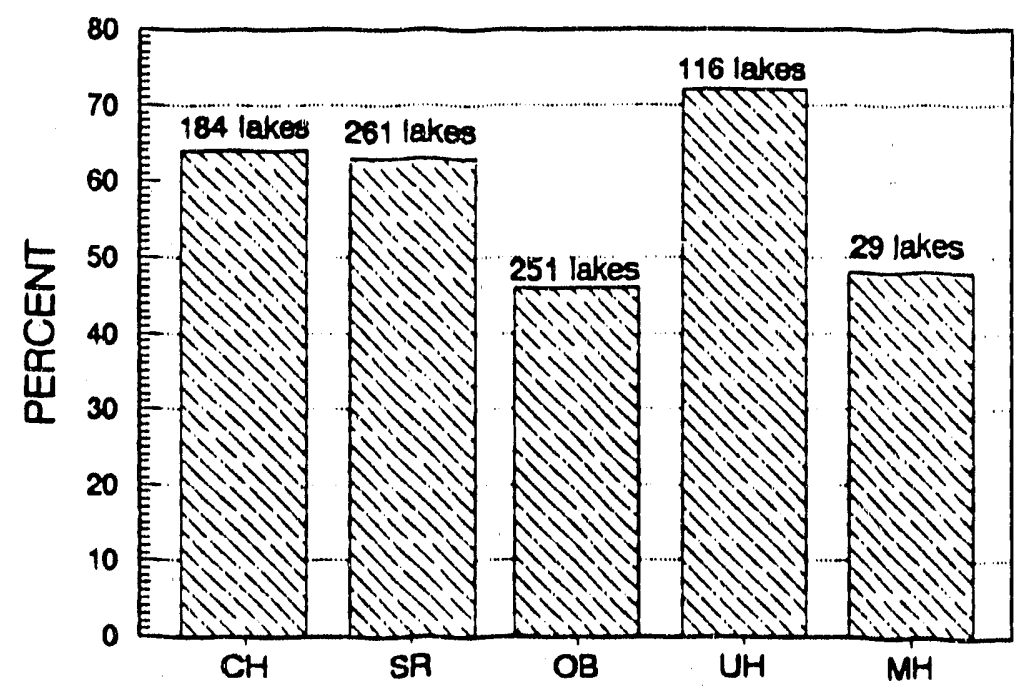

Figure 3.2-2 Brown bullhead (a) spatial distribution in relation to the Adirondack Park and (b) bar chart of occurrence by watershed. 


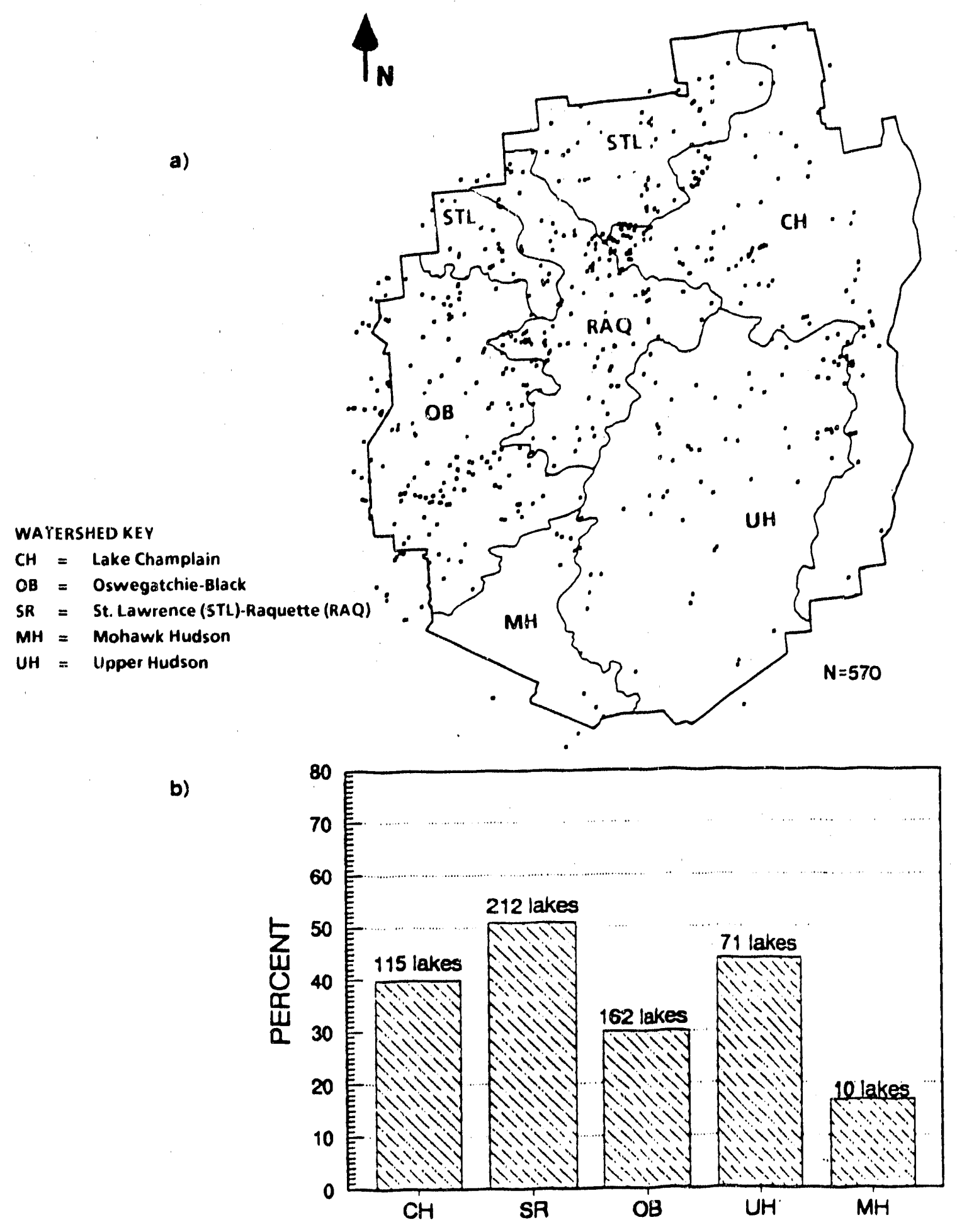

Figure 3.2.3 White sucker (a) spatial distribution in relation to the Adirondack Park and (b) bar chart of occurrence by watershed. 
upland lakes and streams in the Adirondack region. Dwarf forms of the species were reported in several Adirondack waters, including the North Branch of the Moose River, by Mather in 1884. It is uncertain whether these dwarf forms represent a different species or only a physiological response to different environmental conditions.

Golden shiner was the most common cyprinid species captured in ALSC surveys, occurring in 566 lakes or $50 \%$ of the lakes with fish present (Figure 3.2-4). Golden shiner were present in Lake George in the early 1800 s, but are not native to waters in the central Adirondacks. The most probable original source for the species is Lake Champlain (Rafinesque 1817, 1820). The introduction of golden shiner into many central Adirondack waters may be a relatively recent phenomenon; for example, golden shiner first appeared in the North Branch of the Moose River drainage system in the 1950s (Schofield and Driscoll 1987). The popular use of golden shiners as bait by sport fishermen has probably contributed to its present widespread distribution.

Yellow perch, the fourth most abundant species caught, occurred in 346 lakes, or $30 \%$ of the lakes with fish (Figure 3.2-5). Yellow perch, like golden shiner, are not native to upland Adirondack waters, but are often found in large numbers in these waters today. Among lakes where the species occurred, the mean catch was 65.7 fish, the highest value for any of the species collected by the ALSC. The high catch rate for yellow perch may reflect, in part, its susceptibility to the ALSC sampling gear, but is also probably indicative of the prolific nature of the species. Prior to 1900, yellow perch were rare in the Adirondacks except in large lakes such as Lake George (Mather 1884). Approximately 200,000 yellow perch were stocked into interior Adirondack lakes between 1919 and 1932 (George 1980). Since that time, this species has invaded most of the major lakes in the Adirondacks and many smaller upland lakes. Once established, it is not uncommon for yellow perch to multiply rapidly, often resulting in large populations of stunted fish that can outcompete native species. Yellow perch are strong competitors, and their introduction has been associated with the decline of sport fish species such as brook trout in some Adirondack lakes.

Pumpkinseed was the most common centrarchid captured by the ALSC; a total of 13,048 individuals were caught in 502 lakes, approximately $45 \%$ of the lakes with fish present. Like the brown bullhead, historical records suggest that pumpkinseed were present in many Adirondack lakes in the $1800 \mathrm{~s}$ (Mather 1884), although its distribution appears to have expanded since that time.

Brook trout is considered the most important indigenous sport fish in Adirondack waters and was the second most common species caught by the ALSC. Altogether, 8002 brook trout were captured in 579 lakes, or $52 \%$ of the lakes with fish present (Figure 3.2-6). Anecdotal accounts of brook trout occurrence in the 1800 s indicate that the species was also widespread historically in the region. Many 


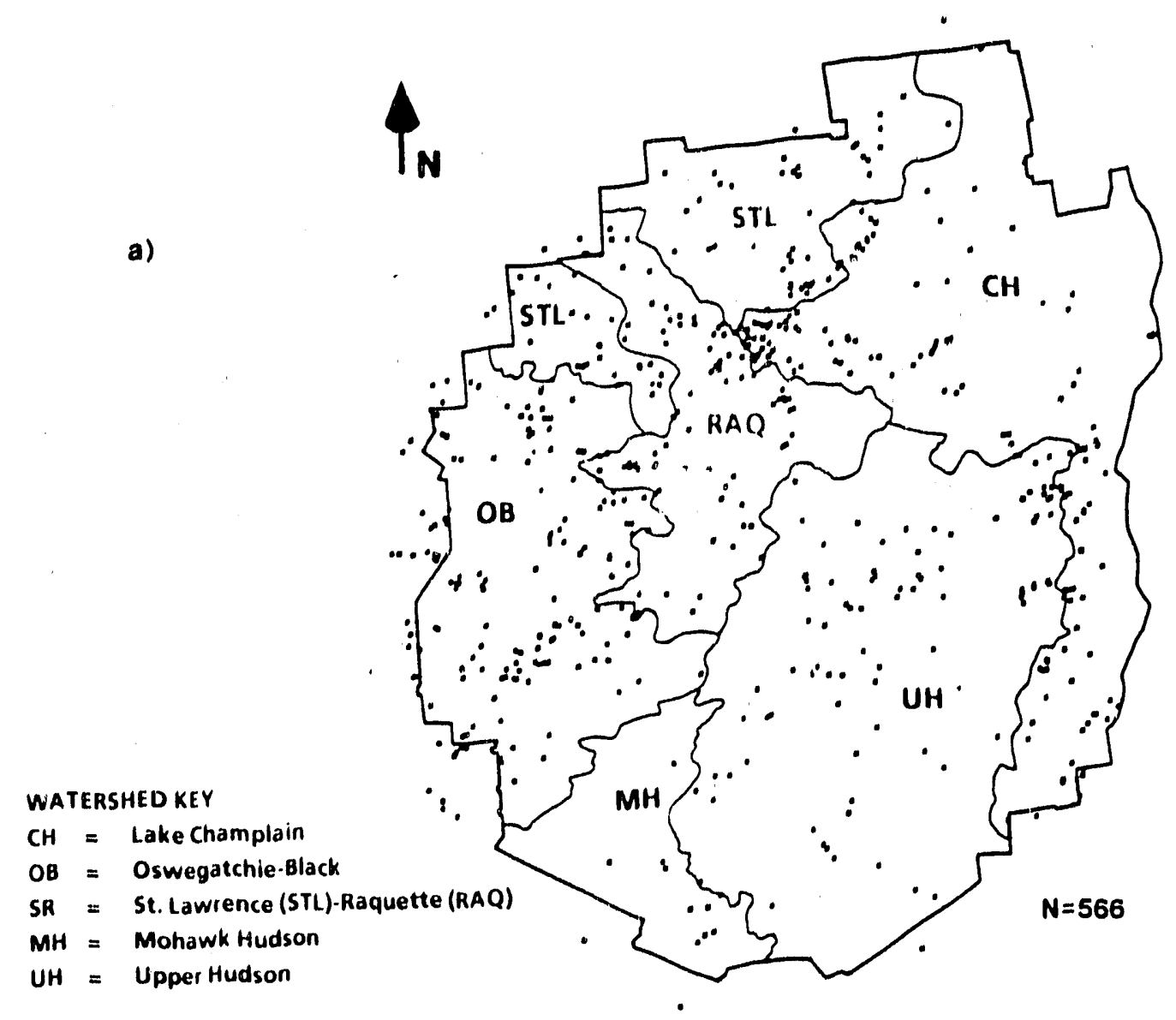

b)

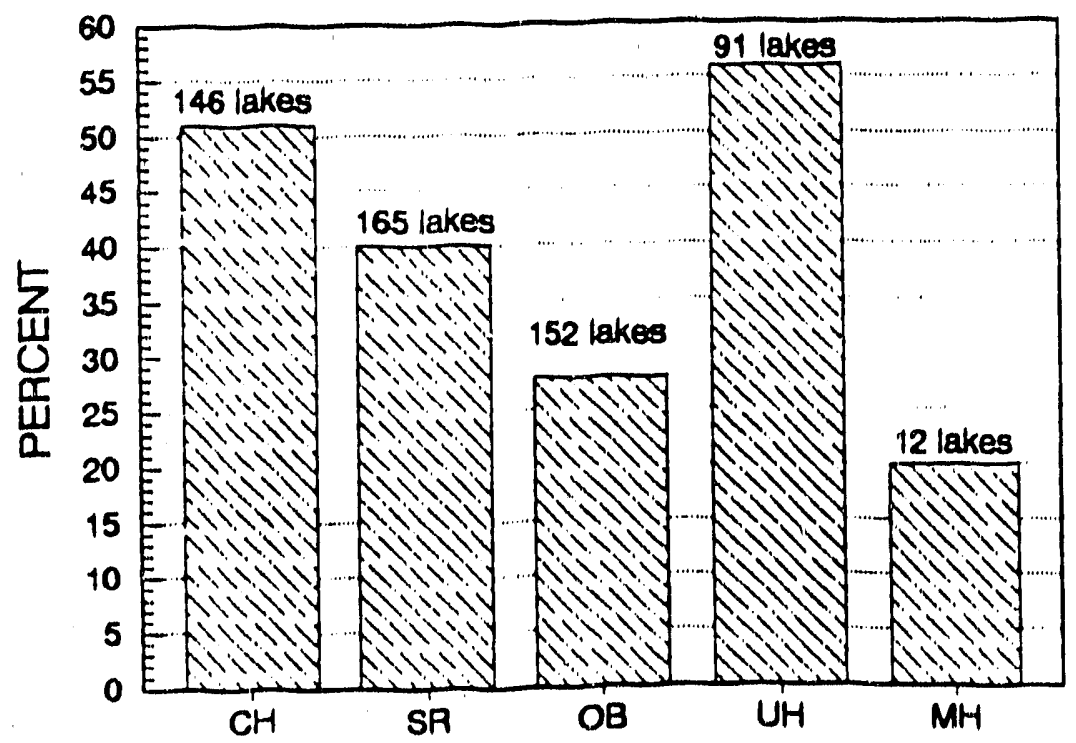

Figure 3.2-4. Golden shiner (a) spatial distribution in relation to the Adirondack Park and (b) bar chart of occurrence by watershed. 


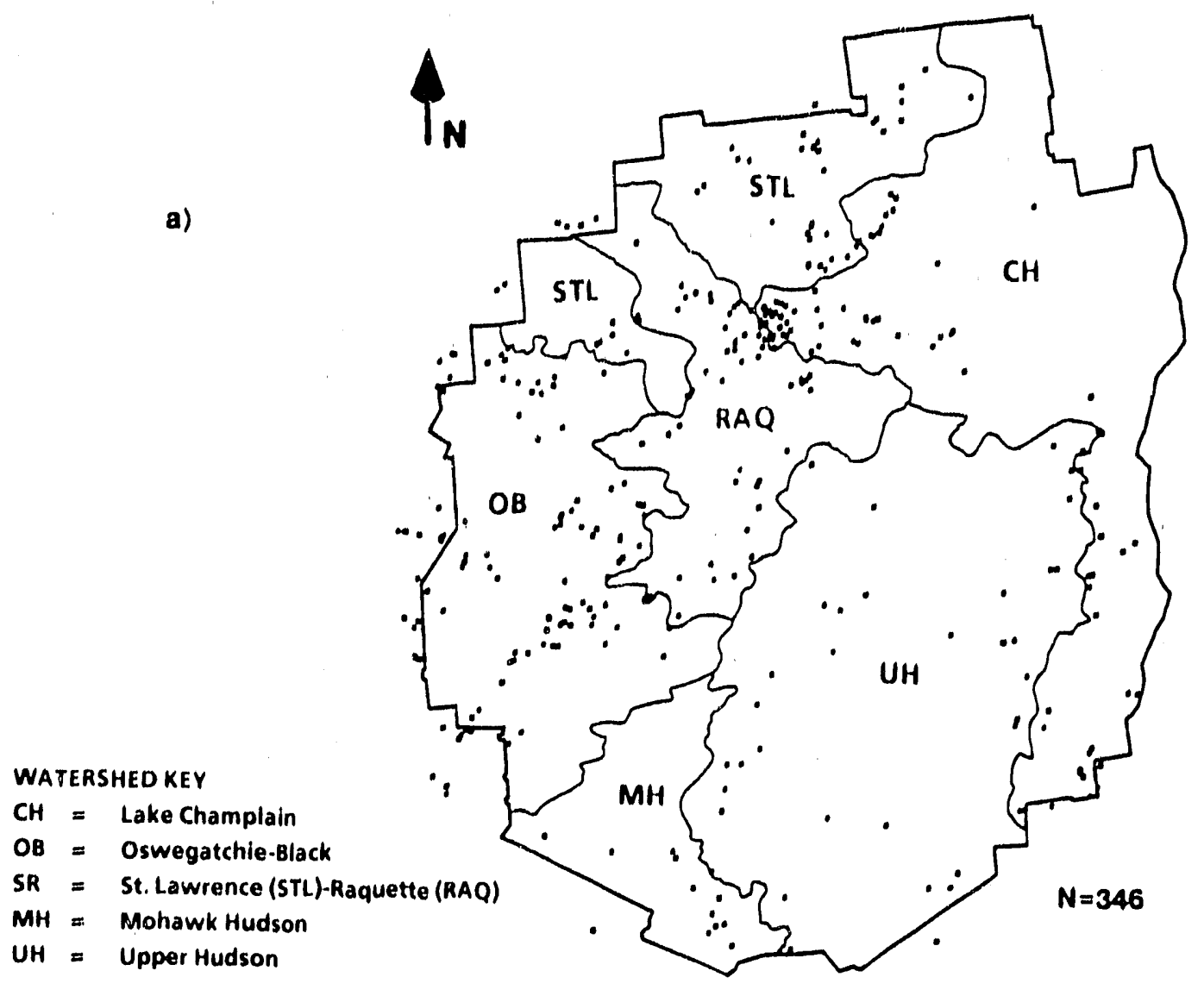

b)

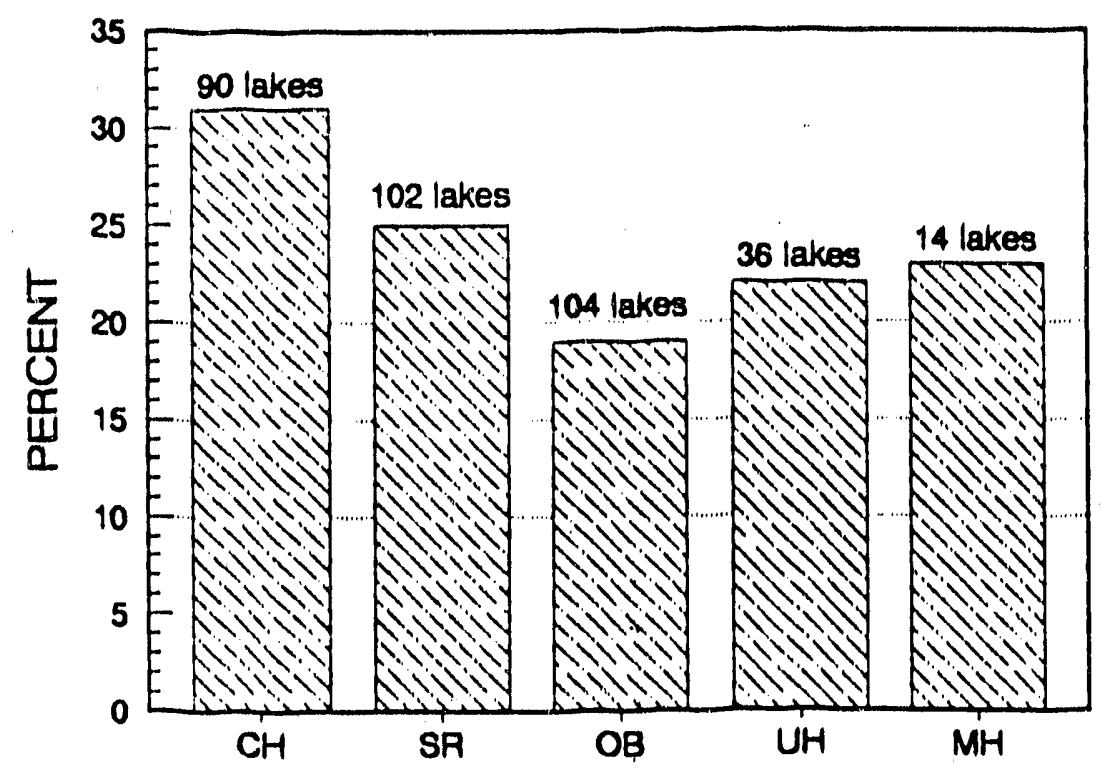

Figure 3.2-5 Yellow perch (a) spatial distribution in relation to the Adirondack Park and (b) bar chart of occurrence by watershed. 


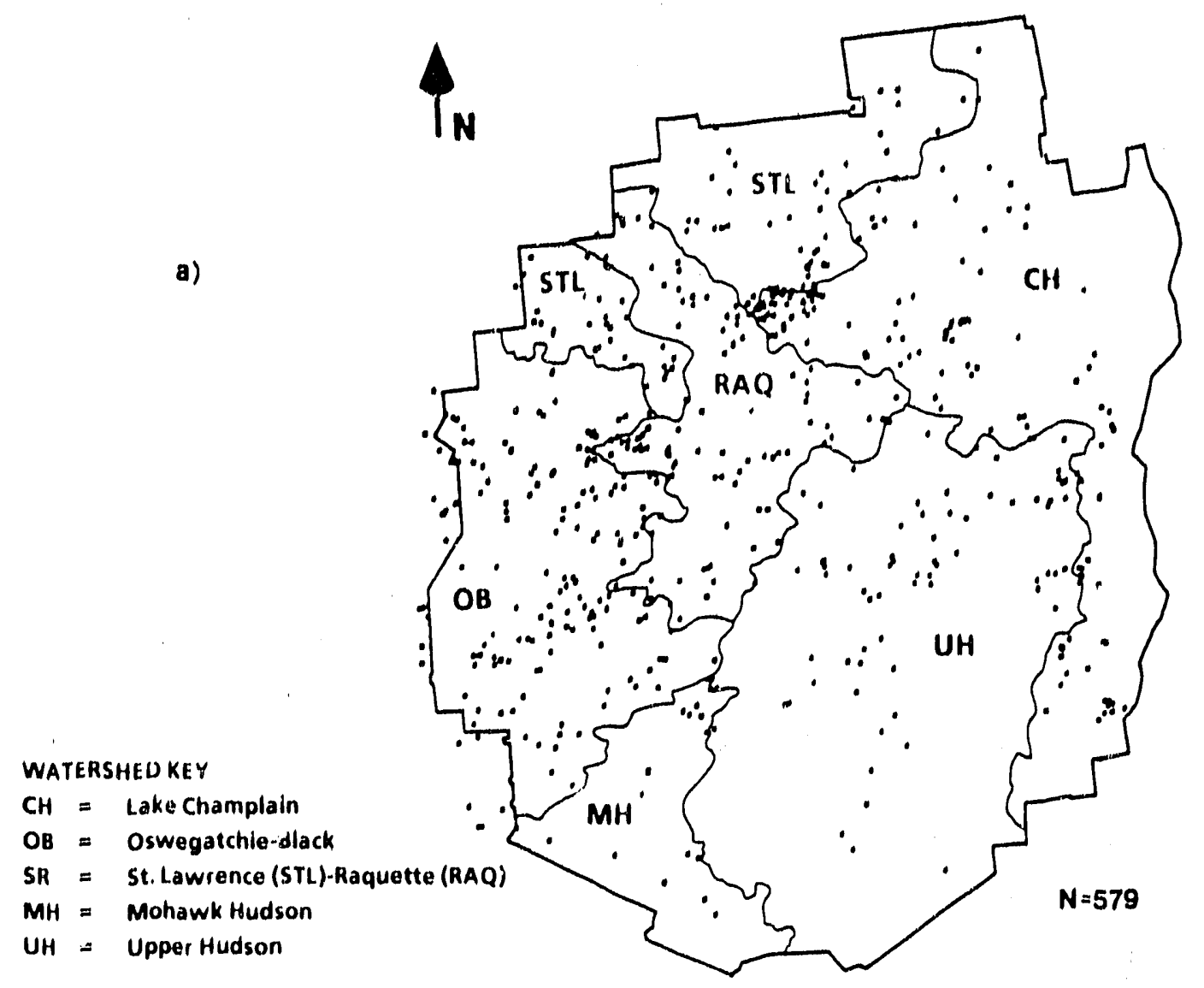

b)

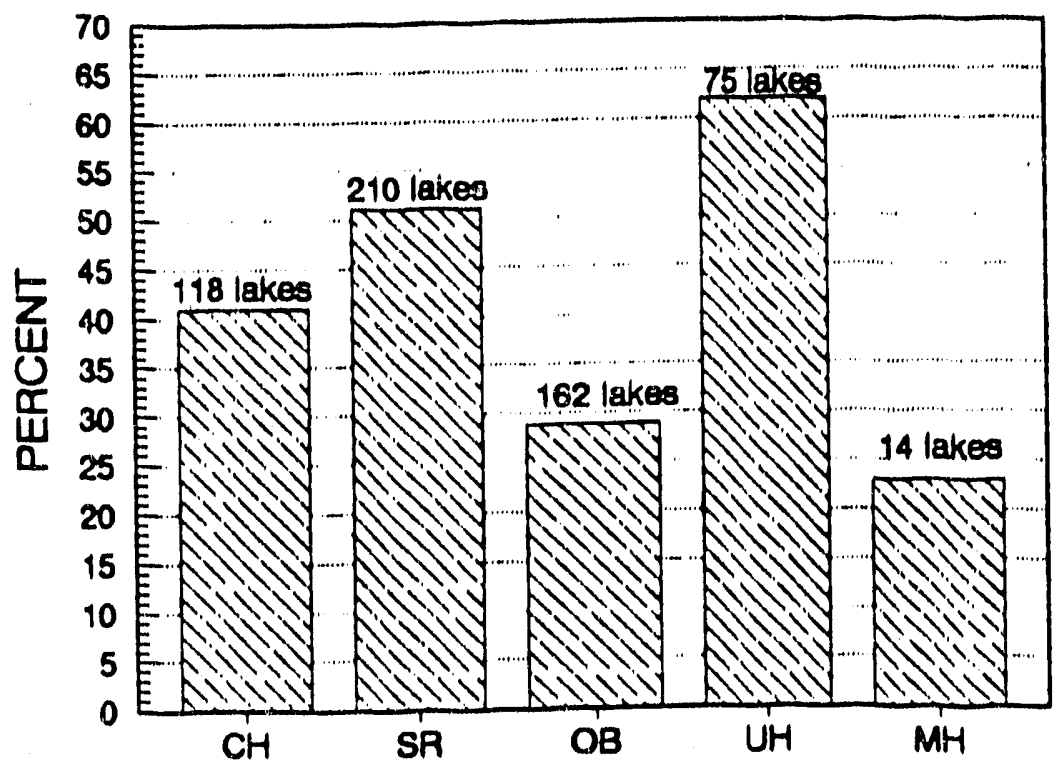

Figure 3.2-6 Brook trout (a) spatial distribution in relation to the Adirondack Park and (b) bar chart of occurrence by watershed. 
of the lakes investigated by Mather (1884) contained brook trout. Pfelfier (1979) reported a total of 693 lakes with brook trout in the Adirondack ecological zone. Currently, there are 11 lakes in New York State with no stocking historles that have been identified as self-sustaining heritage strain (genetically isolated) brook trout waters; 10 of these lakes are located in the Adirondack region (Keller 1979). Seven heritage strain brook trout lakes were surveyed by the ALSC. Seventy-two of the lakes surveyed by the ALSC with brook trout (12\% of the brook trout lakes) were classified as having natural spawning brook trout populations (natural spawning adequate or NSA waters). This group includes both heritage strain brook trout lakes and lakes with prevlous stocking histories that now support unstocked reproducing populations. Lakes were classified as NSA if more than five brook trout were caught and if the lake had not been stocked within 5 years prior to the ALSC survey. Because reliable stocking data were not available for private waters, only public and mixed ownership lakes were considered for the NSA classification. Natural reproduction of brook trout also occurs in some stocked waters, although the maintenance of present-day brook trout population levels is dependent upon stocking. Brook trout are relatively short-lived in Adirondack lakes. Approximately $85 \%$ of all brook trout captured were less than 3 years old; ages ranged from 0 to 6 years with a mean value of 1.6 years.

Lake trout (Salvelinus ne naycush), along with brook trout, were early post glacial colonizers of Adirondack lakes. In contrast to brook trout, lake trout occur in fewer, generally larger, lakes. Plosila (1977) reported that lake trout populations occurred in 100 public and private Adirondack lakes; the mean size of these lakes was about 370 ha. During the ALSC survey, 330 lake trout were caught in 53 waters, with a mean surface area of 58 ha. Several of the larger, well-known lake trout lakes in the Adirondacks were excluded from the ALSC survey because of the limitation nn lake size (maximum 203 ha; see Section 1) used during the ALSC lake selection process. Combining the waters with lake trout identified by Plosila (1977) witn lakes surveyed by the ALSC with previously uridentified lake trout populations (mostly smaller lakes) results in a total of 124 known lake trout waters in the Adirondack region. Additional unidentified lake trout waters may occur in the Mohawk-Hudson and Upper Hudson watersheds. Plosila (1977) estimated that about $75 \%$ of the lakes with lake trout in New York State occur in the Adirondacks. As of 1977, lake trout populations in 24 Adirondack lakes were maintained or supplernented with stocking, while the rest $(80 \%)$ were supported by natural reproduction. Present stocking efforts are thought to be comparable to :hose in 1977.

Salmonids captured by the ALSC that are not native to the Adirondacks include brown trout (Salmo trutta), rainbow trout (Onchorhynchus mykiss), splake (Salvelinus fontinalis $\times$ Salvelinus namaycush), Kokanee (Onchorhynchus nerka), and tiger trout (Salvelinus fontinalis $\times$ Salmo trutta). Brown trout and rainbow trout, have been stocked and managed in Adirondack waters since the early fish 
management efforts of the late 1800s. Kokanee, tiger trout, and splake are more recent Introductions.

Brown trout originated from Germany and ralnbow trout from the western United States (George 1980). Adirondack populations of these two species are maintained by stocking, since neither have attained much spawning success. A total of 394 brown trout were caught in 59 ALSC lakes. Rainbow trout were caught in 32 lakes, but ALSC survey efforts failed to capture this species in some lakes where they are known to occur. Rainbow trout tend to be pelagic and may have been inadequately sampled by the primary ALSC gear, l.e., gill nets set on the lake bottom (see Section 3.1.1).

Kokanee, also known as sockeye salmon, were introduced into several Adirondack lakes in the $1950 \mathrm{~s}$. Only a few of these introductions were successful, however (George 1980). Kokanee, like rainbow trout, are generally pelagic and thus may not have been adequately sampled by the ALSC sampling gear. Kokanee were captured by the ALSC in 10 lakes. The reproductive success of kokanee in Adirondack lakes, as for rainbow and brown trout, is negligible.

Northern pike (Esox lucius) were first introduced into the Adirondacks in the mid-1800s. Fish were transferred from Lake Champlain and Lake George into large Adirondack lakes such as Schroon Lake, Long Lake, and Tupper Lake (George 1980). Few northern pike have been reported in waters in the western and southwestern Adirondacks, even in larger lakes that have been extensively sampled. Likewise, few northern pike were collected by the ALSC in these areas. During the ALSC survey, 723 northern pike were caught in 105 lakes.

Largemouth bass (Micropterus salmoides) and smallmouth bass (Micropterus dolomieui) were also both introduced into the Adirondacks. Fish of both species were transferred from Lake Champlain into large Adirondack lakes in about 1850 and by 1872 were also being stocked into upland lakes (George 1980). Mather (1884) reported that black bass occurred in large Adirondack lakes such as Raquette Lake, Tupper Lake, Blue Mountain Lake, and the Fulton Chain. ALSC surveys caught largemouth bass in 112 lakes and smallmouth bass in 98 lakes, distributed throughout the Adirondacks.

Relative to other fish species, especially well-known sport fish, little is k.nowil abbout the distribution of native cyprinid species in Adirondack lakes prior to 1900. Mather (1884) reported that the following species were present in at least some Adirondack lakes: common shiner (Notropis cornutus), fallfish (Semotilus cornutus), creek chub (Semotilus atromaculatus), northern redbelly dace (Phoxinus eos), eastern blacknose dace (Rhinichthys atratulus), longnose dace (Rhinichthys 
cataractae), and lake chub (Couesius plumbeus). These species are generally considered to be native to the Adirondack region since their presence dates to the earliest available records.

Common cyprinid species caught by the ALSC include creek chub (caught in 438 lakes), northern redbelly dace (218 lakes), and the common shiner (156 lakes); these specles occurred in lakes throughout the Adirondack region. Less common species such as pearl dace (Semotilus margarita) (caught in 58 lakes) and the eastern blacknose dace ( 47 lakes) were prevalent only in eastern and northern areas; they were captured infrequently in the western and southwestern Adirondacks.

In addition to analyses for individual fish species, cyprinid species expected to be especially sensitive to acidic conditions were considered as a group. Sensitive minnows were defined as all members of the family Cyprinidae caught by the ALSC except for those species rated as tolerant of $\mathrm{pH}<5.0 \mathrm{in}$ at least some waters by Baker and Christensen (in press). Thirteen species were included in the sensitive minnow group:

eastern silvery minnow
mimic shiner
bridle shiner
brassy minnow
bluntrose minnow
cutlips minnow
finescale dace
fathead mirnow
fallfish
longnose dace
blacknose dace
pearl dace
common shiner

Hybognathus nuchalis
Notropis volucellus
Notropis bifrenatus
Hybognathus hankinsoni
Pimephales notatus
Exoglossum maxillingua
Chrosomus neogaeus
Pimephales promelas
Semotilus corporalis
Rhinichthys cataractae
Rhinichthys atratulus
Semotilus margarita
Notropis cornutus

Sensitive minnows were caught in 311 lakes distributed in all five Adirondack watersheds, but were most common in the St. Lawrence-Raquette (136 lakes) and Lake Champlain (74 lakes) watersheds (Figure 3.2-7). The Oswegatchie-Black and Mohawk-Hudson watersheds had the lowest occurrence of sensitive mirnows, $9 \%$ and $13 \%$, respectively. Of the 13 sensitive minnow species, common shiner was captured most frequently (Figure 3.2-8a). More than half of the lakes with sensitive minnows contained common shiners. Other common sensitive minnow species were pearl dace, blacknose dace, fathead minnow, fallfish, and cutlips minnow. Among lakes with sensitive minnows present, between one and four species occurred per lake. Approximately $77 \%$ of the lakes with sensitive minnows contained only 1 of the 13 species (Figure 3.2-8b) 


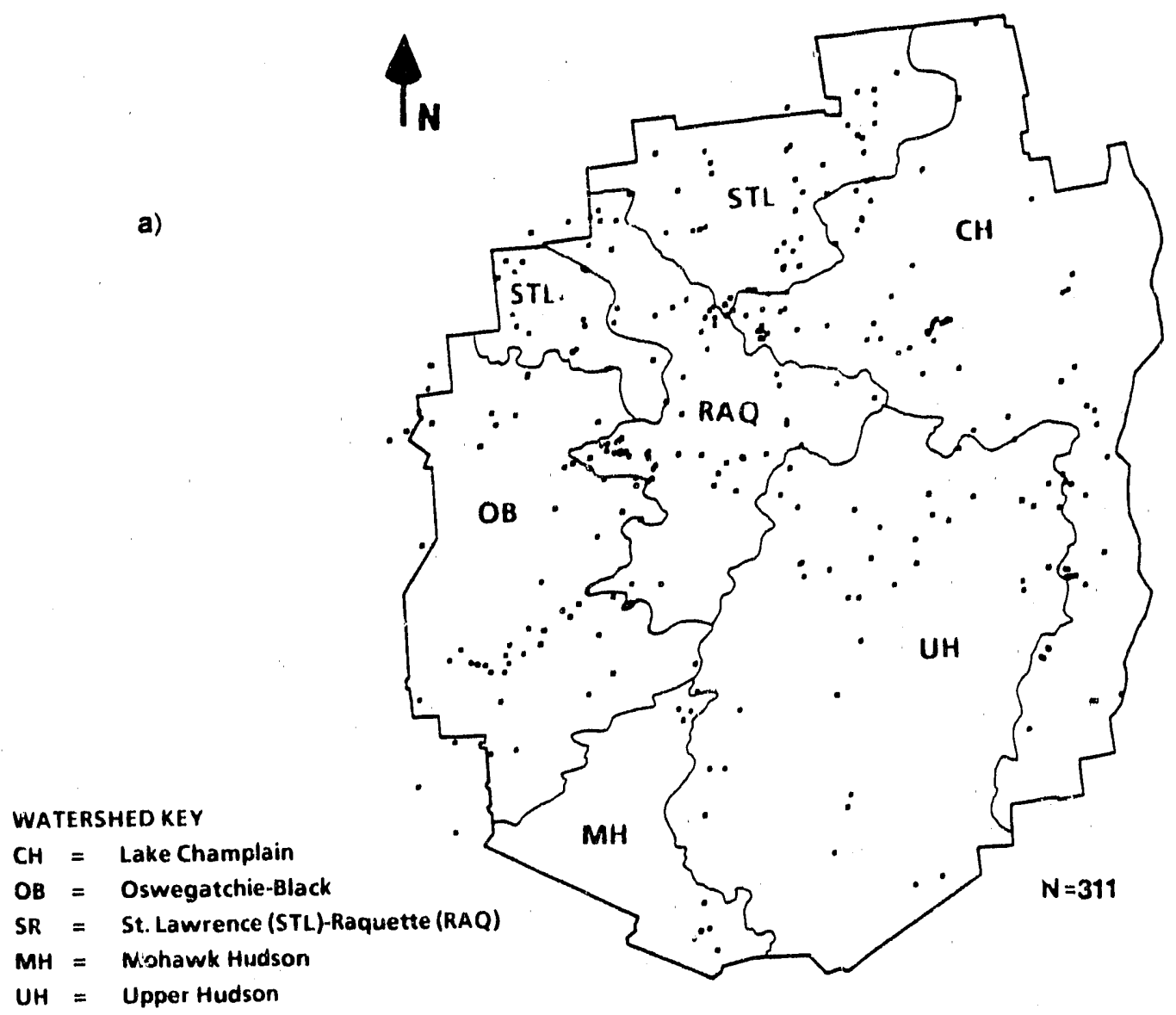

b)

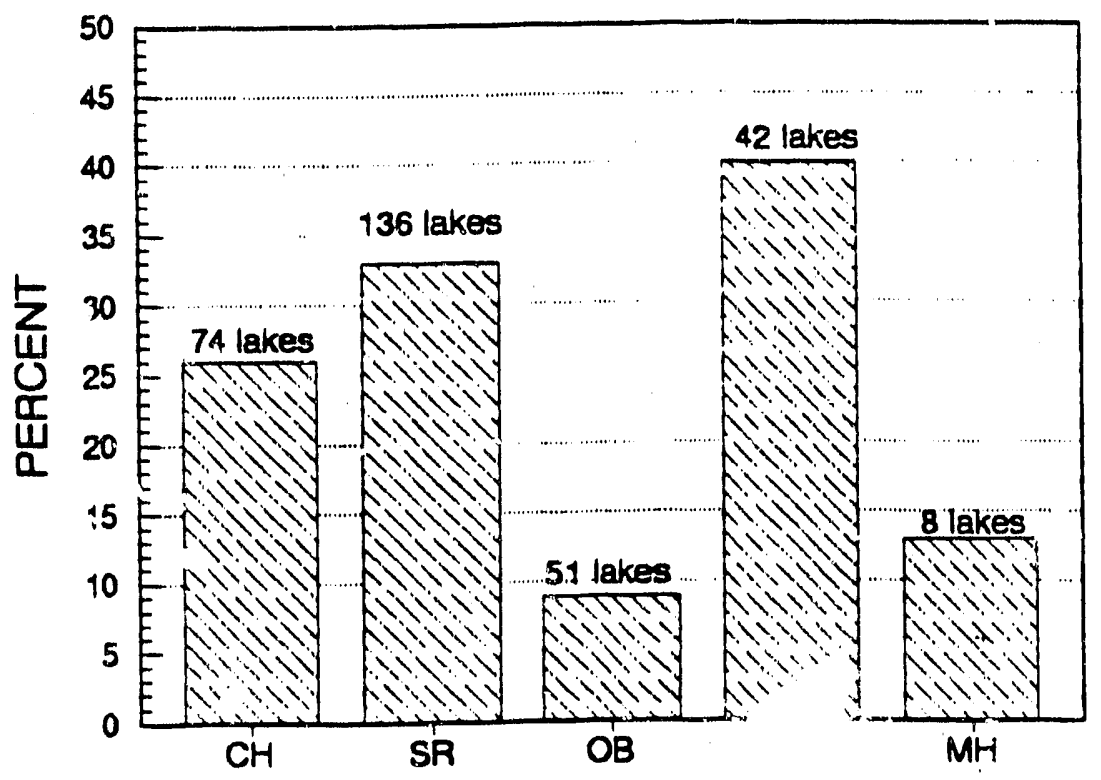

Figure 3.2-7 Sensitive minnows (a) spatial distribution in relation to the Adirondach park and (b) bar chart of occurrence by watershed. 

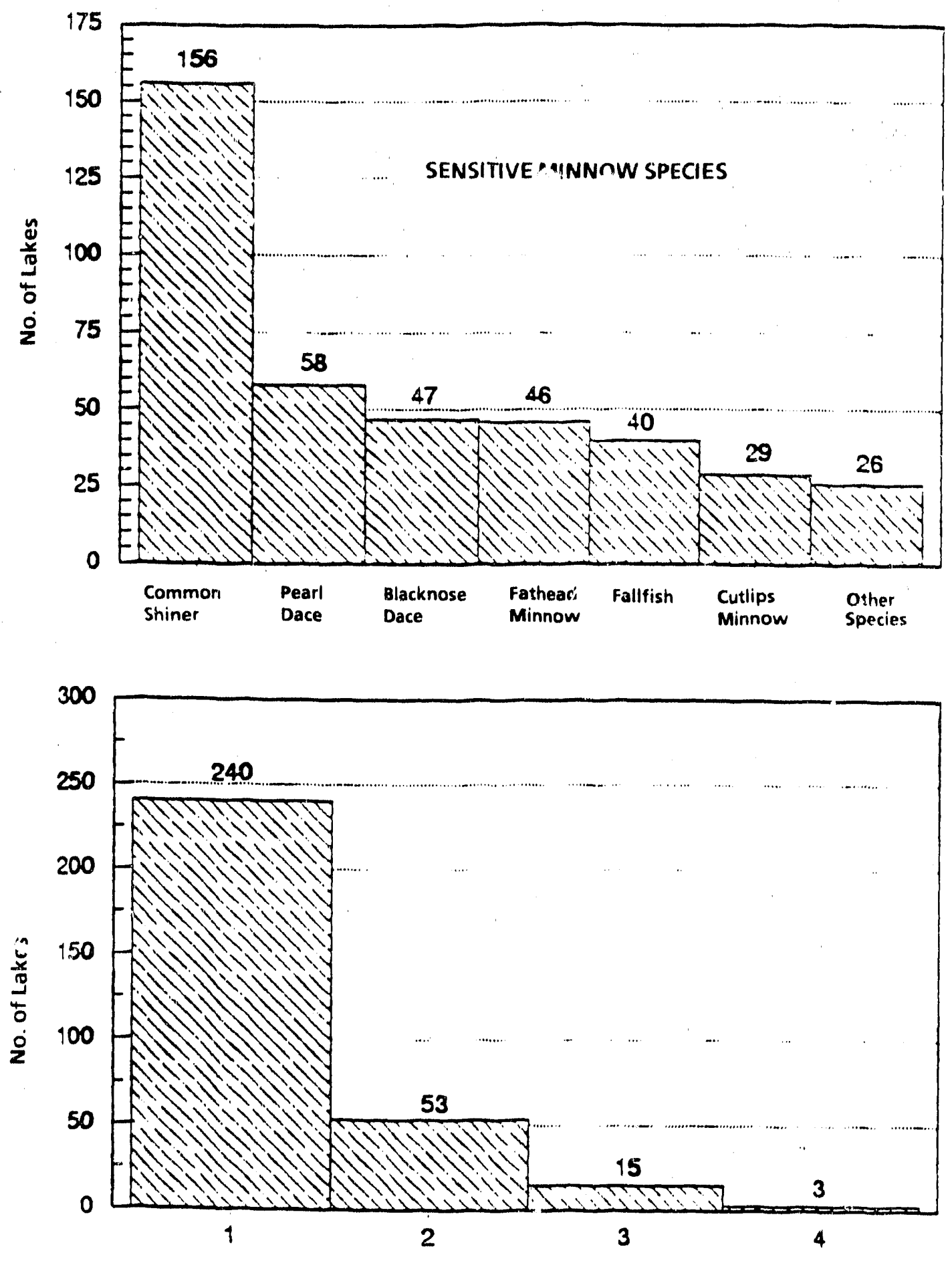

NUMBER OF SPECIES

Figure 3.2-8 (a) Frequency histograms of common sensitive minnows captured in AL.SC lakes and (b) the number of sensitive minnow species captured in lakes represented by this group. 
In general, the most common species caught by the ALSC (brown bullhead, yellow perch, golden shiner, brook trout, white sucker) also showed the greatest tolerance of acidic conditions, judging by their occurrence in lakes with relatively low $\mathrm{pH}$ and high levels of estimated $\mathrm{i}$ i.urganic $\mathrm{Al}$

(Figures 3.2-9 and 3.2-10). Brown bullhead was the species most frequently caught in lakes with summer, surface field pH measurements below 5.0 (occurring in 61 low-pH lakes), followed by brook trout (25 lakes), pumpkinseed ( 15 lakes), yellow perch ( 14 lakes), and golden shiner ( 11 lakes). Sensitive minnows were not caught in any lakes with field $\mathrm{pH}<5.0$. Likewise, common sport fish other than brook trout (e.g., lake trout, northern pike, smallmouth bass, and largemouth bass) were rarely captured in lakes with field $\mathrm{pH}$ below 5.5 and were never captured at $\mathrm{pH}<5.0$.

The presence of self-sustaining populations of fish in lakes with low $\mathrm{pH}$ and elevated Al levels demonstrates the ability of these species to survive and reproduce in acidic environments. The absence of a species from low-pH lakes, on the other hand, does not necessarily result from acid sensitivity; many fuctors may restrict the distribution of fish in Adirondack lakes. Northern pike, for example, spawn in vegetated littoral zones, a habitat that is uncommon in the generally small, low-pH lakes (Rahel 1986), accounting perhaps for the absence of the species at $\mathrm{pH} \leq 5.0$. Patterns of fish absence relative to lake $\mathrm{pH}$ and other lake characteristics are explored further in Sections 3.4 and 3.5 .

As explained in Section 2.4, Adirondack lakes were classified according to lake and watershed characteristics expected to influence the susceptibility of these systems to acidic deposition.

Table 3.2-2 summarizes thie percentage of the fish resource, for selected fish species, occurring in each of these lake classes. These analyses provide a preliminary basis for defining the proportion of the fish resource at greatest risk from continued acidification; they are not intended to infer causes for the absence of fish species from particular lake classes. Mounded seepage lakes and lakes in watersheds with thin till, in particular, may be susceptible to effects from acidic deposition (see Section 2.4). Twenty-five percent of the lakes in which the ALSC caught brook trout fall within these two lake classes; $15 \%$, if the brook trout lakes were classified as low-DOC, mounded seepage or thintill drainage lakes. Other important sport fish species occur relatively infrequently in these two lake classes: $10 \%$ of the lake trout lakes were classified as mounded seepage or thin-till drainage lakes; $6 \%$ of the lakes with small mouth or largemouth bass; $3 \%$ of the lakes with rainbow or brown trout; and $3 \%$ of the lakes with northern pike. Thus, the majority of lakes currently supporting sport fish species would appear to be relatively insensitive to acidic deposition, i.e., were classified as flowthrough seepage lakes or drainage lakes in watersheds with intermediate or thick till or which were carbonate influenced. Mounded seepage lakes and thin-tilled drainage lakes also generally support fewer fish speries rompared to the species richness in the other five lakes classes (Figure $32-11$ ) 
a)

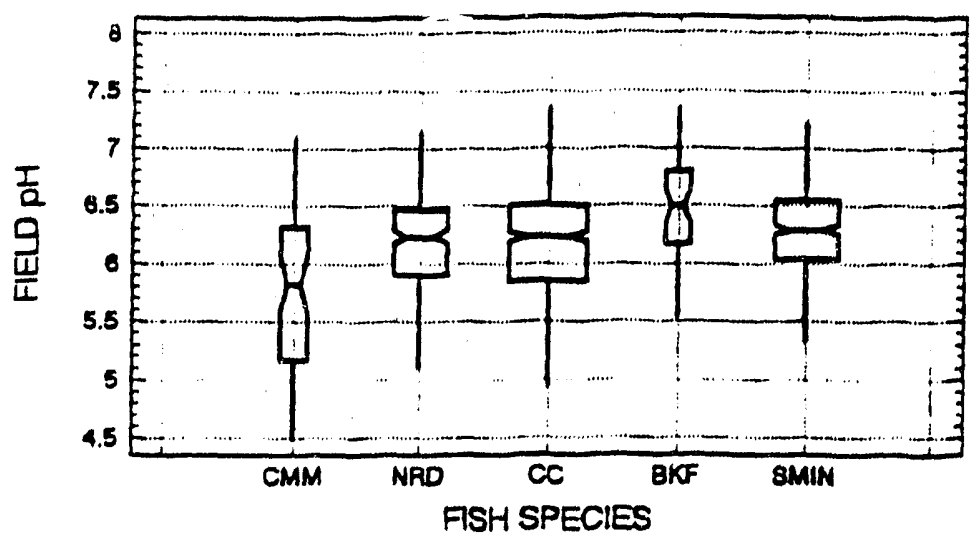

b)

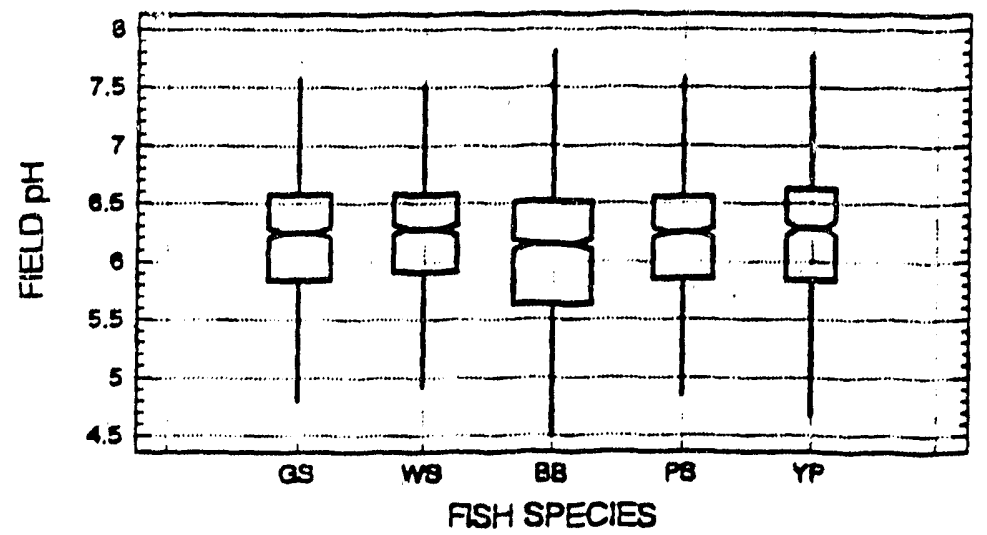

c)

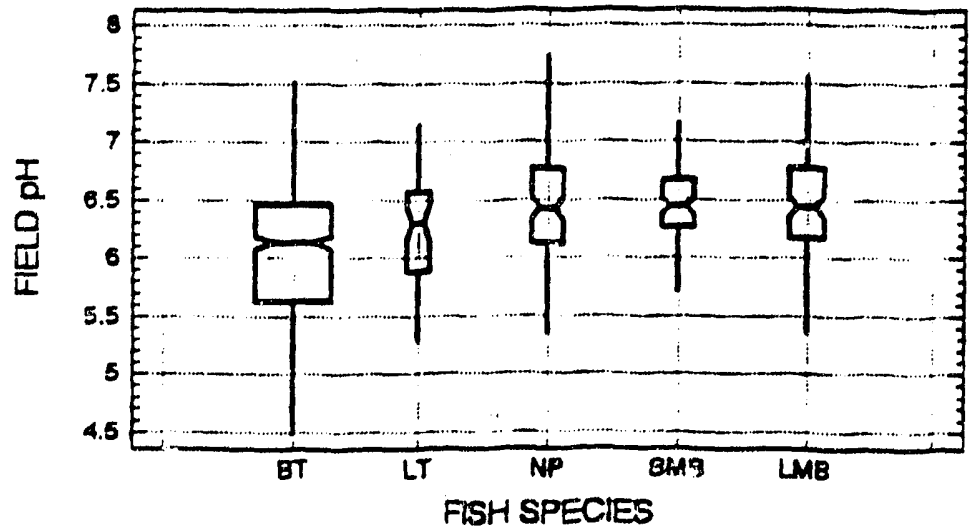

$>\langle$ (bar) $=$ median

\}$\langle$ (noich) $=90 \%$ confidence interval about the median

$\square=$ upper quartile of data

= lower quartile of data (whisker) = iange of minimum to maximum values in the data
$\mathrm{BB}=$ brown bullhead

BKF $\approx$ banded killifish

$B T=$ brook trout

$\mathrm{CC}=$ creek chub

CMM = central mudminnow
GS = golden shiner

LMB = largemouth bass

$\mathrm{LT}=$ lake trout

NP = northern pike

NRD = northern redbelly dace
PS = pumpkinseed

SN:B = smallmouth bass

SMIN = sensitive mirnow group

$W S=$ white sucker

$Y P=$ yellow perch

Figure 3.2-9 Notched box and whisker plots of field pH for selected fish species. 
a)

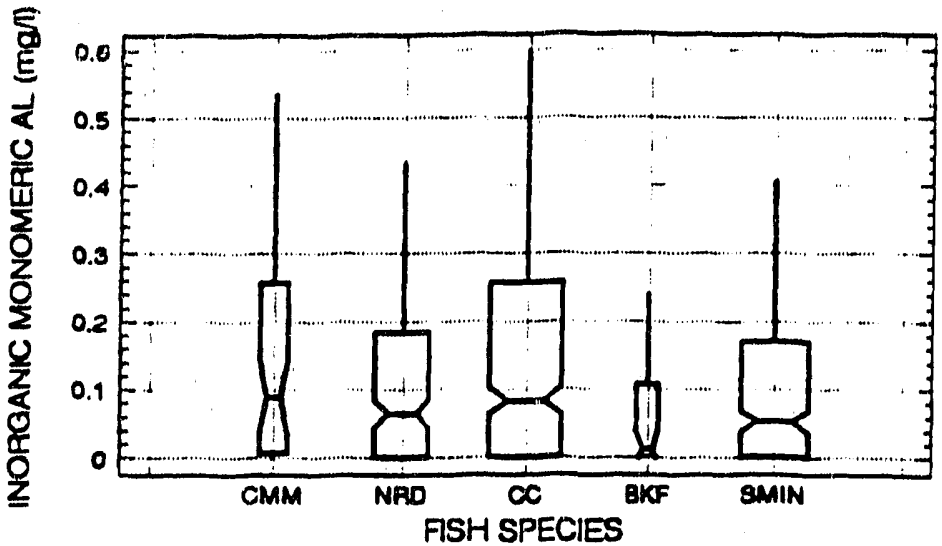

b)

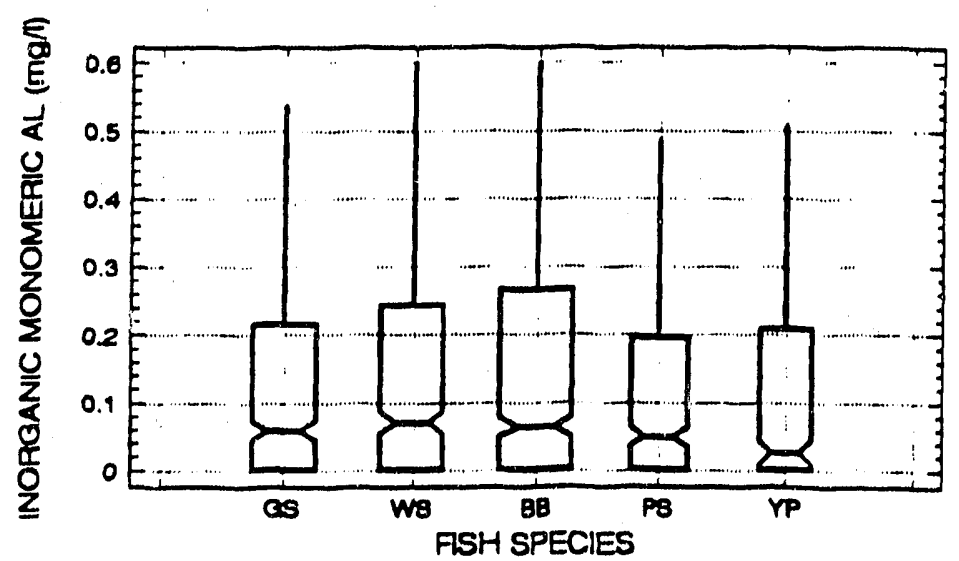

c)

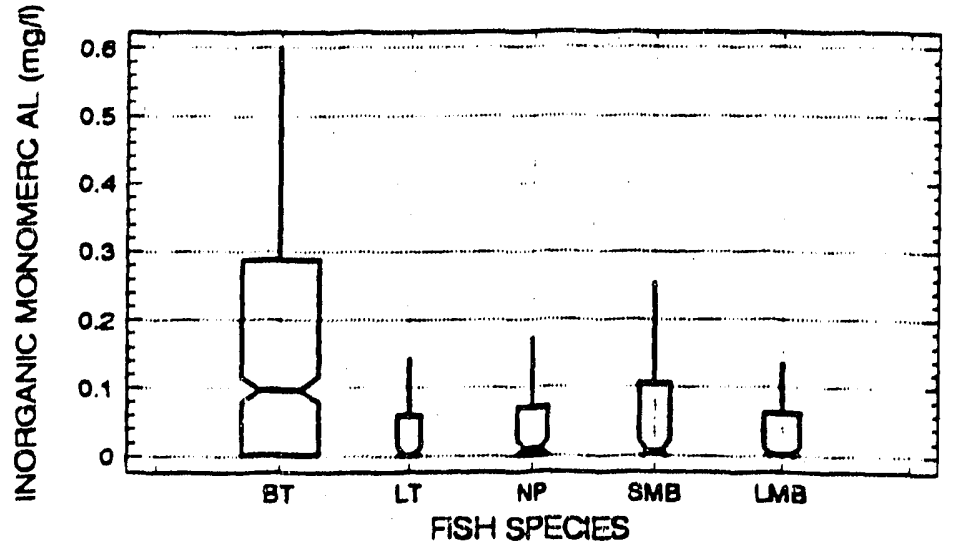

$>($ bar $)=$ median

\}$\langle$ (notch) $=90 \%$ confidence interval about the median $\square$ = upper quartile of data

= lower quartile of data (whisker) = range of mirumum to maximum values in the data
$B B=$ brown bullhead

BKF = bancied killifish

BT $=$ brook trout

$C E=$ creek chub

CMiM = rentıal mudminnow
GS = golden shiner

LMB = largemouth bass

LT = lake trout

NP = northern pike

NRD = northern redbelly dace
PS = pumpkinseed

SMB = smallmouth bass

SMIN = sensitive minnow group

WS $=$ white sucker

$Y P=$ yellow perch

Figure 3.2-10 Notched box and whisker plots of inorganic monomeric Al for fish species collected in ALSC surveys. 


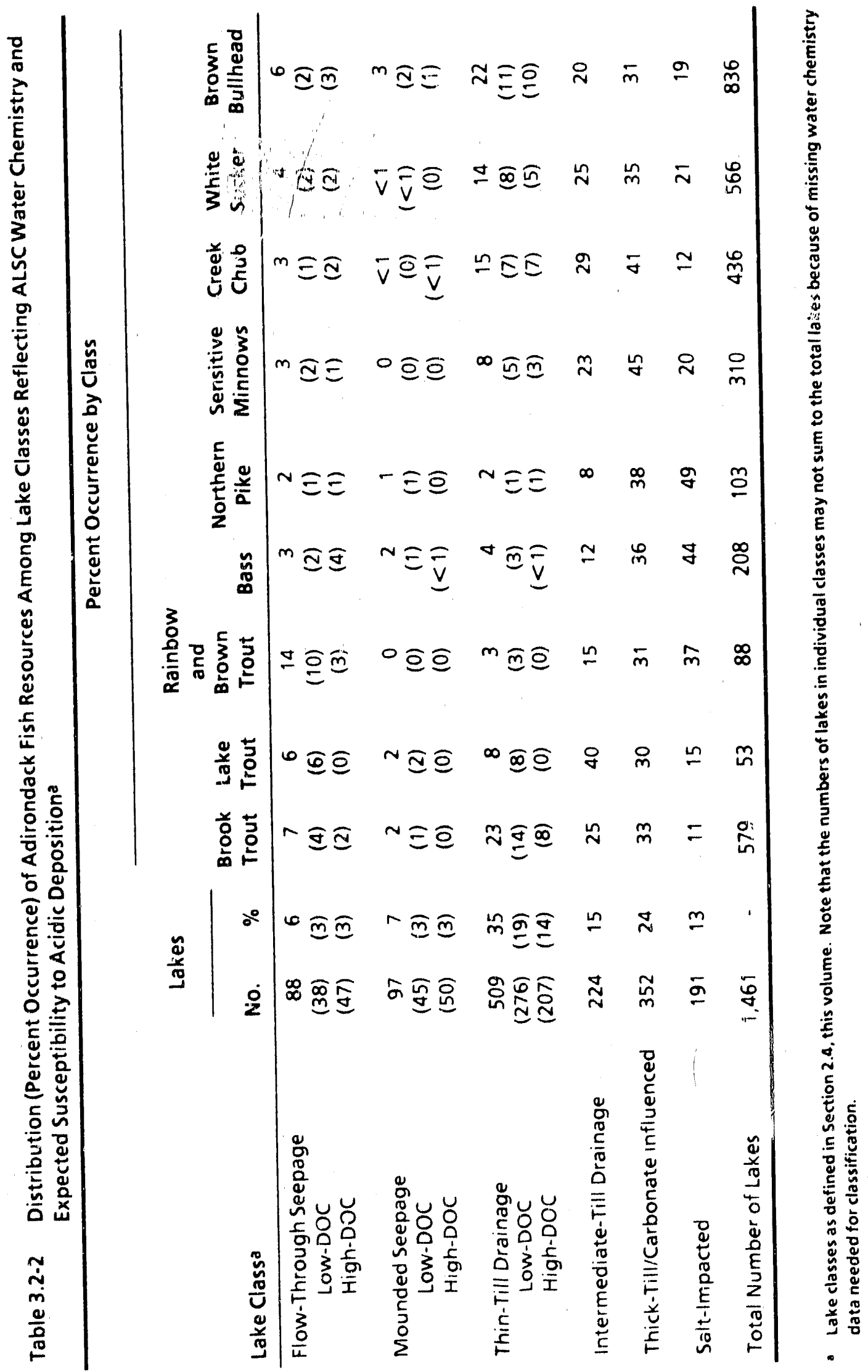




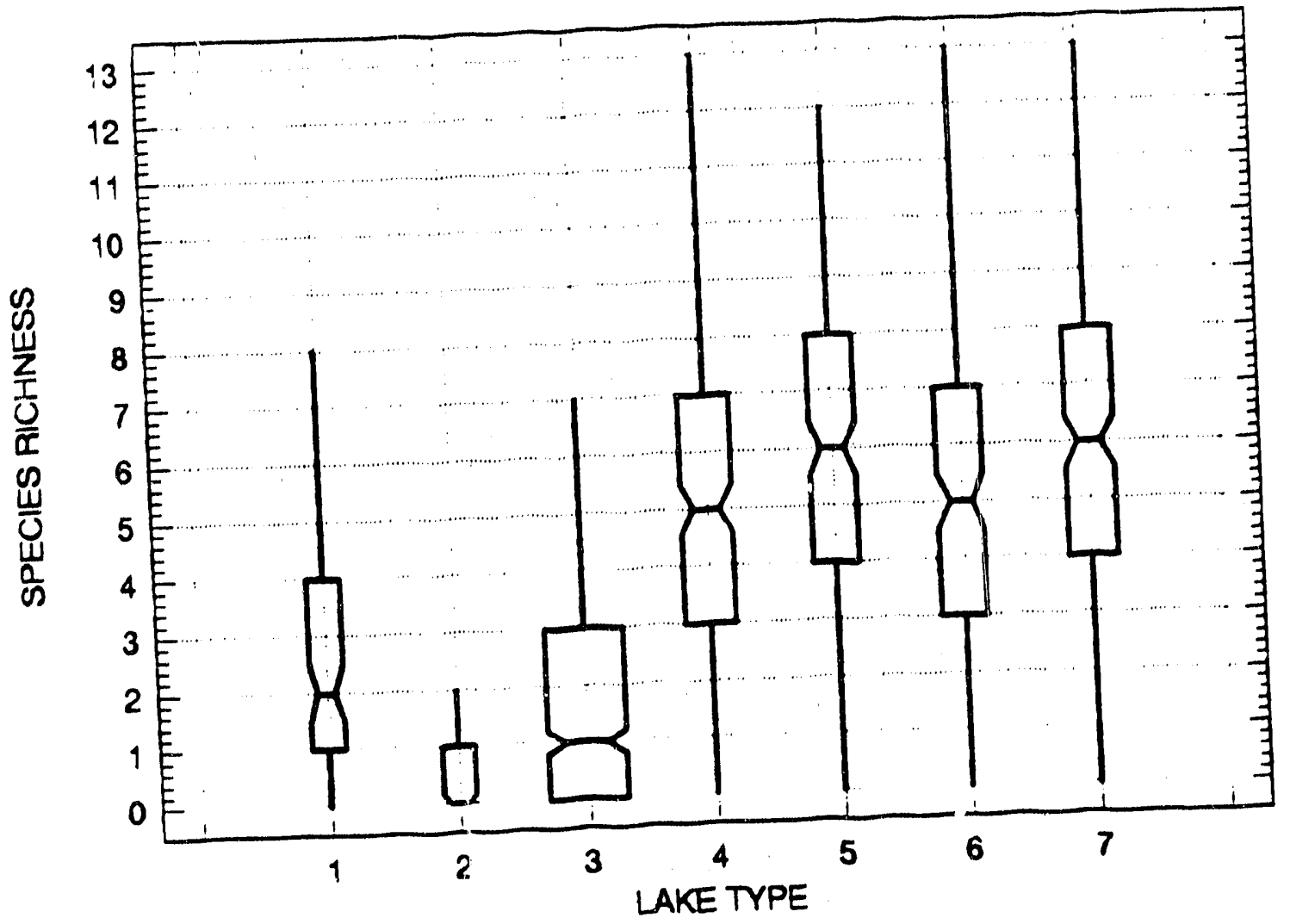

(1) FLOW THROUGH SEEPAGE

(4) "MEDIUM TILL DRAINAGE

(2) MOUNDED SEEPAGE

(5) THICK TIUL DRAINAGE

(3) THIN TILL DRAINAGE

(6) CARBONATE INFLUENCED

(7) SALT IMPACTED

1 (whisker) = range of minimum to

maximum values in the data

L $\{$ (notch) $=90 \%$ confidence interval about the median

- lower quartile of data

Figure 3.2-11 Notched box and whisker plots of species richness in Adirondack lake classes. 


\subsubsection{Characteristics of Lakes with No Fish}

Of the 1469 lakes surveyed by the ALSC, one or more fish species were caught in 1123 lakes (76\%), while no fish were caught in 346 lakes $(24 \%)$. Lakes without fish occurred throughout the Adirondack ecological zone but were concentrated in the western and southwestern Adirondacks (Figure 3.2-12). This area of the Adirondacks is characterized by large numbers of small, high-elevation lakes with low pH (Figure 3.2-13) (Kretser et al. 1989) and also receives relatively high levels of both total precipitation and acidic deposition (Driscoll et al., in press). Even within this area, however, lakes with fish present were interspersed with lakes with no fish. For example, $61 \%$ of the fishless lakes sampled by the ALSC were found in the Oswegatchie-Black watershed in the southwestern Adirondacks. Within this watershed, 211 lakes, or $39 \%$ of the 545 lakes sampled, had no fish (Table 3.2-3). The remaining 135 lakes without fish were distributed across the other four watersheds: Lake Champlain, 37 lakes (13\% of the lakes in the watershed); St. Lawrence-Raquette, 61 lakes (15\%); Upper Hudson, 14 lakes (9\%); and the Mohawk-Hudson, 23 lakes (38\%).
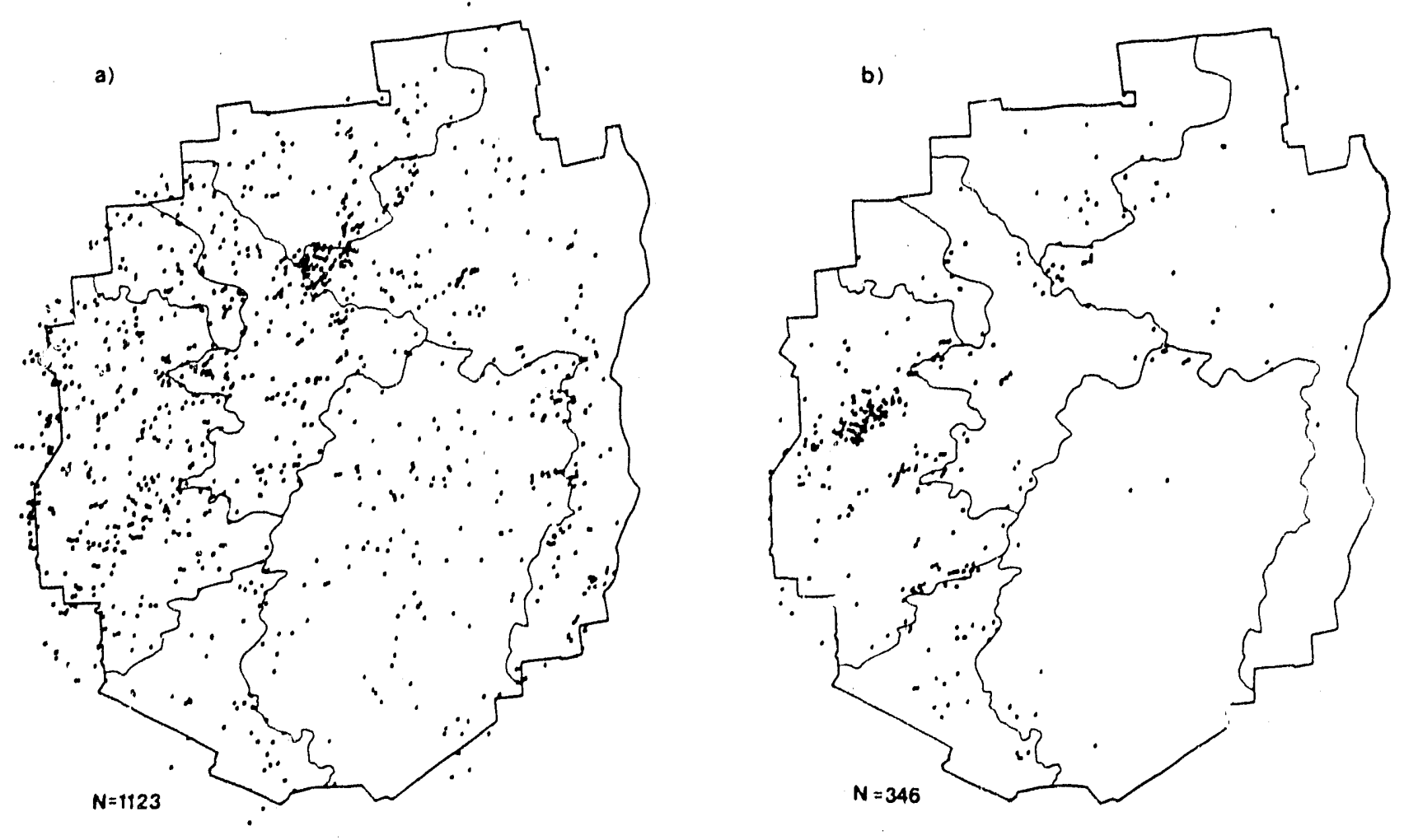

Figure 3.2-12 Spatial distribution of ALSC lakes with (a) fish present and (b) fish absent. 
(a)

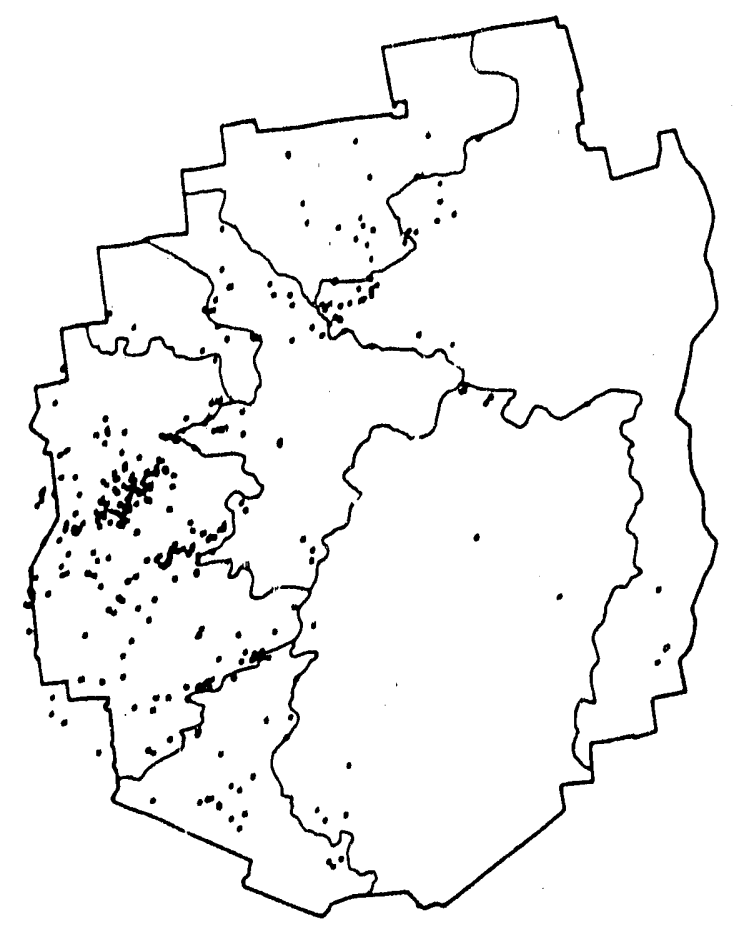

(c)

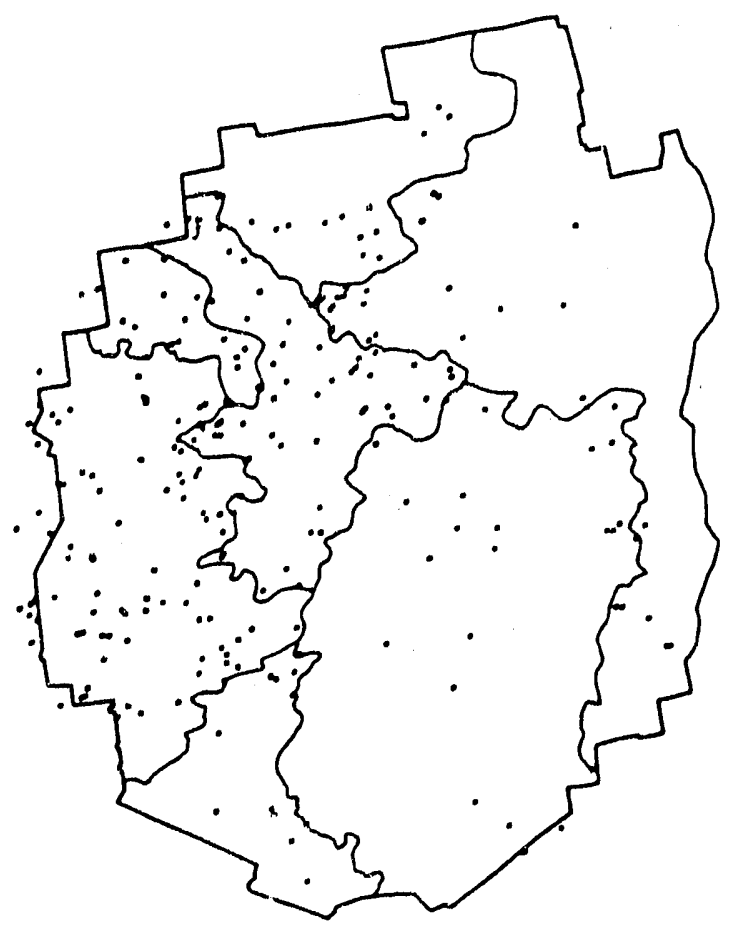

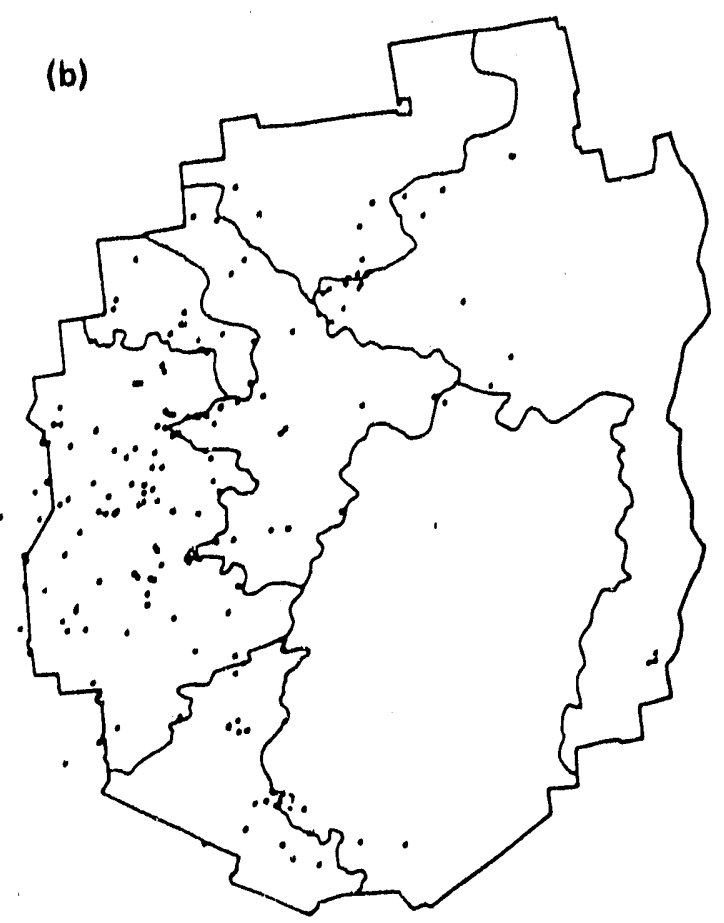

(d)

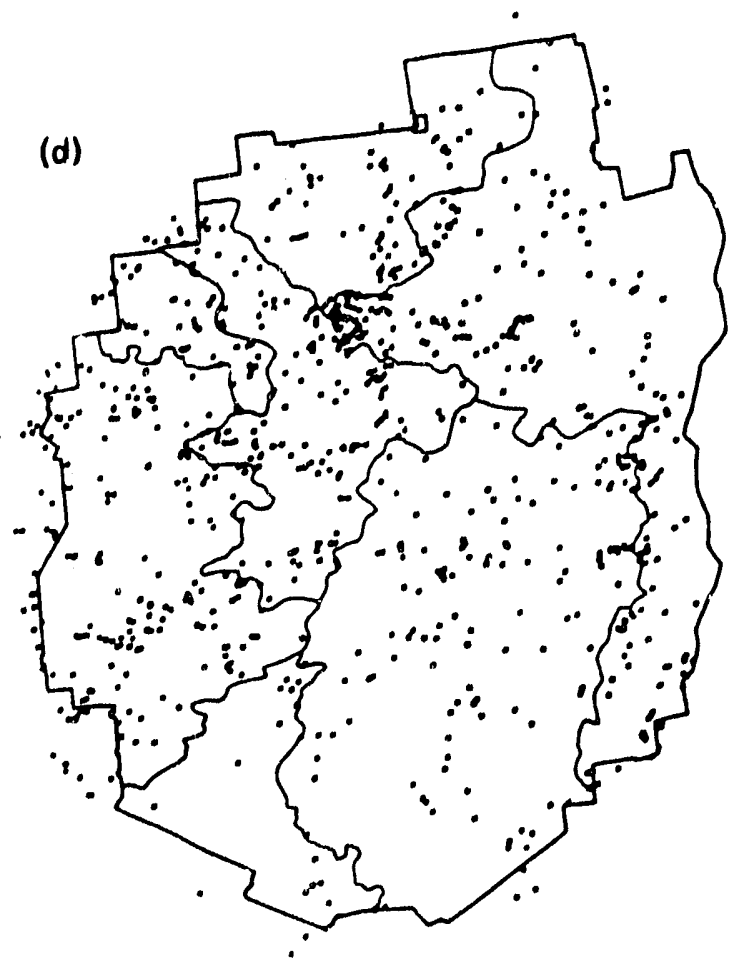

Figure 3.2-13 Distribution of ALSC lakes by pH class: (a) $\mathrm{pH} \leq 5.0$. (b) $5.0<\mathrm{pH} \leq 5.5$, (c) $5.5<\mathrm{pH} \leq 6.0$, and (d) $>6.0$. 
Table 3.2.3 Fish Presence and Absence by Watershed

\begin{tabular}{|c|c|c|c|}
\hline Watershed & Total & Fish Absent & Fish Present \\
\hline \multicolumn{4}{|l|}{ Total } \\
\hline Count & 1,469 & 346 & 1,123 \\
\hline Row Percent & 100 & 100 & 100 \\
\hline Column Percent & 100 & 100 & 100 \\
\hline Total Percent & 100 & 24 & 76 \\
\hline \multicolumn{4}{|l|}{ Lake Champlain } \\
\hline Count & 287 & 37 & 250 \\
\hline Row Percent & 100 & 13 & 87 \\
\hline Column Percent & 20 & 11 & 22 \\
\hline Total Percent & 20 & 3 & 17 \\
\hline \multicolumn{4}{|l|}{ St. Lawrence-Raquette } \\
\hline Count & 415 & 61 & 354 \\
\hline Row Percent & 100 & 15 & 85 \\
\hline Column Percent & 28 & 18 & 32 \\
\hline Total Percent & 28 & 4 & 24 \\
\hline \multicolumn{4}{|l|}{ Oswegatchie-Black } \\
\hline Count & 545 & 211 & 334 \\
\hline Row Percent & 100 & 39 & 61 \\
\hline Column Percent & 37 & 61 & 30 \\
\hline Total Percent & 37 & 14 & 23 \\
\hline \multicolumn{4}{|l|}{ Upper Hudson } \\
\hline Count & 162 & 14 & 148 \\
\hline Row Percent & 100 & 9 & 91 \\
\hline Column Fercent & 11 & 5 & 13 \\
\hline Total Percent & 11 & 1 & 10 \\
\hline \multicolumn{4}{|l|}{ Mohawk-Hudson } \\
\hline Count & 60 & 23 & 37 \\
\hline Row Percent & 100 & 38 & 62 \\
\hline Column Percent & 4 & 7 & 3 \\
\hline Total Percent & 4 & 2 & 3 \\
\hline
\end{tabular}

Lakes without fish comprised approximately $7 \%$ (1642 ha) of the total lake surface area sampled by the ALSC. Fishless lakes in the Oswegatchie-Black watershed accounted for 1295 ha of lake surface area, representing $18 \%$ of the total surface area in the watershed and $79 \%$ of the total surface area with fish absent.

The majority of fishless lakes were located on public lands. Forty-five percent of the lakes surveyed by the ALSC were privately owned. Of the 663 private lakes sainpled, no fish were caught in $93(14 \%)$. In contrast, $233(29 \%)$ of the 806 lakes surveyed on public land were fishless. An additional 20 lakes with mixed public and private ownership were fishless. 
Lakes without fish were significantly $(p \leq 0.05)$ smaller and shallower than lakes with fish present (Figure 3.2.14) Nearly $70 \%$ of the lakes without fish had a surface area $\leq 4$ ha; about $90 \%$ were smaller than 10 ha (Figure 3.2-15). Lakes $\leq 4$ ha were not sampled during the Eastern Lake Survey (FLS) (see Section 2.1.3.5). Sixty percent of the fishless lakes had a mean depth $\leq 2 \mathrm{~m}$. Fishless lakes also occurred at significantly ( $p \leq 0.05$ ) higher elevations and had smaller watersheds than lakes with fish present (Figure 3.2-14). Forty-four percent of the fishless lakes were found at elevations above $600 \mathrm{~m}$ (Figure 3.2-15); no fish were caught in $65 \%$ of the lak w. surveyed at elevations $>600 \mathrm{~m}$. Schofield (1976) also reported a high frequency (more than 50\% of the lakes surveyed) of fishless lakes at high elevations in the Adirondacks.

Chemically, lakes without fish had significantly $(\mathrm{p} \leq 0.05)$ lower field $\mathrm{pH}$, calcium ( $\mathrm{Ca}$ ), and acid neutralizing capacity (ANC) as well as higher estimated inorganic $A l$ than did lakes with fish present (Figure 3.2-16). Of the 343 fishless lakes with nonflagged field pH data, $263(77 \%)$ had midsummer field $\mathrm{pH}$ values $\leq 5.0$ (figure 3.2-17). The remaining fishless lakes were found in the following $\mathrm{pH}$ ranges: $\mathrm{pH} 5.1-5.5,52$ lakes; $\mathrm{pH} 5.6-6.0,15$ lakes; and $\mathrm{pH}>6.0,13$ lakes. A similar number of fishless lakes, 267 lakes and $77 \%$ of the lakes sampled, had ANC $\leq 0 \mu \mathrm{eq} / \mathrm{L}$. Eighty-nine percent of the fishless lakes had ANC $<25 \mu \mathrm{eq} / \mathrm{L}$, and $93 \%$ had ANC $<50 \mu \mathrm{eq} / \mathrm{L}$. Small changes in ANC in the range of -25 to $25 \mu \mathrm{eq} / \mathrm{L}$ ( $60 \%$ of the fishless lakes) can result in large changes in $\mathrm{pH}$ (see Section 2.3 ). Finally, the vast majority $(95 \%)$ of the fishless lakes had fairly low levels of $\mathrm{Ca}_{1} \leq 100 \mu \mathrm{eq} / \mathrm{L}(\leq 2 \mathrm{mg} / \mathrm{L})$.

Inorganic Al concentrations that are toxic to fish vary depending on the fish species, life stage, $\mathrm{pH}, \mathrm{Ca}$, and other factors (5. 4 and Schofield 1982, Johnson et al. 1987, Mount et al. 1989). Most of the lakes with fish present had estimated inorganic Al concentrations $<250 \mu \mathrm{g} / \mathrm{L}$ (Figure 3.2-16). In contrast, fishless lakes had a wide range of values. About $75 \%$ of the drainage lakes without fish had estimated inorganic Al levels $>500 \mu \mathrm{g} / \mathrm{L}$ (Figure 3.2-18). On the other ind, seepage lakes, both with and without fish, had quite low levels of inorganic Al.

Forty-six lakes were classified by the ALSC as bog ponds (seepage lakes with at least $90 \%$ of the shoreline vegetation composed of Sphagnum spp.). No fish were caught in any of these lakes (representing $13 \%$ of the fishless lakes). In addition, no fish were caught in $29 \%$ of the ALSC lakes classified as marginal bogs (seepage or drainage lakes with $50-90 \%$ of the shoreline vegetation composed of Sphagnum spp: $n=194$ lakes) or $20 \%$ of the nonbog waters (seepage or drainage lakes with $<50 \%$ of the shoreline surrounded by Sphagnum spp; $n=1229$ lakes) (Figure 3.2-19a). The absence of fish from bogs prcbably reflects the combined effects of low DO concentrations, poor spawning substrate, and naturally low-pH lavels in these waters. However, a substantial portion 
a)

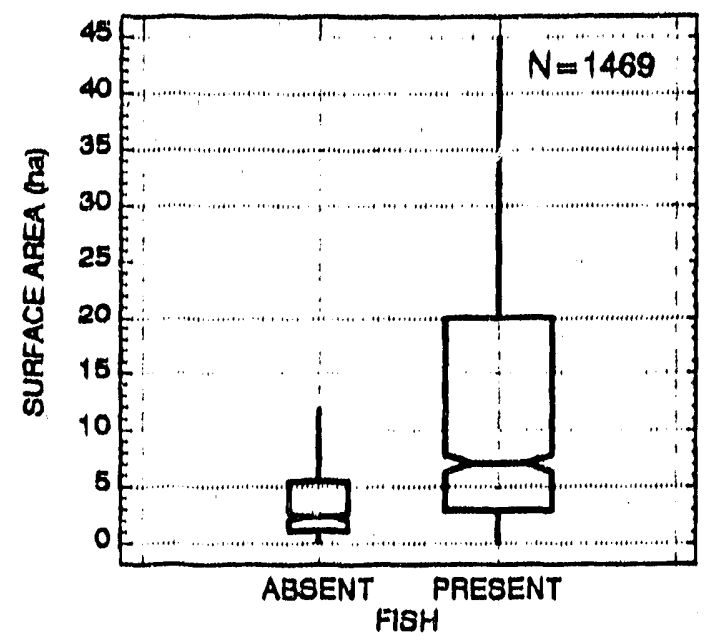

c)

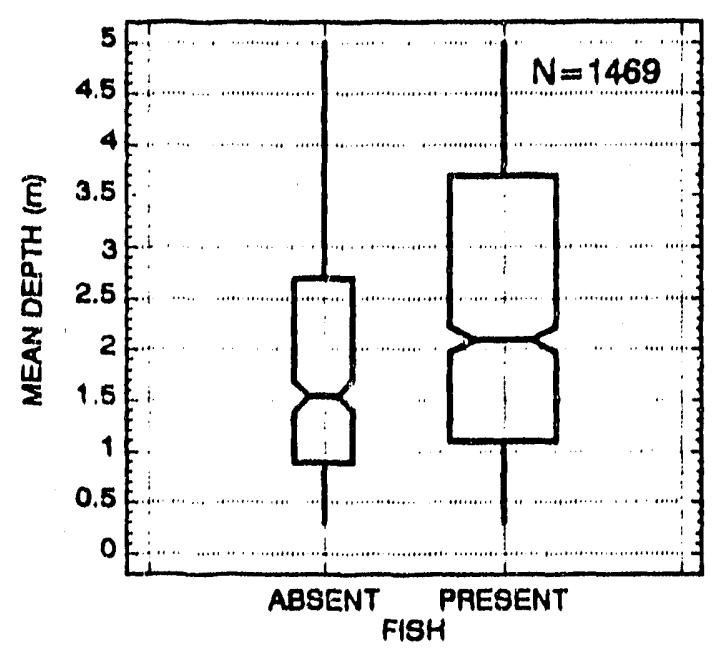

b)

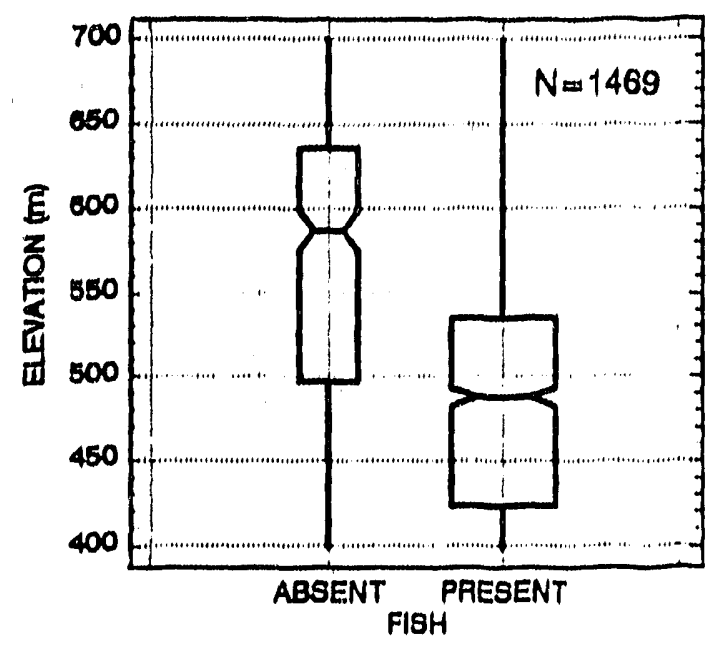

d)

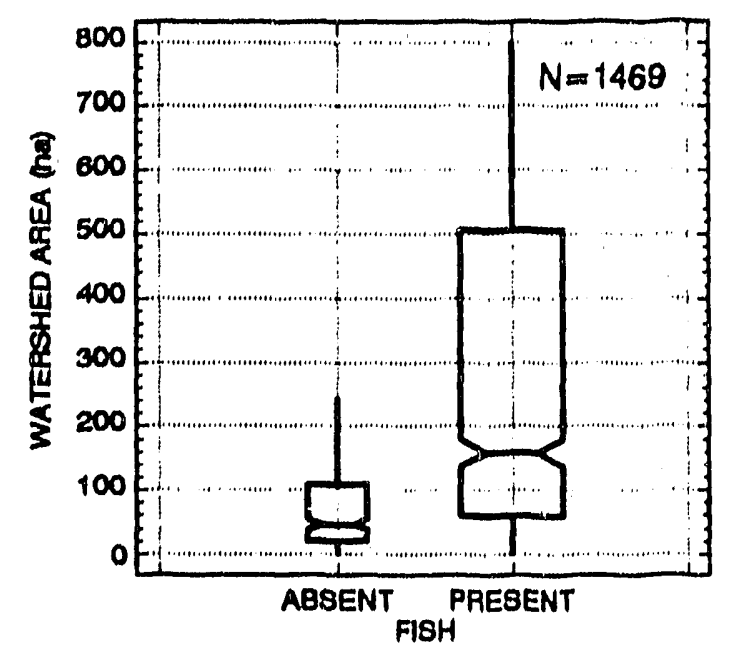

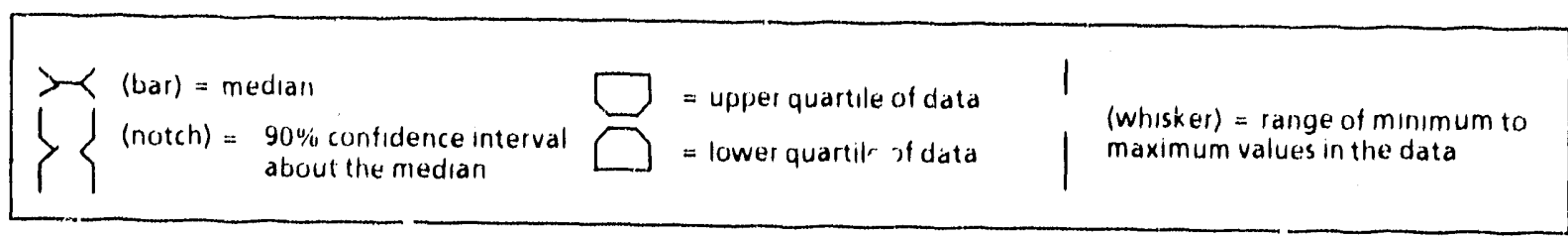

Figure 3.2-14 Notched box and whisker plots of (a) surface area, (b) elevation, (c) mean depth, and (d) watershed area by fish presence or absence for ALSC lakes. 

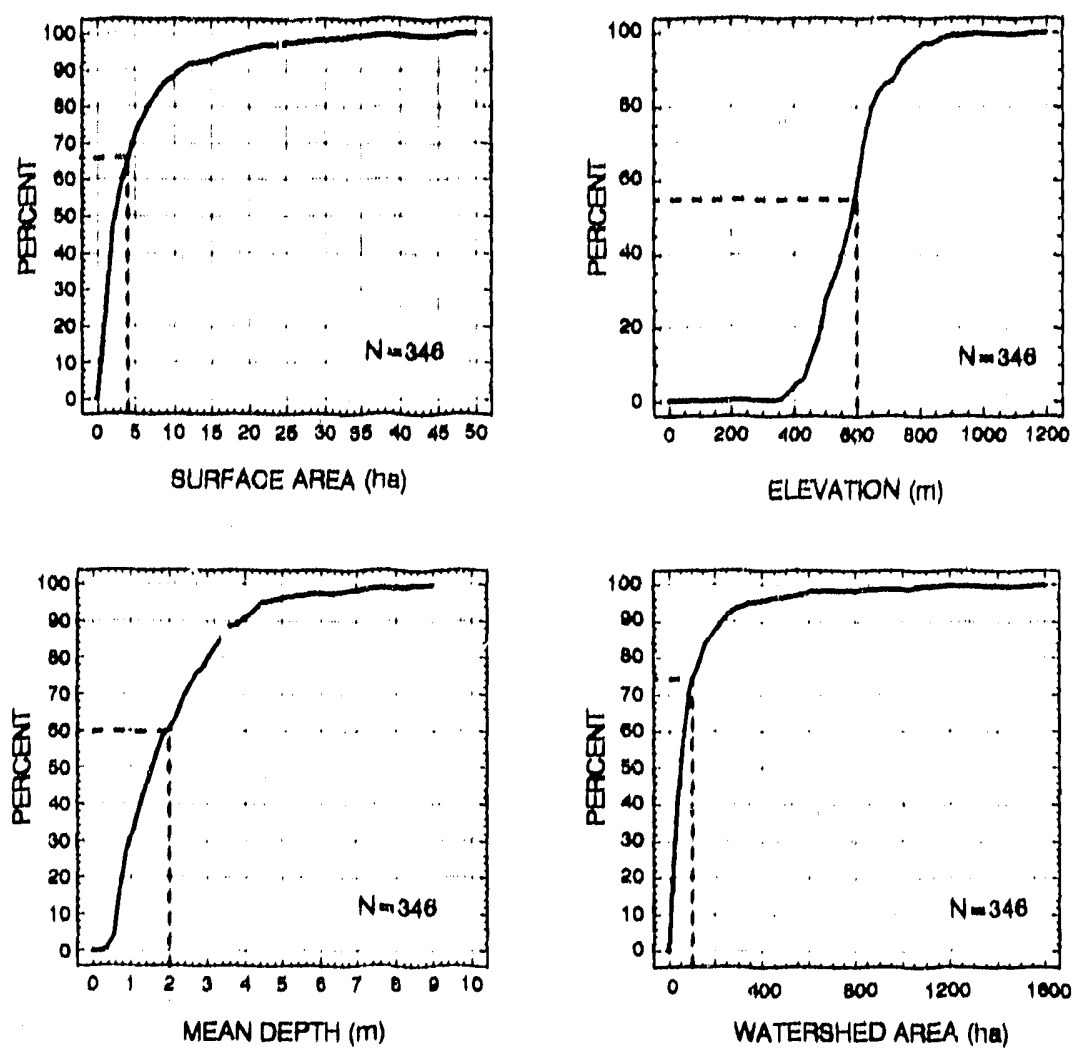

Figure 3.2-15 Cumulative frequency distributions of (a) surface area, (b) elevation, (c) mean depth, and (d) watershed area for ALSC lakes with fish absent.

$(71 \%)$ of the lakes without fish were in nonbog lakes. An additional 16\% of the fishless lakes were considered to be marginal bogs.

Among the lake classes based on water chemistry and hydrology (Section 2.4), the vast majority (89\%) of the lakes without fish fall within two lake classes: (1) mounded seepage lakes and (2) drainage lakes with thin-till watersheds (Figure 3.2-19b). Half of the lakes included in these two classes had no fish, while $2-18 \%$ of the lakes in the other five major lake classes were fishless. Seepage lakes, in general, were more frequently fishless $(40 \%)$ than were drainage lakes $(20 \%)$, al though lakes classified as mounded seepage lakes ( $\mathrm{Ca}<50 \mu \mathrm{eq} / \mathrm{L}$ ) were much more likely to be fishless $(65 \%)$ than were lakes classified as flow-through seepage lakes ( $\mathrm{Ca}>50 \mu \mathrm{eq} / \mathrm{L})(18 \%$ fishless) All but two of the lakes classified as bogs by the ALSC fall within the mounded seepage lake class.

A number of the lakes without fish ( $n=87 ; 25 \%$ of the fishless waters) were small lakes ( $\leq 4$ ha) at high elevations $(>600 \mathrm{~m})$. Small, high-elevation lakes may be subject to periodic winterkills and also tend to have poor substrate for spawning and poor access for fish immigration. Many of these small, high-elevation lakes also have low pH (Figure 32 20). Thus, a number of factors may account for the 
a)

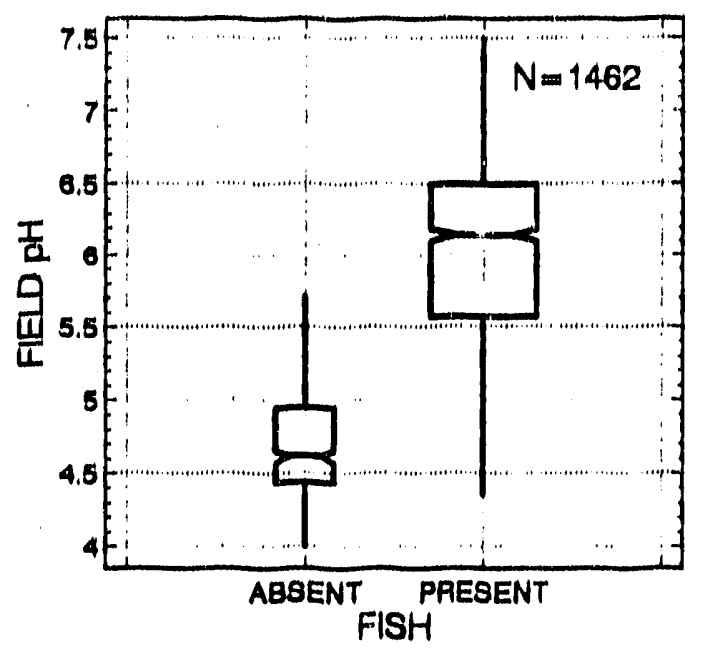

c)

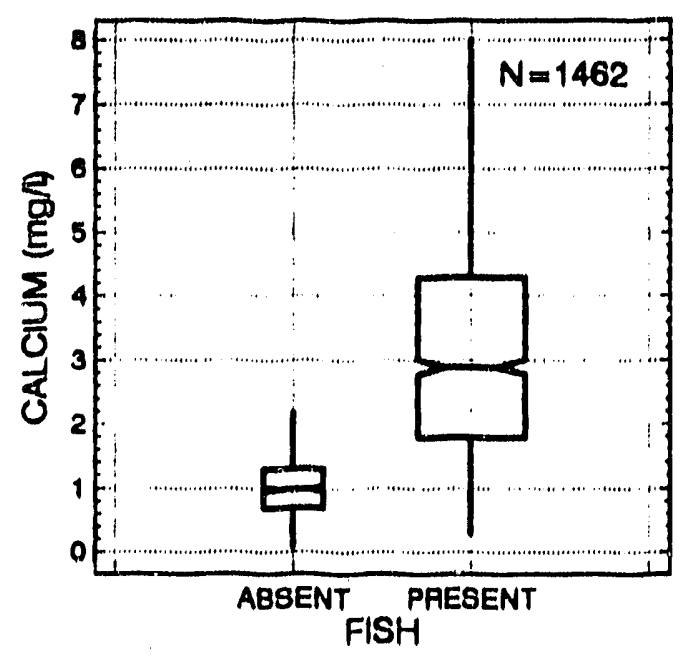

b)

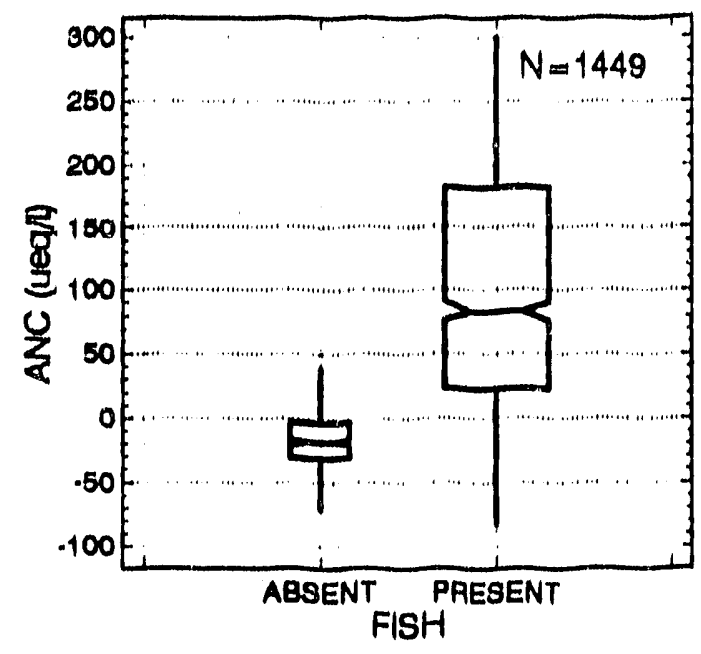

d)

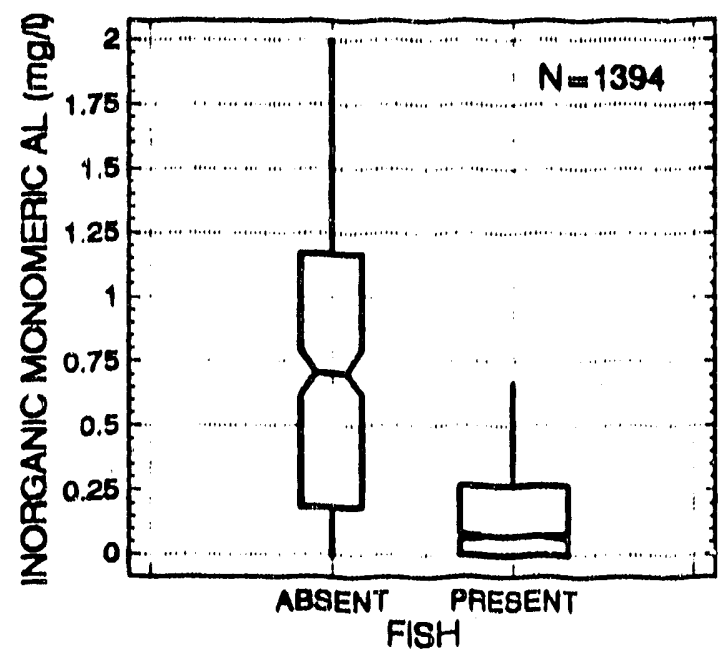

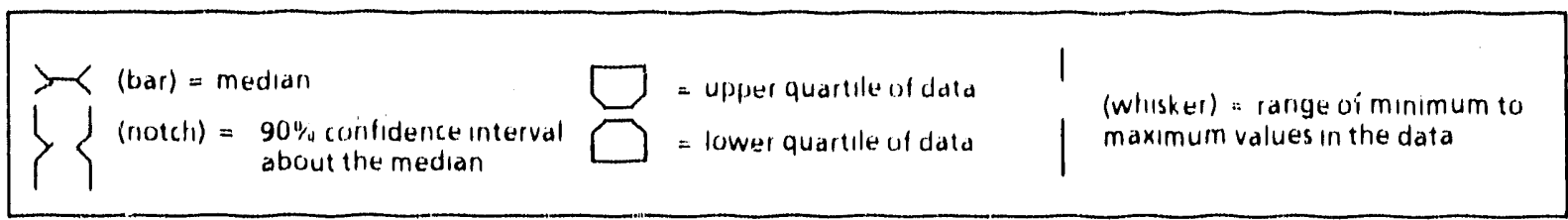

Figure 3.2-16 Notched box and whisker plots of (a) field pH, (b) ANC, (c) calcium, and (d) inorganic monomeric Al by fish presence or absence for ALSC lakes. 

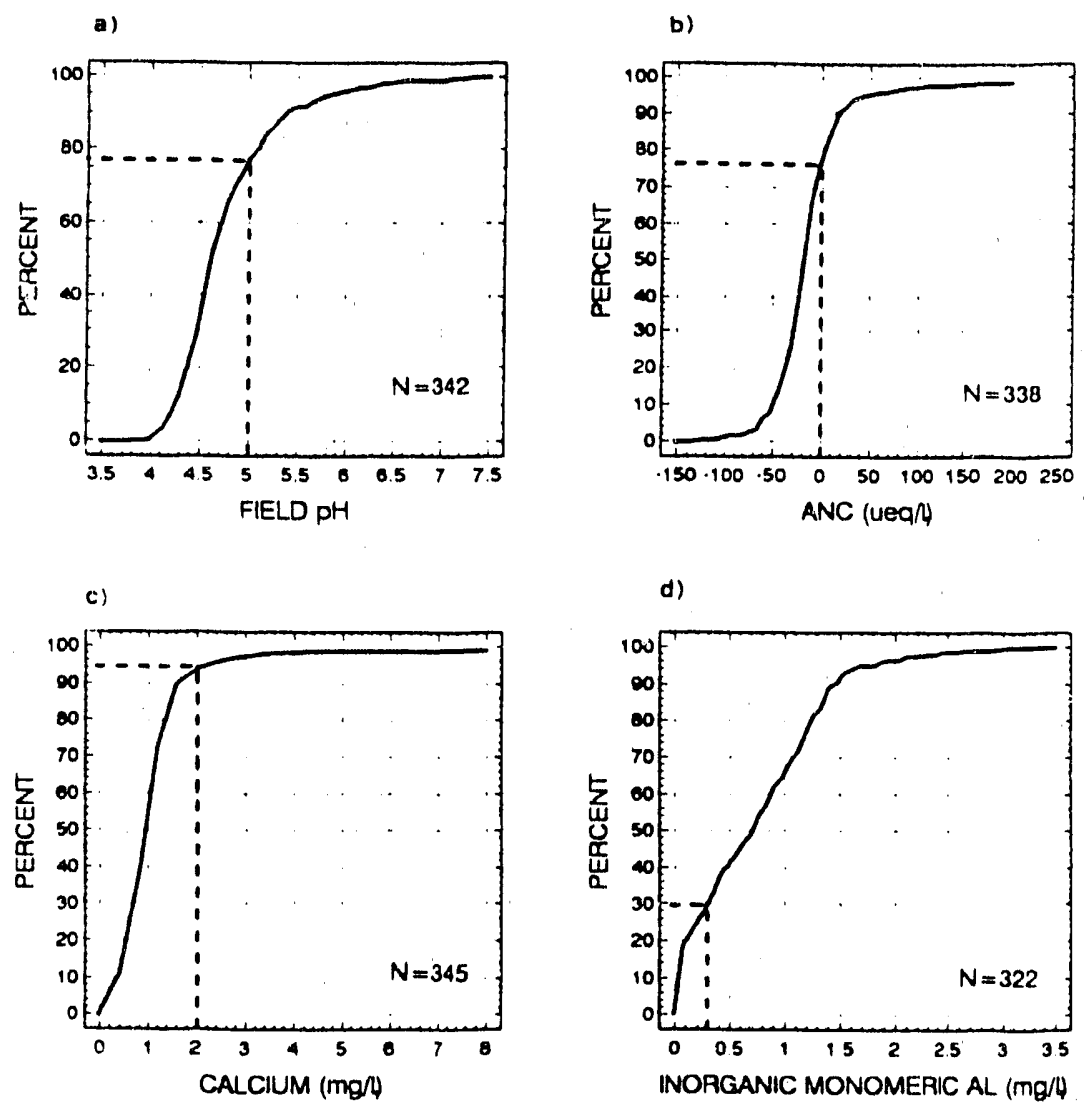

Figure 3.2-17 Cumulative frequency distributions of (a) field pH, (b) ANC, (c) calcium, and (d) inorganic monomeric Al for ALSC lakes with fish absent.

absence of fish from these waters, and the primary reason for fish absence is likely to vary among lakes. For example, no fish were caught in $44 \%$ of the sma!! ! $\leq 4$ ha), high-elevation ( $>600 \mathrm{~m}$ ), nonbog drainage lakes with $\mathrm{pH}>5.5$ (Figure $3.2-21$ ); the absence of fish from these lakes probably results from factors other than acidity. In contrast, $96 \%$ of the small, high-elevation drainage lakes with $\mathrm{pH} \leq 5.0$ were fishless. The small, high-elevation lakes without fish also had significantly ( $p \leq 0.05$ ) lower $\mathrm{pH}$ than did small, high-elevation lakes with fish, suggesting that low $\mathrm{pH}$ plays an important role in the absence of fish from at least some of these lakes.

The estimated fraction of the $\mathrm{H}^{+}$supported by organics, as defined in Section 2.51 , provides an approximate index of the acidity sources in Adirondack lakes Among fishless lakes, nearly $60 \%$ apparently had greater than one-half af their $\mathrm{H}^{*}$ supported by organics based on summer, surfacewater chemistry (Figure 3.2-22). Sources of acidity and $\mathrm{H}^{+}$are of interest, however, primarily in low-pH lakes, where the $\mathrm{H}^{*}$ and associated acid-base chemistry variables may have adverse effects on fish communities. Among fishless lakes with $\mathrm{pH} \leq 5.0$, excluding the 46 bog lakes, nearly an equal number of lakes were dominated by mineral acids as by organic acids (i.e. $<0.5$ and $>05$, respectively of $1.1^{+}$was supported by organics). In addition, low-pH lakes with a low estimated 
a)
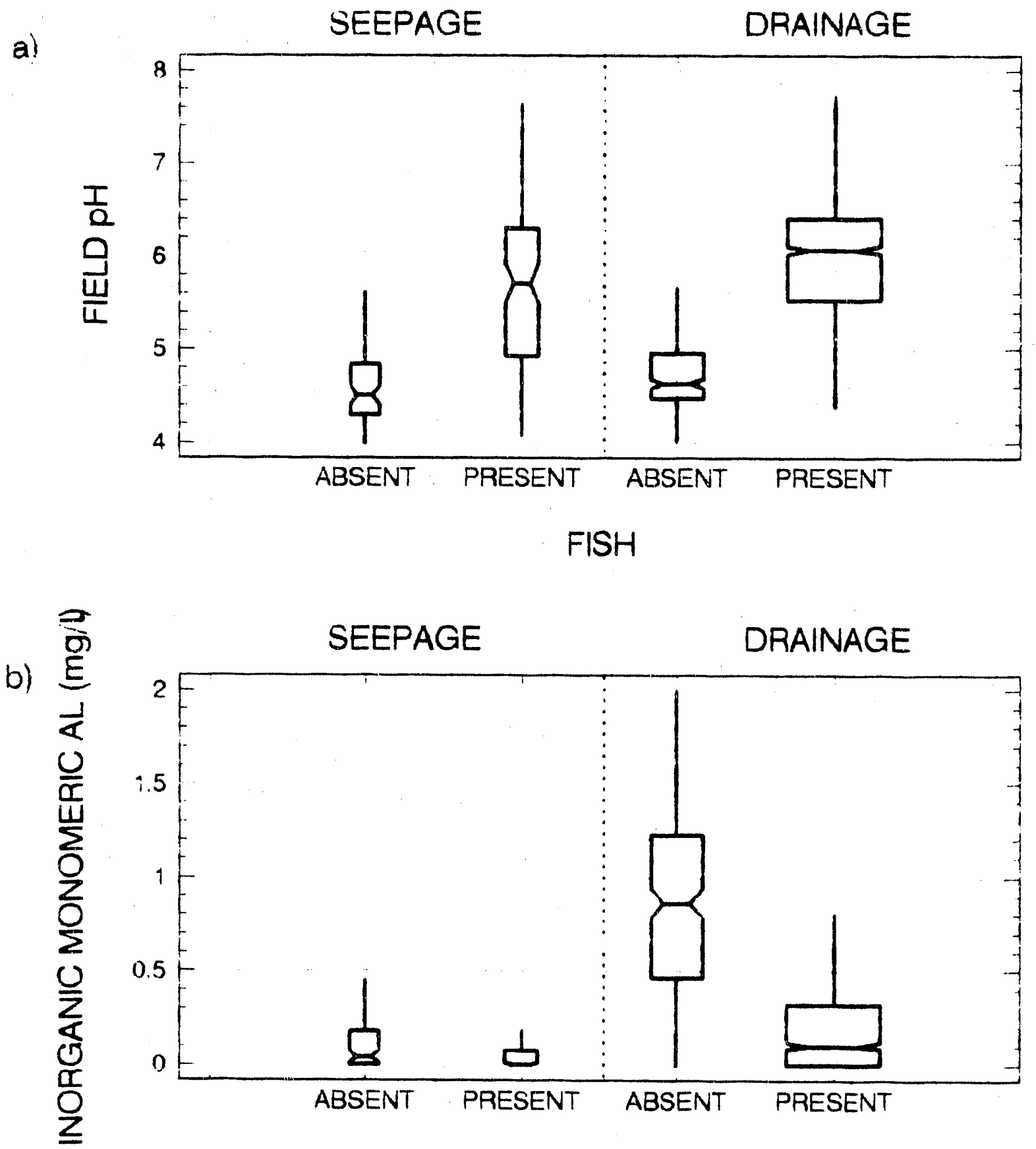

$\mathrm{FISH}$

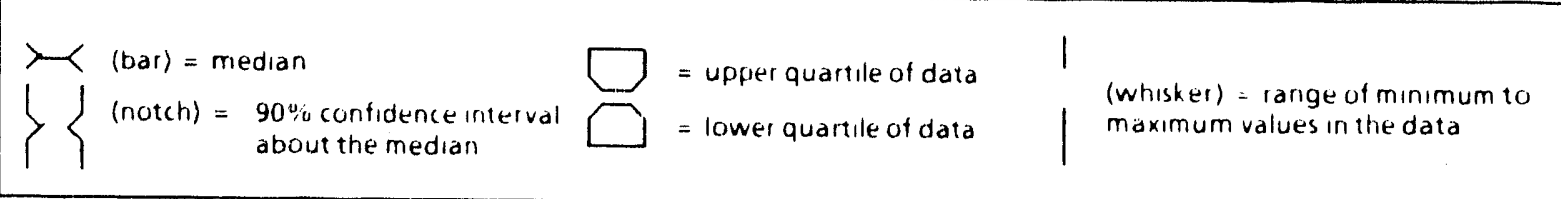

Figure 3.2-18 Notched box and whisker plots of (a) field pH and (b) estimated inorganic Al by fish presence or absence for ALSC seepage and drainage lakes. 
a)

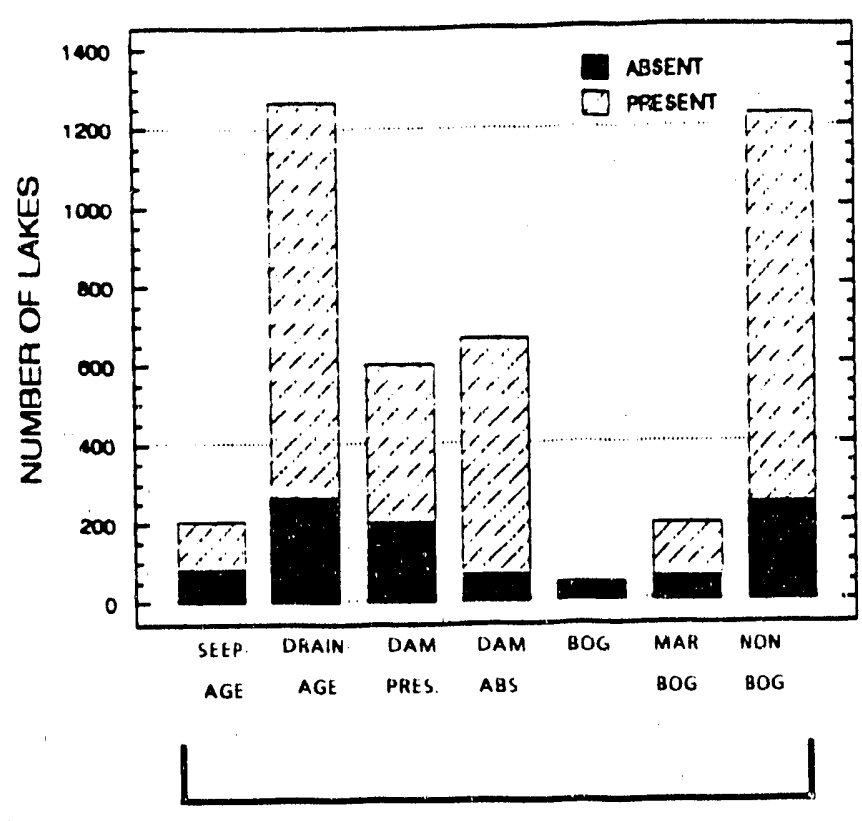

b)

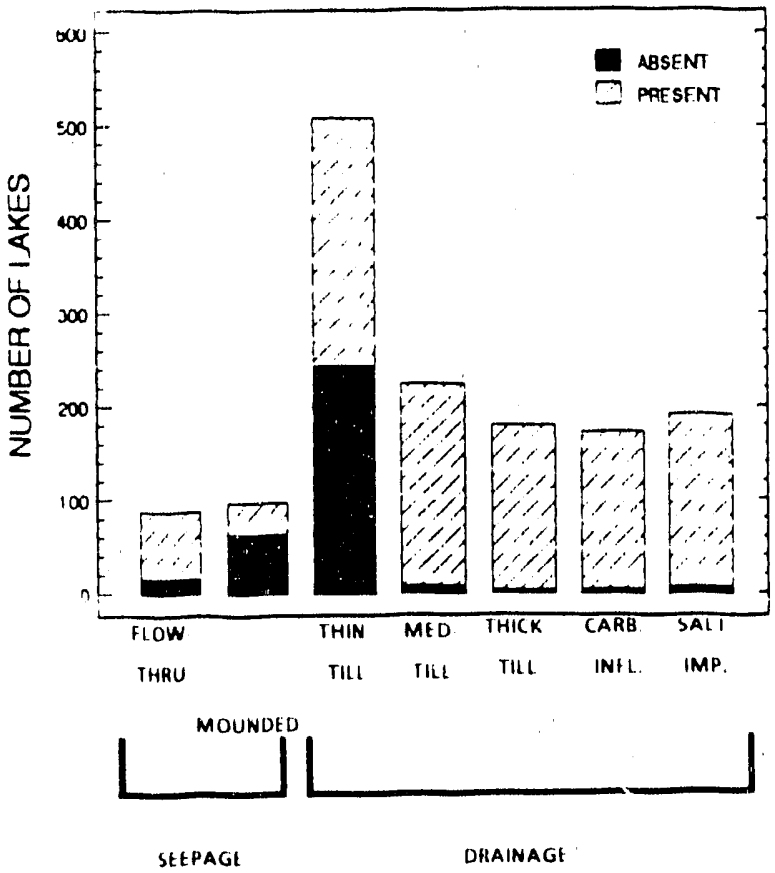

Figure 3.2-19 Fish presence and absence for lake categories defined by (a) the ALSC based on field observable characteristics and (b) measured water chemistry and hydrology.

fraction ( $\leq 0.5)$ of the $\mathrm{H}^{+}$supported by organics were, on average, more likely to be fishless than were lakes with organics as the dominant source of acidity (Figure 3.2-23). Thus, although the source of acidity cannot be determined definitively, the high acidity in many of these low-pH fishless lakes cannot be attributed predominantly to natural organics and appears to have resulted, at least in part. from atmospheric inputs of strong mineral acids.

No similar relationship is evident between fish presence/absence and DOC levels in low-pH lakes (Figure 3.2-24), indicating that DOC, by itself, is a fairly poor index of potential effects on fish.

Finally, the relationship between the estimated fraction of $\mathrm{H}^{+}$supported by organics and the occurrence of fishless lakes can be examined specifically for those lake classes containing the majority of fishless lakes: mounded seepage and thin-till drainage lakes (Figure 3.2-25). Most of the high-DOC mounded seepage lakes with $\mathrm{pH} \leq 5.0$ were fishless and also had a high fraction of the $H^{*}$ supported by organics. Many of these lakes were calegorized as bogs by the ALSC. Thus, the absence of fish from these lakes may result principally from the lack of suitable fish habitat in bogs. Among low-pH, low-DOC mounded seepage lakes, on the other hand, the majority of lakes without fish had a low 

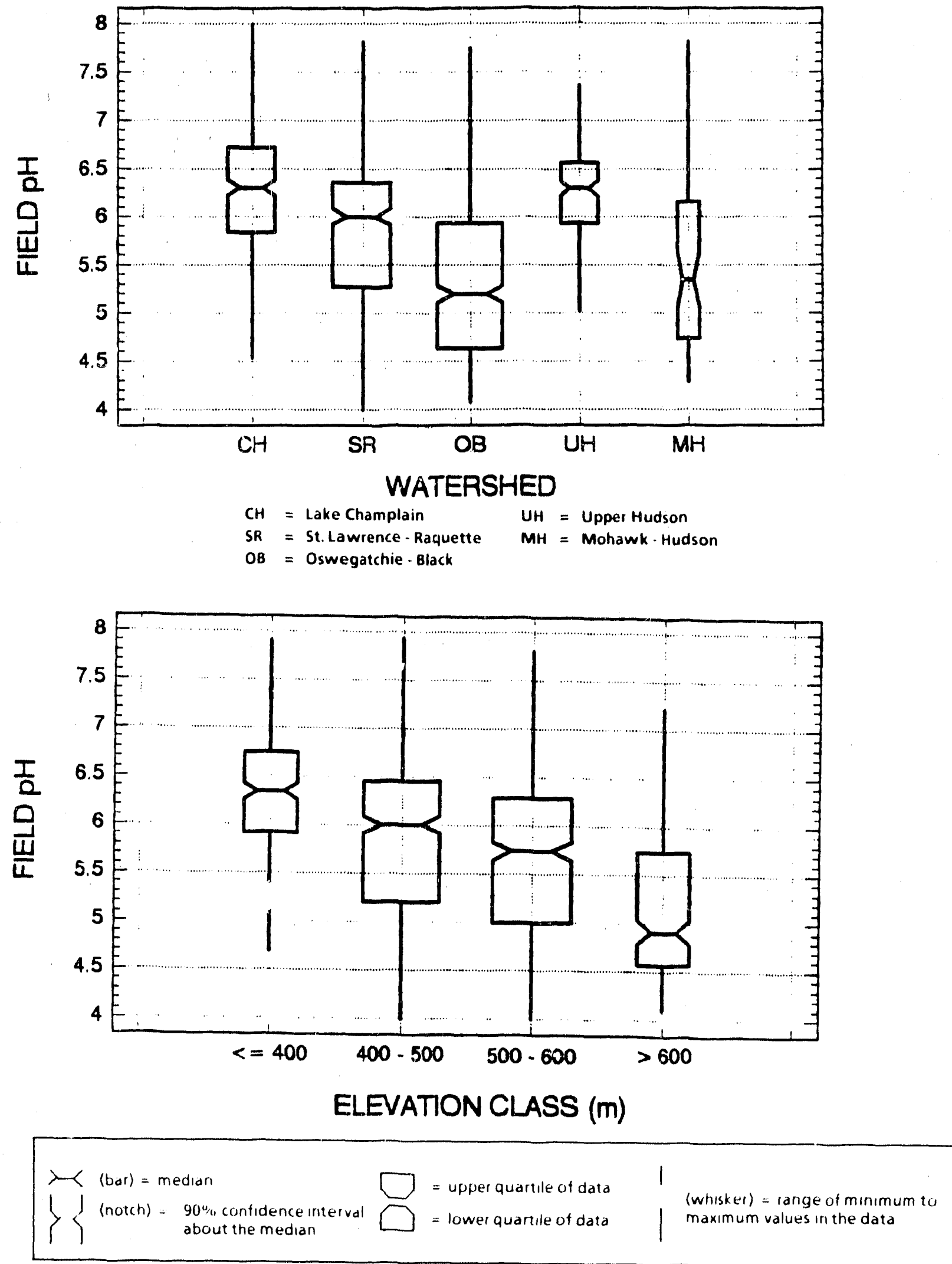

Figure 3.2-20 Notched box and whisker plots of field pH for (a) lakes at $>600 \mathrm{~m}$ elevation in the five major Adirondack watersheds and (b) lake elevation classes. 


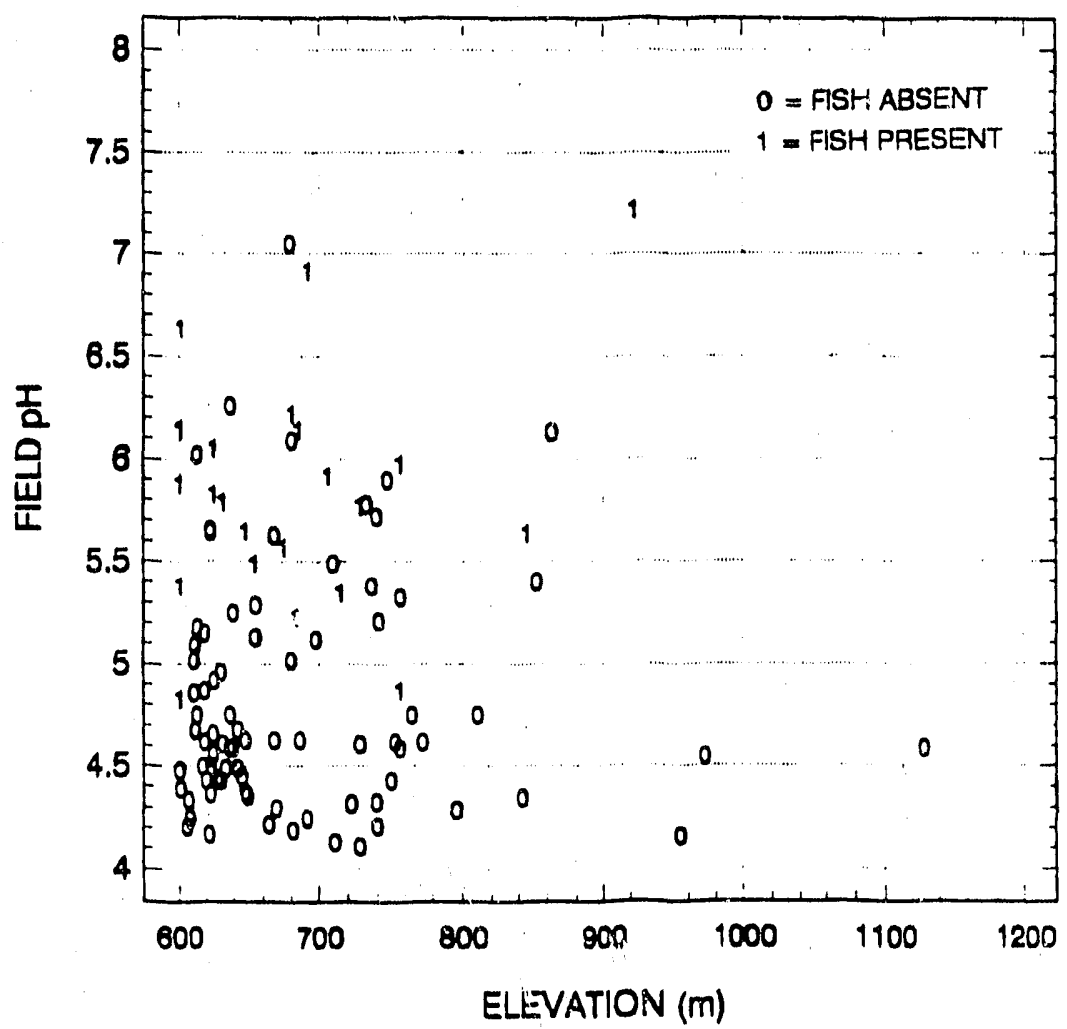

Figure 3.2-21 Field $\mathrm{pH}$ and elevation for small ( $\leq 4 \mathrm{ha}$ ), high-elevation ( $>600 \mathrm{~m}$ ), nonbog drainage lakes with fish present or absent.

fraction of the $H^{*}$ supported by organics; also the proportion of lakes that were fishless was substantially higher for lakes with a low fraction of the $\mathrm{H}^{+}$supported by organics than for lakes apparently dominated by organic sources of acidity. In thin-til! drainage lakes with low pH, fishless lakes were fairly equally distributed between lakes with high and low fractions of the $\mathrm{H}^{*}$ supported by orgarics. ihe proportion of lakes in which no fish were caught was somewhat higher, however, among lakes dominated by mineral rather than organic acids.

Thus, lakes 'without fish have a diversity of characteristics, reflecting the number of factors that determine a lake's suitability for fish survival and reproduction. Forty-six of the fishless lakes were characterized as bogs, which are naturally poor fish habitat. Thirty lakes had a field $\mathrm{pH}>5.5$; the absence of fish from these lakes probably results from factors other than acidity. Of the remaining 270 fishless lakes, 219 had $\mathrm{pH} \leq 5.0$ and 51 had pH 5 0.5.5. Approximately half (145 lakes; $54 \%$ ) of these low-pH, fishless lakes had a relatively high estimated fraction $(>0.5)$ of the $\mathrm{H}^{*}$ supported by organics ( 116 lakes had $>0.9$ of the $H^{*}$ supported by orgarsics). The remaining 125 lakes had a low estimated fraction ( $\leq 0.5$ ) of the $H^{+}$supported by organics ( 81 lakes with $\leq 0.1$ ) and appear to be dominated instead by mineral acids. All but five of these lakes had pH $\leq 50$. Thirty-one of the 
(a)

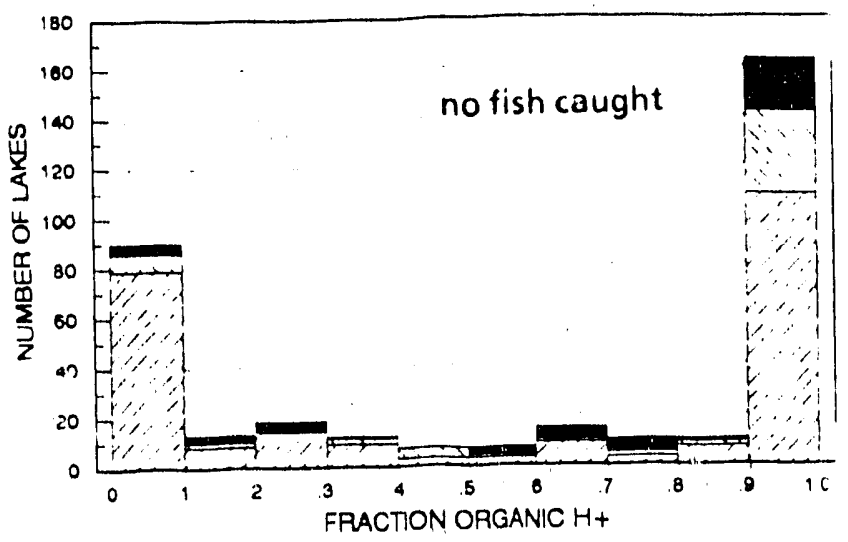

(b)

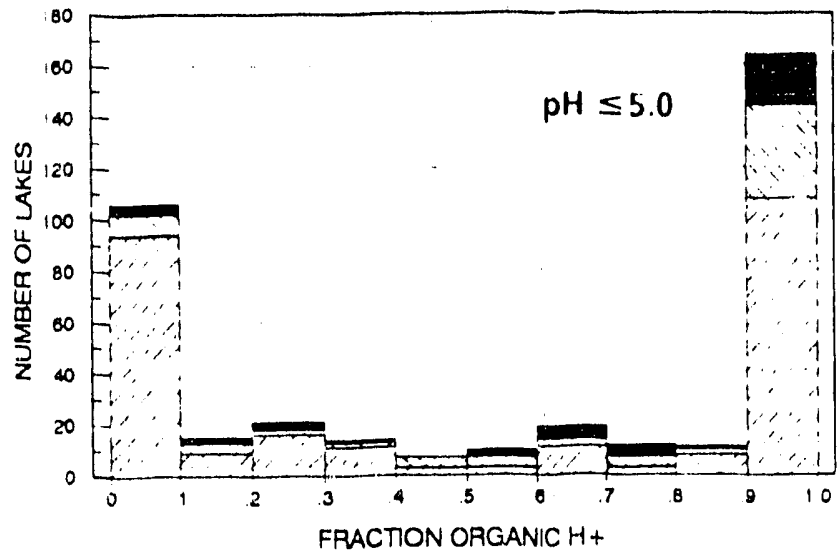

NON-BOG

MAR. BOQ

$B O Q$

Figure 3.2-22 Estimated fraction of hydrogen ion concentration supported by organics for (a) lakes with no fish caught and (b) lakes with no fish caught and with $\mathrm{pH} \leq \mathbf{5 . 0}$.

low-pH mineral acid lakes were small ( $\leq 4$ ha) lakes at high elevation $(>600 \mathrm{~m})$. Some portion of these small, high-elevation lakes would lack fish regardless of the lake $\mathrm{pH}$ (perhaps about $40 \%$ or 12 lakes, based on the proportion of small, high-elevation lakes with $\mathrm{pH}>5.5$ that were fishless). Thus, although reasons for the absence of fish cannot be identified with certainty, an estimated 113 lakes do not have organics as the dominant source of acidity and have no obvious explanation for the total absence of fish other than acid-base chemistry. For these lakes, acidic deposition is the most reasonable explanation for the observed fish absence

The relationship between fish presence/absence and lake characteristics is explored further using multivariate regression analyses in Section 3.4. The potential effecis of acid-base chemistry and other lake characteristics on individual fish species and species richness are also examined in subsequent sections (Sections 3.4 through 3.6). Changes in fish species composition or lower species richness may occur at more moderate environmental conditions than those that result in the total absence of fish from a lake. 

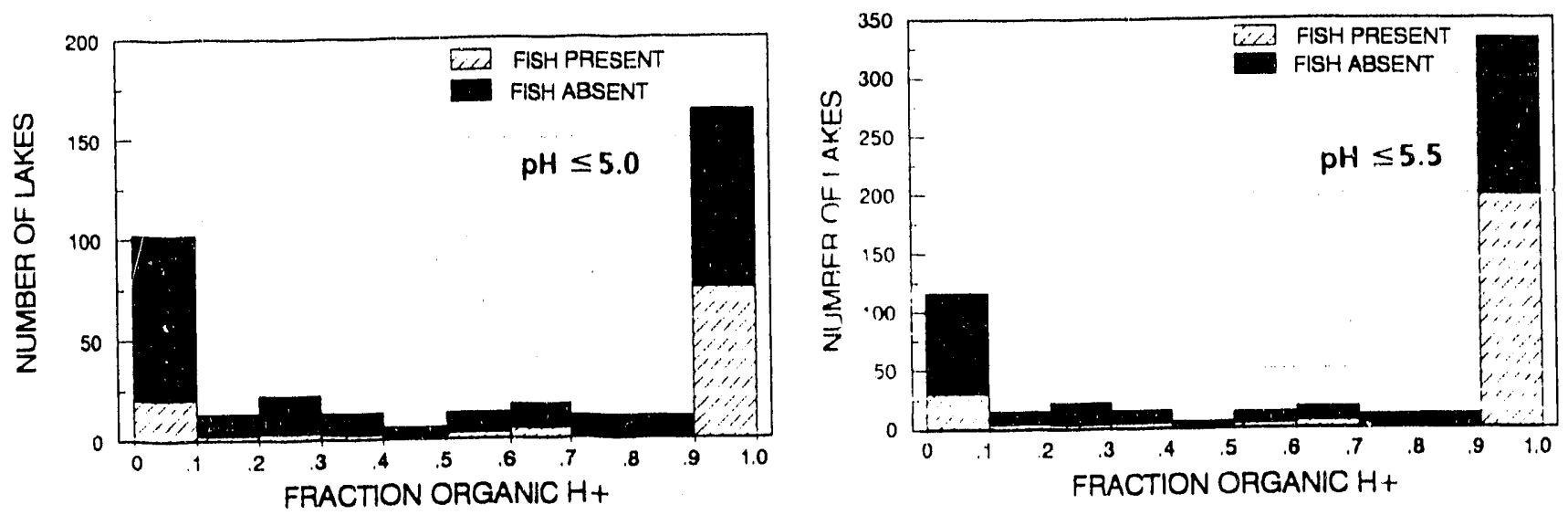

Figure 3.2-23 Estimated fraction of hydrogen ion concentration supported by organics (summer surface-water chemistry) for lakes with fish present and absent for (a) lakes with field $\mathrm{pH} \leq \mathbf{5 . 0}$ and (b) lakes with field $\mathrm{pH} \leq \mathbf{5 . 5}$.

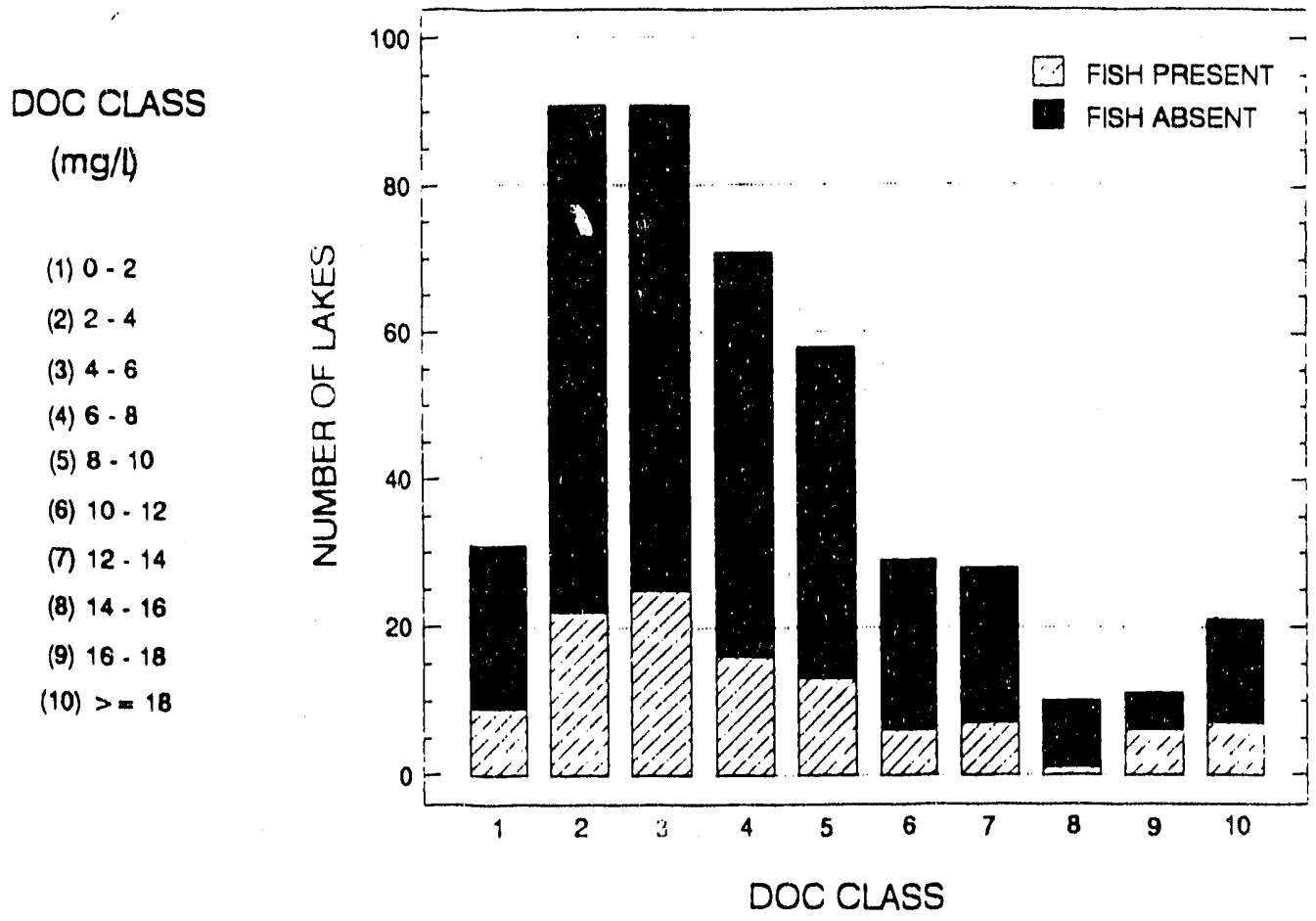

Figure 3.2-24 Numbers of lakes with fish present and absent by DOC classes. 

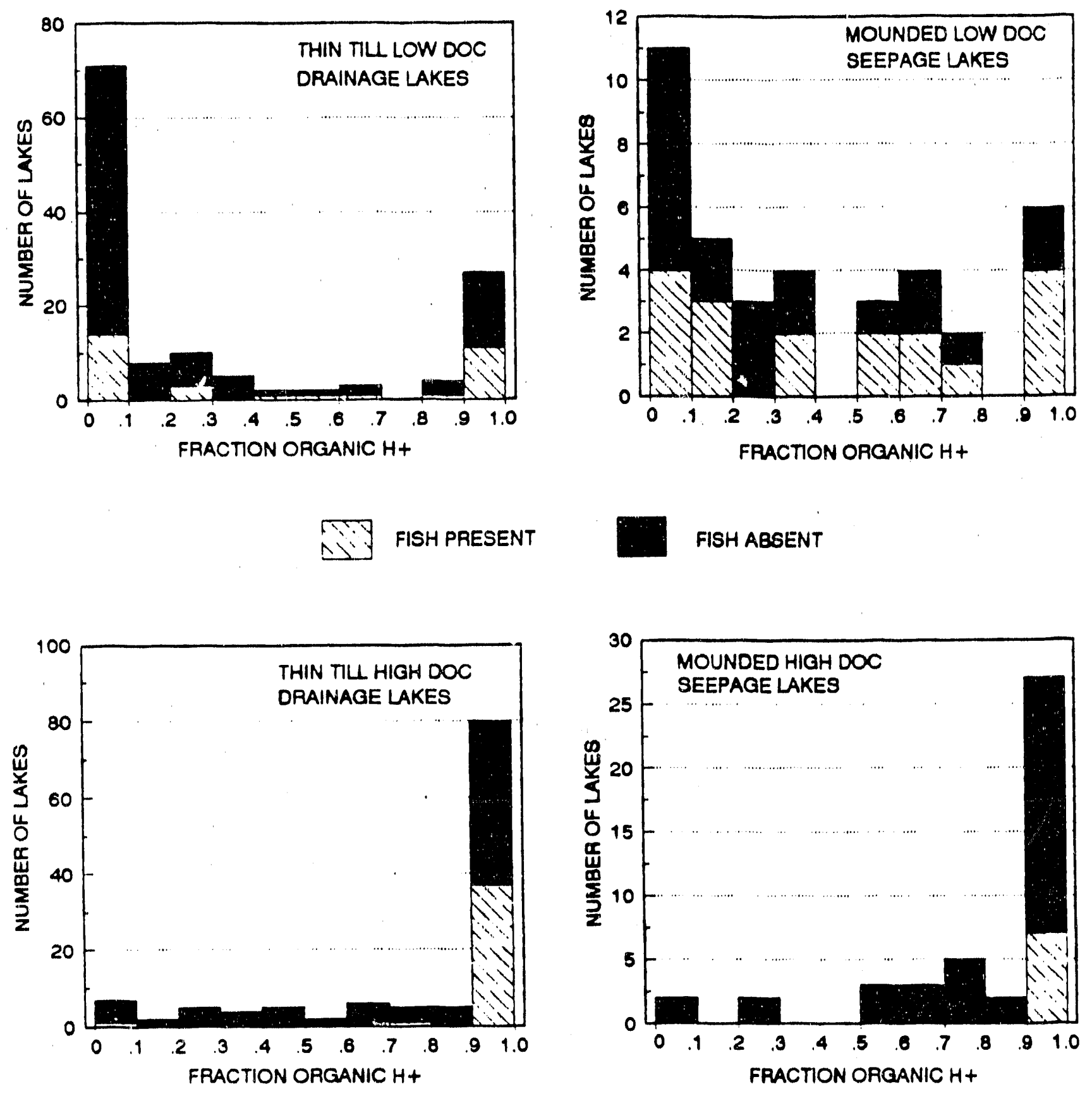

Figure 3.2-25 Estimated fraction of hydrogen ion concentration supported by organics (summer surface-water chemistry) for lakes with field $\mathrm{pH} \leq \mathbf{5 . 0}$ and fish present and absent in selected lake classes. 


\subsection{HABITAT SUITABILITY FOR BROOK TROUT NATURAL REPRODUCTION IN ADIRONDACK LAKES}

\section{Schofield}

\subsubsection{Introduction}

The brook trout (Salvelinus fontinalis) is the primary gamefish indigenous to the Adirondack region. Although brook trout are still widely distributed across the major drainage basins of the Adirondacks, they are notably absen : from many acidic waters in the western drainages (Kretser et al. 1989). Several management programs and experimental liming studies in the Adirondacks (Kretser and Colquhoun 1984, Schofield et al. 1986, Gloss et al. 1989) have demonstrated that brook trout populations can be established and maintained successfully by stocking in a variety of acidic lake types (including bog, seepage, and drainage lakes) if water quality is controlled by limestone applications and other physical and chemical conditions are suitable for brook trout survival. However, relatively few self-maintaining brook trout populations (i.e., natural spawning adequate or NSA) have been established after acidic lakes were limed and stocked. Successful natural reproduction by stocked trout was observed in only 1 of 10 limed drainage lakes in the Extensive Liming Study (Schofield et al. 1986), and intensive efforts (including repeated lake liming, stor.king, and spawning habitat improvement) to develop an NSA brook trout population in one acidified Adirondack lake (Woods Lake) have been unsuccessful to date (Gloss et al. 1989).

The brook trout has been described as an obligate, groundwater-spawning species in both lake and stream environments (Benson 1953, Webster 1962, Webster and Eriksdottir 1976). Observations on brook trout spawning behavior and reproductive success in Adirondack lakes support this hypothesis (Webster 1962, Webster and Eriksdottir 1976). NSA brook trout populations in Adirondack lakes generally spawn only in nearshore areas or tributary streams having well-defined groundwater seepage zones. In brook trout lakes where tributaries support natural reproduction, nearshore seepage areas are also generally used for spawning. However, the relative contributions of recruitment from tributary and in-lake spawning to population maintenance are not generally known. Some NSA populations have been established in Adirondlack lakes where brook trout were previously absent or not self maintaining by installing artificial spawning boxes that receive piped-in tributary water to simulate groundwater upwelling (Webster 1962, Gloss et al. 1989). Spawning substrate composition is probably secondary in importance to groundwater seepage velocity and quality for successful natural reproduction. Although gravel tends to be the preferred substrate, brook trout have been observed spawning over silt and sand bottoms having low velocity seepage zones (Webster 1962, Gloss et al. 1989). Reproductive success tends to be limited in these latter 
situations by high egg mortality within the redds, and recruitment is probably not adequate to maintain viable populations. Lakes having significant groundwater flux are also likely to have areas with suitable spawning subsurate as a result of sorting effects by percolating ground water.

Additionally, very small spawning areas with suitable substrate and groundwater percolation are often adequate to maintain successful natural reproduction (Webster 1962, Carline 1980).

Prediction of NSA status (either historically or in the future) for the large number of currently acidic Adirondack lakes not supporting brook trout would be of value from both management and assessment perspectives. The ALSC data base was used in this study to examine the relationships between habitat characteristics and the reproductive status of Adirondack brook trout populations. The primary objective of this study was to evaluate criteria suitable for identifying Adirondack lakes with the potential to support brook trout natural reproduction. Based on the general knowledge of brook trout spawning requirements described above, it was hypothesized that Adirondack lakes receiving significant groundwater contributions to nearshore zones should have the greatest potential for NSA brook trout status.

\subsubsection{Methods}

\subsubsection{Approach}

Brook trout were captured in 579 ALSC lakes surveyed during the period 1984-87. This subset of lakes was initially used to evaluate criteria suitable for identifying lakes with the potential to support natural brook trout reproduction. These lakes were classified into NSA (72 lakes) and non-NSA (507) categories in the data base. Lakes were designated NSA (Kretser et al. 1989) if they had not been stocked within 5 years of the survey, 5 or more trout were present in the survey sample, and the lake was of public or public/private ownership. (The latter criterion was to ensure valid stocking histories.) All other lakes in which brook trout were captured but that did not meet these criteria were designated non-NSA. Although these criteria adequately identified some NSA populations, this classification scheme could not be used to compare habitat characteristics between categories because the non-NSA category could include lakes that have reproducing brook trout populations.

For the purpose of this study, it was necessary to more specifically identify lakes that contain only brook trout of stocked origin and lakes with brook trout originating from natural repioduction. This classification was primarily accomplished by using the presence or absence of young-of-the-year (YOY) brook trout in the survey sample and stocking records to establish origin. The new categories created and their identifying criteria are outlined in Figure 3.3-1. Since young-of-year brook trout were not vulnerable to the sampling gear during the spring moiths, only lakes sampled in the fall (September - November) were selected for this analysis. Additionally, lakes stocked with fall 


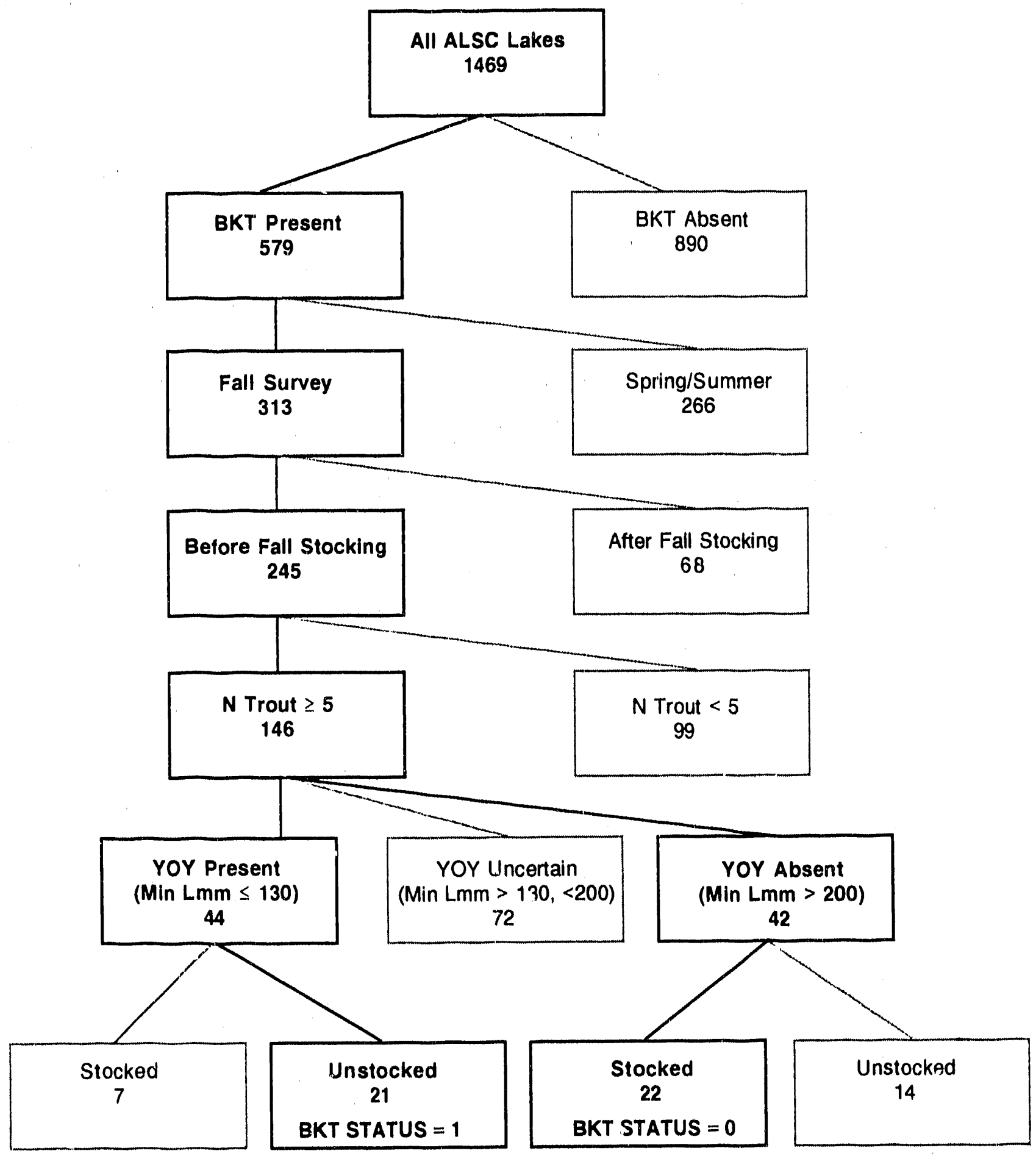

Figure 3.3-1 Screening criteria utilized in development of brook trout status classification for ALSC lakes. 
fingerling brook trout during the year of survey and prior to sampling were excluded to eliminate young-of-year of stocked origin. A minimum length criterion, rather than age, was used to establish presence/absence of young-of-year trout because not all fish from each lake were aged and also to exclude potential aging errors. Using length frequencies by age class for all brook trout captured during fall surveys (Figure 3.3-2), young-of-year presence was based on occurrence of fish $\leq 130 \mathrm{~mm}$ and young-of-year absence was based on minimum length $\geq 200 \mathrm{~mm}$. Fish of intermediate size were classified as uncertain YOY status. The bimodal length distribution for age $0+$ fish (Figure 3.3-2) could have resulted from a number of factors such as aging errors, differences in time of fry emergence, and/or variations in population growth rates. However, there was no significant difference $(p<0.05)$ in mean lengths of age $0+$ brook trout from stocked and unstocked lakes. Only lakes where five or more trout were obtained in the survey sample were used to minimize the effects of small sample size on minimum length of trout captured (Figure 3.3-3). Lakes that had young-ofyear present and that were not stocked during the year of the survey were classified as naturally reproducing populations (BKT STATUS $=1$ ). Lakes where no young-of-year were captured and which had been stocked for at least 5 years prior to the survey were classified as lakes not supporting natural reproduction $($ BKT STATUS $=0$ ).

\subsubsection{Analyses}

Comparisons of physical, chemical, and morphometric variables potentially related to habitat suitability for brook trout reproduction and presence in the ALSC data base were conducted for the young-of-year presence/absence and stocking categories described above using a two-factor analysis of variance model (Snedecor and Cochran 1980). Category I (YOY present, unstocked) and Category II (YOY absent, stocked) brook trout lakes were coded to values of 1 and 0 , respectively. This coded variable (STATUS) was used for nonparametric paired comparisons to identify variables potentially useful as indices of habitat suitability for brook trout natural reproduction and in subsequent models of reproductive status developed by logistic regression analysis (Steinberg 1988). Pairwise comparisons included contingency table analysis for categorical variables and Kolmogorov-Smirnov chi-square tests for continuous variables (Hollander and Wolfe 1973). Independen: variables with skewed distributions were normalized by $\log _{10}$ (or $\log _{10} x+1$ for variables with 0 values) prior to use in logistic regression analyse's. A log likelihood chi-square statistic was used as a test of the hypothesis that model coefficients are equal to zero. Model performance was evaluated by comparison of the sum of predicted probabilities with observed numbers of lakes in each STATUS category and by comparison of the predicted numbers of lakes in each category', based on probabilities $\geq 0.5$ (Category I) or $<0.5$ (Category II) for both caiibration and verification data sets. The latter data included lakes not utilized in model calibration, but classified as INSA by ALSC criteria. These were 


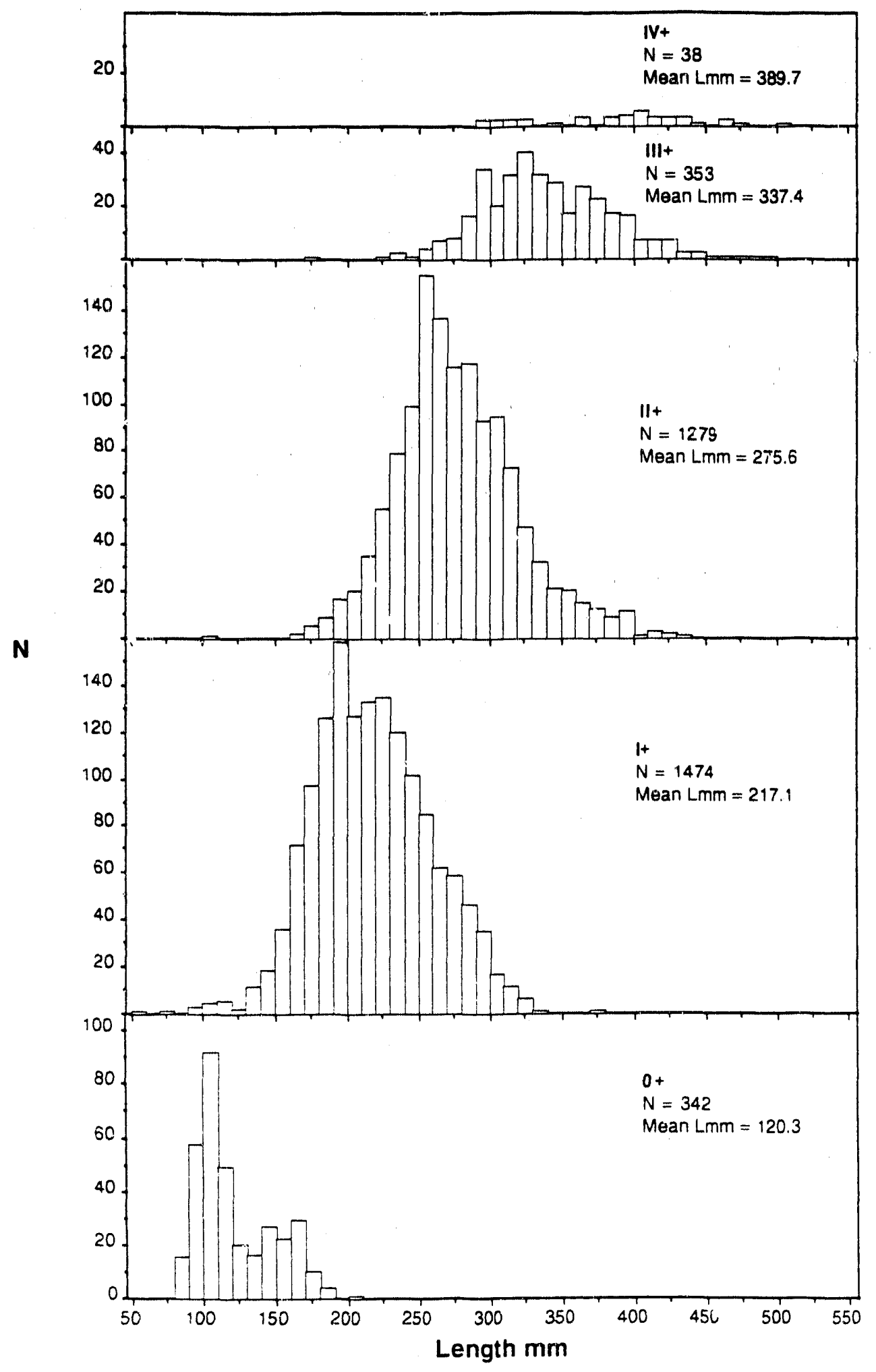

Figure 3.3-2 Length frequency distributions for brook trout captured during fall surveys in ALSC lakes (September - November, 1984-87). 


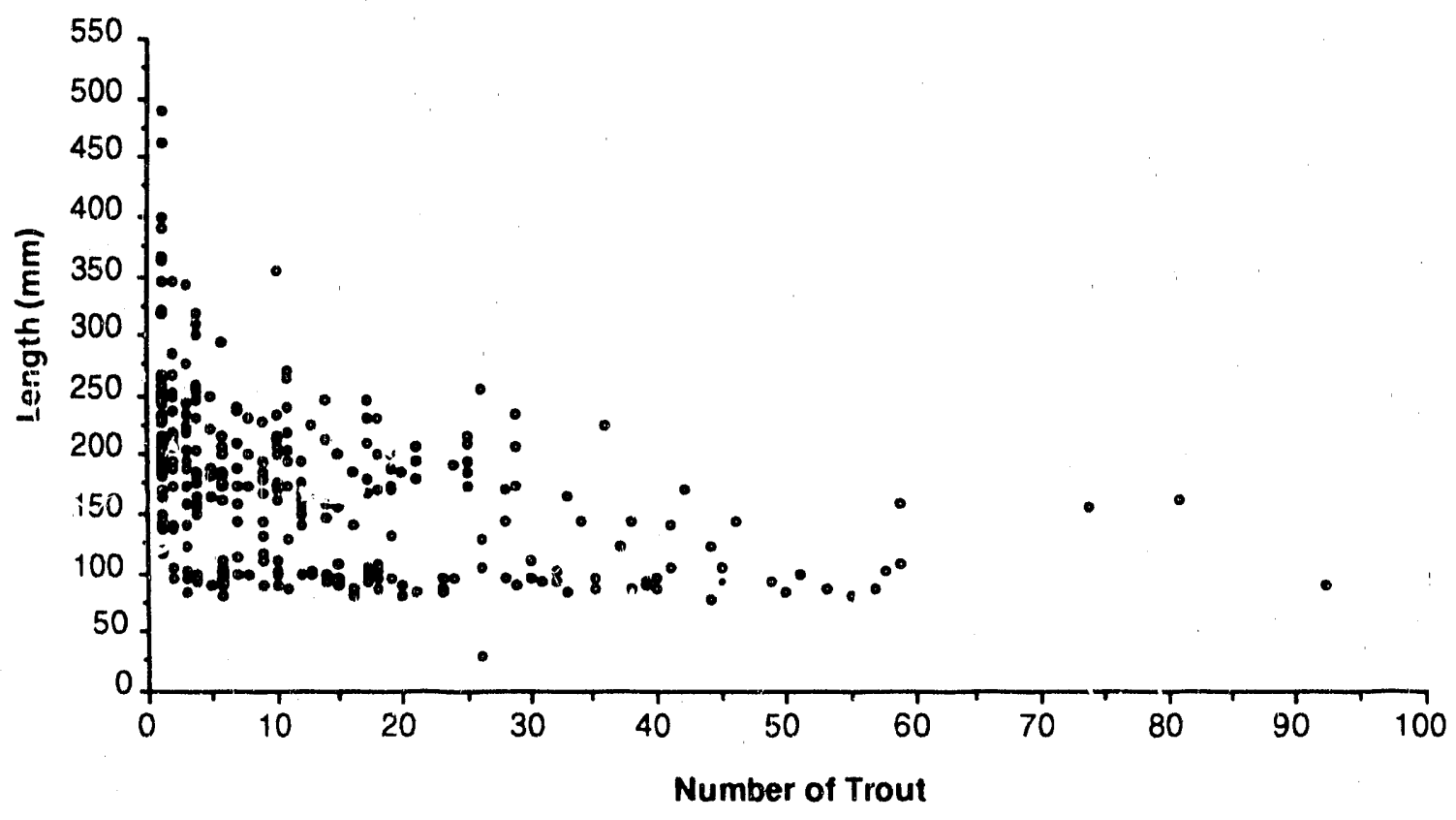

Figure 3.3-3 Relationship between sample size and minimum length of brook trout captured in ALSC lakes during fall survey periods.

lakes where young-of-year were not captured is ". "surveys, or the lakes had been surveyed in the spring. Logistic models were then applied to all other categories of ALSC lakes for assessment of potential habitat suitability for brook trout natural reproduction.

\subsubsection{Results and Discussion}

\subsubsection{Evaluation of Sampling Efficiency for Young-of-Year Brook Trout}

The presence or absence of young-of-year brook trout in the survey samples was used as a primary screening criterion for identifying lakes that supported natural reproduction at the time of the ALSC surveys (Figure 3.3-1). The classifications of presence/absence of young-of-year brook trnut were compared for lakes sampled before and after fall fingerling stockings to evaluate the adequacy of the sampling effort. A total of 122 AiSC lakes had been stocked with fall fingerling brook trout either shortly before or after sampling occurred. For this group of lakes, 53 had been sampled before stocking, and 69 were sampled after stocking (a lew days to weeks after). Comparisons of young-ofyear presence /absence frequencies for these two groups of lakes indicated that lakes sampled after fall fingerling stocking had a higher frequency of young-of-year presence than lakes sampled before 
stocking (Table 3.3-1). As noted previously, sample size may affect minimum length of trout captured, and this is evident from comparisor. of percentages of lakes identified as havirig young-ofyear, for the two groups of lakes, in relation to number of trout in the sample. Figure 3.3-4). The minimum sample size selected for scre $\in$ ning ( $\geq 5$ trout) yields an approximate "YOY identification efficiency" of approximately $80-90 \%$ In addition to the effects of sampling efficiency on identification of young-of-year presence/absence, unknown contributions from natural reproduction (stocked fish were not marked) may also have affected these estimates

\subsubsection{Comparisons Between Brook Trout Lake Categories}

Utilizing the screening process illustrated in Figure 3.3-1, a total of 64 ALSC brook trout (BKT) lakes were identified for comparisons of habitat characteristics. This sample included 56 drainage lakes and 8 seepage lakes. None of the 579 BKT lakes were classified as bog ponds. There were 21 unstocked BKT lakes with young-of-year present and 22 stocked BKT lakes without young-of-year (Table 3.3-2). Summary characteristics for these lakes are given in Table 3.3-3. These 43 lakes were distributed across all of the major drainage basins in the Adirondack Park (Figure 3.3-5).

All summer surface: water chemistry (and fall data for silica, $\mathrm{SiO}_{2}$ ), morphometric, and selected biological variabies : total number fish species and presence/absence of yellow perch and smallmouth bass) available in the ALSC data base were used in two-factor analysis of variance for the stocked and YOY category lakes described above These analyses were conducted utilizing all 64 lakes and excluding salt-impacted lakes ( 3 ) and seepage lakes. The only variables yielding significant $F$ values in this analysis, with and without exclusions, were $\mathrm{SiO}_{2}$ (summer and fall) and sodium (Na) (Table 3.3-4). Salt-impacted lakes with high chloride $(\mathrm{Cl})$ ( $>1 \mathrm{mg} / \mathrm{L}$ ) also tended to have higher $\mathrm{Na}$ and $\mathrm{SiO}_{2}$ concentrations, hence the exclusion effects on significance levels for these variables. Similarly, BKT seepage lakes have significantly lower $\mathrm{SiO}_{2}$ and $\mathrm{Na}$ concentrations than drainage lakes (Table 3.3-5) Mean flushing rates were significantly higher for lakes with young-of-year present, without exclusions. However, when high $\mathrm{Cl}$ and seepage lakes were excluded from the analysis, no significant differences in mean flushing rates were obtained.

Paired comparisons between reproductive BKT STATUS categories (Table 3.3-6) indicate that BKT lakes supporting natural reproduction tend to lie at higher elevation and have larger watershed areas and higher flushing rates than lakes not sıpporting natural reproduction. Lakes having natural reproduction were exclusively drainage lakes, whereas lakes not supporting reproduction were both seepage and drainage types. BKT STA IUS 1 lakes also tended to be higher $\mathrm{pH}, \mathrm{Ca}$, and ANC lakes However, highly significant differences in the distributions of $\mathrm{SiO}_{2}$ and $\mathrm{Na}$ (excluding salt-impacted lakes) concentrations were the most distinguishing characteristics of these lakes, as noted above 
Table 3.3-1 Comparison of Young-of-Year Presence/Absence in ALSC Lakes Surveyed before and after Fall Fingerling Stocking

Coded Chi-Square

$X 1$ : Survey before/after Stocking

Y1: YOY Category

Summary Statistics

DF:

Total Chi-square

2

46.554

Percents of Column Totals

\begin{tabular}{|c|c|c|c|}
\hline & Before & After & Totals \\
\hline Present & $9.43 \%$ & $71.01 \%$ & $44.26 \%$ \\
\hline Unknown & $45.28 \%$ & $17.39 \%$ & $29.51 \%$ \\
\hline Absent & $45.28 \%$ & $11.59 \%$ & $26.23 \%$ \\
\hline Totals & $100.00 \%$ & $100.00 \%$ & $100.00 \%$ \\
\hline
\end{tabular}

Observed Frequency Table

\begin{tabular}{|c|c|c|}
\hline & Before & After \\
\hline Present & 5 & 49 \\
\hline Unknown & 24 & 12 \\
\hline Absent & 24 & 8 \\
\hline Totals & 53 & 69 \\
\hline
\end{tabular}



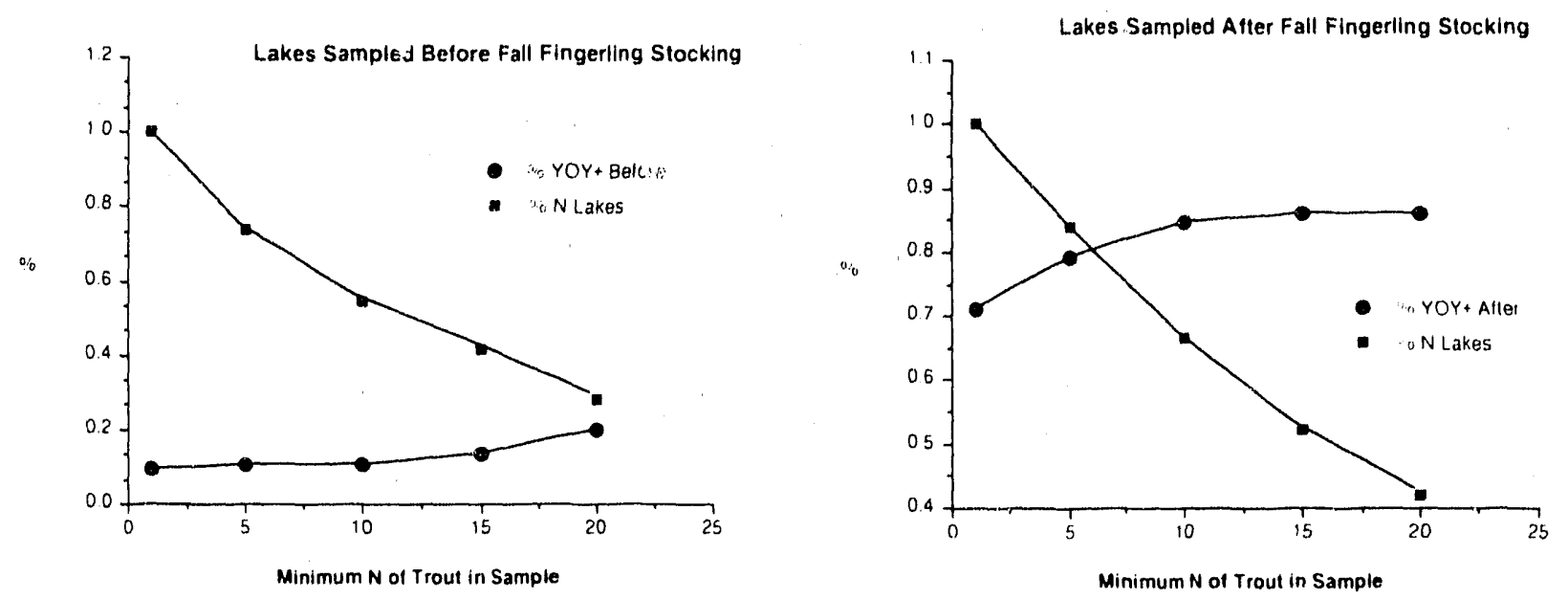

Figure 3.3-4 Effect of minimum number of trout in sample on proportions of lakes surveyed
with young-of-year present.

Physical habitat features such as nearshore substrate composition, spawning substrate quality (subjective categorical rating), and the number of inlet streams were not significantly different for lakes with and without natural reproduction. Although tributary spavuning may contribute significantly to lake-dwelling brook trout populations in some waters, neither the number of streams potentially available for spawning nor simple presence/absence of tributary streams (chi-square $=0.026, p=0.87$ ) were significantly related to the presence/absence of natural reproduction in this group of lakes. Brook trout catch per unit effort (CPUE for gill nets only) was greater in lakes with natural fish reproduction, and mean length tended to be lower in these populations as well, suggesting higher population densities of younger and/or slower growing trout. Lakes with natural reproduction also tended to have more fish species; however, the presence/absence of potential competitor/predators such as yellow perch (Perca flavescens) was not significantly different in the two repraductive BKT STATUS categories. 
Table 3.3-2 ALSC Lakes Classified by Stocking and Young-of-Year Categories

\begin{tabular}{|c|c|c|c|c|}
\hline Pond \# & Pond Name & Stocking & YOY & Status \\
\hline 020157 & Embody pond & stocked & absent & 0 \\
\hline 030172 & Little Clear pond & stocked & absent & 0 \\
\hline 050625 & First Lake Essex chain & stocked & absent & 0 \\
\hline 020400 & Lapland pond & stocked & absent & 0 \\
\hline 020224 & Slush pond & stocked & absent & 0 \\
\hline 050636 & Barker pond & stocked & absent & 0 \\
\hline 040704 & Middle Settlement lake & stocked & absent & 0 \\
\hline 050188 & Wilcox lake & stocked & absent & 0 \\
\hline 020188 & Sunday pond & stocked & absent & 0 \\
\hline 050282 & Shiras pond & stocked & absent & 0 \\
\hline 040907 & Round pond & stocked & absent & 0 \\
\hline 040620 & Payne lake & stocked & absent & 0 \\
\hline 040967 & Brewer lake & stocked & absent & 0 \\
\hline 040850 & Squaw lake & stocked & absent & 0 \\
\hline 050388 & Hewitt pond & stocked & absent & 0 \\
\hline 020357 & Grizzle ocean & stocked & absent & 0 \\
\hline 050294 & Twin pond (lower) & stocked & absent & 0 \\
\hline 020373 & Upper Black Mountain pond & stocked & absent & 0 \\
\hline 060207 & Palmer pond & stocked & absent & 0 \\
\hline 0.40876 & Icehouse pond & stocked & absent & 0 \\
\hline 040619 & Cleveland lake & stocked & absent & 0 \\
\hline 020056 & Chub pond & stocked & absent & 0 \\
\hline 020191 & Little Clear pond & unstocked & present & 1 \\
\hline 050541 & Hour pond & unstocked & present & 1 \\
\hline 040887 & Lost pond & unstocked & present & 1 \\
\hline 050577 & Nate pond & unstocked & present & 1 \\
\hline 020229 & Morgan (Cooper Kill) pond & unstocked & present & 1 \\
\hline $050460 A$ & Dixpond & unstocked & present & 1 \\
\hline 020180 & Whey pond & unstocked & present & 1 \\
\hline 050457 & Sand pond & unstocked & present & 1 \\
\hline 030256 & Black pond & unstocked & present & 1 \\
\hline 050602 & Upper Dug Mountain pond & unstocked & present & 1 \\
\hline 060272 & First Anthony pond & unstocked & present & 1 \\
\hline 060294 & Lower Sargent pond & unstocked & present & 1 \\
\hline 040987 & Evans pond & unstocked & present & 1 \\
\hline $030043 A$ & Skiff pond & unstocked & present & 1 \\
\hline 020394A & Little Jabe pond & unstocked & present & 1 \\
\hline 060274 & Third Anthony pond & unstocked & present & 1 \\
\hline 070928 & Laurence pond & unstocked & pres,ent & 1 \\
\hline $060315 A$ & Raquette lake reservoir & unstocked & pre'ient & 1 \\
\hline 020330 & Lilypad pond & unstocked & present & 1 \\
\hline 040706 & Grass pond & unstocked & present & 1 \\
\hline 020277 & Upper Ausable lake & unstocked & present & 1 \\
\hline
\end{tabular}


Table 3.3-3 Summary Characteristics of ALSC BKT Status 1 (Unstocked, YOY Present) and Status 0 (Stocked, YOY Absent) Brook Trout Lakesa

\begin{tabular}{|c|c|c|}
\hline Variable & BKT Status 1 & BKT Status 0 \\
\hline Number of lakes & 21 & 22 \\
\hline Elevation (m) & $\begin{array}{c}563.1 \\
(361-922)\end{array}$ & $\begin{array}{c}500.7 \\
(375.645)\end{array}$ \\
\hline Surface Area (ha) & $\begin{array}{c}21.37 \\
(1.2-142.3)\end{array}$ & $\begin{array}{c}12.60 \\
(0.8-67.0)\end{array}$ \\
\hline Maximum Depth (m) & $\begin{array}{c}6.70 \\
(0.6-23.5)\end{array}$ & $\begin{array}{c}8.51 \\
(1.2-18.9)\end{array}$ \\
\hline Mean Depth $(\mathrm{m})$ & $\begin{array}{c}2.93 \\
(0.6-10.8)\end{array}$ & $\begin{array}{c}3.57 \\
(0.8-7.6)\end{array}$ \\
\hline Number of Inlets & $\begin{array}{c}1.3 \\
(0-4)\end{array}$ & $\begin{array}{c}0.9 \\
(0.5)\end{array}$ \\
\hline $\mathrm{pH}$ & $\begin{array}{c}7.02 \\
(5.15-8.24)\end{array}$ & $\begin{array}{c}6.41 \\
(4.93-7.72)\end{array}$ \\
\hline $\mathrm{Ca}(\mathrm{mg} / \mathrm{L})$ & $\begin{array}{c}4.72 \\
(1.23-26.5)\end{array}$ & $\begin{array}{c}2.69 \\
(0.73-7.84)\end{array}$ \\
\hline $\mathrm{DOC}(\mathrm{mg} / \mathrm{L})$ & $\begin{array}{c}4.77 \\
(1.9-9.7)\end{array}$ & $\begin{array}{c}5.18 \\
(0-10.7)\end{array}$ \\
\hline $\mathrm{Na}(\mathrm{mg} / \mathrm{L})$ & $\begin{array}{c}0.98 \\
(0.39-1.91)\end{array}$ & $\begin{array}{c}0.49 \\
(0.05-1.05)\end{array}$ \\
\hline $\mathrm{SiO}_{2}(\mathrm{mg} / \mathrm{L})$ & $\begin{array}{c}5.04 \\
(0.1-11.5)\end{array}$ & $\begin{array}{c}1.49 \\
(0-4.9)\end{array}$ \\
\hline Number of Fish Species & $\begin{array}{c}4.2 \\
(1-13)\end{array}$ & $\begin{array}{c}3.3 \\
(1-11)\end{array}$ \\
\hline
\end{tabular}

a Mean and (range) for selected variables.

DOC = dissolved organic carbon 


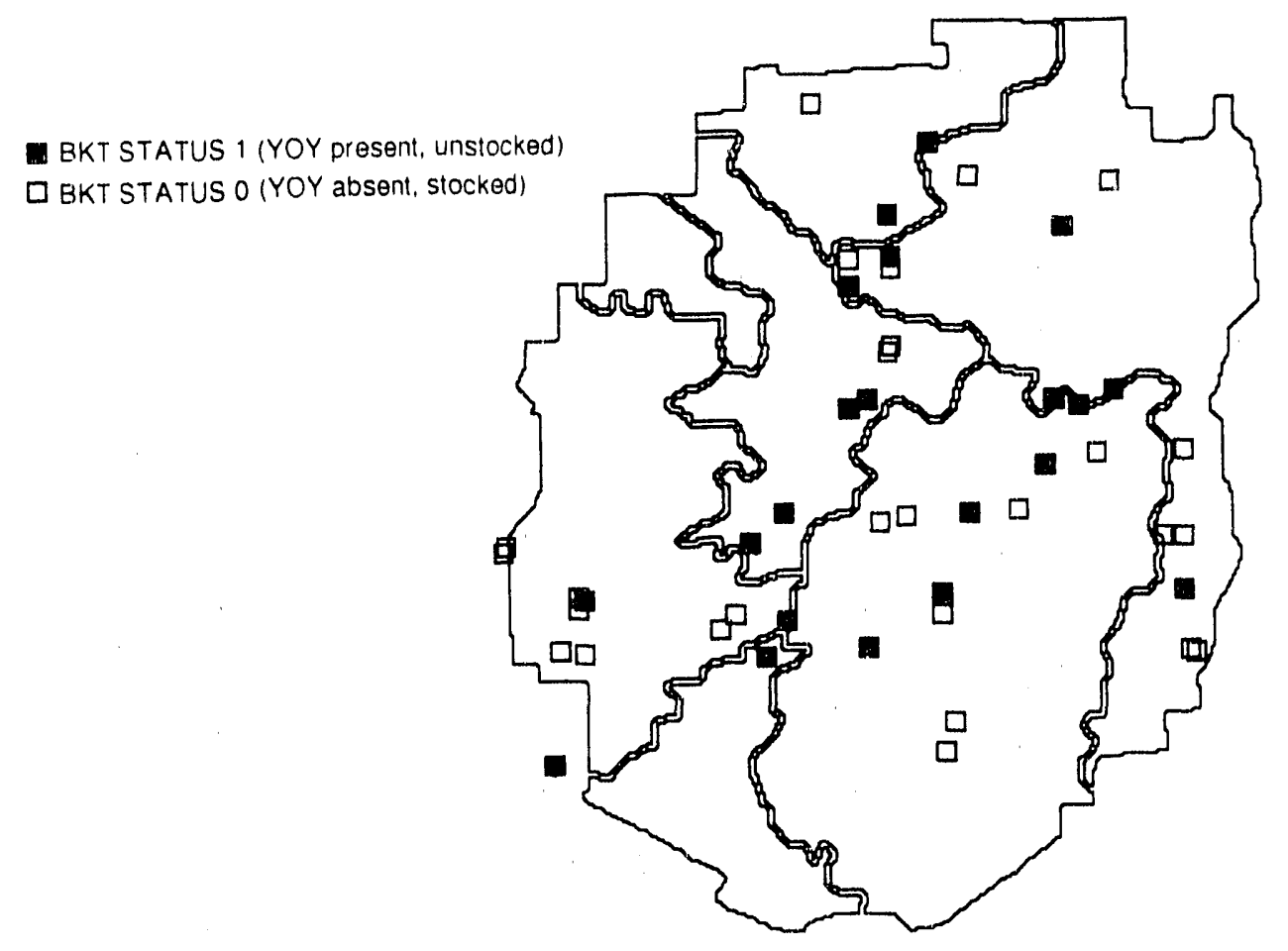

Figure 3.3-5 Distribution of ALSC BKT lakes by STATUS category.

\subsubsection{Indices of Groundwater and Brook Trout Spawning Habitat Suitability}

The identification of $\mathrm{SiO}_{2}$ and/or $\mathrm{Na}$ as pc tential indicators of suitable habitat for brook trout natural reproduction in Adirondack lakes lends strong support to the hypothesis that groundwater is of primary importance for successful natural reproduction. Both $\mathrm{SiO}_{2}$ and $\mathrm{Na}$ tend to be higher in Adirondack lakes receiving greater inputs of groundwater (Peters and Driscoll 1987, Newton et al. 1987), and this observation is also supported by the comparison of $\mathrm{SiO}_{2}$ levels in the ALSC BKT seepage and drainage basins (Table 3.3-5). It should also be noted that none of the 50 BKT seepage lakes in the ALSC data base were rated NSA, and none were classified as BKT STATUS 1 in this analysis. Although specific seepage lake types were not considered in this analysis, the results suggest that they are predominantly waters receiving minir.;i groundwater influx. A summary comparison of cumulative frequency distributions for summer $\mathrm{SiO}_{2}$ levels in various BKT lake types illustrates the differences between the categories evaluated above (Figure 3.3-6). There is also a marked similarity in the distribution of $\mathrm{SiO}_{2}$ levels in non-BKT lakes and BKT lakes classified as not supporting natural reproduction, suggesting that ground water may have limited influence on both groups. 
Table 3.3-4 Comparison of F Values and Probability Levels $(P)$ for Selected Variables with Significant Differences Between Stocking and Young-of-Year Categories in Two-Way ANOVA

\begin{tabular}{|c|c|c|c|c|c|c|}
\hline Variable & $\mathbf{N}$ & Exclusion & F Stock & P Stock & F YOY & PYOY \\
\hline $\mathrm{SiO}_{2}$ (summer) & $\begin{array}{l}64 \\
61 \\
54\end{array}$ & $\begin{array}{c}\text { none } \\
\text { salt } \\
\text { salt, seepage }\end{array}$ & $\begin{array}{l}2.18 \\
7.72 \\
5.08\end{array}$ & $\begin{array}{l}0.1448 \\
0.0074 \\
0.0287\end{array}$ & $\begin{array}{r}14.21 \\
7.84 \\
5.17\end{array}$ & $\begin{array}{l}0.0004 \\
0.0070 \\
0.0274\end{array}$ \\
\hline $\mathrm{SiO}_{2}$ (fall) & $\begin{array}{l}64 \\
61 \\
54\end{array}$ & $\begin{array}{c}\text { none } \\
\text { salt } \\
\text { salt, seepage }\end{array}$ & $\begin{array}{l}5.69 \\
8.14 \\
5.52\end{array}$ & $\begin{array}{l}0.0203 \\
0.006 \\
0.0228\end{array}$ & $\begin{array}{r}14.21 \\
8.28 \\
5.62\end{array}$ & $\begin{array}{l}0.0004 \\
0.0060 \\
0.0216\end{array}$ \\
\hline$N^{\prime} \cdot a$ & $\begin{array}{l}64 \\
61 \\
54\end{array}$ & $\begin{array}{c}\text { rone } \\
\text { salt } \\
\text { salt, seepage }\end{array}$ & $\begin{array}{l}2.11 \\
7.39 \\
4.22\end{array}$ & $\begin{array}{l}0.1513 \\
0.0087 \\
0.0453\end{array}$ & $\begin{array}{r}15.24 \\
3.21 \\
1.23\end{array}$ & $\begin{array}{l}0.0002 \\
0.0786 \\
0.2735\end{array}$ \\
\hline $\mathrm{Cl}$ & $\begin{array}{l}64 \\
61 \\
54\end{array}$ & $\begin{array}{c}\text { none } \\
\text { salt } \\
\text { salt, seepage }\end{array}$ & $\begin{array}{l}8.94 \\
2.68 \\
1.06\end{array}$ & $\begin{array}{l}0.0040 \\
0.1071 \\
0.3083\end{array}$ & $\begin{array}{r}12.32 \\
1.41 \\
0.33\end{array}$ & $\begin{array}{l}0.0009 \\
0.2482 \\
0.5662\end{array}$ \\
\hline Flush rate & $\begin{array}{l}64 \\
61 \\
54\end{array}$ & $\begin{array}{c}\text { none } \\
\text { salt } \\
\text { salt,seepare }\end{array}$ & $\begin{array}{l}0.01 \\
2.44 \\
1.96\end{array}$ & $\begin{array}{l}0.9221 \\
0.1238 \\
0.1675\end{array}$ & $\begin{array}{l}5.3 \varepsilon 4 \\
1.607 \\
1.282\end{array}$ & $\begin{array}{l}0.0237 \\
0.2100 \\
0.2629\end{array}$ \\
\hline
\end{tabular}

Table 3.3-5 One-Factor ANOVA of Summer Surface Silica by Seepage/Drainage Lake Classification

Analysis of Variance Table

\begin{tabular}{lrrrr} 
Source & DF & Sum Squares & Mean Square & F-Test \\
\hline & 1 & 413.172 & 413.172 & \\
Between groups & 577 & 4429.879 & 7.677 & $p=.0001$ \\
Within groups & 578 & 4843.051 & &
\end{tabular}

\begin{tabular}{lrrcc} 
Group & Count & Mean & Standard Deviation & Standard Error \\
\hline Seepage & 50 & 0.658 & 1.346 & \\
Drainage & 529 & 3.665 & 2.867 & 0.190 \\
& & & & 0.125 \\
\hline
\end{tabular}


Table 3.3-6 Summary Results of Paired Comparisons Between Lakes With and Without Natura' Reproductiona

\begin{tabular}{|c|c|}
\hline Explanatory Variable & BKT Natural Reproduction \\
\hline Elevation & $\star(+)$ \\
\hline Watershed Area & $\star(+)$ \\
\hline Surface Area & NS \\
\hline Littoral Area & NS \\
\hline Maximum Depth & NS \\
\hline Mean Depth & NS \\
\hline Shoreline Distance & NS \\
\hline Frushing Rate & ${ }^{\star}(+)$ \\
\hline Number of Inlets & NS \\
\hline Seepage/Drainage & $\star *(+)$ \\
\hline $\mathrm{pH}$ & $\star(+)$ \\
\hline $\mathrm{Ca}$ & $\star(+)$ \\
\hline ANC & $*(+)$ \\
\hline Al & NS \\
\hline DOC & NS \\
\hline Total P & NS \\
\hline $\mathrm{Cl}$ & $\star(+)$ \\
\hline NA & $\star \star \star(+)$ \\
\hline $\mathrm{Na}(\mathrm{Cl}<20 \mu \mathrm{M})$ & $\star \star \star(+)$ \\
\hline $\mathrm{SiO}_{2}$ (Sumrner) & $\star \star \star(+)$ \\
\hline $\mathrm{SiO}_{2}$ (Fall) & $\star \star \star(+)$ \\
\hline Substrate Quality & NS \\
\hline$\%$ Gravel \& Rubble & NS \\
\hline Beaver Dam & NS \\
\hline Stratification & NS \\
\hline Road Distance & NS \\
\hline Bog Influence & NS \\
\hline Species Richness & ${ }^{\star}(+)$ \\
\hline Yellow Perch & NS \\
\hline BKT CPUE & ${ }^{\star}(+)$ \\
\hline BKT Mean Length & ${ }^{*}(-)$ \\
\hline
\end{tabular}

*** $p \leq 0.001 ; * * p \leq 0.01 ; * p \leq 0.05 ;$ NS $p>0.05$

a Significance levels based on contingency table Chi-square for categorical variables and Kolmogorov-Smirnov chi-square for continuous variables. 


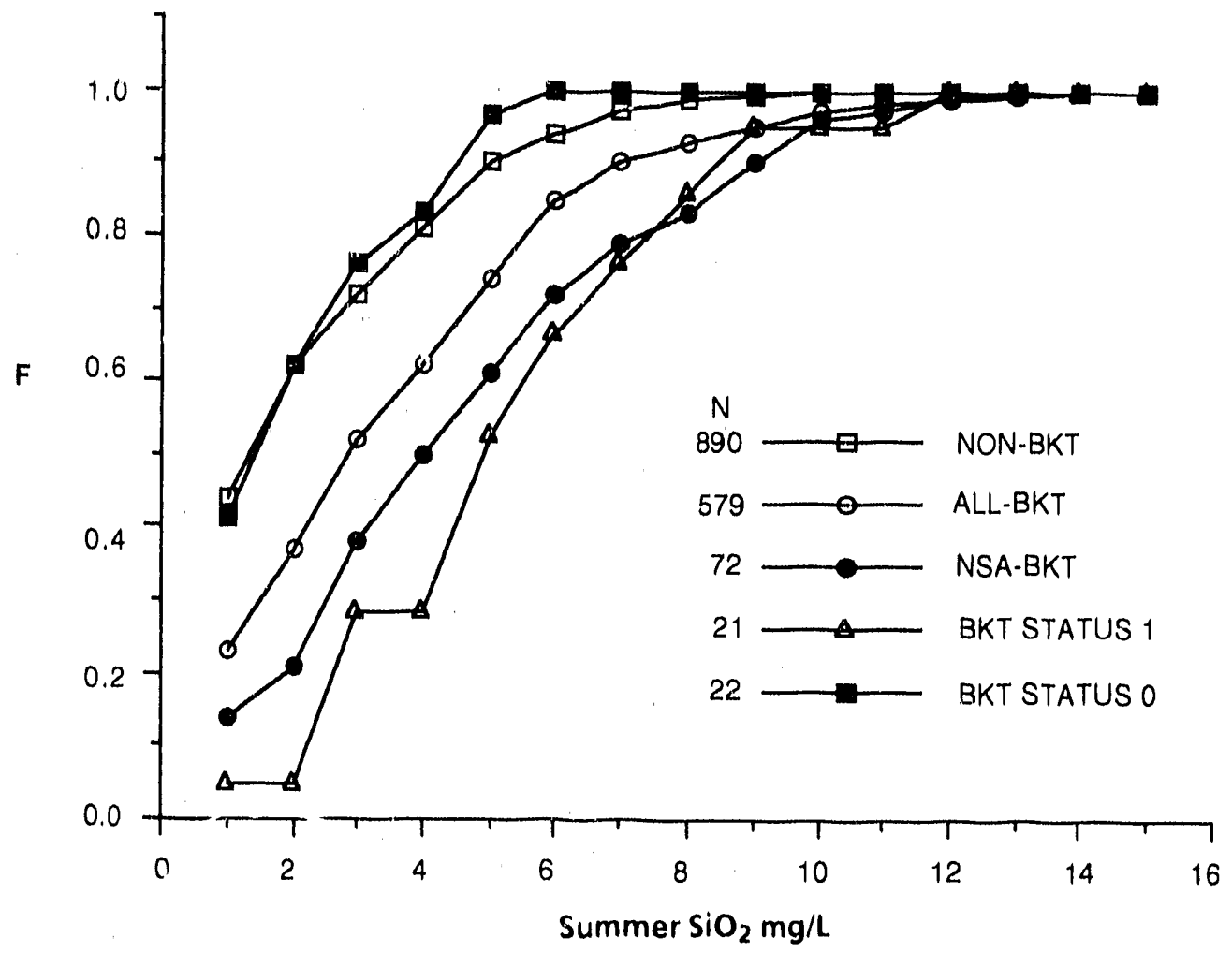

Figure 3.3-6 Cumulative frequency distributions of summer surface silica for ALSC lakes of various brook trout (BKT) categories.

Evaluation of Silica as an Indicator of Groundwater Influence. Seasonal variation in surface $\mathrm{SiO}_{2}$ concentrations that might be induced by diatom uptake is a potential source of error in identifying groundwater influence. Comparison of $\mathrm{SiO}_{2}$ levels in summer surface and deep water samples from the same lakes (Figure 3.3-7) suggests that surface water depletion by diatom uptake and remineralization in deeper water does occur. However, there is considerable scatter in this relationship. Fall and spring surface $\mathrm{SiO}_{2}$ concentrations were more closely related to summer surface $\mathrm{SiO}_{2}$ levels (Figure 3.3-8), suggesting that seasonal variations in surface water concentrations that might be induced by biological activity are relatively minor compared to ground water influence in this group of lakes. This conclusion is supported by the comparable levels of significance for both summer and fall $\mathrm{SiO}_{2}$ in the analyses discussed above and by the inclusion of $\mathrm{Na}$ in these analyses, which is primarily a by-product of silicate weathering and is not influenced by diatom uptake.

Other factors that might influence groundwater contributions to Adirondack lakes that were not revealed in the analyses described above, but which are probably of significance in basins with reiatively small groundwater aquifers, are related to nearshore morphology and substrate composition. Measurements of groundwater seepage in Woods Lake (Staubitz and Zarriello 1989) 


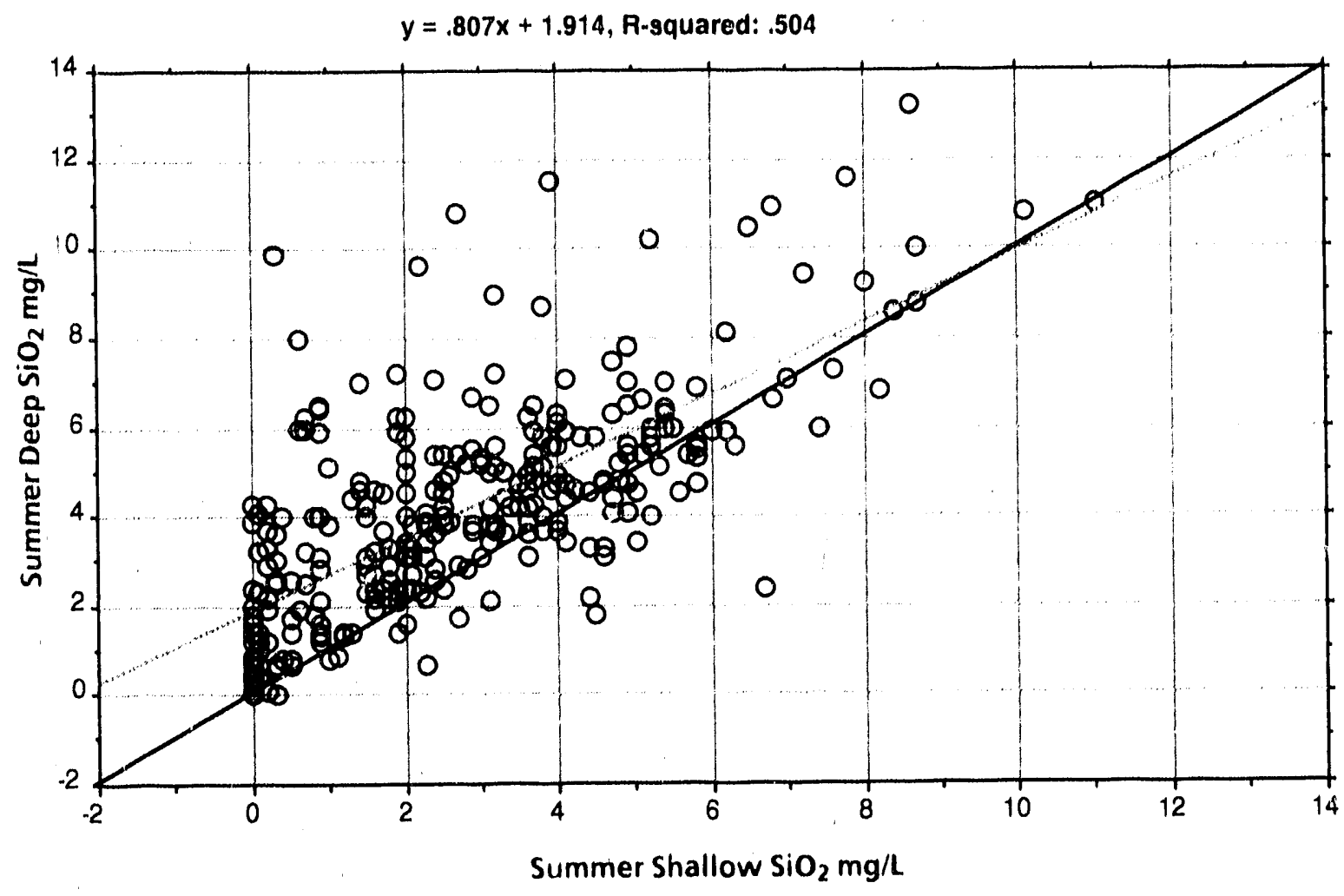

Figure 3.3-7 Comparison of summer surface silica with deep water silica for ALSC brook trout (BKT) lakes.

demonstrated that seepage decreases exponentially with distance from the shore and that the area of rapid seepage is partially controlled by the depth of permeable material along the lake shore. Using only data for BKT drainage lakes, significant correlations $(p \leq 0.05)$ were found between $\mathrm{SiO}_{2}$ (summer surface) and the following variables related to nearshore structure: percent sand in littoral zone $(r=0.161)$, percent bedrock $(r=-0.177)$, maximum depth $(r=-0.215)$, and mean depth $(r=-0.190)$. Lakes with beaver dams on the outlets had significantly lower summer surface $\mathrm{SiO}_{2}$ concentrations (Table 3.3-7). A lower $m$ an percentage of sand in the littoral zone and a higher percentage of muck (Table 3.3-8) were a... observed in lakes with outlet beaver dams. Beaver dam head height was inversely related to summer surface $\mathrm{SiO}_{2}$ levels for thin-till lakes with outlet beaver dams (Figure 3.3-9). These observations suggest that siltation and flooding of nearshore zones in small Adirondack waters impounded by beaver activity may significantly reduce the influx of groundwater by reducing permeability in nearshore zones. Impoundment may also increase back pressure from elevated water levels (e.g., inverse relationships between $\mathrm{SiO}_{2}$ and depth and head height ) in thin-till lakes with marginal groundwater aquifers; however, more detailed analyses would be required to substantiate these hypotheses. 

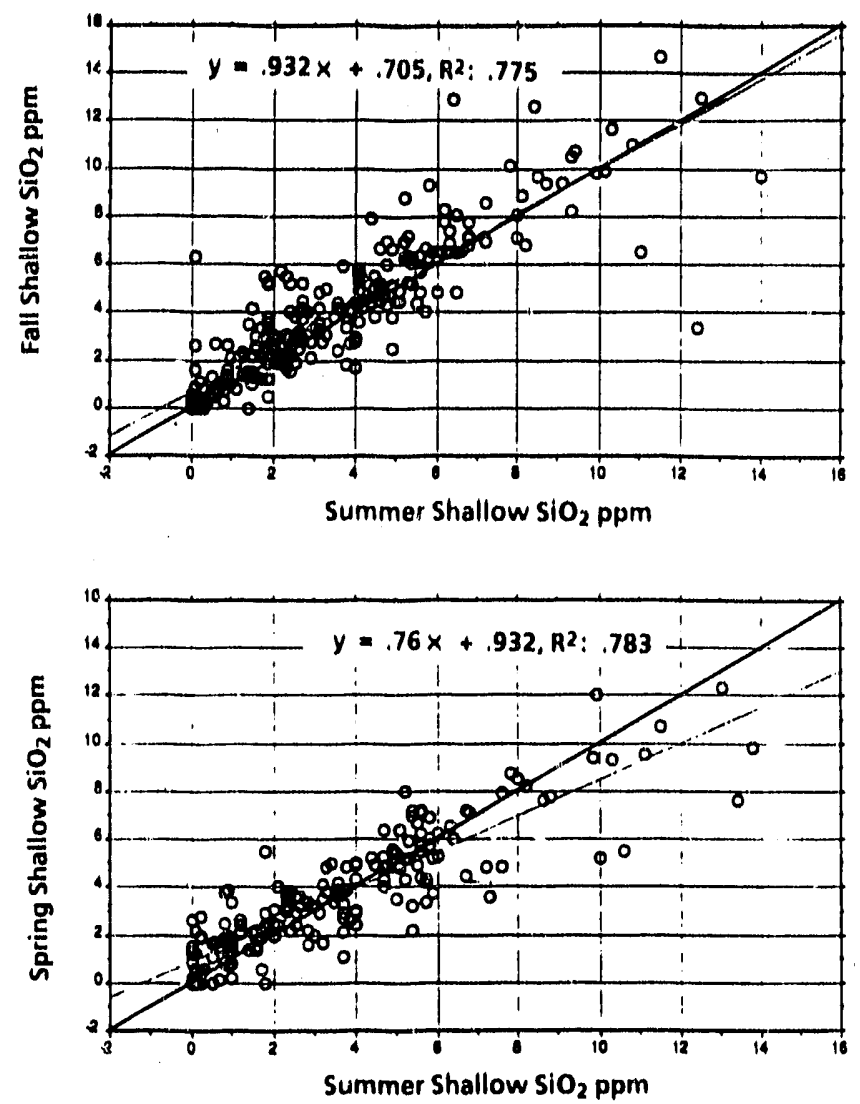

Figure 3.3-8 Comparisons of summer surface silica with spring and fall levels in ALSC brook trout (BKT) lakes.

Table 3.3-7 Comparison of Summer Surface Silica Concentrations in ALSC Drainage Lakes With (Group 1) and Without (Group 2) Beaver Dams on the Outlet

Analysis of Variance Table

\begin{tabular}{lrrrr} 
Source & DF & Sum Squares & Mean Square & F-Test \\
\hline & 1 & 107.714 & 107.714 & 13.309 \\
Between groups & 527 & 4233.423 & 8.033 & $p=.0003$ \\
Within groups & 528 & 4341.137 & &
\end{tabular}

\begin{tabular}{lcccc} 
Group & Count & Mean & Standard Deviation & Standard Error \\
\hline Group 1 & 226 & 3.143 & 2.659 & 0.177 \\
Group 2 & 303 & 4.055 & 2.958 & 0.170 \\
\hline
\end{tabular}


Table 3.3-8 Comparison of Percent Sand and Muck in Littoral Zones of ALSC Drainage Lakes With (Group 1) and Without (Group 2) Beaver Dams on the Outlet

\begin{tabular}{lrrrr} 
& \multicolumn{4}{c}{$\%$ Sand in Littoral Zone } \\
& \multicolumn{4}{c}{ Analysis of Variance Table } \\
Source & DF & Sum Squares & Mean Square & F-Test \\
\hline & 1 & 13805.026 & 13805.026 & 31.287 \\
Between groups & 527 & 232533.983 & 441.241 & $\mathrm{p}=.0001$ \\
$\begin{array}{l}\text { Within groups } \\
\text { Total }\end{array}$ & 528 & 246339.009 & &
\end{tabular}

\begin{tabular}{lcccc} 
Group & Count & Mean & Standard Deviation & Standard Error \\
\hline Group 1 & 226 & 13.765 & 18.666 & 1.242 \\
Group 2 & 303 & 24.092 & 22.592 & 1.298 \\
\hline
\end{tabular}

$\%$ Muck in Littoral Zone

Analysis of Variance Table

\begin{tabular}{lrccc} 
Source & DF & Sum Squares & Mean Square & F-Test \\
\hline & & & & \\
Between groups & 1 & 44313.096 & 44313.096 & 42.35 \\
Within groups & 527 & 551435.01 & 1046.366 & $p=.0001$ \\
Total & 528 & 595748.106 & &
\end{tabular}

\begin{tabular}{lcccc} 
Group & Count & Mean & Standard Deviation & Standard Error \\
\hline Group 1 & 226 & 67.261 & 28.869 & 1.920 \\
Group 2 & 303 & 48.759 & 34.713 & 1.994 \\
\hline
\end{tabular}

\subsubsection{Potential for Brook Trout Natural Reproduction in Adirondack Lakes}

Relatively few NSA BKT lakes (72) were identified from survey catch data and stocking records. The potential for brook trout natural reproduction in unclassified BKT waters and in ALSC lakes where no brook trcut were captured during the surveys was assessed by employing logistic regression models 


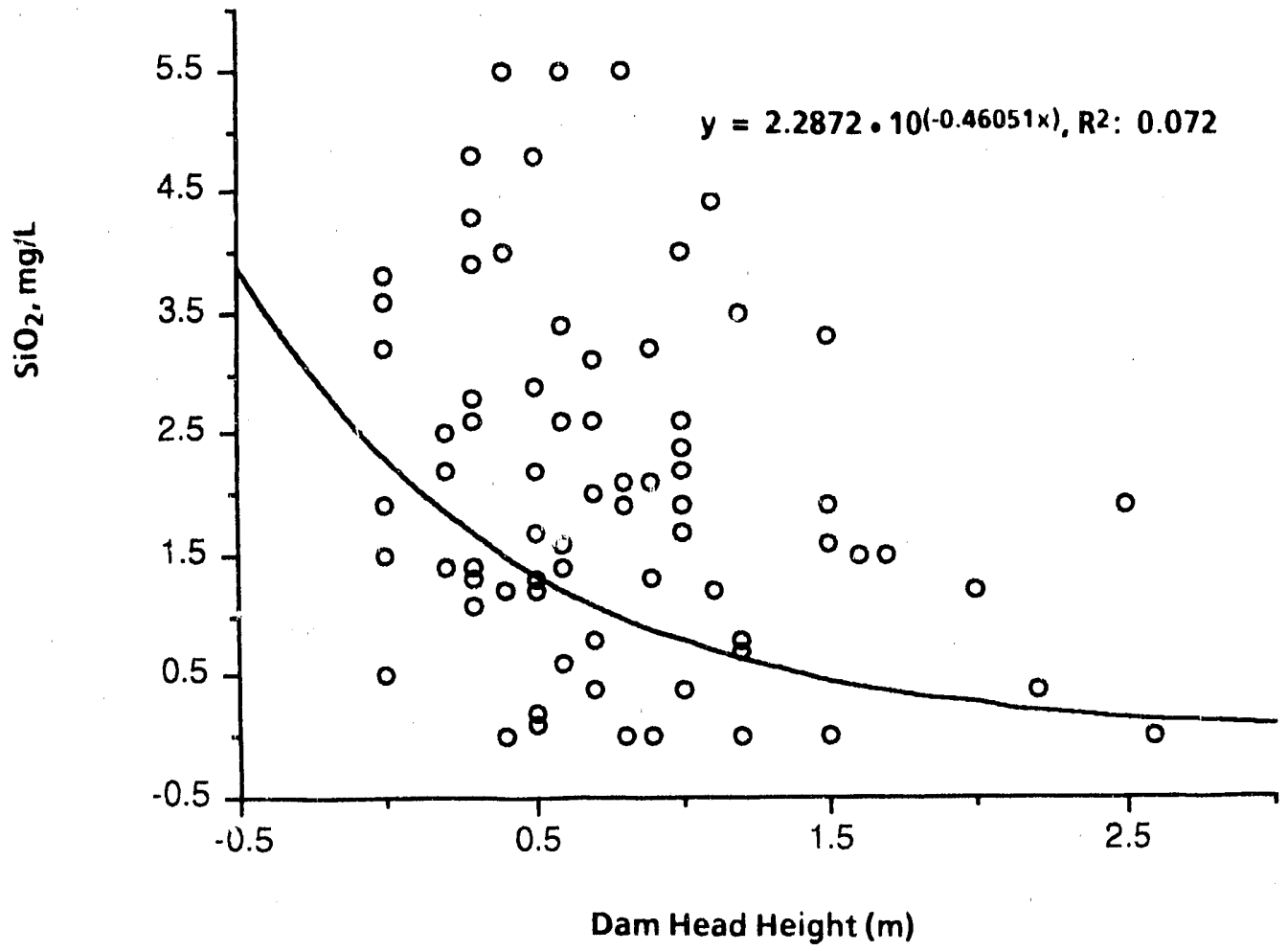

Figure 3.3-9 Fall surface silica in ALSC thin-till lakes with outlet beaver dams as a function of dam head height.

of BKT STATUS. Parameters for logistic regressions of BKT STATUS as functions of summer surface $\mathrm{SiO}_{2}$, summer surface $\mathrm{Na}$ (excluding salt-impacted lakes), and fall su rface $\mathrm{SiO}_{2}$ concentrations [all transformed as $\left.\log _{10}(x+1)\right]$ and fits to observed BKT status are presented in Figure 3.3-10. None of the other independent variables listed in Table 3.3-6 were significant in multivariate logistic regression models containing either $\mathrm{SiO}_{2}$ or $\mathrm{Na}$ as additional independent variables Unfortunately, the considerable overlap in $\mathrm{SiO}_{2}$ and $\mathrm{Na}$ concentrations between BKT STATUS categories tends to limit the predictive capabilities of these simple models. The best fits were obtaineci with either summer surface $\mathrm{SiO}_{2}$ or fall surface $\mathrm{SiO}_{2}$ as independent variables, based on either the proportions of correct classification or sum of predicted probabilities (71-86\% correct classification, Table 3-3-9). Differences in predicted probabilities of natural reproduction based on fall and summer surface $\mathrm{SiO}_{2}$ models (Figure 3.3-11) indicate that temporal variation in $\mathrm{SiO}_{2}$ concentrations are most likely to result in uncertain predictions for lakes having $\mathrm{SiO}_{2}$ concentrations in the STATUS overlap range of $1.4 \mathrm{mg} /$ $\mathrm{SiO}_{2}$. The proportions of ALSC rated NSA lakes classified as having natural reproduction (60-74\%), based on summer surface or fall surface $\mathrm{SiO}_{2}$ concentrations is less than would be desired for this "verification" data set (Table 3.3-11). However, as discussed previously, actual recovery rates of young-of-year 

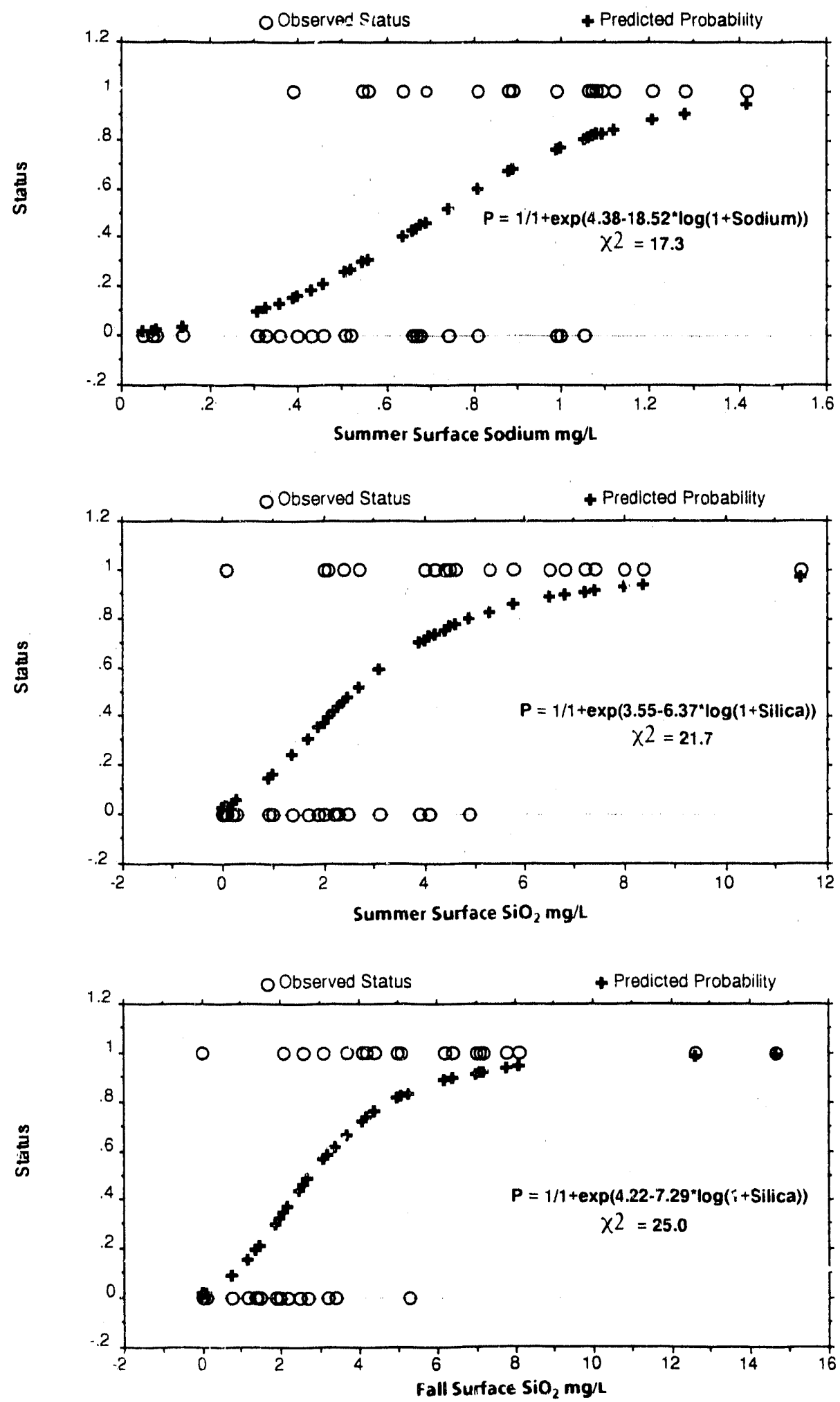

Figure 3.3-10 Logistic regressions of brook trout status in relation to silica and sodium. 
Table 3.3-9 Calibration Statistics for Logistic Regression Models of Probability of Brook Trout Natural Reproduction as Functions of Silica and Sodium Concentrations a

Summer Surface Sootium Model

\section{Calibration Statistics}

Lakes with Natural Reproduction

Lakes without Nat:-ral Reproduction

$N=19$

$N=22$

$\Sigma p=12.5$

$\Sigma(1-p)=15.5$

$\% \Sigma p=65.6$

$\% \Sigma(1-p)=70.3$

$N p \geq 0.5=13$

$\mathrm{Np}<0.5=17$

$\% N p \geq 0.5=68.4$

$\% N p<0.5=77.3$

\section{Summer Surface Silica Model}

Lakes with Natural Reproduction

Lakes without Natural Reproduction

$N=21$

$\Sigma p=14.9$

$\% \Sigma p=71.2$

$N p \geq 0.5=17$

$\% N p \geq 0.5=81.0$

$$
\begin{gathered}
N=22 \\
\Sigma(1-p)=15.9 \\
\% \Sigma(1-p)=72.5 \\
N p<0.5=18 \\
\% N p<0.5=81.8
\end{gathered}
$$

\section{Fall Surface Silica Model}

Lakes with Natural Reproduction

Lakes without Natural Peproduction

$N=21$

$\Sigma p=15.7$

$\Sigma \% p=74.9$

$N p \geq 0.5=18$

$\% N p \geq 0.5=85.7$

$$
\begin{gathered}
N=22 \\
\Sigma(1-p)=16.7 \\
\% \Sigma(1-p)=76.0 \\
N p<0.5=19 \\
\% N p<0.5=86.4
\end{gathered}
$$

a Satt lakes excluded from sodium model.

$(\Sigma p=$ sum predicted probabilities; $N p=$ number of lakes with predicted probability $\geq 0.5$ or $<0.5$ ). 


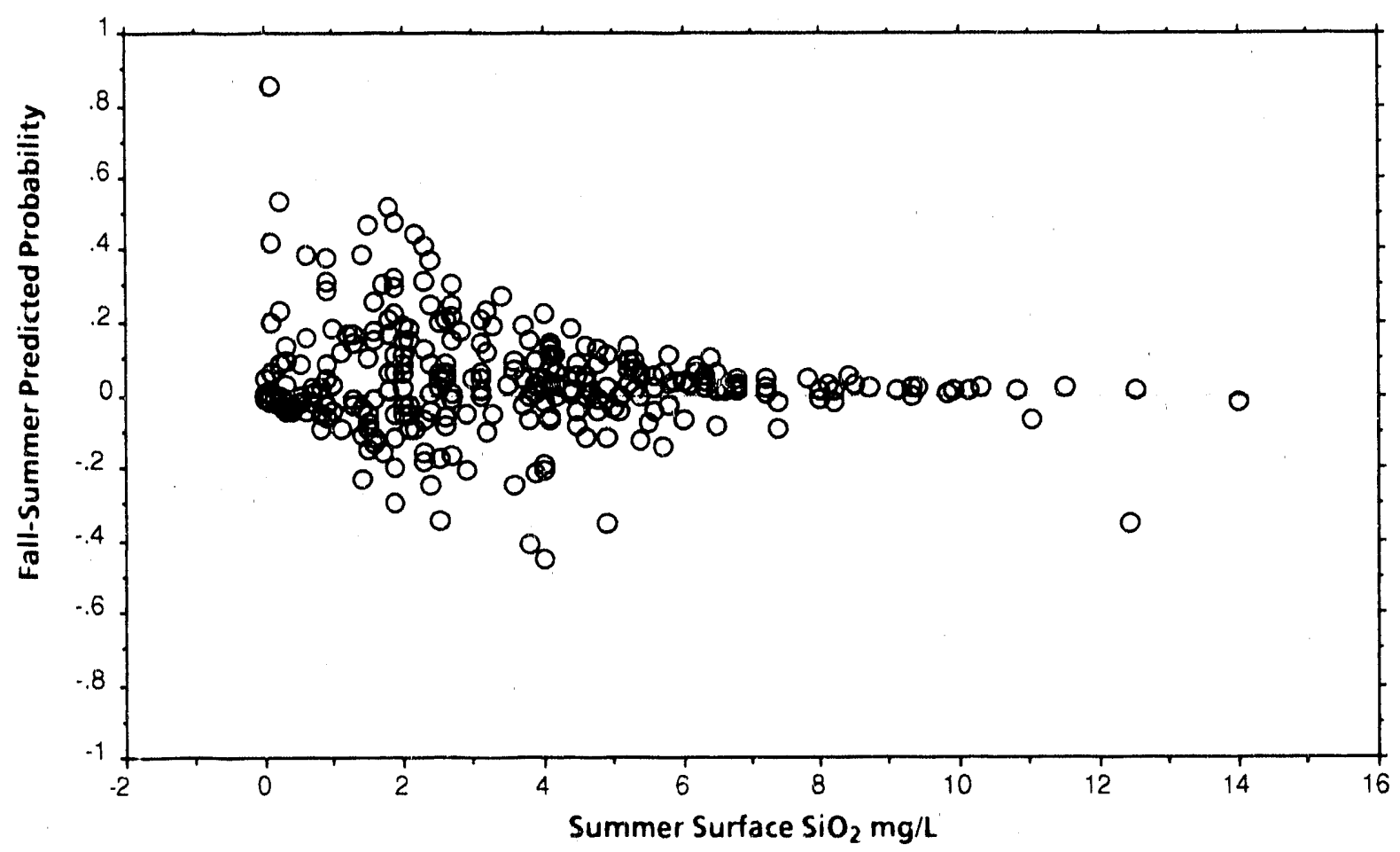

Figure 3.3-11 Effect of seasonal variation on predicted probability of brook trout natural reproduction in relation to summer surface silica concentration.

from fall-fingerling-stocked waters by survey sampling was only slightly better in identifying youngof-year present lakes (Table 3.3-1)

Estimates of potential BKT STATUS for other ALSC lake categories were obtained with the model based on summer surface $\mathrm{SiO}_{2}$ (Table 3.3-11). For all ALSClakes, 39\% were estimated to have potential for natural reproduction, with a greater proportion (51\%) for those lakes currently having brook trout in comparison to lakes where brook trout were not caught in the surveys $(31-33 \%$ with predicted potential for natural reproduction). Lakes classified as thick-till type (see Section 2.4) had the highest poter.tial for brook trout natural reproduction and also had the highest proportion of known NSA populations ( $21 \%$ of ALSC thick-till lakes). Seepage and thin-till lake types had the lowest proportions of known NSA populations ( 0 and $13 \%$, respectively) and the lowest predicted probabilities for natural reproduction. Acidic non-BKT lakes with summer surface $\mathrm{pH} \leq 5$ had the lowest estimated percentage of lakes with potential for natural reproduction (10-15\%). These observations simply reflect the generally low $\mathrm{SiO}_{2}$ levels found in acidic lakes (both thin-till drainage and seepage types) having limited groundwater contributions (Figure 3.3-12). Based on both summer and spring or fall surface $\mathrm{SiO}_{2}$ levels, there would appear to be a very limited number of currently 
Table 3.3-10 Verification Statistics for Logistic Regression Models of Probability of Brook Trout Natural Reproduction as Functions of Silica and Sodium Concentrationsa,b

\begin{tabular}{lccc}
\hline \multirow{2}{*}{ Parameter } & Model & Model & Model \\
\cline { 2 - 4 } $\mathrm{N}$ & Summer Sodium & Summer Silica & Fall Silica \\
$\Sigma \mathrm{p}$ & 55 & 58 & 58 \\
$\% \Sigma \mathrm{p}$ & 29.7 & 35.0 & 37.3 \\
$\mathrm{~Np} \geq 0.5$ & 54.0 & 60.3 & 64.3 \\
$\% \mathrm{~Np} \geq 0.5$ & 29 & 38 & 43 \\
& 52.7 & 65.5 & 74.1 \\
\hline
\end{tabular}

- Salt lakes excluded from sodium model.

b Verification data set includes NSA lakes not utilized in model calibration (lakes without young-of-year present in sample or sampled in spring)

( $\sum_{p}=$ sum of predicted probabilities; $N p=$ number of lakes with predicted probability $\geq 0.5$.)

Table 3.3-11 Predicted Potential for Brook Trout Natural Reproduction in ALSC Lakes Based on Summer Surface Silica Concentration

\begin{tabular}{|c|c|c|c|c|c|}
\hline Category & $\mathbf{N}$ & $\Sigma_{p}$ & $\% \Sigma_{p}$ & $N p \geq 0.5$ & $\% N p \geq 0.5$ \\
\hline All Lakes & 1469 & 586.5 & 39.9 & 577 & 39.3 \\
\hline BKT Lakes & 579 & 293.2 & 50.6 & 299 & 51.6 \\
\hline Non-BKT & 890 & 293.3 & 33.0 & 278 & 31.2 \\
\hline $\mathrm{pH}<5$ & 351 & 53.9 & 15.4 & 34 & 9.7 \\
\hline Mounded Seepage & 97 & 7.9 & 8.2 & 5 & 5.2 \\
\hline Flow-Through Seepage & 88 & 19.4 & 22.4 & 13 & 14.8 \\
\hline Carbonate-Influenced & 176 & 64.6 & 36.7 & 44 & 25.0 \\
\hline Thin-Till & 509 & 117.2 & 23.0 & 86 & 16.9 \\
\hline Intermediate-Till & 224 & 115.5 & 51.6 & 124 & 55.4 \\
\hline Thick-Till & 180 & 145.3 & 80.7 & 178 & 98.9 \\
\hline
\end{tabular}




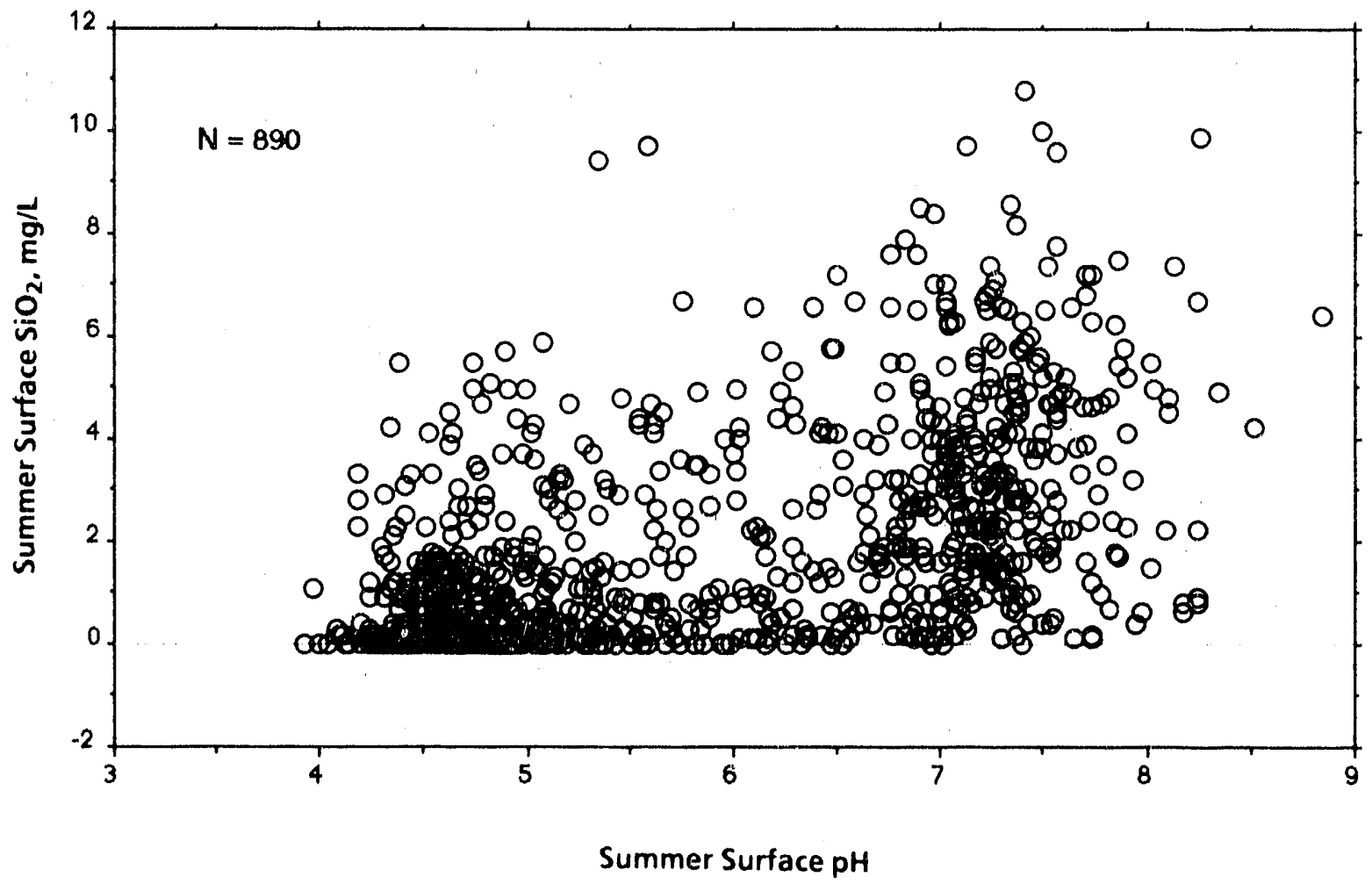

Figure 3.3-12 Comparison of summer surface silica and pH for ALSC non-BKT lakes.

acidic lakes with the potential to support brook trout natural reproduction if $\mathrm{pH}$ levels were increased either by liming or reduction of acidic inputs. Only 21 lakes having a pH $\leq 5$ and surface $\mathrm{SiO}_{2} \geq 2.5$ $\mathrm{mg} / \mathrm{L}$ (corresponds to predicted probability of natural reproduction of $\geq 0.5$ ) were identified from the ALSC non-BKT lakes. These lakes were located primarily in the Oswegatchie/ Black drainage system (Figure 3.3-13 and Table 3.3-12), where the highest frequency of acidic lakes is currently found (Kretser et al. 1989). Four of the 21 lakes had brook trout present, and one was classified as saltinipacted. One of the 21 lakes located in the High Peaks region (Avalanche Lake) previously supported brook trout. The historical status of the remaining lakes appearing to have potential for. brook trout natural reproduction has not been determined.

\subsubsection{Conclusions}

Based on extensive management experience and knowledge of Adirondack brook trout populations, Webster (1962) noted that many Adirondack lakes have generally poor conditions for brook trout natural reproduction. He cited the lack of groundwater or spring seepage and the siltation of spawning grounds by beaver activity as primary reasons for the lack of natural reproduction in many 


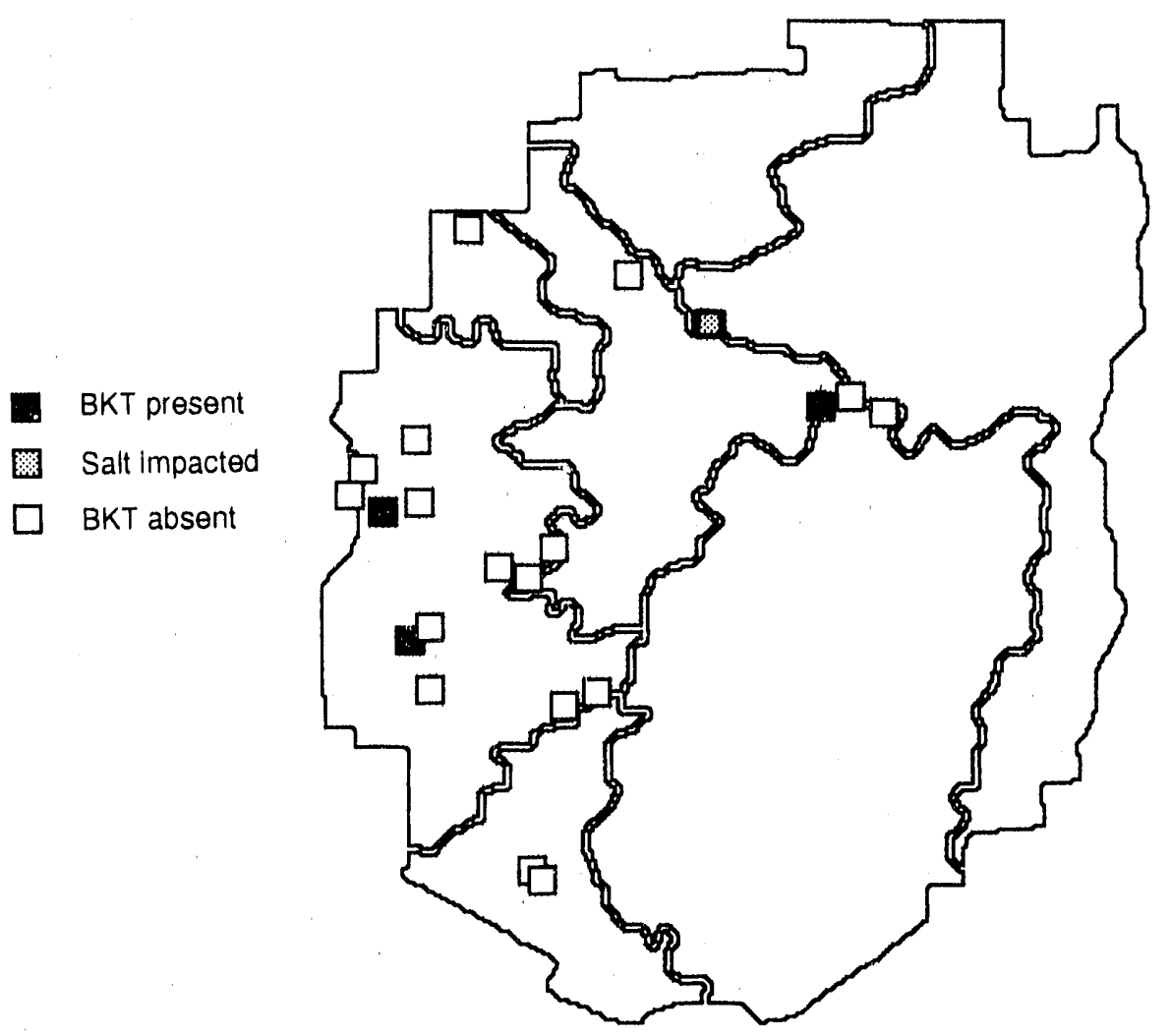

Figure 3.3-13 Distribution of 21 ALSC lakes with surface summer surface air-equilibrated pH $\leq 5$ and both summer and spring/fall surface silica $\geq 2.5 \mathrm{mg} / \mathrm{L}$. One lake was salt impacted, three had brook trout.

lakes otherwise suitable for supporting brook trout populations. Evaluation of the relationships between habitat characteristics and brook trout reproductive success in the ALSC lakes generally supports these observations. The only variables strongly related to brook trout natural reproduction were chemical indices of groundwater influence on surface water chemistry, specifically $\mathrm{SiO}_{2}$ and $\mathrm{Na}$ concentrations. Thus, the results of this study support the hypothesis that Adirondack lake spawning brook trout populations are strongly dependent on groundwater seepage for successful natural reproduction.

It is gerierally accepted that beaver activity on small tributary streams results in degradation of potential brook trout spawning habitat (Webster 1962). However, this potential impact could not be directly evaluated because of the absence of information on tributary status in the ALSC data base. However, the relationships between be.ıver dam presence/absence and littoral substrate composition for the ALSC lakes did tend to support. the view that siltation of nearshore areas may contribute to degradation of potel. n-lake spawning habitat. In addition to changes in the physical composition of the substrate, siltation and flooding of nearshore areas may also result in diminished groundwater seepage. Evidence or this effect was suggested by the inverse relationship observed 
Table 3.3-12 ALSC Non-BKTa Lakes with Summer $\mathrm{pH} \leq 5 \mathrm{~b}$ and both Summer Surface and Spring or Fall Silica $\geq 2.5 \mathrm{mg} / \mathrm{L}$

\begin{tabular}{llllrlll}
\hline \multirow{2}{*}{ Pond \# } & Name & & \multicolumn{2}{c}{ Summer } & & \multicolumn{2}{c}{ Spring/Fall } \\
\cline { 6 - 8 } & & Type & pH & DOC & Si & pH & Si \\
\hline 020261 & Scott pond & Thin & 4.74 & 6.6 & 5.50 & 4.83 & 4.90 \\
030318 & Marshun-named & Thin & 4.74 & 20.7 & 5.00 & 4.74 & 3.90 \\
040235 & Un-named pond & Thin & 4.77 & 15.7 & 3.40 & 4.60 & 2.80 \\
040238 & Round pond & Thin & 4.90 & 16.2 & 5.00 & 5.15 & 3.00 \\
$040288 E$ & Un-named pond & Thin & 4.63 & 15.8 & 4.10 & 4.63 & 2.80 \\
040444 & Un-named pond & Thin & 4.82 & 17.1 & 5.10 & 4.84 & 2.70 \\
040681 & Blackfoot pond & Thin & 4.31 & 8.7 & 2.90 & 4.54 & 2.60 \\
040757 & Little Chief pond & Thin & 4.44 & 8.2 & 3.30 & 4.50 & 3.20 \\
040771 & Un-named pond & Thin & 4.62 & 15.0 & 3.90 & 4.70 & 2.60 \\
040774 & Russianlake & Thin & 4.95 & 1.9 & 4.40 & 4.79 & 4.40 \\
040803 & Bloodsucker pond & Thick & 4.62 & 18.9 & 4.50 & 4.71 & 4.30 \\
040871 & Un-named pond & Thin & 4.67 & 4.6 & 2.70 & 4.64 & 3.30 \\
040886 & Jimmy pond & Thin & 4.41 & 10.4 & 2.50 & 4.27 & 4.90 \\
050707 & Avalanche lake & Thin & 4.99 & 4.2 & 5.00 & 4.93 & 5.50 \\
060050 & Rock pond & Interm & 4.78 & 26.5 & 4.70 & 4.79 & 4.80 \\
070819 & Cold Springlake & Thin & 4.79 & 12.3 & 2.90 & 5.13 & 3.80 \\
070820 & Un-named pond & Thin & 4.67 & 17.0 & 3.00 & 4.75 & 4.40 \\
& & & & & & & \\
\hline
\end{tabular}

a Non-BKT = Lakes with no brook trout caught by the ALSC

b Air-equilibrated $\mathrm{pH}$ value

between beaver dam head height and surface $\mathrm{SiO}_{2}$ levels, as well as the generally lower mean $\mathrm{SiO}_{2}$ levels in lakes with beaver dams. A very large proportion of the ALSC drainage lakes surveyed had beaver dams present on the outlets (48\%, Kretser et al. 1989), so this phenomenon is poteritially significant for brook trout natural reproduction in the Adirondack region

Although attempts were made to develop predictive models of potential NSA status using $\mathrm{SiO}_{2}$ as a surrogate index of groundwater contribution and habitat suitability, the overlap in observed $\mathrm{SiO}_{2}$ levels between BKT STATUS categories was too great to permit rigorous assessments using the simple models developed in this study. However, a general screening of the ALSClakes by $\mathrm{pH}$ and $\mathrm{SiO}_{2}$ categories suggests that relatively few $(<15 \%)$ of currently acidic $(\mathrm{pH} \leq 5)$ ALSC lakes have the potential to support brook trout natural reproduction, based on a predominance of low surface water $\mathrm{SiO}_{2}$ levels in these waters. Although it is possible that low $\mathrm{SiO}_{2}$, acidic thin-till lakes may have tributary streams with potential spawning habitat, knowledge of the analytical geology of these basins suggests that this possibility is remote. It is generally accepted that acidic drainage lakes in the Adirondack region receive limited groundwater inputs, relative to surface runoff (Newton et al. 1987), hence this finding is not surprising However, a more thorough evaluation of 
the relationships between surface water chemistry indices of groundwater influence and the actual occurrence of nearshore or tributary groundwater seepage zones potentially avallable for brook trout spawning would be valuable for further assessment efforts. 


\title{
3.4 PATTERNS OF FISH SPECIES DISTRIBUTION IN RELATION TO LAKE/WATERSHED CHARACTERISTICS
}

\author{
- S. Christensen, K. Reckhow, J. Beauchamp, J. Shaakir-All, J. Coe, J. Baker, E. Smith, and \\ J. Gallagher
}

The distribution of fish among Adirondack lakes is influenced by a large number of environmental and anthropogenic factors. The ALSC survey data, and the spatial association between fish presence/absence and lake characteristics, may be used to examine alternative hypotheses regarding the relative importance of these various factors in determining fish population success. Of particular interest is the degree to which lake acidity (i.e., low pH and elevated levels of inorganic Al) may restrict fish distributions from waters that might otherwise be suitable for fish survival.

Multivariate regression analyses were used to identify lake and watershed rharacteristics and fishery management practices significantly associated with the occurrence of fish and the presence/absence of selected fish species in Adirondack lakes. Because of the complexity of these tasks and the number of different analyses, the methods and results are presented in detail in report appendices and c nly summarized briefly here. Appendix A, by $S$. Christensen et al., provides a discussion of the advantages and limitations of multivariate regression; describes the methods for variable selection and evaluation; and presents the results for 30 different regression analyses involving various lake subsets and fish species. In addition, robust regression analyses were conducted to evaluate the sensitivity of the model results to individual influential data points. Appendix B, by K. Reckhow, provides a discussion of the advantages and uses of robust regression and the results for selected models.

Three measures of fish status were examined: brook trout presence/absence, creek chub presence/absence, and the presence or absence of any fish species (fish/no fish). Brook trout was selected as the major sport fish occurring in the smaller, higher-elevation lakes that may be more susceptible to acidic deposition. Creek chub are widely distributed among Adirondack lak es and, based on earlier field bioassay experiments (Johnson et al. 1987), are expected to be relatively acid sensitive. Fish/no fish was selected as the extreme response, both with regard to surface water acidity and other factors that affect habitat suitability.

Fifty variables derived from the ALSC data base were identified that may potentially influence fish distributions (see Section 3 1.3). These were grouped into six broad categories:

1. acidification response variables (e.g., pH, $\mathrm{Al}$, and $\mathrm{Ca}$ )

2. baseline habitat suitability variables (e.g., minimum dissolved oxygen, elevation)

3. productivity-related variables (e.g., total phosphorus, P)

4. natural reproduction and access variables (e g. lake type) 
5. anthropogenic control variables (e g., stocking and reclamation)

6. biological variables (e.g., the presence of other species that may compete with or prey upon the species of interest)

The basis for variable selection and the expected relationships to fish presence/absence are explained more fully in Table 3.1-3. Variables were transformed (usually log transformed) as needed to eliminate skewed distributions, thereby reducing the potential effects of influential observations on regression results.

Initially, bivariate comparisons were conducted to evaluate differences in the characteristics of lakes with and without fish, using the nonparametric Mann-Whitney lest for continuous explanatory variables and a contingency table analysis for categorical variables (Table 3.4-1). All but 5 of the 50 variables examined were significantly $(p \leq 0.05)$ associated with at least one of the three fish response variables (all but two were associated at $p \leq 0.10$ ). Clearly, lakes without fish, or without brook trout or creek chub, differ in many ways from lakes supporting fish. For example, lakes without fish were significantly ( $p \leq 0.05$ ) smaller and shallower, and occurred at higher elevations than lakes in which fish were caught. Fishless lakes also had significantly lower $\mathrm{pH}, \mathrm{ANC}$, and $\mathrm{Ca}$, and higher levels of Al (total and estimated inorganic Al) than did lakes with fish, and were more likely to be seepage lakes and bog lakes and to have a dam at the lake outlet blocking the downstream access. Both brook trout and creek chub occurred less frequently in smaller lakes, while brook trout were found more often in deeper lakes and creek chub more often in shallow lakes; differences in lake elevation were not significant. Lakes without brook trout and creek chub also had significantly lower $\mathrm{pH}, \mathrm{ANC}, \mathrm{Ca}$, and base cations, and higher $\mathrm{Al}$; these lakes were more likely to be bogs or marginal bogs and to support other fish species considered to be potential competitors (for brook trout) or predators (for creek chub). Lakes with brook trout present were also much more likely to have been stocked during the past 5 years than were lakes in which no brook trout were caught; presumably brook trout are generally not stocked into waters in which they cannot survive.

Interpretation of the results from these bivariate comparisons is hindered, however, by the strong correlations between many of the lake and watershed characteristics of interest. For example, lakes at higher elevation tend to be smaller, shallower, and to have lower $\mathrm{pH}$. Is lake $\mathrm{pH}$ a significant predictor of fish occurrence even after accounting for the potential effects of elevation, area, depth, and other factors on fish presence/absence? Multivariate regression analyses were used to evaluate the combined and interrelated effects of these variables on patterns of fish distribution. Regression analyses, by themselves, canno: prove cause-and-effect relationships, but may provide support, on a regional scale, for existing hypotheses about factors that influence fish distributions and habitat suitability 
Table 3.4-1 Candidate Explanatory Variables and Summary of Results from Mann-Whitney and Contingency Table Analyses to Test for Differences between Lakes with Fish Present and Absent

\begin{tabular}{|c|c|c|c|}
\hline \multirow[b]{2}{*}{ Explanatory Variableb } & \multicolumn{3}{|c|}{ Response Variablesa } \\
\hline & Brook Troutc & Creek Chubc & Fish/No Fishe \\
\hline \multicolumn{4}{|l|}{ 1. Acidification Response Variables } \\
\hline Field $\mathrm{pH}$ & $\star \star \star \star(+)$ & $\star \star \star(+)$ & $\star \star \star \star(+)$ \\
\hline ANC & $\star \star \star \star(+)$ & $\star \star \star \star(+)$ & $\star \star \star(+)$ \\
\hline Total Al & $\star \star \star(-)$ & $\star(-)$ & $\star \star \star(-)$ \\
\hline Estimated Inorganic Al & $\star \star \star *(-)$ & $\star \star \star \star(-)$ & $\star \star \star(-)$ \\
\hline Total Al:DOC & $\star \star \star(-)$ & $\star \star \star(-)$ & $\star \star \star(-)$ \\
\hline Estimated Inorganic Al:DOC & $\star \star \star(-)$ & $\star \star \star(-)$ & $\star \star \star \star(-)$ \\
\hline $\mathrm{Ca}$ & $\star \star \star *(+)$ & $\star \star \star(+)$ & $\star \star \star(+)$ \\
\hline $\mathrm{Ca}+\mathrm{Mg}$ & $* \star \star n+1$ & $\star \star *(+)$ & $\star * \star *(+)$ \\
\hline Sum of Base Cations & $\star \star \star *(+)$ & $\star \star \star \star(+)$ & $\star \star \star n(+)$ \\
\hline $\mathrm{Na}$ & $\star \star \star(+)$ & $\star \star \star \star(+)$ & $\star \star \star *(+)$ \\
\hline $\mathrm{pCa} / \mathrm{pH}$ & $\star \star \star(-)$ & $\star \star \star(-)$ & $\star \star \star(-)$ \\
\hline DOC & $\star \star \star(-)$ & $\star \star(+)$ & ${ }^{\star}(-)$ \\
\hline Flushing Rate & $\star \star \star(-)$ & $\star \star \star(+)$ & NS \\
\hline \multicolumn{4}{|l|}{ 2. Baseline Habitat Suitability Variables } \\
\hline Minimum DO & NS & $\star \star \star \star(+)$ & $\star *+1$ \\
\hline Maximum Temperature & NS & $\star \star(\cdot)$ & $\star *+1$ \\
\hline Summer Minimum Temperature & **(-) & NS & NS \\
\hline Thermal Stratificationd & $* \star(+)$ & $\star \star(\cdot)$ & NS \\
\hline Maximum Depth & $\star \star \star(+)$ & $\star \star(-)$ & $\star \star \star(+)$ \\
\hline Elevation & NS & NS & $\star \star \star \star(-)$ \\
\hline Full Bogd & $\star \star(-)$ & $\star \star \star(-)$ & $\star \star \star *(-)$ \\
\hline Bog or Marginal Bogd & $\star \star \star(-)$ & ${ }^{\star}(-)$ & $\star \star \star(-)$ \\
\hline Beaver Influenced & NS & $\star(+)$ & NS \\
\hline Number of Macrophyte Taxae & --. & $\star \star \star(+)$ & $\star \star \star \star(+)$ \\
\hline Percent Open Water & $\cdots$ & $\star \star \star(+)$ & $\star \star \star \star(+)$ \\
\hline \multicolumn{4}{|l|}{ 3. Productivity-related Variables } \\
\hline Total P & *(-) & NS & NS \\
\hline Conductivity ( $H^{\prime}$-adjusted) & $\star \star \star(+)$ & $\star \star \star(+)$ & $\star \star \star(+)$ \\
\hline Area & $\star \star \star(+)$ & $\star \star \star(+)$ & $\star \star \star(+)$ \\
\hline Volume & $\star \star \star(+)$ & $\star \star \star(+)$ & $\star \star \star(+)$ \\
\hline Mean Depth & $\star \star \star *(+)$ & *(-) & $\star * *(+)$ \\
\hline Modified Morphoedaphic Index & NS & $\star \star \star(+)$ & $\star \star \star(+)$ \\
\hline Watershed:Lake Area Ratio & NS & $\star \star \star(+)$ & $\star \star(+)$ \\
\hline Littoral Area & $\star \star(+)$ & $\star \star \star \star x(+)$ & $\star \star \star *(+)$ \\
\hline Shoreline Development Index & NS & $\star \star \star(+)$ & $\star \star \star *(+)$ \\
\hline
\end{tabular}

(Continued) 
Table 3.4-1 Continued

\begin{tabular}{|c|c|c|c|}
\hline \multirow[b]{2}{*}{ Explanatory Variableb } & \multicolumn{3}{|c|}{ Response Variables } \\
\hline & Brook Troutc & Creek Chubc & Fish/No Fishc \\
\hline \multicolumn{4}{|c|}{ 4. Natural Reproduction and Access Variables } \\
\hline Lake Typed & NS & $\star \star \star(+)$ & $\star \star \star \star(+)$ \\
\hline Number of Inlets & $* *(+)$ & $\star \star \star(+)$ & $\star \star \star(+)$ \\
\hline Number ol Outlets & NS & $\star \star \star(+)$ & $\star \star * *(+)$ \\
\hline $\mathrm{SiO}_{2}$ & $* * *(+)$ & $\ldots$ & $\star \star \star(+)$ \\
\hline Blocked Downstream Accessd & $\star \star \star \star(-)$ & $\star \star \star(-)$ & $\star \star \star(-)$ \\
\hline Substrated & $* * *(+1$ & $\cdots$ & $\star \star \star(+)$ \\
\hline \multicolumn{4}{|l|}{ 5. Anthropogenic Control Variables } \\
\hline Distance to Nearest Road & NS & NS & $\star \star \star(-)$ \\
\hline Road Typed & NS & $\star(-)$ & NS \\
\hline Brook Trout Stockedd & $\star * \star *(+)$ & $\ldots$ & $\cdots$ \\
\hline Stocking of Competitorsd & $* *(+)$ & $\cdots$ & $\cdots$ \\
\hline Ownershipd & $\cdots$ & NS & $\star \star \star *(+)$ \\
\hline Reclamationd & $\ldots$ & NS & $\cdots$ \\
\hline Reclamation within last 10 yearsd & $\cdots$ & NS & $\cdots$ \\
\hline Slocking of Any Speciesd & $\cdots$ & $\star \star \star *(+)$ & $\star \star \star(+)$ \\
\hline \multicolumn{4}{|l|}{ 6. Biological Variables } \\
\hline Presence of Competitorsd & $\star \star(-)$ & $\star \star \star(+)$ & $\cdots$ \\
\hline Presence of Predatorsd & $\cdots$ & $\star \star \star *(-)$ & $\cdots$ \\
\hline Presence of Associates & $\star \star \star(+)$ & $\star \star \star(+)$ & $\cdots$ \\
\hline
\end{tabular}

a Sign of correlation noted in parentheses.

b See Appendix A for further detail on the definition and transformations of explanatory variables.

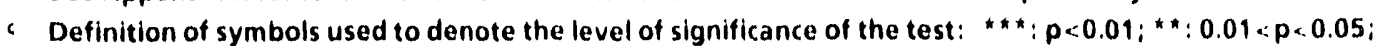

$*: 0.05<p<0.10 ;$ NS: $p>0.10$. A $\cdots$ indicates that the variable is not applicable.

d Categorical variables: $1=$ yes, $0=$ no; except for lake type where $1=$ drainage, $0=$ seepage; road type, where 0 denotes 4-wheel drive and 1 denotes 2 -wheel drive road; and ownership, where 1 denotes private ownership and 0 denotes public or mixed ownership.

- Treated as categorical variable; sign based on median values for absent vs. present categories.

Models relating patterns of fish distribution to lake and watershed characteristics were developed using maximum likelihood logistic regression because of the binary nature of the response variable fish presence/absence. Procedures for model development and evaluation were as follows:

- Highty collinear variables (in essence, candidate explanatory variables that were highly correlated with each other in a multivariate context and thus provided redundant information) were eliminated based on collinearity diagnostics. Generally, 5-7 variables were eliminated per analysis. Criteria used to select variables for elimination and the specific variables eliminated in each analysis are discussed further in Appendix A. 
- The data set was divided into two-thirds for model development and calibration and onethird for model evaluation. Lakes limed within 10 years of the ALSC survey or with potential problems with measured chemical concentrations, as defined in Section 2.1.4.3, were excluded from all analyses.

- Variables significantly associated with fish presence/absence were selected using the stepwise logistic regression procedure (PROC LOGIST) (Harrell 1986) from SAS Institute.

- If the selected model included biological variables (e.g., the presence or absence of other fish species that may prey upon or compete with the species of interest), a second set of analyses was run excluding the biological variables from the candidate variable list.

- Analyses were conducted on several different data sulssets to explore the relative importance of the candidate explanatory variables for various groups or types of lakes. For example, reliable stocking information is available only for public and mixed ownership waters in the Adirondacks. Thus, analyses evaluating the significance of stocking involved only nonprivate lakes surveyed by the ALSC. Additional analyses focused specifically on patterns of brook trout distribution in nonstocked lakes presumably supported by riatural reproduction (i.e., nonprivate waters with no records of brook trout stocking in the 5 years preceding the ALSC survey). Creek chub analyses were conducted both for Adirondack lakes, in general, and by watershed groups, for waters in the western. Adirondacks where low-pH lakes are prevalent and also for waters in the eastern Adirondacks where acidic lakes are much less common. Seven different lake groups were assessed in total. The list of candidate explanatory variables was modified as appropriate for certain lake groups (e.g., stock.ing data were rot considered in nonstocked lakes).

- The final models were used to predict fish presence/absence for the remaining one-third of the data set, comparing the observed and predicted pattern of fish presence/absence to evaluate model performance.

- A select subset of the models (two models predicting brook trout presence/absence) were re-fit using robust regression techniques (Appendix B) and diagnostics (Appendix A.2) to determine the sensitivity of the model coefficients, in particular the pH coefficient, to influential data points

The regression results, as expected, varied among analyses, data sets, and candidate variable lists, although some consistent patterns were evident. In general, the types of variables selected and the directions of their influence were consistent with expectations.

Four nonacidification-related varia'sles were particularly important in predicting the presence or absence of brook trout: (1) stocking, (2) $\mathrm{SiO}_{2}$ concentrations, and the presence or absence of fish species considered to be either (3) competitors with or (4) common associates of brook trout. Among public and mixed ownership waters where we have reliable information on fish stocking, the occurrence of brook trout stocking was the single most important variable for predicting brook trout presence/absence in the ALSC survey. Higher $\mathrm{SiO}_{2}$ concentrations were also strongly associated with the presence of brook trout, especially among lakes not stocked in the past 5 years. Consistent with the results in Section $33, \mathrm{SiO}_{2}$ would appear to be a reasonable regional predictor of conditions suitable for brook trout natural reproduction. Biological variables were also important and highly 
significant $(p<0.0001)$ predictors of brook trout presence/absence in multivariate regressions. Brook trol: were less likely to be caught in lakes supporting one or more species considered as potential competitors (e.g., yellow perch or largemouth bass) and more likely to be caught in lakes with fish species commonly associated with brook trout. These results are not surprising, although they should be interpreted with caution. To some degree, these inter-species relationships may reflect the indirect effects of other lake characteristics (e.g , lake $\mathrm{pH}$ ) that may jointly affect the distribution of a number of fish species. Other nonacidification-related variables identified as significant predictors of brook trout presence/absence in a number of analyses include (1) distarice to the nearest road (brook trout were more likely to be cauc " in more remote lakes further from roads) and (2) substrate type (brook trout were caught less often in waters with essentially a!l of the observable substrate composed of materials considered poor spawning substrate, i.e., mud, silt, clay, or organics).

The selected mrdels for creek chub presence/absence and fish/no fish also included a large number and diversity of nonacidification variables. For example, lake characteristics strongly associated with the abserice of creek chub in multivariate analyses were (1) the occurrence of other fish species considered likely creek chub predators (e.g., largemouth bass and northern pike); (2) the absence of a lake outlet or inlets; (3) lower flushing rates; and (4) a smaller lake area or littoral area. In a sirniiar manner, smaller, shallower lakes, at higher elevations and with lower flushing rates were less likely to support any fish species.

While many factors influence fish distributions in Adirondack lakes, in all cases one or more variables related to surface water acid-base chemistry (variable group 1, most often lake $\mathrm{pH}$ ) was also selected as a significant (generally $p \leq 0.01$ ) predictor of the presence/absence of brook trout and creek chub, and fish/no fish (Tables 3 4-2 and 3.4-3). Even after accounting for differences in brook trout distribution related to stocking, other biota, groundwater inflow $\left(\mathrm{SiO}_{2}\right)$, substrate, and other factors, lakes without brook trout still had lower $\mathrm{pH}$ relative to lakes with brook trout present. Likewise, in all multivariate analyses conducted for fish/no fish and the presence or absence of creek chub, at least one acidification response variable (either $\mathrm{pH}$ or the ratio of $-\log _{10}$ (calcium concentration in moles/L) to $\mathrm{pH}$, denoted $\mathrm{p}(\mathrm{a} / \mathrm{pH}$ ) was included as a highly significant variable in each model (Table 34 -3). The importance of $\mathrm{pH}$ as a predictor of creek chub presence/absence was greater for western Adirondack watersheds, which contain a high proportion of the low-pH Adirondack lakes, than for eastern watersheds. These results support the hypothesis that lake $\mathrm{pH}$ (and/or other acidification-related variables) plays an important role in restricting the distribution of fish from at least some Adirondack lakes.

Although the emphasis for this report is on interpretation of the ALSC survey results, the regression models developed can also be used for prediction, i e, to predict the probahility of fish presence as a 
Table 3.4-2 Greatest Level of Significance of Any Variable Within Each of Six Explanatory Variable Groups for Brook Trouta

\begin{tabular}{|c|c|c|c|c|c|c|c|}
\hline \multirow{2}{*}{$\begin{array}{l}\text { Lake } \\
\text { Groupb }\end{array}$} & \multirow{2}{*}{$\begin{array}{c}\text { Variable } \\
\text { Setb }\end{array}$} & \multicolumn{6}{|c|}{ Explanatory Variable Groupc,d } \\
\hline & & 1 & 2 & 3 & 4 & 5 & 6 \\
\hline 1 & B1 & $\star \star \star$ & & & $\star \star \star \star$ & $\star \star \star \star$ & $\star \star \star \star$ \\
\hline 1 & B1A & $\star \star \star$ & & & $\star * \star *$ & $\star \star \star \star$ & $\star \star \star \star$ \\
\hline 1 & $\mathrm{~B} 1 \mathrm{~B}$ & $\star \star \star$ & & & $\star \star \star$ & $\star \star \star$ & $\star \star \star$ \\
\hline 1 & BO & $\star \star \star$ & & & $\star \star \star$ & $\star \star \star$ & $\ldots$ \\
\hline 1 & $B O A$ & $\star \star \star$ & & & $\star \star \star \star$ & $\star \star \star$ & --. \\
\hline 1 & $\mathrm{BOB}$ & $\star \star \star$ & $\star$ & & $\star \star \star$ & $\star \star \star$ & $\ldots$ \\
\hline 2 & B1 & $\star$ & $\star \star$ & & $\star \star \star$ & $\star \star \star \star$ & $\star \star \star \star$ \\
\hline 2 & BO & $\star \star \star$ & & & $\star \star \star$ & $\star \star \star$ & 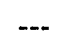 \\
\hline 3 & BO & $\star \star \star$ & & & $\star \star \star$ & $\star \star \star$ & -.- \\
\hline 4 & B1 & $\star \star \star \star$ & & $\star \star \star \star$ & $\star \star \star \star$ & $\star \star \star \star$ & $\star \star \star$ \\
\hline 4 & BO & $\star \star \star$ & $\star \star \star$ & $\star \star \star \star$ & $\star \star \star$ & $\star \star \star \star$ & $\cdots$ \\
\hline 4 & $\mathrm{BOE}$ & $\star \star \star \star$ & $\star \star \star$ & & $\star \star \star$ & & $\ldots$ \\
\hline $1 \mathrm{H}$ & B1 & $\star \star \star$ & $\star \star \star$ & & $\star \star \star$ & $\star \star \star$ & $\star \star \star$ \\
\hline $1 H$ & BO & $\star \star \star$ & $\star \star$ & & $\star \star \star$ & $\star \star \star$ & $\cdots$ \\
\hline $4 H$ & BO & $\star \star \star \star$ & $\star \star \star$ & $\star \star \star$ & $\star \star \star \star$ & $\star \star$ & --. \\
\hline $4 \mathrm{H}$ & BOE & $\star \star \star$ & $\star \star \star$ & $\star \star \star$ & $\star \star \star \star$ & & --. \\
\hline $4 H$ & BOENA & * & $\star \star \star \star$ & $\star \star *$ & $\star \star \star \star$ & & -- \\
\hline
\end{tabular}

a Represented in the stepwise-selected logistic model.

b Lake groups and variable sets are explained in Appendix A.

6 Explanatory variable groups are (see Table 3.4-1 for more details): (1) acidification-response variables; (2) baseline habitat suitability variables; (3) productivity-related variables; (4) natural reproduction and access variables; (5) anthropogenic control variables; and (6) biological variables.

d Definition of symbols used to denote the level of significance of the test: ${ }^{\star \star}: p<0.01 ;{ }^{\star *}: C .01<p<0.05 ;{ }^{\star}: 0.05<p<0.1$. A blank indicates that no variables from this group are included in the model. A -.. indicates that the variables in this group are excluded trom the analysis.

function of acidification- and nonacidification-related variables, both for individıal lakes and for the Adirondack region as a whole. The higher the coefficient for $\mathrm{pH}$, in general, the more responsive the model to changes in $\mathrm{pH}$. It is of interest, therefore, to compare estimates of the $\mathrm{pH}$ coefficient among the various models for different lake groups and sets of predictor variables. The estimates of the coefficient vary substantially, for example, from 0.66 to 2.26 for models of brook trout presence/absence (Table 34 -4). Robust regression techniques (one-step Huber estimator with a "gentle" scale factor) also resulted in a marked change in the $\mathrm{pH}$ coefficient, increasing the estimated coefficient from 1.51 to 2.30 and from 1.16 to 1.51 in the two models exarnined Thus, although the multivariate regression analyses provide strong support for the hypothesis that low pH levels are an important factor restricting the occurrence of fish in some Adirondack lakes, by themselves these 
analyses have difficulty in isolating and quantifying the effect of lake $\mathrm{pH}$ on fish presence/absence.

Examples of model applications are provided in Appendix A.

Table 3.4-3 Greatest Level of Significance of any Variable Within each of Six Explanatory Variable Groups for Creek Chub and Fish versus No Fisha

\begin{tabular}{|c|c|c|c|c|c|c|c|}
\hline \multirow{2}{*}{$\begin{array}{l}\text { Lake } \\
\text { Groupb }\end{array}$} & \multirow{2}{*}{$\begin{array}{c}\text { Variabie } \\
\text { Setb }\end{array}$} & \multicolumn{6}{|c|}{ Explanatory Variable Groupc,d } \\
\hline & & 1 & 2 & 3 & 4 & 5 & 6 \\
\hline \multicolumn{8}{|c|}{ Creek Chub } \\
\hline 5 & $B 1 A$ & $\star \star \star$ & $\star \star \star$ & $\star \star \star$ & $\star \star$ & & $\star \star \star$ \\
\hline 5 & $B 1 B$ & $\star \star \star$ & & $\star \star \star$ & $\star \star$ & & $\star \star \star *$ \\
\hline 5 & BOB & $\star \star \star$ & & $\star \star \star$ & $\star \star \star$ & & $-\cdots$ \\
\hline 6 & B1B & $\star \star \star$ & & $\star \star \star$ & & $\star \star$ & $\star \star \star ~$ \\
\hline 6 & BOB & $\star \star \star$ & & & $\star \star$ & & $\cdots$ \\
\hline 7 & B 1B & $\star \star \star$ & * & $\star \star \star$ & & & $\star \star \star$ \\
\hline 7 & $\mathrm{BOB}$ & $\star \star$ & * & $\star \star$ & * & $\star \star \star$ & $\cdots$ \\
\hline \multicolumn{8}{|c|}{ Fish versus No Fish } \\
\hline 5 & BOA & $\star \star \star$ & $\star \star \star$ & $\star \star \star$ & & $\star \star$ & $\cdots$ \\
\hline 5 & $\mathrm{BOB}$ & $\star \star \star$ & $\star \star \star$ & $\star \star \star$ & & $\star \star$ & -.. \\
\hline
\end{tabular}

Represented in the stepwise-selected logistic model.

b Lake groups and variable sets are explained in Appendix A.

c Explanatory variable groups are (see Table 3.4-1 for more details): (1) acidification response variables; (2) baseline habitat suitability variables; (3) productivity related variables; (4) natural reproduction and access variables: (5) anthropogenic control variables; and (6) biological variables.

d Definition of symbols used to denote the greatest level of significance of the test: $* \star *: p<0.01 ; * \star 0.01<p<0.05$; $\star: 0.05<p<0.1$. A blank indicates that no variables from this group are included in the model. A m... indicates that the variables in this group are excluded from the analysis. 
Table 3.4-4 Comparison of Values of the Coefficients of the pH Term in Stepwise-Selected Logistic Models of Brook Trout Presence/Absence in Adirondack Lakes

\begin{tabular}{cccc}
\hline $\begin{array}{c}\text { Lake } \\
\text { Groupa }\end{array}$ & $\begin{array}{c}\text { Variable } \\
\text { Seta }\end{array}$ & $\begin{array}{c}\text { pH } \\
\text { Coefficientb }\end{array}$ & $\begin{array}{c}\text { Standard } \\
\text { Error }\end{array}$ \\
\hline 1 & & $1.25^{\star \star \star}$ & \\
1 & B1 & $1.32^{\star \star \star}$ & 0.404 \\
1 & B 1B & $1.51^{\star \star \star}$ & 0.393 \\
$1 L$ & BO & $2.11 \star \star \star$ & 0.353 \\
$1 L$ & BO(S) & $2.05^{\star \star \star}$ & 0.496 \\
1 & BO(F) & $1.32^{\star \star \star}$ & 0.637 \\
2 & BOB & $N S$ & 0.325 \\
2 & B1 & $1.16^{\star \star \star}$ & NS \\
$2 L$ & BO & $200^{\star \star \star}$ & 0.280 \\
$2 L$ & BO(S) & $2.26^{\star \star \star}$ & 0.534 \\
3 & BO(F) & $1.16^{\star \star \star}$ & 0.569 \\
4 & BO & $0.708^{\star \star \star}$ & 0.281 \\
4 & B1 & $0.660^{\star \star \star}$ & 0.146 \\
4 & BO & $0.877^{\star \star \star}$ & 0.207 \\
& BOE & & 0.193 \\
\hline
\end{tabular}

- Lake groups and variable sets are described in Appendix $A$.

b Definition of symbols used to denote the greatest level of significance of the test: ***:p<0.01. NS denotes not selected in the model. 


\subsection{FISH SPECIES DISTRIBUTION PATTERNS IN SELECTED ADIRONDACK DRAINAGE SYSTEMS}

\section{Schofield}

\subsubsection{Background}

When fish are presented with potentially adverse environmental conditions, such as increased acidity, they may respond to the changing quality of their environment either by physiological regulation within species- or strain-specific zones of tolerance, or they may behaviorally regulate the quality of their environment by moving to areas that are within their zones of physiological tolerance. Opportunities for emigration/immigration by fish species and redistribution to habitats offering suitable water quality for survival need to be considered when assessing fish species distribution patterns in relation to acidification. Discrete watersheds are logical areal units for assessing fish species distribution patterns in glaciated regions such as the Adirondacks where the majority of lakes are drainage types open to fish movement. The integrated effects of differential physiological tolerances to acidification and behavioral regulation of environmental quality were examined in this study by determining fish species distribution patterns in relation to spatial water quality gradients within selected watersheds exhibiting different ranges in lake water quality. Using discrete drainage systems, where longitudinal gradients in water quality exist, allows these fish distribution regulatory processes to be expressed in terms of watershed-specific species distribution patterns. This approach could also provide a means of assessing the recolonization potential for sensitive fish species within watersheds that currently exhibit marked acidification gradients

A general pattern of decreasing lake acidity from small headwater lakes to larger downstream basins was documented in studies of the North Branch of the Moose River in the western Adirondacks (Driscoll et al. 1987). Correlated patterns in species richness and occurrences of acid-tolerant and sensitive fish species were associated with this longitudinal water quality gradient in the North Branch of the Moose River (Schofield and Driscoll 1987). The hypothesis that species distribution patterns across acidity gradients reflect the relative physiological tolerances of the species to acidification was supported in this latter study by the observed species distributions and their measured tolerances to acidity. The primary objective of the current study was to further assess the application of this hypothesis to other Adirondack watersheds by using information on fish species occurrence and water quality available in the ALSC data base. 


\subsubsection{Approach}

Four discrete watersheds representative of major drainage basins in the western and eastern Adirondack region were selected for analyses of fish distribution. The two western watersheds selected (Moose River and Beaver River) were known to contain a high proportion of acidic lakes in contrast to the two eastern watersheds (Ausable River and Schroon River) where the majority of lakes are not acidic (Kretser et al. 1989). The Moose River watershed was further subdivided into North Branch and South Branch to maintain a reference to earlier studies of the North Branch of the Moose River (Schofield and Driscoll 1987). Nonacidic, eastern Adirondack watersheds were selected primarily as reference systems for comparison of '́actors affecting fish distribution that are not related directly to acidity, but which are common to all watersheds. Seepage lakes do not provide the potential for fish immigration/emigration, hence only drainage lakes were considered for this analysis in all watersheds. Additionally, reclaimed lakes were excluded from these analyses.

Comparisons were made both within and between watersheds (separately and geographically grouped into western and eastern systems) of species richness (number of fish species caught per lake) and the presence/absence of brook trout (Salvelinus fontinalis), yellow perch (Perca flavescens), acid-tolerant species, and acid-sensitive cyprinid species. The acid-tolerant and acid-sensitive species groups were of the same composition described in Appendix C. Brook trout was selected for individual evaluation because of its importance as a managed game species in the region and yellow perch because of its hypothesized significance as a competitor to Adirondack brook trout populations. Variables utilized for these comparisons were representative of major categorical factors potentially affecting fish distribution, including acidity (summer surface $\mathrm{pH}$ ), physical habitat suitability (beaver presence/absence, bog development, summer stratified/unstratified), habitat diversity (lake surface area), access (surface elevation, dam presence/absence), productivity (mean depth and total phosphorus, P), and competition/predation (presence/absence of competing or predatory species). Additional comparisons of fish cominunity associations were made in relation to the general ALSC lake classification scheme (see Section 2.4)

Statistical analyses employed included stepwise multiple linear regression (Snedecor and Cochran 1980), muitinomial logistic regression (Steinberg 1988), Kolmogorov-Smirnov (KS) tests for comparisons of continuous variables, and contingency table chi-square comparisuns of categorical frequencies (Hollander and Wolfe 1973)

Species richness model development was conducted with nonreclaimed, drainage lakes, excluding lakes in the selected eastern and western watersheds $(n=908)$. Stepwise multiple linear regression analysis of species number was utilized to identify potential predictor variables. The dependent 
variable and all continuous independent variables were normalized by $\log _{10}(1+x)$ transformation for this latter analysis. Multinomial logistic regression analysis was used to develop a predictive model of species richness distribution. A new dependent variable, species richness class, was created for this analysis by assigning each lake to one of four integer-coded species number classes $(1=0$ species, $2=1$ to 3 species, $3=4$ to 7 species, $4=8$ to 13 species). These uneven species richness classes normalized the distribution of observed species number across the range of 1 to 13 species found in the ALSC lakes, and fishless lakes were included as a separate class. Logistic regression analysis provided a means of estimating the probabilities of a lake's having the number of fish species identified by each of the four discrete classes. The coefficient estimates produced by the multinomial logistic model differ considerably from linear regression models in that a complete set of coefficients is estimated for each choice class but one. The left out, or reference, option is indexed by the greatest permissible value of the dependent variable ( 4 in this case). The null hypothesis that all model coefficients except the constant are equal to zero was evaluated by a log likelihood ratio chi-square test and by the t-statistic for individual parameter coefficient estimates. Predicted numbers of lakes in each species richness class, for the selected eastern and western watersheds, were obtained by summing the predicted probabilities, calculated from the logistic model, in each species richness class. Comparisons between observed and predicted species richness class distributions were made by a chisquare test.

\subsubsection{Results and Discussion}

\section{Watershed Characteristics}

The locations and relative sizes of the selected eastern and western Adirondack watersheds are illustrated on the Adirondack Park drainage system map (Figure 3.5-1) and the distribution of ALSC drainage lakes within each of the watersheds is shown in Figure 3.5-2 Lake density (number per unit of watershed area) is highest in the western basins of the Adirondacks, particularly the Beaver River watershed, and the number of ALSC lakes represented in the samples from each watershed reflects this distribution (Table 3.5-1). Although there was no significant difference in the distribution of lake area between watersheds, lakes in the western watersheds exhibited significantly different distributions of $\mathrm{pH}$, elevation, and fish species compared to lakes in the eastern watersheds (Table 3.5-1). A total of 36 fish species were collected from lakes in the eastern watersheds and 25 species were found in the western lakes Species found only in the eastern lakes included round whitefish, rainbow trout, Allantic salmon, tiger trout, rainbow smelt, northern pike, cutlips minnow, eastern silvery minnow, bluntnose minnow, longnose dace, fallfish, yellow bullhead, redbreast 


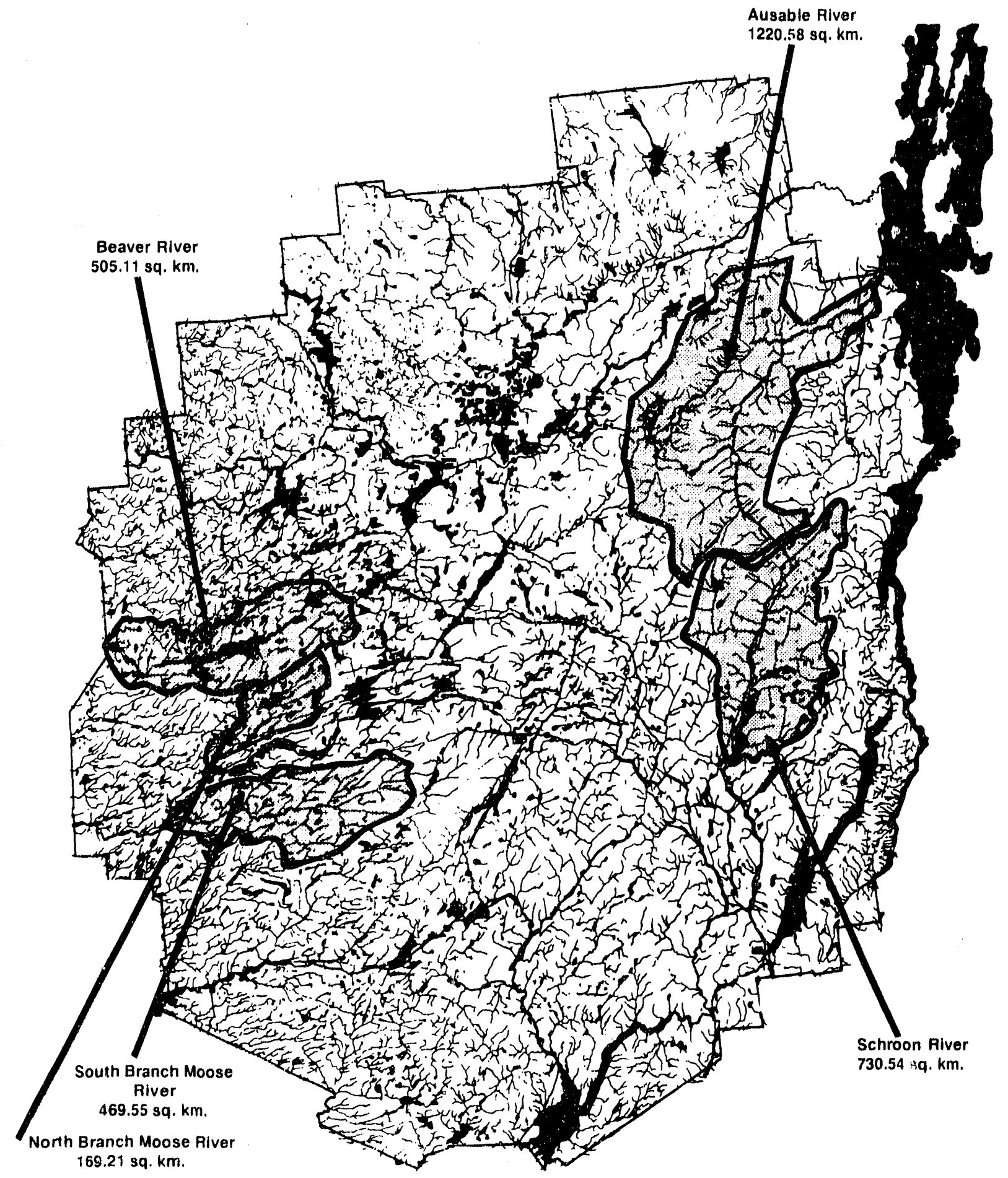

Figure 3.5-1 Location and areas of selected watersheds in the eastern and western Adirondack region. 


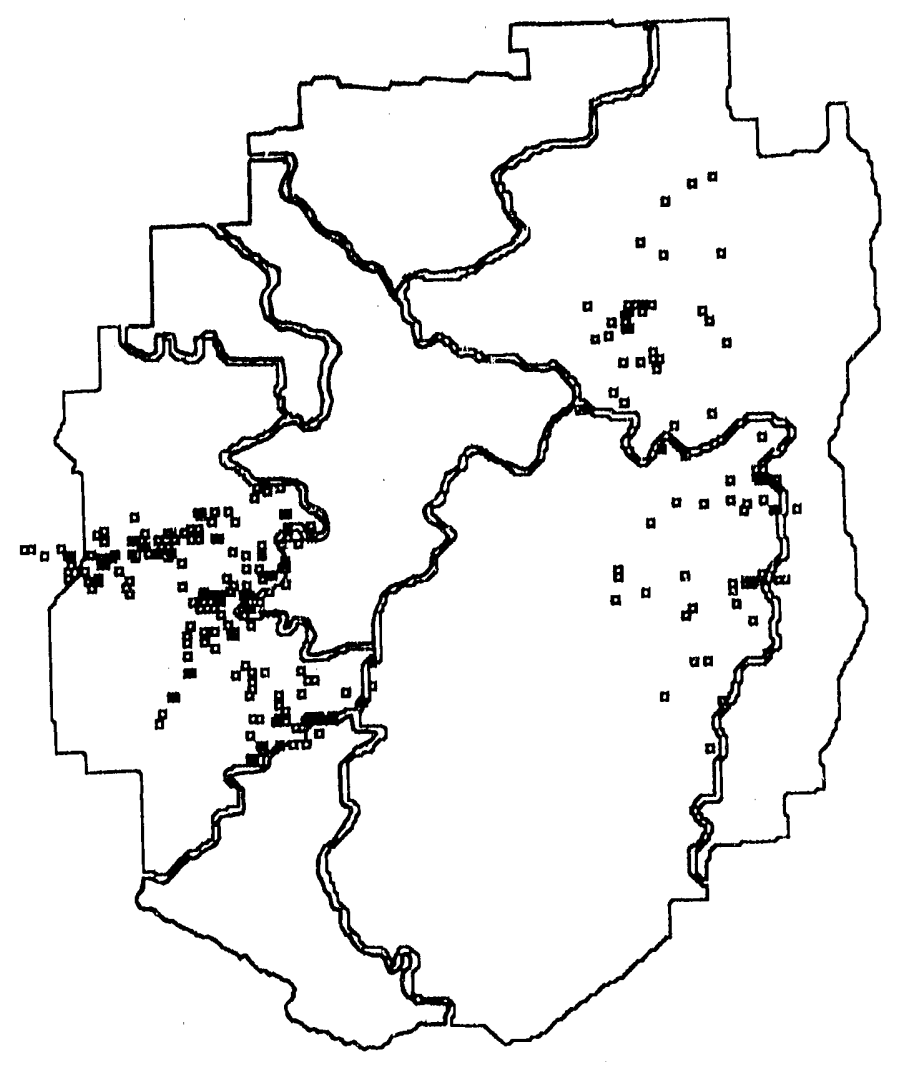

Figure 3.5-2 Distribution of drainage lakes in the Beaver, Moose, Ausable, and Schroon River watersheds.

sunfish, largemouth bass, and slimy sculpin. Species found only in western lakes included lake whitefish, central mudminnow, longnose sucker, and brook stickleback.

Outlet beaver dams were more frequent on lakes in western watersheds, but there was no significant difference in the distribution of stratified and unstratified lakes between watersheds (Table 3.5-2). Since seepage lakes were excluded from this analysis, the majority of lakes in all watersheds fell into the nonbog category (Table 3.5-2).

Comparison of the regional distribution of thick-till and thin-till lake types (Figure 3 5-3) indicates that very few acidic, thin-till type lakes occur in the eastern Adirondacks, whereas thick-till lakes (only one lake of this type had a $\mathrm{pH}<5$ ) are more widely distributed in the Adirondacks. This general distribution pattern is reflected in the relative proportions of lake types observed in the selected eastern and western watersheds (Table 3.5-3). Eastern watersheds have significantly higher proportions of carbonate and thick-till types in comparison to a higher proportion of thin-till lakes in 
Table 3.5-1 Characteristics of ALSC Drainage Lakes in Discrete Drainage Systems of the Western and Eastern Adirondack Regions

\begin{tabular}{|c|c|c|c|c|c|}
\hline System & $\mathbf{N}$ & $\begin{array}{l}\text { Elevation } \\
\text { Metersa,b }\end{array}$ & $\begin{array}{c}\text { Surface Area } \\
\text { hab }\end{array}$ & $\mathrm{pH}^{\mathrm{a}, \mathrm{b}}$ & $\begin{array}{l}\text { Species } \\
\mathrm{Na}, \mathrm{b}\end{array}$ \\
\hline Schroon & 39 & $\begin{array}{c}390 \\
(246-680)\end{array}$ & $\begin{array}{c}13.3 \\
(1.0-70.4)\end{array}$ & $\begin{array}{c}7.13 \\
(6.11-7.85)\end{array}$ & $\begin{array}{c}5.6 \\
(1-13)\end{array}$ \\
\hline Ausable & 33 & $\begin{array}{c}600 \\
(295-972)\end{array}$ & $\begin{array}{c}8.3 \\
(0.3-61.7)\end{array}$ & $\begin{array}{c}6.94 \\
(4.41-7.83)\end{array}$ & $\begin{array}{c}4.4 \\
(0-10)\end{array}$ \\
\hline Beaver & 104 & $\begin{array}{c}545 \\
(294-681)\end{array}$ & $\begin{array}{c}16.4 \\
(0.5-131.7)\end{array}$ & $\begin{array}{c}5.29 \\
(4.27-7.36)\end{array}$ & $\begin{array}{c}2.2 \\
(0-9)\end{array}$ \\
\hline N. Branch Moose & 35 & $\begin{array}{c}592 \\
(524-692)\end{array}$ & $\begin{array}{c}15.7 \\
(0.4-90.5)\end{array}$ & $\begin{array}{c}5.28 \\
(4.28-7.23)\end{array}$ & $\begin{array}{c}2.7 \\
(0-10)\end{array}$ \\
\hline S. Branch Moose & 47 & $\begin{array}{c}679 \\
(493-908)\end{array}$ & $\begin{array}{c}18.6 \\
(0.6-55.0)\end{array}$ & $\begin{array}{c}5.38 \\
(4.13-7.54\end{array}$ & $\begin{array}{c}1.5 \\
(0-8)\end{array}$ \\
\hline
\end{tabular}

a Significant ( $p \leq 0.001$, KS chi-square: differences between western and eastern basins

b Values indicated are means with ranges in parentheses

Table 3.5-2 Comparison of Bog, Beaver Dam, and Stratification Categories for Drainage Lakes in Western and Eastern Adirondack Basins

\begin{tabular}{|c|c|c|c|c|c|c|}
\hline \multirow{2}{*}{$\begin{array}{l}\text { Basin } \\
\text { West }\end{array}$} & \multicolumn{2}{|c|}{$\%$ Bug \% Nonbog } & \multicolumn{2}{|c|}{$\begin{array}{l}\text { Beaver Dam } \\
\% \text { Present } \% \text { Absent }\end{array}$} & \multirow{2}{*}{$\frac{\% \text { Stratified }}{40.3}$} & \multirow{2}{*}{$\frac{\% \text { Unstratified }}{59.7}$} \\
\hline & 14.5 & 85.5 & 64.0 & 36.0 & & \\
\hline East & 9.7 & 90.3 & 44.4 & 55.6 & 51.4 & 48.6 \\
\hline Chi-square & \multicolumn{2}{|c|}{ ris } & \multicolumn{2}{|c|}{. } & \multicolumn{2}{|r|}{ ns } \\
\hline
\end{tabular}

the west. This regional pattern of lake types reflects the greater geologic sensitivity of western Adirondack lakes to acidification (see Section 2.4)

There is a higher proportion of fishless lakes in the western Adirondack watersheds compared to eastern systems. Comparing only lakes containing fish, fewer western Adirondack lakes contain sensitive cyprinid species, whereas a greater proportion of western lakes harbor yellow perch. However, the frequencies of occurrence of lakes having brook trout, acid-tolerant species, or 

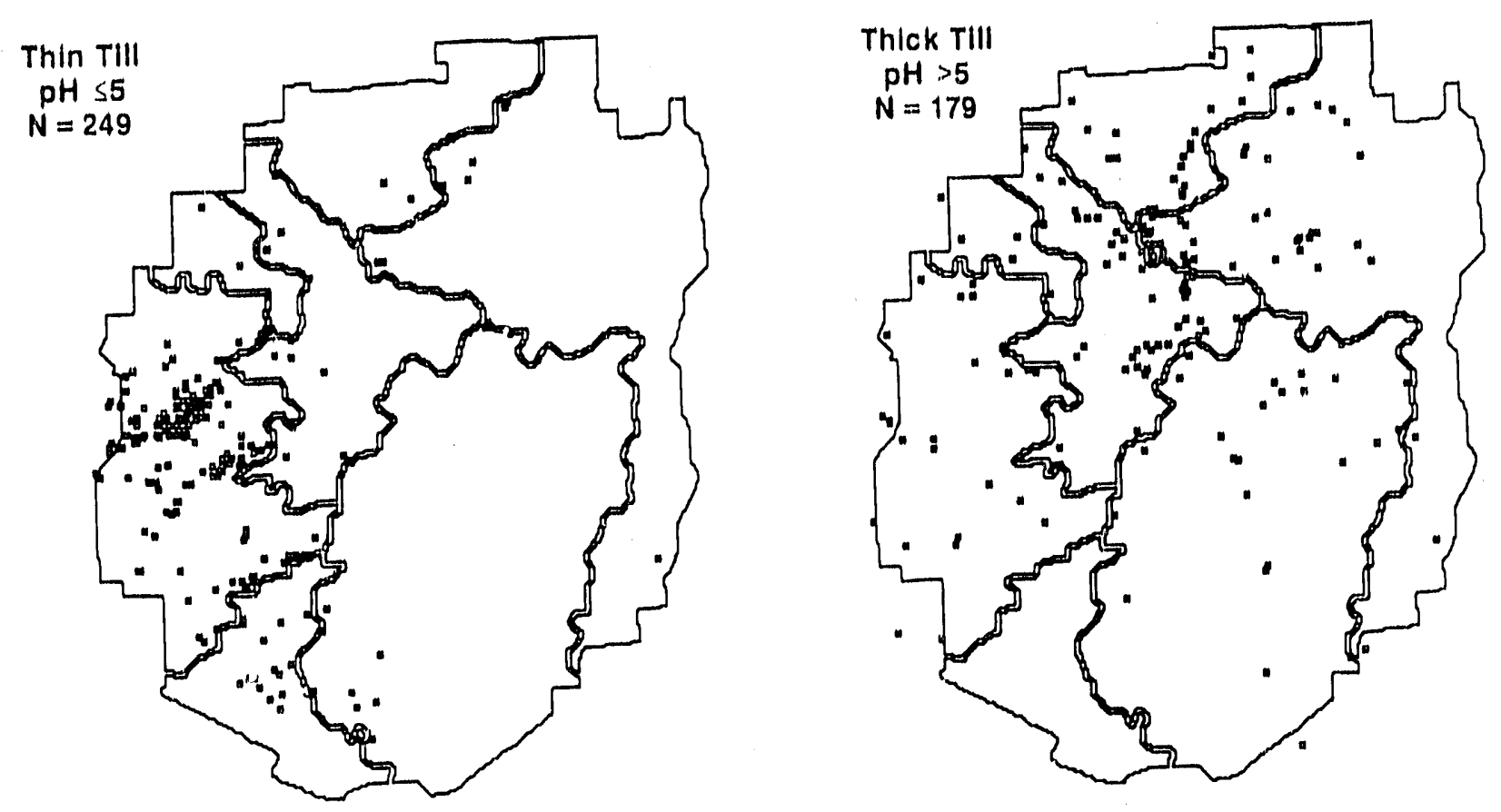

Figure 3.5-3 Distributions of thin- and thick-till ALSC lakes.

potential predatory/competitive species were not significantly different in western and eastern watersheds (Tuble 3.5-4)

\section{Species Richness Comparisons Between Watersheds.}

Several regional studies of fish species richness in relation to habilat characteristics have demonstrated that lake surface area is an appropriate index of habitat diversity for assessing potential species numbers in nonacidic lakes (Matuszek and Beggs 1988; Rago and Weiner 1986;

Rahel and Magnuson 1983). In mountainous areas, such as the Adirondacks, elevation is an additional factor associated with longitudinal gradients in species richness (Schofield and Driscoll 1987). Finally, lake $\mathrm{pH}$ is known to be a primary determinant of species richness in regions containing a significant proportion of acidic lakes (Matuzsek and Beggs 1988). Although other habitat-related variables such as indices of productivity, fish access, and anthropogenic influences may be locally significant, they are generally not as important as lake size, elevation, and $\mathrm{pH}$ in regional or watershed-scale analyses of species richness patterns. These observations were supported by a stepwise multiple linear regression analysis of species richness for ALSC drainage lakes $(n=1166$, 
Table 3.5.3 Comparison of ALSC Drainage Lake Type Frequencies Between Eastern and Western Watersheds

Coded Chi-Square: Region vs Lake "ype

Summary Statistles

\begin{tabular}{|l|l|}
\hline DF: & 3 \\
\hline Total Chi-Square: & 113.3 \\
\hline
\end{tabular}

\begin{tabular}{|c|c|c|c|}
\hline \multicolumn{4}{|c|}{ Observed Frequency Table } \\
\hline & East & West & Totals: \\
\hline Carb & 23 & 4 & 27 \\
\hline Thick & 15 & 13 & 28 \\
\hline Interm & 12 & 20 & 32 \\
\hline Thin & 4 & 146 & 150 \\
\hline Totals: & 54 & 183 & 237 \\
\hline
\end{tabular}

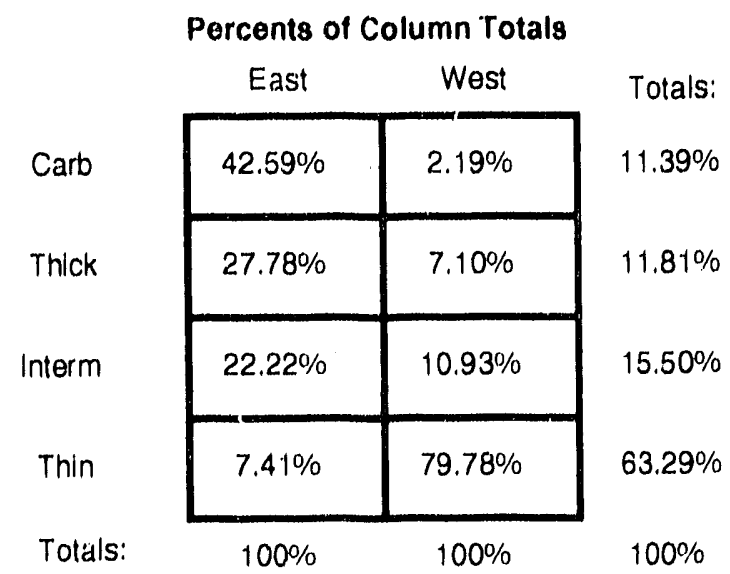


Table 3.5.4 Characteristics of Fish Communities in ALSC Drainage Lakes in Western and Eastern Adirondack Drainage Systems

\begin{tabular}{|c|c|c|c|c|c|c|}
\hline \multirow[b]{2}{*}{ System } & \multirow[b]{2}{*}{$\begin{array}{c}\% \\
\text { Fishless }\end{array}$} & \multicolumn{5}{|c|}{$\%$ Lakes Within Watershed With Species or Group } \\
\hline & & $\begin{array}{l}\text { Acid } \\
\text { Tolerant }\end{array}$ & $\begin{array}{l}\text { Yellow } \\
\text { Perch }\end{array}$ & $\begin{array}{l}\text { Pred.I } \\
\text { Comp. }\end{array}$ & $\begin{array}{l}\text { Brook } \\
\text { Trout }\end{array}$ & $\begin{array}{l}\text { Sensitive } \\
\text { Cyprinid }\end{array}$ \\
\hline Schroon & 0.0 & 89.7 & 25.6 & 30.8 & 56.4 & 8.2 \\
\hline Ausable & 15.2 & 50.0 & 17.9 & 10.7 & 78.6 & 46.4 \\
\hline Beaver & 50.0 & 86.5 & 55.8 & 19.2 & 48.1 & 9.6 \\
\hline S. Branch Moose & 57.4 & 45.0 & 10.0 & 5.0 & 65.0 & 15.0 \\
\hline N. Branch Moose & 42.9 & 90.0 & 70.0 & 10.0 & 65.0 & 30.0 \\
\hline $\begin{array}{l}\text { Ch1-square } \\
\text { West versus East }\end{array}$ & $* *$ & ns & "n & ris & ns & ** \\
\hline
\end{tabular}

excluding reclaimed lakes). In this analysis, lake $\mathrm{pH}$, surface area, and elevation accounted for $66 \%$ $\left(R^{2 * 100}\right)$ of the regional variation in species richness. Other variables selected in the stepwise regression (DOC, monomeric $\mathrm{Al}, \mathrm{SiO}_{2}, \mathrm{Ca}$, mean depth, total $\mathrm{P}$, presence/absence of summer stratification, and presence/absence of outlet beaver dams) collectively contributed only an additional $4 \%$ to the regional variation in species richness (total $R^{2}=0.698$ ).

Multinomial logistic regressiorı analysis was used to model the relationship between species richness, lake surface area, elevation, and pH (Table 3.5-5). Model plots of predicted probabilities for each of the species richness classes as a function of $\mathrm{pH}$ for lakes in the surface areas of 2 and 200 ha, at elevations of 400 and $700 \mathrm{~m}$ are shown in Figures 3.5.4 to 3.5-7. The model predicts high probabilities of species absence in small ( 2 -ha) high-elevation lakes at pH levels $<6$ and below $\mathrm{pH} 5.0$ in intermediate size lakes ( $20 \mathrm{ha}$ ) at the same elevation. The probabilities of encountering lakes with greater species richness increases with both increased $\mathrm{pH}$ and surface area, as illustrated in the examples plotted.

Predicted distributions were obtained for the selected eastern and western watersheds simply by summing predicted probabilities for lakes in each species richness class to obtain estimates of the number of lakes in each class (Table 3.5-6). Observed species richness class distributions of lakes within eastern and western watersheds were not significantly different (eastern $x^{2}=7.5, p=0566$; 
Table 3.5-5 Parameters for Multinomial Logistic Regression Model of Species Richness Class as a Function of Summer Surface $\mathrm{pH}, \log _{10}\left(1+\right.$ Area), and $\log _{10}(1+$ Elevation $) \mathrm{a}, \mathrm{b}$

\begin{tabular}{|c|c|c|c|c|c|}
\hline $\begin{array}{l}\text { Species } \\
\text { Richness } \\
\text { Class }\end{array}$ & $N$ & Parameter & Estimate & Standard Error & T-Statistic \\
\hline 0 & 161 & $\begin{array}{r}\text { Constant } \\
p H \\
\text { Area } \\
\text { Elevation }\end{array}$ & $\begin{array}{r}16.2890 \\
-3.7274 \\
-6.0402 \\
16.4144\end{array}$ & $\begin{array}{l}7.13316 \\
0.3059 \\
0.5216 \\
2.4960\end{array}$ & $\begin{array}{r}-2.283 \\
-12.186 \\
-11.581 \\
6.576\end{array}$ \\
\hline $1-3$ & 240 & $\begin{array}{r}\text { Constant } \\
\mathrm{pH} \\
\text { Area } \\
\text { Elevation }\end{array}$ & $\begin{array}{r}11.4766 \\
-1.9134 \\
-4.2874 \\
2.3878\end{array}$ & $\begin{array}{l}4.6274 \\
0.2228 \\
0.3428 \\
1.4509\end{array}$ & $\begin{array}{r}2.480 \\
-8.589 \\
-12.505 \\
1.646\end{array}$ \\
\hline $4-7$ & 346 & $\begin{array}{r}\text { Constant } \\
\mathrm{pH} \\
\text { Area } \\
\text { Elevation }\end{array}$ & $\begin{array}{r}7.0494 \\
-0.8960 \\
-2.2949 \\
1.0688\end{array}$ & $\begin{array}{l}3.7398 \\
0.2025 \\
0.2417 \\
1.1018\end{array}$ & $\begin{array}{r}1.885 \\
-4.425 \\
-9.496 \\
0.970\end{array}$ \\
\hline 8.13 & 161 & & & & \\
\hline
\end{tabular}

a Calibration data ( $N=908$ ) excludes seepage, reclaimed, and selected westeast watershed lakes.

b Log likelihood ratio $x^{2}=894.92,9 \mathrm{df}$.

western $x^{2}=8.2, p=2216$ ). However, these observed distributions were significantly different between eastern and western watersheds $\left(x^{2}=583, p=.0001\right)$, with notably higher proportions of fishless lakes in the western watersheds. Comparison of observed distributions with predicted distributions of lakes by species richness class within watersheds were not significantly different, except for the Beaver River watershed (Table 3.5-6). The discrepancy between observed and predicted frequencies of lakes with 0 and $1-3$ species in the Beaver River watershed may reflect additional toxicity factors in these lakes that are not adequately expressed by $\mathrm{pH}$ alone in the regional logistic model. This hypothesis is supported by comparison of the independent variables selected in stepwise multiple linear regression analyses of species richness for lakes in the Beaver River and Moose River watersheds (Table 3.5-7). The selection of monomeric $\mathrm{Al}$ and $\mathrm{Ca}$ in the Beaver River regression analysis, instead of $\mathrm{pH}$ which was selected in the Moose River regression, suggests potentially greater $\mathrm{Al}$ toxicity in low-pH waters of the Beaver River drainage. Although mean monomeric $\mathrm{Al}, \mathrm{Ca}$, and $\mathrm{DOC}$ concentrations were not significantly different between watersheds $(p \leq .05)$, the slightly lower mean Ca and DOC levels in the Beaver River lakes may be sufficient to 


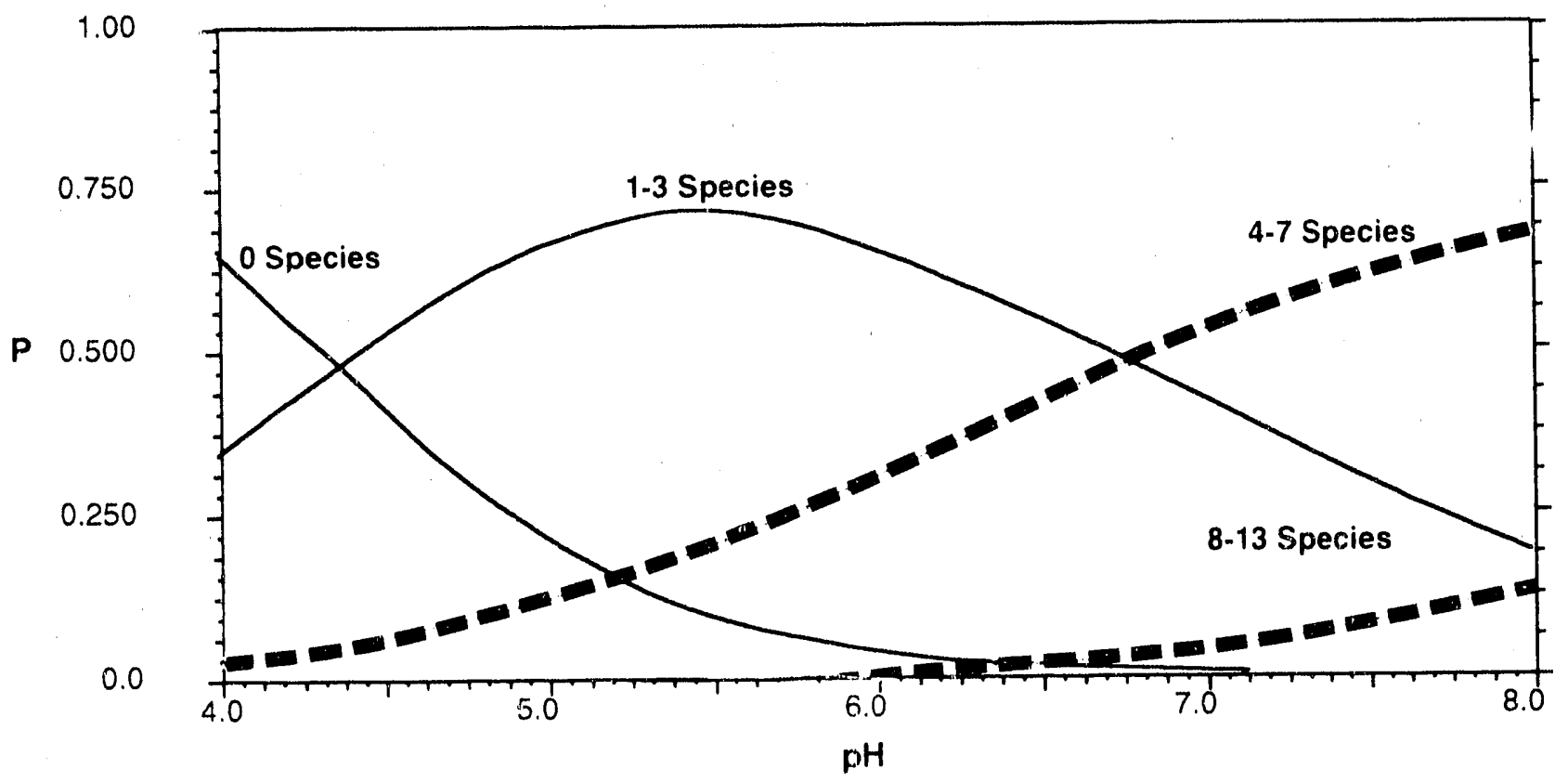

Figure 3.5-4 Predicted probabilities for fish species richness classes in a lake with 2-ha surface area at $\mathbf{4 0 0} \mathrm{m}$ elevation.

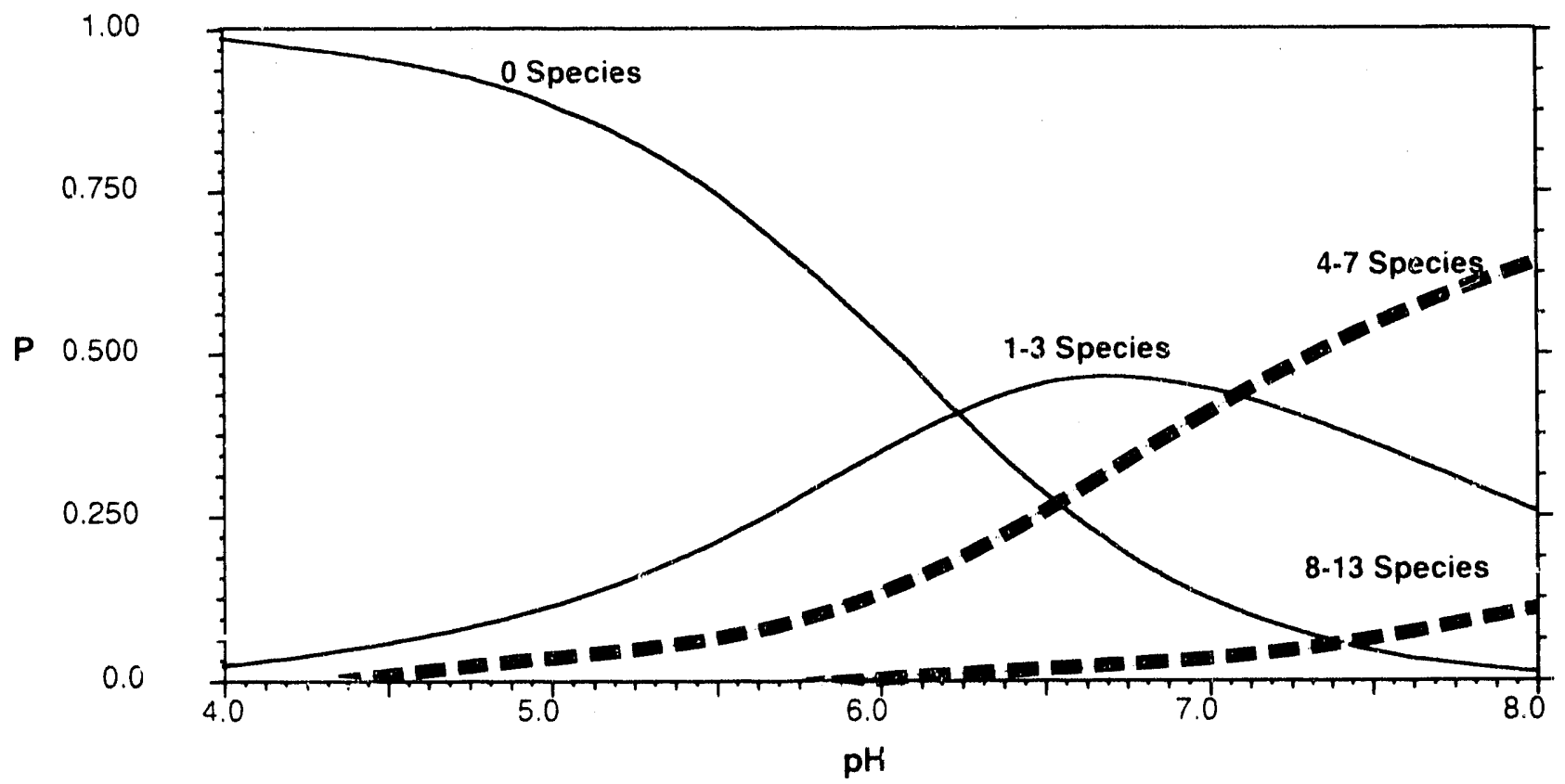

Figure 3.5-5 Predicted probabilities for fish species richness classes in a lake with 2-ha surface area at 700 m elevation. 


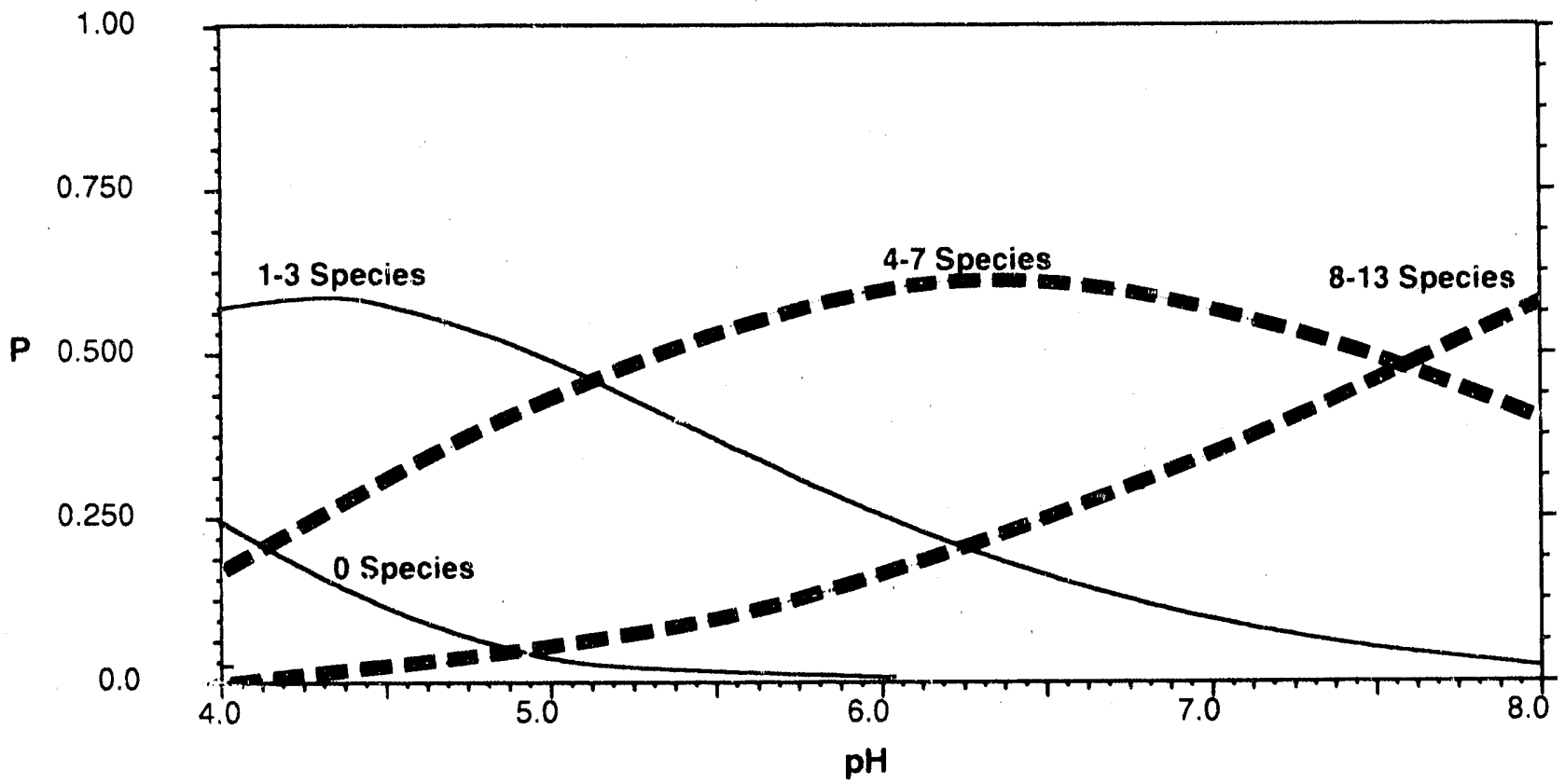

Figure 3.5-6 Predicted probabilities for fish species richness classes for a 20-ha lake at $400 \mathrm{~m}$ elevation.

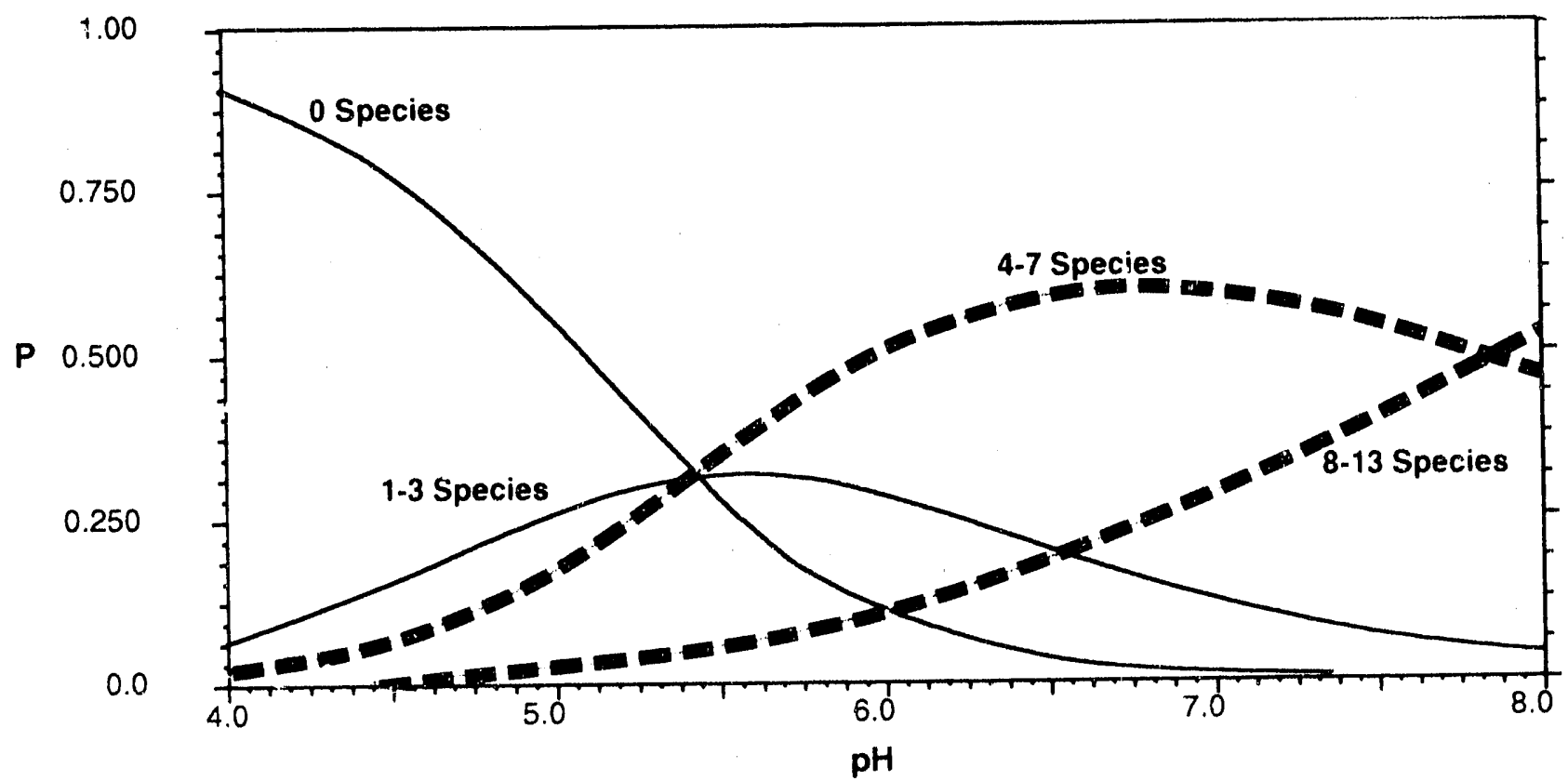

Figure 3.5-7 Predicted probabilities for fish species richness classes for a 20-ha lake at $700 \mathrm{~m}$ elevation. 
Table 3.5-6 Observed and Predicted Species Richness Class Distributions for Lakes in Selected Adirondack Watersheds

\begin{tabular}{|c|c|c|c|c|c|c|c|c|c|c|c|c|}
\hline \multirow{3}{*}{$\begin{array}{l}\text { Species } \\
\text { Richnes } \\
\text { Class }\end{array}$} & & \multicolumn{4}{|c|}{ Eastern Watersheds } & \multicolumn{7}{|c|}{ Western Watershedsa } \\
\hline & & \multicolumn{2}{|c|}{ Schroon } & \multicolumn{2}{|c|}{ Ausable } & \multirow[b]{2}{*}{.} & \multicolumn{2}{|c|}{ Beaver } & \multicolumn{2}{|c|}{ N. Branch Moose } & \multicolumn{2}{|c|}{ S. Branch Moose } \\
\hline & & Obs. & Pred." & Obs. & Pred." & & Obs. & Pred.A & Obs. & Pred.a & Obs. & Pred.A \\
\hline 0 & $\begin{array}{l}N \\
\%\end{array}$ & $\begin{array}{l}0 \\
0\end{array}$ & $\begin{array}{l}0 \\
0\end{array}$ & $\begin{array}{r}5 \\
15\end{array}$ & $\begin{array}{r}5 \\
16\end{array}$ & & $\begin{array}{l}52 \\
50\end{array}$ & $\begin{array}{l}42 \\
40\end{array}$ & $\begin{array}{l}15 \\
43\end{array}$ & $\begin{array}{l}16 \\
46\end{array}$ & $\begin{array}{l}27 \\
57\end{array}$ & $\begin{array}{l}27 \\
57\end{array}$ \\
\hline $1-3$ & $\begin{array}{l}N \\
\%\end{array}$ & $\begin{array}{r}7 \\
18\end{array}$ & $\begin{array}{r}9 \\
23\end{array}$ & $\begin{array}{r}8 \\
24\end{array}$ & $\begin{array}{r}8 \\
24\end{array}$ & & $\begin{array}{l}18 \\
17\end{array}$ & $\begin{array}{l}30 \\
29\end{array}$ & $\begin{array}{r}8 \\
23\end{array}$ & $\begin{array}{r}9 \\
24\end{array}$ & $\begin{array}{l}10 \\
21\end{array}$ & $\begin{array}{l}10 \\
21\end{array}$ \\
\hline 4.7 & $\begin{array}{l}N \\
\%\end{array}$ & $\begin{array}{l}24 \\
62\end{array}$ & $\begin{array}{l}21 \\
54\end{array}$ & $\begin{array}{l}14 \\
42\end{array}$ & $\begin{array}{l}16 \\
47\end{array}$ & & $\begin{array}{l}29 \\
28\end{array}$ & $\begin{array}{l}25 \\
24\end{array}$ & $\begin{array}{r}7 \\
20\end{array}$ & $\begin{array}{r}8 \\
23\end{array}$ & $\begin{array}{r}9 \\
19\end{array}$ & $\begin{array}{r}8 \\
18\end{array}$ \\
\hline $8-13$ & $\begin{array}{l}N \\
\%\end{array}$ & $\begin{array}{r}8 \\
21\end{array}$ & $\begin{array}{r}9 \\
23\end{array}$ & $\begin{array}{r}6 \\
11\end{array}$ & $\begin{array}{r}4 \\
13\end{array}$ & & $\begin{array}{l}5 \\
5\end{array}$ & $\begin{array}{l}7 \\
6\end{array}$ & $\begin{array}{r}5 \\
14\end{array}$ & $\begin{array}{l}2 \\
7\end{array}$ & $\begin{array}{l}1 \\
2\end{array}$ & $\begin{array}{l}2 \\
4\end{array}$ \\
\hline Total & $\mathrm{N}$ & 39 & & 33 & & & 104 & & 35 & & 47 & \\
\hline $\begin{array}{l}x^{2} O-P \\
p\end{array}$ & & & $\begin{array}{r}0.984 \\
0.6114\end{array}$ & & $\begin{array}{r}1.250 \\
0.7410\end{array}$ & & & $\begin{array}{r}8.392 \\
0.0386\end{array}$ & & $\begin{array}{r}4.799 \\
0.1872\end{array}$ & & $\begin{array}{l}625 \\
9907\end{array}$ \\
\hline
\end{tabular}

- Predicted number of lakes in each species richness class obtained by summing predicted probablitities from logistic regression model of species richness class on summer surface $\mathrm{pH}$ and $\log _{10}(1+$ surface area $)$.

Table 3.5-7 Stepwise Multiple Linear Regression Analyses for Species Richness for the Beaver River and Moose River (North and South Branch) Watersheds

\begin{tabular}{|c|c|c|c|c|c|}
\hline \multicolumn{3}{|c|}{$\begin{array}{l}\text { Beaver River Watershed } \\
95 \text { lakes } \\
R^{2}=0.739\end{array}$} & \multicolumn{3}{|c|}{$\begin{array}{c}\text { Moose River Watershed } \\
69 \text { lakes } \\
R^{2}=0.732\end{array}$} \\
\hline Variable & F to Remove & $\begin{array}{l}\text { Standard } \\
\text { Value }\end{array}$ & Variable & F to Remove & $\begin{array}{c}\text { Standard } \\
\text { Value }\end{array}$ \\
\hline Area & 34.4 & 0.341 & Elevation & 29.9 & -0.438 \\
\hline $\mathrm{Ca}$ & 28.0 & 0.380 & $\mathrm{pH}$ & 23.7 & 0.381 \\
\hline Al & 15.7 & -0.307 & Sirfface Area & 22.1 & 0.347 \\
\hline Elevation & 64 & -0.150 & DOC & 4.4 & 0.153 \\
\hline DOC & 4.5 & 0.124 & & & \\
\hline
\end{tabular}

a All variables transformed as $\log _{10}(1+x)$ 
enhance Al toxicity. Additionally, when monomeric Al was added as a fourth independent variable to the regional logistic model the fit between observed and predicted species richness class distributions for the Beaver River watershed was significantly improved $\left(X^{2} O-P=6.2, p=0.1006\right)$.

The effects of increased $\mathrm{pH}$ on species richness distributions within watersheds were examined by invoking the following two scenarios: A-setting of the $\mathrm{pH}$ of all lakes with a $\mathrm{pH}<6.5$ to $\mathrm{pH} 6.5$; $B$-Increasing $C_{B}-C_{A}$ of each lake by $15 \mu$ eq/L. New pH values were estimated in a manner similar to that described in Section 2.5.2.1, for each lake in Scenario $B$ by using the incremented $C_{B}-C_{A}$ and observed $D O C$ values in regression equations derived from summer surface chemistry data for ALSC drainage lakes (Table 3.5.8). Predicted species richness distributions were then recalculated from the

Table 3.5-8 Regression Equations Used to Estimate $\mathrm{pH}$ from $\mathrm{C}_{B}-\mathrm{C}_{\mathrm{A}}$ and $\mathrm{DOC}$

\begin{tabular}{|c|c|c|c|}
\hline$C_{B}-C_{A}$ Range & Regression Equation & $\mathbf{N}$ & $\mathbf{R}^{2}$ \\
\hline$<0$ & $\mathrm{pH}-=\log _{10}\left(\left(1 / D O C * 3.185-0.397^{*}\left(C_{B}-C_{A}\right)-5 / 756\right)^{3 / 1} e^{6}\right)$ & 225 & 0.721 \\
\hline 0.50 & $\mathrm{pH}=5.74-0.114 * D O C+0.024^{*}\left(C_{B}-C_{A}\right)$ & 210 & 0.723 \\
\hline $50 \cdot 100$ & $p H=6.072-0.108 * D O C+0.0 .15^{*}\left(C_{B}-C_{A}\right)$ & 147 & 0.795 \\
\hline$>100$ & $\mathrm{pH}=7.189-0.061 * D O C+0.002 *\left(C_{B}-C_{A}\right)$ & 374 & 0.777 \\
\hline
\end{tabular}

new pH values, lake area, and elevation with the logistic model. Scenario A was conducted simply to evaluate changes in potential species richness with acidity effects removed from the model.

Scenario $B$ was discussed in Section 2.5.2.5 and is based on model predictions of changes in $C_{B}-C_{A}$ resulting from a $30 \%$ reduction in sulfate deposition.

The Scenario $\mathrm{A}$ pH increase (mean $\mathrm{pH}$ change $=0.684$, SD -0.784 ) had no significant effect on species richness distribution patterns in the eastern watersheds where $\mathrm{pH}$ levels were initially high. However, highly significant changes in species richness distributions with in western watersheds were obtained when low-pH lakes were elevatea to $\mathrm{pH} 6.5$ (Table 3.5-9) The predicted frequency of fishless lakes in the western watersheds was reduced from approximately $40-57 \%$ to $3-19 \%$, and the frequency of lakes with 4-7 species approximately doubled. More important, the marked differences in observed species richness distribution patterns between western and eastern watersheds noted above essentially disappeared when pH levels are set to a minimum of 6.5 (predicted species richness class distributions at $\mathrm{pH} 6.5$, western versus eastern $\mathrm{x}^{2}=4.7, \mathrm{p}=0.9684$ ). Although this manipulation of lake $\mathrm{pH}$ is somewhat arbitrary, the analysis demonstrates that the acidic, species-depauparate lakes 
Table 3.5-9 Predicted Species Richness Class Distributions for Lakes in Selected Adirondack Watersheds Based on Observed pH and with pH Levels Increased to a Minimum pH of $6.5^{\mathrm{a}}$

\begin{tabular}{|c|c|c|c|c|c|c|c|c|c|c|c|}
\hline \multirow{3}{*}{$\begin{array}{l}\text { Species } \\
\text { Richness } \\
\text { Class }\end{array}$} & & \multicolumn{4}{|c|}{ Eastern Watershedsa } & \multicolumn{6}{|c|}{ Western Watershedsa } \\
\hline & & \multicolumn{2}{|c|}{ Schroon } & \multicolumn{2}{|c|}{ Ausable } & \multicolumn{2}{|c|}{ Beaver } & \multicolumn{2}{|c|}{ N. Branch Moose } & \multicolumn{2}{|c|}{ S. Branch Moose } \\
\hline & & Obs. & Pred. & Obs. & Pred. & Obs. & Pred. & Obs. & Pred. & Obs. & Pred. \\
\hline \multirow[t]{2}{*}{0} & $N$ & 0 & 0 & 5 & 4 & 42 & 5 & 16 & 2 & 27 & 9 \\
\hline & $\%$ & 0 & 0 & 16 & 12 & 40 & 4 & 46 & 7 & 57 & 19 \\
\hline \multirow[t]{2}{*}{$1-3$} & $N$ & 9 & 9 & 8 & 9 & 30 & 36 & 9 & 11 & 10 & 16 \\
\hline & $\%$ & 23 & 23 & 24 & 26 & 29 & 34 & 24 & 32 & 21 & 35 \\
\hline \multirow[t]{2}{*}{4.7} & $N$ & 21 & 21 & 16 & 16 & 25 & 49 & 8 & 17 & 8 & 18 \\
\hline & $\%$ & 54 & 54 & 47 & 48 & 24 & 48 & 23 & 48 & 18 & 38 \\
\hline \multirow[t]{2}{*}{8.13} & $N$ & 9 & 9 & 4 & 4 & 7 & 14 & 2 & 5 & 2 & 4 \\
\hline & $\%$ & 23 & 23 & 13 & 13 & 6 & 14 & 7 & 14 & 4 & 8 \\
\hline Total & $N$ & & 39 & & 33 & & 104 & & 35 & & 47 \\
\hline $\begin{array}{l}x^{2} O \cdot P \\
p\end{array}$ & & & $\begin{array}{r}0 \\
1.000\end{array}$ & & $\begin{array}{r}0.361 \\
0.9482\end{array}$ & & $\begin{array}{r}321.2 \\
0.0001\end{array}$ & & $\begin{array}{r}104.9 \\
0.0001\end{array}$ & & $\begin{array}{r}44.8 \\
0.0001\end{array}$ \\
\hline
\end{tabular}

- Predicted number of lakes in each species richness class obtained by summing predicted probabilities from logistic regression model of species richness class on pH, surface area, and elevation.

prevalent in western Adirondack watersheds do have the potential (based on surface area and elevation) to support more diverse fish communities at higher $\mathrm{pH}$ levels

The $\mathrm{pH}$ change resulting from the uniform $15 \mu \mathrm{eq} / \mathrm{L} C_{B}-C_{A}$ addition to each lake was relatively small (mean pH change $=0.18$ units, $S D=0.294$ ) and there were no significant changes in species richness distributions within either eastern or western watersheds as a result of this $\mathrm{pH}$ change (Table 3.5-10).

Fish Species and Community Comparisons within Eastern and Western Watersheds

All fish species. There were no fishless drainage lakes in the Schroon River watershed. Analyses of factors associated with fish presence/absence in the other watersheds (Table 3.5-11) indicated that fishless lakes were smaller and lower in pH than lakes with fish in all other watersheds. Fishless lakes also tended to be associated with beaver dam presence in the Beaver River watershed and with higher elevation in the South Branch of the Moose River. None of the other factors listed in Table 3.5-11 were significantly associated with fish presence/absence in these watersheds. 
Table 3.5-10 Predicted Species Richness Class Distributions for Lakes in Selected Adirondack Watersheds Based on Observed $\mathrm{pH}$ and at a $\mathrm{pH}$ Associated with a $15 \mu \mathrm{eq} / \mathrm{L}$ Increase in $C_{B} \cdot C_{A}{ }^{a}$

\begin{tabular}{|c|c|c|c|c|c|c|c|c|c|c|c|}
\hline \multirow{3}{*}{$\begin{array}{l}\text { Species } \\
\text { Richnes: } \\
\text { Class }\end{array}$} & & \multicolumn{4}{|c|}{ Eastern Watersheds } & \multicolumn{6}{|c|}{ Western Watersheds } \\
\hline & & \multicolumn{2}{|c|}{ Schroon } & \multicolumn{2}{|c|}{ Ausable } & \multicolumn{2}{|c|}{ Beaver } & \multicolumn{2}{|c|}{ N. Branch Moose } & \multicolumn{2}{|c|}{ S. Branch Moose } \\
\hline & & Obs. & Pred. & Obs. & Pred. & Obs. & Pred. & Obs. & Pred. & Obs. & Pred. \\
\hline \multirow[t]{2}{*}{0} & $N$ & 0 & 0 & 5 & 4 & 36 & 15 & 13 & 7 & 24 & 16 \\
\hline & $\%$ & 0 & 0 & 22 & 18 & 38 & 16 & 45 & 22 & 62 & 42 \\
\hline \multirow[t]{2}{*}{1.3} & $N$ & 8 & 7 & 6 & 6 & 28 & 31 & 7 & 7 & 7 & 9 \\
\hline & $\%$ & 26 & 22 & 26 & 27 & 29 & 33 & 25 & 25 & 19 & 24 \\
\hline \multirow{2}{*}{4.7} & $N$ & 18 & 18 & 9 & 10 & 24 & 35 & 7 & 11 & 6 & 10 \\
\hline & $\%$ & 56 & 58 & 40 & 42 & 33 & 37 & 23 & 39 & 15 & 27 \\
\hline \multirow[t]{2}{*}{8.13} & $N$ & 5 & 6 & 3 & 3 & 6 & 13 & 2 & 4 & 1 & 3 \\
\hline & $\%$ & 17 & 20 & 12 & 14 & 7 & 14 & 7 & 14 & 4 & 7 \\
\hline Total & $N$ & & 31 & & 23 & & 94. & & 29 & & 38 \\
\hline$x^{2}$ O-P & & & 0 & & 0.350 & & 36.9 & & $\begin{array}{r}7.597 \\
\end{array}$ & & 378 \\
\hline$p$ & & & 1.000 & & 0.9504 & & 0.0001 & & 0.0551 & & 608 \\
\hline
\end{tabular}

- Predicted number of lakes in each species richness class obtained by summing pre dicted probabilities from logistic regression model of species richness class on pH, surface area, and elevation.

Brook trout. High-elevation, stratified lakes without yellow perch or other predators/competitors were more likely to have brook trout in the Schroon River watershed, and $\mathrm{pH}$ was not a significant factor affecting brook trout presence/absence in this watershed (Table 3.5-12). In the Ausatile watershed, brook trout presence was also negatively associated with predator/competitor presence, but no other factors were significantly associated with brook trout presence/absence.

Although yellow perch occurred more frequently in lakes of the western watersheds (Table 3.5-4) and predator/competitor speries were also present in these waters, there were no significant negative associations between brook trout presence/absence and the occurrence of these species in the western watersheds Rather, a positive association between yellow perch presence and brook trout presence was observed in lakes of the North Branch of the Moose River. Brook trout occurred more frequently in larger, higher-pH, lower-elevation, and stratified waters of the latter watershed. In the Beaver River and South Branch of the Moose River, brook trout presence was also associated with higher $\mathrm{pH}$ and larger lake surface area 
Table 3.5-11 Comparisons of Fish Presence/Absence within Western and Eastern Drainage Systems in Relation to Habitat Characteristics

\begin{tabular}{lccccc}
\hline Variable & Schroona & Ausablea & Beavera & $\begin{array}{c}\text { Northern } \\
\text { Branch } \\
\text { Moose }\end{array}$ & $\begin{array}{c}\text { Southern } \\
\text { Branch } \\
\text { Moose }\end{array}$ \\
\hline $\mathrm{pH}$ & $\mathrm{na}$ & $\star(+)$ & $\star \star(+)$ & $\star \star(+)$ & $\star \star(+)$ \\
Elevation & $\mathrm{na}$ & $\mathrm{ns}$ & $\mathrm{ns}$ & $\mathrm{ns}$ & $\star(-)$ \\
Area & $\mathrm{na}$ & $\star \star(+)$ & $\star \star(+)$ & $\star(+)$ & $\star(+)$ \\
Stratification & $\mathrm{na}$ & $\mathrm{ns}$ & $\mathrm{ns}$ & $\mathrm{ns}$ & $\mathrm{ns}$ \\
Beaver & $\mathrm{na}$ & $\mathrm{ns}$ & $\star \star(-)$ & $\mathrm{ns}$ & $\mathrm{ns}$ \\
Dam & $\mathrm{na}$ & $\mathrm{ns}$ & $\mathrm{ns}$ & $\mathrm{ns}$ & $\mathrm{ns}$ \\
Bog & $\mathrm{na}$ & $\mathrm{ns}$ & $\mathrm{ns}$ & $\mathrm{ns}$ & $\mathrm{ns}$ \\
\hline
\end{tabular}

* $p \leq 0.05$

** $p \leq 0.001$

a Sign in () Indicates negative or positive association with fish presence and habitat factor

Table 3.5-12 Comparisons of Brook Trout Presence/Absence within Western and Eastern Drainage Systems in Relation to Other Fish Presence and Habitat Characteristics

\begin{tabular}{lccccc}
\hline Variable & Schroona & Ausablea & Beavera & $\begin{array}{c}\text { Northern } \\
\text { Branch } \\
\text { Moose }\end{array}$ & $\begin{array}{c}\text { Southern } \\
\text { Branch } \\
\text { Moosea }\end{array}$ \\
\hline $\mathrm{pH}$ & $\mathrm{ns}$ & $\mathrm{ns}$ & $* \star(+)$ & $\star \star(+)$ & $\star \star(+)$ \\
Elevation & $\star \star(+)$ & $\mathrm{ns}$ & $\mathrm{ns}$ & $\star \star(-)$ & $\mathrm{ns}$ \\
Area & $\mathrm{ns}$ & $\mathrm{ns}$ & $\star(+)$ & $\star(+)$ & $\star(+)$ \\
Stratification & $\star(+)$ & $\mathrm{ns}$ & $\mathrm{ns}$ & $\star \star(+)$ & $\mathrm{ns}$ \\
Beaver & $\mathrm{ns}$ & $\mathrm{ns}$ & $\mathrm{ns}$ & $\mathrm{ns}$ & $\mathrm{ns}$ \\
Dam & $\mathrm{ns}$ & $\mathrm{ns}$ & $\mathrm{ns}$ & $\mathrm{ns}$ & $\mathrm{ns}$ \\
Bog & $\mathrm{ns}$ & $\mathrm{ns}$ & $\mathrm{ns}$ & $\mathrm{ns}$ & $\mathrm{ns}$ \\
Predators & $* \star(-)$ & $\star(-)$ & $\mathrm{ns}$ & $\mathrm{ns}$ & $\mathrm{ns}$ \\
Yellow Perch & $\star \star(-)$ & $\mathrm{ns}$ & $\mathrm{ns}$ & $\star \star(+)$ & $\mathrm{ns}$ \\
\hline
\end{tabular}

* $p \leq 0.05$

$* * 0.001$

a Sign in () Indicates negative or positive association with fish presence and habitat factor 
These associations suggest that competition and predation factors, which are predominant in determining brook trout distribution patterns in eastern watersheds, are largely suppressed in western drainages where acidity is of greater significance in determining brook trout distribution within drainage systems.

Yellow perch. This species showed a tendency to occur more frequently at lower elevations in all watersheds examined except the Ausable River (Table 3.5.13) Yellow perch presence was also

Table 3.5-13 Comparisons of Yellow Perch Presence/Absence within Western and Eastern Drainage Systems in Relation to Habitat Characteristics

\begin{tabular}{|c|c|c|c|c|c|}
\hline Variable & Schroona & Ausablea & Beavera & $\begin{array}{c}\text { Northern } \\
\text { Branch } \\
\text { Moosea }\end{array}$ & $\begin{array}{c}\text { Southern } \\
\text { Branch } \\
\text { Moosea }\end{array}$ \\
\hline $\mathrm{pH}$ & ns & ns & $* \star(+)$ & $* *(+)$ & ns \\
\hline Elevation & $\star \star(-)$ & ns & $\star \star(-)$ & $\star \star \star(-)$ & $\star(-)$ \\
\hline Area & $x^{*}(+)$ & ns & $* x(+)$ & $\star \star(+)$ & $\star(+)$ \\
\hline Stratification & ns & ns & ns & ns & ns \\
\hline Beaver & ns & ns & $\star \star *(-)$ & ns & ns \\
\hline Dam & ns & ns & $*(-)$ & ns & ns \\
\hline Bog & ns & ns & ns & ns & ns \\
\hline Predators & $\star \star *(+)$ & ns & $\star \star *(+)$ & ns & ns \\
\hline
\end{tabular}

associated with higher lake $\mathrm{pH}$ in two of the three western watersheds (Beaver River and North Branch of the Moose River) with the highest frequency of occurrence lor this species and with larger lake size in all watersheds except the Ausable, where relatively few lakes contained yellow perch. The only additional factor examined that exhibited a negative association with yellow perch presence was beaver dam presence in the Beaver River watershed, which was also a significant factor for all fish species presence/absence in this system. Yellow perch tended to be associated with the predator/competitor species group in the Beaver River watershed The patterns observed for yellow perch distribution within these systems is consistent with earlier observations on the introduction and distribution of this species in the Adirondack region in general and specifically in the North Branch of the Moose River (Schofield and Driscoll 1987) The contrasting relationships between yellow perch and brook trout occurrence in eastern and western systems were discussed in the previous section. 
Table 3.5-15 Comparisons of Acid-Sensitive Cyprinid Species Presence/Absence within Western and Eastern Drainage Systems in Relation to Habitat Characteristics

\begin{tabular}{|c|c|c|c|c|c|}
\hline Variable & Schroona & Ausablea & Beavera & $\begin{array}{c}\text { Northern } \\
\text { Branch } \\
\text { Moosea }\end{array}$ & $\begin{array}{c}\text { Southern } \\
\text { Branch } \\
\text { Moosea }\end{array}$ \\
\hline $\mathrm{pH}$ & ns & ns & $* \star(+)$ & $\star \star(+)$ & $\star \star(+)$ \\
\hline Elevation & ns & $*(-)$ & ns & ns & ns \\
\hline Area & ns & ns & ns & $* \star(+)$ & ns \\
\hline Stratification & ns & ns & ${ }^{\star}(+)$ & $\star(+)$ & ns \\
\hline Beaver & ns & ns & ns & $\star \star(-)$ & ns \\
\hline Dam & ns & ns & ns & ns & ns \\
\hline Bog & ns & ns & ns & ns & ns \\
\hline Predators & ns & ns & ns & $* *(+)$ & ns \\
\hline Yellow Perch & $*(-)$ & ns & ns & $*(+)$ & ns \\
\hline
\end{tabular}

* $p \leq 0.05$

* $p \leq 0.001$

a Sign in () indicates negative or positive association with fish presence and habitat factor]

The positive association between this group of species and both yellow perch and predator/competitor groups in the North Branch of the Moose River was similar to the relationships between these latter groups and brook trout that were noted previously. These common occurrences probably reflect the larger size, greater potential habitat diversity, and generally higher $\mathrm{pH}$ of the downstream lakes of this watershed. Although most headwater lakes in this system are accessible to all of the species examined, low pH levels in these upstream lakes would prohibit survival of the more sensitive species (Schofield and Driscoll 1987)

Fish species associations in ALSC lake types As noted previously (Figure 3.5-3), 1hin-till lake types are situated predominantly in the western Adirondacks and have lower $\mathrm{pH}$ levels than other drainage lake types (see Section 2.4). Comparisons were made of species associations between thin-till lakes and other drainage lake types (carbonate, thick-till, and intermediate-till) for four watersheds (Table 3.5-16). There were no thin-till drainage lakes represented in the Schroon River watershed. Considering all fish species, fish occurred more frequently in the nonthin-till lake types in the South Branch of the Moose River, Beaver River, and Ausable River watersheds. Brook trout occurred more frequently in nonthin-till lake types in all western watersheds, but not in the Ausable River system. Yellow perch occurred less frequently in thin-till lakes in the Beaver River watershed, and acid. 
Table 3.5-16 Comparisons of Percentages of ALSC Lakes Containing Different Fish Associations in Thin-Till Basins and all Other Drainage Basin Types

\begin{tabular}{|c|c|c|c|c|c|}
\hline $\begin{array}{l}\text { Drainage System - } \\
\text { Watershed Typea }\end{array}$ & All Fish & $\begin{array}{l}\text { Brook } \\
\text { Trout }\end{array}$ & $\begin{array}{l}\text { Yellow } \\
\text { Perch }\end{array}$ & $\begin{array}{l}\text { Tolerant } \\
\text { Species }\end{array}$ & $\begin{array}{l}\text { Sensitive } \\
\text { Cyprinid } \\
\text { Species }\end{array}$ \\
\hline N. Br. Moose-Thin & 48.2 & 22.2 & 29.6 & 44.4 & 11.1 \\
\hline N. Br. Moose-Other & 87.5 & 87.5 & 75.0 & 75.0 & 37.5 \\
\hline$P$ & ns & $\star \star$ & ns & ns & ns \\
\hline S. Br. Moose-Thin & 24.2 & 12.1 & 3.0 & 6.1 & 0.0 \\
\hline S. Br. Moose-Other & 90.9 & 63.6 & 9.1 & 45.4 & 27.3 \\
\hline$P$ & ^* & $\star \star$ & ns & $\star \star$ & $\star \star$ \\
\hline Beaver-ihin & 40.7 & 18.6 & 23.3 & 37.2 & 4.6 \\
\hline Beaver-Other & 94.4 & 50.0 & 50.0 & 72.2 & 5.6 \\
\hline $\mathrm{P}$ & $\star \star$ & 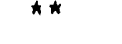 & " & «* & nis \\
\hline Ausable-Thin & 25.0 & 25.0 & 0.0 & 0.0 & 0.0 \\
\hline Ausable-Other & 89.5 & 73.7 & 10.5 & 47.1 & 42.1 \\
\hline$P$ & ** & ns & ns & ns & ns \\
\hline
\end{tabular}

* $p \leq 0.05$

* $p \leq 0.001$

- Thin = thin-till; Other = Carbonate-influenced, thick-till, and intermediate-till combined.

iolerant-species occurred less fr: fuently in thin-till lakes in the Beaver River and South Branch of the Moose River systems. A significant negative association between acid-sensitive species occurrence and thin-till lake type was observed only for the South Branch of the Moose River.

\subsubsection{Conclusions}

The pattern of decreased species richness with decreased lake surface area and lower lake pH observed in a previous study of the North Branch of the Moose River (Schofield and Driscoll 1987) was also evident in the ALSC data obtained for lakes in the same watershed. Similar relationships were documented for two adjacent, discrete watersheds (South Branch of the Moose River and Beaver River) in the Black River drainage basin. Two reference watersheds in the eastern Adirondacks (Schrnon River and Ausable River) including lakes with a comparable iake size and elevation ranges exhibited a lower frequency of fishless lakes and greater species richness. The low frequency of acidic lakes in the eastern basins was attributed to a predominance of thick-till and carbonate lake types (see Section 24 ) in comparison to primarily acid-sensitive, thin-till lakes in the western basins. Lake size (surface area), elevation, and pH effects on species richness were uncoupled by employing a 
logistic regression model of species richness distribution as a function of lake area and $\mathrm{pH}$. When acidity effects were removed in the model (by arbitrarily adjusting low-pH lakes to $\mathrm{pH}$ 6.5) the marked differences in species richness distribution patterns between eastern and western watersheds was eliminated. However, the persistence of a small fraction (4-19\%) of fishless lakes in these watersheds (particularly lakes at higher elevations in the South Branch of the Moose River) after removal of acidity effects, suggests that other factors associated with high elevation (e.g., winterkill and limited access) may be significant for this population of lakes. Compared to the gain in potential species richness for previously fishless waters (model estimate for all ALSC drainage lakes gaining one or more species with increase in minimum pH to $6.5=201$ lakes) of the number of fishless drainoge lakes remaining after removal of acidity effects is relatively small (only 50 lakes). This analysis suggests that the species-impoverished, acidic lakes prevalent in western Adirondack watersheds have the potential (based on the surface area/elevation-species richness relationship) to support diverse fish communities, comparable to those present in the eastern Adirondack region, if $\mathrm{pH}$ levels should increase significantly. Although other habitat factors (e.g., productivity, access for fish immigration, disturbance factors) may locally modify potential species richness for individual lakes, these other variables were not found to be strongly influential on a regional scale.

The DDRP modeling exercise (see Section 2.52 .1) suggested a maximum increase in $C_{B}-C_{A}$ of $15 \mu$ eq/ $L$ for Adirondack lakes following a $30 \%$ reduction in $\mathrm{SO}_{4}$ deposition. When $\mathrm{C}_{\mathrm{B}^{-}}-\mathrm{C}_{\mathrm{A}}$ of the eastern and western drainage lakes were increased by $15 \mu \mathrm{eq} / \mathrm{L}$, no significant changes in predicted species richness distributions between watersheds were found as a result of the relatively small pH change produced by this manipulation. When this scenario was applied to all ALSC drainage lakes (excluding salt-impacted and reclaimed lakes and lakes with missing DOC values, $N=968$ ) the predicted decrease in the percentage of fishless lakes was slightly less than $20 \%$ for an increase in median $C_{B D}-C_{A}$ of $15 \mu \mathrm{eq} / \mathrm{L}$ (Figure 3.5-8). Extending the range of $C_{H}-C_{A}$ change (by increasing or decreasing $C_{B-}-C_{A}$ of each lake by +50 to $-90 \%$ of its $\mathrm{SO}_{4}$ concentration) suggests that reduction in $\mathrm{SO}_{4}$ deposition sufficient to increase median $C_{H}-C_{A}$ levels by $>50 \mu \mathrm{eq} / \mathrm{L}$ or increase median $\mathrm{pH}$ by $>0.5$ units would be required to obtain a $50 \%$ or greater potential reduction in the number of fishless drainage lakes (Figure 3.5-8). The potential for achieving this level of $C_{B}-C_{A}$ change and corresponding $\mathrm{pH}$ change by greater reductions in $\mathrm{SO}_{4}$ deposition have not yet been determined.

Comparisons of acidity and other habitat factors associated with the presence/absence of selected species and species groups having different physiological acid tolerance were made for all discrete watersheds. All fish species and groups of species examined uniformly exhibited lower frequencies of occurrence in acidic lakes of the western Adirondack watersheds, whereas no consistent relationships between lake acidity and species occurrence were observed in the eastern drainages Although other 

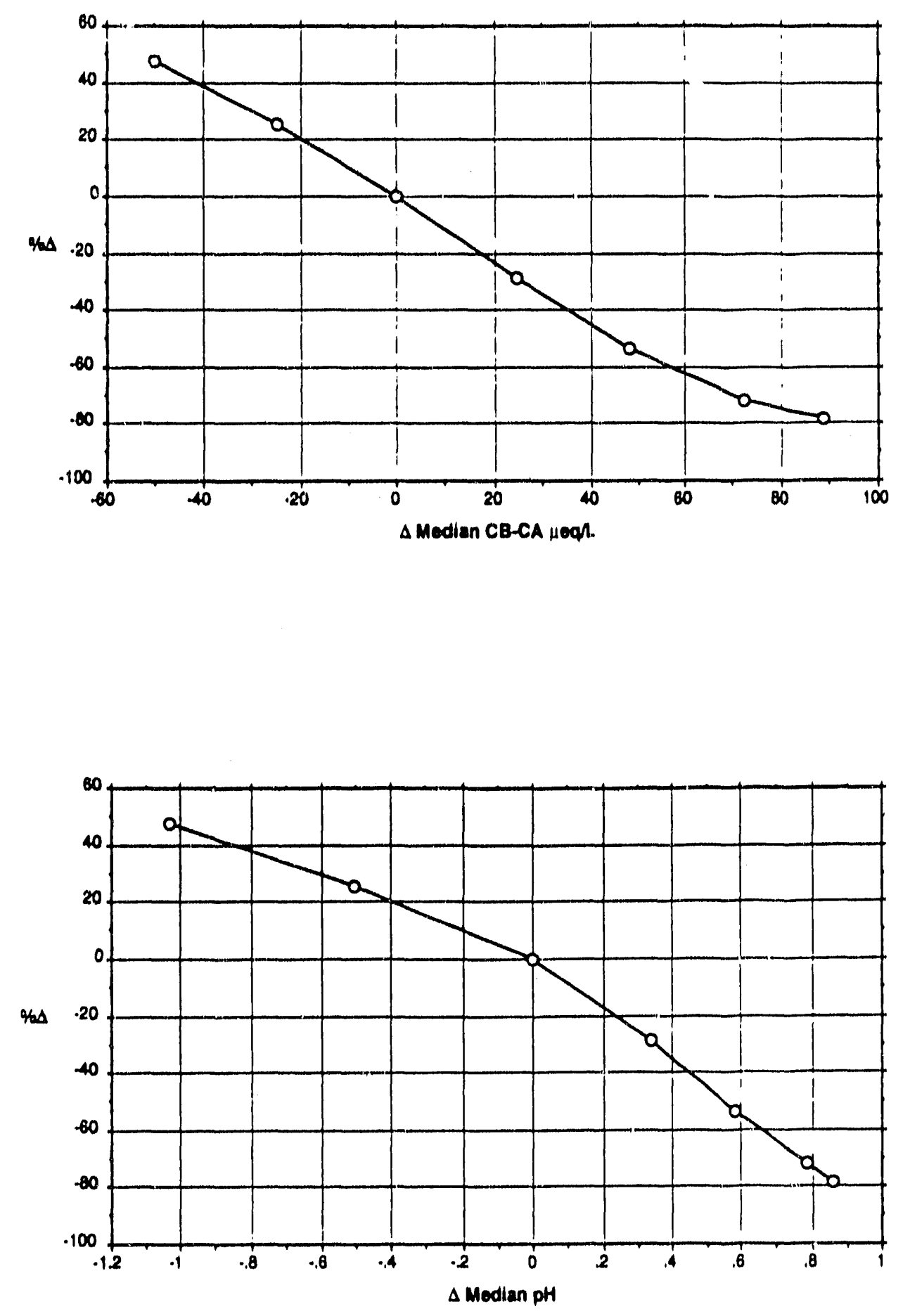

Figure 3.5-8 Percent change in the number of fishless drainage lakes as a function of change in median $\mathrm{C}_{\mathrm{B}}-\mathrm{C}_{\mathrm{A}}$ and change in median $\mathrm{pH}$. 
habitat factors not directly related to acidity were significantly related to particular species or species group occurrence in the individual western watersheds, there was no consistent pattern across watersheds in the importance of these other factors (e.g, predation, competition, physical habitat suitability, beaver influence) as was observed for acidity.

In the absence of significant acidification in the eastern watersheds tnat were examined, predation/competition emerged as the primary factor associated with the presence/absence of both brook trout and the acid-sensitive cyprinid group in lakes of this region. Although yellow perch and other exotic competitor/predator species are widespread in the western Adirondack watersheds, these species (yellow perch in particular) appeared to exhibit a positive association with the acidsensitive cyprinid group and brook trout in lakes of this region. This apparent anomaly was attributed to the physiological limitation of high acidity in smaller, higher-elevation lakes in the western watersheds and the availability of adequate habitat diversity and water quality to support populations of all species groups in the larger, circumneutral, lower-elevation lakes of those systems exhibiting acidity gradients. Removing acidity-related physiological constraints to recolonization in currently acidic, species-depauperate lakes of the western watersheds (by either liming or reduction of acidic inputs) could result in repopulation primarily by the well-established, more acid-tolerant species that have a competitive advantage over more desirable species such as the brook trout and native cyprinid species. Restructuring and control of fish community composition may well require more extensive use of fisheries management techniques, such as reclamation and barrier dam construction in these western Adirondack watersheds. 


\subsection{HISTORICAL CHANGES IN FISH COMGUNITIES IN ADIRONDACK LAKES}

\section{J. Baker, W. Warren-Hicks, J. Gallagher, and S. Christensen}

Of the 1469 lakes surveyed by the ALSC, $868(59 \%)$ were surveyed for fish in one or more years prior to the ALSC survey. An additional 109 lakes $(7 \%)$ had historical reports of fish species occurrence. Our objective was to use this historical information to assess changes in Adirondack fish rommunities through time and also probable causes for observed trends in the fish community. Of primary interest is the relative importance of fish population losses resulting from acidic deposition and lake acidification. The following questions were addressed:

- Are there more fishless lakes in the Adirondacks now than in the past?

- Do Adirondack lakes support fewer fish species now than in the past?

- How many lakes (and what proportion of the lakes with adequate data) appear to have lost fish populations?

- What types of fish species have been lost?

- Are there obvious explanations, unrelated to acidic deposition, for observed fish population losses, such as a change in stocking, introductions of new species, or reclamation?

- How many fish populations have been lost with no apparent cause, other than perhaps surface water acidification?

- Do lakes that have lost fish populations have (a) lower pH and ANC or (b) lower levels of DO or shallow-water at high-elevation conditions making them likely to experience winterkill, (c) introductions of non-native species, (d) active beaver populations, or (e) other characteristics that may affect fish communities?

\subsubsection{Data Limitations}

Assessments of historical changes in fish communities were based on surveys and related information collected by the NYSDEC since the early 1900 s. As part of the first statewide biological survey, conducted in the Adirondack region from 1929 to 1934, 304 of the ALSC lakes (21\%) were sampled for fish (NYSDEC 1930, 1931, 1932, 1933, 1934, 1935). Of the 564 other lakes with pre-ALSC surveys, 3 were initially surveyed in 1935-39, 36 between 1940 and 1949, 325 between 1950 and 1959, 82 in 1960-69, and 118 in 1970 or later (Figure 3.6-1). Changes in Adirondack fish communities that occurred before these earliest surveys are not accounted for in this analysis. As a result, the total change in fishi comminunities may be underestimated to an untnown degree 


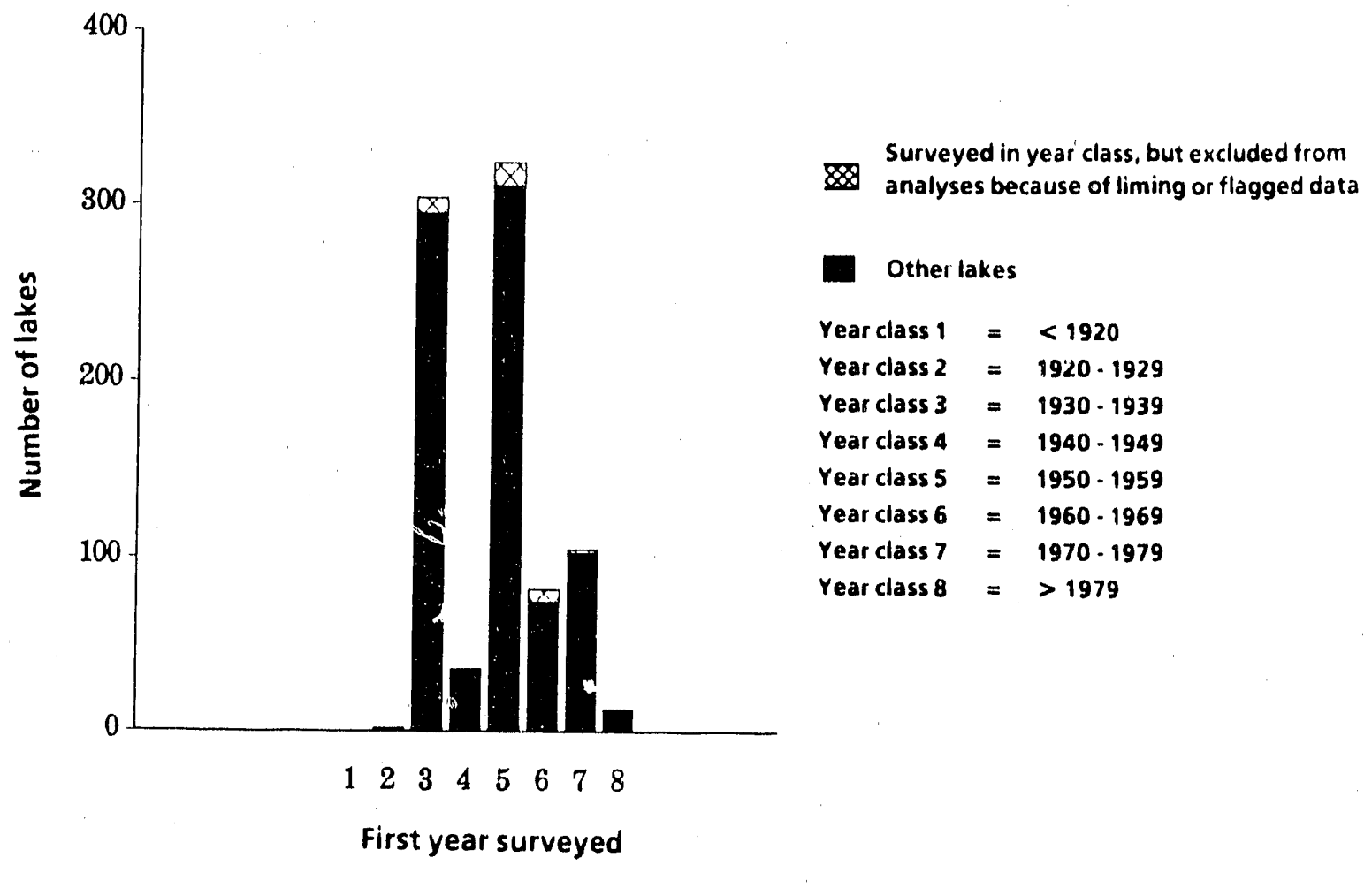

Figure 3.6-1 Numbers of lakes with historical survey data, by year of initial survey. Lakes limed within 10 years preceding the ALSC survey or with flagged water chemistry data are noted.

A second limitation relates to the quality of the historical fish surveys. Many of the surveys conducted in 1929-34 were designed to comprehensively sample fish communities in New York waters and to identify all fish species occurring in a lake or stream. In contrast, surveys conducted in later years, particularly in the 1950s and 1960s, often focused on selected sport fish species. Small fish, (e.g., minnows) and species difficult to capture with standard sampling gear (e.g. largemouth bass) may be underrepresented in these samples. Thus, surveys dating from the 1950s and 1960s provide poor documentation of the historical presence of some fish species and, as a result, may again underestimate the net change in the fish community.

Many factors influence fish community composition and changes in fish communities through time For example, besides acidic deposition, Retsch et al. (1982) listed the following as possibly pl aying a role in the observed loss of fish populations from Adirondack lakes:

- natural acidification and natural environmental conditions (e.g., low $\mathrm{O}_{2}$ concentrations) responsible for the absence of fish in some waters 
- changes in fish stocking and management efforts through time, in particular the decline in numbers of fish reared annually for stocking in the Adirondacks and the decline in the number of lakes stocked

- introductions (accidental or otherwise) of non-native fish species (e.g., yellow perch) that may prey upon or compete with native populations in the lakes

- increases in fishing pressure over the last several decades

- alteration of natural habitats resulting from construction of dams (man-made or beaver) that can eliminate fish spawning areas, block fish migration, or create unfavorable physical/chemical conditions for fish

- forestry practices that can alter water chemistry and cause erosion and siltation problems.

To the extent possible with the available data, all of these factors have been considered in assessing probable causes for observed fish community trends (see Section 3.6.3). Unfortunately, in many ways the historical data base is incomplete and difficult to interpret (Table 3.6-1). Definitive conclusions regarding specific causes for the loss of a species in a given lake are often not possible. Regional patterns of population loss, however, provide an added dimension for evaluating the relative importance of these factors.

A final concern is the potential for "false absences," i.e., incorrectiy classifying a lake as having lost a Sish population when the species still occurs in the lake. While such mistakes may occur, we expect that for most fish species they are relatively minor. The final status of the population is defined by the catch or no catch of the species during ALSC surveys. Fish sampling protocols used by the ALSC were specifically designed to effectively capture most species common in Adirondack lakes. Species or groups that may have been missed on occasion by the ALSC survey, however, include nearshore minnow species, rainbow trout, and kokanee salmon (see Section 3.1)

\subsubsection{Background}

Several other analyses of long-term trends in fish communities in Adirondack lakes have been completed. Results from these studies are briefly reviewed here, extracted from Driscoll et al. (in press).

Schofield (1976) provided the first evidence for loss of Adirondack fish communities in relation to lake acidity. Forty high-elevation ( $>600 \mathrm{~m}$ ) Adirondack lakes surveyed in the 1930 s were resurveyed in 1975. In the 1930s, 4 of these lakes had no fish caught, while 21 lakes had no fish caught in 1975.

Thus, 17 of the 40 lakes $(42 \%)$ had apparently lost their fish communities over the 40 -year period. The majority of the fishless lakes in 1975 ( 19 of 21 lakes) had pH $<50$. 
Table 3.6-1 Available Data on Factors That May Iniluence Fish Population Status and Fish Community Changes Over Time in Adirondack Lakes

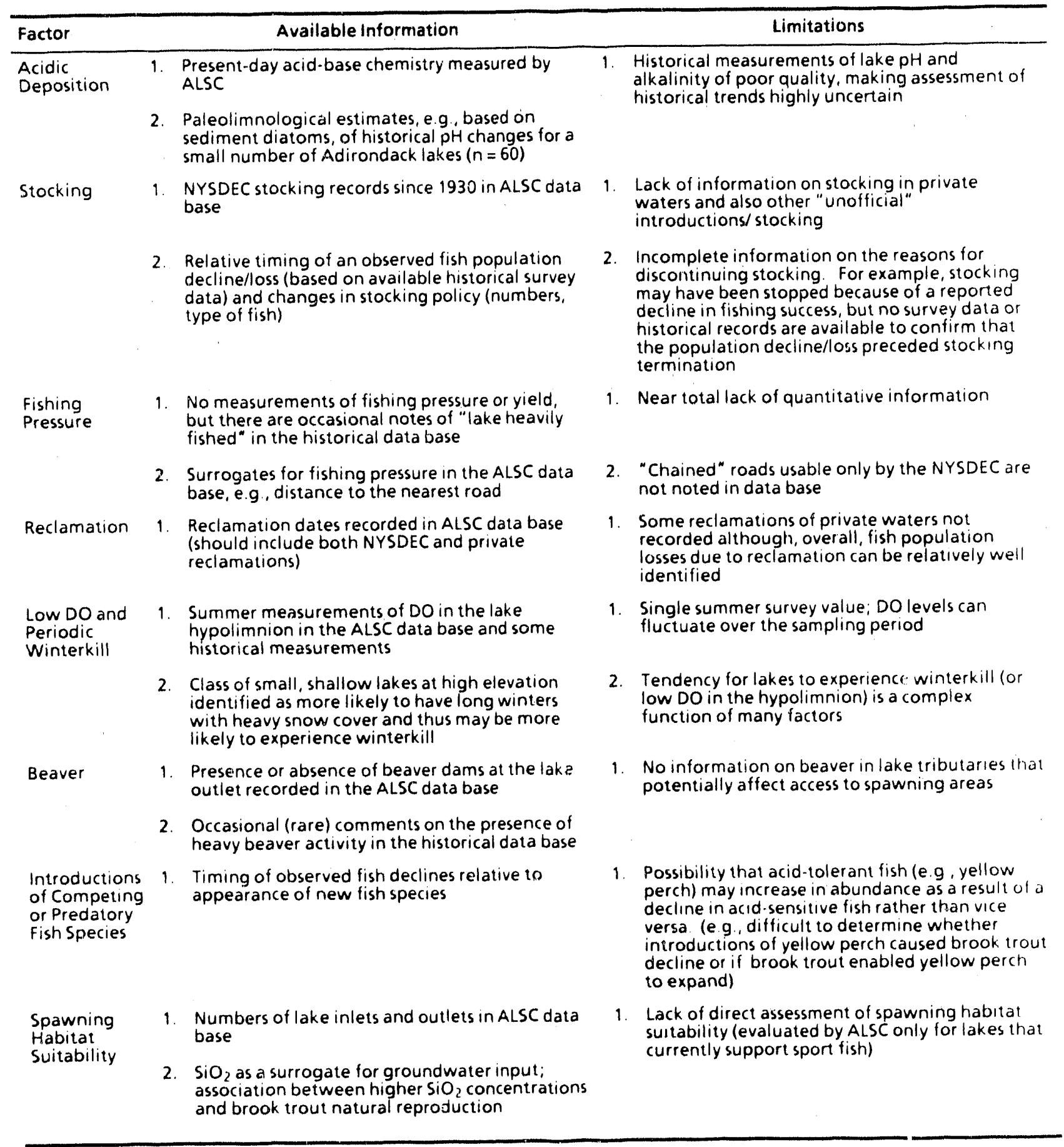


Baker and Harvey (1984; see also Haines and Baker 1986) extended this analysis by compiling all available historical fisheries data for Adirondack lakes, collected from the 1920 s through 1983. Changes in fish communities over time, and possible explanations for observed trends, were evaluated without reference to lake identity or water chemistry. For those lakes with sufficient survey data, ratings were assigned that defined (1) the strength of the evidence suggesting a fish population decline or loss and (2) the likelihood that any observed decline or loss resulted from factors other than acidification. Lakes rated as having lost one or more populations of fish without any obvious alternative explanation (other than perhaps acidification) had significantly ( $p \leq 0.05$ ) lower present-day $\mathrm{pH}$ values than did lakes without fish population declines.

Eight of the lakes evaluated for fishery trends by Baker and Harvey (1984) have also been assessed independently using paleoecological techniques and sediment diatoms to estimate long-term trends in lake $\mathrm{pH}$. In general, the results from fishery trend analyses and paleoecological analyses were consistent. Lakes that had lost fish populations without obvious alternative explanations also had experienced trends in sediment diatoms indicative of lake acidification (Haines and Baker 1986)

Schofield and Driscoll (1987) provided a detailed chronology of changes in fish species distributions for lakes in the North Branch of the Moose River watershed, starting with studies conducted as early as 1882 and including comprehensive surveys of fish communities in the watershed in 1982-83 as part of the Regional Interrated Lake-Watershed Acidification Study (RILWAS) project Dramatic changes in the composition 6 : tish communities inhabiting these lakes first became apparent during the 1940s, following a long period of relative stability from 1882 to 1931. Recruitment failure and declines in fish condition factors were dorumented for lake trout populations in Big Moose Lake during the 1940s and 1950s. Paleoecological analyses of sediment diatoms in Big Moose Lake suggest a rapid decline in lake $\mathrm{pH}$ during that period from pH about 5.8 prior to 1950 to $\mathrm{pH}<5$ in recent years (Charles et al. 1987). Many minnow and dace species, expected to be relatively sensitive to acidity (Mills and Schindler 1986), have likewise disappeared from acidic lakes in the North Branch of the Moose River watershed. In contrast, acid-tolerant species, such as yellow perch, central mudminnow, and banded killifish, are still widely distributed in the basin and are typically dominant fish species in acidic lakes.

Pfeiffer and Festa (1980) reviewed the historical NYSDEC records and concluded that 180 Adirondack lakes had lost fish populations apparently as a result of acidification. The specific methods and basis for this analysis were not presented, however

All of these studies have concluded that fish population declines have occurred in at least some Adirondack lakes and that fish population losses are generally associated with current low pH values 
or $\mathrm{pH}$ declines. The analyses presented in this document expand upon the Schofield (1976) and Baker and Harvey (1984) analyses by taking advantage of the extensive data base developed by the ALSC on the current status of fish communities and water chemistry of Adirondack lakes.

\subsubsection{Methods}

Historical data for Adirondack lakes have been independently compiled in two data bases:

1. the Fish Information Network (FIN) completed in 1984 with funding from the U.S. Environmental Protection Agency (EPA) (Baker et al. 1984)

2. the NYSDEC Biological Survey Unit Historical Data Base finalized in early 1989 for all but the Upper Hudson and Mohawk-Hudson watersheds in the Adirondacks

Both of these data bases were used to evaluate historical trends in Adirondack fish communities.

With few exceptions, records of historical fish species occurrence in the two data sets were consistent, increasing our confidence that data entry errors were reasonably small. The following actions were used to resolve cases of disagreement:

- In general, the NYSDEC data base was treated as the primary data source

- Data in FIN were given preference only when the historical NYSDEC data base appeared inconsistent with the ALSC results. [For example, the NYSDEC data base treats interconnected lakes as a single unit, compiling all historical records under a single lake identification number, while both the ALSC and FIN data bases maintain these lakes as separate entries in the data base.]

- In some instances, the original hard copies of survey results stored at Ray Brook, NY, were examined

Two general types of analyses were conducted:

1. direct statistical comparisons between the survey data collected in 1929-34 and the ALSC results for 1984.87

2. qualitative assessments of changes in fish communities and fish populations using all of the available survey data and associated information in the FIN and NYSDEC data bases

For those lakes sampled in both 1929-34 and 1984-87, the following statistical analyses were conducted:

- Fisher exact test (Fleiss 1981) chi-square comparisons of the number of lakes where no fish weie caught as well as with and without selected species of fish, in 1929-34 versus 1984-87

- Wilcoxon signed rank test (Hollander and Wolfe 1973) comparing species richness (number of fish species caught) in 1929-34 versus $1984-87$ 
- Kolmogorov-Smirnov (KS) tests (Hollarider and Wolfe 1973) comparing the distributions of lake characteristics (e.g., lake $\mathrm{pH}$ ) for lakes with and without fish caught, and with and without individual species of fish caught, in 1929-34 versus $1984-87$

- for lake characteristics defined as discrete classes (e.g., seepage versus drainage lakes), Fisher exact chi-square comparisons of the number of lakes with and without fish in each class in $1929-34$ versus $1984-87$

The procedures for qualitative assessments of fish community changes and probable explanations for observed trends were more complex. A detailed description of the evaluation procedures and codes used is provided in Appendix $C$ and is summarized below.

All assessments of fish community status were conducted blindly, i.e., with no information on surface water chemistry (except for measurements of DO). J. Baker evaluated all lakes; 74 lakes were also evaluated by J. Gallagher. Results from these two independent assessments are compared and discussed in Appendix D. The results presented in Section 3.6.4 are based on evaluations by J. Baker.

Four types of information were recorded for each lake surveyed by the ALSC: (1) summary information on the types and amount of historical (pre-ALSC) data available; (2) an evaluation of changes in individual fish populations, i. e. for individual fish species; (3) an assessment of changes in the occurrence of sensitive minnow species (as a group; see Section 3.2.1); and (4) an overall evaluation of changes in the fish community as a whole. Evaluations of fish population status were conducted for 16 fish species selected as either important sport fish species or nongame species common in Adirondack lakes:

$\begin{array}{ll}\text { brook trout } & \text { Salvelinus fontinalis } \\ \text { lake trout } & \text { Salvelinus namaycush } \\ \text { rainbow trout } & \text { Oncorhynchus mykiss } \\ \text { brown trout } & \text { Salmo trutta } \\ \text { lake whitefish } & \text { Coregonus clupeaformis } \\ \text { smallmouth bass } & \text { Micropterus dolomieui } \\ \text { largemouth bass } & \text { Micropterus salmoides } \\ \text { northern pike } & \text { Esoxlucius } \\ \text { white sucker } & \text { Catostomus commersoni } \\ \text { brown bullhead } & \text { Ictalurus nebulosus } \\ \text { pumpkinseed } & \text { Lepomis gibbosus } \\ \text { yellow perch } & \text { Perca flavescens } \\ \text { golden shiner } & \text { Notemigonus crysoleucas } \\ \text { creek chub } & \text { Semotilus atromaculatus } \\ \text { common shiner } & \text { Notropis cornutus } \\ \text { northern redbelly dace } & \text { Chrosomus eos }\end{array}$


Several types of information were recorded for each fish species or group:

- the first and last years in which the species (or group) was caught in the lake

- the first and last years in which the species was reported to occur or observed in the lake

- a rating of the strength of the evidence for determining whether the species occurred in the lake historically (pre-ALSC)

- a rating of the strength of the evidence for determining whether the species is currently absent from the lake

- a rating of the strength of the evidence that the population has declined (e.g., declined markedly in abundance or ceased to reproduce) but still present in the lake

- a listing of possible explanations for an apparent loss or decline in the fish population (or minnow group) based on the available data

- a summary rating of the likelihood that an apparent population loss or decline, if one occurred, resulted from acidification

Specific rankings of the evidence for historical occurrence of the species (PAST) are shown in

Table 3.6-2. Most analyses of possible fish population losses consider only those lakes with confirmed catch of the species in the past, i.e., with PAST $=8$ or 9 . In some cases, lakes in which the species was reported or observed but not caught (i.e., PAST $=4-7$ ) are also included.

The current status of the fish population was defined principally by the ALSC survey results (i.e., presence or absence of the species in the ALSC fish collections). Rankings of the evidence that a fish species was absent from a lake at the time of the ALSC survey (ABSENT) are shourn in Table 3.6-3.

Combining the evidence for historical occurrence (PAST) with the evidence for current absence (ABSENT) provides the basis for evaluating fish population losses over time. Rankings of the evidence for fish population declines were also recorded, as described in Appendix $C$, but are not discussed further because of the difficulties and uncertainties in detecting long-term trends in fish abundance and reproductive success

Possible causes for fish population losses were considered within six major categories:

(1) reclamation, (2) habitat suitability, (3) biological interactions and indices, (4) beaver activity,

(5) fishing pressure and fishery management practices (other than reclamation and stocking), and

(6) stocking. A detailed description of the classes and codes used is provided in Appendix $C$. Examples of conditions that were identified are listed in Table 3.6-4. Additional information on fish stocking was also recorded for the six sport fish species, including (1) the first and last year in which the species 
Table 3.6-2 Rankings of the Evidence for Historical Occurrence of the Species (PAST)

\begin{tabular}{|c|c|}
\hline Rankinga & Definition \\
\hline 0 & $\begin{array}{l}\text { one or more historical surveys conducted; species never caught, sighted, reported, or } \\
\text { stocked (excluding lakes that meet the criteria specified for PAST }=1 \text { ) }\end{array}$ \\
\hline 1 & $\begin{array}{l}\text { one or two historical surveys conducted; anly brown bulihead caught or reported; no } \\
\text { other species sighted, reported, or stocked (used for brook trout evaluations only) }\end{array}$ \\
\hline 2 & $\begin{array}{l}\text { no historical survey data available (i.e., no surveys conducted with at least some } \\
\text { potential for collecting the fish species of interest); species never reported, sighted (nor } \\
\text { listed as occurring in historical data of uncertain origin) and not stocked }\end{array}$ \\
\hline 3 & $\begin{array}{l}\text { fish species never caught, reported, or sighted in any historical surveys/studies, but } \\
\text { stocked at least once into the lake }\end{array}$ \\
\hline 4 & $\begin{array}{l}\text { one or more historical surveys conducted; species never caught but reported to occur } \\
\text { (based on anecdotal information or data of uncertain origin) or visually sighted }\end{array}$ \\
\hline 5 & $\begin{array}{l}\text { no historical surveys; species reported to occur (anectodal information) in the lake at } \\
\text { some time in the past }\end{array}$ \\
\hline 6 & $\begin{array}{l}\text { no historical surveys; species visually sighted in the lake (or sighted and reported to } \\
\text { occur based on anectodal information) }\end{array}$ \\
\hline 7 & $\begin{array}{l}\text { no historical surveys; species listed as occurring in the lake based on information of } \\
\text { uncertain origin }\end{array}$ \\
\hline 8 & $\begin{array}{l}\text { one or more historical surveys conducted; fish species caught in only one survey and } \\
\leq 5 \text { specimens collected; in addition, fish species never reported or visually sighted in } \\
\text { other years }\end{array}$ \\
\hline 9 & $\begin{array}{l}\text { one or more historical surveys conducted, with the fish species caught in more than } \\
\text { one survey or, if only one historical survey available, with either }(a)>5 \text { specimens } \\
\text { collected in this one survey or (b) } \leq 5 \text { specimens collected but the fish species was also } \\
\text { reported or sighted in some other year }\end{array}$ \\
\hline
\end{tabular}

a In order of increasing confidence that the species occurred in the past

was stocked, (2) whether or not the species occurred in the lake prior to stocking, and (3) identification of populations clearly supported by stocking with no natural reproduction.

Finally, an overall summary rating (CAUSE) was recorded, indicating the likelihood that a population loss, if one occurred, resulted from acidification (Table 3.6-5). Fish population losses were classified as occurring apparently as a result of acidification if (1) alternative causes for the loss could not be clearly identified based on the available data and (2) the fish species lost were those considered to be most acid sensitive (i.e., the pattern of change in fish community composition was consistent with the expected effects from acidification). 
Table 3.6-3 Rankings of the Evidence that the Fish Species is Currently Absent from the Lake (ABSENT)

\begin{tabular}{cl}
\hline Rankinga & \multicolumn{1}{c}{ Definition } \\
\hline 0 & $\begin{array}{l}\text { fish species caught by the ALSC } \\
1\end{array}$ \\
fish species not caught by the ALSC but reported to occur or visually sighted by the \\
ALSC (as listed in the comments section of the ALSC data base) \\
2 & $\begin{array}{l}\text { fish species not caught by ALSC; however, species considered marginally susceptible to } \\
\text { capture using the ALSC gear and sampling techniques, and the fish species was caught } \\
\text { only sporadically in historical surveys in the lake with no apparent trend in the catch/no } \\
\text { catch pattern through time }\end{array}$ \\
3 & $\begin{array}{l}\text { fish species not caught by ALSC; species considered marginally susceptible to the ALSC } \\
\text { gear and sampling techniques; one or more historical surveys with the species not } \\
\text { caught but consistently reported or observed }\end{array}$ \\
& $\begin{array}{l}\text { fish species not caught by the ALSC; no historical survey data available } \\
\text { one or more historical surveys available; species not caught by the ALSC but caught in } \\
\text { the preceding historical survey (excluding lakes that meet the criteria for ABSENT = 2) }\end{array}$ \\
& $\begin{array}{l}\text { two or more historical surveys available; species neither caught by the ALSC nor caught } \\
\text { in the precedirig survey but caught in one or more earlier surveys (excluding lakes that } \\
\text { meet the criteria for ABSENT = 2) }\end{array}$ \\
7 & $\begin{array}{l}\text { fish species not caught by the ALSC; one or more historical surveys available and } \\
\text { specias never caught (excluding lakes that meet the criteria for ABSENT = 3) }\end{array}$
\end{tabular}

a In order of increasing confidence that the fish species is now absent

In addition to the species-specific ratings defined above, changes in the fish community as a whole were evaluated and rated on a scale of 0 to 5 , in order of increasing confidence that a fish cornmunity decline (i.e., loss of one or more fish species) has occurred as a result of acidification (Table 3.6-6). Since the sensitivity of the fish community to acidification varies depending on the species occurring in the lake, the fish community composition (historically and at present) was also rated according to the expected acid sensitivity of the species (FISHTYPE; defined in Appendix C)

The results from these assessments were analyzed in a manner fairly sirnilar to that described for the direct statistical comparisons between the ALSC and 1929-34 survey data. Numbers of lakes apparently losing fish populations were enumerated, categorized by the types of evidence available. For each fish species and for sensitive minnows as a group, lake charasteristics were then compared for three lake classes: 
Table 3.6.4 Examples of Codes and Conditions Considered in Identifying Possible Explanations for Apparent Fish Population Losses

Reclamation

$11=$ lake reclaimed with rotenone in 1975 or before; species not restocked and species never caught or reported since the lake reclamation

Habitat Suitability

$20=$ reported winterkill problem

$22=D O$ values measured in the deepest waters $\leq 1 \mathrm{mg} / \mathrm{L}$ and/or high proportion of the DO measurements below $5 \mathrm{mg} / \mathrm{L}$, suggesting potentially severe problems with low DO

23 = lake relatively small ( $<5$ ha), shallow (mean depth $55 \mathrm{~m}$ ), and at high elevation $(\geq 500 \mathrm{~m}$ ) and thus may be subject to periodic freezing and/or winterkill

$24=$ recorded (i.e. noted in comments written by field biologist) major change in lake level (increase or decrease)

$\therefore \dot{0}=$ major decrease in the amount of open water; lake now heavily choked with aquatic vegetation or sphagnum

28 = bog pond with predominately muck substrate

Biological Interactions and Indicators

$31=$ yellow perch introduced or appear in the lake coincident with the gradual decline and/or loss of the species

$32=$ other species considered to be potential competitors or heavy predators introduced into the lake coincident with the gradual decline/loss of the species (see Table 1 in Appendix C)

$34=$ species not native to the Adirondacks and introduced into a habitat likely to be marginal as indicated by the presence of atypical cohabiting species, e.g., bass populations introduced into lakes dominated by salmonids

$35=$ other species considered equally or more sensitive to acidity than the species of interest (see Figure 1 in Appendix C) also seem to have disappeared from the lake for no obvious reason (other than perhaps acidification)

$36=$ species considered equally or more acid sensitive than the species of interest caught in the lake by the ALSC

Beaver

$41=$ historical records include comments about adverse effects of beaver on the fish population

42 - heavy beaver activity noted during historical surveys, although iio specific comments recorded about potential adverse effects on the fish population

43 = heavy beaver activity noted in ALSC comments

Fishing Pressure and Fisheries Management

51 = historical records by field biologist indicate lake subject to heavy fishing pressure

53 = historical records by field biologist indicate other fishery management problems adversely affecting the fish species of interest

Stocking

$62=$ species caught and reasonably abundant in a survey conducted $\leq 5$ years before stocking was stopped, or after stocking was stopped

$65=$ reported decline of the species recorded in comments from the field biologist(s) before stocking was discontinued

66 = the absence of the species confirmed in one survey conducted prior to the cessation of stocking

$72=$ species replacement - stocking of species stopped while stocking of another similar but more acid-sensitive species was initiated. Following the change in stocking policy, this new species was caught while the original species was not

$77=$ species stocked for a number of years but never caught in the lake. Apparent stocking failure confirmed by the absence of the species in one or more surveys conducted no later than 5 years after stocking was stopped. No obvious competing or predatory species occur in the lake 
Table 3.6-5 Ratings of Probable Causes for Apparent Fish Population Losses (CAUSE)

\begin{tabular}{cl}
\hline Ratinga,b & \multicolumn{1}{c}{ Definition } \\
\hline 0 & $\begin{array}{l}\text { population healthy; fish species caught by the ALSC and no apparent decline in } \\
\text { abundance } \\
1\end{array}$ \\
2 & likvious explanations for the apparent fish population loss or decline \\
3 & $\begin{array}{l}\text { no obvious alternative explanations (other than perhaps surface water acidification) } \\
\text { for the observed fish population loss or decline }\end{array}$ \\
4 & $\begin{array}{l}\text { no apparent alternative explanation and a clear pattern of fish community change } \\
\text { that is consistent with expected effects from acidification; several fish species affected } \\
\text { no apparent alternative explanations and a very clear pattern of fish community } \\
\text { change that is consistent with expected effects from acidification; all or most fish } \\
\text { species lost }\end{array}$
\end{tabular}

- In order of decreasing evidence for effects from factors other than acidification and ther efore increasing likelihood that acidification was responsible for the observed fish population decline or loss

b An additional rating class, CAUSE $=9$, was used if the available information was insufficient to assign CAUSE $=0.5$.

1. lakes in which the fish species (or group) was present in the past and also caught by the ALSC

2. lakes in which the fish species was present in the past but not caught by the ALSC

3. lakes that appear to have lost fish populations apparently as a result of -idification (i.e., CAUSE $=3.5$.

Statistical differences in lake characteristics between lake classes were determined using the KS test for continuous variables and chi-square comparisons for discrete lake characteristics. Discrete variables with greater than two categories were converted to binary variables: (1) public and mixed ownership lakes versus privately owned waters and (2) bogs and marginal bogs versus nonbog waters. Analyses were conducted for two data subsets for a given species: (1) lakes with confirmed presence of the species in the past (i.e., capture in an historical survey) and (2) lakes in which the species was collected, reported, or observed in the past. Most analyses were re itricted to lakes surveyed and with recorded presence of the species before 1970 .

Unless otherwise noted, lakes limed within 10 years preceding the ALSC survey or with potential errors in the ALSC water chemistry data (identified during data base certification, Section 2.1.4.3) were excluded from analyses of historical changes in fish communities. The number of lakes affected 
Table 3,6.6 Ratings of Changes in the Fish Community Status as a Whole

\begin{tabular}{cl}
\hline Ratinga,b & \multicolumn{1}{c}{ Definition } \\
\hline 0 & The community appears "healthy" with very little or no change in fish species \\
composition through time; for lakes with only recent survey data, a fairly large \\
number of species was collected by the ALSC, and the community composition was \\
generally characteristic for lakes in the Adirondacks, including acid-sensitive tish \\
species. \\
One or two species have apparently declined in abundance and/or disappeared from \\
the lake. However, any changes in species composition through time appear random \\
and are apparently due to normal fluctuations or fisheries management practices. \\
One or two species have apparently declined irt abundance and/or disappeared from \\
the lake. These species are nol, however, considered acid sensitive (relative to other \\
species in the lake), and it is unlikely that population declines or losses resulted from \\
acidification. Neither the evidence for loss of populations nor indications of the \\
potentlal influence of acidificatior, are particularly strong. A number of populations \\
have maintained constant. or increased leveis of abundance over time. \\
Several species have disappeared from the lake for no apparent reason other than \\
perhaps acidification. These species are expected to be acid sensitive relative to the \\
other species remaining in the lake, suggesting the possibility that the community \\
decline may be a result of acidification. Alternatively, all or most fish species have \\
disappeared although alternative explanations for population loss cannot be entirely \\
dismissed.
\end{tabular}

a In order of increasing confidence that a fish community decline (l.e., loss of one or more fish species) has occurred as a result of acidification

b Additional codes for CAUSE were also used to denote lakes with no fish caught in historical surveys, that may have always been fishless, and for other special cases. These codes are defined in Appendix $C$.

by these exclusion criteria was relatively small (Figures $3.6-1$ to 3.6-3). Of the 868 lakes with historical survey data, $32(4 \%)$ were deleted because of liming or flagged water chemistry data. 


\subsubsection{Results}

\subsubsection{Quantity of Historical Data Available}

Excluding lakes limed within 10 years of the ALSC survey or with flagged water chemistry data

- 836 of the ALSC lakes had been surveyed in one or more years prior to the ALSC survey

- 720 were surveyed before 1970

- 295 were surveyed in 1929-1934

- 128 were surveyed in 1929-34 using both gill nets and seines

Of the 720 lakas surveyed before $1970,39 \%$ were surveyed in only one year prior to the ALSC survey, while $26 \%$ were surveyed in four or more years pre-ALSC (Figure 3.6-2). An additional 106 lakes

(a)

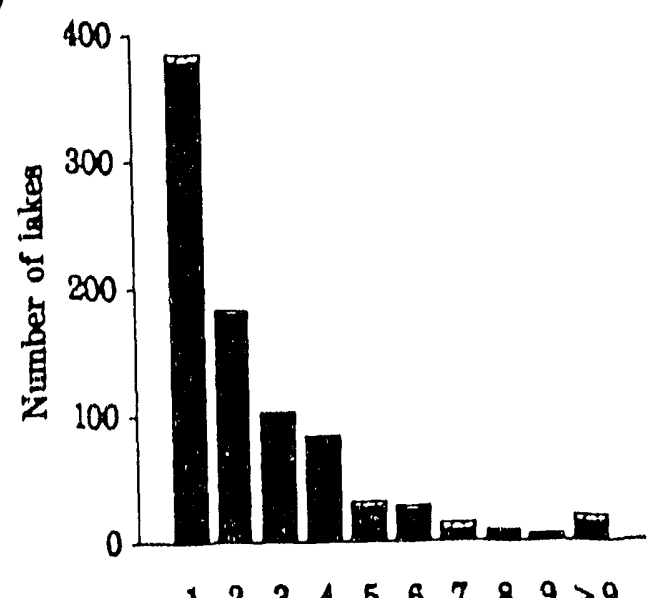

Number of years surveyed (b)

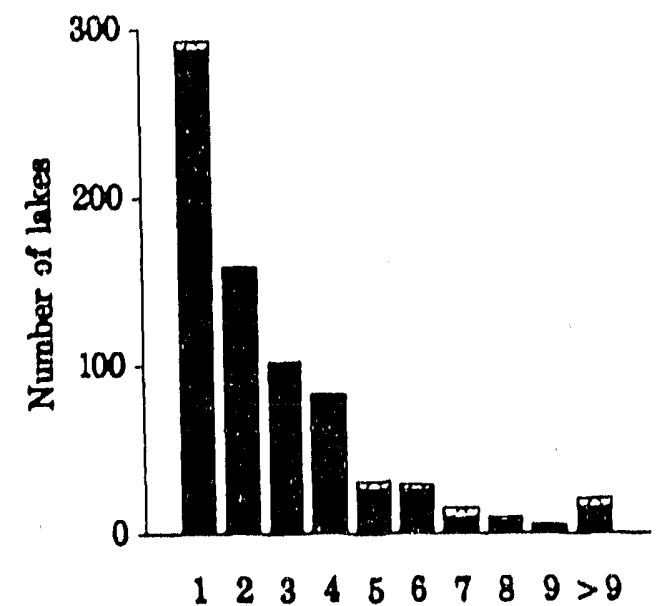

Number of years surveyed

Surveyed in year class, but excluded from

28 analyses because of liming or flagged data

1. Otherlakes

Figure 3.6-2 Number of years in which lakes were surveyed prior to the ALSC survey: (a) all lakes with historical survey data and (b) only lakes first surveyed before 1970.

(excluding 3 limed or flagged lakes) had some historical (pre-ALSC) information (e.g, rcports of fish occurrence or visual observations of fish), but no confirmed historical surveys (Figure 3.6-3). Forty-six lakes have records of historical fish stocking but no other pre-ALSC data. 


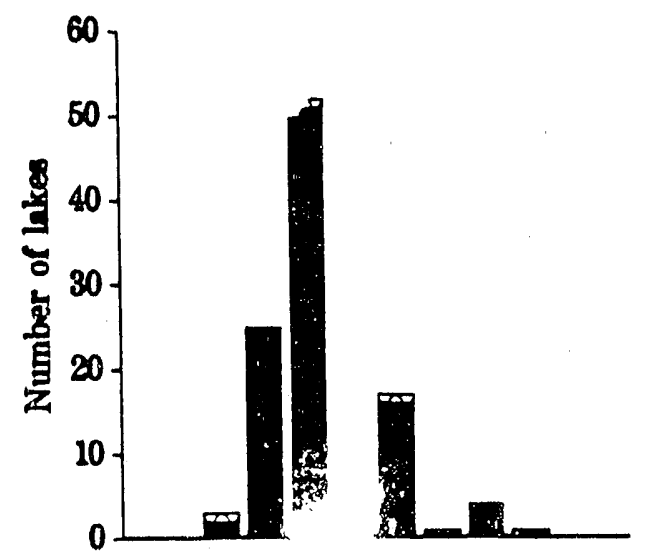

$\begin{array}{llllllll}1 & 2 & 3 & 4 & 5 & 6 & 7 & 8\end{array}$

Earliest listing of unconfirmed species

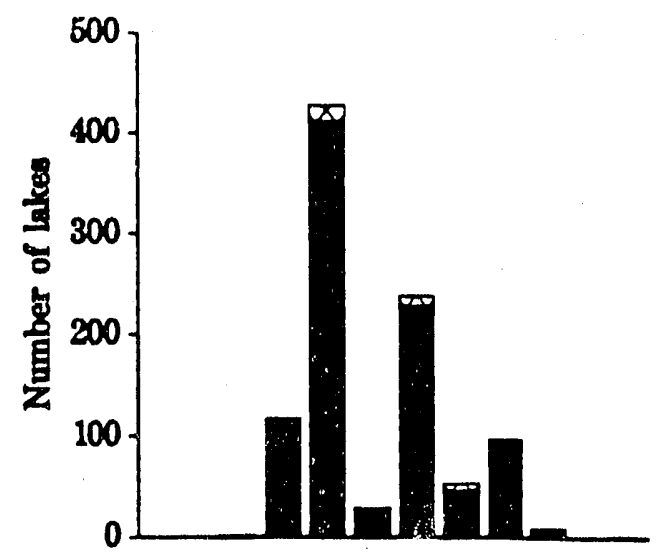

12345678

Earliest record of historical information

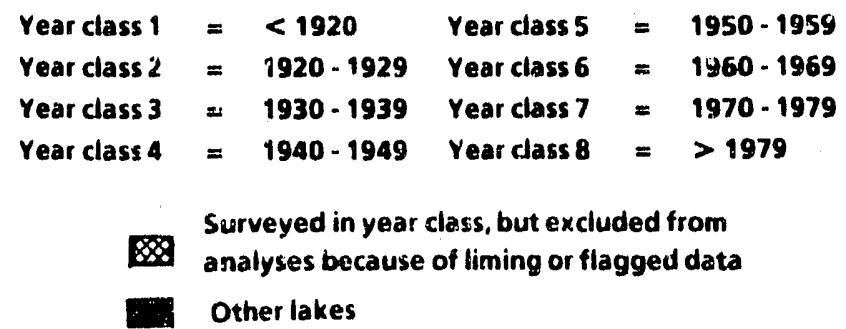

Surveyed in year class, but excluded from

$\$$ analyses because of liming or flagged data

Other lakes

Figure 3.6-3 Numbers of lakes with (a) historical reports or abservations of fish occurrence hut no pre-ALSC survey and (b) lakes with either historical survey data or reports/observations of fish occurrence, sorted by first year with historical information.

\subsubsection{Characteristics of Lakes with Historical Data}

Results from analyses of historical trends in fish communities may be misleading if the lakes for which we have historical information are not representative of Adirondack lakes in general. Prior to the 1970s, NYSDEC sampling efforts tended to focus on lakes more likely to yield a productive sport fishery. As a result, the lakes for which wo have historical survey data are significantly $(p \leq 0.001 ; \mathrm{KS}$ test) larger an " deeper and have higher $\mathrm{pH}$ and species richness (numbers of species caught by the ALSC) compa ed to the full set of ALSC lakes (Figures 3.6-4 and 3.6-5). In addition, the following types of lakes are significantly $(\leq 0.001)$ underrepresented in the subset of ALSC lakes with historical data: bogs and marginal bogs, seepane lakes, lakes with beaver dams on the lake outlet, and lakes in which ALSC did not catch fish (Table 3.6-7)

The more restrictive the definition of "historical daca," the less representative are the for which we can evaluate trends through timie. For example, while $26 \%$ of the lakes sampled! LSC (excluding limed and ilagged lakes) have field pH < 5.0 , the percentage of low-pH lakes drops to $18 \%$ for lakes with pre-1970 survey data, $12 \%$ for lakes surveyed $1929-34$, and only $4 \%$ for lakes surveyed 

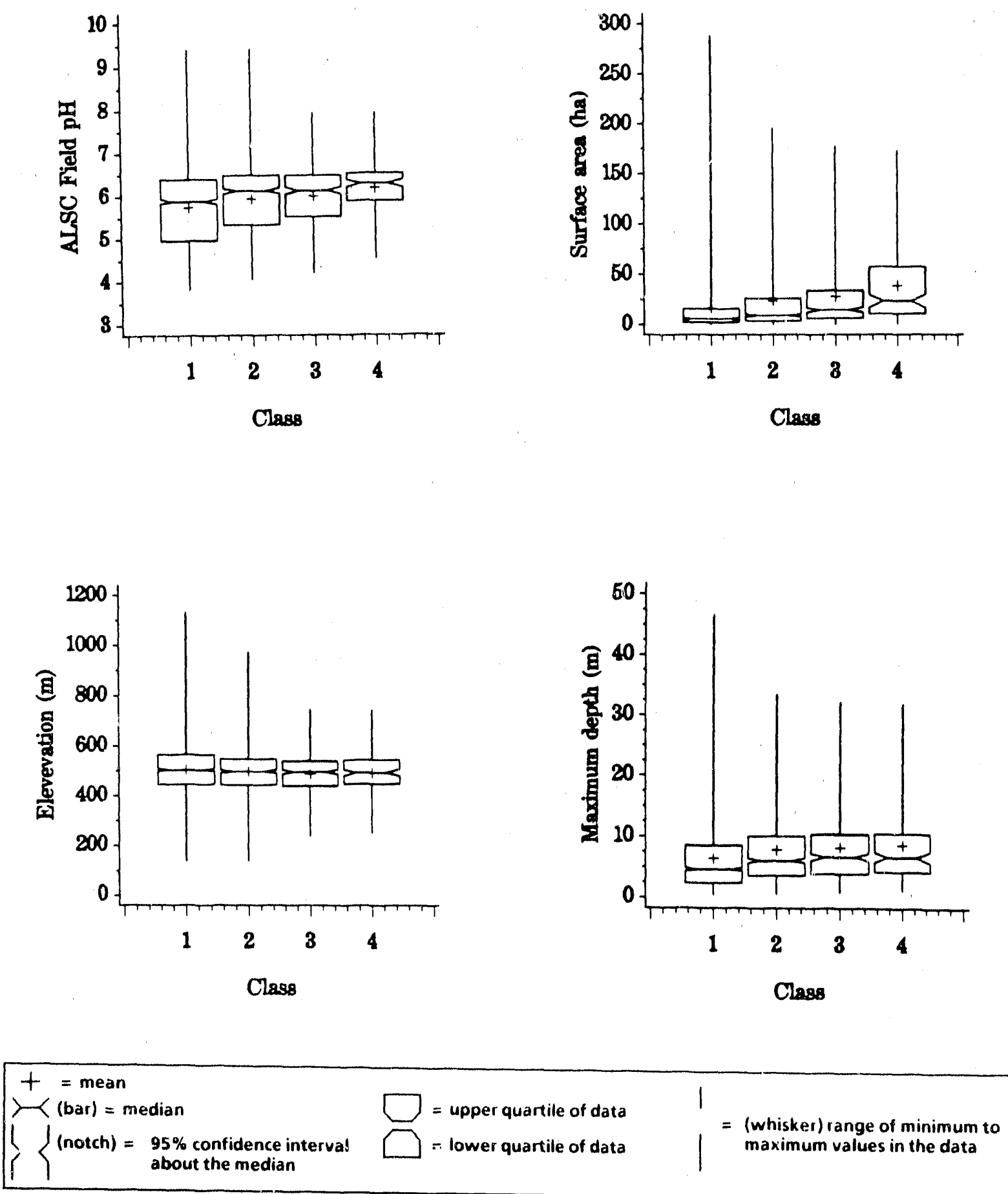

Figure 3.6-4 Comparisons of the characteristics of four lake classes: (1) lakes surveyed by the ALSC. (2) ALSC lakes surveyed before 1970. (3) ALSC lakes surveyed in 1924-34, and (A) A.ISC !a!:es surveyed in 1920-3a using hoth gi!! nets and seines. 


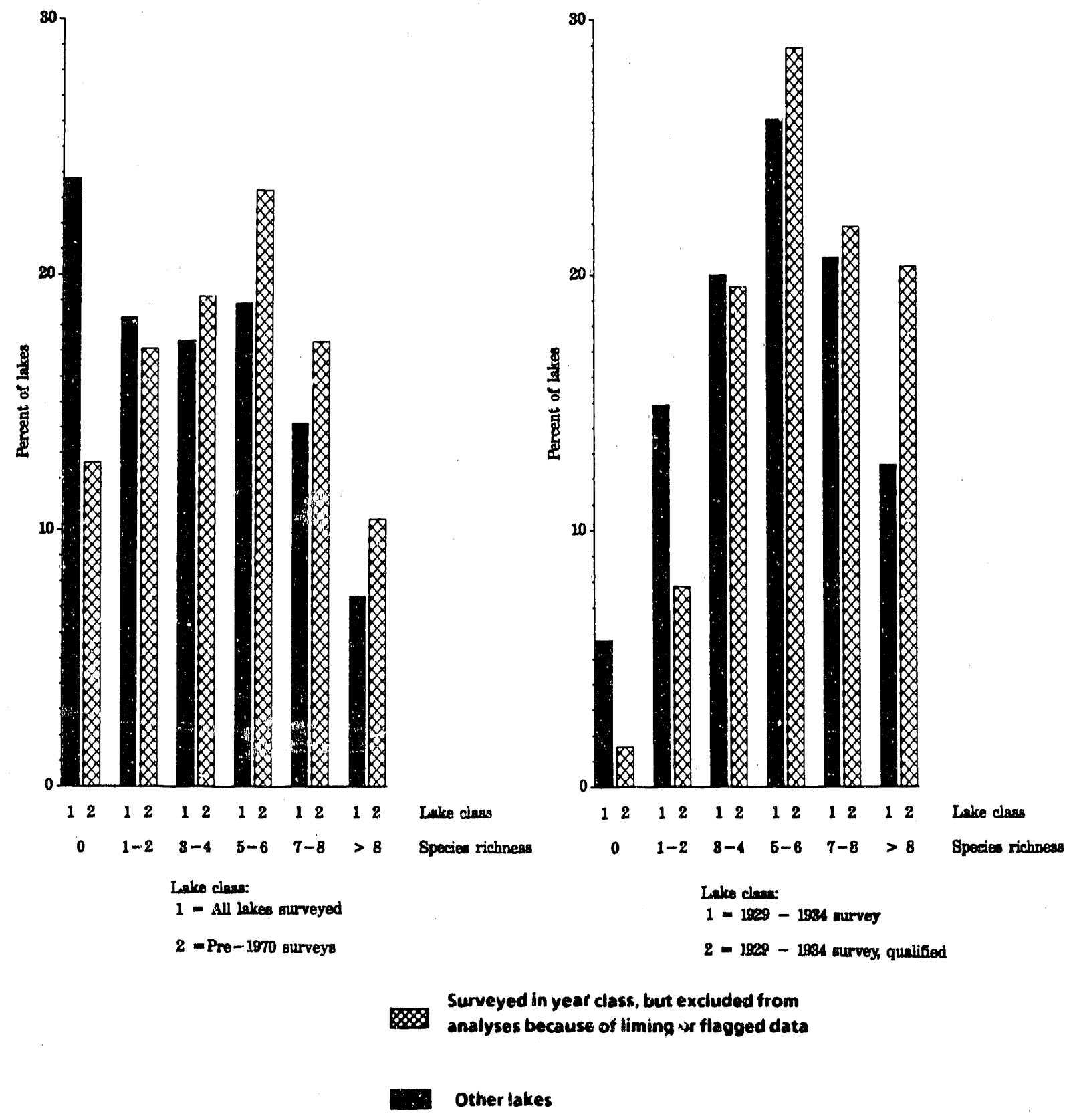

Figure 3.6-5 Percentage of lakes by ALSC species richness class for (a) all lakes surveyed by the ALSC (lake class 1) and ALSC lakes surveyed before 1970 (class 2); and (b) ALSC lakes surveyed in 1924-39 (class 1) and in 1929-34 using both gill nets and seines íćass 2i). 
in 1929-34 using both gill nets and seines. In a similar manner, relatively few "fishless" lakes, i.e., with no fish caught by the ALSC, were sampled historically. Of the 340 fishless lakes in the ALSC survey (excluding 6 fishless lakes limed within 10 years of the ALSC survey or with flagged water chemistry data), only 91 (27\%) had been surveyed prior to 1970,17 (5\%) in 1929-34, and only 2 of these lakes $(1 \%)$ were surveyed in $1929-34$ using both gill nets and seines.

Clearly, we cannot assume that the changes in fish communities observed in lakes with historical data are representative of Adireniack lakes (or ALSC lakes) as a whole. Evaluation of these trends can still be informative, however, particularly if the limitations of the historical data set are recognized

Table 3.6-7 Comparisons of the Characteristics of Lakes Surveyed by the ALSC to ALSC Lakes With Historical Survey Data

\begin{tabular}{|c|c|c|c|c|}
\hline \multirow[b]{3}{*}{ Lake Characteristics } & \multirow[b]{3}{*}{$\begin{array}{c}\% \text { of } \\
\text { all ALSC Lakes } \\
(n=1430)\end{array}$} & \multicolumn{3}{|c|}{$\%$ of ALSC Lakes with Historical Surveys } \\
\hline & & \multirow[b]{2}{*}{$\begin{array}{c}\text { Surveyed } \\
\text { before } 1970 \\
(n=720)\end{array}$} & \multicolumn{2}{|c|}{ Surveyed 1924-34 } \\
\hline & & & $\begin{array}{c}\text { all } \\
(n=295)\end{array}$ & $\begin{array}{l}\text { gill nets + seines } \\
\qquad(n=128)\end{array}$ \\
\hline \multicolumn{5}{|l|}{ Bog Influence } \\
\hline $\begin{array}{l}\text { Bog } \\
\text { Marginal Bog } \\
\text { Nonbog }\end{array}$ & $\begin{array}{r}3 \\
13 \\
84\end{array}$ & $\begin{array}{l}2^{\star \star} \\
8 \\
90\end{array}$ & $\begin{array}{l}<1^{* *} \\
7 \\
92\end{array}$ & $\begin{array}{l}0^{\star} \\
8 \\
92\end{array}$ \\
\hline \multicolumn{5}{|l|}{ Beaver Dam } \\
\hline $\begin{array}{l}\text { Present } \\
\text { Absent }\end{array}$ & $\begin{array}{l}47 \\
53\end{array}$ & $\begin{array}{l}40^{\star} \\
60\end{array}$ & $\begin{array}{l}36^{\star \star} \\
64\end{array}$ & $\begin{array}{l}31^{\star \star} \\
69\end{array}$ \\
\hline \multicolumn{5}{|l|}{ Lake Type } \\
\hline $\begin{array}{l}\text { Seepage } \\
\text { Drainage }\end{array}$ & $\begin{array}{l}13 \\
87\end{array}$ & $\begin{array}{l}11 \text { ns } \\
89\end{array}$ & $7^{\star}$ & $\begin{array}{l}3^{\star \star} \\
97^{\star}\end{array}$ \\
\hline \multicolumn{5}{|l|}{ Ownership } \\
\hline $\begin{array}{l}\text { Public } \\
\text { Mixed } \\
\text { Private }\end{array}$ & $\begin{array}{r}46 \\
9 \\
45\end{array}$ & $\begin{array}{l}51^{\star \star} \\
12 \\
37\end{array}$ & $\begin{array}{l}42 n 15 \\
12 \\
46\end{array}$ & $\begin{array}{l}41 \text { ns } \\
13 \\
45\end{array}$ \\
\hline \multicolumn{5}{|l|}{ ALSC Fish } \\
\hline $\begin{array}{l}\text { Absent } \\
\text { Present }\end{array}$ & $\begin{array}{l}24 \\
76\end{array}$ & $\begin{array}{l}13^{\star \star} \\
87^{-1}\end{array}$ & $\begin{array}{l}6^{\star \star} \\
94\end{array}$ & $\begin{array}{l}2^{\star \star} \\
98\end{array}$ \\
\hline
\end{tabular}

ns Distribution not significantly different $(p>0.05)$ from the distribution for the full ALSC sample

* Chi-square test comparison to full ALSC sample significant at $p \leq 0.05$

* Chi-square test significarit at $p \leq 0.001$ 


\subsubsection{Direct Comparisons: ALSC and 1929-34 Surveys}

Potential differences in the results from the ALSC and 1929-34 fish surveys were examined for (1) numbers of fishless lakes, (2) the presence or absence of individual fish species, and (3) the total number of fish species caught (i.e., species richness). Comparisons with the ALSC results were made for two data subsets: (1) all lakes surveyed for fish between 1929-34 with no restrictions on sampling methods (ranging from angling only, or short gill net sets of 2-4 hours, to more comprehensive sampling using multiple gear types) ( $n=295$ lakes) and (2) only those lakes surveyed in 1929-34 using both gill nets and seines ( $n=128$ lakes). There were several discrepancies between the FIN and NYSDEC historical data bases regarding the number of lakes surveyed in these years (particularly lakesurveyed where no fish were caught). These differences were resolved by examining the original survey forms at Ray Brook, NY.

Relying strictly on records of fish caught and considering all 295 of the lakes sampled in 1929-34, it would appear that there were more fishless lakes in the Adirondacks historically than at present, although the shift in the numbers of lakes with and without fish caught is not statistically significant ( $p>0.05$; Fisher chi-square analysis). The ALSC caught no fish in $17(6 \%)$ of the 295 lakes, while the historical records indicate that no fish were caught in 28 lakes $(9 \%)$. Nine lakes had no fish caught either in $1929-34$ or by the ALSC (Table 3.6-8)

\section{Table 3.6-8 Numbers (and Percentages) of Lakes With and Without Fish Caught in 1929-34 versus $1984-87$}

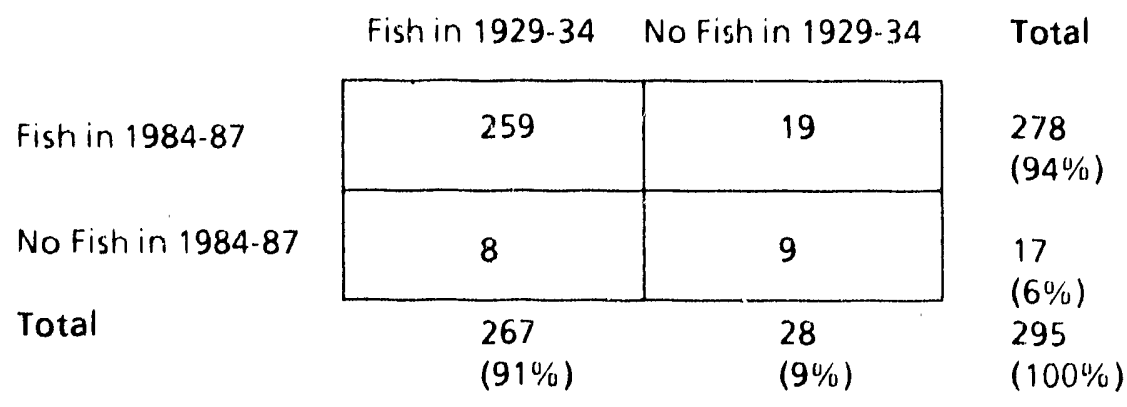

A number of the 295 lakes surveyed in 1929-34 were sampled rather crudely, however, using very short-term gill net catrhes of 2-4 hours or with angling only. In 11 lakes, no fish were caught, but one or more fish species was listed as reported to occur, dropping the number of historically fishless lakes from 28 to 17. Of the 295 lakes, 8 had no fish caught or reported in both 1929-34 and 1984-87; 9 had 
fish in 1929-34, but none were caught by the ALSC; and 9 other lakes had no fish caught or reported in 1929-34 but did have fish in 1984-87 (Table 3.6-9).

Alternatively, rather than relying on sus of fish occurrence, we can restrict the data subset to just those lakes sampled more intensively 199794 (using both gill nets and seines). Unfortunately, as observed in Section 3.6.4.2, relatively few of these lakes now have low-pH levels. Of the 128 lakes in the data set, no fish were caught in only 2 of these lakes in 1929-34, and 2 lakes in 1984-87

(Table 3.6-10). None of the lakes had no fish caught in both surveys. The two lakes with no fish caught by the ALSC had summer surface field pH measurements of 5.0 and 6.5, while the two lakes apparently fishless in 1929-34 had pH levels (in 1984-87) of 5.5 and 7.0. Four lakes with fish present in both 1929-34 and 1984-87 had $\mathrm{pH}<5.0$.

Schofield (1976) reported an increase in the number of fishless lakes at high elevations (above $600 \mathrm{~m}$ ) in the Adirondacks (see Section 3.6.2). Twenty of the lakes surveyed by the ALSC and in 1929.34 occurred at elevations $\geq 600 \mathrm{~m}$. No fish were caught or reported in three of these lakes in both 1929-34 and 1984-87. Three additional lakes had fish in 1929-34 but none in 1984-87. Thus, the number of lakes without fish doubled but still represented only $30 \%$ of the lakes sampled in 1984-87. Results for lakes at $\geq 500 \mathrm{~m}$ elevation were similar.

Although the numbers of lakes with and without fish do not appear to have changed markedly, it is still possible that the types of lakes that are fishless may have changed over the 50- to 60-year period. The characteristics of four classes of lakes are compared in Figure 3.6-6 and Table 3.6-11:

- lakes with fish caught or reported in both 1929-34 and 1984-87 ( $n=269)$

Table 3.6-9 Numbers (and Percentages) of Lakes With and Without Fish Caught or Reported in 1929-34 versus 1984-87

\begin{tabular}{|c|c|c|c|}
\hline & Fish in 1929-34 & No Fish in $1929-34$ & Total \\
\hline Fish in $1984-87$ & 269 & 9 & $\begin{array}{l}278 \\
(94 \%)\end{array}$ \\
\hline No Fish in $1984-87$ & 9 & 8 & $\begin{array}{l}17 \\
(6 \%)\end{array}$ \\
\hline Total & $\begin{array}{l}278 \\
(94 \%)\end{array}$ & $\begin{array}{l}17 \\
(6 \%)\end{array}$ & $\begin{array}{c}295 \\
(100 \%)\end{array}$ \\
\hline
\end{tabular}


Table 3.6-10 Numbers (and Percentages) of Lakes With and Without Fish Caught in 1929-34 versus 1984-87, for the 128 Lakes Sampled in 1929-34 Using Both Gill Nets and Seines

\begin{tabular}{|c|c|c|c|}
\hline & Fish in 1929-34 & No Fish in 1929-34 & Total \\
\hline Fish in 1984.87 & 124 & 2 & $\begin{array}{l}126 \\
(98 \%)\end{array}$ \\
\hline No Fish in 1984-87 & 2 & 0 & 2 \\
\hline Total & $\begin{array}{l}126 \\
(98 \%)\end{array}$ & $\begin{array}{c}2 \\
(2 \%)\end{array}$ & $\begin{array}{l}128 \\
(100 \%)\end{array}$ \\
\hline
\end{tabular}

- lakes with fish present in $1929-34$ but not in 1984-87 $(n=9)$

- lakes with no fish in both $1929-34$ and $1985-87(n=8)$

- lakes that had no fish caught or reported in 1929-34 but had fish caught by the ALSC in 1984-87 $(n=9)$ (see Table 3.6-9)

Lakes that appear to have lost fish since 1929-34 had significantly ( $p \leq 0.05 ; \mathrm{KS}$ test) lower $\mathrm{pH}$, higher estimates of inorganic Al concentrations, and occurred at higher elevations than did lakes with fish present in both 1929-34 and 1984-87. Likewise, lakes that have apparently always been fishless also had lower $\mathrm{pH}$, higher inorganic Al, occurred at higher elevations, and were significantly smaller compared to lakes with fish present in both 1929-34 and 1984-87. No significant differences $(p>0.05)$ among lake classes were detected for lake depth, minimum DO levels (measured by the ALSC), or dissolved organic carbon (DOC).

Sample sizes (for lakes with no fish) were too small for statistical tests of among-lake differences in discrete lake characteristics. Several general observations car t,a made, however (see Table 3.6-11). All of the lakes that seem to have lost ish since 1929-34 were classified by the ALSC as nonbog lakes, while 37\% of the lakes that had no fish in both 1929-34 and 1984-87 were classified as bogs or marginal bogs. A higher proportion of the lakes that have apparently lost fish had beaver dams at the lake outlet (71\% of the drainage lakes), compared to lakes that still supported fish in 1984-87 ( $35 \%$ of which had beaver dams at the outlet). In contrast, lakes with apparent introductions of fish had a lower frequency $(17 \%)$ of occurrence of beaver dams at the outlet. Introductions of fish also tended to occur more often in private waters than in public or mixed ownership waters. 

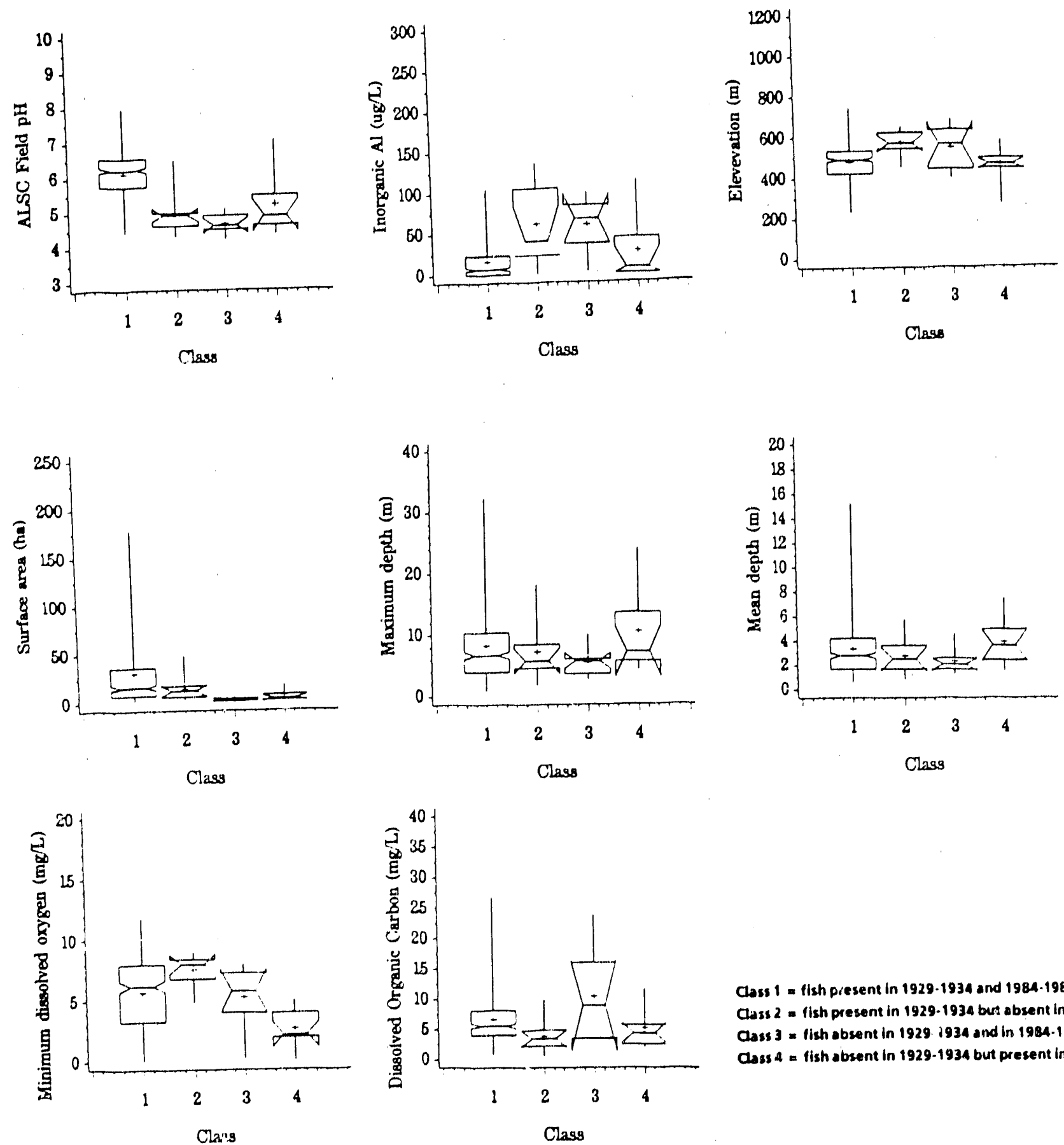

Class 1 = fish present in 1929.1934 and 1984.1987 (269) Cass 2 = fish present in 1929-1934 bus absent in 1984.1987 (9) Cass 3 = fish absent in 1929. 2934 and in 1984-1987 (8) Cass $4=$ fish absent in 1929-1934 but present In $1984-1987$ (9)

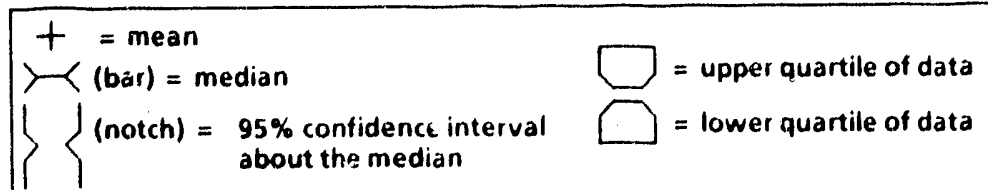

$=$ (whisker) range of minimum to maximum values in the data

Figure 3.6.6 Comparisons of lake characteristics arnong four classes of fish presenceiabsence (1929-1934 versus 1984-1987). 
Table 3.6-11 Percentage of Lakes in Each Lake Class (Defined by Fish Presence/Absence in 1929-34 and 1984-87) for Selected Lake Characteristics

\begin{tabular}{|c|c|c|c|c|}
\hline \multirow[b]{2}{*}{ Lake Characteristics } & \multicolumn{2}{|c|}{ Fish 1929-34 } & \multicolumn{2}{|c|}{ No Fish 1929-34 } \\
\hline & $\begin{array}{l}\text { Fish 1984-87 } \\
(n=269)\end{array}$ & $\begin{array}{l}\text { No Fish 1984-87 } \\
\qquad(n=9)\end{array}$ & $\begin{array}{l}\text { No Fish 1984-87 } \\
\quad(n=8)\end{array}$ & $\begin{array}{c}\text { Fish 1984-87 } \\
(n=9)\end{array}$ \\
\hline \multicolumn{5}{|l|}{ Bog Influence } \\
\hline Bog & 0 & 0 & 12 & 0 \\
\hline Marginal Bog & 7 & 0 & 25 & 22 \\
\hline Nonbog & 93 & 100 & 63 & 78 \\
\hline \multicolumn{5}{|l|}{ Beaver Dam } \\
\hline Present & 35 & 71 & 60 & 17 \\
\hline Absent & 65 & 29 & 40 & 83 \\
\hline \multicolumn{5}{|l|}{ Ownership } \\
\hline Public & 42 & 67 & 63 & 22 \\
\hline Mixed & 13 & 0 & 0 & 0 \\
\hline Private & 46 & 33 & 37 & 78 \\
\hline \multicolumn{5}{|l|}{ Lake Type } \\
\hline Seepage & 5 & 22 & 37 & 33 \\
\hline Drainage & 95 & 78 & 63 & 67 \\
\hline
\end{tabular}

Similar analyses can be conducted for individual fish species by comparing patterns of fish species presence/absence in 1929-34 versus 1984-87. Analyses focused on two data subsets: (1) the full set of lakes sampled in 1929-34 $(n=295)$ considering the fish species present if it was either caught or reported and (2) lakes surveyed in 1929 -34 with both gill nets and seines $(n=128)$ considering the fish species only if it was caught in the sampling gear. Only five fish species (or taxa) occurred in fewer lakes in 1984-87 than in 1929-34 in both data sets: lake whitefish, smallmouth bass, creek chub, common shiner, and sensitive minnows (Table 3.6-12). Only sensitive minnows, as a group, experienced a statistically significant ( $p \leq 0.05$; Fisher chi-square ana!ysis) decline in the number of lakes with fish present, and only for those lakes sampled using both gill nets and seines. To some degree, the lower frequency of occurrence of minnows in 1984-87 may result from the less effective sampling of nearshore areas by the ALSC (using small-mesh gill nets and minnow traps) compared to the seining efforts conducted in 1929-34. Four fish species occurred in a significantly $(p \leq 0.05)$ greater number of lakes during the ALSC survey than in 1979-34: largemouth bass, golden shiner, yellow perch, and brown bullhead. Lake characteristics associated with these changes in fish presence/absence are discussed in Section 3.4 .4

The final comparison between the 1929-34 and 1984-87 survey data involves the measure of species richness, i.e., the number of fish species caught Analyses were conducted only for the 128 lakes sampled in 1929-34 using both gill nets and seines, and only fish species actually caught were included 
Table 3.6-12 Percentage of Lakes with Individual Fish Species in 1929-34 versus 1984-87, Using Two Data Subsetsa,b

\begin{tabular}{|c|c|c|c|c|c|}
\hline \multirow[b]{2}{*}{ Fish Species } & \multirow[b]{2}{*}{ Data Seta } & \multicolumn{4}{|c|}{ Percentage of Lakes with Fish Species Present } \\
\hline & & $\begin{array}{l}\text { Both 1929-34 } \\
\text { and 1984-87 }\end{array}$ & 1929.34 & $1984-87$ & $\begin{array}{c}\text { Proportional } \\
\text { Change Since } \\
1929-34 b\end{array}$ \\
\hline \multirow[t]{2}{*}{ Brook trout } & a & 38.6 & 56.3 & 51.2 & -0.09 \\
\hline & b & 35.9 & 46.9 & 57.8 & +0.23 \\
\hline \multirow[t]{2}{*}{ Lake trout } & a & 4.4 & 9.8 & 6.4 & -0.34 \\
\hline & $b$ & 3.1 & 6.2 & 6.2 & 0.00 \\
\hline \multirow[t]{2}{*}{ Rainbow trout } & $\mathrm{a}$ & 0.3 & 2.7 & 2.0 & -0.25 \\
\hline & $b$ & 0.8 & 1.6 & 3.1 & $+1.00^{\dagger}$ \\
\hline \multirow[t]{2}{*}{ Brown trout } & a & 0.0 & 1.4 & 3.7 & +1.75 \\
\hline & $b$ & 0.0 & 0.8 & 4.7 & $+5.00^{\dagger}$ \\
\hline \multirow[t]{2}{*}{ Lake whitefish } & $a$ & 1.4 & 4.8 & 2.7 & -0.43 \\
\hline & $b$ & 2.3 & 7.8 & 4.7 & -0.40 \\
\hline \multirow[t]{2}{*}{ Sinallmouth bass } & $a$ & 10.2 & 17.3 & 13.2 & -0.24 \\
\hline & b & 12.5 & 21.1 & 16.4 & -0.22 \\
\hline \multirow[t]{2}{*}{ Largemouth bass } & a & 1.7 & 1.7 & 11.5 & $+5.80^{\star \star}$ \\
\hline & $b$ & 0.8 & 0.8 & 10.9 & $+13.00^{\star \star}$ \\
\hline \multirow{2}{*}{ Northern pike } & a & 5.4 & 8.8 & 7.5 & -0.15 \\
\hline & $b$ & 4.7 & 6.2 & 8.6 & +0.37 \\
\hline \multirow[t]{2}{*}{ White sucker } & a & 40.3 & 52.5 & 56.9 & +0.08 \\
\hline & $b$ & 50.0 & 64.8 & 65.6 & +0.01 \\
\hline \multirow{2}{*}{ Brown bullhead } & a & 48.8 & 55.6 & 78.0 & $+0.40^{\star \star}$ \\
\hline & $b$ & 47.7 & 52.3 & 84.4 & $+0.61^{\star \star}$ \\
\hline \multirow[t]{2}{*}{ Pumpkinseed } & $\mathrm{a}$ & 39.0 & 50.2 & 55.6 & +0.11 \\
\hline & $\mathrm{b}$ & 52.3 & 64.8 & 63.3 & -0.02 \\
\hline \multirow[t]{2}{*}{ Yellow perch } & a & 18.0 & 24.8 & 34.9 & $+0.41^{\star}$ \\
\hline & $b$ & 21.9 & 26.6 & 39.8 & $+0.50^{\star}$ \\
\hline \multirow[t]{2}{*}{ Golden shiner } & $\mathrm{a}$ & 5.8 & 8.8 & 51.2 & $+4.81^{\star \star}$ \\
\hline & $b$ & 7.8 & 11.7 & 62.5 & $+4.33^{\star \star}$ \\
\hline \multirow[t]{2}{*}{ Creek chub } & a & 25.4 & 39.7 & 39.3 & -0.01 \\
\hline & $b$ & 42.2 & 58.6 & 50.8 & -0.13 \\
\hline \multirow[t]{2}{*}{ Common shiner } & a & 8.8 & 22.4 & 16.6 & -0.26 \\
\hline & $b$ & 15.6 & 33.6 & 21.9 & -0.35 \\
\hline \multirow[t]{2}{*}{ N. redbelly dace } & $a$ & 4.8 & 14.9 & 15.9 & +0.07 \\
\hline & $b$ & 9.4 & 28.1 & 18.7 & -0.33 \\
\hline \multirow[t]{2}{*}{ Sensitive minnows } & $\mathbf{a}$ & 17.6 & 34.9 & 28.5 & -0.18 \\
\hline & $b$ & 30.5 & 56.2 & 38.3 & $-0.32^{\star}$ \\
\hline
\end{tabular}

- Data set a = all lakes surveyed in $1929 \cdot 34(n=295)$, with fish species collecied or reported considered present Data set $b=$ lakes surveyed in $1929-34$ using both gill nets and seines $(n=128)$, fish species caught considered present

b $\quad *=p \leq 0.05$; Fisher exact chi-square analysis: * $=p \leq 0.001 ;^{\dagger}=$ sample size per cell too small to conduct statistical comparison 
in the calculation of species richness. Overall, significantly $(p \leqslant 0.005)$ more fish species were caught by the ALSC in 1984.87 in these 128 lakes than in the initial 1929-34 surveys. The mean increase in species richness was 0.72 species (Figure 3.6-7). The change in species richness (expressed as either the net difference or as a proportional change in the number of species caught) appeared unrelated, however, to any lake characteristic (e.g., Figure 3.6-8). Differences in sampling techniques in 1929-34 versus 1984-87 make interpretation of this result tenuous. In addition, lelatively few of the lakes sampled in 1929-34 using gill nets and seines currently have low pH (e.g. 4\% have pH $\leqslant 5.0)$. Thus, the biological significance of this result is uncertain.

Comparisons between survey data for 1929-34 and 1984-87 were, therefore, generally inconclusive. Marked changes in the numbers of lakes with and without fish, or individual fish species, were not evident. In part these results may reflect (1) the types of lakes sampled in 1929-34, focusing on larger lakes with higher $\mathrm{pH}$, and (2) errors in sampling, especially for lakes surveyed less intensively (i.e., without both gill nets and seines) in 1929-34.

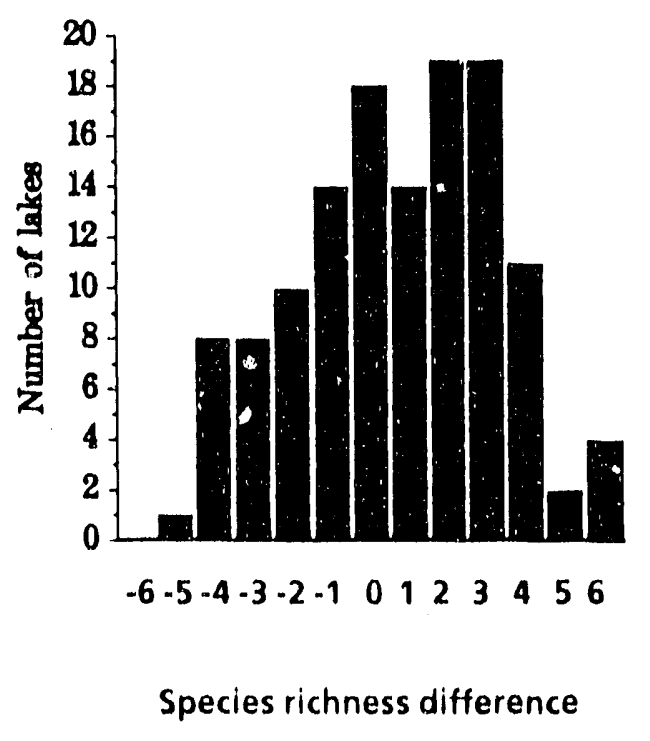

Fig ure 3.6-7 Frequency histogram of difference in the number of species caught by the ALSC minus the number of species caught in the 1929-34 for the 128 ! akes sampled in 1929-34 using both gill! nets and seines. 
(a)

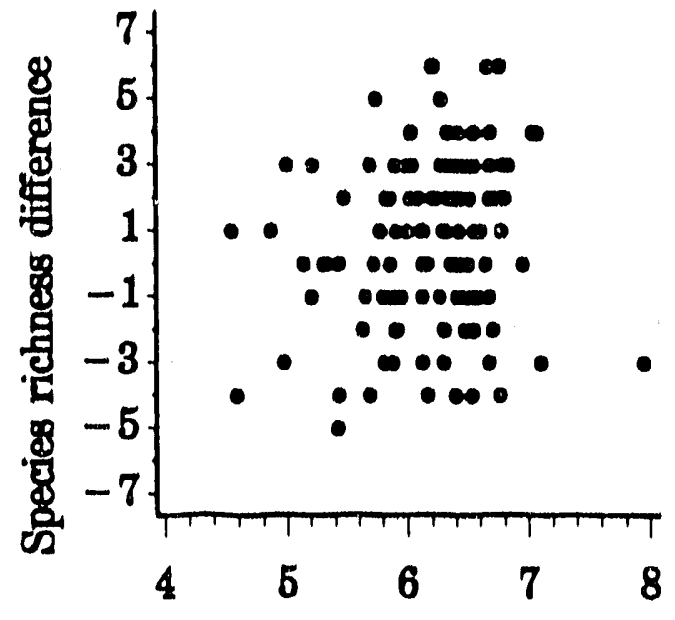

ALSC Field pH (b)

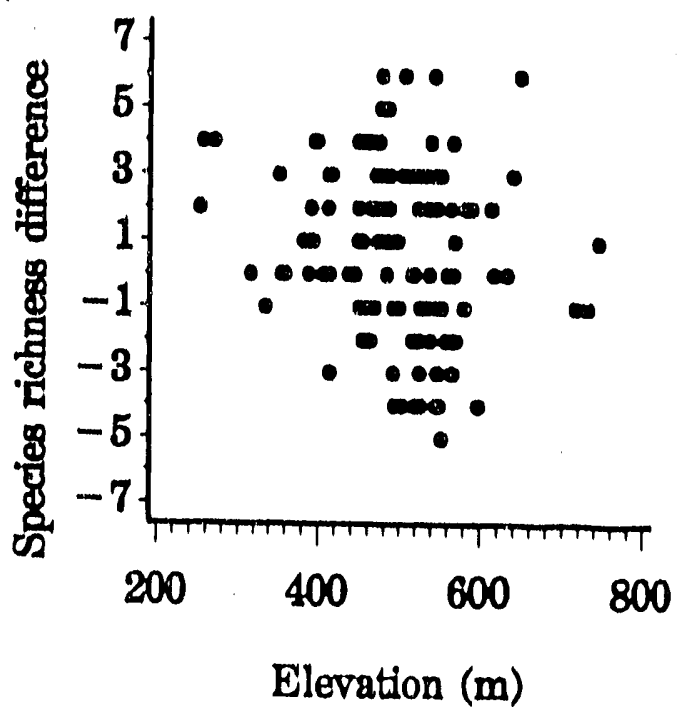

(d)

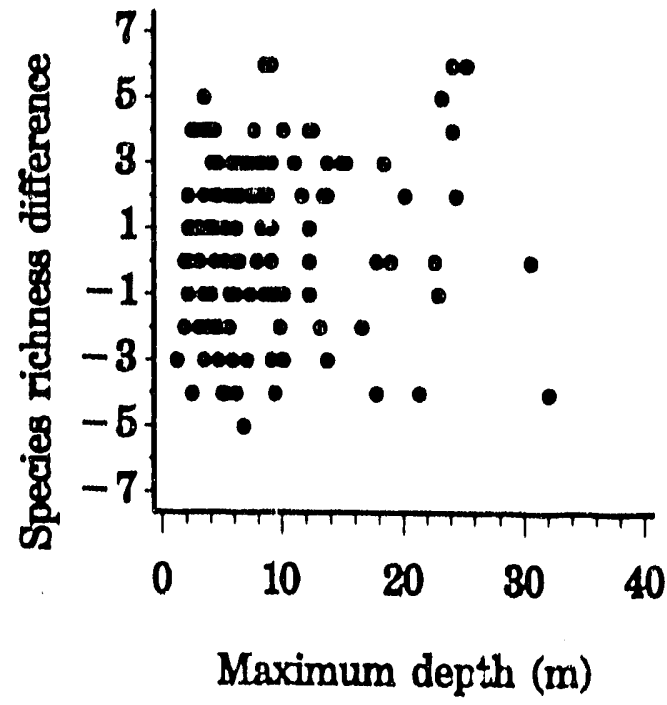

Figure 3.6-8 Difference in the number of species caught in 1984-87 minus 1929-34, for the 128 lakes sampled in 1929-34 using gill nets and seines, plotted as a function of (a) ALSC summer surface fleld pH, (b) elevation, (c) lake area, and (d) maximum depth. 


\subsubsection{Assessments of Fish Population and Community Changes}

When we expand our analyses beyond the 1929.34 historical data base, concerns regarding the completeness of the historical record increase. In particular, species may have occurred in a lake historically that were not caught or recorded as present in historical surveys. Because of this limitation, these analyses focus on, ist the subset of lakes for which we have evidence that a given species occurred in the past. Lakes th at still support the species (i.e., the species was caught by the $\mathrm{ALSC}$ ) are then compared to lakes from which the species has apparently been lost. In interpreting these results, it is important to remember that lakes that have lost fish may be underrepresented in our sample for two reasons: (1) as demonstrated in Section 3.6.4.2, lakes for which we have historical data tend to have higher $\mathrm{pH}$, to be larger, and to support more fish species than Adirondack lakes (surveyed by the ALSC) in general and (2) fish populations lost prior to the earliest comprehensive survey are not included in the data subset, biasing the sample toward lakes that still support the species of interest. On the other hand, fish population losses may be overestimated for those species, particularly rainbow trout and perhaps small minnow species concentrated in littoral areas, that were not effectively sampled by the ALSC (see Section 3.2.1).

Tables 3.6-13 and 3.6-14 present the following information for each fish species:

- the number of lakes for which we have evidence that the species occurred in the past

- the number and proportion of these lakes from which the species has apparently disappeared

- the number and proportion of lakes for which acidification is considered a likely reason for the observed fish population loss (i.e., CAUSE $=3-5$ )

For each species and analysis, the numbers of lakes for which fish population losses were attributed to factors other than acidification exceeded the number of lakes for which acidification was considered the primary cause for the observed population loss. Common alternative explanations that could be identified with the available data include lake reclamation (especially for nonsport fish), change in stocking policy (for sport fish), and the introduction of potential competitors or predators (see Table 3.6-15).

Considering the full sample of lakes with historical (pre-ALSC) information and all lakes in which the species was caught, reported, or observed in the past, the numbers of lakes evaluated as having lost fish populations apparently as a result of acidification varied from 0 for brown trout and northern pike to 61 for brook trout (10\% of the lakes in which brook trout were caught, reported, or observed in the past) (Table 3.6-13). Sensitive minnows had disappeared from 43 lakes (201\% of the lakes with 
Table 3.6-1.3 Apparent Fish Population Losses and Losses Apparently due to Acidification in Lakes with Confirmed or Reported Historical Fish Species Occurrence

\begin{tabular}{|c|c|c|c|c|c|c|}
\hline \multirow{4}{*}{ Fish Specles } & \multicolumn{6}{|c|}{ Evidence for Historical Occurrence } \\
\hline & \multicolumn{3}{|c|}{ Confirmed Catcha } & \multicolumn{3}{|c|}{ Reported or Observedb } \\
\hline & \multirow{2}{*}{ Total } & \multicolumn{2}{|c|}{$\begin{array}{c}\text { Species Not Caught } \\
\text { by ALSCc }\end{array}$} & \multirow{2}{*}{ Total } & \multicolumn{2}{|c|}{$\begin{array}{c}\text { Species Not Caught } \\
\text { by ALSCC }\end{array}$} \\
\hline & & Total & $\begin{array}{l}\text { Acidification } \\
\text { Related }\end{array}$ & & Total & $\begin{array}{l}\text { Acidification } \\
\text { Helacedd }\end{array}$ \\
\hline Brook trout & 472 & $\begin{array}{c}141 \\
(30 \%)\end{array}$ & $\begin{array}{c}46 \\
(10 \%)\end{array}$ & 120 & $\begin{array}{c}68 \\
(57 \%)\end{array}$ & $\begin{array}{c}15 \\
(120 / 11)\end{array}$ \\
\hline Lake trout & 66 & $\begin{array}{c}34 \\
(52 \%)\end{array}$ & $\begin{array}{c}6 \\
(9 \%)\end{array}$ & 28 & $\begin{array}{c}25 \\
(89 \%)\end{array}$ & $\begin{array}{c}6 \\
(21 \%)\end{array}$ \\
\hline Rainbow trout & 55 & $\begin{array}{c}37 \\
(67 \%)\end{array}$ & $\begin{array}{c}i \\
(2 \%)\end{array}$ & 20 & $\begin{array}{c}20 \\
(100 \%)\end{array}$ & $\begin{array}{c}2 \\
(10 \%)\end{array}$ \\
\hline Brown trout & 44 & $\begin{array}{c}20 \\
(45 \%)\end{array}$ & $\begin{array}{c}0 \\
(0 \%)\end{array}$ & 15 & $\begin{array}{c}14 \\
(93 \%)\end{array}$ & $\begin{array}{c}0 \\
(0 \%)\end{array}$ \\
\hline Lake whitefish & 29 & $\begin{array}{c}17 \\
(59 \%)\end{array}$ & $\begin{array}{c}1 \\
(3 \%)\end{array}$ & 13 & $\begin{array}{c}13 \\
(100 \%)\end{array}$ & $\begin{array}{c}3 \\
(23 \%)\end{array}$ \\
\hline Smallmouth bass & 96 & $\begin{array}{c}41 \\
(43 \%)\end{array}$ & $\begin{array}{c}2 \\
(2 \%)\end{array}$ & 41 & $\begin{array}{c}31 \\
(76 \%)\end{array}$ & $\begin{array}{c}1 \\
(2 \%)\end{array}$ \\
\hline Largemouth bass & 39 & $\begin{array}{c}6 \\
(15 \%)\end{array}$ & $\begin{array}{c}0 \\
(0 \%)\end{array}$ & 28 & $\begin{array}{c}14 \\
(50 \%)\end{array}$ & $\begin{array}{c}2 \\
(7 \%)\end{array}$ \\
\hline Northern pike & 54 & $\begin{array}{c}19 \\
(35 \%)\end{array}$ & $\begin{array}{c}0 \\
(0 \%)\end{array}$ & 34 & $\begin{array}{c}14 \\
(41 \%)\end{array}$ & $\begin{array}{c}0 \\
(0 \%)\end{array}$ \\
\hline White sucker & 418 & $\begin{array}{c}83 \\
(20 \%)\end{array}$ & $\begin{array}{c}25 \\
(6 \%)\end{array}$ & 14 & $\begin{array}{c}6 \\
(43 \%)\end{array}$ & $\begin{array}{c}3 \\
(21 \%)\end{array}$ \\
\hline Brown bullhead & 510 & $\begin{array}{c}73 \\
(14 \%)\end{array}$ & $\begin{array}{c}16 \\
(3 \%)\end{array}$ & 101 & $\begin{array}{c}26 \\
(26 \%)\end{array}$ & $\begin{array}{c}9 \\
(9 \%)\end{array}$ \\
\hline Pumpkinseed & 358 & $\begin{array}{c}81 \\
(23 \%)\end{array}$ & $\begin{array}{c}13 \\
(4 \%)\end{array}$ & 41 & $\begin{array}{c}18 \\
(44 \%)\end{array}$ & $\begin{array}{c}3 \\
(7 \%)\end{array}$ \\
\hline Yellow perch & 261 & $\begin{array}{c}67 \\
(26 \%)\end{array}$ & $\begin{array}{c}2 \\
(1 \%)\end{array}$ & 46 & $\begin{array}{c}20 \\
(43 \%)\end{array}$ & $\begin{array}{c}0 \\
(0 \%)\end{array}$ \\
\hline Golden shiner & 251 & $\begin{array}{c}50 \\
(20 \%)\end{array}$ & $\begin{array}{c}12 \\
(5 \%)\end{array}$ & 19 & $\begin{array}{c}4 \\
(21 \%)\end{array}$ & $\begin{array}{c}0 \\
(0 \%)\end{array}$ \\
\hline Creek chub & 265 & $\begin{array}{c}100 \\
(38 \%)\end{array}$ & $\begin{array}{c}29 \\
(11 \%)\end{array}$ & 37 & $\begin{array}{c}13 \\
(35 \%)\end{array}$ & $\begin{array}{c}6 \\
(16 \%)\end{array}$ \\
\hline Common shiner & 128 & $\begin{array}{c}71 \\
(55 \%)\end{array}$ & $\begin{array}{c}23 \\
(18 \%)\end{array}$ & 11 & $\begin{array}{c}11 \\
(100 \%)\end{array}$ & $\begin{array}{c}1 \\
(9 \%)\end{array}$ \\
\hline N. redbelly dace & 66 & $\begin{array}{c}41 \\
(62 \%)\end{array}$ & $\begin{array}{c}10 \\
(15 \%)\end{array}$ & 7 & $\begin{array}{c}6 \\
(86 \%)\end{array}$ & $\begin{array}{c}1 \\
(14 \%)\end{array}$ \\
\hline Sensitive minnows & 194 & $\begin{array}{c}92 \\
(47 \%) \\
\end{array}$ & $\begin{array}{c}40 \\
(21 \%) \\
\end{array}$ & 26 & $\begin{array}{r}17 \\
(65 \%) \\
\end{array}$ & $\begin{array}{c}3 \\
(12 \%) \\
\end{array}$ \\
\hline $\begin{array}{l}\Rightarrow \quad \text { PAST }=B \text { Or } 9 \\
\text { PAST }=4.7\end{array}$ & & $\begin{array}{l}\text { ABSEN } \\
\text { ¿ CAUSE }\end{array}$ & & & & \\
\hline
\end{tabular}


Table 3.6-15 Alternative Explanations for Observed Fish Population Losses: Numbers of Lakes Coded for Selected Possible Causes for Decline Other Than Acidification

\begin{tabular}{|c|c|c|c|c|c|c|}
\hline \multirow[b]{2}{*}{ Code(s)a } & \multicolumn{6}{|c|}{ Alternative Explanations } \\
\hline & $\begin{array}{l}\text { Reclamation } \\
111-12\end{array}$ & $\begin{array}{c}\text { Low DO } \\
20-22\end{array}$ & $\begin{array}{c}\text { Competitors/ } \\
\text { Predators } \\
\text { 31-33 }\end{array}$ & $\begin{array}{c}\text { Beaver } \\
25,41.44\end{array}$ & $\begin{array}{c}\text { Fishing } \\
\text { Pressure } \\
51.52\end{array}$ & $\begin{array}{c}\text { Cessation of } \\
\text { Stocking } \\
62,71-74\end{array}$ \\
\hline Brook trout & 12 & 63 & 104 & 6 & 1 & 67 \\
\hline Lake trout & 22 & 9 & 27 & 0 & 0 & 22 \\
\hline Rainbow trout & 16 & 7 & 23 & 0 & 0 & 50 \\
\hline Brown trout & 7 & 1 & 19 & 0 & 0 & 33 \\
\hline Lake whitefish & 8 & 3 & 13 & $\hat{\imath}$ & 0 & 13 \\
\hline Smallmouth bass & 19 & 1 & 40 & 0 & 0 & 5 \\
\hline Largemouth bass & 2 & 0 & 17 & 0 & 0 & 5 \\
\hline Northern pike & 13 & 0 & 8 & 0 & 0 & - \\
\hline White sucker & 39 & 0 & 21 & 2 & - & - \\
\hline Brown bullhead & 37 & 6 & 6 & 0 & - & - \\
\hline Pumpkinseed & 59 & 0 & 21 & 0 & - & - \\
\hline Yellow perch & 66 & 1 & 4 & 0 & $\cdot$ & - \\
\hline Golden shiner & 16 & 1 & 20 & 0 & - & - \\
\hline Creek chub & 25 & 1 & 58 & 1 & - & - \\
\hline Common shiner & 28 & 1 & 39 & 0 & - & - \\
\hline N. redbelly dace & 10 & 1 & 15 & 0 & - & - \\
\hline Sensitive minnows & 29 & 1 & 52 & 0 & - & - \\
\hline TOTAL & 110 & 76 & 217 & 7 & 1 & 104 \\
\hline
\end{tabular}

a Codes are defined in Appendix C, variables CAUSE 1 tu CAUSE 5

some evidence for historical occurrence) apparently as a result of acidification, creek chub from 35 lakes $(12 \%)$, white sucker from 28 lakes $(6.5 \%)$, brown bullhead from 25 lakes $(4 \%)$, common shiner from 24 lakes $(17 \%)$, and northern redbelly dace from 11 lakes $(15 \%)$. The pattern of change and proportion of populations apparently affected by acidificatior. are fairly similar for samples further restricted to include only those lakes with confirmed historical presence of the species (i.e., capture in an historical survey) prior to 1970 or in 1929-34 (Table 3.6-14).

Lake characteristics associated with fish population losses are illustrated in Tables 3.6-16 to 3.6-18 and Figurer $3.6-9$ to $3.6-10$ for lakes with confirmed presence of the species before 1970 . If all population 
Table 3.6-16 Lake Characteristics Associated with the Loss of Fish Populations (all Possible Causes), Compared to Lakes That Still Support the Speciesa

\begin{tabular}{|c|c|c|c|c|c|c|c|c|c|c|c|c|c|c|}
\hline & $\frac{e^{2}}{3}$ & $\begin{array}{c}\vec{T} \\
\stackrel{0}{s}\end{array}$ & $\underset{\frac{s}{\infty}}{\stackrel{s}{*}}$ & $\stackrel{8}{8}$ & $0^{0}$ & $\frac{5}{5}$ & $\begin{array}{c}5 \\
5 \\
5 \\
5\end{array}$ & రั & క) & $\overbrace{0}^{\frac{a}{8}}$ & $\frac{e^{5}}{\frac{2}{3}}$ & ${ }_{0}^{5}$ & 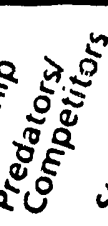 & $\frac{0}{5}$ \\
\hline Brook trout & $\star \star$ & $\star \star$ & ns & ns & ns & ns & ns & ns & ns & ns & * & $\star$ & ** & $\star \star$ \\
\hline Lake trout & ns & ns & ns & ns & ns & ns & ns & ns & - & - & - & ns & ns & - \\
\hline Rainbow trout & ns & ns & ns & ns & ns & ns & ns & ns & - & - & - & ns & ns & $\star$ \\
\hline Brown trout & ns & ns & ns & ns & ns & ns & ns & ns & - & - & - & - & - & - \\
\hline Lake whitefish & ns & ns & ns & * & * & * & ns & ns & - & - & - & - & - & - \\
\hline Smallmouth bass & ns & ns & ns & $\star$ & ns & ns & ns & ns & - & - & - & ns & - & - \\
\hline Largemouth bass & ns & ns & ns & ns & ns & * & $\star$ & ns & - & - & - & - & - & - \\
\hline Northern pike & ns & ns & ns & ns & ns & ns & ns & ns & - & ns & - & ns & - & \\
\hline White sucker & ns & ns & ns & * & ns & ns & * & * & - & ns & - & ns & * & \\
\hline Brown bullhead & * & ns & 夫 & ^ & ns & * & ns & $\star \star *$ & ns & $\star$ & $\star$ & * & $\star \star$ & \\
\hline Pumpkinseed & ns & ns & * & * & ns & ns & ns & * & - & * & - & * & * * & \\
\hline Yellow perch & * & ns & * & + & ns & ns & ns & ns & - & $\star$ & ns & $\star \star$ & $\star \star$ & \\
\hline Golden shiner & ns & ns & ns & ns & ns & ns & ns & ns & - & ns & - & ns & ns & \\
\hline Creek chub & ns & ns & ns & ns & ns & ns & ns & * & - & ns & - & ns & $\star \star$ & \\
\hline Common shiner & ns & ns & ns & ns & ns & ns & ns & ns & - & ns & - & ns & ns & \\
\hline N. redbelly dace & ns & ns & ns & ns & ns & ns & ns & ns & - & ns & - & ns & - & \\
\hline Sensitive minnows & * & ns & ns & ns & ns & ns & ns & ns & - & ns & - & ns & ns & \\
\hline
\end{tabular}

a Analyses conducted on lakes with confirmed presence of the species before 1970, and fish population loss defined as in Table 3.6-14

b Presence of bass and esocid species in the ALSC survey

c Stocking within 5 years of the ALSC; public and mixed ownership waters only

* $\quad p \leq 0.05$, using a KS test for continuous variables and fisher exact chi-square analysis for discrete variables

$\star \star \quad p \leq 0.0001$

- Sample size per lake class too small for a valid statistical test 


\begin{tabular}{|c|c|c|c|c|c|c|c|c|c|c|c|c|c|c|}
\hline & $\begin{array}{c}\frac{1}{2} \\
\frac{2}{3} \\
3 .\end{array}$ & $\begin{array}{l}\overline{8} \\
\text { o } \\
5\end{array}$ & 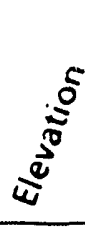 & $\stackrel{8}{8}$ & $\begin{array}{c}5 \\
8 \\
5 \\
5\end{array}$ & $\underbrace{8}$ & $\begin{array}{l}0 \\
\vdots \\
\equiv\end{array}$ & 8 & S & $\overbrace{}^{8}$ & 这 & : & 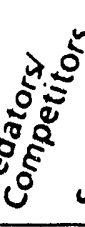 & ". \\
\hline Brook trout & $\star \star$ & $\star \star$ & * & ns & ns & ns & ns & * & - & $\star$ & - & ns & - & $\star \star$ \\
\hline Lake trout & ns & ns & ns & ns & ns & ns & ns & ns & - & - & - & - & - & - \\
\hline Rainbow trout & - & - & - & - & - & - & - & - & - & - & - & - & - & - \\
\hline Brown trout & - & - & - & - & - & - & . & - & - & - & - & - & - & - \\
\hline Lake whitefish & - & - & - & - & - & - & - & - & - & - & - & - & - & - \\
\hline Smallmouth bass & - & - & - & - & - & - & - & - & - & - & - & - & - & - \\
\hline Largemouth bass & - & - & - & - & - & - & - & - & - & - & - & - & - & - \\
\hline Northern pike & . & - & - & - & - & - & - & - & - & - & - & - & - & \\
\hline White sucker & $\star \star$ & * & * & ns & ns & ns & ns & ns & - & ns & . & ns & * & \\
\hline Brown bullhead & ** & $\star \star \star$ & $\star \star$ & ns & ns & ns & ns & ns & - & - & - & ns & - & \\
\hline Pumpkinse d & * * & $\star$ & $\star$ & * & ns & ns & ns & ns & - & - & - & ns & - & \\
\hline Yellow perch & - & - & 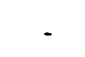 & - & - & - & - & - & - & - & - & - & - & \\
\hline Golden shiner & ns & ns & ns & ns & ns & ns & ns & ns & - & - & - & - & - & \\
\hline Creek chub & ^ & ns & ns & ns & ns & ns & ns & ns & - & ns & - & $\star$ & - & \\
\hline Common shiner & * & ns & ns & ns & ns & ns & ns & ns & - & ns & - & ns & - & \\
\hline N. redbelly dace & ns & ns & ns & ns & ns & ns & ns & ns & - & - & - & - & - & \\
\hline Sensitive minnows & * & $\star$ & ns & ns & ns & ns & * & ns & - & ns & - & ns & ns & \\
\hline
\end{tabular}

a Analyses conducted on lakes with confirmed presence of the species before 1970, and fish population loss defined as in Table 3.6-14

b Presence of bass and esocid species in the ALSC survey

c Stocking within 5 years of the ALSC; public and mixed ownership waters only

* $p \leq 0.05$, using a KS test for continuous variables and Fisher exact chi-square analysis for discrete variables

$\star * p \leq 0.0001$

- Sample size per lake class too small for a valid statistical test 


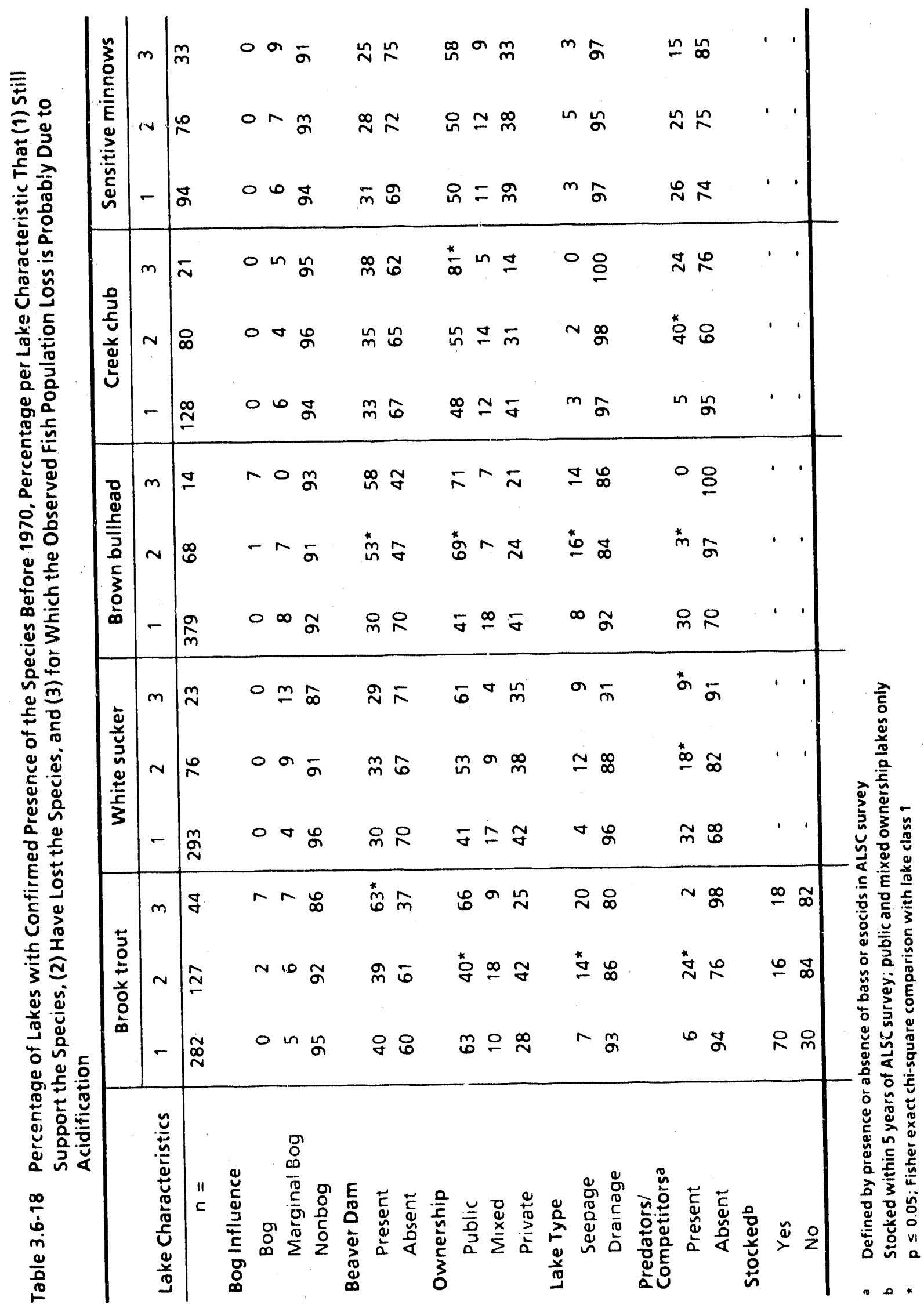



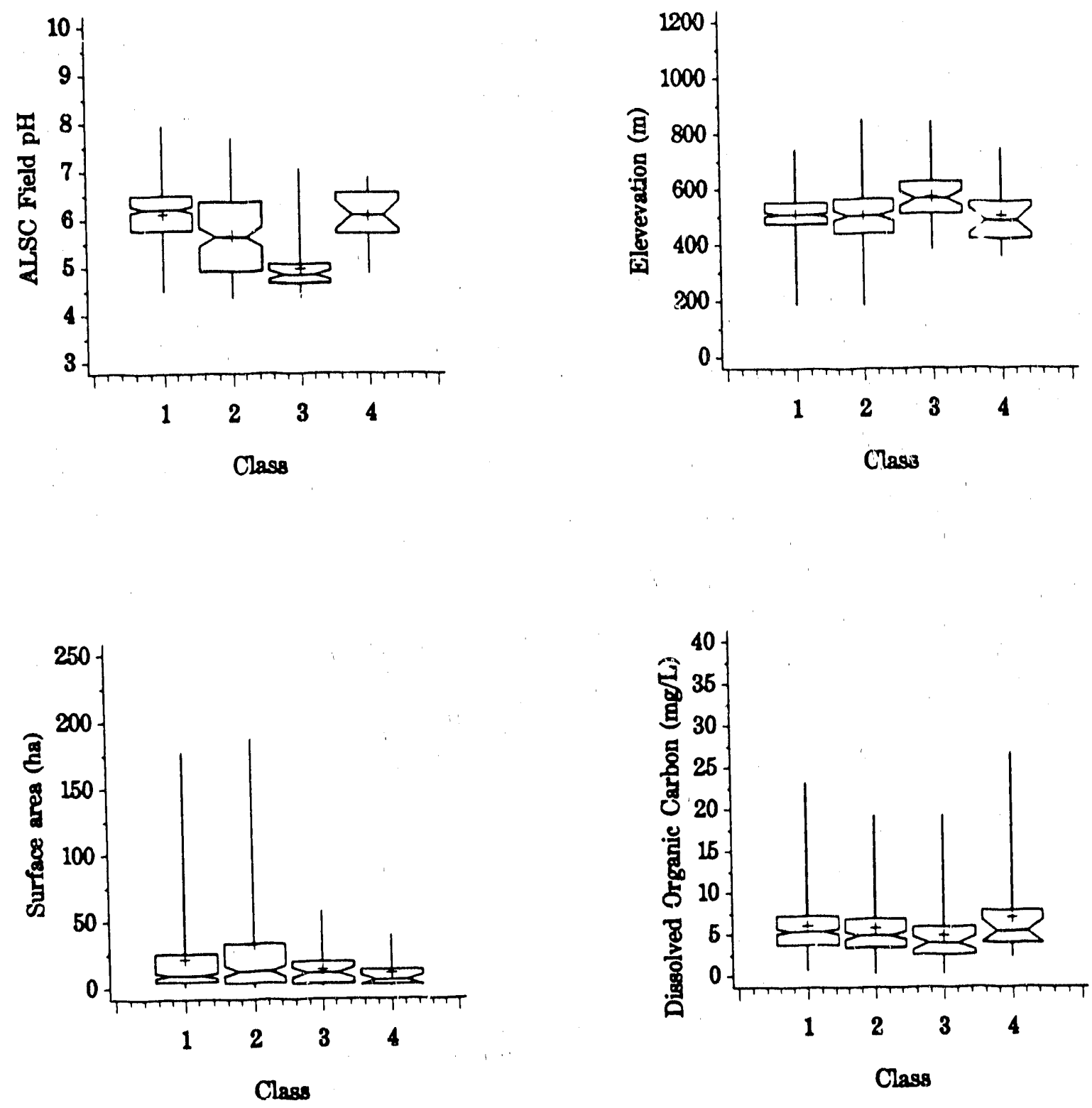

Class $1=$ lakes with confirmed pre-1970 presence that still support brook trout

Class 2 = lakes with confirmed pre-1970 presence that have apparently lost brook trout

Class 3 = lakes that have appasently lost brook trout as a result of acidification

Class 4 = lakes with no brook trout in pre-1970 survey that now have brook trout

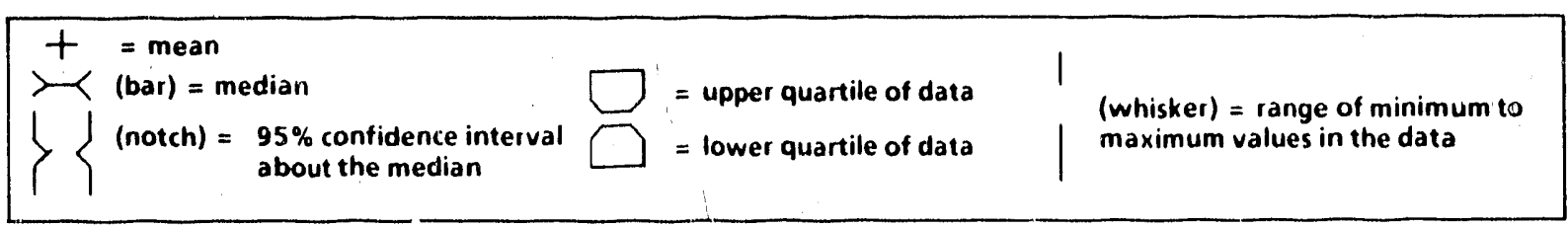

Figure 3.6-9 Comparisions of the characteristics of four classes of brout trout presence/absence in historical and ALSC surveys. 

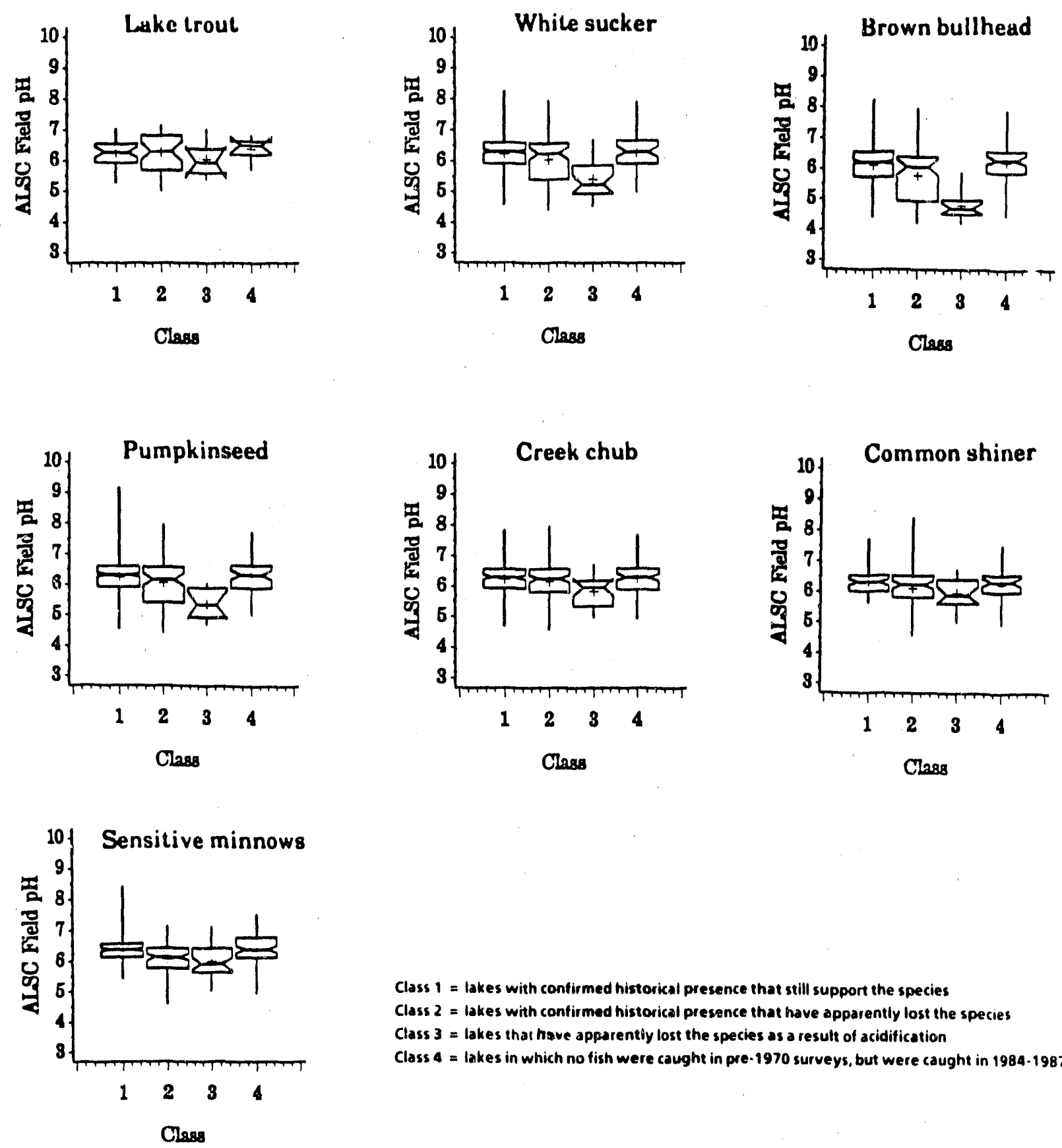

Class $1=$ lakes with confirmed historical presence that still support the species Class 2 = lakes with confirmed historical presence that have apparently lost the species Class 3 = lakes that have apparentiy lost the species as a result of acidification Class $4=$ lakes in which no fish were caught in pre-1970 surveys, but were caught in 1984.1987

$\square=$ upper quartile of data = lower quartile of data (whisker) = range of minimum to maximum values in the data

Figure 3.6-10 Comparision of ALSC summer surface field pH among four lake classes with historical and current fish species presence/absence. 
losses are considered, independent of the reason for the observed loss, statistically significant differences between lakes with and without fish occur for a diverse set of lake characteristics (Table 3.6-16). With few exceptions, where significant differences $(p \leq 0.05)$ were identified, lakes that had lost fish populations had lower $\mathrm{pH}$ and $\mathrm{DOC}$ and higher concentrations of inorganic $\mathrm{Al}$ and minimum DO; occurred at higher elevations; were smaller and shallower (except for brown bullhead which were lost more often in deeper lakes); and were more likely to be seepage lakes or, for drainage lakes, were more likely to have a beaver dam at the lake outlet, compared to lakes that still support the fish species of interest. Brook trout population losses occurred more frequently in privately owned lakes, while brown bullhead, pumpkinseed, and yellow perch losses occurred more often in public or mixed ownership waters. Lakes that had lost brook trout and creek chub were also more likely to have populations of bass and esocids present in 1984-87, while white sucker, brown bullhead, pumpkinseed, and yellow perch populations were lost more frequently from lakes without these species.

In contrast, if we eliminate lakes that appear to have lost fish populations for reasons other than acidification, a more consistent and stronger pattern of association with lake $\mathrm{pH}$ and estimated inorganic $\mathrm{Al}$ is evident (Table 3.6-17; Figure 3.6-10). For seven species (including the sensitive minnow group) fish populations had been lost from at least 10 lakes apparently as a result of acidification. For each of these species, the lakes apparently impacted by acidification had significantly $(p \leq 0.05)$ lower levels of summer surface field $\mathrm{pH}$ than did lakes still supporting the fish species. Five of these species also had significantly higher estimated levels of in.organic Al in lakes classified as losing fish populations apparently as a result of acidification. For four species, fish population losses were also significantly correlated with higher lake elevation. Unfortunately, statistical associations could be examined for relatively few of the discrete lake characteristics because of the small sample size in some cells. Among public and mixed ownership waters, lakes that had been stocked with brook trout within 5 years of the ALSC survey were significantly $(p \leq 0.05)$ less likely to have lost brook trout populations. It is unlikely that the NYSDEC would continue to stock waters unsuitable for fish survival. Similar analyses using records of stocking in any year prior to the ALSC survey indicated no significant association between stocking and the current status of brook trout in these lakes

A relatively high proportion of the lakes that have lost fish populations apparently as a result of acidification were mounded seepage lakes or drainage lakes in watersheds with thin till (Table 3.6-15), based on the lake classification scheme defined in Section 2.4. Both lake classes would be considered relatively susceptible to effects from acidic deposition. For example, $91 \%$ of the lakes losing brook trout apparently as a result of acidification were classified as mounded seepage or thin-till drainage lakes; $70 \%$ were classified as low-DOC mounded seepage or thin-till drainage lakes 
Table 3.6-19 Percentage of Lakes That (a) Have Lost Fish Species Apparently as a RESult of Acidification and (b) That Still Support Fish Which Are Classified as .Mounded Seepage or Thin-Till Drainage Lakes

\begin{tabular}{lccccc}
\hline & \multicolumn{2}{c}{ All Lakes } & & \multicolumn{2}{c}{ Low-DOC (Clearwater) Lakes } \\
\cline { 2 - 3 } \cline { 6 - 6 } \multicolumn{1}{c}{ Fish Species } & Lost & Still Present & & Lost & Still Present \\
\hline Brook trout & 91 & 24 & & 70 & 18 \\
White sucker & 68 & 17 & & 64 & 11 \\
Brown bullhead & 86 & 23 & & 64 & 15 \\
Pumpkinseed & 55 & 16 & & 45 & 12 \\
Creek chub & 48 & 14 & & 30 & 9 \\
Common shiner & 32 & 11 & & 26 & 9 \\
Sensitive minnows & 29 & 10 & & 21 & 6 \\
\hline
\end{tabular}

In contrast, only $24 \%$ of the lakes with brook trout still present ( $18 \%$ for low DOC lakes) Nere included in these two lake classes. Species such as creek chub, common shiner, and sensitive minnows occur less often in these lake classes (see Table 32 2-2), but even for these species the percentage of lakes classified as mounded seepage or thin till drainage was substantially higher for lakes losing fisn populations apparently as a result of acidification (29-48\%) than for lakes with the fish species still present $(10-14 \%)$.

For white sucker, brown bullhead, and pumpkinseed, the percentage of lakes with a fairly low $(\leq 0.5)$ estimated fraction of the $H^{+}$supported by organics ( $i$ e., lakes apparently dominated by mineral acids; see Section 2.5) was generally higher for lakes that had lost the species apparently as a result of acidification than for lakes that still support the species (Table 3.6-20). Even so, for all fish species, a substantial percentage (30-100\%) of the lakes that had lost fish populations apparently as a result of acidification appeared to have over half of the $\mathrm{H}^{*}$ supported by organics. Thus, fish population losses and the estimated fraction of the $\mathrm{H}^{*}$ supported by organics were not clearly associated.

Changes in the fish community as a whole were also evaluated with regard to potential effects from acidification. Lakes that had lost one or more populations of fish apparently as a result of acidification were rated between 3 and 5 for fish community status, while lakes with stable fish communities or with changes in the fish community apparently resulting from factors other than acidification were rated between 0 and 2 (see Table 3.6-6). At the same time, fish communities were 
Table 3.6-20 Percentage of Lakes That Have Lost Fish Populations Apparently as a Result of Acidification and That Still Support the Fish Species with $\leq 50 \%$ of the Hydrogen Ion Concentration Supported by Organics

\begin{tabular}{|c|c|c|c|c|}
\hline \multirow[b]{3}{*}{ Fish Species } & \multicolumn{4}{|c|}{ Percentage of Sample with $\leq 50 \%$ of $\mathrm{H}^{+}$Support by Organics } \\
\hline & \multicolumn{2}{|c|}{ Lakes with $\mathrm{pH} \leq \mathbf{5 . 0}$} & \multicolumn{2}{|c|}{ Lakes with $\mathrm{pH} \leq 5.5$} \\
\hline & Lost & Still Present & Lost & Still Present \\
\hline Brook trout & 42 & 47 & 36 & 23 \\
\hline White sucker & 29 & 0 & 31 & 0 \\
\hline Brown bullh :ad & 64 & 16 & 58 & 12 \\
\hline Pumpkinseed & 75 & 8 & 57 & 3 \\
\hline Creek chub & 0 & 17 & 0 & 8 \\
\hline Common shiner & - & - & 0 & - \\
\hline Sensitive minnows & - & - & 0 & 0 \\
\hline
\end{tabular}

rated according to their expected sensitivity to acidity, on a scale from 1 to 5 with 5 being the most sensitive (e.g. fish communities with sensitive minnows, see Appendix C)

Of the 988 ALSC lakes with at least some historical information, 858 were rated as fish community status (0-5) and fish community type 1-5. (The remaining lakes were of indeterminate status or had no fish caught ore reported when first studied.) Sixteen percent (140) of these lakes were considered to have lost one or more fish populations apparently as a result of acidification (i.e., were rated as fish community status 3-5) (Table 3.6-21). Likewise, of the 720 lakes surveyed before 1970, 662 were rated as fish community status $0-5$, and of these, $19 \%$ (124 lakes) had lost one or more fish populations apparently as a result of acidification. By fish community type, the number and percentage of lakes/fish communities considered apparently adversely affected by acidification were as follows:

- fish rommunity type 1 (e g., with brown bullhead and yellow perch), 3 lakes ( $12 \%$ )

- type 2 (e.g., brook trout and northern pike), 43 lakes (36\%)

- type 3 (e.g., white sucker, largemouth bass), 30 lakes (19\%)

- type 4 (e.g., creek chub, lake trout), 23 lakes (9\%)

- type 5 (e.g., sensitive minnows), 41 lakes (13\%)

The characteristics of lakes with fish community status rated 3.5 are compared to those rated $0-2$ in Table 3.6-22 and Figures 3.6-11 and 36-12. Fish communities classified as adversely affected by 
Table 3.6-21 Numbers of Lakes by Rating of Fish Community Status and Fish Community Typea

\begin{tabular}{crrrrrr}
\hline & \multicolumn{7}{c}{ Fish Community Type } & \multicolumn{1}{c}{ Total } \\
\cline { 2 - 7 } Fish Community Status & 1 & 2 & 3 & 4 & 5 & Tol \\
\hline 0 & 20 & 40 & 51 & 84 & 98 & 293 \\
1 & 0 & 21 & 48 & 94 & 115 & 278 \\
2 & 2 & 15 & 27 & 49 & 54 & 147 \\
3 & 3 & 31 & 22 & 22 & 35 & 113 \\
4 & 0 & 9 & 5 & 1 & 6 & 21 \\
5 & 0 & 3 & 3 & 0 & 0 & 6 \\
Total & 25 & 119 & 156 & 250 & 308 & 858 \\
\hline
\end{tabular}

a Hatings of fish community status defined in Table 3.6-6 and Appendix $C_{\text {; }}$ fish community type discussed above and explained in Appendix $C$.

acidification consistently occurred in lakes with lower $\mathrm{pH}$ and in lakes with higher levels of inorganic $\mathrm{Al}$ and at higher elevations. With only two exceptions (lake area for fish community type 2 and DOC for type 4), no other lake characteristics were significantly associated with these ratings of fish community status.

\subsubsection{Discussion and Conclusions}

The available evidence supports the conclusion that some Adirondack fish communities have been adversely affected by acidification. Problems with the quantity and quality of the historical data, however, preclude quantitative estimates of the regional extent and magnitude of these effects. Lakes with historical data are not representative of Adirondack lakes as a whole. They tend to be larger and deeper and to have higher $\mathrm{pH}$ and more diverse fish communities; thus they would be expected to be less susceptible to effects from acidic deposition. In addition, historical surveys, including many of the 1929-34 surveys, seem to be relatively poor indices of the historical absence of fish or the absence of individual fish species. As a result, trend analyses limited :o lakes with confirmed historical fish presence seem most appropriate. Fish population losses that may have occurred prior to these earliest records of fish occurrence are not accounted for in these analyses. Finally, causes for observed fish population losses, in many cases, cannot be definitively established based on the available historical information. Both positive and regative errors probably occur, i.e., fish population losses attributed to other factors may have, in fact, been caused by acidification, and vice versa. The magnitude of these errors cannot be deterinined although the consistent statistical 
Table 3.6-22 Lake Characteristics Associated with Fish Community Changes Rated as Apparently Resulting from Acidification by Fish Community Typea

\begin{tabular}{|c|c|c|c|c|}
\hline \multirow[b]{2}{*}{ Lake Characteristics } & \multicolumn{4}{|c|}{ Fish Community Typeb } \\
\hline & 2 & 3 & 4 & 5 \\
\hline Lake pH & $\star \star$ & $\star \star$ & $\star$ & * \\
\hline Inorganic Al & * & $\star$ & ns & * \\
\hline Elevation & $\star$ & $\star$ & $\star$ & * \\
\hline Area & $\star$ & ns & ns & ns \\
\hline Maximum depth & ns & ns & ns & ns \\
\hline Mean depth & ns & ns & ns & ns \\
\hline Minimum DO & ns & ns & ns & ns \\
\hline DOC & ns & ns & $\star$ & ns \\
\hline Bog influence & ns & - & - & - \\
\hline Beaver dam & ns & ns & ns & ns \\
\hline Lake type & ns & - & " & - \\
\hline Ownership & ns & ns & ns & ns \\
\hline
\end{tabular}

a Statistical comparison of lakes with fish community status ratings of $\mathbf{0 - 2}$ vs. 3-5, using KS tests for continuous variables and Fisher exact chi-square analyses for discrete variables

b Ratings of fish community type defined in Appendix $C$

* $p \leq \mathbf{0 . 0 5}$

* $p \leq 0.0001$

ns $p>0.05$

- Sample size per cell too small for valid statistical test

association between low $\mathrm{pH}$ and fish populations losses rated as apparently resulting from acidification supports the overall validity of the approach.

Six fish species, plus the sensitive minnow group, were classified as lost, apparently as a result of acidification from at least 10 lakes with confirmed presence of the species prior to 1970: brook trout ( 44 lakes; $11 \%$ of the lakes with adequate historical data), sensitive minnows ( 33 lakes, 19\%) sucker ( 23 lakes, $6 \%)$, creek chub ( 21 lakes, 10\%), common shiner (18 lakes, 15\%), brown bullhead (14 lakes, $3 \%$ ), and pumpkinseed ( 11 lakes, $3 \%$ ). While the numbers of lakes and fish populations affected are not known with certainty, at least for some fish species the effects from acidification appeai nontrivial. Other fish species were classified as lost apparently as a result of acidification in fewer lakes, e.g., lake trout (6 lakes, $9 \%$ ), rainbow trout ( 1 lake, $2 \%$ ), and smallmouth bass ( 2 lakes,

\footnotetext{
Minnow species occurring in nearshore areas may not have been effectively sampled by the ALSC, resultıng in "false absences" and possibly overestimating, to some degree, the numbers of lakes losing the sensitive minnow group
} 


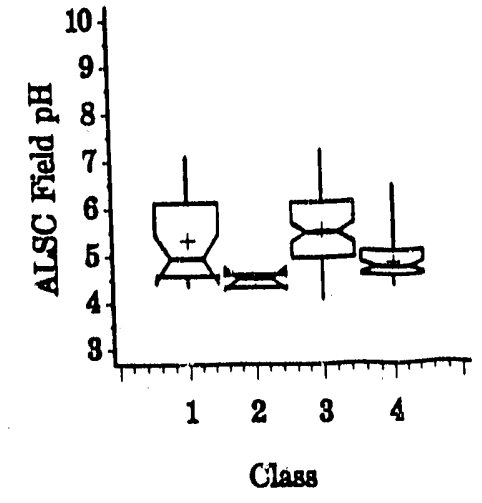

1 = slatus $0-2$, type $1 \quad 2=$ status $3 \cdot 5$, type 1 $3=$ slatus $0-2$, type $2 \quad 4=$ status $3 \cdot 5$, type 2

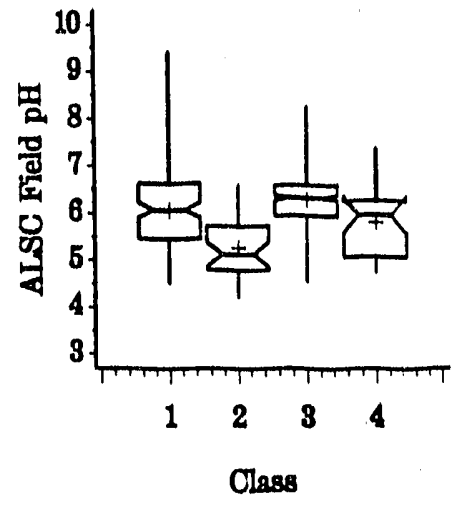

$1=$ stulus 0.2 , type $3 \quad 2=$ stalus 3.5, type 3 $3=$ slatus 0.2 , type $4 \quad 4=$ status 3.5 , type 4

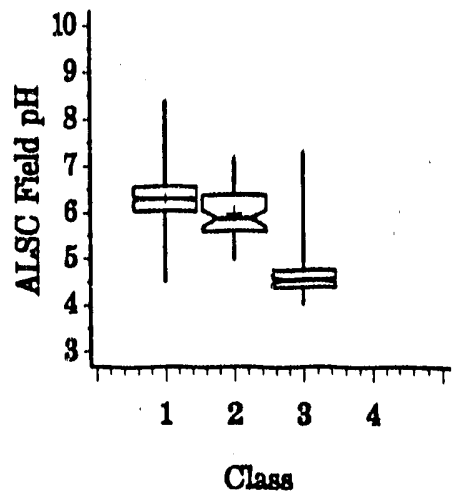

$1=$ stulus 0.2, type 5 $3=$ status 6.9 (always fishless)

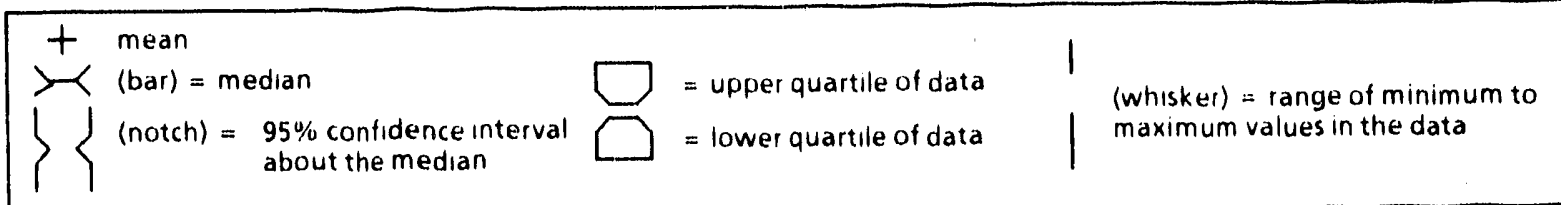

Figure 3.6-11 Comparisons of ALSC summer surface field pH for lakes with fish community status 0.2 versus 3.5 for various fish community types

$2 \%$ ). Three fish species lost no populations apparently as a result of acidification: brown trout, largemouth bass, and northern pike. The effects of acidification and acidic deposition vary among fish species as a function of (1) the sensitivity of the species to acidic conditions (low pH and elevated Al levels) and (2) the degree to which the species occurs in waters likely to experience a significant change in acidity. Thus, while brook trout are relatively acid tolerant, they tend to occur in smaller lakes at higher elevations that may be more susceptible to acidification as a result of acidic deposition. Other sport fish species, such as lake trout, rainbow trout, or bass, may be more arid sensitive but also occur more often in larger, lower-elevation lakes with higher ANC.

Acidification is not the only factor, however, nor necessarily the dominant factor, influencing Adirondack fish communities. Other causes for the loss of substantial numbers of Adirondack fish populations include lake reclamation, changes in stocking policy, and the introduction (or invasion) of competitory and predatory species. In contrast to acidification, however, these alternative causes generally affected only some fish species within the fish community, resulted in species replacements 
rather than a net decline in species richness, or were the direct result of fishery management practices designed to improve sport fishing opportunities in the region.

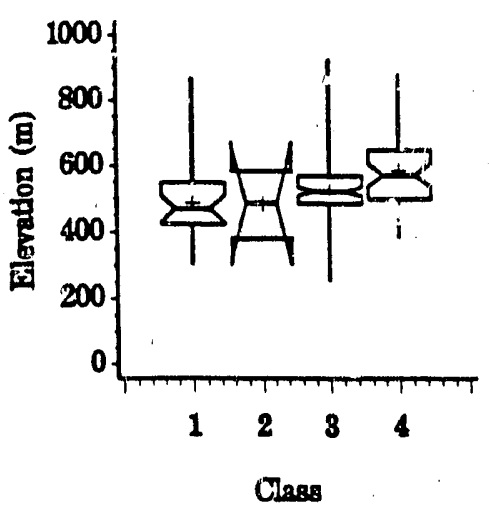

$1=$ stalus 0.2 , type $1 \quad 2$ = status $3 \cdot 5$, type 1 $3=$ slullus 0.2 , uype $2 \quad 4=$ status 3.5 , type 2

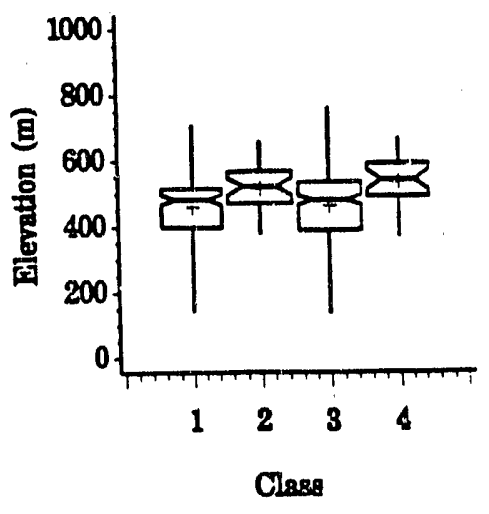

$1=$ status 0.2, type $3 \quad 2$ = status 3.5, type 3 3 = slatus 0.2 , type $4=$ slatur $3 \cdot 5$, type 4

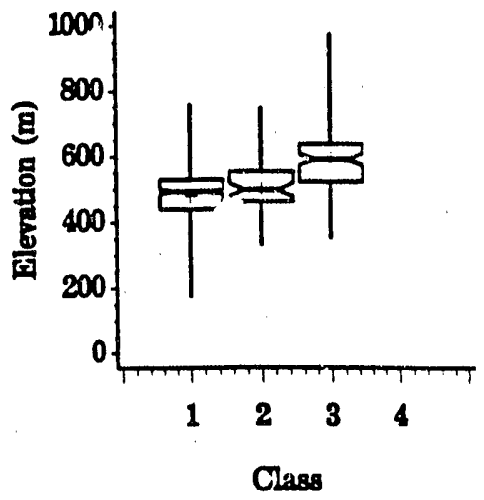

$1=$ stulus 0.2 , type $5 \quad 2=$ stalus 35 , type 5 $3=$ status 6.9 (always fishless)
1 (whisker) = range of minimum to maximum values in the data

Figure 3.6-12 Comparisons of lake elevation for lakes with fish community status $0-2$ versus 3-5 for various fish community types. 


\section{SECTION 3 - REFERENCES}

Baker, J.P., and S.W. Christensen. In |rress. Effects of acidification on biological communities in aquatic ecosystems. In: D.F. Charles, ed. Acidic Precipitation and Surface Water Acidification: Regional Case Studies. Springer-Verlag, New York.

Baker, J.P., and T.B. Harvey. 1984. Critique of Acid Lakes and Fish Population Status in the Adirondack Region of New York State. Final Project Report. EPA-600/3-86/046. U.S. Environınental Protection Agency, Washington, DC.

Baker, J., and C. Schofield. 1982. Aluminum toxicity to fish in acidic waters. Water, Air, Soil Pollut. 18:289-309.

Baiker, J.P. T.B. Harvey, and J. Nicolette. 1984. Compilation of Available Data on the Status of Fish Populations in Regic of the Eastern United States Susceptibie to Acidic Deposition Final Report. U.S. Environmental Protection Agency, Corvallis, OR.

Benson, N.G. 1953. The importance of groundwater to trout ponulations in the Pigeon River MI. Trans. 18th N. Am. Wildl. Conf: 269-281.

Carline, R.F. 1980. Features of successful spawning site development for brook trout in Wisconsin ponds. Trans. Am. Fish. Soc. 109:453-457.

Charles, T.F., 7.R. Whitehead, D.R. Engstrom, B.D. Fry, R.A. Hites, S.A. Norton, and J. Owen. 1987 Paleolimnological evidence for recent acidification of Big Moose Lake, Adirondack Mountains, NY. Biogeochemistry 3:267-296

Colquhoun, J., W. Kretser, and M. Pfeiffer. 1984. Acidity Status Update on Lakes and Streams in New York State. New York State Department of Environmental Conservation, Albany

Driscoll, C.T., R.M. Newton, C.P. Gubala, L.P. E'" "*, and S.W. Christensen. In press. Regional analysis of surface water acidification in the Adirondack Mountains of New Yurk. In: D.F. Charles, ed. Acidic Precipitation and Surface Water Acidification: Regional Case Studies. Springer-Verlag, New York.

Driscoll, C.T., C.P. Yatsko, and F.J. Unangst. 1987. Longitudinal and temporal trends in the water chemistry of the North Branch of the Moose River basirı. Biogeochemistry 3:37-61

Fleiss, J.L. 1981 Statistical Methods for Rates and Proportionr. Second edition. John Wiley \& Sons, New York.

George, C.J. 1980. The Fishes of the Adirondack Park. New York Department of Environmental Conservation, Albany.

Gloss, S.P., C.L. Schofield, R.L. Spateholts, and B.A. Plonski. 1989. Survival, growth, reproduction, and diet of brook trout (Salvelinus fontinalis) stocked into acidic lakes after liming to mitigate acidity. Can. J. Fish. Aquat. Sci. 46:277-2S6

Haines, T.A., and J.P. Baker. 1986. Evidence of fish population responses to acidification in the eastern United Stales. Water, Air, Soil Pollut. 31: 605-629

Hollander, M., and D.A. Wolfe. 1973. Nonparametric Statistical Methods. John Wiley \& Sons, New York. 
Johnson, D.W., H.A. Simonin, J.R. Colquhoun, and F.M. Flack. 1987. In situ toxicity tests of fishes in acid waters. Biogeochemistry 3:181-208.

Keller, W.T. 1979. Management of Wild and Hybrid Brook Trout in New York Lakes, Ponds and Coastal Streams. New York State Department of Environmen :-; Conservation, Albany

Kretser, W., and J. Colquhoun. 1984. Treatment of New York's Adirondack lakes by liming. Fisheries 9:36-41.

Kretser, W., J. Gallagher, and J. Nicolletie. 1989 Adirondack Lakes Study, 1984.1987: An evaluation of fish communities and water chemistry. Summary report. Adirondack Lakes Survey Corp., Ray Brook, NY, $345 \mathrm{pp}$.

Mather, F. 1884. Memoranda Relating to Adirondack Fishes with Descriptions of New Species from Researches Made in 1982. Wee, Parsons and Co., Albany, NY.

Matuszek, J.E., and G.L. Beggs. 1988. Fish species richness in relation to lake area, $\mathrm{pH}$, and other abiotic factors in Ontarin, lakes. Can. J. Fish. Aquat Sci. 45:1931-1941

Mills, K.H., and D.W. Schindler. 1986. Biological indicators of lake acidification Watter, Air, and Soil Pollut. 30:779-789.

Mount, D.R., J.E. Breck, S.W. Christensen, W.A. Gern, M.D. Marcus, C.G. Ingersoll, D.D. Gulley, D.G. McDonald, B.R. Parkhurst, W. Van Winkle, C.M. Wood, and H.L. Bergman. 1989. Physiologic, Toxicologic and Population Responses of Brook Trout to Acidification: Interim Report of the Lake Acidification and Fisheries Project. EPRI EN 6238. Electric Power Research Institute, Palo Alto, CA.

Newton, R.M., J. Weintraub, and R. April. 1987. The relationship between surface water chemistry and geology in the North Branch of the Moose River. Biogeochemistry 3:21-35

New York Stare Conservation Department. 1935. A Biological Survey of the Mohawk-Hudson Watershed. Supplement to the 24th Annual Report [1934]. J.B. Lyon Company Printers, Albany, NY.

New York State Conservation Department. 1934 A Biological Survey of the Raquette Watershed Supplement to the 23rd Annual Report [1933]. J.B. Lyon Company Printers, Albany, NY.

New York State Conservation Department. 1933. A Biological Survey of the Upper Hudson Watershed. Supplement to the 22nd Annual Report [1932]. J.B. Lyon Company Printers, Albany, NY.

New York State Conservation Department. 1932. A Biological Survey of the Oswegatchie and Black Watersheds. Supplement to the 21st Annual Report [1931]. J.B. Lyon Company Printers, Albany, NY.

New York State Conservation Department. 1931 A Biological Survey of the St Lawrence Watershed. Supplement to the 20th Annual Report [1930] J.3. Lyon Company Printers, Albany, NY

New York State Conservation Department. 1930. A Biological Survey of the Champlain Watershed Supplemant to the 19th Annual Report [1929]. J B. Lyon Company Printers, Albany, NY

Parkhurst, B.R. 1987 A Comparison of Laboratory and in Situ Bioassays for Evaluating the Toxicity of Acidic Waters to Brook Trout Ph.D. Thesis, Department of Zoology and Physiology, University of Wyoming, Laramie 
Peters, N.E., and C.T. Driscoll. 1987. Hydrogeologic controls of surface-water chemistry in the Adirondack region of New York State. Biogeochemistry 3:163-180.

Pfeiffer, Martin H. 1979. A Comprehensive Plan for Fish Management. New York Department of Environmental Conservation, Albany, NY.

Pfeiffer, M., and P. Festa. 1980. Acidity Status of Lakes in the Adirondack Region of New York in Relation to Fish Resources. FW-P168 (10/80). New York. State Department of Environmental Conservation, Albany.

Plosila, D.S. 1977. A Lake Trout Management Program for New York State. New York State Department of Environmental Conservation, Albany, NY.

Rafinesque, C.S. 1817. First decade of new North American fishes. American Manthly Magazine Critical Review 2:120-121.

Rafinesque, C.S. 1820. Annals of Nature, or Annual Synopsis of New Genera and Species of Animals, Plants, etc., Discovered in North America. First annual number for 1820. British Museum, London.

Pages $1-16$

Rago, P.J., and J.G. Weiner. 1986. Does $\mathrm{pH}$ affect fish species richness when lake area is considered. Trans. Amer. Fish. Soc. 115:438-447.

Rahel, F.J. 1986. Biogeographic influences on fish species composition of northern Wisconsin lakes with applications for lake acidification studies. Can. J. Fish. Aquat. Sci. 43:124-134.

Rahel, F.J., and J.J. Magnuson. 1983. Low pH and the absence of fish species in naturally acidic Wisconsin lakes: inferences for cultural acidification. Can. J. Fish. Aquat. Sci. 40:3-9

Retsch, W., A. Everett, P. Duhaime, and R. Nothwanger. 1982. Alternative Explanations for Aquatic Ecosystem Effects Attributed to Acidic Deposition. Utility Air Regulatory Group, Everett and Associates, Rockville, MD.

Schofield, C.L 1976. Acid precipitation: Effects on fish. Ambio 5:228-230.

Schofield, C.L. 1976. Dynamics and Management of Adirondack Fish Populations. Prcject Report April 1, 1975-March 31, 1976, No. F-28-R-4, New York Stäte Department of Environmental Conservation, Albany.

Schofield, C.L., and C.T. Driscoll, 1987. Fish species distribution in relation to water quality gradients in the North Branch of the Moose River Basin. Biogeochemistry 3:63-85

Schofield, C.L., and i.R. Trojnar. 1980. Aluminum toxicity to brook trout (Salvelinus fontinalis) in acidified waters. Pages 347-366. In: T.Y. Toribara, M.W. Miller, and P.E. Morrow, eds. Polluted Rain. Plenum Press, New York

Schofield, C.L., S.P. Gloss, B. Plonski, and R. Spateholts. 1989. Production and growth efficiency of brook trout (Salvelinus fontinalis) in two Adirondack Mountain (New York) lakes following liming. Can. J. Fish. Aquat. Sci. 46:333-341.

Schofield, C.L., S.P. Gloss, and D. Josephson. 1986 Extensive Evaluation of Lake Liming, Restocking Strategies, and Fish Population Response in Acidic Lakes Following Neutralization by Liming. NEC$86 / 18$, Interim Progress Report to the U.S. Fish and Wildlife Service, Washington, DC 
Snedecor, G., and W. Cochran. 1980. Statistical Methods. Lowa State University Press, Ames.

Staubitz, W.W., and P.J. Zarriello. 1989. Hydrology of two headwater lakes in the Adirondack Mountains of New York. Can. J. Fish. Aquat. Sci. 46:268-276.

Steinberg, D 1988. LOGIT: A supplementary module for SYSTAT and SYGRAPH SYSTAT, InC

Evanston, IL.

Webster, D.A 1962. Artificial spawning facilities for brook trout, Salvelinus fontinalis. Trans. Am. Fish. Soc 91:168-174.

Webster, D.A., and G. Eiriksdottir. 1976. Upwelling water as a factor influencing choice of spawning sites by brook trout (Salvelinus fontinalis). Trans Am. Fish. Soc. 105:416-421. 


\section{SECTION 4}

\section{SUMMARY AND CONCLUSIONS}

In Section 1, questions of particular interest to the ALSC Management Committee were identified relating to the chemistry and fish communities of Adirondack lakes. Our responses to these questions are summarized below, based upon the detailed data analyses and results described in Sections 2 and 3 .

\subsection{WATER CHEMISTRY}

Before addressing questions, it is worthwhile to make some summary observations regarding the ALSC data base. Chemical data were analyzed for 1469 lakes throughout the Adirondack ecological zone. Each lake was sampled during summer (July and August) and again in either spring (April through June) or fall (September through November). Quality assurance/quality control (QAVQC) analyses of the ALSC chemical data indicate that they are of high precision and internally consistent. The QAVQC analyses resulted in flags being placed on only $1 \%$ of the data records

\subsubsection{What Is the Influence of Mineral Acids and Bases on Hydrogen Ion Concentration?}

Mineral acids and bases influence hydrogen ion $\left(H^{*}\right)$ concentration largely through their effects on acid neutralizing capacity (ANC). For this reason their influence on ANC is summarized first, and then the influence on $\mathrm{H}^{+}$is addressed.

Variations in ANC correlate well with variations in the sum of the base cation concentrations $\left(C_{B}\right)$, but not with the sum of the mineral acid anion concentrations $\left(C_{A}\right)$. This is because $C_{A}$ is relatively constant across the Adirondacks, whereas $C_{B}$ varies widely.

Processes that supply base cations to solution are isn-specific. Sodium ( $\mathrm{Na}$ ) and silica $\left(\mathrm{SiO}_{2}\right)$ concentrations are well correlated, indicating a comrnon source -- mineral weathering. Calcium (Ca) and magnesium (Mg) also co-vary but do not correlate well with $\mathrm{SiO}_{2}$. This indicates that cation exchange is a significant source of these cations. iron ( $\mathrm{Fe})$ and manganese $(\mathrm{Mn})$ concentrations are elevated in the lower waters of some lakes duc to reducing conditions. This leads to an ephemera! increase in $C_{B}$ and $A N C$. When the lakes mix and oxic conditions are restored, these ions largely precipitate from solution. Aluminum (Al) concentrations are highly $\mathrm{pH}$ dependent, with the highest 
Al concentrations observed at low pH in drainage lakes. In summer samples, when Al concentrations are typically lowest, much of the Al present is complexed with organic matter and fluoride (F).

Sulfate $\left(\mathrm{SO}_{4}\right)$ is the dominant mineral acid anion in ALSC lakes. Sulfate concentrations are lowest in seepage lakes, commonly about $40 \mu \mathrm{eq} / \mathrm{L}$ less than in drainage lakes. This is due in part to the longer hydraulic retention time in seepage lakes, which allows slow $\mathrm{SO}_{4}$ reduction reactions more time to decrease lake $\mathrm{SO}_{4}$ concentration. Nitrate $\left(\mathrm{NO}_{3}\right)$ typically influenct, ANC during events such as snowmelt. Chloride $(\mathrm{Cl})$ concentrations are generally low, except in lakes impacted by road salt.

The relative magnitudes of $C_{B}$ and $C_{A}$ determine the influence of mineral acids and bases on $\mathrm{H}^{+}$ concentration. If $C_{B}$ is greater than $C_{A}$, the water has net mineral base in solution, and any $H^{+}$present must be supported by nonmineral acids. If $C_{A}$ is greate; than $C_{B}$, the difference $\left(C_{A}-C_{B}\right)$ is the extent to which mineral acids are supporting $H^{*}$ in solution. Based on these principles, mineral acids are supporting more than half of the $\mathrm{H}^{*}$ present in 124 of the 256 drainage lakes sampled with $\mathrm{pH}$ values of 5 or less. Mineral acids support over $90 \%$ of the $\mathrm{H}^{+}$present in 83 of these lakes. In seepage lakes with $\mathrm{pH}<5$, mineral acids support more than half of the $\mathrm{H}^{+}$present in 30 of 92 lakes, with 12 of the 30 lakes having more than $90 \%$ of their $\mathrm{H}^{*}$ supported by mineral acids.

\subsubsection{What is the influence of Other Acids and Bases on Hydrogen Ion Concentration?}

The "other" acids and bases include organic acids and aqueous carbon dioxide $\left(\mathrm{CO}_{2}\right)$. Together, these solutes depress $\mathrm{pH}$ values in ALSC waters by about 0.5 to $2.5 \mathrm{pH}$ units over the $C_{B}-C_{A}$ range from 0 to $200 \mu$ eq/L. Volatile acids (largely $\mathrm{CO}_{2}$ ) were found to depress $\mathrm{pH}$ by about 0.3 to 1 units for ANC. values greater than about $50 \mu \mathrm{eq} / \mathrm{L}$. Organic acids depressed $\mathrm{pH}$ most markedly at $C_{B}-C_{A}$ values between 0 and $50 \mu \mathrm{eq} / \mathrm{L}$, where depressions ranged from 0.5 to $2.5 \mathrm{pH}$ units.

The strength of organic acids, their influence on ANC, and their role in supporting $\mathrm{H}^{+}$in solution have been elucidated using the ALSC data. A fraction of the organic acid present is relatively strong, as demonstrated by the relationship between anion deficit and dissolved organic carbon (DOC) concentration over the $\mathrm{pH}$ range from 4 to 4.5. In this range, the anion deficit (and thus strong organic acid concentration) is about 4.5 to $5.0 \mu \mathrm{eq} / \mathrm{my}$ of DOC. The pre ence of waters with net mineral base $\left(C_{B}-C_{A}>0\right)$ but with $\mathrm{pH}$ values $<5$ further demonstrates the strength of the organic acids.

The strength of organic acids also has an impact on the difference observed between $C_{B}-C_{A}$ and $G$ ran ANC. Measured vaiues of Gran ANC are generally lower than estimates of $A N C$ based on $C_{B}-C_{A}$. Two possible explanations for this discrepancy have been proposed: (1) systematic underestimation of titrated ANC caused by curvature in the Gran $F_{1}$ function induced by DOC, and (2) organic acid 
contributions to the strong acid correspondent that are not included in $C_{A}$. The difference between $C_{B}-C_{A}$ and $G r a n A N C$ is highly correlated with $D O C$ concentration over the $\mathrm{pH}$ range from 4 to 4.5 , as is the anion deficit. The slope of the $\left(C_{B}-C_{A}-G \operatorname{ran} A N C\right)$ versus $D O C$ curve is slightly larger than the slope for the anion deficit versus DOC curve ( 5.4 versus $4.8 \mu \mathrm{eq} / \mathrm{L}$ per $\mathrm{mg}$ of $\mathrm{DOC}$ ). This suggests that about $90 \%$ of the difference between $C_{B}-C_{A}$ and $G$ ran $A N C$ can be attributed to the presence of strong organic acids, while the remainder appears to be due to curvature in the Gran $F_{1}$ junction.

As a result of their strong acid component, organic acids, by themselves, can produce negative values for ANC. Thus, the common assumption that negative ANC values are indicative ci acidification solely from mineral acids is incorrect.

Finally, as a corollary to the statements under Question 1, organic acids support more than half of the $\mathrm{H}^{+}$present in 132 of the 256 drainage lakes sampled with pH values of 5 or less. Of the 132 lakes, 105 have over $90 \%$ of their $\mathrm{H}^{+}$supported by organic acids. In seepage lakes with $\mathrm{pH}$ values of 5 or less organic anions support more than half of the $\mathrm{H}^{*}$ present in 62 of 92 lakes and over $90 \%$ in 40 of the 62 lakes.

\subsubsection{What Is the Influence of Geomorphic Characteristics (e.g., Soil Thickness, Wetlands) on Lake Water Quality?}

Geomorphic characteristics do have significant impacts on Adirondack lake water quality. Thick soil and till deposits increase the lateral flow carrying capacity of the more alkaline soil horizons and also the size of the groundwater reservoir. This allows infiltration access to higher concentrations of exchangeable base cations and also allows slow acid neutralizing reactions, such as mineral weathering, to proceed further towar $\mathrm{A}$ completion. In watersheds with thin permeable media, much of the incoming precipitation is forced to flow laterally through acidic upper soil horizons where less neutralization of acid inputs can occur. Wetlands, including those resulting from beaver activity, release large quantities of organic acids into surface waters They also provide enhanced conditions for $\mathrm{SO}_{4}$ reduction

Thus, geomorphic characteristics influence $C_{B}, C_{A}$, and organic acid concentrations, all of which influence $\mathrm{H}^{+}$concentration as discussed in the response to Questions 1,2 , and 5

\subsubsection{Can Lakes Be Classified Based Upon Water Quality Measurements to Estimate Unmeasured yet Influential Geologic Characteristics?}

A classification scheme was developed to group the ALSC lakes according to their chemical characteristics. This approach was based in part upon the mechanistic analyses performed during the Integrated Lake-Watershed Acidification Study (ILWAS) and Regional Integrated Lake-Watershed 
Acidification Study (RILWAS). Using the resulting classification scheme, drainage lakes were classified as thick-, intermediate-, or thin-till systems or as carbonate-influenced waters, on the basis of $\mathrm{Ca}$ concentration and $\mathrm{Ca}$ to $\mathrm{SiO}_{2}$ molar ratio. These classes were further broken down based on DOC concentration, which indicates the influence of wetlands

Seepage lakes were classified as mounded or flow-through, also based on Ca concentration. DOC subclasses were created as indicators of intimate contact with wetlands or littoral bogs or beaverimpacted areas. The chemical characteristics and sizes of each of the classes are summarized in Table 4.1-1.

Table 4.1-1 Characteristics of Lake Classesa

\begin{tabular}{|c|c|c|c|c|}
\hline Lake Classb & Ca Criterion & $\begin{array}{c}\text { DOC } \\
\text { Criterion }\end{array}$ & Other & $\begin{array}{c}\text { Number of } \\
\text { Lakes }\end{array}$ \\
\hline $\begin{array}{l}\text { Thin-Till Drainage } \\
\text { Low-DOC } \\
\text { High.DOC }\end{array}$ & $<50 \mu \mathrm{M}$ & $\begin{array}{l}<500 \mu \mathrm{M} \\
>500 \mu \mathrm{M}\end{array}$ & & $\begin{array}{l}509 \\
276 \\
207\end{array}$ \\
\hline $\begin{array}{l}\text { Intermediate-Till Drainage } \\
\text { Low-DOC } \\
\text { High-DOC }\end{array}$ & $50.75 \mu \mathrm{M}$ & $\begin{array}{l}<500 \mu \mathrm{M} \\
>500 \mu \mathrm{M}\end{array}$ & & $\begin{array}{l}224 \\
102 \\
112\end{array}$ \\
\hline $\begin{array}{l}\text { Thick-Till Drainage } \\
\text { Low-DOC } \\
\text { High-DOC }\end{array}$ & $>75 \mu \mathrm{M}$ & $\begin{array}{l}<500 \mu \mathrm{M} \\
>500 \mu \mathrm{M}\end{array}$ & $\mathrm{Ca} / \mathrm{Si}<2$ & $\begin{array}{r}179 \\
77 \\
99\end{array}$ \\
\hline Carbonate-Influenced & $>75 \mu \mathrm{M}$ & & $\mathrm{Ca} / \mathrm{Si}>2$ & 173 \\
\hline $\begin{array}{l}\text { Flow-Through Seepage } \\
\text { Low-DOC } \\
\text { High-DOC }\end{array}$ & $>25 \mu \mathrm{M}$ & $\begin{array}{l}<500 \mu \mathrm{M} \\
>500 \mu \mathrm{M}\end{array}$ & & $\begin{array}{l}88 \\
38 \\
47\end{array}$ \\
\hline $\begin{array}{c}\text { Mounded Seepage } \\
\text { Low-DOC } \\
\text { High DOC }\end{array}$ & $<25 \mu \mathrm{M}$ & $\begin{array}{l}<500 \mu \mathrm{M} \\
>500 \mu \mathrm{M}\end{array}$ & & $\begin{array}{l}97 \\
45 \\
50\end{array}$ \\
\hline Salt-Impacted & & & $\mathrm{Cl}>20 \mu \mathrm{M}$ & 192 \\
\hline
\end{tabular}

a When parameters were missing, classification using those parameters was not done. For example, the number of high-and low-DOC flow-through seepage lakes totaled 85 rather than 88 (the total number of flow-through seepage lakes) because $D O C$ samples were missing for 3 lakes.

b LOW DOC $=<500 \mu \mathrm{mol} / \mathrm{L} ; \mathrm{High} \mathrm{DOC}=\geq 500 \mu \mathrm{mol} / \mathrm{L}$ 


\subsubsection{Can Estimates Be Made of the Change in pH Resulting from Changes in Acidic Depositic , and/or DOC Concentration?}

Analysis of the sensitivity of ALSC lakes to changes in acidic deposition involved development of a nomograph based upon the ALSC data. Using the nomograph, changes in $\mathrm{H}^{+}$concentration (and thus $\mathrm{pH}$ ) can be predicted given changes in $\mathrm{C}_{\mathrm{B}^{-}} \mathrm{C}_{\mathrm{A}}$ and/or $D O C$ by making simple vectorial movements on the graph

The U,S. EPA Direct/Delayed Response Project (DDRP) involved the application of three dynamic simulation models (ILWAS, MAGIC, and ETD) to predict changes in $C_{B} \cdot C_{A}$ as a result of a $30 \%$ decrease in atmospheric sulfur (S) deposition. All three models predicted increases of about 5 to $15 \mu \mathrm{eq} / \mathrm{L}$ for Adirondack lakes.

Given the DDRP results, the response of represent ative ALSC lakes from the four lowest ANC classes (high-and low-DOC thin-till drainage lakes and high-and low-DOC muunded seepage lakes) to a $15 \mu \mathrm{eq} / \mathrm{L}$ increase in $\mathrm{C}_{\mathrm{B}} \cdot \mathrm{C}_{\mathrm{A}}$ was determined using the nomograph. The predicted increases in $\mathrm{pH}$ ranged from 0.17 to 0.38 units (Table 4.1-2). If small increases in DOC occur simultaneously -- as has been suggested by empirical studies in Wisconsin, the Adirondacks, Canada, and Norway -- the increases in $\mathrm{pH}$ would be less. Increases in DOC of about 2 to $4 \mathrm{mg} / \mathrm{L}$ would offset the increases in $\mathrm{pH}$.

Table 4.1-2 Changes in pH Given Changes in $C_{B} \cdot C_{A}$ and DOC

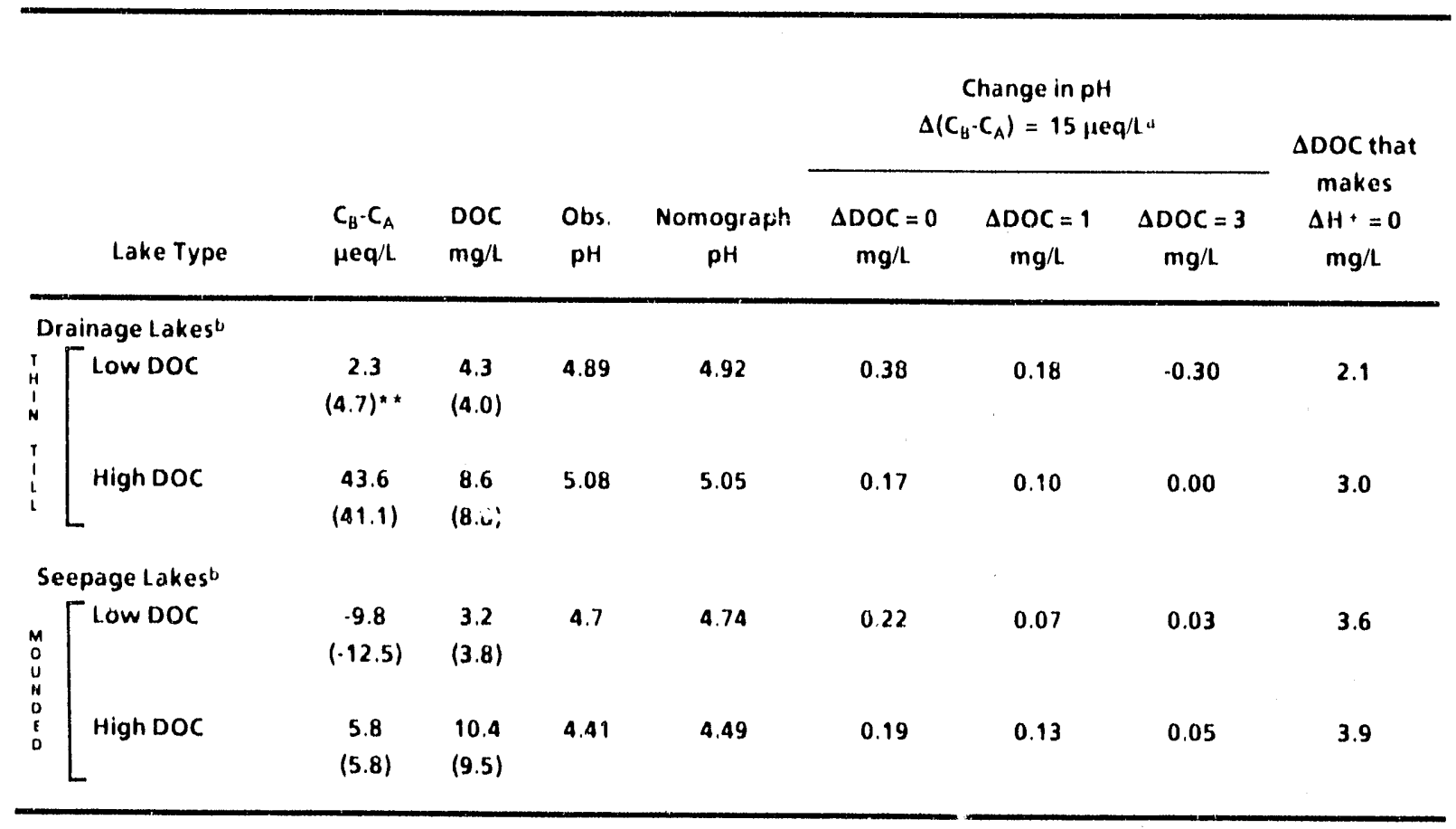

a U.S.EPA DDRP's projected CB-CA increase for a $30 \%$ decrease in sultur deposition.

b $\quad$ LOW DOC $=<500 \mu \mathrm{mol} / \mathrm{L} ; \mathrm{High} \mathrm{DOC}= \pm \mu \mathrm{mol} / \mathrm{L}$

() indicate median values for the specific lake class. 


\subsubsection{Is There Evidence of Time Trends in the Water Quality of Adirondack Lakes?}

Analysis of time trends was not possible using the ALSC data alone. However, monthly data records were available for the period 1982-89 for 17 lakes in the Adirondacks. Unfortunately, even these records were generally too short to detect small trends in water quality. An exception occurred for lake $\mathrm{SO}_{4}$ concentration. Statistically significant decreases in $\mathrm{SO}_{4}$ concentration $(-2.1 \mu \mathrm{eq} / \mathrm{L} / \mathrm{yr})$ were noted over the period of record.

\subsection{FISH COMMUNITIES}

\subsubsection{Where Do Fish Occur? Where Do They Not Occur?}

One or more fish species were caught in $1123(76 \%)$ of the lakes surveyed by the ALSC; 346 lakes $(24 \% ; 7 \%$ of the lake area) had no fish caught and are presumed fishless. Lakes with fish were distributed throughout the Adirondack region, while fishless lakes were concentrated largely in the western and southwestern Adirondacks (see Figure 3.2-12). This area of the Adirondacks is characterized by large numbers of small ( $<4 \mathrm{ha}$ ), high-elevation lakes and also receives high levels of precipitation and acidic deposition. Sixty-one percent of the lakes without fish were found in the Oswegatchie-Black watershed in the southwestern Adirondacks; $39 \%$ of all lakes sampled in this watershed had no fish (see Table 3.2-3). The remaining fishless lakes were distributed across the other four watersheds: Lake Champlain, 37 lakes (13\% of the lakes in the watershed); St. LawrenceRaquette, 61 lakes (15\%); Upper Hudson, 14 lakes (9\%); and the Mohawk-Hudson, 23 lakes (38\%).

Fifty-three fish species (including three hybrids) were captured during the survey. The number of species caught per lake ranged from 0 (fishless) to 13, with a median value of 3 . Lakes in the western and southwestern Adirondacks, on average, supported fewer fish species than did lakes in the northern and eastern Adirondacks (see Figure 3 2-1). Median values for species richness ranged from 1 in the Oswegatchie-Black and Mohawk-Hudson watersheds to 5 species per lake in the Lake Champlain watershed.

Four fish species were caught in over half of the lakes with fish present: brown bullhead (occurring in $75 \%$ of the lakes with fish present), brook trout (52\%), white sucker $(51 \%)$, and golden shiner $(50 \%)$. Other common fish species, caught in $>10 \%$ of the lakes with fish, were pumpkinseed $(45 \%)$, creek chub (39\%), yellow perch (31\%), northern redbelly dace ( $19 \%)$, and common shiner $(14 \%)$. Brook trout is the most important indigenous and widely distributed sport fish species in Adirondack lakes. Additional sport fish that occur in the region include largemouth bass (caught in 112 lakes), northern pike ( 105 lakes), smallmouth bass ( 98 lakes), brown trout ( 59 lakes), lake trout ( 53 lakes), and rainbow trout ( 32 lakes). All of these species were generally distributed in lakes throughout the Adirondacks. 
On the other hand, minnow species expected to be particularly sensitive to acidic conditions were found less frequently in lakes in the western and southwestern Adirondacks.

\subsubsection{Did Fish Occur Historically in These Lakes?}

Relatively few of the lakes that are currently fishless were sampled during the initial statewide comprehensive biological surveys in 1929-34. Thus, we cannot answer with great confidence whether these lakes historically supported fish. Of the 17 currently fishless lakes that were sampled in 1929-34, about one half ( $n=9$ lakes) had one or more fish species caught or reported to occur at that time. The other half ( $n=8$ lakes) have apparently always been fishless, al though it is possible that some lakes lost fish communities prior to these earliest fish surveys.

The total absence of all fish from a lake is a fairly extreme condition, and historical trends in the occurrence of individual fish species are also of interest. For most species, no marked changes are evident in the numbers of lakes with the fish species present now versus in 1929-34. Only sensitive minnows (as a group) had a statistically significant decline in the numbers of lakes supporting the taxa; the lower sampling intensity for minnows by the ALSC than in the 1929-34 surveys may at least partially account for this apparent decline. Four other species appear to have expanded their distribution in Adirondack lakes: largemouth bass, golden shiner, yellow perch, and brown bullhead. However, many of the lakes sampled in 1929.34 were larger lakes at lower elevations, which today have relatively high $\mathrm{pH}$. Fish communities in these lakes would be less likely to have been impacted by acidification, compared to fish in Adirondack lakes as a whole

To partially compensate for this bias, historical surveys conducted after 1929-34 but before 1970 were also considered in evaluating historical fish trends. Unfortunately, many of these surveys were not intended to comprehensively sample the fish community. As a result, al though the historical presence of a species may be demonstrated by its capture in these surveys, the absence of the species from the sample is probably a poor index of the absence of the species from the lake Therefore, these analyses consider only the subset of lakes with confirmed occurrence of the species in the past (before 1970). This expanded data set is also somewhat biased towards larger, lower-elevation lakes with higher $\mathrm{pH}$, but to a lesser degree than for the subset of lakes surveyed in 1929-34.

Fish population losses were classified as apparently resulting from acidification if (1) no obvious alternative explanations could be identified based on the available information and (2) the shift in fisn community composition was consistent with the pattern expected as a result of acidification (i.e.. species considered acid sensitive were impacted first). Of the 409 lakes with confirmed presence of brook trout in the past (before 1970), 127 (31\%) appear to have lost the species. Forty-four of these 
lakes $(11 \%)$ were considered to have lost brook trout populations as a result of acidification. Similar analyses for other species indicate that between 15\% (for brown bullhead) and 71\% (for northern redbelly dace) of the lakes with confirmed presence of the species before 1970 no longer support the species (see Table 3.6-14). Between 0 (for brown trout, rainbow trout, largemouth bass, and northern pike) and 19\% (for sensitive minnows as a group) of the lakes that historically supported the species have lost populations apparently as a result of acidification. Sixteen percent of the lakes evaluated for historical trends in fish community status appear to have lost one or more fish populations as a result of acidification

\subsubsection{If. Fish Do Not Occur in a Lake or Group of Lakes, Why Not?}

Many factors influence the suitability of a lake for fish survival and reproduction It would be incorrect to assume that all lakes without fish, or those that had lost fish populations, have been impacted by acidic deposition. However, it is also incorrect to assume that because many natural and anthropogenic factors affect fish, that the effects from acidic deposition are necessarily inconsequential. The ALSC data base, and the spatial correlation between fish presence/absence and lake characteristics, may be used to examine alternative hypotheses regarding reasons for the absence of fish or loss of fish through time.

Nearly $80 \%$ of the lakes without fish had low pH $(\leq 5.0)$; about $90 \%$ were classified as either mounded seepage lakes or drainage lakes in watersheds with thin till of the 346 fishless lakes sampled by the ALSC, 46 were categorized as bogs. The absence of fish from bogs probably reflects the combined effects of low concentrations of dissolved oxygen (DO), poor spawning substrate, and naturally low $\mathrm{pH}$ levels in these waters. Thirty lakes had $\mathrm{pH}$ levels $>5.5$, i.e., $\mathrm{pH}$ levels above those expected to cause the loss of all fish species. Of the remaining 270 lakes, about half ( $54 \% ; 145$ lakes) had a high estimated fraction ( $>05)$ of the $\mathrm{H}^{+}$supported by organics. The remaining 125 lakes had less than half of the $\mathrm{H}^{+}$supported by organics and were dominated instead by mineral acids. All but five of these lakes had $\mathrm{pH} \leq 5.0$. Not all of these low-pH, fishless lakes, however, would necessarily be able to support fish in the absence of high acidity. For example, 31 of these lakes were small ( $\leq 4 \mathrm{ha}$ ) lakes at high elevation ( $>600 \mathrm{~m}$ ). Some portion of these small, high-elevation lakes would be expected to lack fish regardless of the lake $\mathrm{pH}$ (perhaps about $40 \%$ based on the proportion of small, high elevation lakes with $\mathrm{pH}>5.5$ that were fishless) because of problems with low oxygen levels during winter, freezing, fish access, or poor spawning substrate. Thus, based on these analyses, the estimated number of surveyed waters that lack fish for which mineral acids and acidic deposition are the most likely primary cause is in the neighborhood of $100-113$, or about $30 \%$ of the fishless lakes sampled by the ALSC. 
Likewise, in multivariate analyses, many lake characteristics were significantly correlated with fish presence/absence as well as the presence/absence of brook trout and creek chub. Factors not directly related to acid-base chemistry that were identified as associated with the absence of fish include small lake size, shallowness, high elevation with lower flushing rates, and the occurrence of bogs or marginal bogs. Similar analyses for creek chub identified lake characteristics surch as the presence of predators, small lake size, the absence of inlets or outlets, and lower flushing rates as significantly associated with the absence of creek chub. For brouk trout, stocking, biological variables (e.g., the occurrence of competitors), and $\mathrm{SiO}_{2}$ (an index of groundwater inflow) were of particular importance in explaining patterns of brook trout presence/absence.

In each of these analyses, however, one or more variables related to surface water acid-base chemistry, generally lake $\mathrm{pH}$, was also found to be a significant predictor of the occurrence of fish and of the occurrence of creek chub or brook trout. Thus, even after accounting as much as possible for the effects of the many other factors that influence fish, lakes without fish (or without creek chub or brook trout) had lower $\mathrm{pH}$ than did lakes with fish present. These results support the conclusion that lake $\mathrm{pH}$ (and/or other acidification-related variables) plays an important role in restricting the distribution of fish and individual fish species from at least some Adirondack lakes that would otherwise be suitable fish habitat.

Similar results were observed in analyses for specific Adirondack drainage systems. Lake pH was an especially important determinant of fish distributions in drainage systems in the western and southwestern Adirondacks, where low $\mathrm{pH}$ lakes are prevalent.

In historical trend analyses, common cause's for fish population losses that could be identified with the available data include lake reclamation, changes in stocking policy (for sport fish), ând the introduction of potential competitors or predators. In contrast to acidification, however, these factors often affected only some species within the fish community, resulting in species replacements rather than a net decline in species richness, or were the direct result of fishery management practices designed to improve sport fishing opportunities in the region. In general, the numbers of lakes for which fish population losses were attributed to factors other than acidification exceeded those for which acidification was rated as the primary cause for the observed fish decline

Lakes that had lost fish populations apparently as a result of acidification had significantly lower $\mathrm{pH}$ and also generally higher estimated levels of inorganic $\mathrm{Al}$ and occurred at higher elevations compared to lakes that still support the fish species. No other lake characteristics were consistently correlated with the observed fish population lusses. In addition, many of these lakes were classified as mounded seepage lakes or drainage lakes in watersheds with thin till, and thus may be relatively 
susceptible to effects from acidic deposition. For example, $91 \%$ of the lakes that had lost brook trout apparently as a result of acidification were classified as mounded seepage or thin-till drainage lakes. In contrast, only $25 \%$ of the lakes that still support brook trout were included in these two lake classes. These findings are consistent with the conclusion that at least some fish populations have been lost from Adirondack lakes as a result of acidification and acidic deposition

\subsubsection{What Fish Could These Lakes Support if the Chemistry Were Suitable?}

The outputs from the multivariate analyses of factors influencing fish distributions provide a basis for estimating the numbers of lakes expected to support a fish species if the water chemistry were suitable. Unfortunately, regional applications of these models were not possible within the schedule for this project. We can, however, explore this question qualitatively

Many of the lakes that are currently fishless (perhaps about half or slightly more than half) have always been fishless and would remain fishless even with reductions in acidic deposition. Some of these waters provide poor fish habitat (e.g., bogs or small, high-elevation lakes that experience frequent winterkills) and would not be expected to support fish regardless of the lake $\mathrm{pH}$. Others are fishless, at least in part, b.cause of natural acidity.

Although native to the Adirondacks, bruok trout have been introduced into some lakes and must be maintained by stocking because of insufficient spawning substrate. Brook trout typically spawn over areas of groundwater upwelling, and high $\mathrm{SiO}_{2}$ levels were significantly correlated with the occurrence of brook trout natural reproduction in Adirondack lakes. Of the ALSC lakes that currently support brook trout, about half were classified as having suitable conditions for natural reproduction based on $\mathrm{SiO}_{2}$ concentrations in the lake. On the other hand, lakes with low pH also tend to have lower $\mathrm{SiO}_{2}$ levels. As a result, relatively few of the lakes (10-15\%) with current $\mathrm{pH} \leq 5.0$ and without brook trout were classified as likely to support brook trout natural reproduction, based on their $\mathrm{SiO}_{2}$ concentrations. Lakes with beaver dams on the lake outlet also tend to have lower $\mathrm{SiO}_{2}$ concentrations, perhaps as a result of increased siltation and changes in substrate composition. A large proportion ( $48 \%$ ) of the drainage lakes surveyed had beaver dams present on the outlets; thus, beaver activity may be a significant factor limiting brook trout natural reproduction in the Adirondack region. Stocking, however, is an integral component of the brook trout management policy for the Adirondacks, expanding the range of brook trout distribution into waters where natural reproduction would not be adequate to maintain the species.

Historical trend analyses also provide an index of the types of species likely to be recovered with improvements in water quality. A total of 159 populations were rated as lost apparently as a result of acidification of these losses, brook trout accounted for $28 \%$; white sucker for $14 \%$; creek chub $13 \%$; 
common shiner $11 \%$; brown bullinead $9 \%$, pumpkinseed $7 \%$; northern redbelly dace $6 \%$; golden shiner 5\%: ar dlake trout, smallmouth bass, yellow perch, and lake whitefish, $<5 \%$ each. Many of the lakes with no fish are smaller lakes at high elevations. Typically, such lakes support fairly simple fish communities.

\subsubsection{How Many of the Lakes with Fish Are at Risk from Acidic Deposition?}

In Section 2.4, lakes surveyed by the ALSC were classified, using the ALSC water chemistry and hydrology data, according to lake and watershed characteristics expected to influence the susceptibility of these systems to acidic deposition. Two of these lake classes, mounded seepage lakes and drainage lakes in watersheds with thin till, wourd be expected to be particularly responsive to changes in atmospheric inputs of strong acids. Of the lakes in which the ALSC caught fish, $27 \%$ were classified as mounded seepage or thin-till drainage lakes; $15 \%$ were low-DOC mounded seepage or thin-till drainage lakes. Twenty-five percent of the lakes in which the ALSC caught brook trout fall within these two lake classes; $15 \%$ of the brook trout lakes were classified as low-DOC mounded seepage and thin-till drainage lakes (see Table 3.2-2). In contrast, other sport fish species occur relatively infrequently in these lake classes: $10 \%$ of the lake trout lakes surveyed by the ALSC were classified as mounded seepage or thin-till drainage lakes; $6 \%$ of the lakes with smallmouth bass or largemouth bass, $3 \%$ of the lakes with rainbow trout or brown trout; and $3 \%$ of the lakes with northern pike. Thus, the majority of lakes currently supporting sport fish species would appear to be relatively insensitive to further acidification, i.e., were classified as flow-through seepage lakes or drainage lakes in watersheds with intermediate or thick till or as carbonate-influenced waters. 


\section{APPENDIX A}

Patterns of Fish Distribution in Relation to Lake/Watershed Characteristics:

Regression Analyses and Diagnostics 
APPENDIX A

\title{
PATTERNS OF FISH DISTRIBUTION IN RELATION TO \\ LAKE/WATERSHED CHARACTERISTICS: REGRESSION ANALYSES AND DIAGNOSTICS 1
}

\author{
Sigurd W. Christensen \\ Environmental Sciences Division \\ Oak Ridge National Laboratory \\ P.O. Box 2008, Oak Ridge, Tennessee 37831-6036 \\ John J. Beauchamp \\ Engineering Physics and Mathematics Division \\ Oak Ridge National Laboratory \\ P.O. Box 2009, Oak Ridge, Tennessee 37831-8083 \\ Jean A. Shaakir-Ali \\ Computing and Telecommunications Division \\ Martin Marietta Energy Systems, Inc. \\ P.O. Box 2008, Oak Ridge, Tennessee 37831-6038 \\ Jan M. Coe \\ Computing and Telecommunications Division \\ Martin Marietta Energy Systems, Inc. \\ P.O. Box 2008, Oak Ridge, Tennessee 37831-6271

$$
\text { Jcan P. Baker }
$$ \\ 3727 Swift Drive \\ Raleigh, North Carolina 27606 \\ Eric P. Smith \\ Virginia Polytechnic Institute and State University \\ Blacksburg, Virginia 24061 \\ Jim Gallagher \\ Adirondack Lakes Survey Corporation \\ Route 86 \\ Ray Brook, New York 12977
}

\footnotetext{
TResearch sponsored in part by the Adirondack Lakes Survey Corporation under contract ERD. 88-778 with the US Department of Energy (DOE), and in part by the US. Environmental Protection Agency (EPA) as a part of the National Acid Precipitation Assessment Program under Interagency Agreement DOE No 1824-1808.A1 (EPA No DW89932112-01) with the U S Department of Energy, under contract DE-AC05-840R21400 with Martin Martetta Energy Systems, Inc Although the research described in this appendix has been funded in part by the United States Environmental Protection Agency (EPA), it has not been subjected to EPA review and therefore does not necessanly reflect the views of EPA and no official endorsement shouid be interred.
} 


\section{CONTENTS}

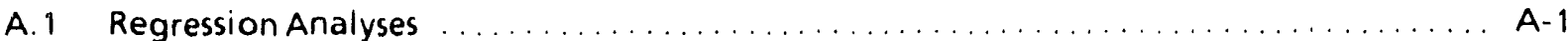

A.1.1 Description of the Method: Advantages and Limitations . . . . . . . . . . . A-1

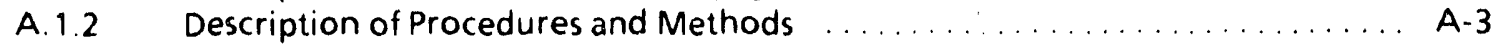

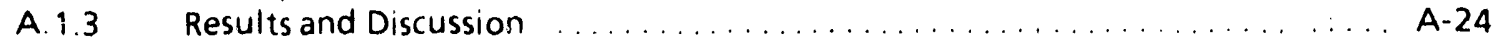

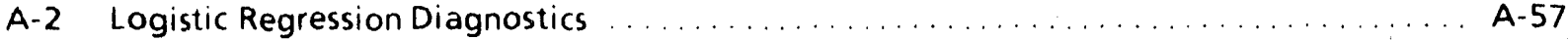




\section{FIGURES}

A-1 Notched box-and-whisker plots of field pH for brook trout, creek chub, and fish/no fish for presence/absence lakes within the calibration and the verification lake subsets.

A-2 Notched box-and-whisker plots of silica (in transformed form) for brook trout, creek chub, and fish/no fish, for presence/absence lakes within the calibration and the verification lake subsets.

A-3 Notched box-and-whisker plots of acid neutralizing capacity (ANC, in transformed form) for brook trout, creek chub, and fish/no fish, for presence/absence lakes within the calibration and the verification lake subsets.

A-4 Notched box-and-whisker plots of dissolved organic carbon (DOC, in transformed form) for brook trout, creek chub, and fish/no fish, for presence/absence lakes within the calibration and the verification lake subsets.

A-5 Notched box-and-whisker plots of lake suiface area (in transformed form) for brook trout, creek chub, and fish/no fish, for presence/absence lakes within the calibration and the verification lake subsets

A-6 Notched box-and-whisker plots of littoral area (in transformed form) for brook trout, creek chub, and fish/no fish, for presence/absence lakes within the calibration and the verification lake subsets

A-7 Notched box-and-whisker plots of lake elevation (in meters) for brook trout, creek chub, and fish/no fish, for presence/absence lakes within the calibration and the verification lake subsets 
A-1 Candidate Explanatory Variables and Summary of Results from Mann-Whitney and Contingency Table Analyses to Test for Differences between Lakes with Fish Present and Absent

A-2 List of Candidate Explanatory Variables, with Results from Mann-Whitney and Contingency Table Analyses to Test for Differences in Explanatory Variable Distributions for Response Variable Categories (Present versus Absent).

A-3 Definitions of Subsetting Variables, Response Variables, and Root Explanatory Variables Transformed before Analysis (Present versus Absent)

A-4 Definition of Lake Groups and Variable Sets Used in Building Models of Fish Presence/Absence in Adirondack Lakes

A-5 Candidate Variables Involved in Multicollinearities and Variables Eliminated from the Candidate List $\left({ }^{*}\right)$ at Each Step of the Initial Collinearity Analysis for Brook Trout

A-6 Candidate Variables Involved in Multicollinearities and Variables Eliminated from the Candidate List (*) at Each Step of the Initial Collinearity Analysis for Creek Chub

A-7 Candidate Variables Involved in Multicollinearities and Variables Eliminated from the Candidate List (*) at Each Step of the Initial Collinearity Analysis for Fish/No Fish

A-8 Variables Selected from Set B1 to Explain the Presence of Brook Trout in Qualified Group 1 Lakes (Biological Variables Included)

A-9 Variables Selected from Set BO to Explain the Presence of Brook Trout in Qualified Group 1 Lakes (Biological Variables Excluded)

A-10 Variables Selected to Explain the Presence of Brook Trout in Qualified Group 2

(Nonprivate, Nonstocked) Lak.es (Biological Variables included)

A-11. Variables Selected to Explain the Presence of brook Trout in Qualified

Group 2. (Nonprivate, Nonstocked) Lakes (Biological Variables Excluded)

A-12 Variables Selected to Explain the Presence of Brook Trout in Qualified Group 3 (Nonprivate, Nonstocked, Non-Fully Bog) Lakes (Biological Variables Excluded)

A-13 Variables Selected to Explain the Presence of Brook Trout in Qualified Group 4 (All Qualifying Calibration) Lakes (Biological Variables Included) 
TABLES

(continued)

A-14 Variables Selected to Explain the Presence of Brook Trout in Qualified Group 4 (all Qualifying Calibration) Lakes (Biological Variables Excluded)

A-15 Variables Selected to Explain the Presence of Brook Trout in Qualified Group 4 (all Qualifying Calibration) Lakes (Biological Variables Excluded) - DDRP Variables

A-16 Variables Selected to Predict the Presence of Brook Trout in Lake Group $1 \mathrm{H}$ (Qualifying Nonprivate Calibration Lakes with $\mathrm{pH}>6$ ) (Biological Variables Excluded)

A-17 Variables Selected to Predict the Presence of Brook Trout in Lake Group $4 \mathrm{H}$ (all Qualifying Calibration Lakes with $\mathrm{pH}>6$ ) (Biological Variables Excluded)

A-18 Variables Selected to Predict the Presence of Brook Trout in Lake Group 4H (all Qualifying Calibration Lakes with $\mathrm{pH}>6$ ) (Biological Variables Excluded)

A-19 Summary of Calibration Results for Brook Trout Models

A-20 Summary of Verification Results for Brook Trout Models

A-21 Greatest Level of Significance of Any Variable within Each of Six Explanatory Variable Groups for Brook Trout

A-22 Variables Selected to Explain the Presence of Creek Chub in Qualified Group 5 (all Qualifying Nonbog Calibration) Lakes (Biological Variables Included), Variable Set B1A

A-23 Variables Selected to Explain the Presence of Creek Chub in Qualified Group 5 (all Qualifying Nonbog Calibration) Lakes (Biological Variables Included), Variable Set B1B

A-24 Variables Selected to Explain the Presence of Creek Chub in Qualified Group 5 (all Qualifying Nonbog Calibration) Lakes (Biological Variäbles Excluded)

A-25 Variables Selected to Explain the Presence of Creek Chub in Qualified Group 6 Lakes (Nonbog Calibration Lakes) in Oswegatchie-Black or Mohawk-Hudson Watershedsa (Biological Variables Included)

A-26 Variables Selected to Explain the Presence of Creek Chub in Qualified Group 6 Lakes (Nonbog Calibration Lakes) in Oswegatchie-Black or Mohawk-Hudson Watersheds (Biological Variables Excluded) 
TABLES

(continued)

A-27 Variables Selected to Explain the Presence of Creek Chub in Qualified Group 7 Lakes (Nonbog Calibration Lakes) in Lake Champlain or Upper Hudson Watersheds (Biological Variables Included)

A-28 Variables Selected to Explain the Presence of Creek Chub in Qualified Group 7 Lakes (Nonbog Calibration Lakes) in Lake Champlain or Upper Hudson Watersheds (Biological Varlables Excluded)

A-29 Summary of Calibration Results for Creek Chub and Fish/No Fish Models

A-30 Summary of Verification Results for Creek Chub and Flsh/No Fish Models

A-31 Greatest Level of Significance of any Variable Within each of Six Explanatory Variable Groups for Creek Chub and Fish versus no Fish

A-32 Variables Selected to Explain the Presence of Fish of any Species (as Opposed to Fishless Lakes) in Qualified Group 5 (all Qualifying Nonbog Calibration) Lakes

A-33 Variables Selected to Explain the Presence of Fish of any Species (as Opposed to Fishless Lakes) in Qualified Group 5 (all Qualifying Nonbog Calibration) Lakes

A-34 Comparison of Values of the Coefficients of the $\mathrm{pH}$ Term in Stepwise-Selected, Logistic Models of Brook Trout Presence/Absence in Adirondack Lakes

A-35 Predicted Probabilities of Brook Trout Presence in Lakes Representative of Four Lake Types, under Current Conditions and under a Projected $30 \%$ Decrease in Deposition, using Models Developed for Lake Group 4

A.36 Summary of Reckhow's Weights for Lake Group 1, Variable B0, 1 Iteration

A-37 Summary of Influential Lakes from Pregibona Diagnostics for Lake Group 1 Variable Set BO

A-38 Summary of Parameter Estimates With and Without Influential Observations for Brook Trout 8-Variable Model Using Lake Group 1 and Variable Set 80 
The Al.SC surveyed 1469 lakes between 1984 and 1987. Of these, 1123 lakes had at least one species of fish, and 346 were fishless. Among the lakes having fish, the patterns of distribution varied widely. Information about many of the factors expected to account for this varlation was collected during the survey. Our objectives here are to

- identify variables (lake and watershed characteristics) that may influence the distribution of selected fish species among Adirondack lakes, and

- examine general patterns of association among these candidate explanatory variables for fish species distributions.

In this report, two complimentary approaches are used to achieve these objectives. One of these, regression analysis, is described in this Appendix and is summarized in Section 3.4; the other, watershed-specific analysis, is described in Section 3.5 .

The regression analysis is divided into three subsections. In Section A. 1, conventional methods are used to fit numerous logistic regression models to identify tactors explaining the presence or absence of brook trout, creek chub, or any species of fish in a variety of subsets of lakes. In Appendix B, robust estimation methods are used to refit two of these models after using a procedure that downweights influential observations. In Section A.2, logistic regression diagnostics are generated for the two models examined in Appendix B.

\section{A.1 Regression Analyses}

This section begins with a description of multiple logistic regression as it applies to the ALSC objectives. This is followed by a description of the procedures and methods we used Finally, we present and discuss our results for brook trout, then for creek chub, and finally for fish presence/absence (presence/absence of any species of fish).

\section{A.1.1 Description of the Method: Advantages and Limitations}

Multiple logistic regression is a statistical procedure for building models that predict the probability of a binary (yes-no) response, such as the occurrence of a fish species, as a function of explanatory variables (Hosmer and Lemeshaw 1989). In this cas?, these variables are derived from attributes of the lakes and their watersheds. Selection procedures can identify particular groups of variables that are the most important in explaining fish occurrence. Based on the statistical associations observed, hypotheses can be formulated concerning cause and effect relationships between the selected variables and the response variable (presence of fish). In this evaluation, separate analyses were 
performed for three response variables: (1) the presence in each lake of brook trout, (2) presence of creek chub, or (3) presence of any fish species.

Multiple regression methods have advantages in comparison to methods that are based on pairwise associations between individual explanatory variables and the response variable. Pairwise comparisons (including univarlate regressions) ignore the effect of other variables. This interferes with interpretation when the variables are not independent. For example, elevation could be selected as being significantly associated with the presence of a species, but this apparent effect could result from a combination of underlying effects of $\mathrm{pH}$ and dissolved oxygen (DO), both of which may be associated with elevation. In a multivariate regression context, there is opportunity for the effect of the different explanatory variables to be considered jointly in approximating the relat onship between the explanatory variables and the probability of fish presence.

However, multiple regression approaches do have significant limitations, especially when applied to encountered or observational data (as opposed to planned or designed data). Planned data are obtained from designed experiments or controlled studies, where all relevant factors are held constant except factors (the "variables") that are the subject of the experiment; these factors are set at specified levels. This is generally not possible for field situations such as lakes in the Adirondacks, where the factors explaining fish presence are numerous and largely uncontrollable.

The limitations of multiple regression approaches arise from a number of sources:

- Model mis-specification. Mis-specification includes two components: the functional form chosen and the explanatory variables included. The first component in this case relates to the fact that the logistic function itself may not represent the true, but unknown, shape of the response to all variables. Probably more limiting is the second component: the fact that many additional variables besides those for which we have detailed information may be important. Examples include the minimum winter temperature, the structure of lower trophic levels (including productivity), and connections between lakes. Some of the "explanatory" power of variables included in our models can be due to their relationships with other potentially causal variables not in the model. This means that caution must be used in interpreting the results to avoid equating the statistical significance of terms selected for inclusion in the model with biological significance or causation.

- Errors-in-variables. Both the response variables (presence of fish) and the explanatory variables may be inaccurately or imprecisely known. Some lakes in which a species of fish were not caught may actually have populations. Therefore, where we discuss presence/absence, we are actually discussing catch/no catch in the ALSC survey. Some of the explanatory variables (e.g., area, elevation, presence of outlets) are well known, while others involve considerable potential error (e.g., estimated inorganic monomeric aluminum, Al) or are known to be unreliable (e.g., stocking information for privatelyowned lakes). The errors-in-variables problem can cause biases in the model coefficients (Reckhow et al. 1987; Fuller 1987). 
- Multicollinearity. When an explanatory variable in a multiple linear regression model is nearly a linear combination of other explanatory variables in a model (i.e., is collinear), the affected parameter estimates in the regression model are unstable and may have large standard errors (Draper and Smith 1981). This arises because of the near singularity of the matrix of explanatory variables. Although significant correlation between two variables implies significant collinearity, nonsignificant correlation between two variables does not necessarily indicate the absence of collinearity, because there may be some linear combination of two or more variables that, taken as a whole, would create a condition of collinearity. We used a statistical technique derived especially for the logistic regression function (Marx and Smith, in press), discussed in more detail below, to identify collections of collinear variables, and we removed a number of variables from the candidate list to avoid the instability in parameter estimates. Such removal of variables, however, creates additional problems of interpretation. This is because the effects of these removed variables, if any, may be incorporated in the coefficients associated with other variables. The importance of alternative approaches to interpretation, such as path analysis, ridge regression, or principal components regression, is therefore increased

The regression models we develop are intended to identify variables that have been selected as being important in predicting the presence or absence of selected fish species (or of any fish species) in various subsets of lakes within the ALSC sample. The models do not prove cause-and-effect relationships between these variables and fish presence. However, we can evaluate the consistency of the relationships identified in these models with existing hypotheses about factors explaining fish presence. In addition, these evaluations may lead to the formulation of additional hypotheses, which could be tested experimentally (e.g., by manipulation) or perhaps statistically (e.g., via examination of additional subsets of the ALSC data set).

\section{A.1.2 Description of Procedures and Methods}

All data base management and statistical analyses were performed using the Statistical Analysis System (SAS®, 1985a, 1985b, and 1985c).

Identification of variables. The first step in applying regression methods was to identify the variables available in the ALSC data base (Kretser et al. 1989) that were potentially important in explaining the presence/absence of brook trout, as discussed in Section 3.1.3 (Table 3.1-3). Six broad categories of variables were defined:

- Acidification response variables

- Baseline habitat suitability variables

- Productivity related variables

- Natural reproduction and access variables

- Anthropogenic contral variables

- Biological variables

Table A-1 lists the explanatory variables considered as candidate variables in analyses for three 
Table A-1 Candidate Explanatory Variables and Summary of Results from Mann-Whitnoy and Contingency Table Analyses to Test for Differences betwen Lakes with Fish Present and Absent

\begin{tabular}{|c|}
\hline Explanatory Varlableb \\
\hline $\begin{array}{l}\text { Acidification Response Varlables } \\
\text { *Field pH } \\
{ }^{\star} \text { Acid Neutralizing Capacity } \\
\text { Total Al } \\
{ }^{\star} \text { Estimated Inorganic Al } \\
\text { Total Al:DOC } \\
\text { Estimated Inorganic Al:DOC } \\
{ }^{\star} \mathrm{Ca} \\
{ }^{\star} \mathrm{Ca}+\mathrm{Mg} \\
\mathrm{Sum} \text { of Base Cations } \\
\mathrm{Na} \\
\text { pCa/pH } \\
{ }^{\star} \text { Dissolved Organic Carbon } \\
\text { *Flushing Rate }\end{array}$ \\
\hline
\end{tabular}

Baseline Habitat Suitability Variables

Minimum DO

Maximum Temperature

*Surnmer Minimum Temperature

Thermal Stratificationd

*Maximum Depth

*Elevation

*Full Bogd

*Bog or Marginal Bogd

* Beaver Influenced

Number of Macrophyte Taxae

Percent Open Water

$\star \star \star(+)$
$\star \star \star(+)$
$\star \star \star(-)$
$\star \star \star(-)$
$\star \star \star(-)$
$\star \star \star(-)$
$\star \star \star(+)$
$\star \star \star(+)$
$\star \star \star(+)$
$\star \star \star(+)$
$\star \star \star(-)$
$\star \star \star(-)$
$\star \star \star x(-)$

$* \star \star(+)$
$\star \star \star(+)$
$\star(-)$
$\star \star \star(-)$
$\star \star \star(-)$
$\star \star \star(-)$
$\star \star \star x(+)$
$\star \star \star(+)$
$\star \star \star(+)$
$\star \star \star(+)$
$\star \star \star(-)$
$\star \star(+)$
$\star \star \star(+)$

$* \star *(+)$

$\star \star \star \star(+)$

$\star \star \star \star(-)$

$\star \star \star *(-)$

$\star \star \star \star *(-)$

$\star \star \star \star(-)$

$\star \star \star(+)$

$\star \star \star \star x(+)$

$\star \star \star \star(+)$

$\star \star \star *(+)$

$\star \star \star \star(-)$

*(-)

NS

NS

NS

$\star \star(-)$

$* \star(+)$

$\star \star \star(+)$

NS

$* \star(-)$

$* \star *(-)$

NS

-...

-..

$* \star \star(+)$

$* \star(-)$

$*(+)$

NS

$* \star(-)$

$* *(-)$

NS

$\star \star \star \star(-)$

$\approx n(-)$

$*(+)$

$\star \star \star \star *)$

$\star \star \star(+)$

$*(+)$

NS

NS

$\star \star \star \star(+)$

$\star \star \star \star(-)$

$\star \star \star \star(-)$

$\star * \star(-)$

NS

$\star \star \star(+)$

$\star \star \star(+)$

Productivity Related Variables

*Total P

Conductivity ( $H^{\prime}$-adjusted)

"Area

* Volume

*Mean Depth

Modified Morphoedaphic Index

${ }^{\star}(-)$

$\star \star \star \star(+)$

NS

$\star \star \star \star(+)$

$\star \star \star *(+)$

$\star \star \star(+)$

NS

Watershed: Lake Area Ratio

* Littoral Area

Shoreline Development Index

NS

$* *(+)$

NS $\star \star \star \star(+)$

$\star \star \star \star(+)$

$\star \star \star *(+)$

$\star(-)$

$\star \star \star \star(+)$

$\star \star \star \star(+)$

$\star \star \star(+)$

$\star * *(+)$
NS

$\star \star \star *(+)$

$\star \star \star \star *(+)$

$\star \star \star \star(+)$

$\star \star \star \star(+)$

$\star \star \star \star(+)$

$\star \star *(+)$

$\star \star \star(+)$

$\star \star \star(+)$

(Continued) 
Table A-1 Continued

\begin{tabular}{|c|c|c|c|}
\hline \multirow[b]{2}{*}{ Explanatory Variableb } & \multicolumn{3}{|c|}{ Response Variables } \\
\hline & Brook Troutc, d & Creek Chubc, d & Fish/No Fishc, d \\
\hline \multicolumn{4}{|l|}{ Natural Reproduction and Access Variables } \\
\hline Lake Typed & NS & $\star \star \star(+)$ & $\star \star \star(+)$ \\
\hline *Number of Inlets & $\star \star(+)$ & $\hbar \star \star(+)$ & $\star \star \star \star(+)$ \\
\hline *Number of Outlets & NS & $\star \star \star(+)$ & $* \star \star(+)$ \\
\hline${ }^{*} \mathrm{SiO}_{2}$ & $\star \star \star(+)$ & $\ldots+$. & $\star \star \star *(+)$ \\
\hline${ }^{\star}$ Blocked Downstream Accesse & $\star \star \star(-)$ & $\star \star \star(-)$ & $\star \star \star(-)$ \\
\hline "Substratee & $* * \star 1+\gamma$ & $\cdots$ & $\star \star \star *(+)$ \\
\hline \multicolumn{4}{|l|}{ Anthropogenic Control Variables } \\
\hline *Distance to Nearest Road & NS & NS & $\star \star \star(-)$ \\
\hline${ }^{\star}$ Road Type & NS & $*(-)$ & NS \\
\hline *Brook Trout Stockede & $\star \star \star(+)$ & $\ldots$ & $\ldots$ \\
\hline Stocking of Competitorse & $\star \star(+)$ & ... & $\cdots$ \\
\hline *Ownershipe & $\ldots$ & NS & $\star \star \star *(+)$ \\
\hline Reclamatione & $\ldots$ & NS & $\ldots$ \\
\hline Reclamation within last 10 yearse & $\cdots$ & NS & -.. \\
\hline Stocking of Any Speciese & $\cdots$ & $\star \star \star \star(+)$ & $\star \star \star *(+)$ \\
\hline \multicolumn{4}{|l|}{ Biological Variables } \\
\hline *Presence of Competitorse & $\star \star(-)$ & $\star \star *(+)$ & $\ldots$ \\
\hline Presence of Predatorse & $\ldots$ & $\star \star \star *(-)$ & $-\cdots$ \\
\hline *Presence of Associatese & $\star \star \star \star(+)$ & $* \star \star(+)$ & -.. \\
\hline
\end{tabular}

a Sign of correlation noted in parentheses

b See Tables A-2 and A-3 and discussion in text below on transformations.

6 Definition of symbols used to denote the level of significance of the test: * * : $p<0.01$ * $^{*}: 0.01<p<0.05$;

": $0.05<p<0.10 ;$ NS: $p>0.10$. A ... indicates that the variable is not applicable.

d To interpret the meaning of the signs of correlation, it is necessary to know the definitions of these categorical varlables. They are defined as follows: 1 = yes, 0 = no, except for lake type where $1=$ drainage, $0=$ seepage; road type where $0=4$-wheel drive and $1=2$-wheel drive road; and ownership, where $1=$ private and $0=$ public or mixed.

- Treaxed as a categorical variable; sign based on median values for absent versus present categories.

* At the second ALSC workshop, 24-25 May 1989, Albany, NY, this variable was judged likely to be among the most important variables explaining brook trout status.

response variables: brook trout, creek chub, and fish versus no fish. Variables with dashes entered under one or more of the respon: variables were not considered relevant as predictors for those analyses. Tables A-2 and A-3 provide a more precise definition of these variables, including some additional variables: subsetting variables, the response variables themselves, and the root variables for those variables that were transformed (any variable beginning with a T in Table A-2 represents a transformed version of the variable). Transformations are discussed further below. In these two 
Table A-2 List of Candidate Explanatory Variables, with Results from Mann-Whitney and Contingency Table Analyses to Test for Differences in Explanatory Variable Distributions for Response Variable Categories (Present versus Absent).

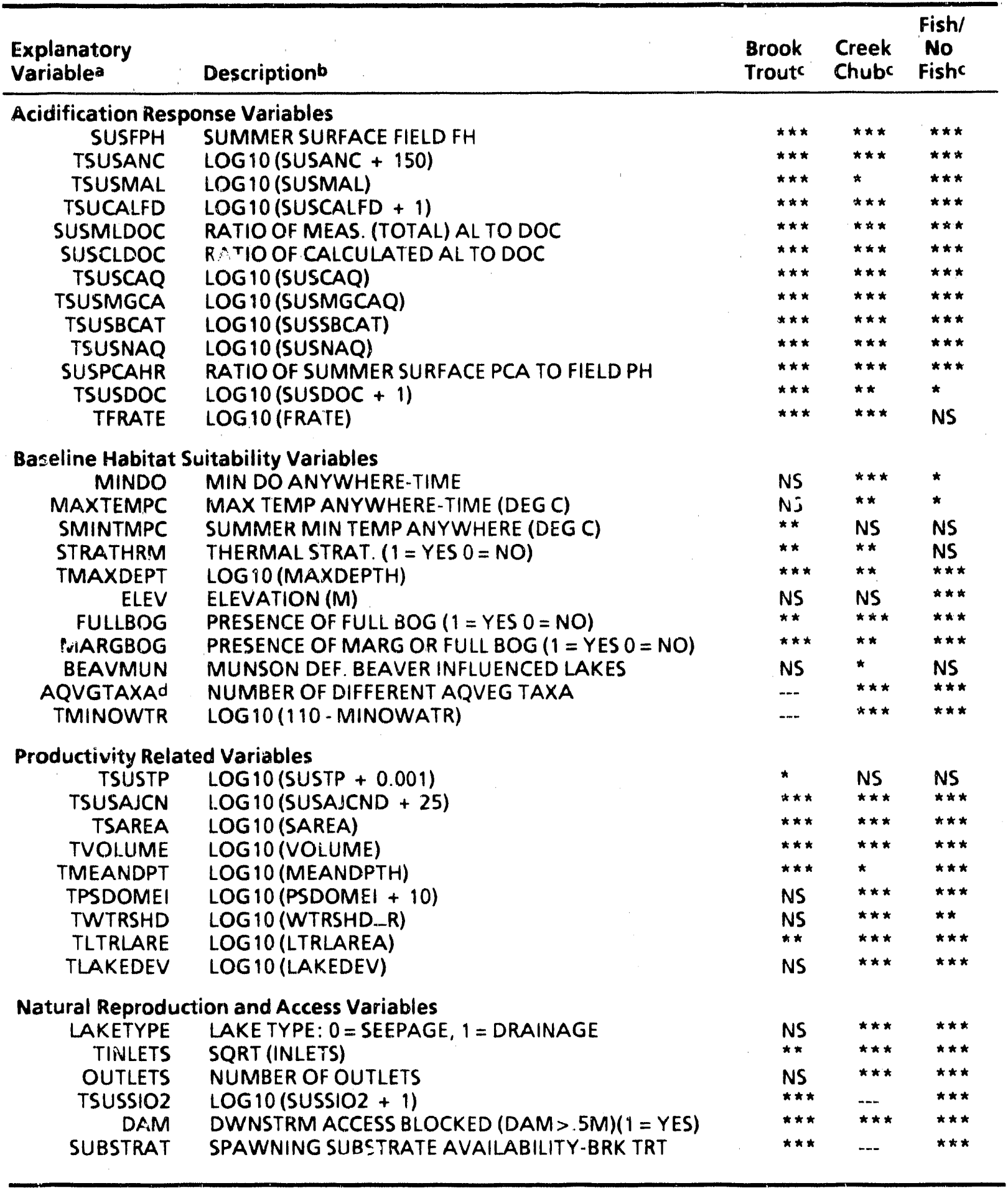


Table A-2 Continued

\begin{tabular}{|c|c|c|c|c|}
\hline $\begin{array}{l}\text { Explanatory } \\
\text { Variablea }\end{array}$ & Descriptionb & $\begin{array}{l}\text { Brook } \\
\text { Troutc }\end{array}$ & $\begin{array}{l}\text { Creek } \\
\text { Chubc }\end{array}$ & $\begin{array}{l}\text { Fish/ } \\
\text { No } \\
\text { Fishe }\end{array}$ \\
\hline \multicolumn{5}{|c|}{ Anthropogenic Control Variables } \\
\hline TDISTANC & LOG 10 (DISTANCE + 1) & NS & NS & $\star \star \star$ \\
\hline ROADTYPE & 2 WHEEL $(1=$ YES $0=$ NO $)$ & NS & * & NS \\
\hline STK_ST & BROOK TROUTS SOCKED $<5 Y(1=$ YES $0=N O)$ & $\star \star \star$ & -.. & ... \\
\hline STK_XXST & STOCKING OF COMPETITORS OR CONTRAINDCTRS & ** & -.. & -- \\
\hline PRIVATE & PRIVATELY OWNED $(1=$ YES $0=$ NO $)$ & ... & NS & $\star \star \star$ \\
\hline OLDRECL & 1 IF EVER RECLAIMED & -.. & NS & $-\ldots$ \\
\hline RCNTRECL & 1 IF RECLAIMED WITHIN 10 YEARS & ... & NS & ... \\
\hline STOCK5 & STOCKING ANY SPECIES $<5$ YR $(1=$ YES $0=N O)$ & $\cdots$ & $\star \star \star$ & $\star \star \star$ \\
\hline \multicolumn{5}{|c|}{ Biological Variables } \\
\hline ANTIST & PRESENCE OF BT COMPETITORS $(1=$ YES $0=$ NO $)$ & $\star \star$ & --- & $-\ldots$ \\
\hline PROST & PRESENCE OF BT ASSOCIATES $(1=$ YES $0=$ NO $)$ & $\star \star \star$ & ... & .... \\
\hline ANTICC & PRESENCE OF CRK CHUB COMPETITORS $(1=$ YES $)$ & ..- & $\star \star \star$ & ... \\
\hline PREDCC & PRESENCE OF CREEK CHUB PREDATORS $(1=$ YES $)$ & $\ldots$ & $\star \star \star$ & $\ldots$ \\
\hline PROCC & PRESENCE OF CRK CHUB ASSOCIATES $(1=$ YES $)$ & $\cdots$ & $\star \star \star$ &.-- \\
\hline
\end{tabular}

a See Table A-1 for English names and directions of relationships. Table A-3 has additional definitions.

b See Table A-3 for further definition of the transformed variables (those beginning with " $T$ ").

"Definition of symbols used to denote the level of significance of the test: ${ }^{\star \star *}: p<0.01 ; * *: 0.01<p<0.05 ;$ *: $0.05<p<0.10 ;$ NS: $p>0.10$. A -...indicates that the variable is not applicable.

d Some of the expected numbers of aquatic vegetation taxa (AQVGTAXA) had small values. Results were confirmed by combining adjacent categories as needed.

tables, the abbreviation ST (for speckled trout) is frequently used in variable names specifically related to brook trout; the abbreviation BT has in past work been used tc denote brown trout.

Development of data base. While the original ALSC data base is structured with multiple observations per lake for many variables, our approach required a data base with one observation per lake. In addition, some variables needed to be derived from information in the data base (e.g., number of aquatic vegetation taxa and blockage of any possible downstream access to the lake). Therefore, we developed an integrated data base containing variables needed for this work as well as for other biological analyses of the ALSC data. We incorporated flags defined by Ron Munson (Section 2.1.4) for some chemical variables. Considerable quality assurance and quality control (QAVC) were performed on the integrated data base, including cross-checking results for most variables with the ALSC. In addition to this project, the integrated data base will be used for the National Acid Precipitation Assessment Program (NAPAP) Assessment (Regional MAGIC model 
Table A-3 Definitions of Subsetting Variables, Response Variables, and Root Explanatory Variables Transformed before Analysisa (Present versus Absent)

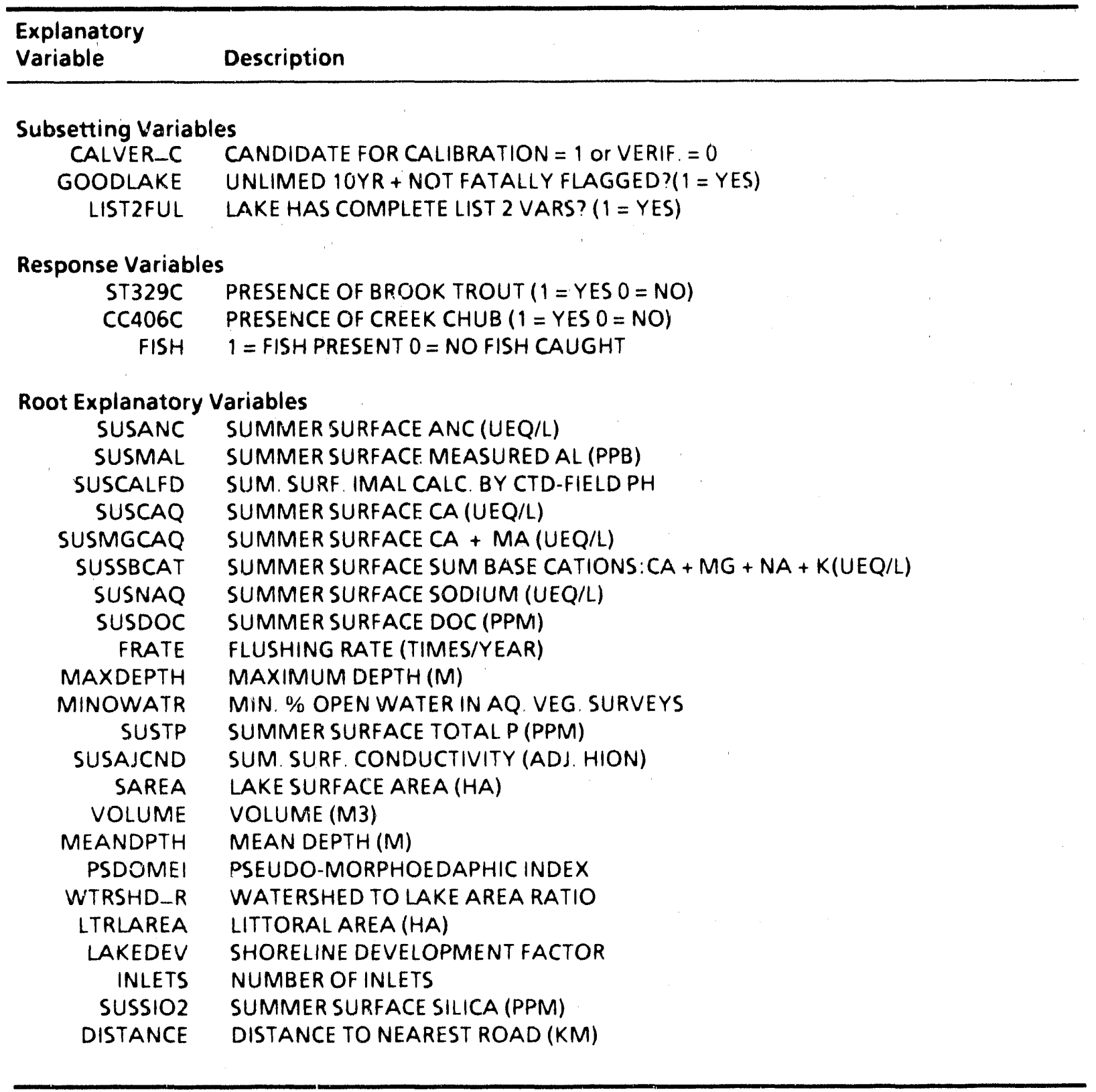

a See rable A-1

calibration and economic analysis), in the EPA Critical Loads project, and by the U. S. Department of Energy

Adaptation of computer codes. Computer codes, written in the Interactive Matrix Language (IML) of the Statistical Analysis System (SAS ${ }^{\circledR} 1985 \mathrm{C}$ ), existed to evaluate collinearity and to identify influential observations (Marx and Smith, in press; Davis 1988). However, because of the size of the ALSC data 
set and the number of variables we wished to examine, these codes required excessive computer mainframe memory for our work. We modified the codes to be able to handle these kinds of large problems.

Transformation. We examined the marginal distributions of the explanatory variables separately for both values of the dependent variable (presence and absence) before using the logistic model to describe the probability of fish presence as a function of the collection of explanatory variables. The set of all ALSC lakes not limed within 10 years of the ALSC survey and not having suspect values of any candidate variables was used. The purpose of this examination was to determine whether these marginal distributions were highly skewed and if the variation in the two groups of lakes (lakes with the species present versus those with the species absent) was significantly different. If a distribution was found to be highly skewed, a form of transformation (usually log) was used so that the transformed marginal distribution would be reasonably symmetric over the range of the explanatory variable. This attempt to achieve a symmetric distribution for the marginal distribution was also generaliy found to improve the homogeneity of variance in the two groups of lakes. In addition, these two properties should help to reduce the effect of potentially influential observations with extreme values of the explanatory variables, and they should help to justify the omission of most interaction terms in our models. Our considerations of transformations were limited for the most part to the following form:

$$
\log _{10}(x+d)
$$

Where:

$x=$ is the original observed explanatory variable

$d=a$ constant chosen to keep from having to take the log of a number $<0$. In a few cases, even when $x>0$, we found that adding a nonzero value to $x$ before transforming helped to improve the symmetry of the marginal distributions.

Pairwise associations. To evaluate whether differences in the values of the explanatory variables existed between the two classifications (fish presentabsent), one of two tests was used on each explanatory variable (listed in Table A-1) in the set of all calibration lakes not limed within 10 years of the ALSC survey and not containing suspect values of any candidate variables. The nonparametric Mann-Whitney test was used for the continuous explanatory variables to test for significant differences in the distributions. A contingency table analysis was used for the categorical variables (e.g., thermal stratification) to test for homogeneity in the distribution of the two classifications. The results are presented in Table A-1. Although this analysis considers each variable separately and ignores the potential effect of multiple predictors, the results are useful in identifying variables that may predict the presence or absence of the fish species. 
In addition to this analysis, notched box-and-whisker plots were prepared that demonstrate the pattern of distribution for each continuous explanatory variable, by species; presence/absence is evaluated separately for the calibration and the verification data sets. Data from the most extensive lake groups possible (Lake Group 4 for brook trout, and Lake Group 5 for creek chub and for fish versus no fish; see Table A-4) were used in these figures. Transformed versions of those variables identified as needing a transformation in the analysis were plotted. The data for seven of the variables are presented in Figures A-1 through A-7. For most variables, three desirable features were noted in the entire collection of figures:

1. There is a basic similarity of the distributions (by fish species) for the calibration subsets in comparison with the verification subsets.

2. A similarity of dispersion exists between the presence/absence categories for most explanatory variables. For both the continuous and the discrete explanatory variables, the ratio of maximum variance to minimum variance was used to evaluate the homogeneity of variance of the untransformed and transformed variables. Although not shown here, this statistic showed an improvement in the homogeneity of variance for the transformed variables when compared to the untransformed variables for most variables. In particular, a number of variables with extreme values for this ratio before transformation showed homogeneous variance after transformation.

3. For most of the transformed variables, the distribution of the transformed variable was reasonably symmetric.

Symmetry and similarity of dispersion are desirable properties in the analysis, particularly for the firstorder models used in our work. Pronounced univariate differences in location between absence and presence (e.g., as evident for field $\mathrm{pH}$ and silica, $\mathrm{SiO}_{2}$ ) would lead to a greater expectation of that explanatory variable being an important predictor in the models than small or nonexistent differences (e.g., DOC). However, it is important to remember that these are univariate relationships, while the models consider multivariate relationships. Therefore, results from the univariate patterns are far from predictable.

Pairwise correlations among the continuous explanatory variables were calculated as a preliminary investigation of the patterns of association among the candidate explanatory variables. Beginning with the initial group of calibration lakes for brook trout (Lake Group 1 in Table A-4), the nonparametric Spearman correlation cuefficient was calculated for two lake subsets: (1) where the fish species were present and (2) where the fish were absent. If two variables were found to be highly correlated from this examination, we would expect these to be potential candidates for identification as collinear in the collinearity diagnostic steps. However, remember that this pairwise correlation is only one form of collinearity that can exist 
Table A-4 Definition of Lake Groups and Variable Sets Used in Building Models of Fish Presence/Absence in Adirondack Lakes

\section{LAKE GROUPS}

\section{General conventions and definitions}

$H, L$ : When $H$ is used after a lake group number $($ e.g., $1 H)$, it denotes that only high-pH lakes $(\mathrm{pH}>6)$ are included in the data set. These are "baseline" models. Similarly, $\mathrm{L}$ denotes that only low-pH lakes $(\mathrm{pH} \leq 6)$ are included in the data set. A few such models were fit to examine the effect on the coefficient of $\mathrm{pH}$ of including only lakes where the role of $\mathrm{pH}$ might be important

"Qualified": Lakes with non-suspect chemistry measurements that have not been limed within 10 years of the ALSC survey date. In addition, one third of all lakes have been reserved for verification purposes. Therefore, for calibration purposes, the qualified data excluded these lakes as well. A final criterion is that qualified lakes must have complete (i.e., nonmissing) observations for all candidate variables being examined. For this reason, the number of qualified lakes may vary from analysis to analysis.

\section{Specific lake groups}

1 Qualified nonprivately owned lakes. Stocking iniormation is considered reliable for these lakes, and stocking information is included in the variable list.

2 Qualified nonstocked (within 5 years) nonprivately owned lakes. Stocking information is not relevant to predicting brook trout presence/absence in these lakes.

3 Qualified nonstocked (within 5 years) nonprivately owned non-fully bog lakes. Stocking information is not relevant to predicting brook trout presence/absence in these lakes.

4 All qualified lakes. Privately owned lakes and bog lakes are included. Stocking information is considered sufficiently unreliable for these lakes that it is not included in the list of candidate predictor variables.

5 Like 4, except bog lakes are excluded.

6 Like 5, except that only lakes in watersheds 04 (Oswegatchie - Black) and 07 (Mohawk Hudson) are included.

7 Like 4, except that only lakes in watersheds 02 (Lake Champlain) and 05 (Upper Hudson) are included. 
Table A-4 Continued

\section{VARIABLE SETS}

\section{Basic definition}

$B 1$ versus $B$ 0: Each variable set identifier begins with either $B 1$ or $B 0$. $B 1$ indicates that biological predictors (presence of other species associated with, or competing with, brook trout; see Table A-1) are included in the list of candidate variables. $\mathrm{BO}$ indicates that the biological variables are excluded.

(S) or (F): $\quad$ The (F) indicates a forced fit. A model was previously selected for the corresponding variable set fit to the lake group with the full range of $\mathrm{pH}$ values included. This specified ("forced") model was fit to the data from only the low $\mathrm{pH}$ lakes $(\mathrm{pH} \leq 6)$, to compare $\mathrm{pH}$ coefficients. The (S) indicates that stepwise selection was applied to the previously selected model, also to compare $\mathrm{pH}$ coefficients.

\section{Modifiers}

In many cases, the variable sets are modified for specific purposes. Letters placed after the basic definitions indicate what modification is being examined.

A

Denotes an alternative set of variables that includes one or more combined variables (negative log of $\mathrm{Ca}: \mathrm{pH}$, measured total $\mathrm{Al}: \mathrm{DOC}$, and calculated inorganic $A l: D O C$ ). When these variables are included in the list of candidate variables for brook trout, two normally included variables ( $\mathrm{pH}$ and measured $\mathrm{Al}$ ) are deleted due to collinearity. For creek chub, $\mathrm{pCa}$ : $\mathrm{pH}$ was already retained in the basic set of variables (Table A-6); due to collinearity, however, only one of the other combined variables could be added (measured total Al:DOC was chosen). For fish versus no fish, $\mathrm{pCa}$ : $\mathrm{pH}$ was not added; again, due to collinearity, measured total Al:DOC was chosen over calculated inorganic Al:DOC for addition to the list of candidate variables.

B

Denotes a different alternative set of variables, in which eight variables which are unreliable for some lakes are eliminated from the list of candidate variables. These variables are minimum DO, maximum temperature, summer minimum temperature, number of macrophyte taxa, percent open water, substrate, distance to nearest road, and road types.

$E$

Denotes a restricted list of variables in the ALSC data base. Only variables that are also available in the EPA's Direct/Delayed Response Project (DDRP) lakes are included. Most of these variables are also available in the EPA's Eastern Lake Survey - Phase 1 (ELS-1) data base.

ENA Like $E$ above, but further restricted to non-acidification response (NA) variables. Variables in variable group 1 (Acidification Response Variables - Table A-1) which might be expected to change in response to changed acidic deposition are removed. Only sodium (Na) and flushing rate are retained from this group. 


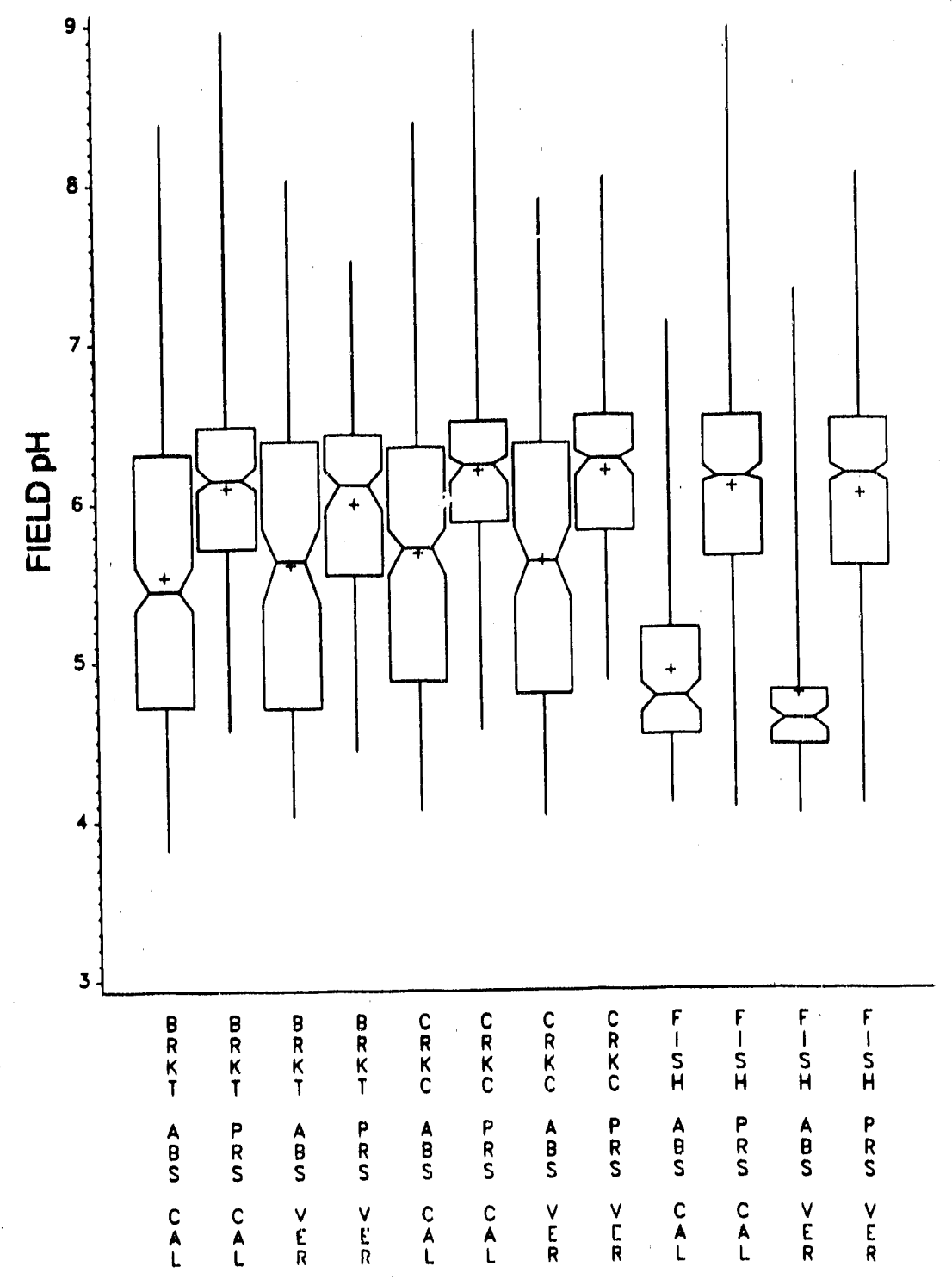

\section{LEGEND}

ABS absent CRKC creek chub

BRKT brook trout PRS present

CAL calibrationsubset VER verification subset

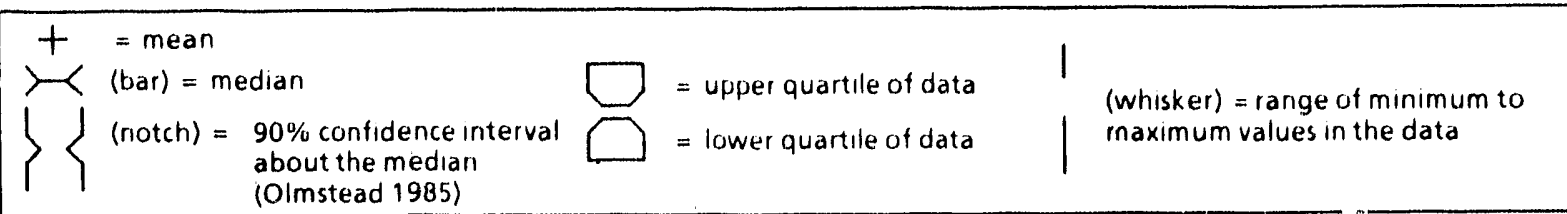

Figure A-1 Notched box-and-whisker plots of field pH for brook trout, creek chub, and $\mathrm{fish} / \mathrm{no}$ fish for presence/absence lakes within the calibration and the verification lake subsets. 

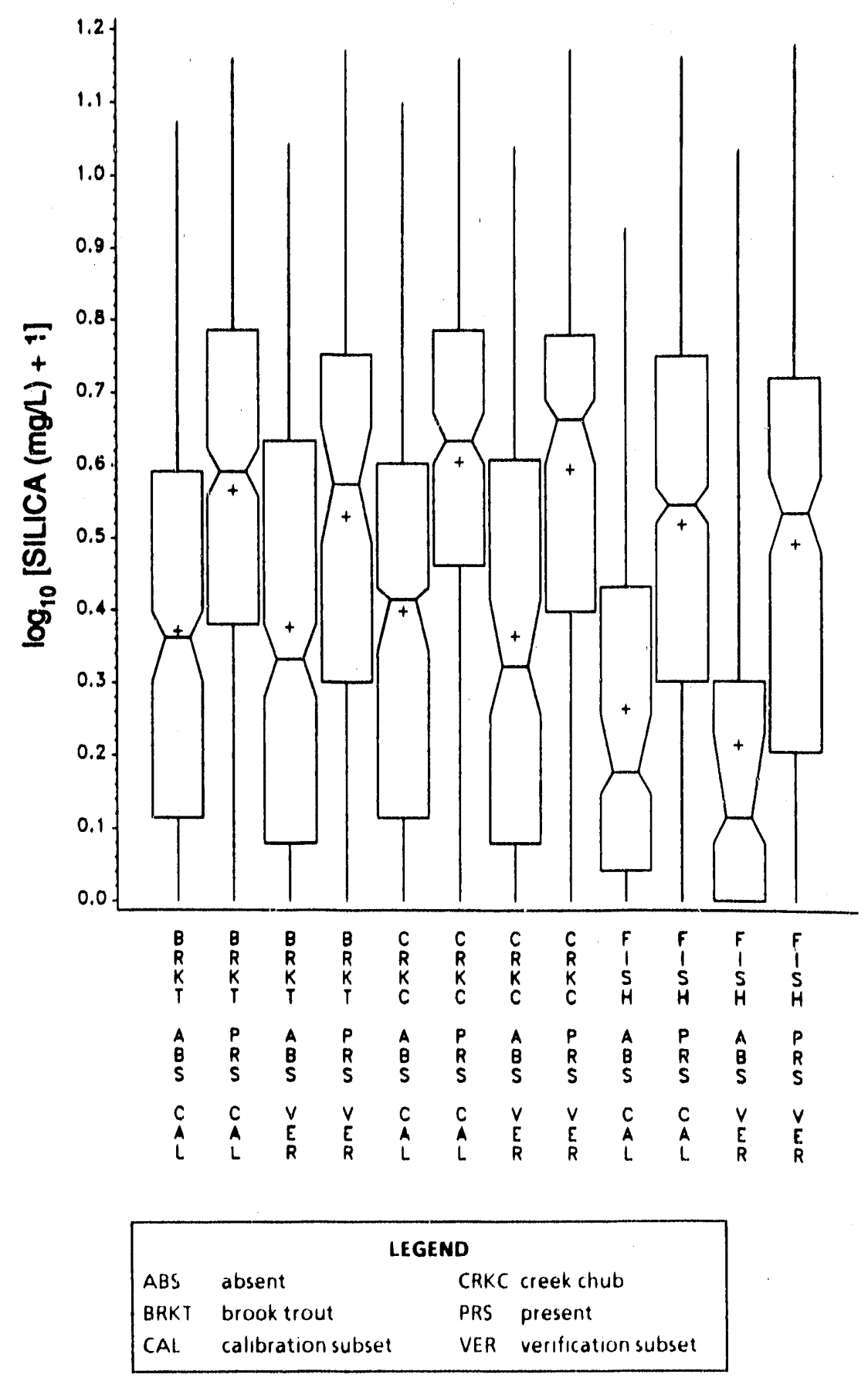

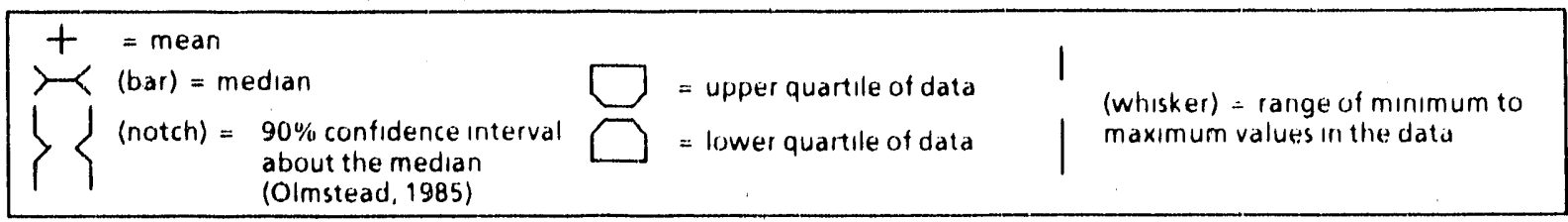

Figure A-2 Notched box-and-whisker plots of silica (in transformed form) for brook trout, creek chub, and fish/no fish, for presence/absence lakes within the calibration and the verification lake subsets. 


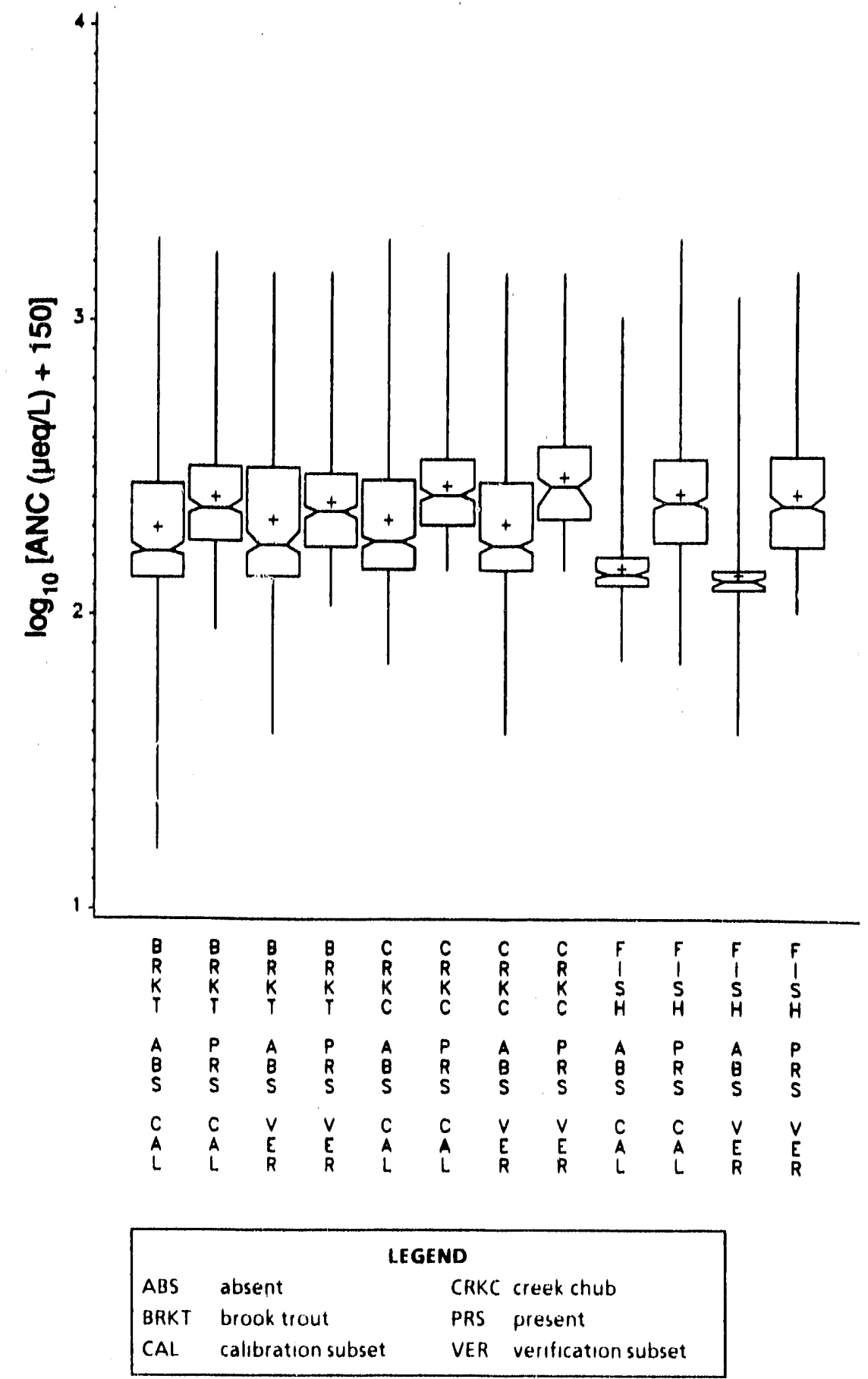

Figure A-3 Notched box-and-whisker plots of acid neutralizing capacity (ANC, in transformed form) for brook trout, creek chub, and fish/no fish, for presence/absence lakes within the calibration and the verification lake subsets. 

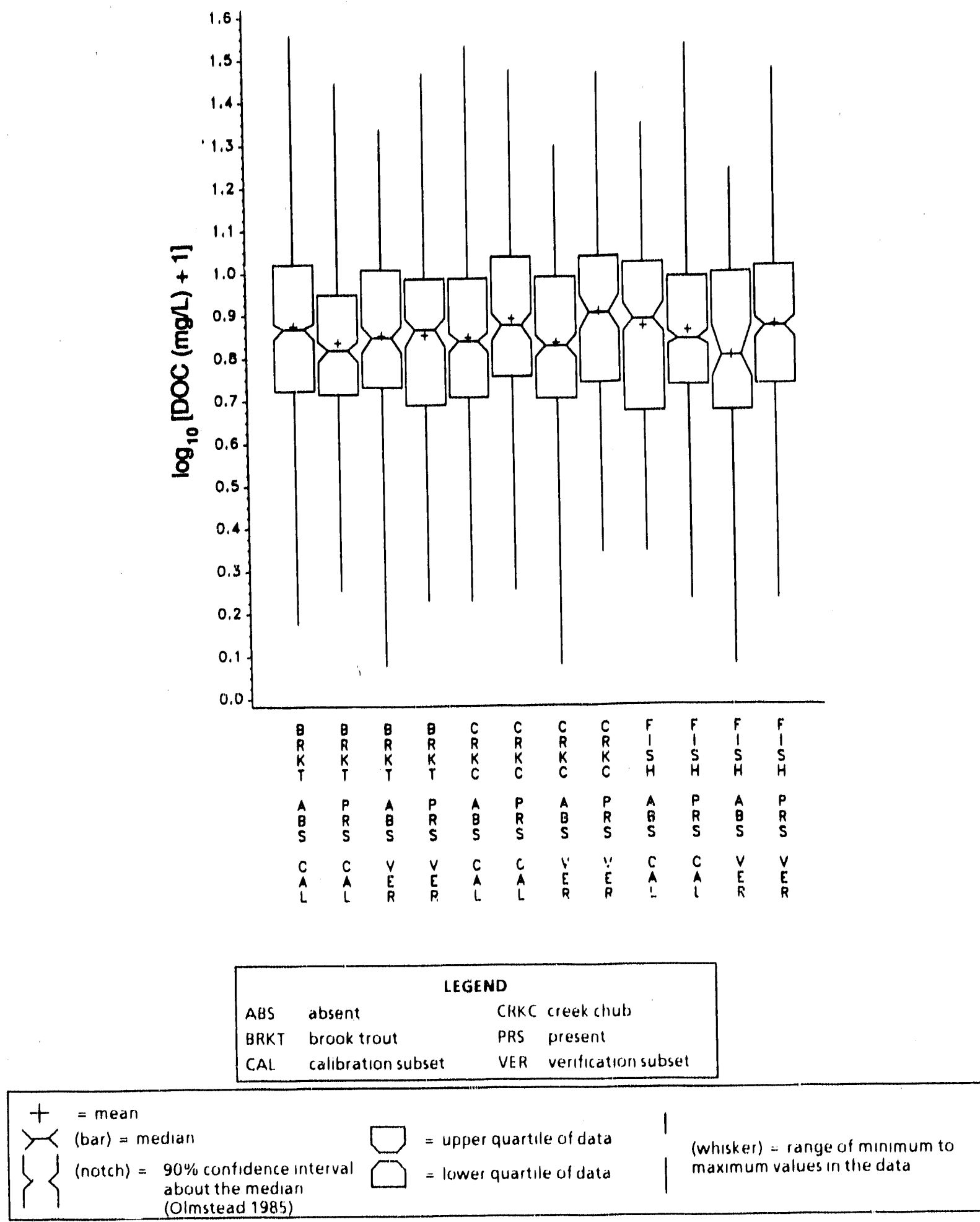

Figure A-4 Notched box-and-whisker plots of dissolved organic carbon (DOC, in transformed form) for brook trout, creek chub, and fish/no fish, for presence/absence lakes within the calibration and the verification lake subsets. 

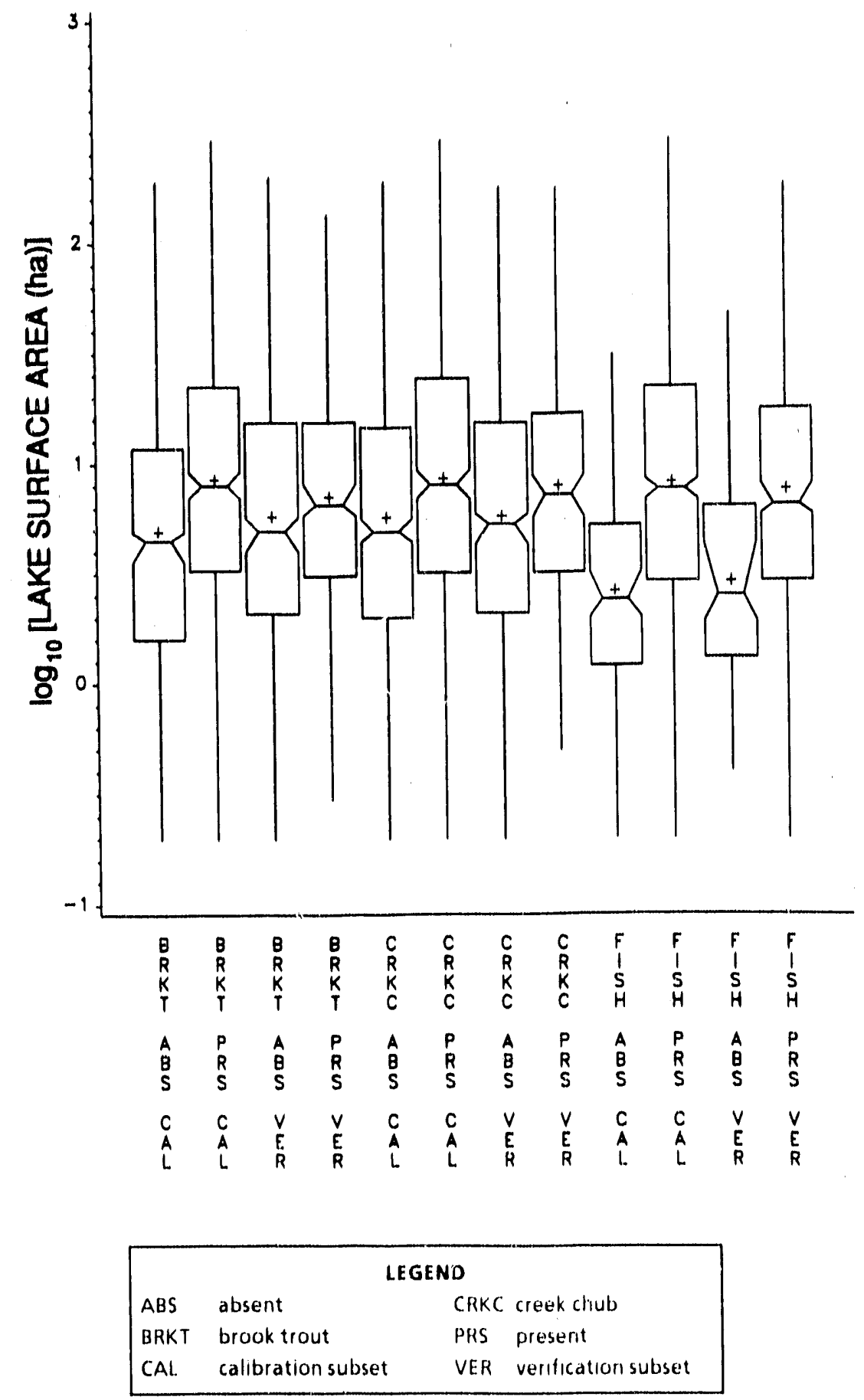

$\left\{\begin{array}{l}\text { (bar) = median } \\ \text { (notch) } \begin{array}{l}\text { 90\% confidence interval } \\ \text { about the median } \\ \text { (Olmstead 1985) }\end{array}\end{array} \quad \begin{array}{l}\text { = upper quartile of data } \\ \text { =lower quartile of data }\end{array}\right.$

Figura A-5 Notched box-and-whisker plots of lake surface area (in transformed form) for brook trout, creek chub, and fish/no fish, for presence/absence lakes within the calibration and the verification lake subsets. 


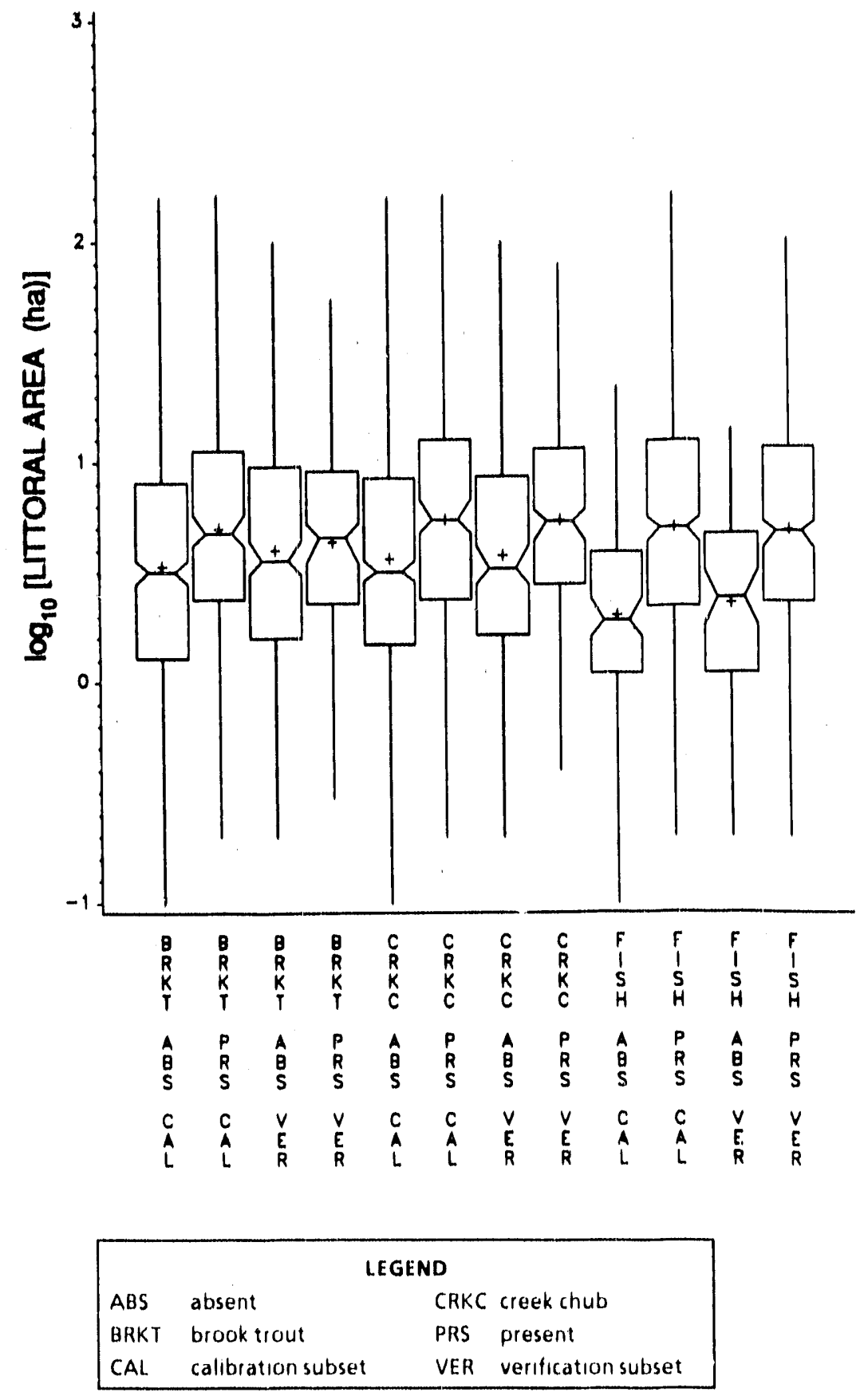

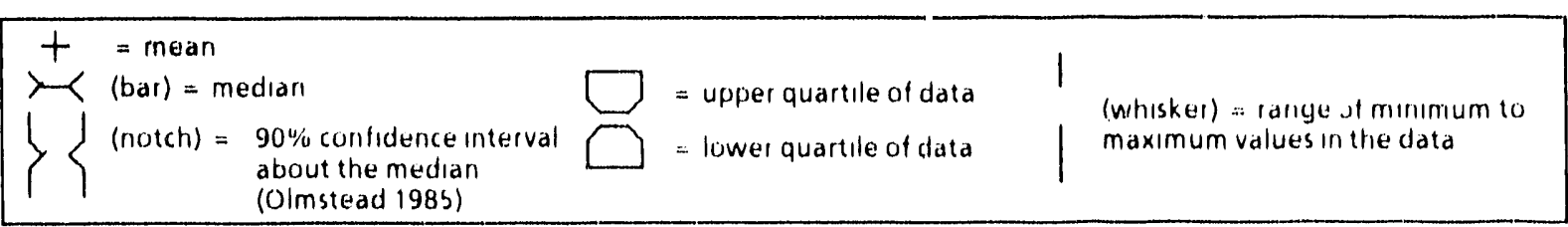

Figure A-6 Notched box-and-whisker plots of littoral area (in transformed form) for brook trout, creek chub, and fish/no fish, for presence/absence lakes withi:. :he calibration and the verification lake subsets. 


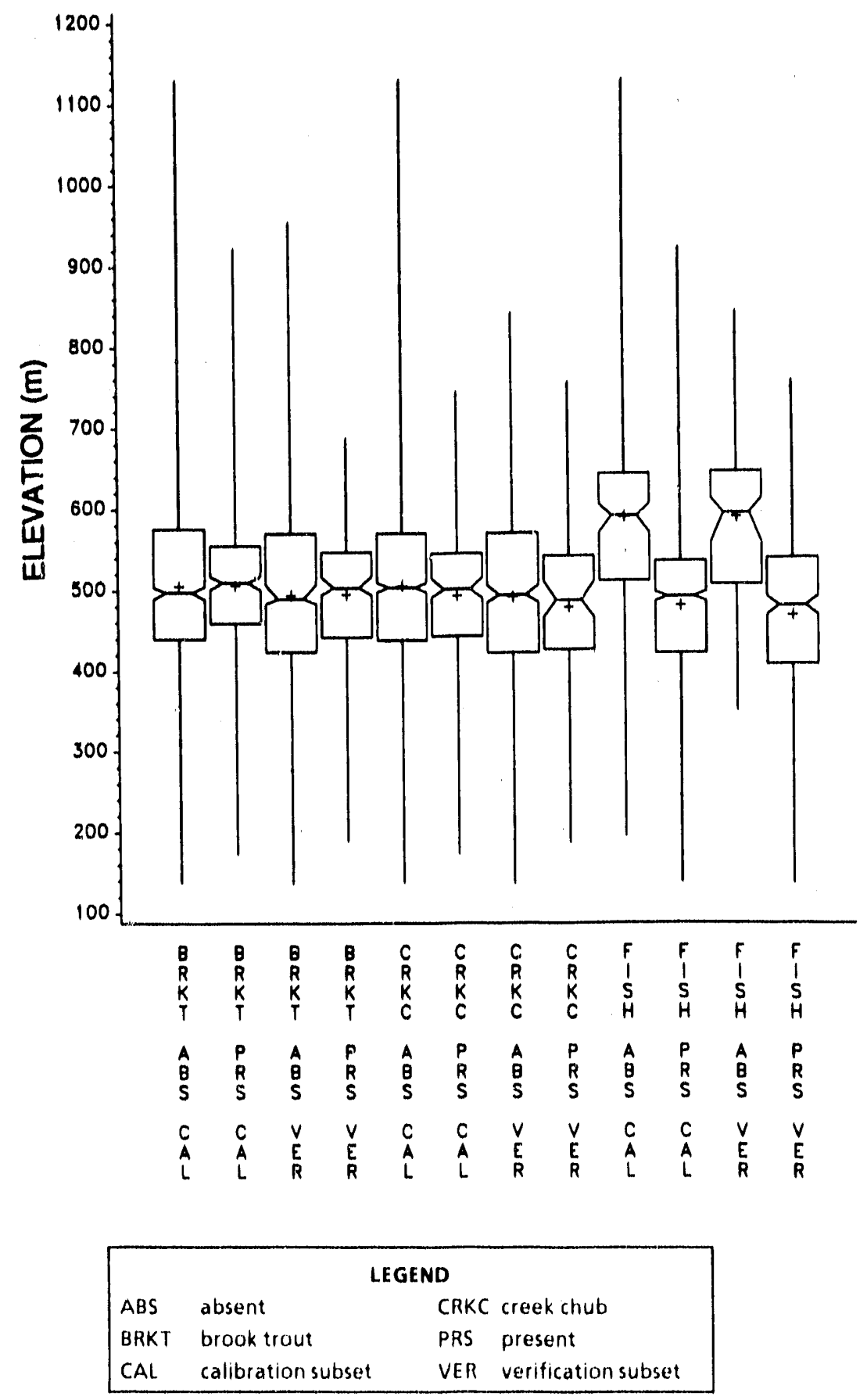

Figure A-7 Notched box-and-whisker plots of lake elevation (in meters) for brook trout, creek chub, and fish/no fish, for presence/absence lakes within the calibration and the verification lake subsets. 
Collinearity The problem of multicollinearity is discussed above (Section A.1.1). The set of lakes chosen as being of main interest for each species (Lake Group 1 for brook trout, Lake Group 5 for creek chub and fish versus no fish; see Table A-4) was used for the main collinearity analysi' Before performing the collinearity analysis, each variable was shifted by subtracting the mean value over the data set being used to eliminate spurious collinearities of the explanatory variables with the intercept. A computer program (Marx and Smith, in press), adapted as explained above, was applied repeatedly to the shifted data. For each run, the collinearity diagnostics were examined. If the largest condition index (CI) was $>30$, a variable was removed from the list of candidate variables iTable A-1). First, the set of parameters corresponding to particular variables (or, rarely, the intercept) having a variance-decomposition proportion (VP) $>0.5$ was identified Next, one of the variables was selected for removal from the list of candidate variables, according to criteria described below. This procedure was followed iteratively until the largest $\mathrm{Cl}$ no longer exceeded 30. Tables A-5 through A-7 show the collinear and eliminated variables for brook trout, creek chub, and fish versus no fish, respectively.

In approximate order of importance, we used the following general criteria to select variables for elimination:

- The intercept was always kept.

- Potentially mechanistic variables were preferred over surrogate variables for retention.

- If the collection contained some related variables and some unrelated ("isolated") variables, one of the related variables was preferred for elimination.

- We attempted to retain at least one variable representing each of the variables $\mathrm{pH}$, aluminum (Al). and $\mathrm{Ca}$

- Variables expected to be most important in explaining brook trout status, as determined at the second ALSC workshop, 24-25 May 1989, Albany, NY, are marked with an asterisk in Table A-1. These were preferred for retention.

- Arbitrarily, variables representing beaver, fishing pressure, or bogs or organic acidity were preferred for retention because these are elements of particular interest, in part due to previous arialyses (Hunsaker et al. 1986).

- Variables considered to be measured or estimated more reliably than other variables were preferred for retention

- Variables available in the EPA's National Surface Water Survey (NSWS) were preferred for retention, as this increased the possibility that the model could be used in other areas. 
Table A-5 Candidate Variables Involved in Multicollinearities and Variables Eliminated from the Candidate List ( $\left.{ }^{*}\right)$ at Each Step of the Initial Collinearity Analysis for Brook Trout

\begin{tabular}{|c|c|c|c|}
\hline Step & $\begin{array}{c}\text { Number } \\
\text { of } \\
\text { Variables }\end{array}$ & $\begin{array}{l}\text { Maximum } \\
\text { Condition } \\
\text { Number }\end{array}$ & Variables Involved in Multicollinearity \\
\hline 1 & 41 & 280.1 & Volume*, area, mean depth \\
\hline 2 & 40 & 69.58 & $\mathrm{Ca}+\mathrm{Mg}^{*}$, sum of base cations \\
\hline 3 & 39 & 65.49 & Full bog ${ }^{*}$, interrspt \\
\hline 4 & 38 & 48.25 & $\begin{array}{l}\text { Modified morphoedaphic index*, area, mean depth, } \\
\text { littoral area }\end{array}$ \\
\hline 5 & 37 & 43.67 & $\mathrm{pCa} / \mathrm{pH}^{*}$, field $\mathrm{pH}, \mathrm{Ca}$ \\
\hline 6 & 36 & 40.08 & $\mathrm{Na}^{*}, \mathrm{Ca}$, sum of base cations \\
\hline 7 & 35 & 29.95 & Area, littoral area \\
\hline
\end{tabular}

Table A-6 Candidate Variables Involved in Multicollinearities and Variables Eliminated from the Candidate List (*) at Each Step of the Initial Collinearity Analysis for Creek Chub

\begin{tabular}{|c|c|c|c|}
\hline Step & $\begin{array}{c}\text { Number } \\
\text { of } \\
\text { Variables }\end{array}$ & $\begin{array}{l}\text { Maximum } \\
\text { Condition } \\
\text { Number }\end{array}$ & Variables Involved in Multicollinearity \\
\hline 1 & 43 & 302.6 & Volume*, area, mean depth \\
\hline 2 & 42 & 91.20 & Full bog ${ }^{*}$, intercept \\
\hline 3 & 41 & 49.95 & $\mathrm{Ca}+\mathrm{Mg}^{*}$, sum of base cations \\
\hline 4 & 40 & 38.71 & $\begin{array}{l}\text { Modified morphoedaphic index }{ }^{*} \text {, area, mean depth, } \\
\text { littoral area, adjusted conductivity }\end{array}$ \\
\hline 5 & 39 & 31.88 & Sum of base cations", $\mathrm{Ca}$ \\
\hline 6 & 38 & 28.00 & $\mathrm{pCa} / \mathrm{pH}$, field $\mathrm{pH}, \mathrm{Ca}$ \\
\hline
\end{tabular}

- Variables were preferred for retention if eliminating them would completely remove a constituent from representation. For example, the sum of base cations would be preferred for retention over the sum of $\mathrm{Ca}+$ magnesium $(\mathrm{Mg})$ because if the sum of base cations were eliminated, Na would no longer be represented among the candidate variables.

- Less-derived variables were preferred for retertion over more-derived variables. For example, lake area and mean depth would be preferred for retention over lake volume, which is derived from them.

- Continuous variables were preferred over discrete variables.

- Variables having a significant bivariate association with the response variable (i.e., those whose values differed significantly between the presence and the absence classes) were preferred for retention over those not significantly associated (Table A-1). 
- If the criteria listed above did not identify a variable to eliminate, then a larger VP value, or a larger variance inflation factor, could be used to eliminate a variable.

Model building. The overall data set of 1,469 lakes was divided into two parts: two thirds ( 979 lakes) for calibration, and one third (490 lakes) for verification (see below). From the 979 calibration lakes, lakes limed within 10 years and lakes containing candidate explanatory variables associated with flags indicating a suspicious value were set aside. Next, for each response variable (e.g., presence/absence of brook trout), lakes lacking a complete set of candidate explanatory variables were set aside, and a data set of main interest was chosen. For brook trout, this data set of main interest, designated "Lake Group 1" (see Table A-4 and Section A.1.3 below for more details) consisted of nonprivate lakes (those for which stocking information is considered reasonably reliable).

The main interpretation was based on the collection of noncollinear variables, using the stepwise selection procedure within PROC LOGIST (Harrell 1986) of SAS ${ }^{\circledR}$ (SAS® 1985a). Stepwise selection was used on the full list of candidate explanatory variables (i.e., including the variables eliminated as a result of collinearity) to check the effect of eliminating variables in the collinearity examination. A further check involved using the backward seiection option on the noncollinear variables.

If the selected models included the biological explanatory variables, additional models were developed with these variables excluded from the candidates. The biological explanatory variables for brook trout (i.e., presence of associates; presence of competitors) were always selected. In addition, different groups of lakes were defined for additional model building. For brook trout,

Table A-7 Candidate Variables Involved in Multicollinearities and Variables Eliminated from the Candidate List (*) at Each Step of the Initial Collinearity Analysis for Fish/No Fish

\begin{tabular}{|c|c|c|c|}
\hline Step & $\begin{array}{c}\text { Number } \\
\text { of } \\
\text { Variables }\end{array}$ & $\begin{array}{c}\text { Maximum } \\
\text { Condition } \\
\text { Number }\end{array}$ & Variables Involved in Multicollinearity \\
\hline 1 & 40 & 268.9 & Volume", area, mean depth \\
\hline 2 & 39 & 96.48 & Full bog*, intercept \\
\hline 3 & 38 & 65.75 & $\mathrm{Mg}+\overline{C a}^{*}, \mathrm{Ca}$ \\
\hline 4 & 37 & 52.70 & $\begin{array}{l}\text { Watershed:lake area ratio*, mean depth, flushing } \\
\text { rate }\end{array}$ \\
\hline 5 & 36 & 46.96 & $\begin{array}{l}\text { Modified morphoedaphic index }{ }^{*} \text {, conductivity } \\
(H+\text {-adjusted), area, mean depth, littoral area }\end{array}$ \\
\hline 6 & 35 & 40.58 & Sum of base cations", Ca \\
\hline 7 & 34 & 35.72 & $\mathrm{pCa} / \mathrm{pH}^{*}$, field $\mathrm{pH}, \mathrm{Ca}$ \\
\hline 8 & 33 & 28.60 & Area, littoral area \\
\hline
\end{tabular}


these groups involved excluding stocked lakes, excluding bog lakes, and including all possible lakes. Stocked lakes were eliminated to focus on lakes where fish presence was natural. However, lakes connected to stocked lakes (i.e., where stocked fish might have access) could not be excluded because of lack of information. For some of these groups, the collection of candidate variables was also modified as appropriate. For example, stocking information is irrelevant to predicting presence/absence in nonstocked lakes. When a different Lake Group was defined, collinearity diagnostics were examined for the variables judged noncollinear for the main group. If necessary, one or more additional variables were eliminated before the stepwise selection was performed.

We present the concordance index, denoted by $C_{i}$ as an index of goodness of fit for the logistic model. This is calculated as a standard part of the LOGIST procedure. The concordance index is the proportion of all possible pairings of a presence lake with an absence lake for which the predicted probability of presence (from the fitted model) for the presence lake is greater than the predicted probability of presence for the absence lake (with an adjustment for ties). This statistic can range between an expected value of 0.5 for a purely random situation (worst fit) to 1.0 for a "perfect" fit.

Verification of Selected Models. The performance of the derived models were evaluated on an independent data set. The results of this verification step could be very helpful in obtaining unbiased estimates of the proportion of lakes correctly classified as having or not having a particular fish species. Using the same data set that was used to develop the model to also estimate the proportion of lakes correctly classified is known to give overly optimistic results.

As soon as the data set for a given species (brook trout, creek chub, or fish/no fish) was appropriately checked for errors and other QAVQC aspects, it was randomly divided into two parts in a 1 to 2 ratio. The larger subset is the one we used to develop the models mentioned in the previous sections. The smaller subset was retained and used in our verification process. There were three aspects to this process:

1. For each lake in the appropriate lake group within the verification subset, a predicted probability of presence was estimated from the derived model. If this predicted probability was greater than 0.5 , we predicted the fish species would be present in that lake. If it was less than 0.5 , we predicted the fish species would be absent from the lake. After doing this for all lakes in this data set, a classification table was constructed from which the proportion of correctly and incorrectly classified lakes could be obtained.

2. Cohen's kappa statistic (see Titus et al 1984) was calculated from the classification table derived from the verification data set. This statistic is used to express the proportion of lakes correctly classified by the selected model, after removing the effect of correct. classification by chance. Confidence limits were also calculated for this statistic to indicate how well the selected models predict fish presence 
3. The sum of the predicted probabilities from the selected model can be used as an estimate of the expected number of lakes in the verification data set with the fish species being present. Since we know the lakes with the fish species present, this known value can be compared with the expected number to compare the different selected models.

\section{A.1.3 Results and Discussion}

The main results are in the form of models selected, by species, for each type of grouping of lakes (see previous section). The results for each species will be discussed first, followed by a comparison of results for all three species.

Brook Trout. Four groupings of lakes were considered for brook trout. Because stocking of brook trout is very common, the first three groupings all excluded privately owned lakes, for which stocking information is unreliable. As discussed in Section A. 2.2, the data buse was further subset to include only "qualified" lakes (Table A-4): calibration lakes not limed within 10 years, not fatally flagged, and containing complete observations for all of the candidate variables (including those eliminated because of collinearity).

- Group 1: "Nonprivate lakes" (qualified $N=444$; brook trout present in 186, absent in 258)

- Group 2: "Nonprivate nonstocked lakes" -- nonprivate lakes that were not stocked within 5 years of the ALSC survey (qualified $N=313$; brook trout present in 70 , absent in 243)

- Group 3: "Nonprivate nonstocked nonbog lakes" -- nonprivate lakes that were not stocked within 5 years of the ALSC survey, and that were not judged to be bog lakes (qualified $\mathrm{N}=305$; brook trout present in 70, absent in 235).

- Group 4: "All qualified lakes" -- including privately owned lakes and bog lakes (qualified $\mathrm{N}=842$; brook trout present in 343 , absent in 499).

For the first grouping, two sets of candidate variables were used in the stepwise selection. Variable set $B 1$ is the full set of relevant noncollinear variables. It is derived from the full set of 42 variables in Table A-1 with entries under brook trout. From this set, ownership (denoting private versus nonprivate ownership) was removed because privately owned lakes were excluded from these groupings. The six variables shown in Table A-5 as eliminated because of collinearity were also removed. Thus, set $B 1$ has 35 candidate explanatory variables. The set includes the two biological variables (presence of associates and presence of competitors); the latter variable also includes presence of species such as smallmouth bass, which indicate unsuitable conditions for brook trout. Because we wanted to see what variables would be selected if these biological variables were not available as part of the "explanation" of brook trout status, we also developed another model. This model used all the variables of $B 1$ except these two biological variables; this set of 33 variables is designated as variable set $B 0$. Results for Lake Group 1, variable set $B 1$ are shown in Table A-8; results for set $\mathrm{B} 0$ are shown in Table A-9. In these tables, variables selected as significant are listed with their 
Table A-8 Variables Selected from Set B1 to Explain the Presence of Brook Trout in Qualified Group 1 Lakes (Biological Variables Included)

\begin{tabular}{|c|c|c|c|c|c|}
\hline Variablea,b & $\begin{array}{l}\text { Standardized } \\
\text { Coefficient }\end{array}$ & & Significance & $\begin{array}{c}\text { Conventional } \\
\text { Coefficient }\end{array}$ & $\begin{array}{c}\text { Variable } \\
\text { Groupc }\end{array}$ \\
\hline Stocking of brook trout & 49.9914 & & $<0.0001$ & 5.40034 & 5 \\
\hline Presence of associates & 36.8326 & & $<0.0001$ & 3.58819 & 6 \\
\hline Presence of competitors & -20.4563 & & $<0.0001$ & -2.29225 & 6 \\
\hline $\mathrm{pH}$ & 21.5926 & & 0.0019 & 1.25419 & 1 \\
\hline $\mathrm{SiO}_{2}(\mathrm{~T}) \mathrm{d}$ & 19.1955 & & $<0.0001$ & 3.15436 & 4 \\
\hline $\operatorname{ANC}(T) d$ & -14.4337 & & 0.0201 & -3.46063 & 1 \\
\hline Distance to nearest road $(T)^{d}$ & 12.3106 & & 0.0038 & 1.64951 & 5 \\
\hline$D O C(T)^{d}$ & -11.4237 & & 0.0071 & -2.74330 & 1 \\
\hline Substrate & 9.8472 & & 0.0156 & 1.06374 & 4 \\
\hline Intercept. & -0.3344 & & 0.2274 & -3.21075 & \\
\hline \multicolumn{6}{|l|}{ Calibration Statistics } \\
\hline \multicolumn{6}{|l|}{ Concordance, $C=0.954$} \\
\hline \multicolumn{6}{|c|}{ Kappa $(95 \%$ Conf. Int. $)=0.76(0.70,0.82)$} \\
\hline \multicolumn{2}{|c|}{ Number of lakes with brook trout present: } & \multicolumn{4}{|l|}{186} \\
\hline \multicolumn{2}{|c|}{ Predicted from classification table: } & 171 & & & \\
\hline \multicolumn{6}{|l|}{ Verification Statistics } \\
\hline \multicolumn{6}{|c|}{ Kappa $(95 \%$ Conf. Int. $)=0.63(0.51,0.74)$} \\
\hline \multicolumn{2}{|c|}{$\begin{array}{l}\text { Number of lakes with brook trout present: } \\
\text { Predicted from classification table: }\end{array}$} & 75 & & & \\
\hline \multirow{2}{*}{\multicolumn{2}{|c|}{$\begin{array}{l}\text { Predicted from classification table: } \\
\text { Predicted from sum of probabilities: }\end{array}$}} & 78 & & & \\
\hline & & 86.6 & & & \\
\hline
\end{tabular}

a Listed in order of the absolute magnitude of their standardized coefficients.

b Stepwise selection, starting with variable set B1 35 noncollinear brook trout candidate variables, including stocking variables), was used to identify these variables.

c Variable groups are defined in Table A-1.

d (T) denotes that a transformed form of the variable was used.

coefficients as estimated from standardized data (we refer to these as standardized coefficients) as well as their significance level and conventional coefficients based on the unshifted and unscaled data. The variable groups are also indicated (these are summarized in later tables). The sign of the coefficient indicates whether the variable's effect on presence of brook trout is predicted to be positive or negative (given the effects of the other variables in the model). The relative importance of the variables is indicated in two ways. If the explanatory variables are uncorrelated, the absolute magnitudes of the standardized coefficients within a given model provide a measure of the relative importance of the variables. In addition, smaller values of the entries in the significance column also 
Table A-9 Variables Selected from Set BO to Explain the Presence of Brook Trout in Qualified Group 1 Lakes (Biological Variables Excluded)

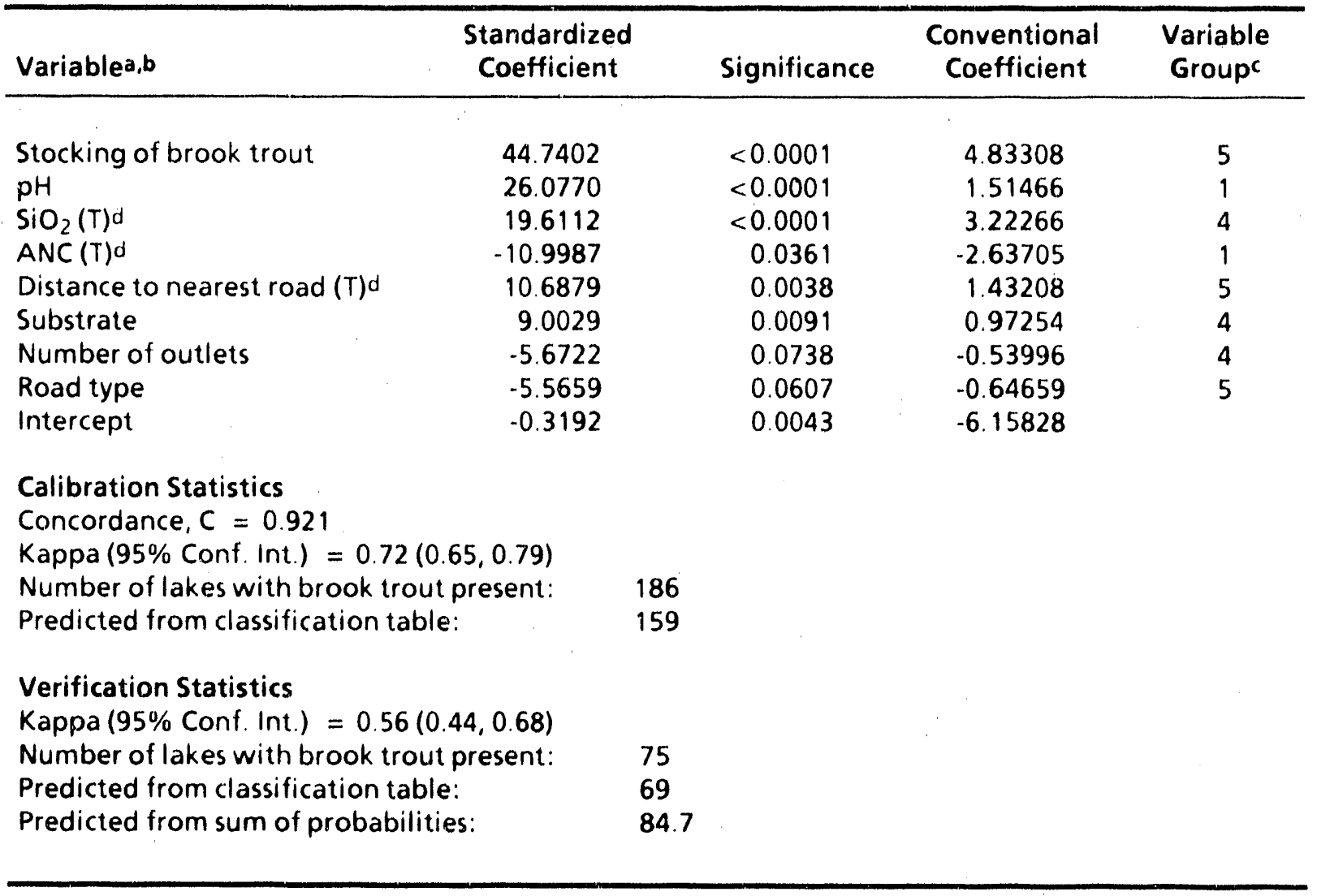

- Listed in order of the absolute magnitude of their standardized coefficients.

b Stepwise selection, starting with varıable set B0 (33 noncollınear brook trout candidate varıables, excluding biological variables but, for this lake group, including stocking varlables), was used to identify these variables

- Varıable groups are defined in Table A. 1

d (T) denotes that a transformed form of the varrable was used

tend to indicate more important variables. While these two measures of importance do not always agree exactly among variables, they tend to follow similar patterns.

For the second grouping, which lacks stocked lakes, the same variable sets B1 and B0 were also used, except that two additional variables had to be removed from each set: stocking of brook trout within 5 years by definition never occurred in this grouping (so it was collinear with the intercept) and lake type (which was also collinear with the intercept because of the finding that none of the nonstocked seepage lakes contained brook trout). Seepage lakes by definition lack outlets, so brook trout had no access to nonstocked lakes. For Lake Group 2, variable set B1 has 33 variables and variable set B0 has 31. The $\mathrm{B} 0$ set of 31 variables was also used for the third grouping (lacking bog lakes). Results for 
Lake Group 2, variable sets $B 1$ and B0, are shown in Tables A-10 and A-11, respectively. Results for Lake Group 3, variable set BO, are shown in Table A-12

For Lake Group 4, the original set of variables used for Lake Group 1 was also used, with three differences: (1) stocking of brook trout was not included, (2) stocking of competitors was not included, and (3) ownership was added (as a possible indicator of fishing pressure). Variable sets $B 1$ and $B 0$ therefore have 34 and 32 candidate explanatory variables, respectively, for Lake Group 4. Results for Lake Group 4, variable sets $B 1$ and $B 0$, are presented in Tables $A-13$ and $A \cdot 14$, respectively. Tables A. 15 through A-18 present results from some additional specialized analyses which were performed to support the NAPAP assessment. Calibration and verification tests of the seven primary brook trout models (those presented in Tables A-8 through A-14) are presented in Tables A-19 and A-20.

Table A-10 Variables Selected to Explain the Presence of Brook Trout in Qualified Group 2 (Nonprivate, Nonstocked) Lakes (Biological Variables Included)

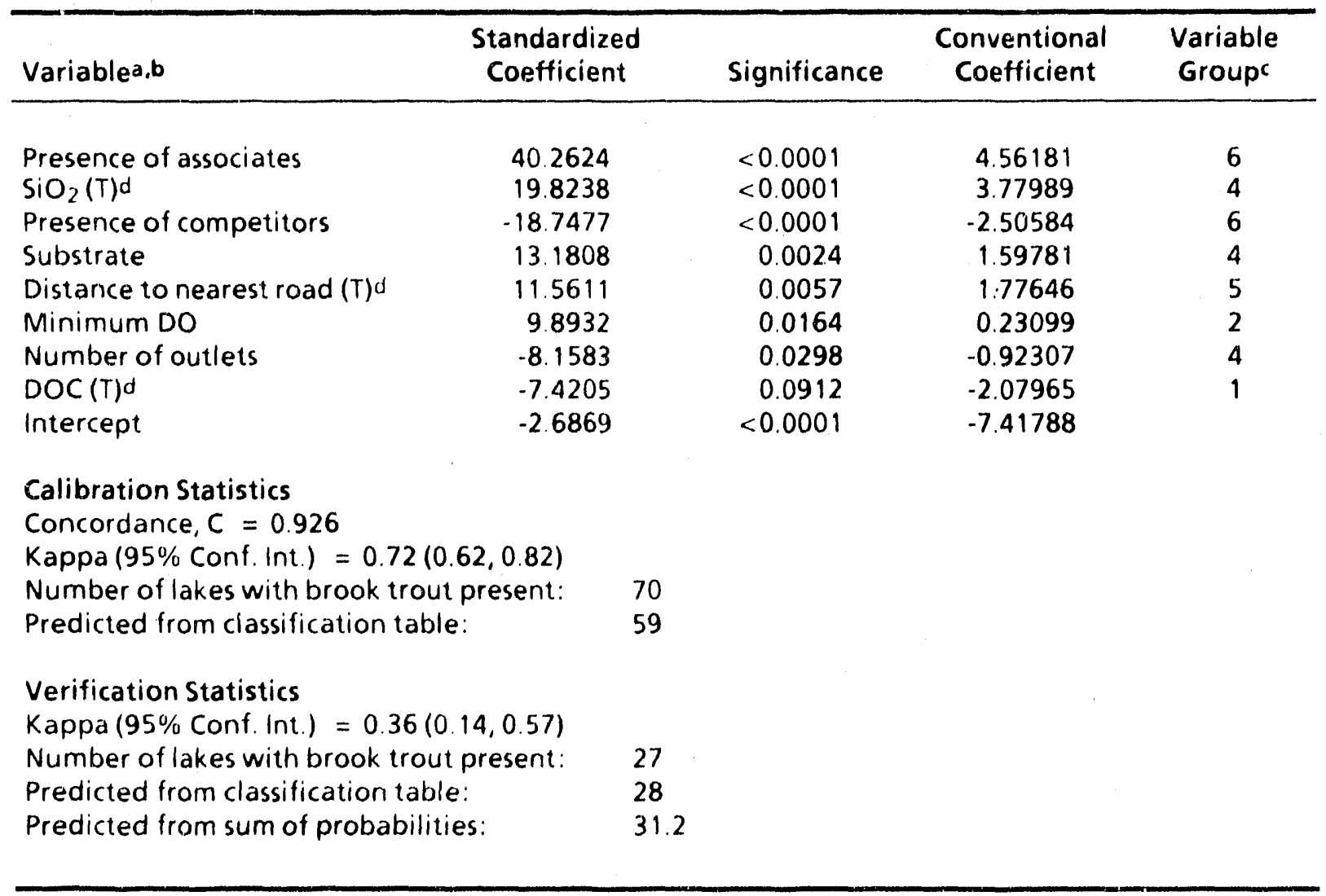

- Listed in order of the absolute magnitude of their standardized coefficients.

b Stepwise selection, starting with variable Set 81 (33 noncollinear brook trout candidate variables, excluding stocking variables), was used to identify these variables

C Variable groups are defined in Table A-1.

d (T) denotes that a transformed form of the variable was used. 
Table A-11 Variables Selected to Explain tl. 'Presence of Brook Trout in Qualified Group 2 (Nonprivate, Nonstocked) Lakes (Blological Variables Excluded)

\begin{tabular}{|c|c|c|c|c|c|}
\hline Variablea,b & \multicolumn{2}{|c|}{$\begin{array}{c}\text { Sitandardized } \\
\text { Coefficient }\end{array}$} & Significance & $\begin{array}{c}\text { Conventional } \\
\text { Coefficient }\end{array}$ & $\begin{array}{c}\text { Variable } \\
\text { Groupc }\end{array}$ \\
\hline $\mathrm{pH}$ & \multicolumn{2}{|l|}{17.1983} & $<0.0001$ & 1.16402 & 1 \\
\hline $\mathrm{SiO}_{2}(\mathrm{~T}) \mathrm{d}$ & \multicolumn{2}{|l|}{16.1885} & $<0.0001$ & 3.08672 & 4 \\
\hline Distance to nearest road $(T) d$ & \multicolumn{2}{|l|}{11.7510} & 0.0010 & 1.80564 & 5 \\
\hline Number of outlets & \multicolumn{2}{|l|}{9.6959} & 0.0252 & 1.59476 & 4 \\
\hline Substrate & \multicolumn{2}{|l|}{7.5802} & 0.0220 & 0.91889 & 4 \\
\hline Intercept & \multicolumn{2}{|l|}{-1.9213} & $<0.0001$ & -12.73038 & \\
\hline $\begin{array}{l}\text { Calibration Statistics } \\
\text { Concordance, } C=0.839\end{array}$ & \multicolumn{5}{|c|}{$\begin{array}{l}\text { Concordance, } C=0.839 \\
\text { Kappa }(95 \% \text { Conf. Int.) }=0.39(0.25,0.54)\end{array}$} \\
\hline \multicolumn{3}{|c|}{ Number of lakes with brook trout present: } & & & \\
\hline Predicted from classification & : & 43 & & & \\
\hline \multicolumn{6}{|l|}{ Verification Statistics } \\
\hline Number of lakes with brook & present: & 27 & & & \\
\hline Predicted from classification & & 18 & & & \\
\hline Predicted from sum of proba & & 33.2 & & & \\
\hline
\end{tabular}

a Listed in order of the absolute magnitude of their standardized coefficients.

b Stepwise selection, starting with variable set BO (31 noncollinear brook trout candidate variables, excluding stocking variables), was used to identify these variables.

c Variable groups are defined in Table A-1.

d (T) denotes that a transformed form of the variable was used.

In general, the types of variables selected and the directions of their influence in these seven models are consistent with expectation. Four variables were consistently important in these models:

- stocking of brook trout within 5 years of the ALSC survey (positively associated)

- presence of species associated with brook trout (positively associated)

- presence of competing species or of species indicating unsuitable conditions for brook trout (negatively associated)

- $\mathrm{SiO}_{2}$ (positively associated)

The first three variables were not always available as candidate variables by necessity or choice. In every case where they were available, however, they were selected and they were of major 
Table A-12 Variables Selected to Explain the Presence of Brook Trout in Qualified Group 3 (Nonprivate, Nonstocked, Non-Fully Bog) Lakes (Blological Variables Excluded)

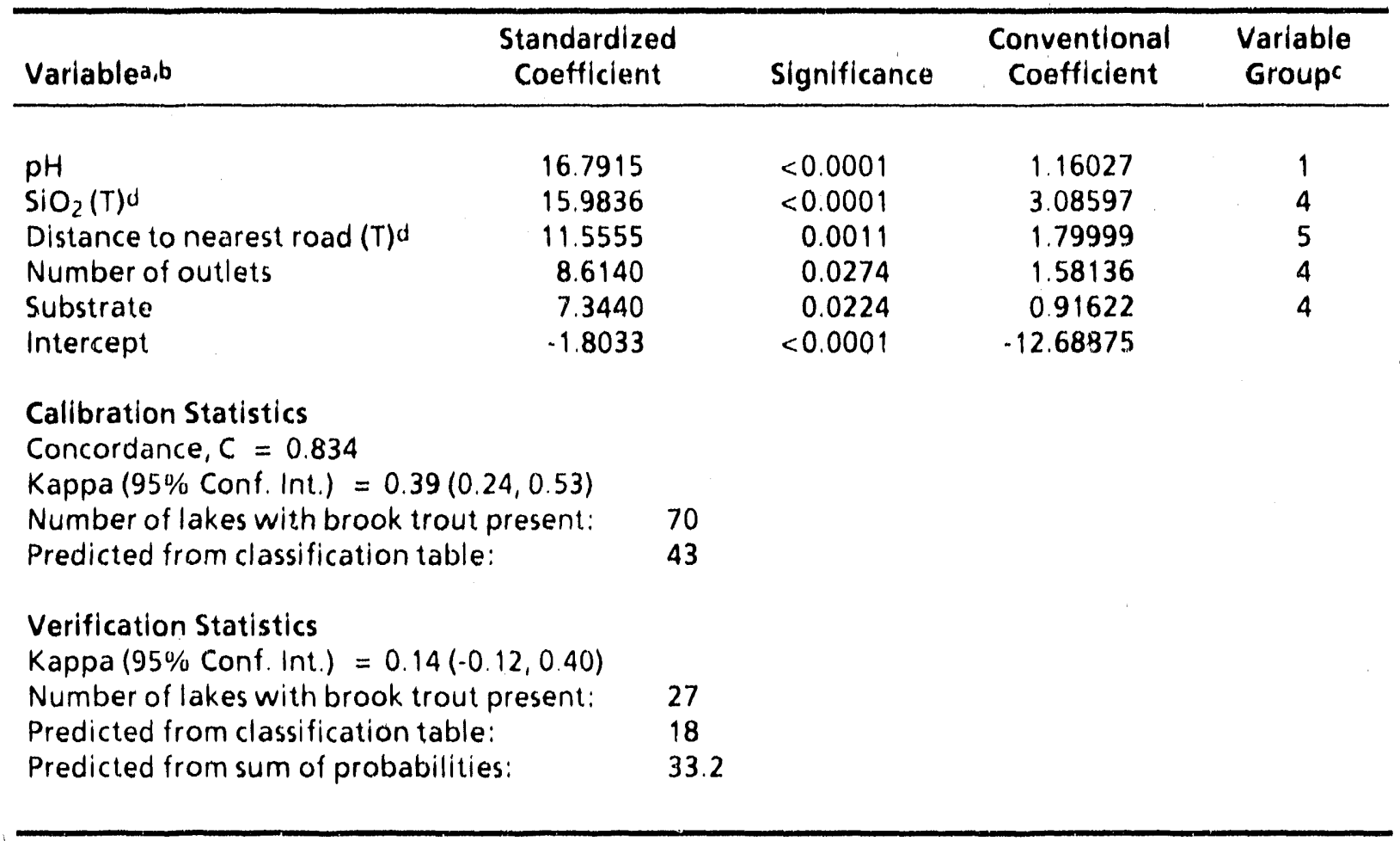

a Listed in order of the absolute magnitude of their standardized coefficients.

b Stepwise selection, starting with variable set BO (31 noncollinear brook trout candidate variables, excluding stocking variables), was used to identify these variables.

- Variable groups are defined in Table A-1.

d (T) denotes that a transformed form of the varlable was used.

importance in the model. Silica was always available; it also was always selected and always of major importance.

Brook trout stocking is widespread in the Adirondacks, and its importance in the model was expected. Similarly, the fact that presence or absence of other species of fish (grouped by a priori expectation of positive or negative effect) can be used to indicate brook trout waters is not surprising. A result that would not have been expected prior to this project is the importance of silica. As discussed in Section 3.3.3, $\mathrm{SiO}_{2}$ appears to indicate greater ground water input, which increases the likelihood that a lake has suitable spawning habitat.

Two additional variables (substrate and distance to the nearest road) were selected in each model, but these appeared to be less important than the variables discussed above. The substrate variable indicates lakes in which some bottom type other than muck, silt, clay, and organic matter was 
Table A.13 Variables Selected to Explain the Presence of Brook Trout in Qualified Group 4 (All Qualifying Calibration) Lakes (Biological Varlables Included)

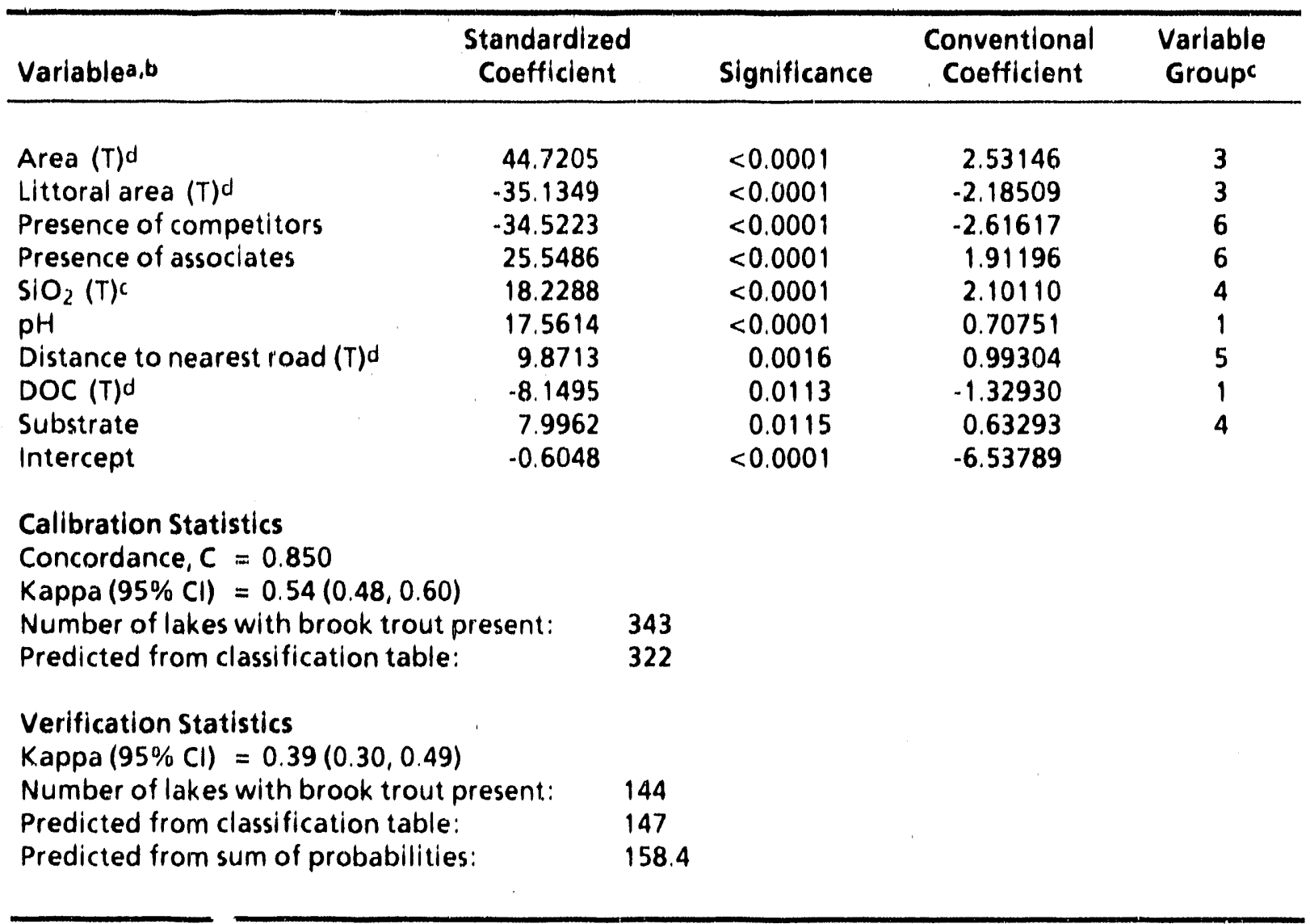

- Listed in order of the absolute magnitude of their standardized coefficients.

b Stepwise selection, starting with variable set 81 (34 noncollinear brook trout candidate variables, excluding stocking variables), was used to identify these variables.

c Variable groups are defined in Table A-1.

d $(T)$ denotes that a transformed form of the variable was used.

observed in the ALSC survey. Because a very small amount of suitable spawning habitat (primarily gravel; see Section 3.3.1) can support a brook trout population and because bottom substrate is only observable in shallow shoreline portion of a lake, it is difficult to establish that a lake does not have suitable substrate. The natural spawning adequate (NSA) criterion in the ALSC data base is an attempt to do this, but because it is only defined for lakes in which brook trout were caught, it is not useful for explaining presence versus absence. The substrate index was created to indicate enough diversity of bottom types that suitable habitat might be available. The fact that it is not more significant may reflect the errors inherent in this indirect approach to estimating presence of spawning habitat. 
Table A-14 Variables Selected to Explain the Presence of Brook Trout in Qualified Group 4 (all Qualifying Calibration) Lakes (Biological Variables Excluded)

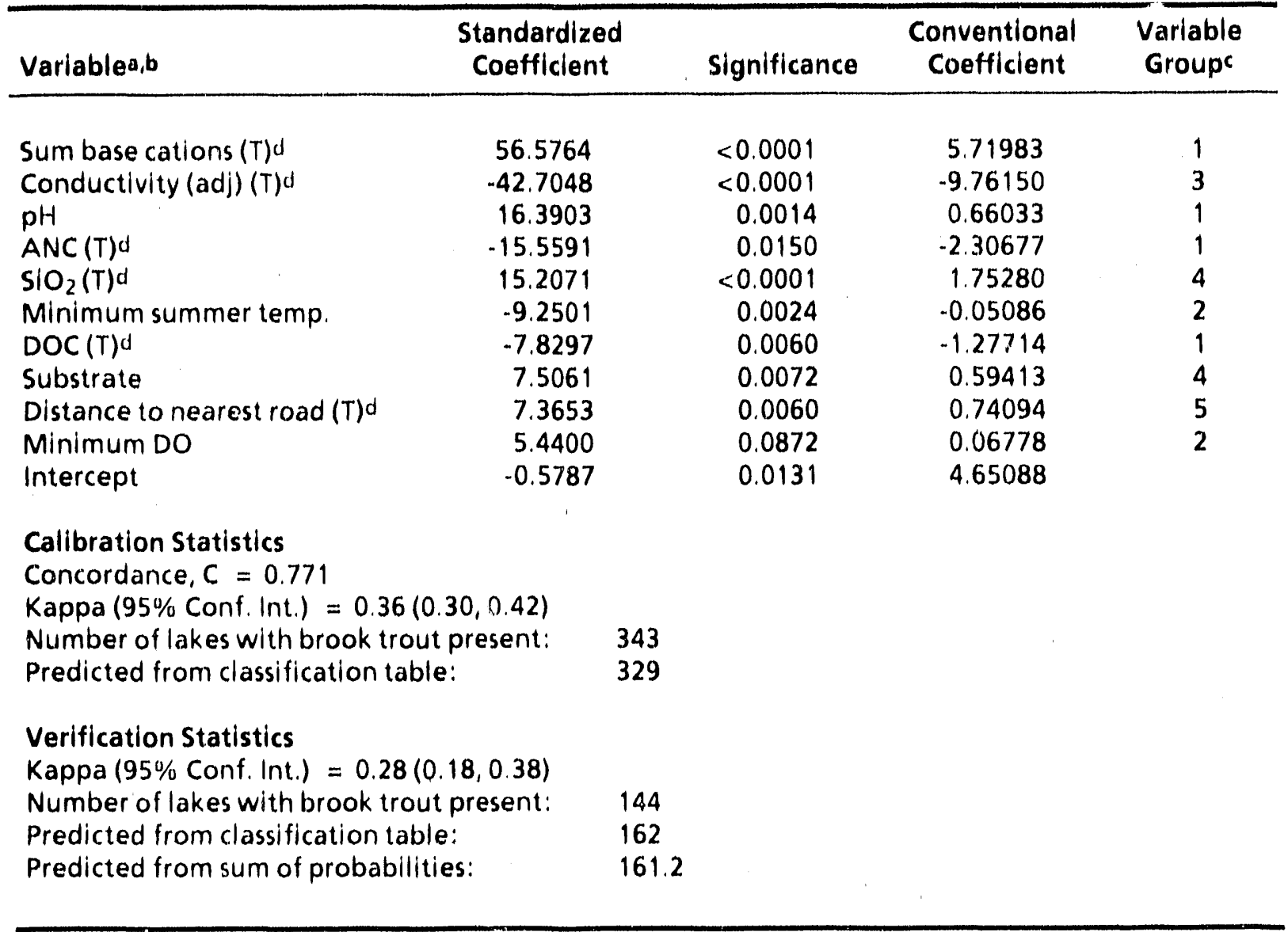

a Listed in order of the absolute magnitude of their standardized coefficients.

b Stepwise selection, starting with variable set BO (32 noncollinear brook trout candidate varlables, excluding stocking variables), was used to identify these variables.

c Variable groups are defined in Table A-1.

d (T) denotes that a transformed form of the variable was used.

The second variable, distance to the nearest road, was always selected. This variable may indicate that fishing pressure is eliminating populations or depressing them to low enough levels that they sometimes were not caught in the ALSC survey. Alternatively, or in addition, this variable may indicate that brook trout waters tend to be more remote than nonbrook-trout waters. Both of these variables (along with six more) are considered of questionable reliability. Distance to the nearest road is flawed as an explanatory variable for many lakes for which the nearest road is not accessible to the public. Substrate types are very difficult to determine, making the variable difficult to estimate. Because of these concerns, alternative analyses were conducted that excluded these variables (see Table A-4, variable set modifier B for a list of the variables; results are summarized in 
Table A.15 Variables Selected to Explain the Presence of Brook Trout in Quallfied Group 4 (all Quallfying Calibration) Lakes (Blological Variables Excluded) - DDRP Variables

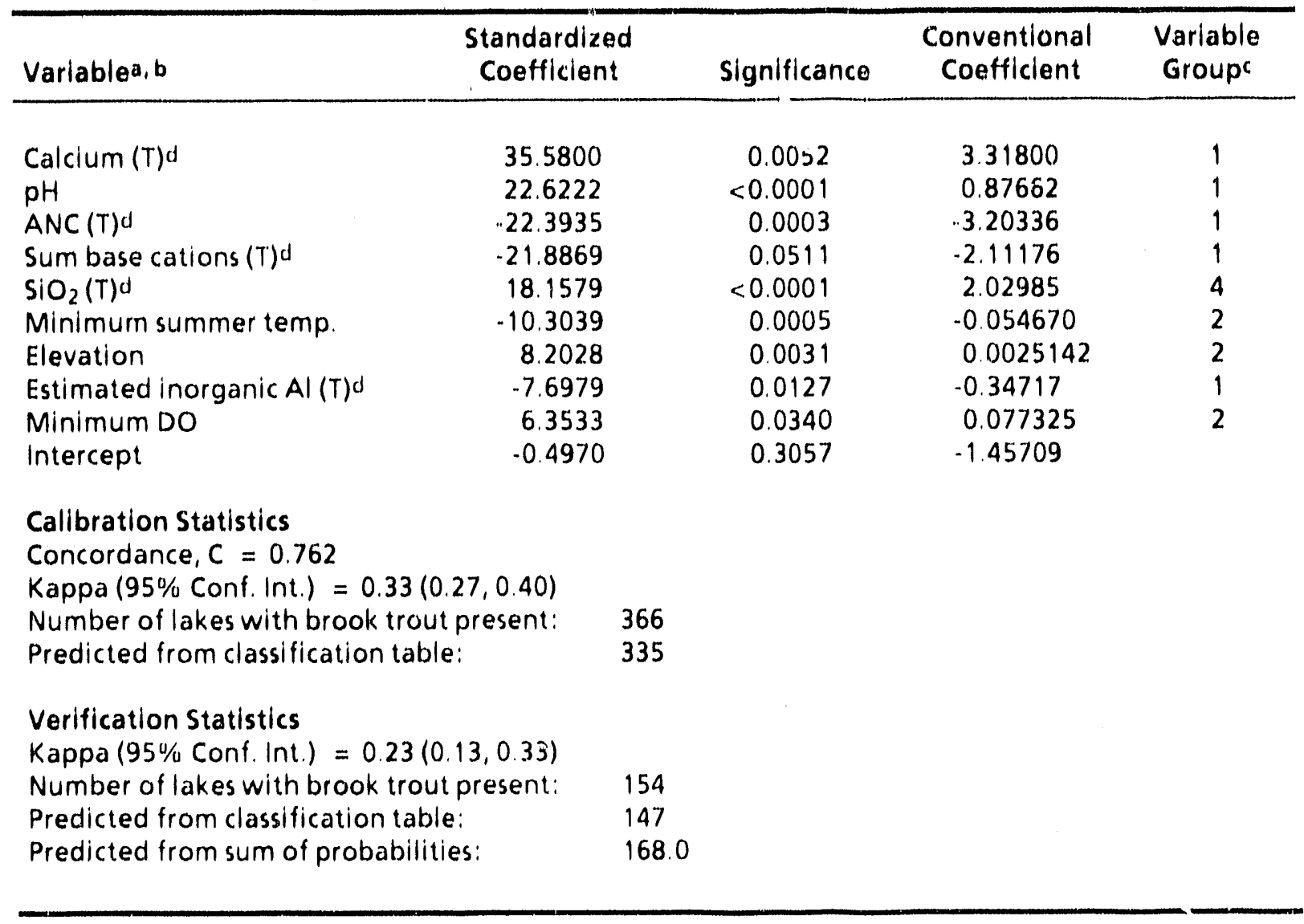

- Listed in order of the absoluta magnitude of their standardized coefficients.

b Stepwise selection, starting with variable set BOE ( 22 noncollinear brook trout candidate variables a vallable in the EPA's DDRP data basel, was used to identify these variables.

(Varlable groups are defined in rable A.4.

d (T) denotes that a transformed form of the variable was used.

later tables). Despite these problems, the consistency of their selection in the model may indicate a stronger influence of these variables, in the lakes for which they are reliable, than would be indicated by their standardized coefficients and significance levels.

The variable $\mathrm{pH}$ is significant in six of the seven models. As expected, it has a positive influence. When it is selected, its importance is high and is similar to that of $\mathrm{SiO}_{2}$. In the model in which it was not selected (Table A-10, for the nonprivate, nonstocked lakes with biological predictors included), the effect of $\mathrm{pH}$ is probably represented by another variable or variables. Lake $\mathrm{pH}$ may, for example, jointly affect the distributions of associates and competitors of brook trout as well as brook tiout themselves. 
Table A-16 Variables Selected to Explain the Presence of Brook Trout in Lake Group 1H (Qualifying Nonprivate Calibration Lakes with pH >6) (Biological Variables Excluded)

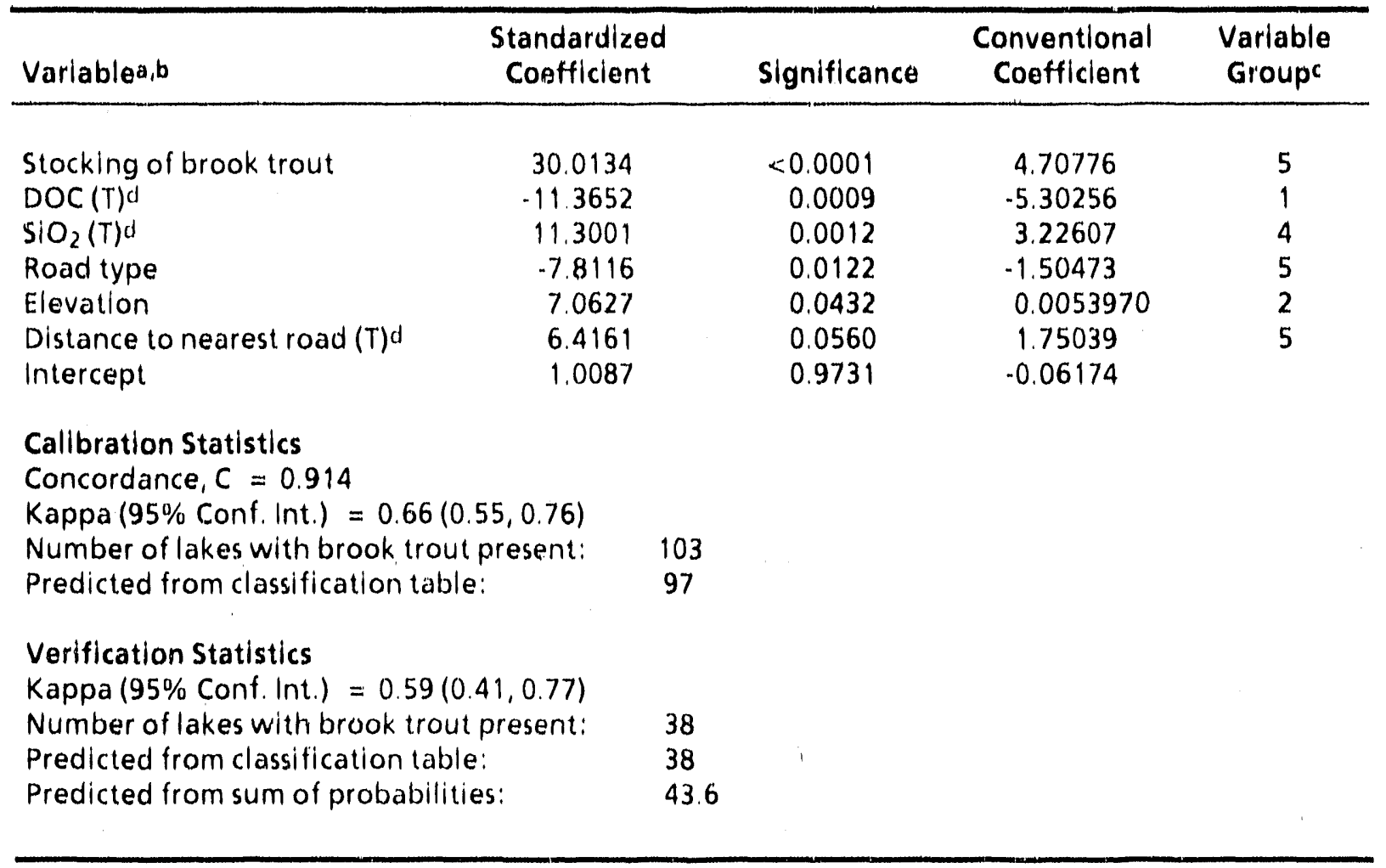

a Listed in order of the absolute magnitude of their standardized coefficients.

b Stepwise selection, starting with varlable set 80 ( 31 noncollinear brook trout candidate variables in the ALSC data base, including stocking variables), was used to identify the se variables.

c Variable groups are defined in Table A.1.

d $(T)$ denctes that a transformed form of the variable was used.

In three of the seven models, acid neutralizing capacity (ANC) is significant, but with a negative sign. This is unexpected because ANC is significantly positively associated with brook trout presence (Table A-1). In these three cases, $\mathrm{pH}$ is also in the model. A possible explanation for the effect of ANC in the model is that at a fixed $\mathrm{pH}$, a higher value of ANC may indicate the presence of greater organic acidity.

Dissolved organic carbon (DOC) is significant in four models, with a negative sign. It is difficult to interpret its function in these models. DOC can mitigate the harmful effects of inorganic monomeric $\mathrm{Al}_{i}$ in this role, it would have a positive sign. It is possible that it is indicating a negative effect of bog conditions on the probability of brook trout presence.

Other variables are significant less frequently, and their signs are usually consistent with expectation. However, in the case of Lake Group 4, variable set B1, lake area is selected as the most important 
Table A-17 Variables Selected to Explain the Presence of Brook Trout in Lake Group 4H (all Qualifying Calibration Lakes with pH >6) (Biological Variables Excluded)

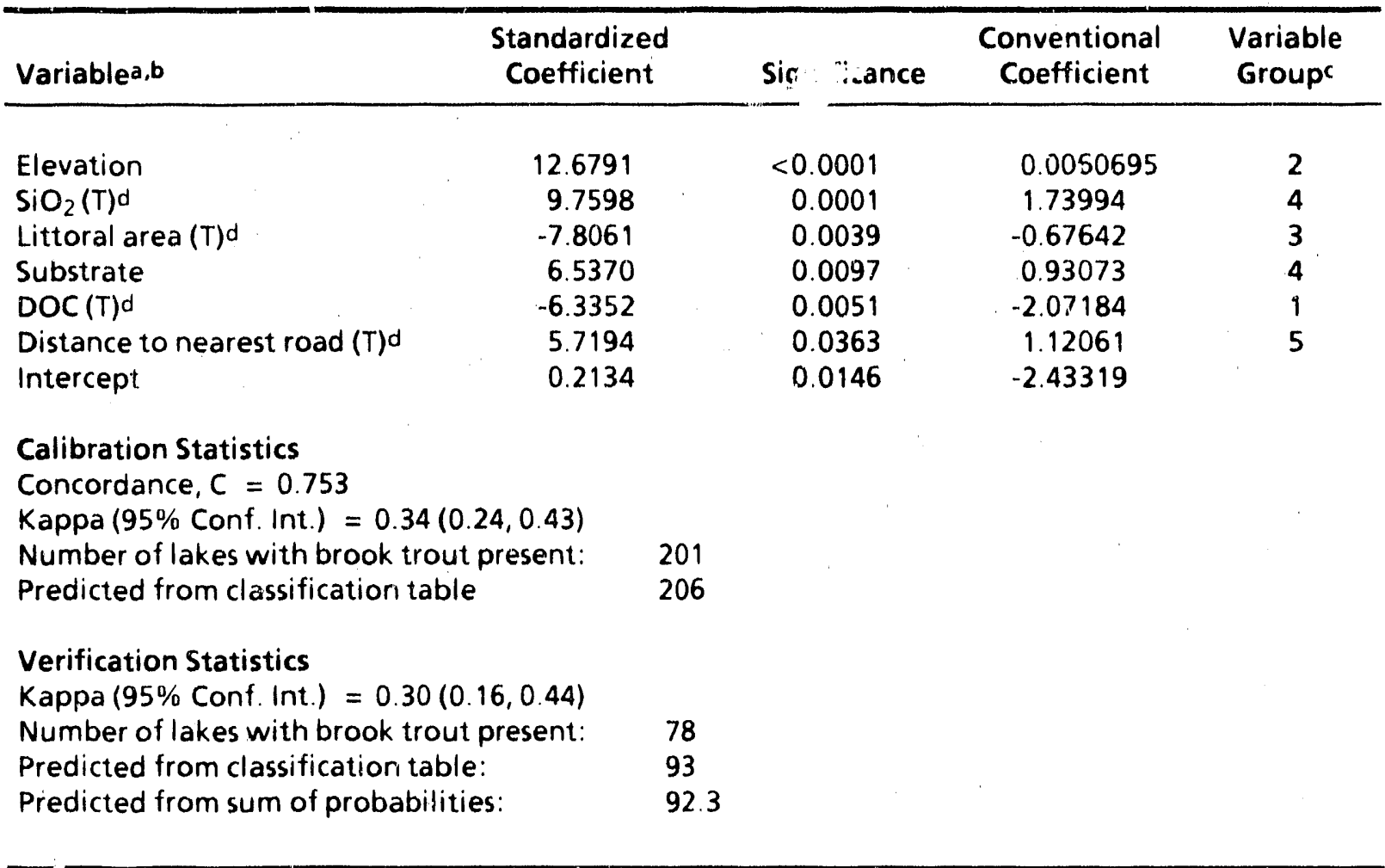

a Listed in order of the absolute magnitude of their standardized coefficients.

b Stepwise selection, starting with variable set $\mathrm{BO}(32$ noncollinear brook truut candidate variables in the ALSC data base. excluding stocking variables), was used to identify these variables.

c Variable groups a re defined in Table A-1.

d (T) denotes that a transformed form of the variable was : 'sed.

variable, with a positive sign; littoral area is selected as the second most important variable, with a negative sign. Neither lake nor littoral area is selected in any other of these seven models. In a subset of lakes with $\mathrm{pH}>6$, lake area enters with a negative sign (Table A-18), without littoral area.

This kind of variable pairing (both the lake area - littoral area and the $\mathrm{pH}-\mathrm{ANC}$ pairing discussed above) and sign switching can be interpreted as a warning against overinterpreting the importance and effect of individual variables selected in these models. For example, with 30 candidate variables, there are $2^{30}$ (i.e., more than a billion) combinations of variables possible in the models. Although the variables retained as candidates are not grossly collinear because of the collinearity analysis, some of the variables are nonetheless related to each other and to a large degree, can substitute for one another 
Table A-18 Variables Selected to Explain the Presence of Brook Trout in Lake Group 4H (all Qualifying Calibration Lakes with pH > 6) (Biological Variables Excluded)

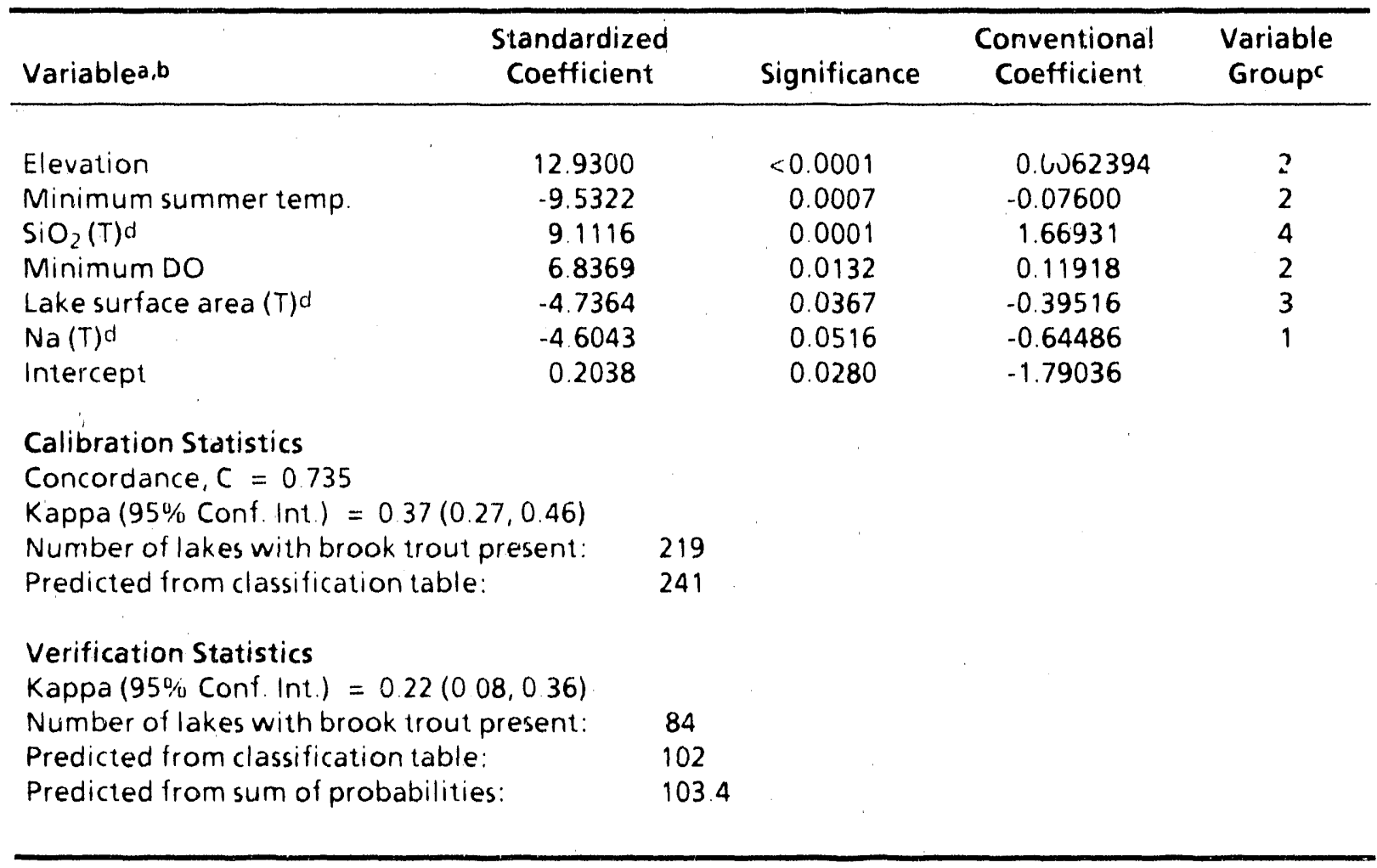

a Listed in order of the absolute magnitude of their standardized coefficients.

b Stepwise selection, starting with variable set BOENA (16 noncollinear brook trout candidate variables from the ALSC data base, excluding variables expected to respond to acidification and those not available in the EPA's DDRP data base). was used to identify these variables.

- Variable groups are defined in Table A.1.

d (T) denotes that a transformed form of the variable was used.

Eliminating many of these variables as candidates results in selection of different combinations of remaining variables, with nearly as good a fit (e.g., Table A-21). In particular, for Lake Group 4, variable set $B O E$ (Table A-15) has only 22 candidate variables (this data set is restricted to variables available in the EPA surveys), while variable set $B O$ (Table A-14) has 32 variables. The resulting models have some variables in common and some differences. Nonetheless, the concordance index indicates nearly as good a fit for the two models. A similar conclusion can be reached by comparing the concordance indices for the the three models in Table A-21 for Lake Group 4H, in whicn the number of candidate variables differs by as much as a factor of 2 .

A more consistent approach to interpretation is shown in Table A-21, where the highest level of significance in each selected model is tabulated, for any variable within each of the six explanatory variatíle groups. Gioups 4 (natural reproduction and acress variables) and 6 (biolongiral variables. 


\begin{tabular}{|c|c|c|c|c|c|c|}
\hline \multirow{3}{*}{$\begin{array}{l}\text { Lake } \\
\text { Groupa }\end{array}$} & \multirow{3}{*}{$\begin{array}{c}\text { Variable } \\
\text { Setb }\end{array}$} & \multirow[b]{3}{*}{ Kappac } & \multicolumn{4}{|c|}{ Classification Table (Prior $=0.5$ ) } \\
\hline & & & \multirow[b]{2}{*}{ Observed } & \multicolumn{2}{|c|}{ Predicted } & \multirow[b]{2}{*}{ Total } \\
\hline & & & & Absences & Presences & \\
\hline \multirow[t]{2}{*}{1} & B1 & $\begin{array}{c}0.76 \\
(0.70,0.82)\end{array}$ & $\begin{array}{l}\text { Absences } \\
\text { Presences }\end{array}$ & $\begin{array}{r}240 \\
33\end{array}$ & $\begin{array}{r}18 \\
153\end{array}$ & $\begin{array}{l}258 \\
186\end{array}$ \\
\hline & & & Total & 273 & 171 & 444 \\
\hline \multirow[t]{3}{*}{1} & BO & 0.72 & Absences & 242 & 16 & 258 \\
\hline & & $(0.65,0.79)$ & Presences & 43 & 143 & 186 \\
\hline & & & Total & 285 & 159 & 444 \\
\hline \multirow[t]{3}{*}{2} & B1 & 0.72 & Absences & 234 & 9 & 243 \\
\hline & & $(0.62,0.82)$ & Presences & 20 & 50 & 70 \\
\hline & & & Total & 254 & 59 & 313 \\
\hline \multirow[t]{3}{*}{2} & BO & 0.39 & Absences & 228 & 15 & 243 \\
\hline & & $(0.25,0.54)$ & Presences & 42 & 28 & 70 \\
\hline & & & Total & 270 & 43 & 313 \\
\hline \multirow[t]{3}{*}{3} & BO & 0.39 & Absences & 220 & 15 & 235 \\
\hline & & $(0.24,0.53)$ & Presences & 42 & 28 & 70 \\
\hline & & & Total & 262 & 43 & 305 \\
\hline \multirow[t]{3}{*}{4} & B1 & 0.54 & Absences & 416 & 83 & 499 \\
\hline & & $(0.48,0.60)$ & Presences & 104 & 239 & 343 \\
\hline & & & Total & 520 & 322 & 842 \\
\hline \multirow[t]{3}{*}{4} & BO & 0.36 & Absences & 377 & $12 ?$ & 499 \\
\hline & & $(0.30,0.42)$ & Presences & 136 & 207 & 343 \\
\hline & & & Total & 513 & 329 & 842 \\
\hline
\end{tabular}

a Group 1: Nonprivate lakes. Group 2: Nonprivate, nonstocked lakes. Group 3: Nonprivate, nonstocked, nonbog lakes. Group 4: All qualified lakes. See Table A-4 for more information.

b Variable set $B 1$ includes the biological variables (presence of associates; presence of competitors). Variable set $\mathrm{B0}$ does not include these biological variables. See Table A-4 for more information.

c Asymptotic $95 \%$ Conf. Int. shown in parenthesis.

when available to the model) are consistently extremely important. Brook trout are less likely to be caught in lakes supporting one or more species considered as potential competitors (e.g. yellow perch or largemouth bass) and are more likely to be caught in lakes where fish species commonly associated with brook trout were caught. Brook trout are also more likely to be caught in lakes with high levels of $\mathrm{SiO}_{2}$. Group 1 (acidification response variables) is always represented and is usually 


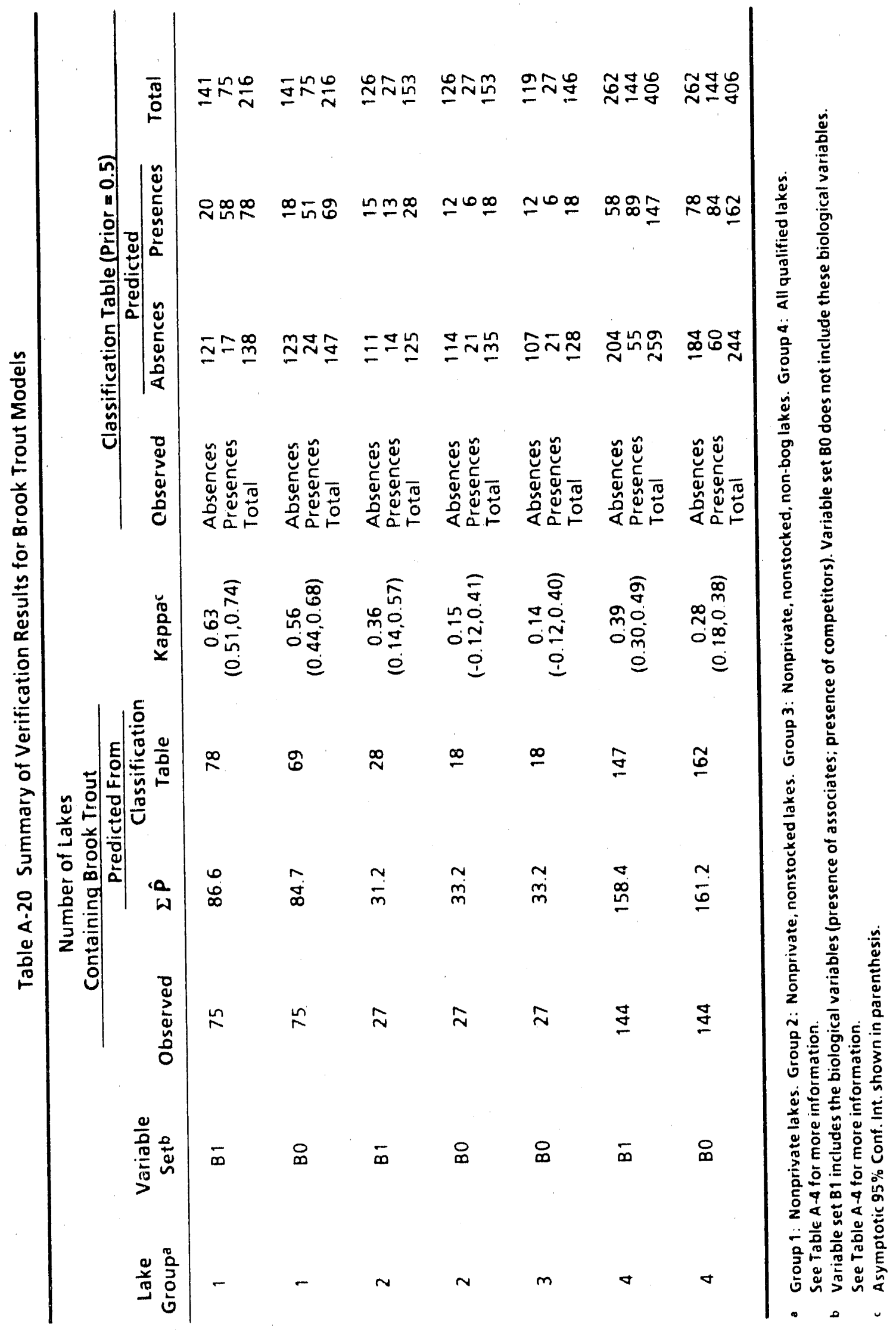




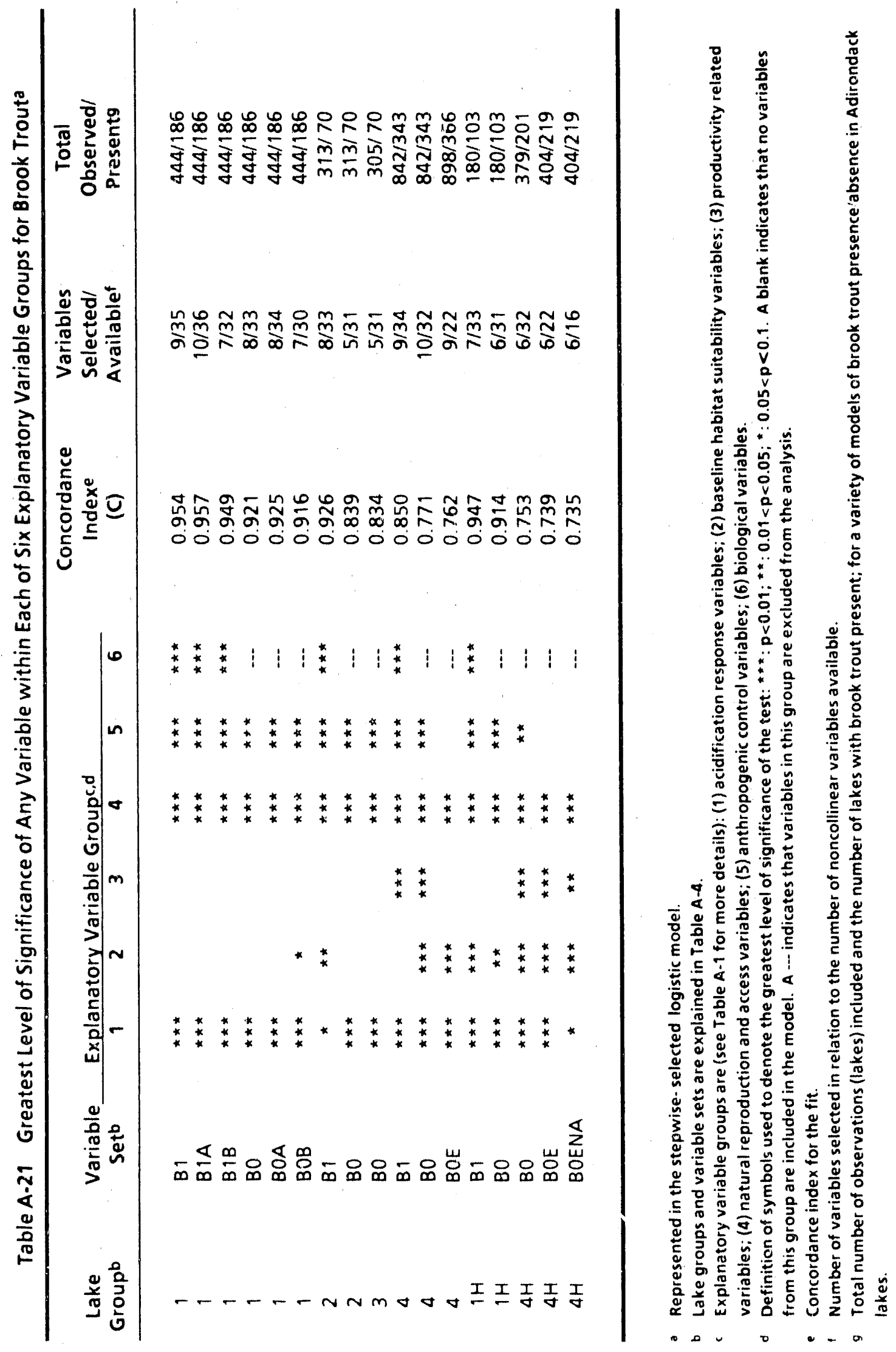


highly important. Lake group 2, variable set B1 (an exception) has already been discussed. In the "H" lake groups $(\mathrm{pH}>6), \mathrm{pH}$ should not be an important factor. Consistent with this expectation, DOC, the sum of base cations, or (in the case of BOENA), sodium (Na) (the only possible choice) were the chosen response variables. Group 5 (anthropogenic variables) is always very important when stocking is available to the model, and usually via other factors even when it is not. In the " $E$ " variable sets, ownership is the only anthropogenic variable available. This is the only situation in which variable group 5 is not important.

Group 2 (baseline habitat suitability variables) is sometimes important in the models, perhaps dependent on both the lake group and on the other variables in the model. Group 3 (productivity related variables) tend to be important only in the weaker models (those with a lower value of the concordance index).

Several special examinations are summarized in Table A-21. The variable sets ending in " $A$ " involved reinstating $\mathrm{pCa}: \mathrm{pH}$, measured $\mathrm{Al}: D O C$, and estimated inorganic $\mathrm{Al}: \mathrm{DOC}$. To resolve collinearities, it was necessary to remove measured $\mathrm{Al}$ and field $\mathrm{pH}$. With variable set $\mathrm{B} 1 \mathrm{~A}, \mathrm{DOC}$ and aluminum terms replaced $\mathrm{pH}$ as highly significant acidification variables; with set $\mathrm{BOA}, \mathrm{pCa}: \mathrm{pH}$ did so. Variable groups and the concordance indices were essentially unchanged. The variable sets ending in " $B$ " had six questionable variables removed from the candidate list (see Table A-4). The selected models had some differences in selected variables, but again the variable groups and concordance indices were sirnilar. The lake groups ending in $\mathrm{H}$ were selected to develop "baseline" models for probability of brook trout presence in lakes where acid-base chemistry should not be a factor. DOC was a significant negative factor in most of these models, perhaps reflecting a preference of brook trout for clear water.

Overall, the fit of the models is best when the biological variables, or the variable indicating the stocking of bruok trout within 5 years, are available to the model. When only nonbiological variables are used for nonstocked lakes (Tables $A-11$ and $A-12)$, only five variables $(\mathrm{pH}$, silica, distance from the nearest road, number of outlets, and substrate type) are able to account reasonably well for the pattern of presences and absences in the calibration data set (Table A-19). However, with the verification data set (Table A-20), the performance of these models is marginal. For brook trout, stocking is a very significant influence, and the choice of lakes to stock evidently reflects good knowledge of suitable conditions. For lakes where natural reproduction or access from other lakes is required, predicting (and hence explaining) brook trout presence/absence from lake and watershed characteristics is considerably more difficult. 
Creek Chub. Individual analyses for creek chub are provided in Tables A-22 through A-28; summaries of these analyses are provided in Tables A.29 through A-31 Because lake stocking is much less important for creek chub than for brook trout, the main analysis was conducted on the largest subset of lakes (i.e., without considering ownership), without stocking variables. Because fully bog lakes never contain fish, these were excluded from the analysis. Otherwise, numerical difficulties would have eliminated the full-bog variable from the list of candidates (as in fact happened for the brook trout analysis). Some additional differences from Lake Group 4 (used for brook trout) arise because of differences in the pattern of missing observations for some of the different variables used for creek

Table A-22 Variables Selected to Explain the Presence of Creek Chub in Qualified Group 5 (all Qualifying Nonbog Calibration) Lakes (Biological Variables Included), Variable Set B1A

\begin{tabular}{|c|c|c|c|c|c|}
\hline Variablea,b & $\begin{array}{c}\text { Standardized } \\
\text { Coefficient }\end{array}$ & & Significance & $\begin{array}{c}\text { Conventional } \\
\text { Coefficient }\end{array}$ & $\begin{array}{l}\text { Variable } \\
\text { Groupc }\end{array}$ \\
\hline $\mathrm{pCa} / \mathrm{pH}$ & -117.9 & & $<00001$ & -26.26446 & 1 \\
\hline $\operatorname{Area}(T) d$ & 618461 & & $<0,0001$ & 375834 & 3 \\
\hline $\mathrm{pH}$ & .55 .1192 & & 00001 & -246034 & 1 \\
\hline Presence of predators & .43 .6526 & & $<0.0001$ & -404148 & 6 \\
\hline Littoral area $(T)$ d & -36.2017 & & 0.0072 & .2 .45183 & 3 \\
\hline Conductivity (adj.) (T)d & -30.3050 & & $<0.0001$ & .7 .31819 & 3 \\
\hline Presence of associates & 283546 & & 0.0001 & 2.53684 & 6 \\
\hline Maximum depth $(T)^{d}$ & .206084 & & 0.0001 & -2.01677 & 2 \\
\hline Watershed: Lake area ratio $(T) \mathrm{d}$ & 14.1058 & & $<0.0001$ & 0.93795 & 3 \\
\hline Number of macrophyte taxa & 90730 & & 0.0071 & 0.07209 & 2 \\
\hline Number of outlets & 8.7403 & & 0.0137 & 0.87134 & 4 \\
\hline Shoreline development index $(T) \mathrm{d}$ & -6.7150 & & 0.0607 & -2.03718 & 3 \\
\hline Intercept & -1.8538 & & $<0.0001$ & 41.01391 & \\
\hline \multicolumn{6}{|l|}{ Calibration Statistics } \\
\hline \multicolumn{6}{|c|}{ Kappa $(95 \%$ Conf. Int $)=0.64(0.58,070)$} \\
\hline \multicolumn{2}{|c|}{ Number of lakes with creek chub present: } & 249 & & & \\
\hline \multicolumn{2}{|c|}{ Predicted from classification table: } & 267 & & & \\
\hline \multicolumn{6}{|l|}{ Verification Statistics } \\
\hline \multicolumn{6}{|c|}{ Kappa $(95 \%$ Conf Int. $)=0.60(0.51,069)$} \\
\hline \multirow{2}{*}{\multicolumn{2}{|c|}{$\begin{array}{l}\text { Number of lakes with creek chub present: } \\
\text { Predicted from classification table: }\end{array}$}} & 127 & & & \\
\hline & & 129 & & & \\
\hline \multicolumn{2}{|l|}{$\begin{array}{l}\text { Predicted from classification table: } \\
\text { Predicted from sum of probabilities: }\end{array}$} & 122.1 & & & \\
\hline
\end{tabular}

a Listed in order of the absolute magnitude of their standardized coefficients.

- Stepwise selection, starting with variable set B1A (39 noncollinear creek chub candidate variables), was used to identify these variables.

c Variable groups are defined in Table A.1.

d (T) denotes that a transformed form of the variable was used. 
Table A-23 Variables Selected to Explain the Presence of Creek Chub in Qualified Group 5 (all Qualifying Nonbog Calibration) Lakes (Biological Variables Included), Variable Set B1B

\begin{tabular}{|c|c|c|c|c|c|}
\hline Variablea,b & $\begin{array}{l}\text { Standardized } \\
\text { Coefficient }\end{array}$ & & Significance & $\begin{array}{c}\text { Conventional } \\
\text { Coefficient }\end{array}$ & $\begin{array}{l}\text { Variable } \\
\text { Groupc }\end{array}$ \\
\hline $\mathrm{pCa} / \mathrm{pH}$ & -130.0 & & $<00001$ & -27.12309 & 1 \\
\hline $\mathrm{pH}$ & -55.8437 & & 0.0002 & -2.33755 & 1 \\
\hline Presence of predators & .44 .2919 & & $<0.0001$ & -3.93176 & 6 \\
\hline Conductivity (adj.) (T)d & -42.4120 & & $<0.0001$ & -9.94440 & 3 \\
\hline Presence of associates & 291768 & & 0.0001 & 2.38535 & 6 \\
\hline $\mathrm{Na}(\mathrm{T})^{\mathrm{d}}$ & 14.1172 & & 0.0167 & 1.30937 & 1 \\
\hline Littoral area & 13.4510 & & 0.0001 & 0.88268 & 3 \\
\hline Watershed:Lake area ratio $(T) d$ & 109821 & & 0.0004 & 0.70734 & 3 \\
\hline Number of outlets & 8.4506 & & 0.0189 & 0.80073 & 4 \\
\hline Presence of competitors & 5.7988 & & 0.0511 & 0.41373 & 6 \\
\hline Intercept & -2.1061 & & $<0.0001$ & 43.56874 & \\
\hline \multicolumn{6}{|l|}{ Calibration Statistics } \\
\hline \multicolumn{6}{|l|}{ Concordance, $C=0.903$} \\
\hline \multicolumn{6}{|c|}{ Kappa $(95 \%$ Conf Int $)=0.58(0.52,0.64)$} \\
\hline \multicolumn{2}{|c|}{ Number of lakes with creek chub present: } & 257 & & & \\
\hline \multicolumn{2}{|c|}{ Predicted from classification table: } & 287 & & & \\
\hline \multicolumn{6}{|l|}{ Verification Statistics } \\
\hline \multicolumn{6}{|c|}{ Kappa $(95 \%$ Cont. Int $)=0.58(049,0.67)$} \\
\hline \multicolumn{2}{|c|}{$\begin{array}{l}\text { Number of lakes with creek chub present: } \\
\text { Predicted from classification table: }\end{array}$} & 131 & & & \\
\hline \multicolumn{2}{|c|}{ Predicted from classification table: } & 142 & & & \\
\hline \multicolumn{2}{|c|}{ Predicted from sum of probabilities: } & 128.3 & & & \\
\hline
\end{tabular}

- Listed in order of the absolute magnitude of theil standardized coefficients.

b Stepwise selection, starting with variable set B18 (32 noncollinear ci eek chub candidate variables, with selected unreliable variables excluded), was used to identify these variables.

c Variable groups are defined in Table A.1.

d $(T)$ denotes that a transformed form of the variable was used.

chub in comparison with brook trout (Table A-1; note dashes as defined in footnote $b$, for brook trout versus creek chub).

An additional set of analyses involved building and comparing models for two groups of watersheds. Lake Group 6 consists of lakes in the Oswegatchie-Black and the Mohawk-Hudson watersheds (coded 04 and 07 , respectively). These two watersheds contain a disproportionately high percentage of acidic lakes and of high-elevation lakes, and receive some of the highest levels of acidic deposition. Lake Group 7 consists of lakes in the Lake Champlain and the Upper Hudson watersheds (coded 02 
Table A-24 Variables Selected to Explain the Presence of Creek Chub in Qualified Group 5 (all Qualifying Nonbog Calibration) Lakes (Biological Variables Excluded)

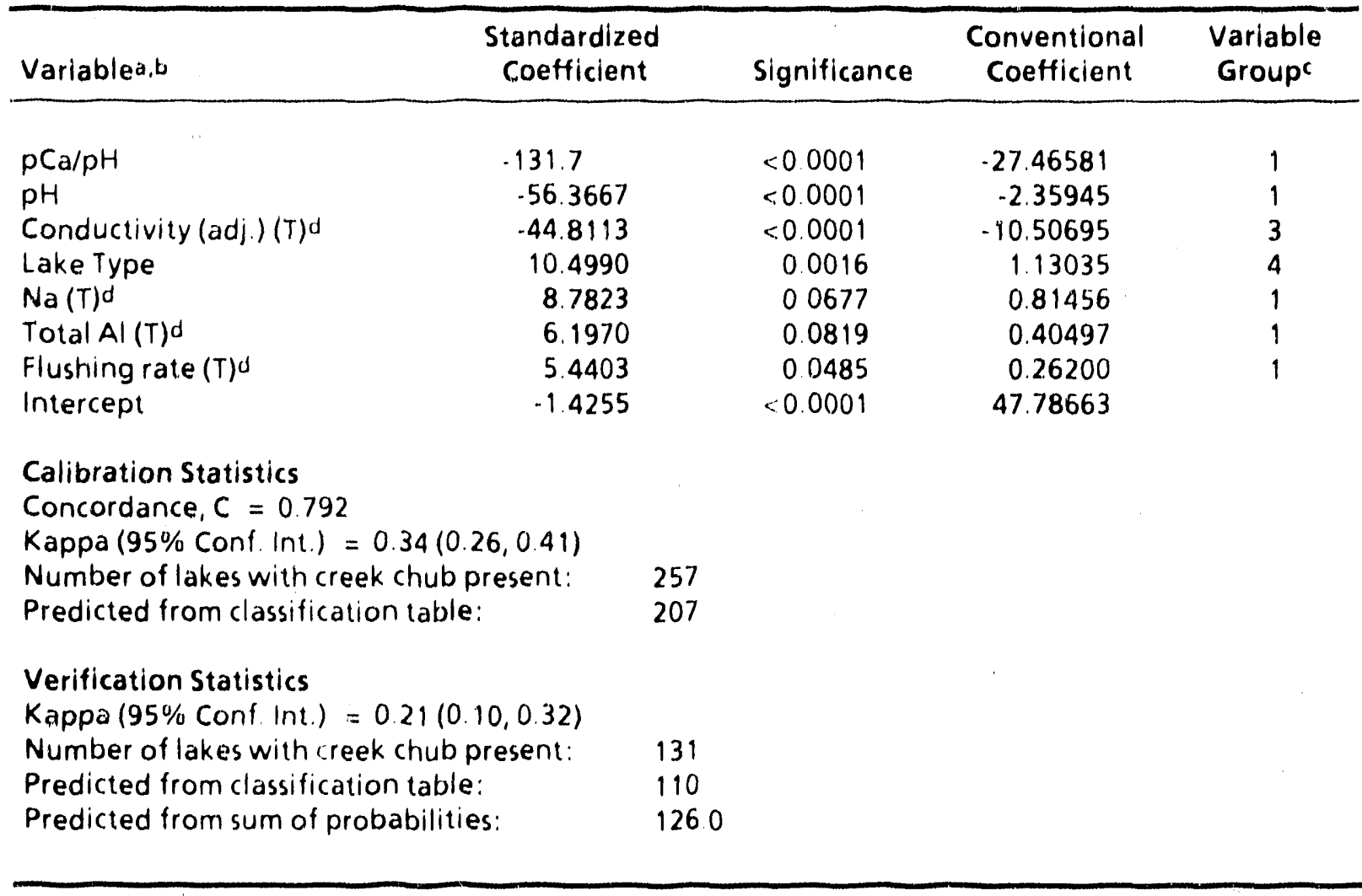

- Listed in order of the absolute magnitude of their standardized coefficients.

b Stepwise selection, starting with variable set 808 (29 noncollinear creek chub candidate variables, with selected unreliable variables excluded), was used to identify these variables

c Variable groups are defined in Table A-1.

d (T) denotes that a transformed form of the variable was used.

and 05 , respectively). This region represents a strong contrast to Lake Group 6, and acidity might be expected to be a less important factor here.

With respect to the variables used in the creek chub analyses, the original collinearity analysis for creek chub (shown in Table A-6) was done on a slightly different subset of lakes and did not consider the ratios of Al:DOC In this original analysis, $\mathrm{PCa}: \mathrm{pH}$ was not eliminated as it had been for brook trout. For the final analyses, we added the Al:DOC terms. A collinearity resulted, and the ratio of estimated inorganic Al:DOC was eliminated to resolve it. This variable set is denoted B1A (Table A-4) The biological variables differed from those for brook trout as follows:

- The competitors included only golden shiner and lake chub 
- The predators (a new category) included northern pike, chain pickerel, muskellunge, and large- and smallmouth bass.

- The associated species were the same as for brook trout, except that creek chub and lake chub were removed and brook trout was added (see competitors above).

Stocking was not included as a predictor in any creek chub analysis, because the lakes included private lakes for which stocking information is not reliable

Most analyses were conducted with variable sets " $B 1 B$ " or " $B O B$." This involved removing candidate variables that are unreliable for at least some lakes (as discussed under Brook Trout; also see

Table A-4). The data for Lake Group 5 was then adjusted by including lakes previously excluded

Table A.25 Variables Selected to Explain the Presence of Creek Chub in Qualified Group 6 Lakes (Nonbog Calibration Lakes) in Oswegatrhie-Black or Mohawk-Hudson Watershedsa (Biological Variables Included)

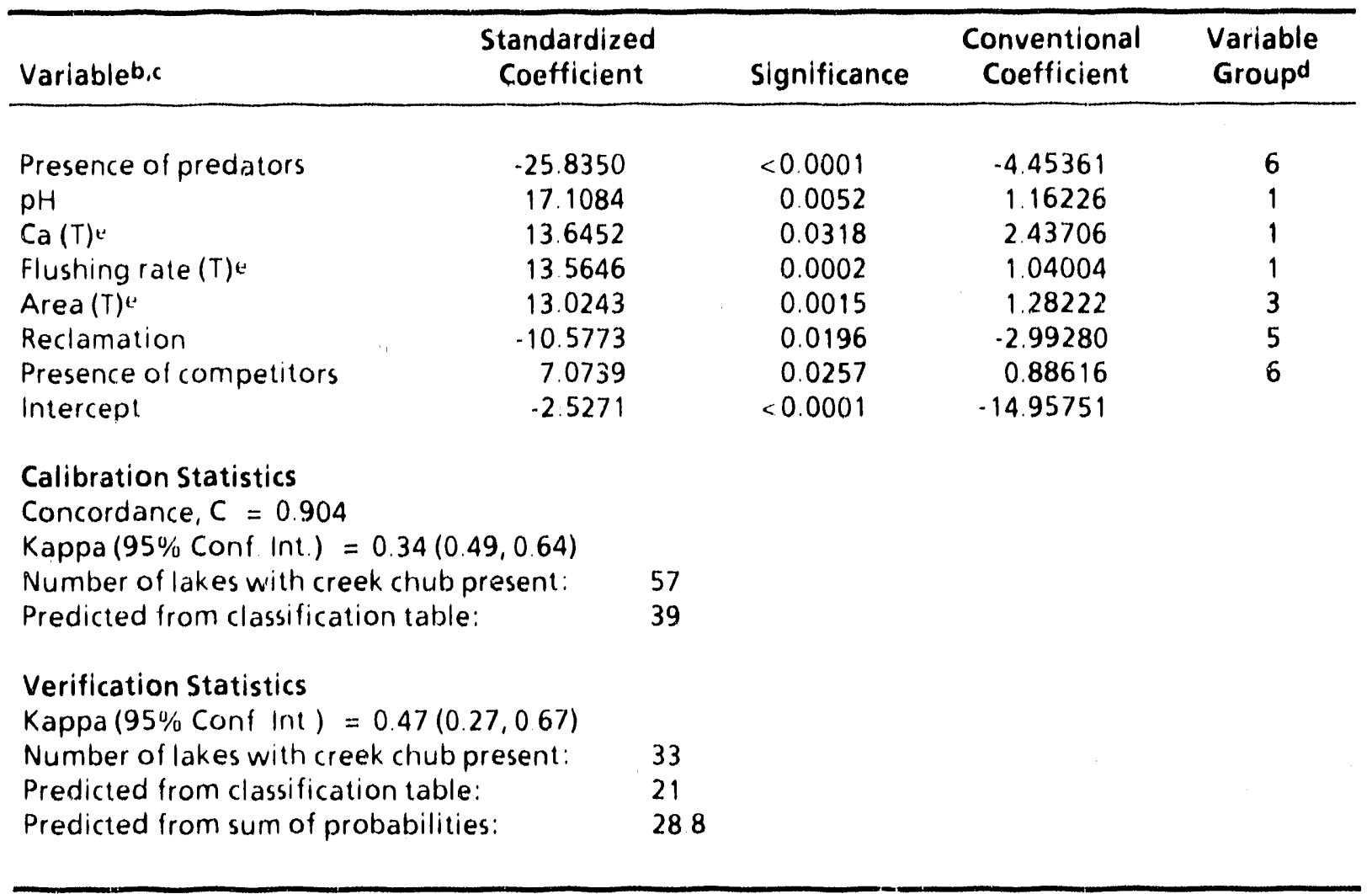

a A preponderance of high-elevation lakes and some of the highest levels of acidic deposition.

b Listed in order of the absolute magnitude of their standardized coefficients.

c Stepwise selection, starting with variable set B1B (a reduced set of 23 noncollinear creek chub candidate variables judged potentially most important, with selected unreliable variables excluded), was used to identify these variables.

a Variable groups are defined in Table A.1.

e (T) denotes that a transformed form of the variable was used. 
Table A.26 Variables Selected to Explain the Presence of Creek Chub in Qualified Group 6 Lakes (Nonbog Calibration Lakes) in Oswegatchie-Black or Mohawk-Hudson Watersheds a (Blological Variables Excluded)

\begin{tabular}{|c|c|c|c|c|c|}
\hline Varlableb,c & \multicolumn{2}{|l|}{$\begin{array}{l}\text { Standardized } \\
\text { Coefficient }\end{array}$} & Significance & $\begin{array}{c}\text { Conventional } \\
\text { Coefficient }\end{array}$ & $\begin{array}{l}\text { Variable } \\
\text { Groupd }\end{array}$ \\
\hline $\mathrm{pH}$ & \multicolumn{2}{|l|}{18.0821} & $<0.0001$ & 1.22840 & 1 \\
\hline Flushing rate $(T) e$ & \multicolumn{2}{|l|}{9.9374} & 0.0004 & 0.76193 & 1 \\
\hline Number of inlets $(T)^{t}$ & \multicolumn{2}{|l|}{7.0603} & 0.0266 & 0.59626 & 4 \\
\hline Intercept & \multicolumn{2}{|l|}{-1.9982} & $<0.0001$ & -9.80190 & \\
\hline \multicolumn{6}{|l|}{ Calibration Statistics } \\
\hline \multicolumn{6}{|c|}{ Concordance, $C=0.843$} \\
\hline \multicolumn{6}{|c|}{ Kappa $(95 \%$ Conf. Int. $)=0.13(-0.07,0.33)$} \\
\hline \multicolumn{2}{|c|}{ Number of lakes with creek chub present: } & 57 & & & \\
\hline \multicolumn{2}{|c|}{ Predicted from classification table: } & 20 & & & \\
\hline \multicolumn{6}{|l|}{ Verification Statistics } \\
\hline \multicolumn{6}{|c|}{ Kappa $(95 \%$ Conf. Int. $)=0.05(-0.21,0.32)$} \\
\hline \multicolumn{2}{|c|}{ Number of lakes with creek chub present: } & 33 & & & \\
\hline \multirow{2}{*}{\multicolumn{2}{|c|}{ Predicted from classification table: }} & 14 & & & \\
\hline & & 29.9 & & & \\
\hline
\end{tabular}

a A preponderance of high-elevation lakes and some of the highest levels of acidic deposition.

b Listed in order of the absolute magnitude of their standardized coefficients.

c Stepwise selection, starting with variable set $80 B$ (a reduced set of 21 noncollinear creek chub candidate variables judged potentially most important, with selected unreliable variables excluded), was used to identify these variables.

d Varlable groups are defined in Table A-1.

e (T) denotes that a transformed form of the variable was used.

because of missing observations for one or more of these removed variables. The exclusion of these variables resulted in different models (Tables A- 22 developed from variable set B 1 A versus A-23 developed from variable set $B 1 B)$, but an essentially identical value of the concordance statistic (0.904 versus 0.903$)$. Variable sets beginning with $B 0$ had the three biological variables removed (competitors, predators, and associates). With Lake Group 5, moving from variable set $\mathrm{BOA}$ to BOB (with the attendant increase in the number of lakes that could be included in the analysis) caused $\mathrm{pCa}: \mathrm{pH}$ to become marginally collinear with $\mathrm{pH}$ and $\mathrm{Ca}$ (maximum condition number $=31.7$ ). To maintain comparability with the other Lake Group 5 analyses, this collinearity was not resolved. However, $\mathrm{pCa}$ : $\mathrm{pH}$ was not included in the candidate variables for the individual watershed analyses (Lake Groups 6 and 7). Although it often has a large explanatory ability in models in which it is included (considering both preliminary brook trout results and these creek chub results), pH effects on fish cannot be separated from Ca effects on fish with this variable. 
Table A-27 Variables Selected to Explain the Presence of Creek Chub in Qualified Group 7 Lakes (Nonbog Calibration Lakes) in Lake Champlain or Upper Hudson Watershedsa (Biological Variables Included)

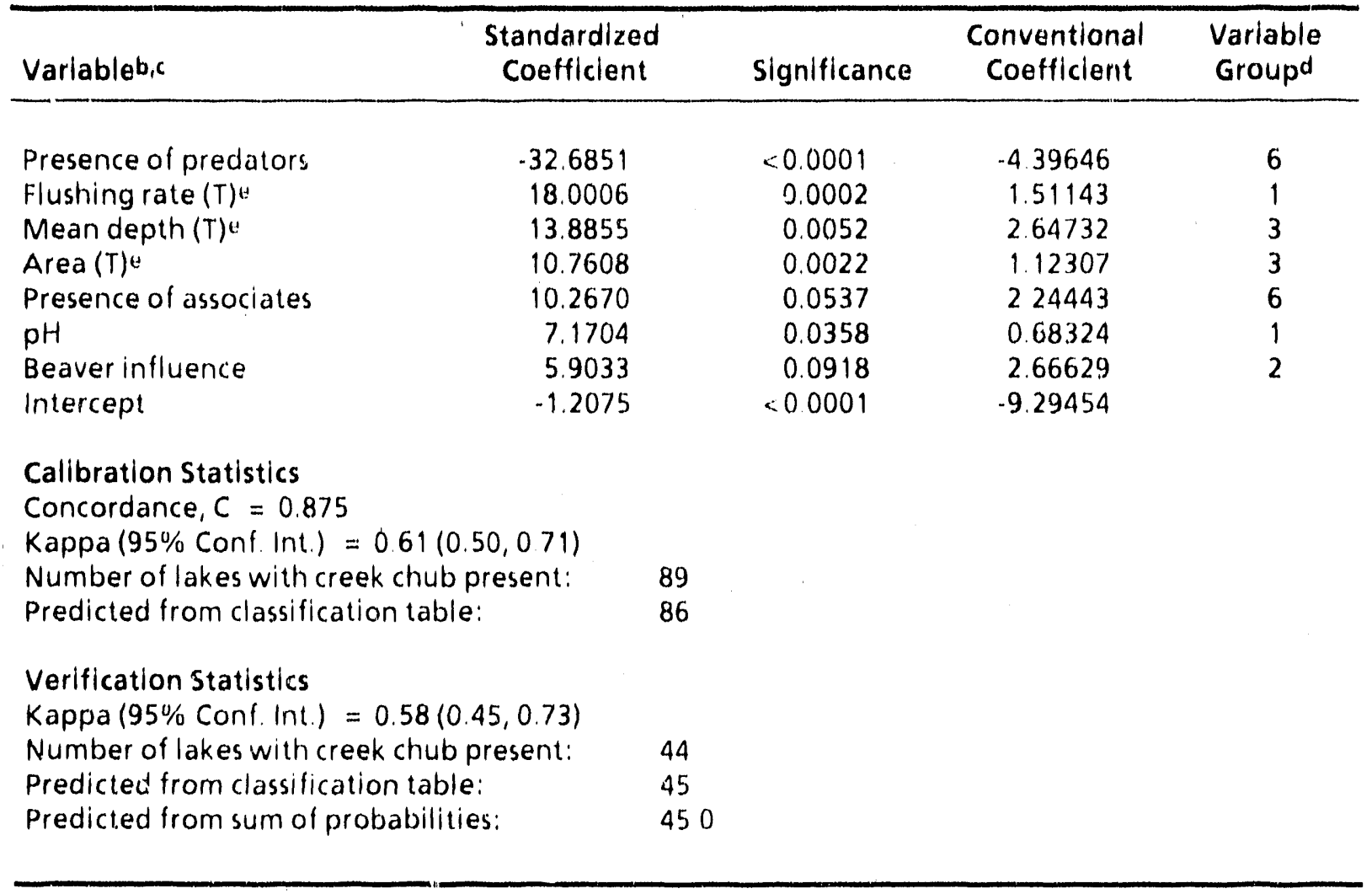

a Represent a contrasi with group 6 lakes with respect to elevation and levels of acidic deposition.

b Listed in order of the absolute magnitude of their standardized coefficients.

- Stepwise selection, starting with variable set B1B (a reduced set of 25 noncollinear creek chub candidate varlables judged potentially most important, with selected unreliable variables excluded), was used Jentify the:e varlables.

d Varlable groups are defined in Table A-1.

- The notation ( $T$ ) after a variable name denotes that a transformed form of the variable was used.

For the watershed analyses (Lake Groups 6 and 7), the number of observations was relatively small (Table A-31, lust column) when compared with the number of explanatory variables being considered. When a model is being developed from a large number of explanatory or predictor variables, the possibility exists of spurious associations between the response variable and the candidate explanatory variables. This occurrence depends on the total number of lakes, the distribution of presences and absences within these lakes, and the number of explanatory variables. The existence of data inadequacies (e.g., insufficient data for the number of predictor variables) usually is manifested by the same kinds of numerical instabilities or difficulties with the parameter estimates that are characteristic of excessive collinearity. For example, the standard errors may be large or the estimated, parameter may have a sign different than expected. 
Table A-28 Varlables Selected to Explain the Presence of Creek Chub in Qualified Group 7 Lakes (Nonbog Calibration Lakes) in Lake Champlain or Upper Hudson Watershedsa (Biological Varlables Excluded)

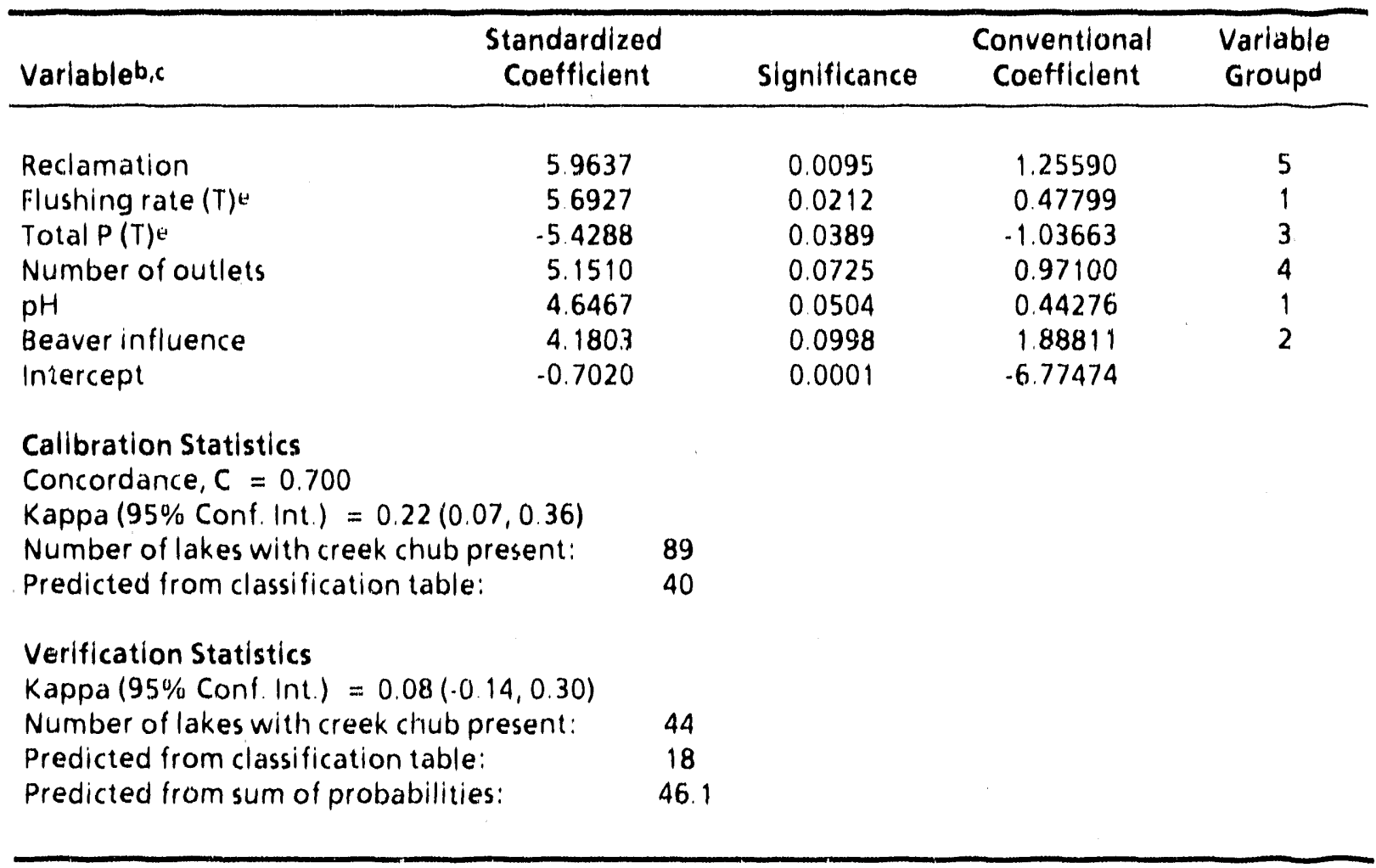

a Represent a contrast with group 6 lakes with respect to elevation and levels of acidic deposition.

b Listed in order of the absolute magnitude of their standardized coefficients.

- Stepwise selection, starting with varlable set $\mathrm{BOB}$ (a reduced set of 22 noncollinear creek chub candidate varlables judged potentially most important, with selected unrellable varlables excluded), was used to identify these variables.

d Variable groups are defined in Table A-1.

- (T) denotes that a transformed form of the variable was used.

To minimize this possibility, the analyses for Lake Groups 6 and 7 used a further restricted set of variables: only those variables considered most likely to be important (marked with an asterisk in Table A-1), and reliable (see modifier B in Table A-4) were included as candidates. Collinearity was also rechecked; lake volume and magnesıum $(\mathrm{Mg})+$ Ca were eliminated for both Lake Groups 6 and 7 to satisfy collinearity constraints. In addition, the (biological) associates variable and the variable indicating recent reclamation had to be removed for Lake Group 6. Deleting these variable; was necessary because in this lake group, the associates variable was alivays 1 when creek chub were present, and recent reclamation was never associated with presence. These conditions caused numerical problems with the analysis. Even with this attempt to reduce the number of candidate 


\begin{tabular}{|c|c|c|c|c|c|c|}
\hline \multirow{3}{*}{$\begin{array}{l}\text { Lake } \\
\text { Groupa }\end{array}$} & \multirow{3}{*}{$\begin{array}{c}\text { Variable } \\
\text { Setb }\end{array}$} & \multirow[b]{3}{*}{ Kappac } & \multicolumn{4}{|c|}{ Classification Table (Prior $=0.5)$} \\
\hline & & & \multirow[b]{2}{*}{ Observed } & \multicolumn{2}{|c|}{ Predicted } & \multirow[b]{2}{*}{ Total } \\
\hline & & & & Absences & Presences & \\
\hline \multicolumn{7}{|c|}{ Creek Chub } \\
\hline 5 & B1A & $\begin{array}{c}0.64 \\
(0.58,0.70)\end{array}$ & $\begin{array}{l}\text { Absences } \\
\text { Presences } \\
\text { Total }\end{array}$ & $\begin{array}{r}424 \\
51 \\
475\end{array}$ & $\begin{array}{r}69 \\
198 \\
267\end{array}$ & $\begin{array}{l}493 \\
249 \\
742\end{array}$ \\
\hline 5 & $B 1 B$ & $\begin{array}{c}0.58 \\
(0.52,0.64)\end{array}$ & $\begin{array}{l}\text { Absences } \\
\text { Presences } \\
\text { Total }\end{array}$ & $\begin{array}{r}478 \\
54 \\
532\end{array}$ & $\begin{array}{r}84 \\
203 \\
287\end{array}$ & $\begin{array}{l}562 \\
257 \\
819\end{array}$ \\
\hline 5 & $\mathrm{BOB}$ & $\begin{array}{c}0.34 \\
(0.26,0.41)\end{array}$ & $\begin{array}{l}\text { Absences } \\
\text { Presences } \\
\text { Total }\end{array}$ & $\begin{array}{l}476 \\
136 \\
612\end{array}$ & $\begin{array}{r}86 \\
121 \\
207\end{array}$ & $\begin{array}{l}562 \\
257 \\
819\end{array}$ \\
\hline 6 & $\mathrm{~B} 1 \mathrm{~B}$ & $\begin{array}{c}0.49 \\
(0.34,0.64)\end{array}$ & $\begin{array}{l}\text { Absences } \\
\text { Presences } \\
\text { Total }\end{array}$ & $\begin{array}{r}263 \\
30 \\
293\end{array}$ & $\begin{array}{l}12 \\
27 \\
39\end{array}$ & $\begin{array}{r}275 \\
57 \\
332\end{array}$ \\
\hline 6 & ВОВ & $\begin{array}{c}0.13 \\
(-0.07,0.33)\end{array}$ & $\begin{array}{l}\text { Absences } \\
\text { Presences } \\
\text { Total }\end{array}$ & $\begin{array}{r}263 \\
49 \\
312\end{array}$ & $\begin{array}{r}12 \\
8 \\
20\end{array}$ & $\begin{array}{r}275 \\
57 \\
332\end{array}$ \\
\hline 7 & $\mathrm{~B} 1 \mathrm{~B}$ & $\begin{array}{c}0.61 \\
(0.50,0.71)\end{array}$ & $\begin{array}{l}\text { Absences } \\
\text { Presences } \\
\text { Total }\end{array}$ & $\begin{array}{r}145 \\
24 \\
169\end{array}$ & $\begin{array}{l}21 \\
65 \\
86\end{array}$ & $\begin{array}{r}166 \\
89 \\
255\end{array}$ \\
\hline 7 & $\mathrm{BOB}$ & $\begin{array}{c}0.22 \\
(0.07,0.36)\end{array}$ & $\begin{array}{l}\text { Absences } \\
\text { Presences } \\
\text { Total }\end{array}$ & $\begin{array}{r}151 \\
64 \\
215\end{array}$ & $\begin{array}{l}15 \\
25 \\
40\end{array}$ & $\begin{array}{r}166 \\
89 \\
255\end{array}$ \\
\hline \multicolumn{7}{|c|}{ Fish versus No Fish } \\
\hline 5 & BOA & $\begin{array}{c}0.73 \\
(0.67,0.80)\end{array}$ & $\begin{array}{l}\text { Absences } \\
\text { Presences } \\
\text { Total }\end{array}$ & $\begin{array}{r}107 \\
22 \\
129\end{array}$ & $\begin{array}{r}38 \\
575 \\
513\end{array}$ & $\begin{array}{l}145 \\
597 \\
742\end{array}$ \\
\hline 5 & $B O B$ & $\begin{array}{c}0.73 \\
(0.67,0.79)\end{array}$ & $\begin{array}{l}\text { Absences } \\
\text { Presences } \\
\text { Total }\end{array}$ & $\begin{array}{r}138 \\
30 \\
168\end{array}$ & $\begin{array}{r}43 \\
608 \\
651\end{array}$ & $\begin{array}{l}181 \\
638\end{array}$ \\
\hline
\end{tabular}

- See Table A-4 for definitions of lake groups.

- See Table A-4 for definitions of variable sets.

c Asymptotic $95 \%$ Conf. Int. shown in parenthesis. 


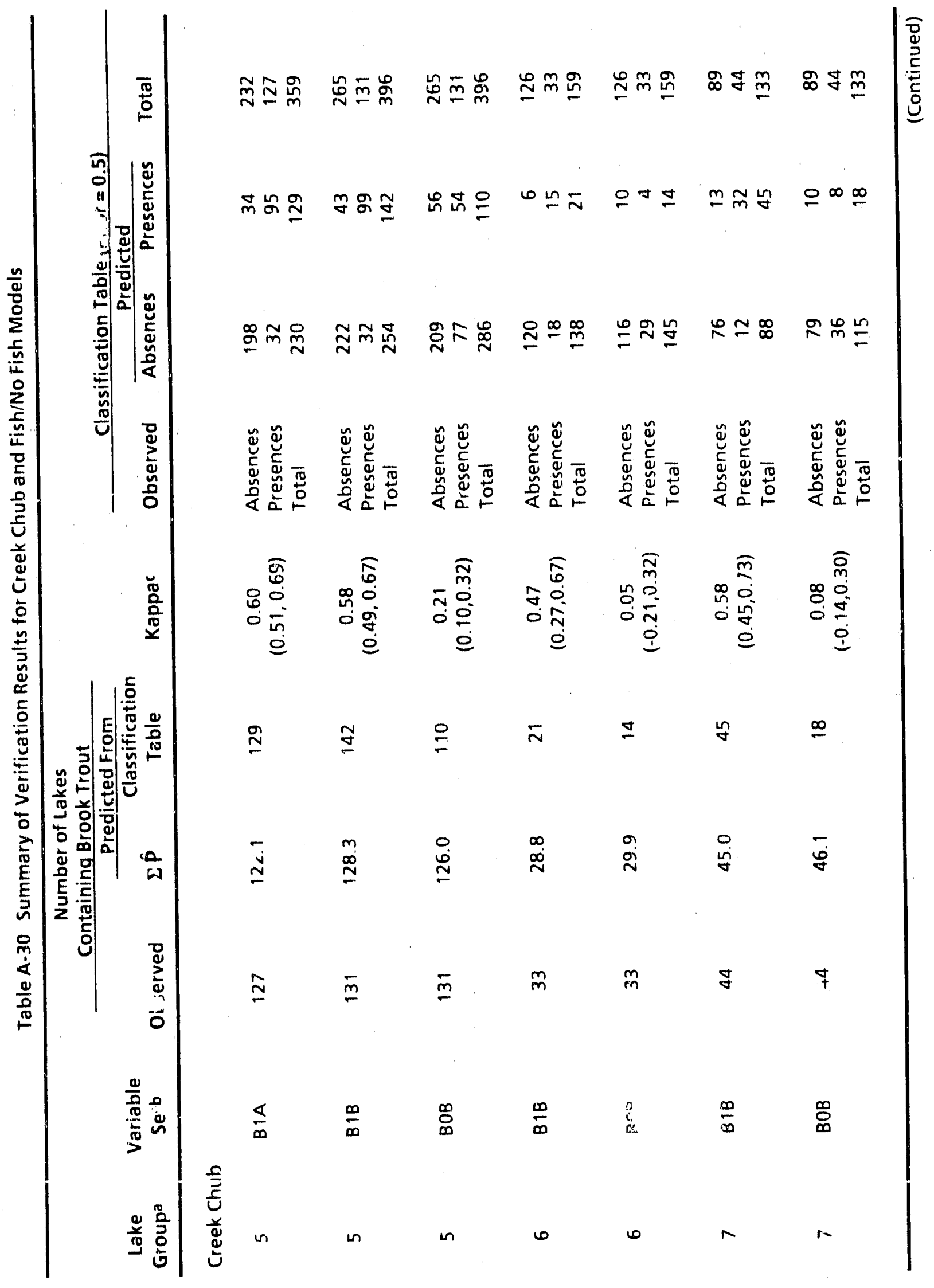




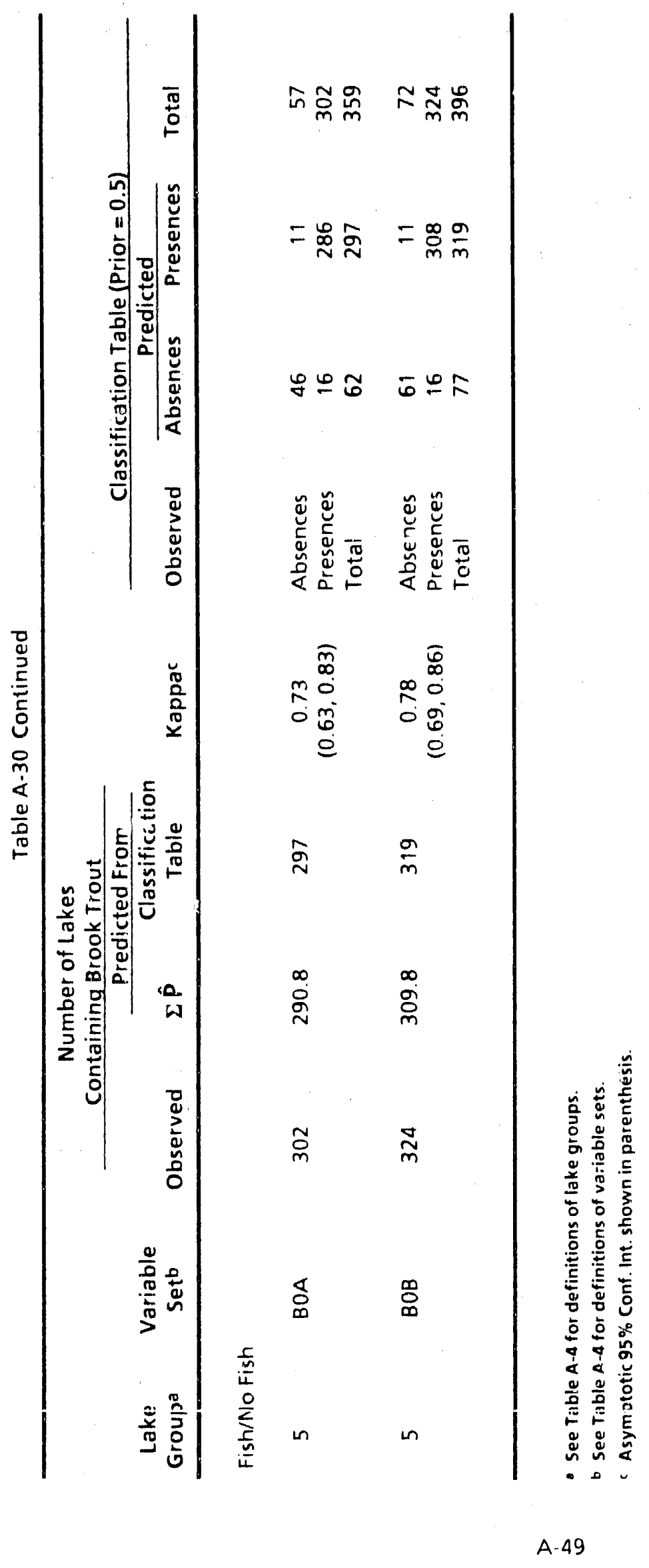




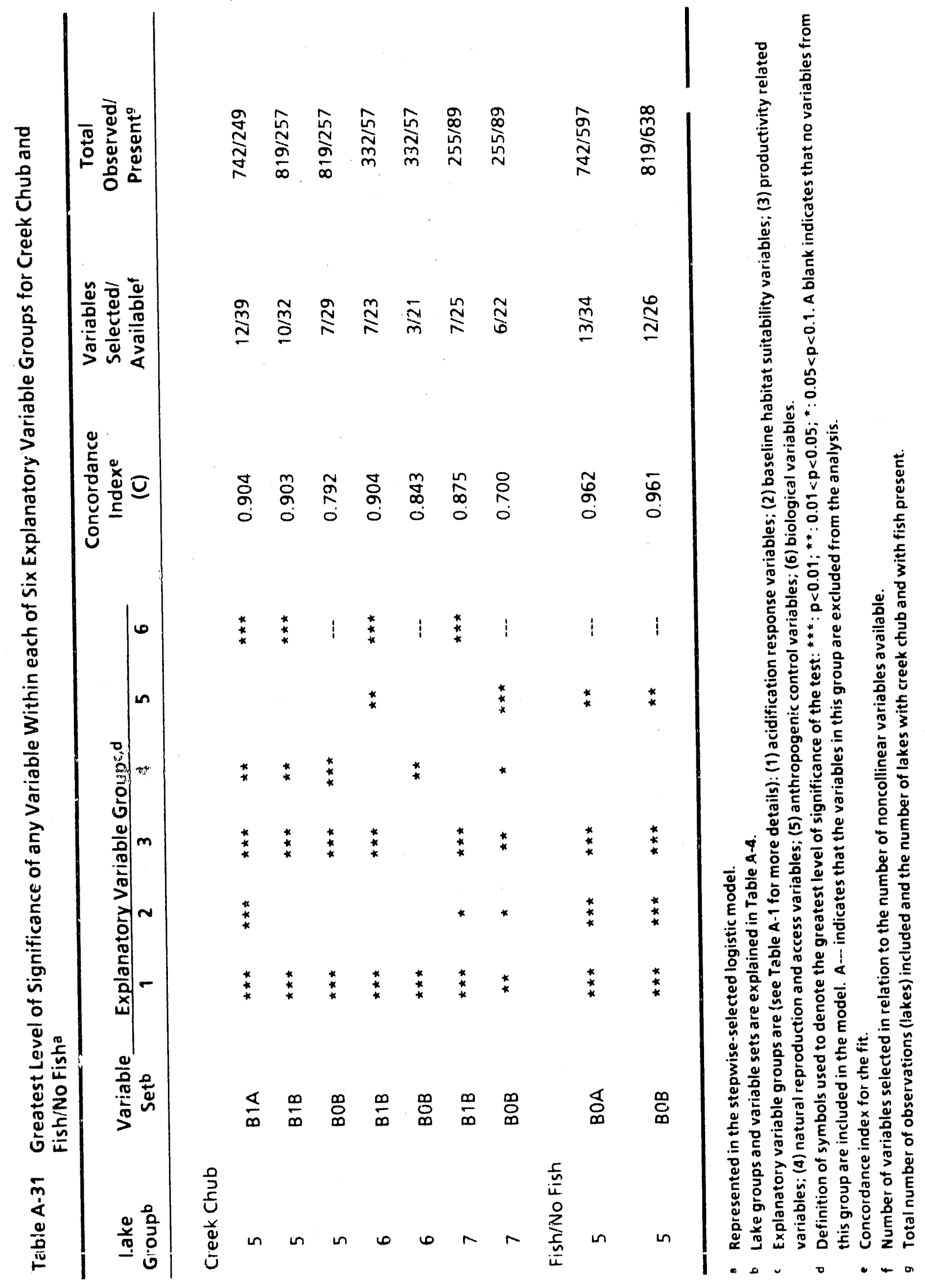


variabies, some of the unexpected results from our derived models may be a result of insufficient sample size for the number of variables in the final selected model

The results are summarized in Table A-31. In general, the nature of variables selected and the signs of the coefficients are consistent with the notion that the less stream-like and the more lake-like conditions are, the less likely it is that creek chub will be found. As for brook trout, biological variables, if they are provided, are always significant in the model. Contrary to expectation, competitors enter in two models with a positive sign. Evidently, the presence of golden shiner and/or lake chub (the "competitors") is a better indicator of conditions suitable for creek chub than it is of the negative influence of competition. Acidification response variables are consistently important. In Lake Group 5, pCa: $\mathrm{pH}$ is highly significant in all cases (Tables A-22 through A-24) Because pCa:pH increases as $\mathrm{pH}$ decreases and $\mathrm{Ca}$ increases, the negative sign indicates higher probability of absence with increasingly stressful $\mathrm{pH}$ and $\mathrm{Ca}$ conditions. Field $\mathrm{pH}$ also enters by itself with a negative sign, indicating it is possibly "fine tuning" the main effect of $\mathrm{pCa}: \mathrm{pH}$. In particular, comparing Lake Group 6 with Lake Group 7 (Tables A-25 and A-26 versus A-27 and A-28), the acidification response variables selected are $\mathrm{pH}$ and flushing rate. The latter is considered an acidification resporise variable not in the sense of responding to acidification, but rather because higher values may indicate the potential for acidic episodes. In its acidification-indicating role, it would be expected to have a negative sign. The positive sign seen here likely indicates that its role for creek chub may be as an indicator of more creek-like conditions. The importance of $\mathrm{pH}$ as an inhibiting factor, particularly in the variable sets that do not include biological explanatory variables, is greater in the Oswegatchie-Black and Mohawk-Hudson watersheds (Lake Group 6) than in the Lake Champlain and Upper Hudson watersheds (Lake Group 7). This is consistent with the greater number of lakes in Lake Group 6 with the potential for acidic stress

Fish versus No Fish. Two analyses have been conducted for the presence of fish of any species, as opposed to fishless lakes ("fish versus no fish"). Biological variables are not involved in these analyses because the presence of fish is the object of the model. To use a subset of this as an explanatory variable as well would not be useful, and vrould lead to numerical problems as well. For similar reasons, stocking is not of major interest as an explanation of fish presence here. Accordingly, stocking was not used as a predictor, and the analyses were conducted using Lake Group 5 (all qualified calibration lakes, regardless of ownership, except for fully bog lakes which never have fish).

We used variable sets $B O A$ and $B O B$. These sets included the variables listed in Table $A-1$, as modified by the exclusions shown in Table A-7 due to collinearity. Measured Al:DOC and estimated A.I:DOC were then added to create set $B O A$; the estimated $A I: D O C$ was then removed to reduce collinearity. 
To create variable set $B O B$, the eight variables listed in Table $A-4$ under modifier " $B$ " were removed, and collinearity was rechecked.

The results are summarized in Tables A-29 through A-31, and the individual models are presented in Tables A-32 and A-33. The selected models have many terms, broadly distributed among the variable groups (Table A-31). They also do a good job of predicting fish presence versus absence, as evidenced by the high values of the concordance statistic on the calibration data and of kappa on both the calibration and the verification data.

It is useful to think of these models as identifying variables that indicate unsuitable conditions. This approach is useful because most lakes have fish, and fish adapt to a wide range of con "ions. If a lake in the Adirondacks lacks fish, one would usually expect a factor or factors representing severe conditions to be able to explain this. Of course, the data base may or may not have good information about the relevant factors for a particular lake (e.g., winter or summer deoxygenation or complete freezing in the winter)

Both acidification-response and other variables are important in both models. Caliturn, pH (coupled with ANC, in the manner already described for brook trout), and Al are selected in both models. These are the three chemical constituents that are considered likely to change in the process of acidification and that are also known to be important to fish. It is interesting that total Al, rather than estimated inorganic $A l$, is selected because the inorganic monomeric fraction of $A l$ is usually most toxic to fish. Nonetheless, the selection of these three terms is consistent with the hypothesis that acid-base chemistry restricts the presence of fish in sorile Adirondack lakes.

Other explanatory variables are also important in the models. Lake area is an important variable; large lakes would not be expected to be fishless. Conductivity was highly significant with a positive sign in the examination of pairwise associations (Table A-1). In these multivariate models, it is highly significant but with a negative sign. It is probably interacting with Ca in these models, with the kind of sign-switching discussed previously. Elevation may indicate winterkills due to frezzing it is difficult to interpret some variables (e.g., sodium; bogs versus marginal bogs). The caution against overinterpretation of these kinds of models, expressed in the Brook Trout subsection, applies here as well.

In summary, these models are able to predict well the presence or absence of fish, without using iniormation about stocking; these predictions are largely based on physical and chemical variables Most signs on the coefficients (indicating the direction of effect) are in accordance with expectation or are at least plausible 
Table A-32 Variables Selected to Explain the Presence of Fish of any Species (as Opposed to Fishless Lakes) in Qualified Group 5 (all Qualifying Nonbog Calibration) Lakes

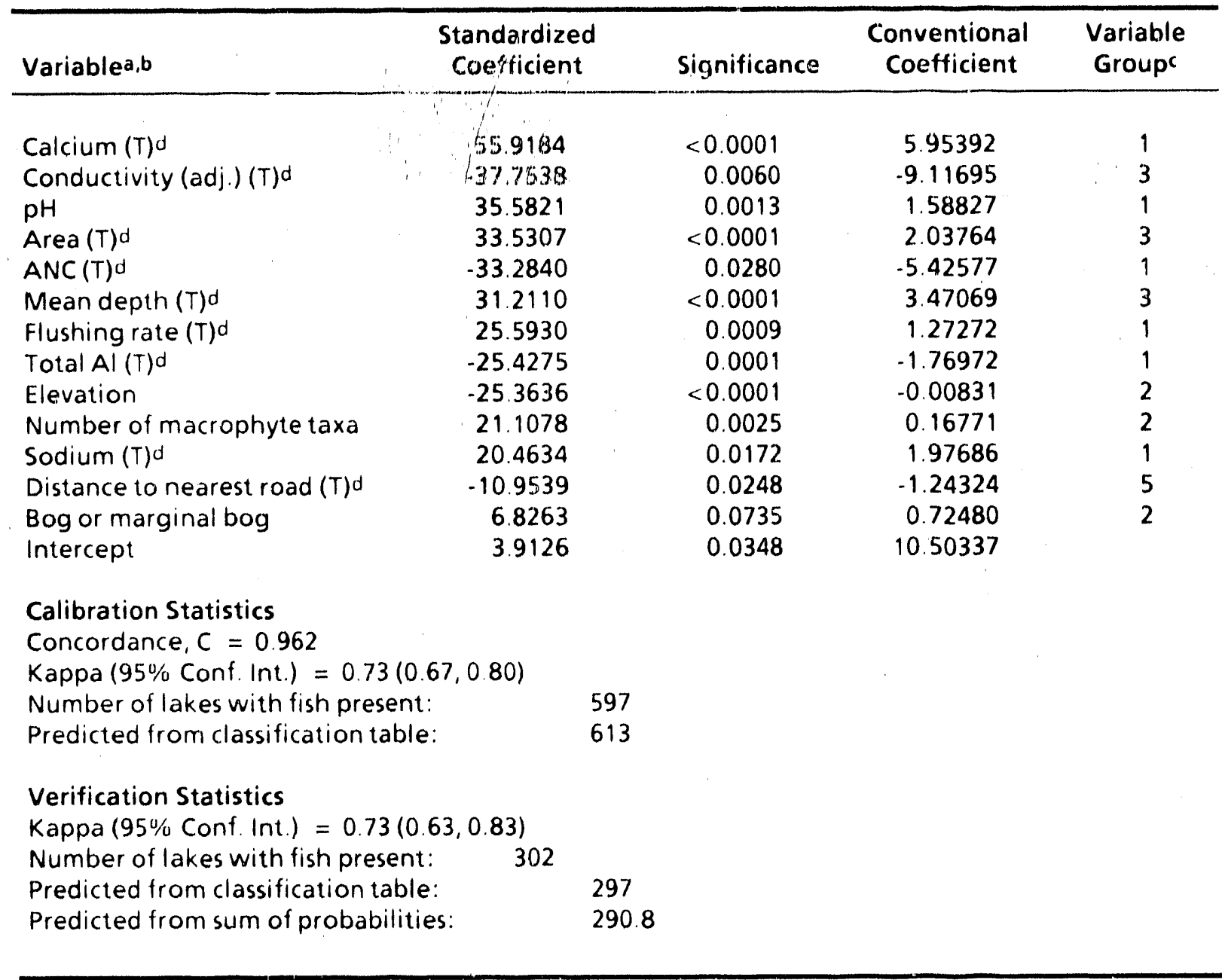

a Listed in order of the absolute magnitude of their standardized coefficients.

b Stepwise selection, starting with variable set BOA (34 noncollinear candidate variables), was used to identify these variables.

c Variable groups are defined in Table A.1.

d (T) denotes that a transformed form of the variable was used.

Projections for Representative Lakes. Although the emphasis in this section is on interpretation rather than prediction, the models we have developed can be used to predict the probaility of presence of the species we have analyzed, both in individual lakes ar,d for large regions. Because there is considerable unexplained variation in most of the models (for brook trout, particularly those not using biological variables and stocking information), regional predictions should generally be much more reliable than predictions for individual lakes. Regional predictions, which will be conducted for the NAPAP, are beyond the scope of this report. Nonetheless, even predictions for 
Table A-33 Variables Selected to Explain the Presence of Fish of any Species (as Opposed to Fishless Lakes) in Qualified Group 5 (all Qualifying Nonbog Calibration) Lakes

\begin{tabular}{|c|c|c|c|c|c|}
\hline Variablea,b & $\begin{array}{l}\text { tandardized } \\
\text { Coefficient }\end{array}$ & & Significance & $\begin{array}{c}\text { Conventional } \\
\text { Coefficient }\end{array}$ & $\begin{array}{l}\text { Variable } \\
\text { Groupc }\end{array}$ \\
\hline $\mathrm{Ca}(\mathrm{T})^{\mathrm{d}}$ & 51.6125 & & $<0.0001$ & 5.29116 & 1 \\
\hline $\mathrm{pH}$ & 46.9246 & & $<0.0001$ & 1.96421 & 1 \\
\hline Area $(T) d$ & 38.3154 & & $<0.0001$ & 2.25293 & 3 \\
\hline Conductivity (adj.) (T)d & -38.2756 & & 0.0021 & -8.97450 & 3 \\
\hline Elevation & -31.8344 & & $<0.0001$ & -0.00997 & 2 \\
\hline Mean depth $(T)^{d}$ & 30.0700 & & $<0.0001$ & 3.21406 & 3 \\
\hline $\operatorname{ANC}(T) d$ & -29.3234 & & 0.0404 & -4.58055 & 1 \\
\hline Total Al (T)d & -28.9212 & & $<0.0001$ & -1.88997 & 1 \\
\hline Flushing rate $(T) d$ & 25.9080 & & 0.0003 & 1.24768 & 1 \\
\hline$N A(T) d$ & 22.7039 & & 0.0076 & 2.10579 & 1 \\
\hline Ownership & 10.3839 & & 0.0218 & 0.72745 & 5 \\
\hline Bog or marginal bog & 8.5939 & & 0.0259 & 0.87074 & 2 \\
\hline Intercept & 3.5327 & & 0.0717 & 8.53240 & \\
\hline \multicolumn{6}{|l|}{ Calibration Statistics } \\
\hline \multicolumn{6}{|l|}{ Concordance, $C=0.961$} \\
\hline \multicolumn{6}{|c|}{ Kappa $(95 \%$ Conf. Int $)=0.73(0.67,0.79)$} \\
\hline Number of lakes with fish present: & & 638 & & & \\
\hline Predicted from classification table: & & 651 & & & \\
\hline \multicolumn{6}{|l|}{ Verification Statistics } \\
\hline \multicolumn{6}{|c|}{$\operatorname{Kappa}(95 \%$ Conf Int $)=0.78(069,0.86)$} \\
\hline Number of lakes with fish present: & & 324 & & & \\
\hline Predicted from classification table: & & 319 & & & \\
\hline Predicted from sum of probabilities: & & 309.8 & & & \\
\hline
\end{tabular}

- Listed in order of the absolute magnitude of their standardized coefficients.

b Stepwise selection, starting with variable set BOB $(26$ noncollinear candidice variables, with selected unreliable variables excluded), was used to identify these variables.

c Variable growps are defined in Table A. 1.

d (T) denotes that a transformed form of the variable was used.

individual lakes can be useful, both to illustrate model results and to explore the sensitivity of the models to changes in individual explanatory variables

In Section 2.4, a lake classification scheme was developed for Adirondack lakes. For four classes of lakes, obtained as the four combinations of thin-till versus mounded, and low DOC versus high DOC, it was possible, as a scenario, to estimate the change in $\mathrm{pH}$ that would be expected given a predicted change in ANC of $15 \mu \mathrm{eq} / \mathrm{L}$ resulting from a $30 \%$ reduction in sulfur deposition (Table $2.5-1$ ). This information, together with four individual lakes identified as typical of each lake class (Ron Munson, 
pers. comm.), can be used to estimate the change in the probability of brook trout presence in each of these typical lakes

Before presenting the results of this analysis, however, it is worthwhile to consider the importance and reliability of the coefficients in the model. The coefficients are important because the predicted changes in the probability of brook trout presence will be governed by all of the terms in the model. The $\mathrm{pH}$ and ANC terms are of particular interest (because these are the variables that change in the scenario). Larger coefficients for a given variable (e.g., $\mathrm{pH}$ and ANC) would lead to a larger predicted change in probability of presence, all other factors being equal. However, the remaining terms in the model are also important. Specifically, if the pre-scenario predicted probability of presence is either very high or very low (determined by all of the terms in the model), the change in the predicted probability of presence for a given model will be lower than if the pre-scenario predicted probability of presence is intermediate (i.e., close to 0.5 )

It is reasonable to question the accuracy of the coefficients in the models, particularly of the coefficients for the $\mathrm{pH}$ term. Concern about the accuracy of the coefficients arise mainly for the three reasons discussed in Section A. 1 1: model mis-specification, errors-in-variables, and multicollinearity.

By way of investigating the extent to which coetficients in these models may not be accurate, coefficients of $\mathrm{pH}$ in all relevant brook trout models are compared in Table A. 34. The coefficients of $\mathrm{pH}$ vary rather widely, from a low value of 0.66 to a maximum of 226 Of particular interest are the shifts in the coefficients for variable set 80 between Lake Group 1 and $1 \mathrm{~L}$, and between Lake Group 2 and $2 \mathrm{~L}$. In these comparisons, only lakes with pH less than or equal to 6 are used in the "L" ("low$\mathrm{pH}$ ") groups. The models selected prior to this restriction are either refitted (forced) to the " $L$ " sets [denoted as (F)], or are used as the basis for selection of an even more reduced model [denoted as (S)]. On these "L" sets, with lakes excluded above a pH of 6 where further increases in $\mathrm{pH}$ should not be important for brook trout presence, the coefficient of $\mathrm{pH}$ increases substantially (nearly doubling between Lake Groups 2 and $2 L$ with the forced fit).

In Appendix B, "robust estimation" methods are applied to two of these cases (Lake Groups 1 and 2 witi variable set $\mathrm{B} 0$ ). In these two cases, after application of a one-step Huber estimator with a gentle scale factor, the $\mathrm{pH}$ coefficients increased from 1.51 to 2.30 for Lake Group 1 and from 1.16 to 1.51 for Lake Group 2. Eliminating observations identified through robust methods as being influential leads to similar increases in the $\mathrm{pH}$ coefficient (Section A.2, later in this Appendix). in addition, two pH-only models have been developed on a set of lakes known, from historical presence of brook trout, to be suitable, and, if the population has disappeared, vvith no other explanation for disappearance except perhaps acidification (Baker et al, in review). The coefficients for these models 
Table A-34 Comparison of Values of the Coefficients of the pH Term in Stepwise-Selected Logistic Models of Brook Trout Presence/Absence in Adirondack Lakes

\begin{tabular}{|c|c|c|c|c|}
\hline $\begin{array}{l}\text { Lake } \\
\text { Groupa }\end{array}$ & $\begin{array}{c}\text { Variable } \\
\text { Seta }\end{array}$ & $\begin{array}{c}\mathrm{pH} \\
\text { Coefficientb }\end{array}$ & $\begin{array}{l}\text { Standard } \\
\text { Error }\end{array}$ & $\begin{array}{l}\text { Concordance } \\
\text { Index } \\
\text { (C) }\end{array}$ \\
\hline 1 & B1 & $1.25^{\star \star \star}$ & 0404 & 0.954 \\
\hline 1 & $\mathrm{~B} 1 \mathrm{~B}$ & $1.32^{\star \star \star}$ & 0.393 & 0.949 \\
\hline 1 & BO & $1.51^{\star \star \star}$ & 0.353 & 0.921 \\
\hline $1 L$ & $B O(S)$ & $2.11^{\star \star \star}$ & 0.496 & 0.937 \\
\hline $1 \mathrm{~L}$ & $B O(F)$ & $2.05^{\star \star \star}$ & 0.637 & 0.937 \\
\hline 1 & $B O B$ & $1.32^{\star \star \star}$ & 0.325 & 0.916 \\
\hline 2 & B1 & NS & NS & 0.926 \\
\hline 2 & $\mathrm{BO}$ & $1.16^{\star \star \star}$ & 0.280 & 0.839 \\
\hline $2 \mathrm{~L}$ & $\mathrm{BO}(\mathrm{S})$ & $2.00 \star \star \star$ & 0.534 & 0.864 \\
\hline 21. & $\mathrm{BO}(\mathrm{F})$ & $2.26^{\star \star \star}$ & 0.569 & 0.873 \\
\hline 3 & $\mathrm{BO}$ & $1.16^{\star \star \star}$ & 0.281 & 0.834 \\
\hline 4 & Bi & $0.708^{\star \star \star}$ & 0.146 & 0.850 \\
\hline 4 & BO & $0.660^{\star \star \star}$ & 0.207 & 0.771 \\
\hline 4 & $B O E$ & $0.877^{\star \star \star}$ & 0.193 & 0.762 \\
\hline
\end{tabular}

Lake groups and variable sets are described in Table A-4.

4 Definition of symbols used to indicate the level of significance of the test: ${ }^{*}: P<0.01 ;$ NS: not selected in the model.

are 3.13 and 5.04, respectively, for models not adjusted and adjusted for anomalous absences. Both of these coefficients are higher than any of the coefficients obtained in this project The robust estimation procedure described in Appendix $B$ was also applied to the nonadjusted model; the coefficient obtained in this manner (one-step Huber estimator) increased to 492 (Baker et al, in review)

Clearly, these models are not particularly successfut in accurately isolating the effects of $\mathrm{pH}$. On the other hand, most of these models contain other acidification-response variables besides $\mathrm{pH}$, and their ability to predict acidification responses may rot be impaired if the relationships among these variables does not change. In reality, however, these relationships likely will change, and it would not be prudent to rely solely on these types of models to predict the consequences of scenarios involving altered acidic deposition. This eads to the consideration of alternative approaches, as described in Baker et al. (in review)

With these caveats, Table A-35 presents the results of this analysis Because two of these representative lakes are privately owned, models involving stocking cannot be used Therefore, the comparison is based on only the models developed for Lake Group 4. In some cases there is essentially 
no change in the predicted probability of brook trout presence. Two factors account for this. First, the models developed frorn variable sets $B O$ and $B O E$ have negative coefficients for the ANC term, which counteract the change in $\mathrm{pH}$. Second, for lake 060055 , the predicted probability of brook trout presence is very low to begin with, so the effect of the increase in $\mathrm{pH}$ is very small. The largest predicted change in the probability of brook trout presence is $0.04(4 \%)$, for lake 040852 .

The three models for Lake Group 4, applied in Table A-35, have the lowest $\mathrm{pH}$ coefficients among the brook trout models we developed (Table A-34). Other models would tend to predict larger changes in brook trout presence for lakes with the same beginning predicted probability of presence. In a regional assessment, however, it is not clear that larger coefficients would lead to predictions of a larger number of lakes gaining brook trout; this depends also on the effects of the other terms of the mode!s. In addition, the four lakes used in this analysis were identified as representative of the lake classes with respect to factors relevant to chemistry, but were not selected with respect to all of the factors included in the models. These results should therefore be viewed as illustrative. An actual assessment of effects would need to consider a larger number of lakes (or representativeness with respect to all factors), and a largar range of models than those applied in Table A.35

\section{A.2 Logistic Regression Diagnostics}

In this section, the robust estimation results given in Appendix B for Lake Group 1 are compared with the results we obtained from an application of Pregibon's logistic regression diagnostics. In the robust estimation results, the potentially influential data points are downweighted as robust estimates of the model parameters are obtained. Table A-36 contains a summary of the weights for the 108 lakes that were downweighted in obtaining the robust parameter estimates. The smaller the weight value, the more severe is the influence of that observation on the resulting estimate

Pregibon's (1981) diagnostics provide measures that indicate the influence of each observation on the following aspects of the model:

1. Goodness of model estimate, i.e., how well does the model predict the sample observation? The components of deviance and chi-square statistics are used to evaluate this aspect. Large values, in absolute value, indicate spurious observations.

2. Coefficient sensitivity, i.e, how much does each observation influence the parameter estimate? Two statistics, $C_{1}$, and $\tilde{C}_{1}$, are used to evaluate the global sensitivity of the observation on the collection of parameter estimates. Large values of these statistics, in the sense of being larger than the major portion of the observations, indicate influential observations 
Table A-35 Predicted Probabilitles of Brook Trout Presence In Lakes Representative of Four Lake Types, under Current Conditions and under a Projected 30\% Decrease in Deposition. using Models Developed for Lake Group 4 (All Qualifying Calibration Lakes)

\begin{tabular}{|c|c|c|c|c|c|c|}
\hline \multirow{2}{*}{$\begin{array}{l}\text { Lake Class } \\
\text { (Pond Number) }\end{array}$} & \multicolumn{2}{|c|}{ Change in } & \multirow{2}{*}{$\begin{array}{c}\text { Basis } \\
\text { (Varlable Set) }\end{array}$} & \multicolumn{3}{|c|}{$\begin{array}{l}\text { Predicated Probabllity of } \\
\text { Brook Trout Presence }\end{array}$} \\
\hline & $(\mu e q / L)$ & (SU) & & Current & Projerted & Change \\
\hline $\begin{array}{l}\text { Thin till, low DOC } \\
(040852)\end{array}$ & 15 & 0.38 & $\begin{array}{l}B 1 \\
B 0 \\
B O E\end{array}$ & $\begin{array}{l}0.130 \\
0.222 \\
0.248\end{array}$ & $\begin{array}{l}0.164 \\
0.249 \\
0.253\end{array}$ & $\begin{array}{l}0.03 \\
0.03 \\
0.04\end{array}$ \\
\hline $\begin{array}{l}\text { Thin till, high DOC } \\
(040568)\end{array}$ & 15 & 0.17 & $\begin{array}{l}\text { B1 } \\
B 0 \\
B O E\end{array}$ & $\begin{array}{l}0.214 \\
0.379 \\
0.366\end{array}$ & $\begin{array}{l}0.235 \\
0.383 \\
0.371\end{array}$ & $\begin{array}{l}0.02 \\
0.00 \\
0.00\end{array}$ \\
\hline $\begin{array}{l}\text { Mounded, low DOC } \\
(030142)\end{array}$ & 15 & 0.22 & $\begin{array}{l}\text { B1 } \\
\text { BO } \\
B O E\end{array}$ & $\begin{array}{ll}0 & 133 \\
0.073 \\
0 & 144\end{array}$ & $\begin{array}{l}0.152 \\
0.076 \\
0.150\end{array}$ & $\begin{array}{l}0.02 \\
0.00 \\
0.01\end{array}$ \\
\hline $\begin{array}{l}\text { Mounded, high DOC } \\
(060055)\end{array}$ & 15 & 019 & $\begin{array}{l}B 1 \\
B 0 \\
B O E\end{array}$ & $\begin{array}{l}0015 \\
0011 \\
0.039\end{array}$ & $\begin{array}{l}0.017 \\
0.011 \\
0.038\end{array}$ & $\begin{array}{l}0.00 \\
0.00 \\
0.00\end{array}$ \\
\hline
\end{tabular}

Table A-36 Summary of Reckhow's Weights for Lake Group 1, Variable Set B0, 1 Iterationa

\begin{tabular}{ccc}
$\begin{array}{c}\text { Woight } \\
\text { in. ige }\end{array}$ & Frequency & $\begin{array}{c}\text { Relative } \\
\text { Frequency }\end{array}$ \\
\hline & & \\
$0.3-0.4$ & 17 & 0.16 \\
$0.4-0.5$ & 16 & 0.15 \\
$0.6-0.6$ & 18 & 0.17 \\
$0.7-0.8$ & 17 & 0.16 \\
$0.8-0.9$ & 17 & 0.16 \\
0.0 .999 & 16 & 0.15 \\
& 7 & 0.06 \\
& Total 108 & \\
\hline
\end{tabular}

- See Appendix $B$.

3. Goodness-of-fit sensitivity, i.e, how much does each observation influence the deviance and chi-square goodness-of-fit statistics? Two statistics, delta ceviance and delta chisquare, indicate the change in these two goodness-of-fit statistics when an observation is omitted. Again, large values indicate an inflitential observation. 
When the data were first submitted to the calculation of these diagnostics, three lakes were found to have outlying values, relative to the remaining data, for at least four of the dlagnostic measures. These three observations were omitted and the reduced data resubmilted to obtain new diagnostic measures. At this second pass, 18 acditional lakes were identified as being potentially influential. $A$ summary of the $21(=18+3)$ ponds identified is given in Table A. 37 ; note that all 17 of the lakes that were downweighted the most in Appendix $B$ were flagged as being influential by many of the diagnostic statistics. As a final cornparison, the 8-variable model was fit to the following data sets:

- full data set of 444 observations

- phase one data set of $441(=444-3)$ observations

- phase two data set of $423(=444-21)$ observations

The results of this are summarized in Table A-38. The estimates for all of the parameters increase in absolute magnitude, indicating a more sharply focused model in the sense that the change in the estimated probability of a fish species being present is more abrupt for a given change in an explanatory variable. This implies that the resulting model should do a better job of estimating the presence of fish in a given lake, and the concordance values for these models reflect this. The orderof-magnitude increase in the coefficient associated with the stocking of brook trout, along with the increase in its associated standard error, is caused by the fact that in the last pass ( $N=423$ ) all lakes with no brook trout present that had been stocked with brook trout have been eliminated because of their influence on the results. Therefore, numerical problems arise in the estimation of accurate coefficients for some of the parameters (e.g., here, stocking of brook trout).

Now that a collection of lakes has been identified as being influential on the derived model, the information on these lakes should be ciosely examined to determine if:

- potential errors exist in the recorded rata for the data at the identified lake,

- different ineasurement techriques were used in obtaining the information for the suspect lake, or

- the values for the explanatory and response variables are plausible.

In addition, the location of the influential lakes, relative to the ones remaining in the data set, should be examined to see if these lakes. are clustered together in a relatively small subarea of the total sampled area. The results of this investigation can be helpful in deciding if modifications need to be made in the proposed model (e g., the inclusion of some additional interaction-type terms). 
Table A-37 Summary of Influentlal Lakes from Preglbona Dlagnostics for Lake Group 1, Variable Set BO

\begin{tabular}{|c|c|c|c|}
\hline \multirow[b]{2}{*}{$\begin{array}{l}\text { Pond } \\
\text { Number }\end{array}$} & \multirow[b]{2}{*}{ Weightb } & \multicolumn{2}{|c|}{ Dlagnostic Summary } \\
\hline & & $\begin{array}{c}\text { Stage } \\
\text { Identifiedc }\end{array}$ & $\begin{array}{l}\text { Significant } \\
\text { Diagnosticsd }\end{array}$ \\
\hline & & & \\
\hline 020008 & 0.47151 & 2 & $c, d$ \\
\hline 020059 & 0.38541 & 2 & $d, e$ \\
\hline 020128 & 0.38107 & 2 & $a, b, c, d, e, f$ \\
\hline 020384 & 0.38158 & 2 & $a, e, f$ \\
\hline 020393 & 0.41552 & 2 & $c, d, e$ \\
\hline 030182 & 0.35600 & 2 & $a, b, c, d, e, f$ \\
\hline 030266 & 0.35769 & 1 & $a, b, e, f$ \\
\hline 030268 & 0.46179 & 2 & $a, b, c, d, e, f$ \\
\hline 030273 & 0.34025 & 1 & $a, b, c, d, e, f$ \\
\hline 040316 & 0.33878 & 2 & $c, d$ \\
\hline 040352 & 0.35785 & 2 & $a, b, c, d, e, f$ \\
\hline 040379 & 0.34792 & 2 & $a, b, c, d, e, f$ \\
\hline 040753 & 0.34549 & 2 & $a, b, c, d, e, f$ \\
\hline 040852 & 0.36727 & 2 & $a, b, c, d, e, f$ \\
\hline 040887 & 0.35244 & 2 & $a, b, e, f$ \\
\hline 040995 & 0.52214 & 2 & $c, d$ \\
\hline 041007 & 0.35334 & 2 & $a, b, c, d, e, f$ \\
\hline 050368 & 0.33091 & 1 & $a, b, c, d, e, f$ \\
\hline $050465 A$ & 0.35930 & 2 & $a, b, c, d, e, f$ \\
\hline 050671 & 0.36859 & 2 & $a, b, e, f$ \\
\hline 070770 & 0.37875 & 2 & $a, e, f$ \\
\hline
\end{tabular}

Pregibon, D. 1981.

- Weight assigned to each lake in the analysis by K. Reckhow (Section 3.4, Appendix B).

1 1 first pass; $2=$ second pass with reduced data set $(N=444 \cdot 3=441$ obs)

d Poorly fit observations

a:abs (Deviance component) $>2$

b:abs (Chi-square component) $>3$

Coefficient sensitivity

$c: C_{1}>0.2$

$d: \dot{C}_{1}>0.2$

Goodness of fit sensitivity

e: $\Delta$ Deviance $>2.0$

f: $\Delta$ Chi.square $>6.0$ 
Table A-38 Summary of Parameter Estimates With and Without Influential Observations for Brook Trout 8-Variable Model Using Lake Group 1 and Varlable Set BO

\begin{tabular}{|c|c|c|c|}
\hline \multirow[b]{2}{*}{ Parameter } & \multicolumn{3}{|c|}{ Estimate (Standard Error) } \\
\hline & 444 Observations & 441 Observations & 423 Observations \\
\hline Stocking of brook trout & $4.8331(0.5394)$ & $5.6179\langle 0.6621\rangle$ & $530665(63.7097)$ \\
\hline $\mathrm{pH}$ & $1.5147(0.3532)$ & $1.7256(0.3782)$ & $29159(0.5690)$ \\
\hline $\mathrm{SiO}_{2}(\mathrm{~T}) \mathrm{a}$ & $3.2227(0.6350)$ & $3.6955(0.6822)$ & $6.2215(1.0486)$ \\
\hline$A N C(T) a$ & $-2.6370(1.2580)$ & $-3.2300(1.3180)$ & $-5.3750(1.7294)$ \\
\hline Distance to nearest road $(T)$ a & $1.4321(0.4943)$ & $15314(0.5219)$ & $26578(0.7164)$ \\
\hline Substrate & $0.9725(0.3731)$ & $10571(0.3930)$ & $1.7617(0.5549)$ \\
\hline Number of oullets & $.0 .5400(0.3021)$ & $.06058(0.3181)$ & $.0 .9377(0.4236)$ \\
\hline Road type & $-0.6466(0.3447)$ & $-0.7987(0.3614)$ & $-1.5206(0.4842)$ \\
\hline Intercept & $-6.1583(2.1579)$ & $-6.2763(2.2652)$ & $-10.6827(3.1713)$ \\
\hline \multicolumn{4}{|l|}{ Goodness-of-Fit Statistics } \\
\hline Chi square & $570.2(P \cdot 0001)$ & $359.5(P>0.50)$ & $172.8(P>0.50)$ \\
\hline Deviance & $301.4(P>0.50)$ & $274.9(P>0.50)$ & $167.0(P>0.50)$ \\
\hline Degrees of freedom & 435 & 432 & 414 \\
\hline Concordance & 0.921 & $\cup 931$ & 0.974 \\
\hline
\end{tabular}

"(T) denotes that a transformed form of the varlable was used. 


\section{APPENDIX A - REFERENCES}

Baker, J., et al. In review. Biological effects of change, , is surface water acid-base chemistry. State-ofScience/Technology Report 13. National Acid Precipitation Assessment Program, Washington, DC.

Davis, C.S. 1988. Detection of influential observations in logistic regression using the $S A S^{\circledR}$ system. Proceedings of SAS ${ }^{\circledR}$ User's Group, International 13:964-969.

Draper, N.R., and H. Smith. 1981. Applied Regression Analysis, 2nd ed. John Wiley \& Sons. New York.

Fuller, W.A. 1987. Measurement Error Models. John Wiley \& Sons, New York.

Harrell, F.E., Jr. 1986. The LOGIST procedure. Pages 269-292. In: SUGI Supplemental Library User's Guide, Version 5 Ed. SAS ${ }^{\circledR}$ Institute, Inc., Cary, NC.

Hosmer, D.W., Jr., and S. Lemeshow 1989. Applied Logistic Regression. John Wiley \& Sons, New York.

Hunsaker, C.T., S.W. Christensen, J.J. Beauchamp, R.J. Olson, R.S. Turner, and J.L. Malanchuk. 1986. Empirical relationships between watershed attributes and headwater lake chemistry in the Adirondack region. ORNL/TM-9838. Oak Ridge National Laboratory, Oak Ridge, TN.

Kretser, W., J. Gallagher, and J. Nicolette. 1989. Adirondack Lakes Study, 1984-1987: An Evaluation of Fish Communities and Water Chemistry. Prepared for Adirondack Lakes Survey Corporation, Ray Brook, NY.

Marx, B.D., and E.P. Smith. In press. Ridge, principai component, and Stein logistic models of fish response to lake acidification. Can. J. Fish. Aquat. Sci.

Munson, R. Personal communication. Tetra Tech, Inc.

Pregibon, D. 1981. Logistic regression analysis. Ann. Stat. 9(4):705-724.

Reckhow, K.H., R.W. Black, I.B. Stockton, Jr., J.D. Vogt, and J. G. Wood. 1987. Empirical models of fish response to lake acidification. Can. J. Fish. Aquat. Sci. 44:1432-1442.

SAS® Institute, Inc. 1985a. SAS® User's Guide: Basics, Version 5 Edition. Cary, NC

SAS ${ }^{\circledR}$ Institute, Inc. 1985b SAS® User's Guide: Statistics, Version 5 Edition. Cary, NC.

SAS®Institute, Inc. 1985c. SAS®/IML User's Guide, Version 5 Edition. Cary, NC.

Titus, K., Mosher, J.A., and Williams, B.K. 1984. Chance-corrected classification for use in discriminant analysis: Ecological applications. Am. Midland Naturalist 111:1-7. 
APPENDIX B

Robust Estimation 


\section{CONTENTS}

List of Figures

\section{FIGURES}

B-1 Observed preserice and absence of brook trout as a function of lake $\mathrm{pH}$ and associated smoothing spline curve for data set $2 \mathrm{BO}$

B-2 Maximum likelihood model predicted probability of brook trout presence as a function of $\mathrm{pH}$, and associated smoothing spline curve, for data set 2BO

B-3 Robust model, $K=2.0$ with one iteration, predicted probability of brook trout presence as a function of $\mathrm{pH}$, and associated smoothing spline curve for data set 2BO

B-4 Robust model, $K=1.345$ with eight iterations, predicted probability of brook trout presence as a function of $\mathrm{pH}$ and associated smoothing spline curve for data set $2 \mathrm{BO}$

B-5 Observed presence and absence of brook trout as a function of lake pH and associated smoothing spline curve for data set 180

B-6 Maximum likelihood model predicted probability of brook trout presence as a function of $\mathrm{pH}$, and associated smoothing spline curve, for data set 1B0

B-7 Robust model, $K=2.0$ with one iteration, predicted probability of brook trout presence as a function of $\mathrm{pH}$, and associated smoothing spline curve for data set $1 \mathrm{BO}$

B-8 Robust model, $K=1.345$ with eight iterations, predicted probability of brook trout presence as a function of $\mathrm{pH}$, and associated smoothing spline curve, for data set 180 


\section{APPENDIX B}

\section{ROBLST ESTIMATION}

- Keckhow

\section{B1 Introduction}

After careful evaluation, improvements in both technology and in analytical methods should be established as part of the standard methods of a field. For example, laboratory and field methods for chemical and biological analyses continually improve as knowledge and technology improve; these improvements often become part of the set of standard methods, and they can be quite important in advancing basic scientific understanding. Likewise, improvements in statistical methods, including the development of methods that are more appropriate for analyzing environmental data, should become part of the set of standard methods for data analysis. Improved statistical methods can also be expected to advance scientific understanding, as they more effectively characterize information and evaluate candidate scientific hypotheses

Conventional statistical estimators like the sample mean and variance as well as procedures like least squares regression analysis are important in summarizing data and understanding relationships, particularly under normality. However, statisticians (e.g., Fisher 1922, Tukey 1960) have long recognized that statistical estimators and procedures that are appropriate for the normal distribution may be quite inefficient and improperly represent the data when normality does not hold. Despite that, the familiarity of the mean, the variance, t-tests, and least squares regression has helped to continue their use. The impression that parametric tests (like the t-test) are resistant to departures from normality also maintain their use. In fact, in common situations where the data are slightly more spread-out (perhaps due to measurement error or outliers) than a normal distribution, the t-test significance level is not greatly affected but the power of the test is affected (Hampel et al. 1986). This means that confidence intervals are too wide and the null hypothesis of "no difference" will be accepted too frequently.

This issue is important in our effort to gain scientific insight from the ALSC data for at least two reasons, both of which involve the combined use of conventional statistics ard robust statistics. By the term "robust" we mean statistics and procedures that describe the structure in the majority of the data and that may be efficient even if an assumed parametric model holds only approximately. With that as a definition, we can say that if the results of both the conventional statistical analysis and tra 
to truly represent the data and not the subjectivity of the data analyst in data screening and selection of statistical methods. In other words, the conventional statistics like the mean and standard deviation, which are highly influenced by data points that diverge from the bulk of the data, tell the same story about the scientific relationships as do the less-familiar robust statistics. Therefore, divergent or outlying data points are not a problem; the investigator should report the conventional statistics and scientific inferences based on those statistics.

However, when conventional and robust analyses differ, the assumed model (e.g., normality) may not be appropriate for all of the data, as it is likely that a few "influential" data points largely determine the result. The companion robust statistical analysis can then be used to identify these data points, using influence diagnostics and robust weights (Hoaglin et al. 1983).

How does this aid scientific analysis of the ALSC data? First, the robust anaiyses provide us with models that reflect the relationships expressed in the majority of the data points. These models may be called robust as they are not dependent on a few influential observations. Second, the influential data points should now be considered targets for special investigations to answer the following questions:

- Are there measurement or recording errors for these observations?

- Do these dara points identify a set (or sets) of lakes that behave differently from the rest of the lakes?

- Based on careful examination of the data from these lakes, are there new hypotheses or models that might be proposed to explain the differences in behavior?

We do not claim that the combined use of conventional and robust methods will lead to new insights or hypotheses in each investigation. However, based on experience, we believe that inferences have greater substantiation when supported by both approaches. Further, the diagnostic feature of robust methods is one of the most effective devices for identifying unusual data (Hampel et al. 1986).

It is often good practice when compiling a data set to use statistical and other criteria to flag and possibly remove extremely unusual data points, as was done with FIN and ALSC. If this type of data screening is undstraken, are robust methods necessary? Yes, for two reasons. First, good data screening may identi.y all outliers in single variable distributions, but it cannot always be designed to identify outliers in multidimensional space. Robust methods can do this. Second, while screening may identify obvious outliers, it is generally ineffective in dealing with data points that are only moderately divergent from the bulk of the data. For this situation, Hampel et al. (1986) cite studies and present work of their own to show the superiority (in terms of variance of the estimator) of 
robust methods over data screening and other judgmental approaches, even when undertaken by experienced statisticians.

\section{B2 Robust Estimators}

The normal distribution occupies a pivotal position in probability and statistical analysis. In the early 19 th century, the normal distribution was proposed by Gauss as a model for the distribution of errors. Gauss's derivation of the normal distribution began with the statement that the most probable value of a quantity observed several times under essentially identical conditions was the arithmetic mean; he then showed that the mean was the most probable value when the errors were normally distributed. Despite the circularity of this reasoning used to support the normal distribution as a model of errors, Laplace (citation?) recognized the importance of the normal distribution in the central limit theorem.

The central limit theorem established that the distribution of the sum of a large number of random variables will be approximately a normal distribution as long as one of the following sets of conditions holds. These conditions are (Benjamin and Cornell 1970): (1) the variables are independent and identically-distributed with finite variance; $(2)$ the variables are bounded, independent, and none has a major influence on the sum; or (3) the variables are bounded and the correlations are near zero for all but a small number of pairs of variables. However, one or a few variables have considerable influence on the sum, the distribution may be far from normal.

Certainly, the central limit theorem has justifiably been responsible for the importance of the normal distribution, but it is probably also true that beliefs such as those of Quetelet in the 19tin century (see Stigler 1986) have resulted in inappropriate use of the normal. Quetelet believed that "all naturally occurring distributions of properly collected and sorted data follow a normal curve" (Stigler 1986). In addition, Quetelet believed that when distributions failed to follow the normal law, then this indicated lack of homogeneity in a group of observations.

Given the attractiveness of a single model for errors, "the normal distribution was considered a universal law for a long period of time. This state of affairs resulted in a delay in the development of quantitative methods for discarding observations, since the normal law admits the possibility of errors of any magnitude. Hence it was assumed that all observations should be retained. Only in the middle of the nineteenth century did the first probabilistic criteria for rejecting observations begin to appear" (Maistrov 1974).

A critical condition for adopting the normal distribution as a plausible model for errors is that none of identically-distributed random disturbances or a large number of random disturbances are large relative to the others. Certainly there are situations where observed concentrations in water 
chemistry studies result from a large number of small effects (e.g., when there are several sources of the chemical variable or mariy factors in the waterbody that contribute to the concentration). Likewise, circumstances exist where this condition does not hold. These include situations with occasional large measurement errors (e.g., due to chemical contamination or misreading instruments) or highly dominant and variable environmental conditions (e.g., infrequently-occurring anoxic conditions in a waterbody). As noted above, the preferred estimators under normality (mean and variance) may perform quite poorly when normality does not hold. This, combined with the recognition that legitimate substantive explanations for a non-normal error distribution exist, are reasons for the current interest in robust statistics.

Several empirical and theoretical analyses have also contributed to the recent appeal of robust statistics. Empirical investigations by Tukey (1960) on contaminated distributions established the considerable effect that even a very small amount of contaminated data has on certain non-resistant statistics. By contaminated data we mean samples drawn from a mixed distribution that is composed of, for example, a standard normal density function with a small number of observations generated by a second normal density function (the contamination) with larger variance. This might occur due to occasional errors of measurement or due to an actual mixture of two populations. Based on asymptotic efficiency (a measure of estimator error as sample size increases toward infinity)، Tukey and others have found that less than $5 \%$ contamination causes the mean to be less efficient than some alternatives, and less than $1 \%$ contamination causes the variance to be less efficient than selected alternatives.

Unfortunately, contamination of data sets appears to be quite common. Several studies reported in Hampel et al. (1986) have found $1-10 \%$ outliers in a variety of data sets, even those that have been carefully screened for outliers. in addition, Jeffreys (1961) and others have found that high quality data sets may be better represented by a t distribution with approximately 5 to 9 degrees of freedom than by a normal distribution. Hampel et al. (1986) have shown the superiority of several resistant (e.g., the median) and robust (e.g., the Huber estimator) alternatives to the mean for a $t$ distribution with a few degrees of freedom or for a contaminated normal. Likewise, Iglewicz (1983) found robust alternatives to the standard deviation to be superior under heavy-tailed contamination of the normal.

One attractive robust estimator of location is that derived by Huber (1981) as a maximum likelihoodtype estimator. In essence, Huber's estimator provides a maximum likelihood location estimator for distributions that are nearly (but not exactly) normal. Huber proposed a "gross error model" that is characterized by: 


$$
F=(1-\mathfrak{c}) G+\mathfrak{u}
$$

Where:

$G=$ an assumed parametric model (e g., normal),

$H=$ an unknown model creating contamination, and

$\varepsilon=$ a small (known) fraction $(0<\varepsilon<1)$.

Thus the model $F$ is similar to (in the "neighborhood" of) the assumed parametric model G. Given a fraction, $\varepsilon$, of contamination, Huber derived a "least favorable distribution" for location to characterize this neighborhood model:

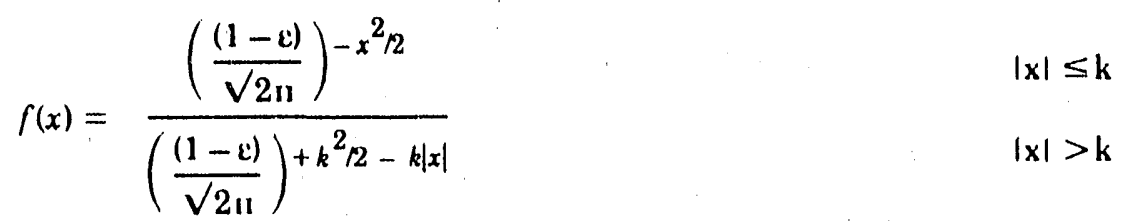

with $k$ related to the fraction of contamination, $k$, by:

$$
\frac{2 \Phi(k)}{k}-2 \phi(-k)=\frac{\varepsilon}{(1-\varepsilon)}
$$

Where:

and

$\phi=$ the standard cumulative normal distribution function

$\Phi=$ its density.

Based on this "neighborhood model," Huber then determined the location estimator that minimized the maximum asymptotic variance of the estimator given a fraction, $\varepsilon$, of contamination from an arbitrary model, $\mathrm{H}$. This estimator is a maximum likelihood estimator for Huber's least favarable distribution. The estimator is the mean when $k$ is infinity ( $\varepsilon$ is zero) and the median when $k$ is zero ( $\varepsilon$ is one). An iterative procedure is required to apply Huber's location estimator and involves reweighting the observations at each step until convergence. The weights are:

$$
u=\frac{1}{k / u}
$$

$$
\begin{aligned}
& |u| \leq k \\
& |u|>k
\end{aligned}
$$

Where:

$$
\begin{aligned}
k & =1 \text { to } 2 \text { in most applications } \\
u & =\frac{(x-h)}{s_{k}} \\
h & =\text { Huber's location statistic } \\
s_{k} & =\text { scale estimator (e.g., normalized median absolute deviation) }
\end{aligned}
$$

The Huber estimate can be calculated as a weighted mean, with the weights defined above. Note that observations, $x$, near $h$ (Huber's location estimate) are given full weight, but observations far from $h$ receive weight less than 1 . 
Huber's approach is appealing because it is based on a plausible model of contamination. The "least favorable distribution" is normal in the center, but is more stretched-out in the tails than the nurmal; these stretched-out distribution tails result from the contamination of the normal. In that situation of contamination, Huber has defined the maximum likelihood estimator for location. The transicion zone between the normal center and the fatter tails is determined by the fraction of contamination.

In most cases where a probatility model is used to characterize a set of data, we assume that the model is a reasonable, but probably not exact, description of the data generating process. For the normal distribution, we now know that the conventional sample estimators for the model p. arameters of mean and variance are optimal (based on efficiency) under normality, but they will not be optimal in many situations when data do not follow a normal distribution. Huber has derived a maximum likelihood estimator that is appropriate for distributions that are in the neighborhood of the normal. This theoretical basis is further supported by many empirical studies of the robustness of the Huber estimator (see Hampel et al. 1986). Studies by Hampel et al. indicate that the Huber estimator is almost as efficient as the mean under normality, yet is apt to be substantially more efficient than the mean for a contaminated normal. Additional studies of the Huber estimator and other robust estimators have shown that the Huber estimator may be preferable over the alternatives if some data screening has already occurred, removing any gross errors.

The Huber location estimate may be calculated using the iteratively reweighted mean estimator presented above. Alternatively, an iterative calculation scheme with the observations computationally-Winsorized (Dixon and Tukey 1968) at each step will also yield the Huber estimate of location. Winsorization is similar to trimming except that observations are not removed (trimmed) from the tails of the empirical distribution, rather they are replaced by a value closer to the center. This value is based on the Huber robust location statistic, $h$, the Huber scale estimator, $s_{k}$, and the Huber scaling constant, $k$. At each iteration, observations, $x$, are Winsorized according to

$$
\begin{aligned}
& \text { if } x>h+k s_{k}, \text { then set } x=h+k s_{k} \\
& \text { if } x<h-k s_{k} \text {, then set } x=h-k s_{k} \\
& x=x \text { otherwise }
\end{aligned}
$$

The procedure is iterated to convergence, and the result is a set of Winsorized observations that may be used to calculate the Huber estimate of location as the arithmetic mean of the Winsorized observations. Replacing the actual observations with pseudo-observations closer to the center has an effect equivalent to downweighting the outlying observations in the calculation of the Huber estimate. 


\section{B3 Robust Analyses of the Logistic Models for Fish Population Response}

The fish population response models fit for subsets (Lake/Variab!e Groups 1BO and 2B0) of the ALSC data base using maximum likelihood logistic regression were evaluated using a robust version of logistic regression. The robust estimation provides a fit to the "central tendency" in the data, while downweighting outlying observations as explained above.

For each data group, both a one-step Huber estimator and a fully-iterated Huber estimator were applied. The one-step estimator involves a single iteration; with a good start value, it can be as asymptotically efficient as a fully-iterated Huber estimator (under normality; Rousseeuw and Leroy 1987). In this application, to observe a wide range of robustness in the fitted inodels for both data sets, the one-step estimator was applied with "gentle" scale factor of $k=2.0$ (slight robustness), and the fully-iterated (eight iterations) estimator was applied with a "strong" scale factor of $k=1.345$ (severe robustness).

Results of the robust estimation are given in a set of tables and figures. The tables (see Appendix A) summarize the conventional maximum likelihood logistic regression model and each robust model (two for group $1 \mathrm{BO}$ and two for group 2B0). Following the model summaries, all lakes in the data sets are tabulated with information on summer surface field pH (SUSFPH), observed brook trout presence/absence (ST329_C), lake name (PONDNAME), robustrass weight (WEIGHT, or W), and predicted presence/absence (PRED, or P).

Eight figures (Figures B.3-1 to B.3-8 are presented that relate presence/absence to summer surface field $\mathrm{pH}$. Four figures are given for each lake/variable group:

- $\mathrm{pH}$ versus observed presence/absence

- $\mathrm{pH}$ versus maximum likelihood model predicted presence/absence

- $\quad \mathrm{pH}$ versus "gentle" robust model predicted presence/absence

- $\mathrm{pH}$ versus "surong" robust model predicted presence/absence.

The figures are presented to show the $\mathrm{pH}$ effect as conveyed in the data and in each model. To facilitate this visual impression of the average $\mathrm{pH}$ effect, a smoothing spline is plotted in each figure. A smoothing spline (Eubank 1988) may be used to fit a model:

$$
Y_{i}=\mu\left(t_{i}\right)+e_{i}
$$

$\mathrm{pH}$ versus presence/absence for

Where:

$y=$ refers to presence/absence,

$\mathrm{t}=$ refers to $\mathrm{pH}$,

$\mu=$ may be considered an estimate for presence/absence at a particular $\mathrm{pH}$, and

$i=$ a lake index. 


\section{Pres Abs Observations vis pH (2BO)}

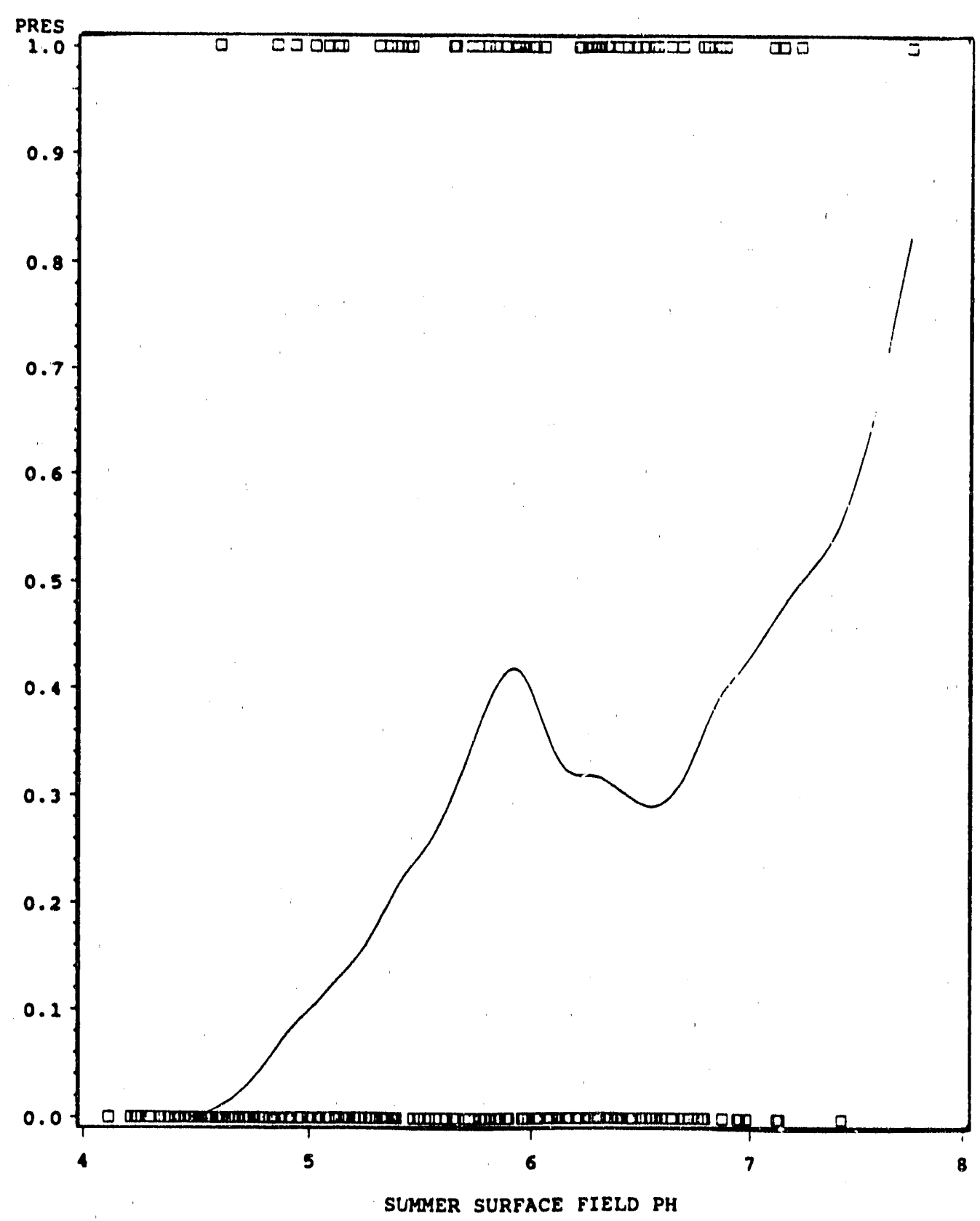

Figure B3-1 Observed presence and absence of brook trout as a function of lake $\mathrm{pH}$, asid associated smoothing spline curve, for data set $2 \mathrm{BO}$. 


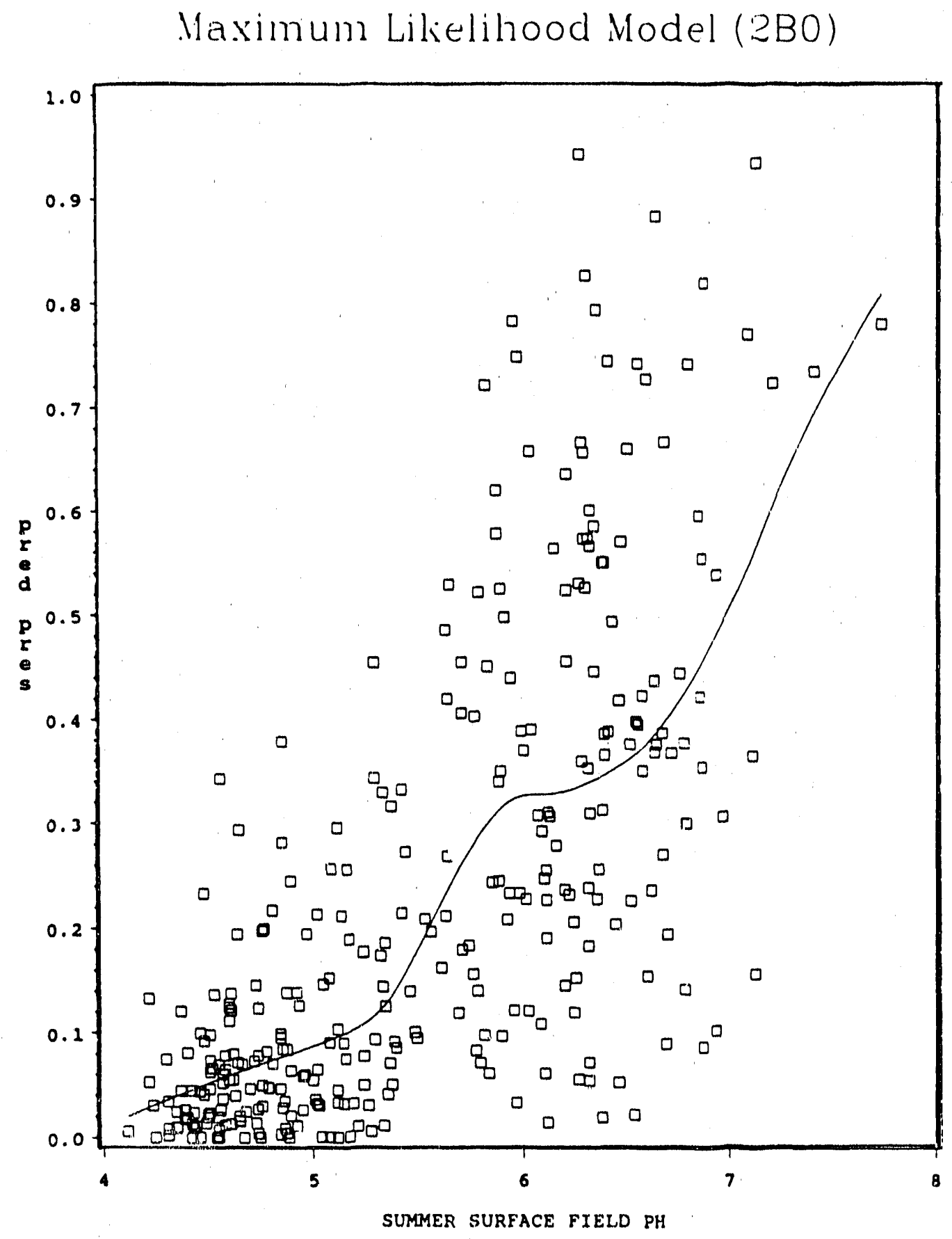

Figure B3-2 Maximum likelihood model predicted probability of brook trout presence as a function of pH, and associated smocthing spline curve, for data set $2 \mathrm{BO}$. 
Robust llodel - 1 Iteration (2BO)

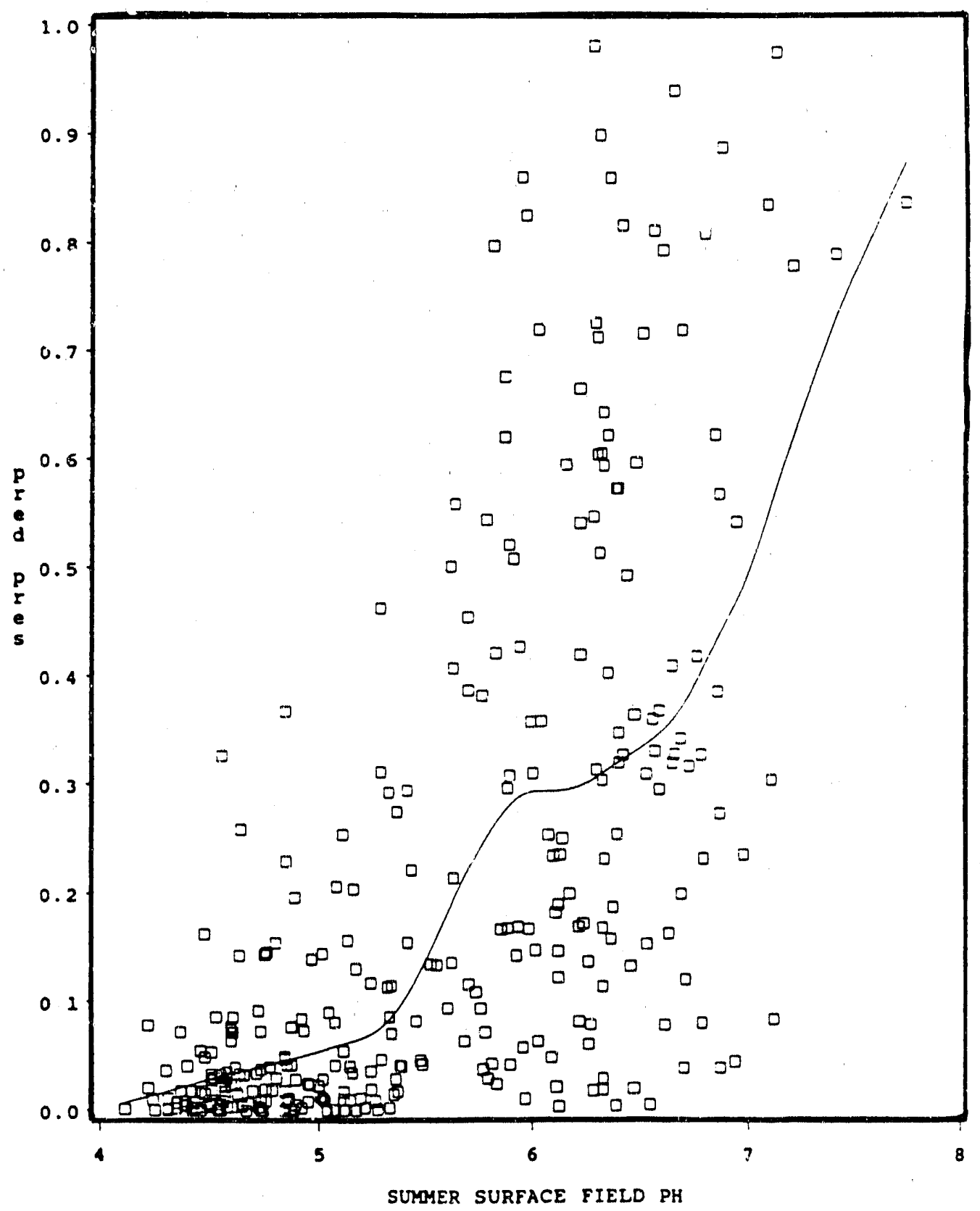

Figure B3-3 Robust model, $K=2.0$ with one iteration, predicted probability of brook trout presence as a function of $\mathrm{pH}$, and associated smoothing spline curve, for data set 280. 


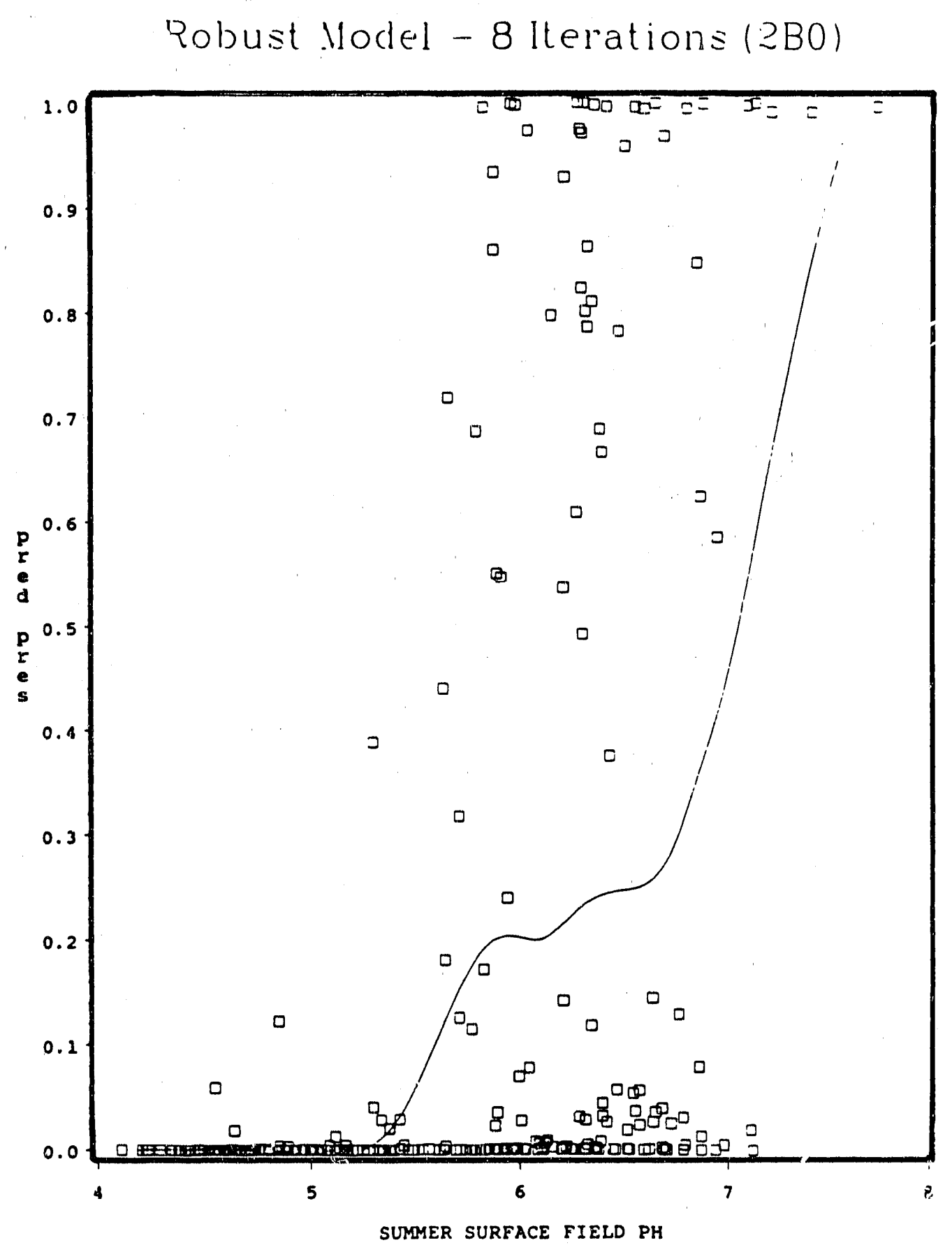

Figure B3-4 Robust model, $K=1.345$ with eight iterations, predicted probability of brook trout presence as a function of $\mathrm{pH}$, and associated smoothing spline curve, for data set 2BO. 
Pres Abs Observations is pH ( $2 \mathrm{BO})$

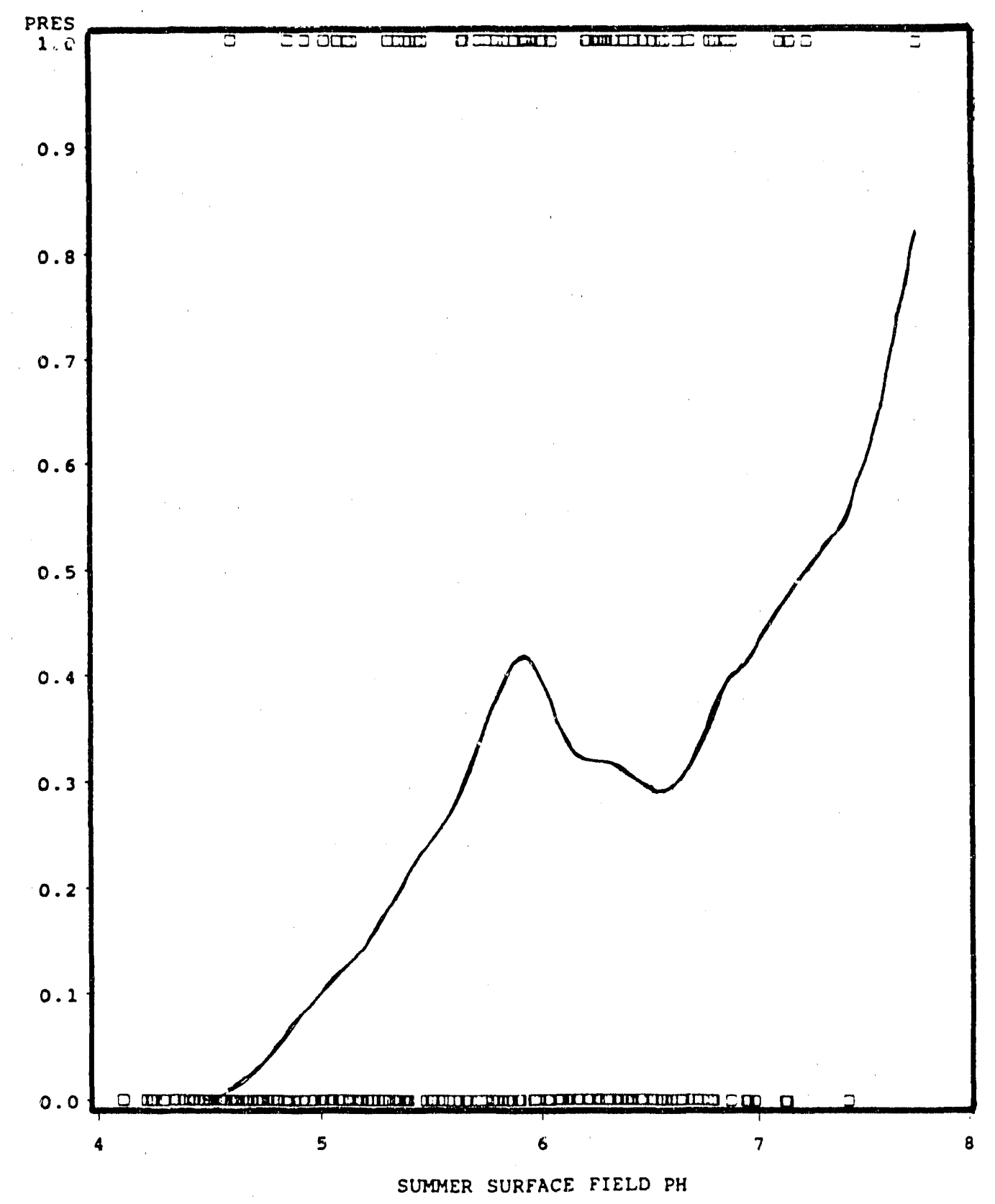

Figure B3-5 Chserved presence and absence of brook trout as a function of lake pH, and associated smoothing spline curve, for data set $1 \mathrm{~B} 0$. 


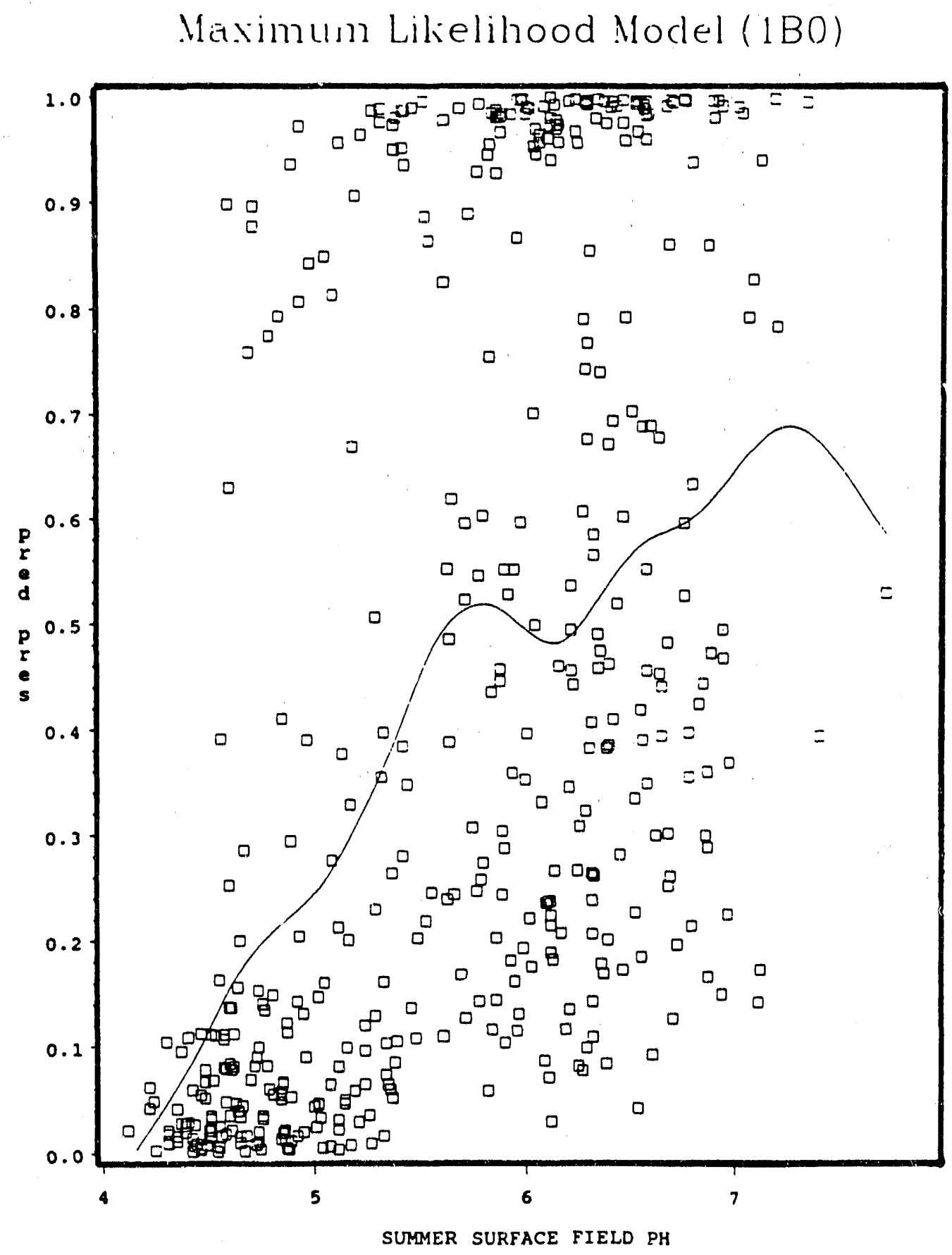

Figure B3-6 Maximum likelihood model predicted probability of brook tro st presence as a function of $\mathrm{pH}$, and associated smoothing spline curve, for data set $1 \mathrm{B0}$. 


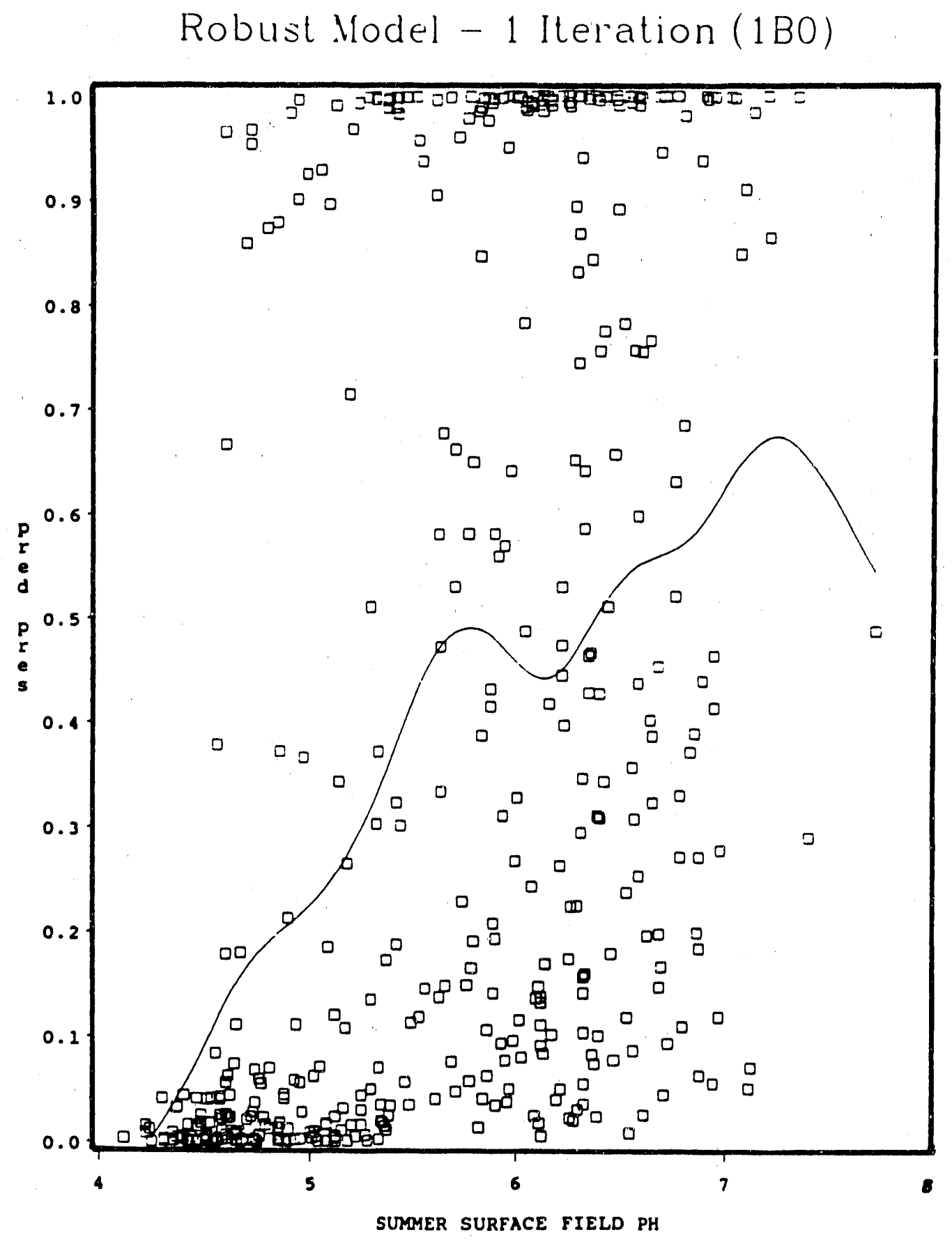

Figure B3-7 Robust model, $K=2.0$ with one iteration, predicted probability of brook trout presence as a function of $\mathrm{pH}$, and associated smoothing spline curve, for data set 1 BO. 


\section{Robust llodel - 8 Iterations (1B())}

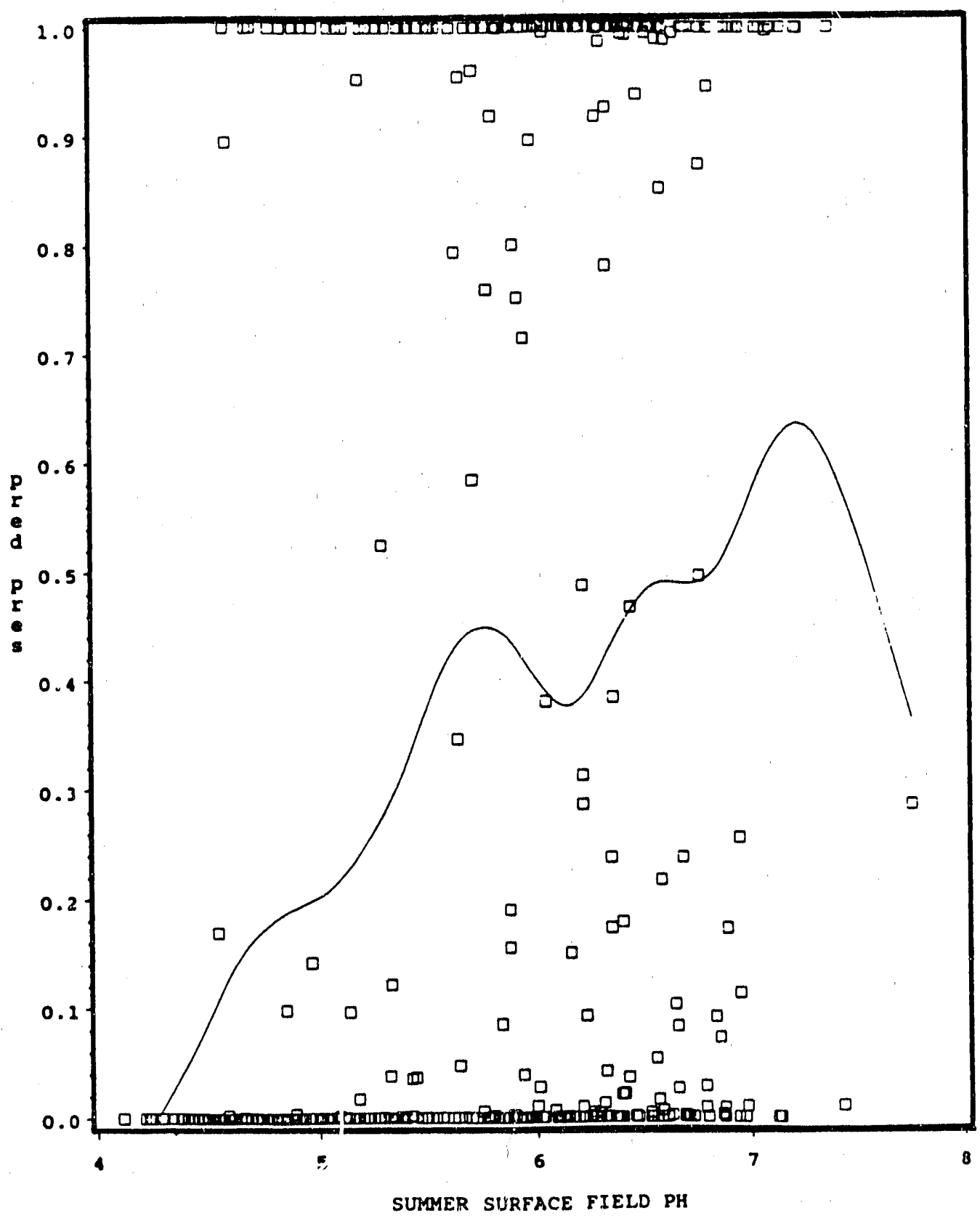

Figure B3-8 Robust model, $K=1.345$ with eight iterations, predicted probability of brook trout presence as a function of $\mathrm{pH}$, and associated smoothing spline curve, for data set 1 BO. 
The only requirement for the deterministic portion of the model $\left[\mu\left(t_{1}\right)\right]$ is that, over all $i$, it has some smoothness. One approach is to estimate the function $\mu$ as that which minimizes the following function:

$$
s(\mu)=\Sigma\left|Y_{i}-\mu\left(t_{i}\right)\right|^{2}+\Phi \int\left(\frac{d f^{2}(x)}{d x^{2}}\right) d x
$$

The first term on the right side of Equation 6 is the conventional squared error criterion, and the second term may be called a "roughness penalty." The parameter $\Phi$ is a smoothing parameter that controls the roughness, or degree of smoothing, by defining the relative weight between the two terms. At one extreme, the squared error term dominates and a linear model is $\mathrm{fit}_{\text {; }}$ at the other extreme, the roughness dominates and the itted function will move from point to point. In this example, a mid-level smoothing parameter of $\Phi=0.44$ was chosen.

The smoothing spline is like a moving average in that it provides a local fit at each point. However, all data points in the local "window" are not weighted equally; data closest to the point of fit are assigned the highest weights. Thus, we might think of the smoothing spline as yielding an average $\mathrm{pH}$ effect, within a small range of $\mathrm{pH}$ values, on brook trout presence/absence.

The smoothing splines suggest somewhat different evidence in the two data groups. In particular, the smoothing spline for group 1B0 never goes much higher than 0.6 for predicted probability of presence, while there is generally a steady upward climb in predicted probability of presence with $\mathrm{pH}$ increase in group $2 \mathrm{BO}$. In data group 1B0, the smoothing spline shows a clear linear relationship between observed presence/absence and $\mathrm{pH}$ between $\mathrm{pH} 4.2-5.8$, which suggests that $\mathrm{pH}$ may be the dominant reason for species presence/absence at low $\mathrm{pH}$. However, in the $\mathrm{pH}$ range of 6.0-7.5, approximately $50-60 \%$ of the lakes did not yield brook trout in the survey. Thus, in this $\mathrm{pH}$ range, there appear to be other important reasons for presence/absence, so $\mathrm{pH}$ alone is not a good predictor of brook trout presence/absence. It is important to note that approximately the same pattern in the smoothing spline is conveyed in the data and in all fitted models; thus, the conclusions appear to be robust. 


\section{APPENDIX B REFERENCES}

Benjamin, J.R., and C.A. Cornell. 1970. Probability, Statistics, and Decision for Civil Engineers. McGraw-Hill, New York.

Dixon, W.J., and J.W. Tukey. 1968. Approximate behavior of the distribution of Winsorized $t$ (trimming/Winsorization 2). Technometrics 10:83-98

Eubank, R.L. 1988. Spline Smoothing and Nonparametric Regression. Marcel Dekker, Inc. New York.

Fisher, R.A. 1922. On the Mathematical Foundations of Theoretical Statistics. Philos. Trans. Roy. Soc. London Ser. A. 222:309-368.

Hampel, F.R., E.M. Ronchetti, P.J. Rousseeuw, and W.A. Stahel. 1986. Robust Statistics: The Approach Based on Influence Functions. John Wiley and Sons. New York.

Hoaglin, D.C., F. Mosteller, and J.W. Tukey. 1983. Understanding Robust and Exploratory Data Analysis. John Wiley and Sons. New York.

Huber, P.J. 1981. Robust Statistics. John Wiley and Sons. New York.

Iglewicz, B. 1983. Robust scale estimators and confidence intervals for location. Pages 404-431. In: Understanding robust and exploratory data analysis, D.C. Hoaglin, F. Mosteller, and J.W. Tukey, eds. John Wiley and Sons. New York.

Jeffreys, H. 1961. Theory of probability Oxford University Press. London.

Maistrov, L.E. 1974. Probability theory: a historical sketch. Academic Press, New York.

Rousseeuw, P.J., and A.M. Leroy. 1987. Robust Regression and Outlier Detection John Wiley and Sons. New York.

Stigler, S.M. 1986. The History of Statistics Harvard University Press. Cambridge, MA.

Tukey. J.W. 1960. A Survey of Sampling from Contaminated Distributions. Pages 448-485. In: Contributions to Probability and Statistics, I. Olkin ed. Stanford Univ. Press, Stanford, CA. 


\section{APPENDIX C}

Procedures for Evaluating Historical Trends in Fish Communities 


\section{APPENDIXC}

\section{PROCEDURES FOR EVALUATING HISTORICAL TRENDS IN FISH COMMUNITIES}

\section{- J. Baker}

\section{PRIMARY QUESTIONS}

1. How many Adirondack lakes have lost populations or fish (of those lakes with adequate historical data)?

2. What types of fish species have been lost?

3. How many fish populations have been lost with no apparent cause (other than perhaps surface water acidification)?

\section{DATA SOURCES}

The New York State Department of Environmental Conservation (NYSDEC) Biological Survey data base served as the primary source of historical information on Adirondack lakes. Historical data on lakes in the Upper Hudson and Mohawk-Hudson watersheds (not yet included within the NYSDEC data base) were obtained from the Fish Information Network (FIN) data base. The current status of fish communities is defined by the Adirondack Lakes Survey Corporation (ALSC) data base.

\section{APPROACH}

All fish community status assessments were conducted blindly, i.e., with no information on surface water chemistry (except for measurements of dissolved oxygen). All remaining information available in the above data bases was reviewed for lakes surve,'ed by the ALSC. Joan P. Baker conducted data reviews for all ALSC lakes, and Jim Gallagher completed a second, independent evaluation of 74 lakes.

Ideally, we would like to define an objective, quantitative measure of the change in ish communities over time. Examples include trends in catch per unit effort (CPUE) or the frequency of catch or no catch for a given fish species in a series of samples over time. Both of these approaches, however, require that fish sampling techniques have been reasonably consistent through time so that a standard unit of sampling effort can be defined for CPUE and the probability of catch (or no catch) varies principally as a function of the abundance of the fish population in the lake. Unfortunately, 
fish sampling techniques and procedures have varied markedly both over time and among lakes. For example, although gill nets and/or trap nets were the primary gear used in most surveys, nets were of different size, were set at different times of the year, and were set at different depths. General gear characteristics have also changed over time, e.g., the shift from gill nets made of cotton to nets of monofilament nylon. Historical surveys were conducted in accordance with the immediate needs of the fishery biologists, ranging from a general survey of fish species present to specific collections of individual species to confirm stocking success, mea sure growth, or collect eggs.

As a result of these variations in sampling procedures, we do not feel that simple quantitative measures such as trends in CPUE or the probability of catch/no catch can be used to accurately express changes in the fish community over time. Instead, we defined semi-quantitative indicators of fish status (i.e., an ordered classification) that incorporate the uncertainties associated with varying, and at times unknown, sampling techniques. Ordered classifications are commonly used whenever different degrees of some phenomenon can be recognized but not expressed with a standard unit of measurement on a coritinuous scale (Snedecor and Cochran 1976, Kleinbaum and Kupper 1978).

Four types of information were recorded for each lake the ALSC surveyed: (1) summary information on the types and amount of historical data available, (2) an evaluation of changes in individual fish populations, i.e., for individual fish species, (3) an assessment of changes in the occurrence of sensitive minnow species (as a group), and (4) an overall evaluation of changes in the fish community as a whole. The terms historical data and historical survey, as used throughout this document, refer to all pre-ALSC information and surveys. Evaluations of fish population status were limited to 16 fish species considered reasonably susceptible to gear employed in most surveys and that were selected as either important sport species or nongame species common in Adirondack lakes (see Table C-1).

Mills and Schindler (1986) observed that minnow species (cyprinids) were relatively sensitive to acidic conditions and that the loss of minnow species may serve as a useful indicator of the eariy stages of lake acidification. Thus, in addition to evaluating changes through time for individual fish species, changes in the presence or absence of sensitive minnow species, as a group, were also assessed. Included in this analysis were all members of the family Cyprinidae, excluding those species specifically noted to be tolerant of $\mathrm{pH}<5.0$ in some waters, based on the literature review completed by Baker and Christensen (in press; also Baker et al. 1988). Thus, the following acid-tolerant species were excluded from this group: golden shiner (Notemigonus crysoleucas), northern redbelly dace (Chrosomus eos), creek chub (Semotilus atromacalutus), and lake chub (Couesius plumbeus). The following minnow species were collected by the ALSC and were identified as potentially sensitive: 
- eastern silvery minnow (Hybognathus nuchalis)

- mimic shiner (Notropis volucellus)

- bridle shiner (Notropis bifrenatus)

- brassy minnow (Hybognathus hankinsoni)

- Dluntnose minnow (Pimephales notatus)

- cutlips minnow (Exoglossum maxillingua)

- finescale dace (Chrosomus neogaeus)

- fathead minnow (Pimephales promelas)

- fallfish (Semotilus corporalis)

- longnose dace (Rhinichthys cataractae)

- blacknose dace (Rhinichthys atratulus)

- pearl dace (Semotilus margarita)

- common shiner (Notropis cornutus)

Table C-1 Fish Species Evaluated for Fish Population Status

\begin{tabular}{llll}
\hline Common Name & & Codea & Samplingb \\
\hline brook trout & Salvelinus fontinalis & ST & $H$ \\
lake trout & Salvelinus namaycush & LT & $\mathrm{M}$ \\
rainbow trout & Oncorhynchus mykiss & RT & $\mathrm{M}$ \\
brown trout & Salmo trutta & $\mathrm{BT}$ & $\mathrm{H}$ \\
lake whitefish & Coregonus clupeaformis & LW & $\mathrm{M}$ \\
smallmouth bass & Micropterus dolomieui & SB & $\mathrm{M}$ \\
largemouth bass & Micropterus salmoides & LB & $\mathrm{M}$ \\
northern pike & Esoxlucius & $\mathrm{NP}$ & $\mathrm{M}$ \\
white sucker & Catostomus commersoni & WS & $\mathrm{H}$ \\
brown bullhead & Ictalurus nebulosus & BB & $\mathrm{H}$ \\
pumpkinseed & Lepomis gibbosus & PS & $\mathrm{M}$ \\
yellow perch & Perca flavescens & YP & $\mathrm{H}$ \\
golden shiner & Notemigonus crysoleucas & GS & $\mathrm{H}$ \\
creek chub & Semotilus atromaculatus & CC & $\mathrm{H}$ \\
common shiner & Notropis cornutus & CS & $\mathrm{M}$ \\
northern redbelly dace & Chrosomus eos & ND & $\mathrm{M}$ \\
\hline
\end{tabular}

a Code specifies the two-letter code used to identify the species in the species-specific variable names defined in the following section on data/codes for fish population status.

b $M$ or $H$ denotes the general susceptibility of the species to the ALSC gear and sampling techniques ( $M=$ marginal; $H=$ high). 
Further details on the procedures and criteria for evaluating changes in fish populations and communities over time are provided in the next section on recorded data and codes.

\section{DATA AND CODES RECORDED}

Variables recorded during historical assessments are grouped into categories: lake liming, types and amount of historical data available, fish population status, and fish communities status. Under each of these categories, relevant variable names are set in bold, all capital letters. Missing data wiere recorded as blanks.

\section{Lake Liming}

Lake liming complicates the assessment of changes in fish communities not only because of its effects on lake chemistry but also because the occurrence of liming is indicative of an acidic lake. Thus, allowing the reviewer to know that the lake was limed violates the procedure of conducting fish community status evaluations blindly (i e., with no information on water chemistry). In earlier evaluations of fish community changes (Baker and Harvey $19 \varepsilon 4$ ), all references to lake liming and all data collected post-liming were deleted from the data base (in this case the IN data base) prior to the data review; changes in the fish community were assessed, therefore, only up to the time of the first lime application. Such an approach would not work, however, for analyses that rely on the ALSC data to define the current status of the fish community. For this assessment, we identified lakes that had been limed and recorded the year(s) limed; lakes that were limed in the 10 years preceding the ALSC survey were then excluded from most data analyses.

- Record of lake liming (LIMED)

$0=$ no record of lake liming

$1=$ lake limed in one or more years in the past

2 = lake reportedly limed (per ALSC comments section)

- Earliest year in which the lake was limed (only the last two digits of the year were recorded, i.e., 1965 was listed as 65) (YR1LIMED)

- Most recent year (last two digits only) in which the lake was limed (YR2LIMFD) (Note: if the lake has been limed only once, then YR1LIMED = YR2LIMED) 


\section{Types and Amount of Historical Data Available}

- Historical fisheries data available (HISTDATA)

$0=$ no historical information (surveys, anectodal data, or visual sightings) available on the fish community in the lake and lake never stocked

$1=$ some historical information available on the fish community in the lake

2 = lake stocked, but no historical information available on the fish community

If no historical data were available (i.e., HISTDATA $=0$ ), then no further information was recorded for the lake (i.e., all remaining variables were left blank)

- Number of years surveyed (excluding ALSC survey), where a survey is defined by confirmed sampling with one or more units of (a) gill nets, (b) trap nets, (c) electrofishing, (d) seines, or (e) rotenone (also, angling if the majority of species caught in later surveys were also caught at this time) (YRSURVEY)

YRSURVEY $=0$ to 99 , indicating the number of years for which historical fish survey data were available (excluding the ALSC data). Multiple surveys in a given year were still recorded as only one year of survey data.

- Years in which the lake was surveyed and quality of survey data available (excluding ALSC data)

SURVEY1 = first year in which the lake was surveyed, recorded as the last two digits of the year (i.e., 1936 was recorded as 36)

QUALITY1 = rating of the general quality of the survey data collected during the first year surveyed

$1=$ good, i.e., multiple units of effort at a number of different locations and depths, using a variety of gear or gear sizes designed to capture both small and large fish (including the use of seines, minnow traps, or small mesh gill or trap nets to catch minnows in shallow waters)

$2=$ moderate, i.e., multiple units of effort at a number of locations and depths, although with one or a few habitats not sampled or sampled poorly. A common example would be a survey that did not include the use of seines or small mesh nets in shallow waters to capture minnow species, although other habitat types were sampled reasonably well. A second example would be a survey of a large deep lake conducted during the summer that sampled only in the shallow littoral zone.

$3=$ poor, i.e, only one gill net or trap net set (excluding surveys that satisfy the criteria specified for Q'JALITY1 = 4) (or seine plus angling)

$4=$ limited, i.e., only one or a few habitats or specific fish spocies sampled. Common examples include (a) only deep water gill net sets used to capture lake trout or lake whitefish, (b) sampling focused on collecting spawning brook trout or lake trout for egg collections, or (c) only shallow water habitats sampled with seines or rotenone.

$9=$ unknown 
SURVEY2 = second year in which lake was surveyed (last two digits)

QUALITY2 = rating of general quality of second survey $(1,2,4$, or 9$)$

SURVEY3 = last year in which lake was surveyed prior to the ALSC survey (last two digits)

QUALITY3 = rating of general quality of last pre-ALSC survey $(1,2,4$, or 9 )

No information is recorded for additional years $(>3)$ surveyed

- Number of years with data on the fish community available, but the source of that data was uncertain (e.g., it was unclear whether the list of species occurring in the lake was derived from an actual fish survey or just anectodal reports of fish present) (YRUNCERT). Only those years without survey data were included (i.e., there was no double accounting of years under variables YRSURVEY and YRUNCERT)

YRUNCERT $=0$ to 9 , where 9 indicates 9 or more years with data for which the source of the data was uncertain.

- Years in which fish data were recorded in the data base although the source of the data was uncertain

UNCERT1 = first year with data (last two digits)

UNCERT2 = second year with data (last two digits)

No information was recorded for additional years with data from uncertain sources

- Number of years with only visual sightings or anectodal data on the fish community in the lake (i.e., reported fish occurrences, but no fish surveys) (YRREPORT). Note: Years with data inclured in YRSURVEY or YRUNCERT were not included in YRREPORT

YRREPGRT $=0$ to 9 , where 9 indicates $:$ or more years with only visual sightings or anectodal data on the fish community

- Years in which only visual sightings or anecdotal data were available

REPORT1 - first year with data (last two digits)

REPORT2 = second year with data (last two digits)

No information was recorded for additional years with only visual sightings or anectodal data

Fish Population Status (By Species)

The following information was recorded for each of the 16 species listed in Table C-1. To distinguish among fish species, the variable names noted below were preceded by a two-letter species code. For example, the stocking variable (STOCK) for brook trout was identified as STSTOCK; for rainbow trout, RTSTOCK. These species codes are noted in Table C-1. 
Note: In these evaluations, the term "survey" was interpreted in a species-specific manner to include or:! 1 lose sampling efforts with the potential for catching the fish species of interest. Two specific examples deserve emphasis:

- To be defined as a "survey" for small minnow species confined to shallow littoral zones, the sampling effort must include a gear able to collect these small fish (i.e, seine, minnow traps, small-mesh gill nets set in shallow waters, small-mesh trap nets set in shallow waters, rotenone used in shallow waters, or electrofishing with a backpack shocker in shallow waters).

- To be defined as a "survey" for coldwater species confined to deeper cold waters during the summer (e.g., lake trout and lake whitefish), sampling efforts conducted during the summer period of thermal stratification must have included the use of gear (e g. largermesh gill nets) set in these deeper waters at or below the thermocline.

If there were questions about the ability of the sampling effort to capture the species, the survey was counted (i.e., only those surveys that we ielt confident would not collect the species were excluded). For example, bass are difficult to catch with gill nets yet sampling with gill nets in the littoral area was counted as a survey for bass. Problems with the general susceptibility of the species to fish sampling gear are included as criteria for some of the codes described below.

Variables relating to fish stocking were included only for the six game fish species: brook trout, lake trout, rainbow trout, lake whitefish, smallmouth bass, and largemouth bass. Information on stocking for brown trout was included in the brown trout comments section.

\section{- Stocking records (STOCK)}

$0=$ no stocking on record

$1=$ species stocked regularly (every year, or every $2-3$ years for $>10$ years). Fish species was reported or caught in surveys conducted prior to the initiation of regular stocking.

2 = species stocked regularly. Fish species not rejorted or caught in surveys conducted prior to the initiation of regular stocking (except for those lakes that meet the criteria for STOCK $=7$ ). ror example, if a lake was stocked with brook trout once in the 1930 s and then regularly 1956-85, and a survey in 1955 found no brook trout

3 = species stocked regularly. No information available (or uncertain information) to determine whether fish species occurred in the lake prior ${ }^{*} \mathrm{o}$ initiation of stocking (except for those lakes that meet the criteria for STOCK $=7$ ). For example, the stocking records in the data base for the most part date back only to the 1930s. It cannot be determined whether earlier stocking occurred.

$4=$ stocking sporadic. Fish species was reported or caught in surveys conducted prior to the initiation of stocking.

5 = stocking sporadic. Fish species was not reported or caught in surveys conducted prior to the initiation of stocking (except for those lakes that met the criteria for STOCK $=7$ ). 
6 = stocking sporadic. No information was available to determine whether fish species occurred in the lake prior to initiation of stocking (except for those lakes that met the criteria for STOCK $=7$ ).

7 = species definitely supported by stocking. All fish caught by ALSC and in all prior surveys were definitely stocked (with a note to that effect recorded in the comments section by the field biologist). Species was not caught or reported in the lake prior to initiation of stocking

8 = stocking reported only (information on dates of reported stocking were noted in the species-specific comments section)

$9=$ sipecial cases

- First year with recorded stocking of the fish species (YR1STK) (all four digits were recorded, e.g., 1937 or 1895). Note: If the records indicated stocking in 1898 and then regularly from 1956 to 1985 , YRIS:TK $=1956$ and the comments section included a no e that the lake was stocked in 1898. Soma discretion was allowed in recording this information to optimize the use of the data base for determining the potential for natural spawning.

- Last year on record in which the fish species was stocked (YR2STK) (all four digits were recorded).

- First year in which the species was caught in the lake (YR1CTH)(last two digits of the year were recorded). (Note: If the species was not collected in a survey [including the ALSC], then this variable was left blank)

- Last year (including ALSC) in which the species was caught in the lake (YR2CTH) (last two digits of the year were recorded).

- First year in which the species was reported to occur or visually sighted, or for which the species was listed as occurring based on data of uncertain origin (YR1RPT) (all four digits recorded).

(Note: This variable was left blank unless the year in which the species was first reported to occur was earlier than the year in which the species was first caught in a field survey)

- Last year (pre-ALSC) in which the species was reported to occur (anecdotal data or data of uncertain origin) or sighted (YR2RPT) (all four digits recorded).

- Evidence to determine whether the species occurred in the lake in the past (PAST). [Note: These codes are listed in rank order of increasing confidence that the species occurred in the past]

$0=$ one or more historical surveys conducted; species never caught, sighted, reported, or stocked (excluding lakes that met the criteria specified for PAST $=1$ )

$1=$ one or two historical surveys conducted; only brown bullhead caught or reported; no other species sighted, reported, or stocked [Used for brook trout evaluations only]

$2=$ no historical survey data available ( 1 e., no surveys conducted with at least some potential for collecting the fish species of interest); species never reported or sighted (nor listed as occurring in historical data of unknown origin), and not stocked

3 = fish species never caught, reported, or sighted in any historical surveys/studies, but stocked at least once into the lake (Stocking must have been recorded in the ALSC data base; reports of stocking in comments section were not sufficient) 
$4=$ one or more historical surveys conducted; species never caught but reported to occur (based on anectodal information or data of unknown origin) or visually sighted

$5=$ no historical surveys; species reported to occur (anectodal information) in the lake at some time in the past (Note: species listed as visually sighted or as occurring based on information of unknown origin were not included in this category)

6 = no historical surveys; species visually sighted in the lake (or sighted and reported to occur based on anectodal information)

7 = no historical surveys; species listed as occurring in the lake based on information of uncertain origin

8 = one or more historical surveys conducted; fish species caught in only one survey and $\leq 5$ specimens collected; in addition, fish species never reported or visually sighted in other years [Also used if there was some question about the historical survey data, e.g., an unresolvable difference between the NYSDEC and FIN historical data bases]

$9=$ one or more historical surveys conducted with the fish species caught in more than one survey or, if only one historical survey available, with either (a) $>5$ specimens collected in this one survey or (b) $<5$ specimens collected but the fish species was also reported or sighted in some other year

- Evidence to determine whether the species is currently absent from the lake (ABSENT) (Note: for fish populations established by stocking [i.t., species not caught in prestocking surveys] only those surveys conducted after the initiation of stocking were considered in assessing the frequency and pattern of fish catch/no catch for the following evaluation of the variable (ABSENT) (Note: these codes are listed in rank order of increasing confidence that the fish species is now absent from the lake]

$0=$ fish species caught by the ALSC

1 = fish species not caught by the ALSC but reported to occur (in the ALSC data base) or visually sighted by the ALSC

2 = fish species not caught by ALSC; species considered marginally susceptible to capture using the ALSC gear and sampling techniques (denoted as $M$ in the above species list) and lake surveyed two or more times historically with the fish species caught only sporadically ( $\leq 50 \%$ of the years sampled) with no apparent trend in the catch/no catch pattern through time (i.e., the surveys in which the species was not caught were evenly dispersed throughout the period of record; no tendency for the species to be absent from the catch more frequently in more recent surveys, including the ALSC survey)

3 = fish species not caught by ALSC; species considered marginally susceptible to capture using the ALSC gear and sampling techniques (denoted as $M$ in the above species list); one or more historical surveys with species not caught but consistently reported or sighted

4 = fish species not caught by ALSC; no historical survey data available

$5=$ one or more historical surveys available; species not caught by ALSC but caught in preceding historical survey (excluding lakes that met the criteria for ABSENT $=2$ ) 
6 = two or more historical surveys available; species not caught by ALSC nor in the preceding survey but caught in one or more earlier surveys (excluding lakes that met the criteria for ABSENT $=2$ )

7 = fish species not caught by ALSC; one or more historical surveys available and species never caught (excluding lakes that met the criteria for ABSENT $=3$ )

- Evidence to determine whether the fish population in the lake may be declining, although still present (i.e., declining in abundance but not yet extinct) (DECLIN). If the species was not caught by the ALSC, this variable was left blank. It should be recognized that detecting a trend in fish abundance is extremely difficult given the natural high variability in CPUE as well as the high variability in sampling techniques used for histurical surveys. Thus, the utility of this variable is somewhat questionable. We chose, however, to record this ir.iormation during the data base review, and then to decide at a later date whether or not to include the results for this variable in the summary report. For this variable, the term "survey" includes only those sampling efforts using gear and techniques with a reasonable likelihood of collecting the species and with data recorded on the numbers of fish caught. INote: These codes are grouped according to the type of evidence available and then ordered within that group by increasing evidence for decline.]

$0=$ fish species caught by the ALSC but never collected in any historical fish surveys (or no historical records of numbers of fish caught) (excluding lakes that met the criteria specified for DECLIN $=5$ or 7 )

1 = fish species caught by the ALSC and also caught in one or more historical surveys; no apparent population decline or decrease in the C.PUE (evaluated subjectively to account for differences in sampling techniques in historit:al surveys), i e., all lakes with historical data except those that met the criteria outlined below for STATUS $\geq 2$

2 = only one historical survey available; numbers of fish caught by the ALSC distinctly lower (by at least an order of magnitude for a comparable level of effort) than the number of fish caught during the historical survey

3 = data available from two or more historical surveys; numbers of fish caught by the ALSC (or the ALSC and one preceding survey) distinctly lower (by at least an order of magnitude for a comparable level of effort) than the numbers caught in earlier historical surveys

4 = data available from three or more historical surveys, with a distinct and consistent decline in the numbers of fish caught over time (total change at least an order of magnitude adjusted for approximately comparable levels of effort among surveys)

5 = all fish collected by the ALSC identified by the field biologist as stocked fish; no historical data available for evaluating the presence of nonstocked fish in the past or all historical surveys also collected only stocked fish

6 = all fish collected by the ALSC identified by the field biologist as stocked fish; historical data available to confirm the presence of nonstocked fish in the lake in the past

7 = species of interest generally long-lived (i.e., lake trout, white sucker, or lake whitefish); only very large, old fish collected by the ALSC; no historical survey data available on fish size and/or age, or smaller (young) fish collected in $<50 \%$ of the historical surveys using gear and techniques suitable for the collection of these smaller, younger fish

8 = species of interest generally long-lived (i.e., lake trout, white sucker, or lake whitefish); only very large, old fish collected by the ALSC; smaller (young) fish collected in $\geq 50 \%$ of 
the historical surveys using gear and techniques suitable for the collection of these smaller, younger fish

$9=$ species of interest generally long-lived (i. e., lake trout, white sucker, or lake whitefisti): only very large, old fish collected by the ALSC; smaller (younger) fish collected in two or more historical surveys (and consistently collected in historical surveys using gear and techniques suitable for the collection of these smaller, younger fish); the absence of smaller, younger fish confirmed in recent years in two or more consecutive surveys (including the ALSC) conducted since 1975

- Evidence to determine potential causes for any observed decline or loss of the fish species from the lake. The following list denotes codes used to identify specific conditions observed in the lake based on the ALSC and historical data. Since more than one of these conditions may hold for any given lake, five separate variables were provided for listing up to five of these codes (CAUSE1, CAUSE2, CAUSE3, CAUSE4, CAUSE5). If greater than five conditions applied, a decision was made about which five appeared to be of greatest importance in defining why changes may have occurred in the fish population over time. The five (or fewer) codes selected were recorded in any order; the listing of codes in variables CAUSE1 to CAUSE5 was not intended to imply any order of relative importance.

The list of alternative conditions are grouped into six major categories: reclamation, habitat suitability, biological interactions and indices, beaver, fishing pressure and fishery management practices (other than reclamation and stocking), and stocking. The codes for each condition consist of two digits, the first digit representing the major category within which the described condition belongs. For example, all codes related to reclamation begin with a 1 (11 to 19). Codes related to fish stocking extend from 61 to 79. Multiple codes from a single category of "causes" can be recorded in CAUSE1 to CAUSE5, if applicable.

A code of 99 for any of the variables CAUSE1 to CAUSE2 indicates that the reviewer identified an important condition or possible explanation for population decline that did not match any of the conditions described below. An explanation of this "other" condition was then provided in the species-specific field (COMM; see below).

Reclamation (1)

11 = lake reclaimed in 1975 or before; species not restocked and species never caught or reported since the lake reclamation

12 = lake reclaimed since 1975; species not restocked and species never caught or reported since the lake reclamation

Note: If the species was restocked after the reclamation, or the species was caught or reported after the reclamation, then neither of the above conditions applies.

Habitat Suitability (2)

$20=$ reported winterkill problem

21 = some measurements of dissolved oxygen (DO) below $5 \mathrm{mg} / \mathrm{L}$ (EPA criteria for 7-day mean minimum value for coldwater fisheries) (historically or measured by the ALSC). although no indications of severe or extensive problems with low DO 
$22=$ DO values measured in the deepest waters $\leq 1 \mathrm{mg} / \mathrm{L}$ and/or high proportion of the DO measurements below $5 \mathrm{mg} / \mathrm{L}$ in the late summer in the hypolimnion (or under winter ice cover), suggesting potentially severe problems with low DO

23 = lake relatively small ( $<5$ ha), shallow (mean depth $\leq 5 \mathrm{~m}$ ), and high elevation ( $\geq 500$ $\mathrm{m}$ ) and thus may be subject to periodic freezing and/or winterkill

$24=$ recorded (i.e., noted in the comments written by field biologists) major change in lake level (increase or decrease)

$25=$ recorded (i.e., noted by field biologist in comment field) construction of a new man made or beaver dam on the lake outlet, or fresh beaver activity

26 - major decrease in the amount of open water; lake now heavily chocked with aquatic vegetation or sphagnum; prior surveys exist indicating that less vegetation or sphagnum occurred in the past

$27=$ fish species generally spawns in tributary streams (i.e., white sucker, creek chub, and common shiner); lake reported by ALSC to have no inlets or outlets

$28=$ bog pond with predominately muck substrate

$29=$ marginal bog pond with predominately muck/organic substrate

\section{Biological Interactions and Indicators (3)}

$31=$ yellow perch introduced or appear in the lake coincident with the gradual decline and/or loss of the species

$32=$ other species considered to be potential competitors or predators introduced into the lake coincident with the gradual decline and/or loss of the species (see Table C-2) ${ }^{1}$

$33=$ several species considered potential competitors or heavy predators occurred in the lake (and still occur in the lake); species of interest never present except in small numbers or stocked only

$34=$ species not native to the Adirondacks and introduced into a habitat likely to be marginal, as indicated by the presence of atypical co-habiting species, i.e., specifically smallmouth and largemouth bass populations introduced into lakes dominated by salmonids and only reported or caught in small numbers historically. (Note: these species were often introduced prior to the stocking records included in the available data bases, e.g., in the 1930s.)

$35=$ other species considered equally or more sensitive to acidity than the species of interest also seem to have disappeared from the lake for no obvious reason (other than perhaps acidification) 1

36 = sprecies considered equally or more acid sensitive than the species of interest (see Baker and Christensen, in press) caught in the lake by the ALSC

\footnotetext{
' All estimates of relative species sensitivity to acidity reter to Figure C. 1 from Bakel and Christensen, in press
} 
37 = only species considered more acid tolerant than the species of interest (see Baker and Christensen, in press) caught in the lake in recent years, but at least some fish caught; the presence of these acid-tolerant species may be indicative of reasonable fish habitat.

38 = lake currently fishless (except for those lakes that meet the criteria for code 39)

$39=$ historical survey data available; no fish caught by the ALSC or in historical surveys

Table C-2 Species that May Significantly Compete with or Prey upon the Species of Interest

\begin{tabular}{|c|c|c|c|c|c|c|c|c|c|c|c|c|c|c|c|c|}
\hline \multirow[b]{2}{*}{$\begin{array}{l}\text { Species Considered } \\
\text { Potential } \\
\text { Competitors or } \\
\text { Heavy Predators }\end{array}$} & \multicolumn{16}{|c|}{ Species of Interest } \\
\hline & 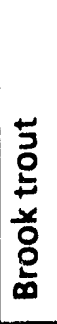 & 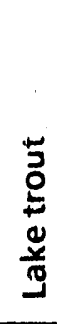 & 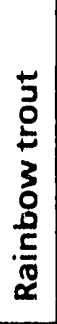 & 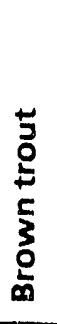 & 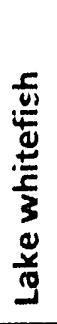 & 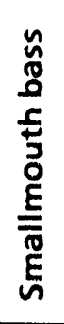 & 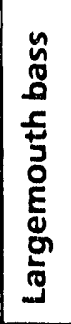 & 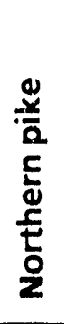 & 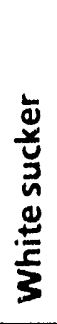 & 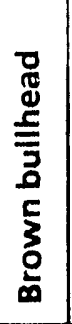 & 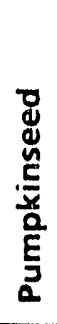 & 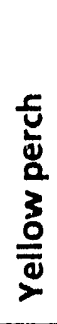 & 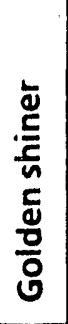 & 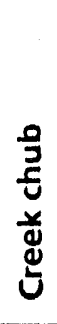 & 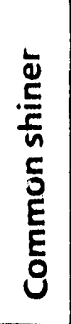 & 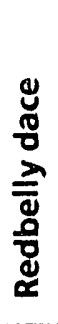 \\
\hline Alewife & & & & & & & & & & & & & $x$ & $x$ & $x$ & $x$ \\
\hline Atlantic salmon & & $x$ & & & $x$ & & & & & & & & & & & \\
\hline Black crappie & & & & & & & & & & & $x$ & & & & & \\
\hline Bluegill & & & & & & & & & & & $x$ & & & & & \\
\hline Brown trout & $x$ & & $x$ & & & & & & & & & $x$ & & & & \\
\hline Chain pickerel & $x$ & & $x$ & $x$ & & & & $x$ & & & & & $x$ & $x$ & $x$ & $x$ \\
\hline Golden shiner & & & & & & & & & & & & & & $x$ & $x$ & $x$ \\
\hline Lake chub & & & & & & & & & & & & & & $x$ & & \\
\hline Largemouth bass & $x$ & & & & & $x$ & & & & & $x$ & & $x$ & $x$ & $x$ & $x$ \\
\hline Northern pike & $x$ & & $x$ & $x$ & & & & & & & & & $x$ & $x$ & $x$ & $x$ \\
\hline Rainbow trout & $x$ & & & & & & & & & & & $x$ & & & & \\
\hline Redbreast sunfish & & & & & & & & & & & $x$ & & & & & \\
\hline Rock bass & & & & & & & & & & & $x$ & & $x$ & & $x$ & $x$ \\
\hline Smallmouth bass & $x$ & & & & & & $x$ & & & & & & $x$ & $x$ & $x$ & $x$ \\
\hline Splake & $x$ & & & & & & & & & & & & & & & \\
\hline Tiger trout & $x$ & & & & & & & & & & & & & & & \\
\hline
\end{tabular}

* Excluding yellow perch 


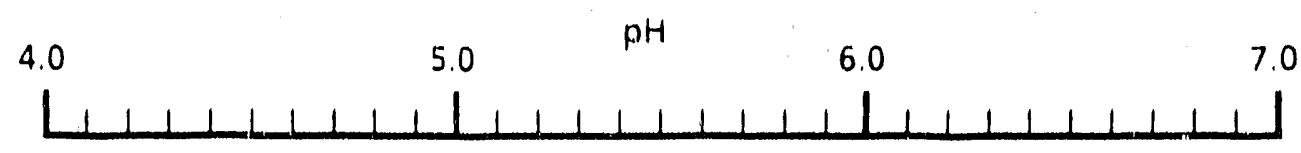

Species

Mudminnow

Yellow perch

Brown bullhead

Pumpkinseed

Largemouth bass

Northern pike

Brook trout

White sucker

Rock bass

Golden shiner
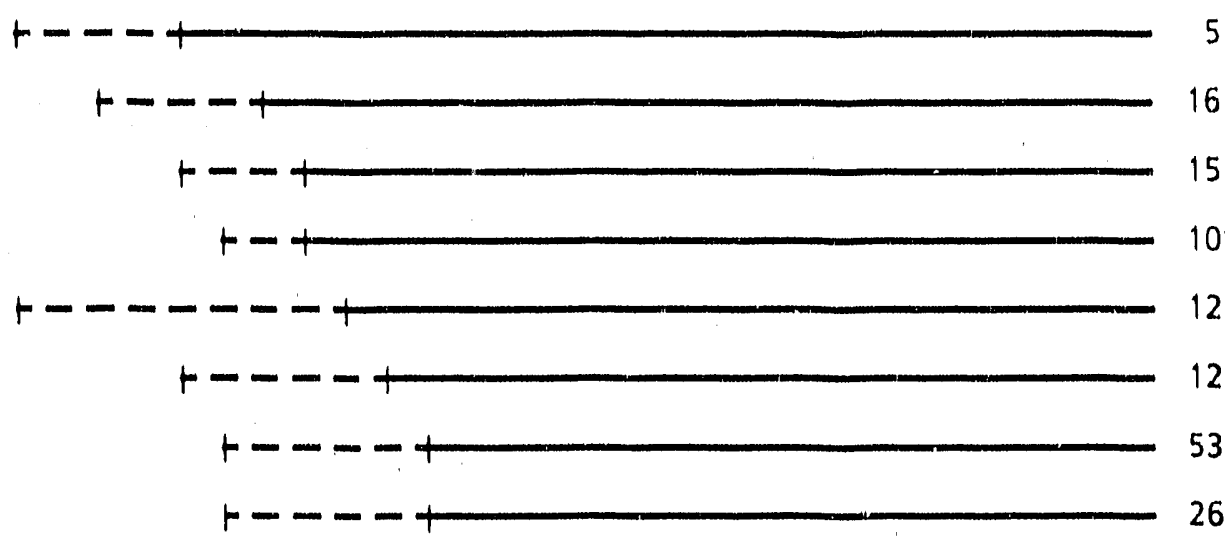

トー- +2

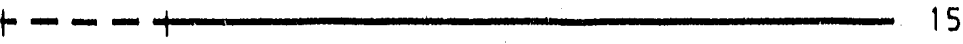

Arctic char

Atlantic salmon

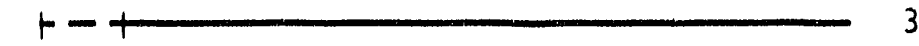

Brown trout
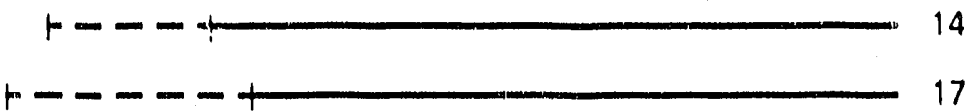

Creek chub

Rainbow trout

Smallmouth bass

Lake trout

Walleye

Redbelly dace

Slimy sculpin

Common shiner

Fathead minnow

Blacknose dace

Bluntnose minnow

Blacknose shiner
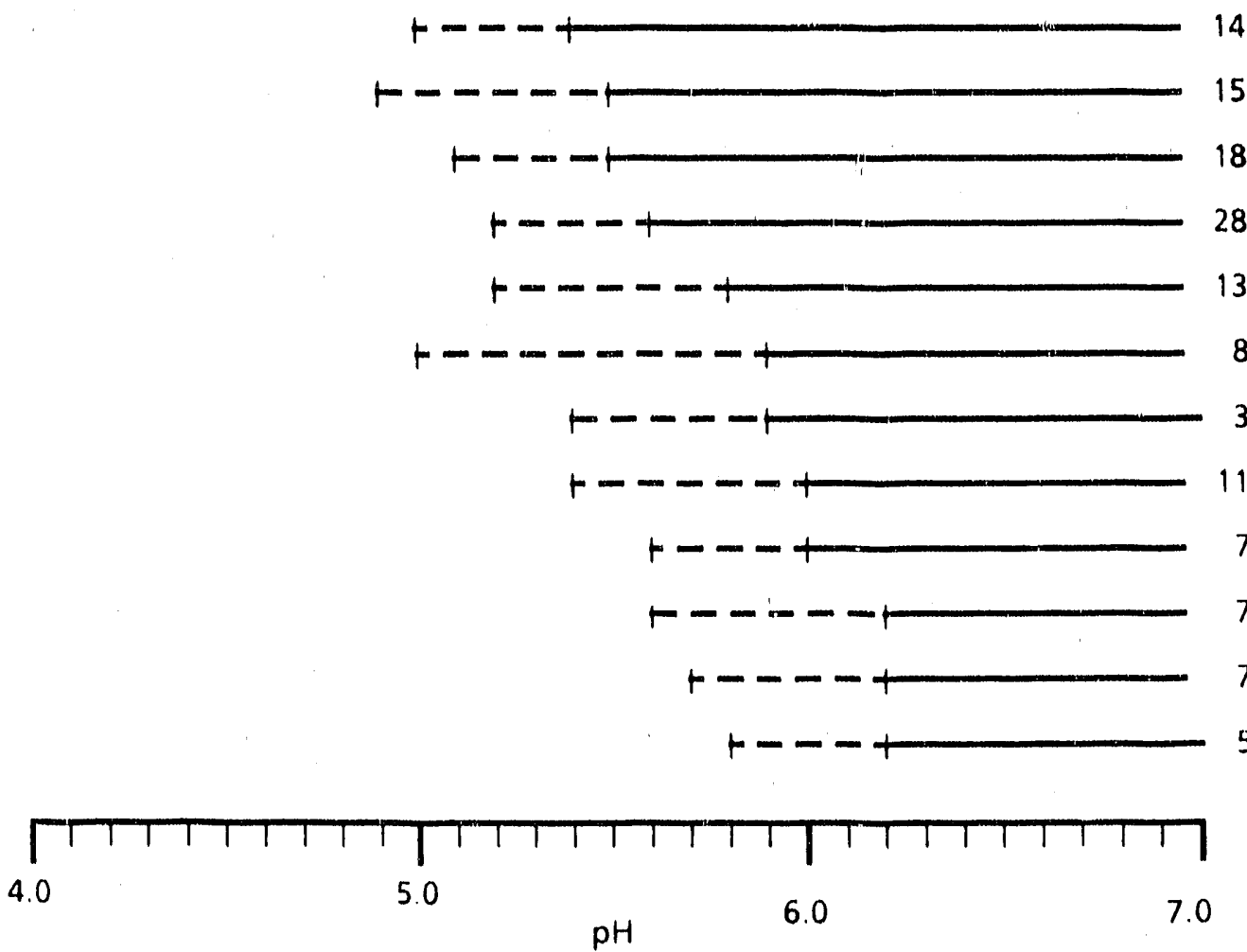

Figure C-1 Estimated "critical" $\mathrm{pH}$ values for effects on fish populations, based on qualitative literature review. Dashed lines reflect the approximate range of uncertainty in the estimated "critical" pH. Number of observations (n) used to derive the estimated "critical" pH noted. Species ranked in order of apparent sensitivity to acidity from least sensitive to most sensitive (Source: Baker and Christensen, in press). 


\section{Beaver.(4)}

$41=$ historical records included comments about adverse effects of beaver on the fish population.

$42=$ heavy beaver activity noted during historical surveys, al though no specific comments about adverse effects on the fish population.

43 = comments were made by ALSC biologists about heavy beaver activity.

44 = ALSC comments about beaver (not heavy)

Note: The ALSC classification of a beaver lake, based on the presence of a beaver dam at the outlet, was also used in data analyses.

\section{Fishing Pressure and Fisheries Managernent (5)}

51 = historical records by field biologist note that the lake was subject to heavy fishing pressure (excluding lakes that met the criteria for CAUSE1 - CAUSE5 $=52$

52 = historical records by field biologist note that the lake was subject to heavy fishing pressure adversely affecting the fish species of interest

53 = historical records by field biologist note other fishery management problems adversely affecting the rish species of interest

\section{Stocking (6-7)}

Note: The following conditions apply only for those species for which some record of stocking occurs in the data base (i.e., stocked in ac least one year) and which were not stocked into the lake in either the year of the ALSC survey or the preceding year. In evaluating these data, we considered the fact that the stocking records available for lakes that are privately owned (as recorded in the ALSC data base) are probably incomplete.

Given the fairly limited historical data available for many lakes, it is often difficult to determine whether stocking was stopped prior to or following an observed decline in the fish population. That is, did the fishery manager stop stocking the lake because of poor returns and a poor survival rate (potentially caused by acidic conditions) or was stocking stopped for other reasons (e.g., reduced availability of fish from the hatchery) leading subsequently to a decline or loss of the species (presuming the population was maintained by stocking with little or no natural reproduction). Two questions are particularly relevant: (1) Did the species occur in the lake prior to the initiation of stocking? (suggesting that the population can reproduce naturally in the lake) and (2) is there recorded evidence of a population decline or loss prior to the cessation of stocking? The first of these questions is addressed by the STOCK variable (described above). The codes defined for CAUSE1 to CAUSE5 focus on the second of these questions. Any interpretation of the degree to which an observed population loss may have been cal ssed by a change in stocking policy requires, therefore, consideration of both the STOCK variable and the stocking codes (61-69) recorded in CAUSE1 to CAUSE5

$61=$ no information available for judging the condition of the population prior to the time when stocking was stopped (i.e., the lake did not meet the criteria outlined for codes 62-67)

$62=$ species caught and reasonably abundant in a survey conducted $\leq 5$ years before stocking was discontinued, or after stocking was stopped 
$63=$ two or more surveys conducted prior to the cessation of stocking, with at least one of these surveys conducted $<5$ years before the end of stocking. Species caught in the survey conducted $<5$ years before stocking was discontinued; however, relatively few fish of the species were caught at that time and the numbers of fish collected in this survey were substantially lower (by an order of magnitude for a comparable effort) than in earlier surveys; or the species was only reported or sighted in the survey conducted prior to the termination of stocking.

$64=$ no survey data available for the 5 years preceding the cessation of stocking. However, species was not included in a listing of species sighted or reported to occur in the lake (based on anectodal data or date from an unknown source) during that time period (i.e., < 5 years before stocking was discontinued).

$65=$ reported decline of the species recorded in comments from the field biologist(s) before stocking was discontinued

66 = the absence of the species confirmed in one survey conducted prior to the cessation of stocking (Note: The species must have been caught or reported in one or more surveys prior to its absence in the catch; see codes $75-77$ for stocking failures.)

$67=$ the absence of the species confirmed in two or more surveys prior to the cessation of stocking (Note: The species must have been caught or reported in one or more surveys prior to its absence in the catch; see codes $75-77$ for stocking failures.)

Additional categories related to fish stocking:

71 = species not native to Adirondack lakes and generally not able to reproduce in Adirondack lakes (i.e., rainbow trout and brown trout). Species maintained by stocking. Stocking was discontinued as a result of change in stocking policy. Species was never caught or reported > about 5 years following the cessation of stocking. Other species (whether stocked or not) are still abundant.

72 = species replacement -- stucking of the species stopped while stacking of another similar species was initiated (e.g. switching from brook trout stocking to brown trout stocking). Following the change in stocking policy, this new species was caught while the original species stocked was not (or was caught only in small numbers). This riew species is considered as or more acid sensitive than the species it replaces.

$73=$ species replacement -- same as for code 72 except that the new species stocked is considered as or more acid tolerant than the species of interest, or there is no available information on the relative acid tolerance of the two species.

74 = stocking discontinued with no evidence for any previous decline in CPUE. Stocking of other species considered more acid sensitive continued successfully (i.e., fish of these species reported or caught in subsequent surveys).

$75=$ species stocked into the lake but never caught. Stocking failure probably a result of community interactions. A number of other species already established in the lake represent potential competitors/predators for the introduced species.

$76=$ species stocked but never caught in the lake. Apparent stocking failure. However, species stocked only once or a few times, or lake not sampled within 5 years of last stocking (to confirm the stocking failure).

$77=$ species stocked for a number of years, but never caught in the lake. Apparent stocking failure confirmed by the absence of the species in one or more surveys conducted no 
later than 5 years after stocking was stopped. No obvious competing or predatory species occur in the lake.

Other (9)

$99=$ other conditions considered important in understanding causes for the fish population decline or loss that do not match any of the conditions specified above. These additional conditions were described in the comment field (COMM).

- Species-specific comments (COMM) regarding possible explanations for any observed decline or population loss that were not adequately described by any of the above precoded conditions; maximum two lines (i.e., 160 characters).

- Summary evaluation of the degree to which an observed fish species declines or loss may be accounted for by the available information on fisheries management practices, physical and chemical characteristics of the lake (excluding information on lake acidity), and the other fish species present in the lake (CAUSE).

$0=$ population healthy; fish species caught by the ALSC and no apparent decline in abundance

1 = obvious explanations for observed loss or decline

2 = likely explanations for loss or decline

$3=$ no obvious alternative explanations (other than perhaps surface water acidification) for the observed fish population loss or decline

$4=$ no apparent alternative explanation and a clear pattern of fish community change that is consistent with expected effects from acidification; several fish species affected

5 = no apparent alternative explanations and a very clear pattern of fish community change that is consistent with experted effects from acidification; all or most fish species lost

$9=$ cannot be determined from available information

\section{Status of Minnows as a Group}

The same set of analyses and variables as outlined above for individual fish species was repeated for potentially sensitive minnow species as a group (defined above in the approach section). The twoletter code used to associate each variable name with the analysis for minnows is MN. Minnows were considered marginally susceptible to the ALSC gear and sampling techniques (sampling M).

\section{Fish Community Status}

All of the background information needed to interpret any observed change in the fisn community as a whole is provided by the species.specific information recorded as described above. In addition, defining detailed criteria for rating fish community changes would be extremely complex given the potential variety of species involved and alternative conditions that may occur. Thus, the fish 
community status rating was a lumped subjective assessment recorded on a scale of 0 to 5

(FISHCOMM). (Note: these codes are listed in ranked order of increasing confidence that a fish community decline has occurred as a result of acidification.] Additional codes (6-9) were also included to denote special circumstances.

$0=$ The commuility appears "healthy." Very few or no change in species composition through time. For lakes with only recent survey data, species richness was high and/or characteristic for lakes in the Adirondacks. Species considered acid-sensitive were present.

1 = One or two species have apparently declined in abundance and/or disappeared from the lake. However, any changes in species composition through time appear random and apparently due to normal fluctuations or fisheries management practices.

$2=$ One or two species have apparently declined in abundance and/or disappeared from the lake. These species were not, however, considered acid sensitive (relative to other species in the lake), and it is unlikely that population declines or losses resulted from acidification. Neither the evidence for loss of populations nor the indications of the potential influence of acidification are particularly strong. A number of populations have maintained constant or increased levels of atundance over time.

3 = Several species have disappeared from the lake for no apparent reason other than perhaps acidification. These species are expected to be acid sensitive relative to the other species remaining in the lake, suggesting the possibility that the community decline may be a result of acidification. Alternatively, all or most fish species have disappeared (e.g., brook trout lost from a brook-trout only lake), although alternative explanations for population loss cannot be completely dismissed.

$4=$ All species or the majority of species have disappeared (for no obvious reason other than perhaps acidification). Any species left are expected to be acid tolerant (e.g., brown bullhead, yellow perch). The absence of most species confirmed by only one sample (i.e., the ALSC survey).

$5=$ All species or the majority of species have disappeared from the lake (for no obvious reason other than perhaps acidification). Any species left are expected to be quite acid tolerant (e.g., brown bullhead, yellow perch, central mudminnow). The absence of most species confirmed by two or more surveys (including the ALSC survey).

$6=$ No fish were ever caught in the lake. No fish were caught by the ALSC and in one or more historical surveys (excluding lakes that met the criteria for FISHCOMM $=7$ or 8 .

$7=$ No fish were ever caught in the lake (i.e., no fish caught by the ALSC and in one or more historical surveys), although fish were stocked into the lake at sometime in the past.

$8=$ No fish were ever caught in the lake (i.e., no fish caught by the ALSC and in one or more historical survey's), although fish were reported to occur historically.

$9=$ None of the above apply; special cases with further explanation provided in the general comments section (COMMENTS; see below) 
- Fish community type relative to potential sensitivity to acidification (FISHTYPE). This variable was used to assist in interpreting the results from the fish community status rating (FISHCOMM) described above. For example, fish communities in small, high elevation lakes may naturally consist of at most two species: brown bullhead and brook trout. If such a lake were acidified, adverse effects on the fish community may not occur until around $\mathrm{pH} 5.0$, given the relative acid tolerance of these two species. Other types of fish communities, with species more sensitive to acidity, may experience significant declines at much higher $\mathrm{pH}$ levels. Thus, in evaluating the relationship between the FISHCOMM variable and current water chemistry, it may be useful to know what types of fish species occurred historically in the lake. Fish species that have been lost from the lake clearly as a result of factors not related to acidification (e.g., reclamation) were not considered in defining FISHTYPE.

$1=$ only' species known to be acid tolerant ever caught, reported, sighted, or stocked into the lake, i.e., brown bullhead, yellow perch, and central mudminnow

2 = only species considered to be fairly acid tolerant ever caught, reported, sighted, or stocked into the lake (i.e., the species listed for FISHTYPE $=1$ plus brook trout and northern pike)

3 = only species considered to be fairly acid tolerant or moderately acid tolerant ever caught, reported, or sighted (e.g., the species listed for FISHTYPE $=1$ or 2 plus largemouth bass, white sucker, pumpkinseed sunfish, rock bass, golden shiner, and lake chub)

4 = some species considered to be moderately acid sensitive caught, reported, or sighted at some time in the lake (e.g., creek chub, brown trout, rainbow trout, lake trout, smallmouth bass)

5 = some species considered to be fairly acid sensitive caught, reported, sighted at some time in the lake (i.e., the minnow species identified above as potentially acid sensitive)

- General comments related to the fish community arsessment (maximum 5 lines) (COMMENTS) 


\section{APPENDIX C - REFERENCES}

Baker, J.P., and S.W. Christensen. In press. Effects of acidification on biological communities in aquatic ecosystems In; Acid Deposition and Aquatic Ecosystems: Regional Case Studies.

Baker, J.P., and T.B. Harvey. 1984. Critique of Acid Lakes and Fish Population Status in the Adirondack Region of New York State. EPA-600/3-86-046, Final Report to the U.S. Environmental Protection Agency, Washington, DC

Baker, J.P., C.S. Creager, W. Warren-Hicks, S.W. Christensen, arid L. Godbout. 1988. Identification of Critical Values for Effects of Acidification on Fish Populations, Final Report to U.S. Environmental Protection Agency, Washington, DC.

Kieinbaum, D., and L. Kupper. 1978. Applied Regression Analysis and Other Multivariate Methods. Duxbury Press, Boston, MA.

Mills, K.H., and D.W. Schindler. 1986. Biological indicators of lake acidification. Water, Air, and Soil Pollut. 30:779-790.

Snedecor, G. and W. Cochran. 1976. Statistical Methods. lowa State University Press, Ames. 
APPENDIX D

Comparison of Assessments of Historical Changes in Fish Communities 


\section{APPENDIX D \\ COMPARISON OF ASSESSMENTS OF HISTORICAL CHANGES IN FISH COMMUNITIES}

\section{J. Baker and J. Gallagher}

J. Baker and J. Gallagher independently evaluated 74 lakes. The results from these independent assessments are compared in Tables D-1 to D-3 for ratings of PAST, ABSENT, and CAUSE for all fish species combined and in Table D-4 for ratings of fish community status. The agreement between these two assessments was, in general, less than desired. For example, the percentage of populations/communities assigned equal ratings in the two assessments was $65 \%$ for PAST, $91 \%$ for ABSENT, $84 \%$ for CAUSE, and $57 \%$ for fish community status. Comparisons were also made after grouping the ratings for $A B S E N T, C A U S E$, and fish community status into the categories used during data analyses: (1) ABSENT $=0$ versus $A B S E N T>3 ;(2)$ CAUSE $=0-2$ versus CAUSE $=3-5$; and (3) fish community status ratings of 0-2 versus 3-5. The percent agreement between J. Baker and J. Gallagher was $100 \%, 94 \%$, and $83 \%$ for the grouped ratings of ABSENT, CAUSE, and fish community status, respectively. Of the 124 fish populations rated by J. Baker as PAST $=8$ or $9,111(90 \%)$ were also rated as PAST $=8$ or 9 by J. Gallagher.

Several fastors may at least partially explain the relatively poor agreement between these two assessments:

- Given the complexity of the instructions for conducting the fish community evaluations, substantial training time may be needed to absorb all of the nuances and specifics of the individual rating values.

- In general, J. Gallagher relied more heavily on the original survey forms at Ray Brook to resolve apparent discrepancies between the FIN and NYSDEC historical data bases, while J. Baker relied principally on the NYSDEC data base.

- J. Gallagher tended to include in the rating of CAUSE uncertainties related to both the evidence for fish population loss and the explanation for the loss, while J. Baker considered only uncertainties related to the probable cause for observed losses (uncertainties regarding the evidence for fish population loss were incorporated within the PAST and ABSENT variables). 
Table D-1 Independent Evaluations of the Variable PAST for 74 Lakes

\begin{tabular}{|c|c|c|c|c|c|c|c|c|c|c|}
\hline \multirow{2}{*}{ Value } & \multicolumn{10}{|c|}{ J. Gallagher } \\
\hline & 0 & 2 & 3 & 4 & 5 & 6 & 7 & 8 & 9 & Total \\
\hline 0 & 22 & 0 & 0 & 0 & 0 & 0 & 0 & 0 & 0 & 22 \\
\hline 2 & 12 & 0 & 0 & 0 & 0 & 0 & 0 & 0 & 0 & 12 \\
\hline 3 & 1 & 0 & 3 & 0 & 0 & 0 & 0 & 1 & 0 & 5 \\
\hline 4 & 4 & 0 & 1 & 4 & 0 & 0 & 0 & 0 & 6 & 15 \\
\hline 5 & 4 & 0 & 1 & 2 & 0 & 0 & 0 & 0 & 0 & 7 \\
\hline 6 & 0 & 0 & 0 & 0 & 0 & 0 & 0 & 0 & 0 & 0 \\
\hline 7 & 0 & 0 & 0 & 1 & 0 & 1 & 0 & 0 & 0 & 2 \\
\hline 8 & 4 & 0 & 0 & 1 & 0 & 0 & 0 & 14 & 14 & 33 \\
\hline 9 & 6 & 0 & 1 & 1 & 0 & 0 & 0 & 5 & 78 & 91 \\
\hline Total & 53 & 0 & 6 & 9 & 0 & 1 & 0 & 20 & 98 & 187 \\
\hline
\end{tabular}

Table D-2 Independent Evaluations of the Variable ABSENT for 74 Lakes

\begin{tabular}{cccccccc}
\hline \multirow{2}{*}{ Value } & \multicolumn{7}{c}{ J. Gallagher } \\
\cline { 2 - 7 } & 0 & 2 & 4 & 5 & 6 & 7 & Total \\
\hline 0 & 143 & 0 & 0 & 0 & 1 & 0 & 144 \\
2 & 0 & 0 & 0 & 0 & 0 & 0 & 0 \\
4 & 0 & 0 & 2 & 0 & 0 & 0 & 2 \\
5 & 1 & 1 & 0 & 14 & 2 & 0 & 18 \\
6 & 1 & 0 & 2 & 3 & 7 & 1 & 14 \\
7 & 1 & 0 & 1 & 1 & 2 & 4 & 9 \\
\hline Total & 146 & 1 & 5 & 18 & 12 & 5 & 187 \\
\hline
\end{tabular}


Table D-3 Independent Evaluations of the Variable CAUSE for 74 Lakes

\begin{tabular}{ccccccc}
\hline \multirow{2}{*}{ Value } & \multicolumn{7}{c}{ J. Gallagher } \\
\cline { 2 - 7 } & 0 & 1 & 2 & 3 & 4 & Total \\
\hline 0 & 138 & 0 & 1 & 0 & 0 & 139 \\
1 & 4 & 5 & 9 & 0 & 0 & 18 \\
2 & 2 & 0 & 11 & 1 & 0 & 14 \\
3 & 3 & 0 & 8 & 3 & 0 & 14 \\
4 & 0 & 0 & 0 & 1 & 0 & 1 \\
\hline Total & 147 & 5 & 29 & 5 & 0 & 186 \\
\hline
\end{tabular}

Table D-4 Independent Evaluations of the Fish Community Status for 74 Lakes

\begin{tabular}{ccccccccc}
\hline \multirow{2}{*}{ Value } & \multicolumn{7}{c}{ J. Gallagher } \\
\cline { 2 - 9 } & 0 & 1 & 2 & 3 & 6 & 7 & 9 & Total \\
\hline 0 & 13 & 0 & 0 & 0 & 0 & 0 & 0 & 13 \\
1 & 4 & 7 & 0 & 0 & 0 & 0 & 0 & 11 \\
2 & 1 & 4 & 1 & 0 & 0 & 0 & 0 & 6 \\
3 & 1 & 2 & 4 & 2 & 0 & 0 & 1 & 10 \\
6 & 0 & 0 & 0 & 0 & 4 & 0 & 5 & 9 \\
7 & 0 & 0 & 0 & 0 & 0 & 1 & 0 & 1 \\
9 & 1 & 0 & 0 & 0 & 0 & 0 & 2 & 3 \\
\hline Total & 20 & 13 & 5 & 2 & 4 & 1 & 8 & 53 \\
\hline
\end{tabular}



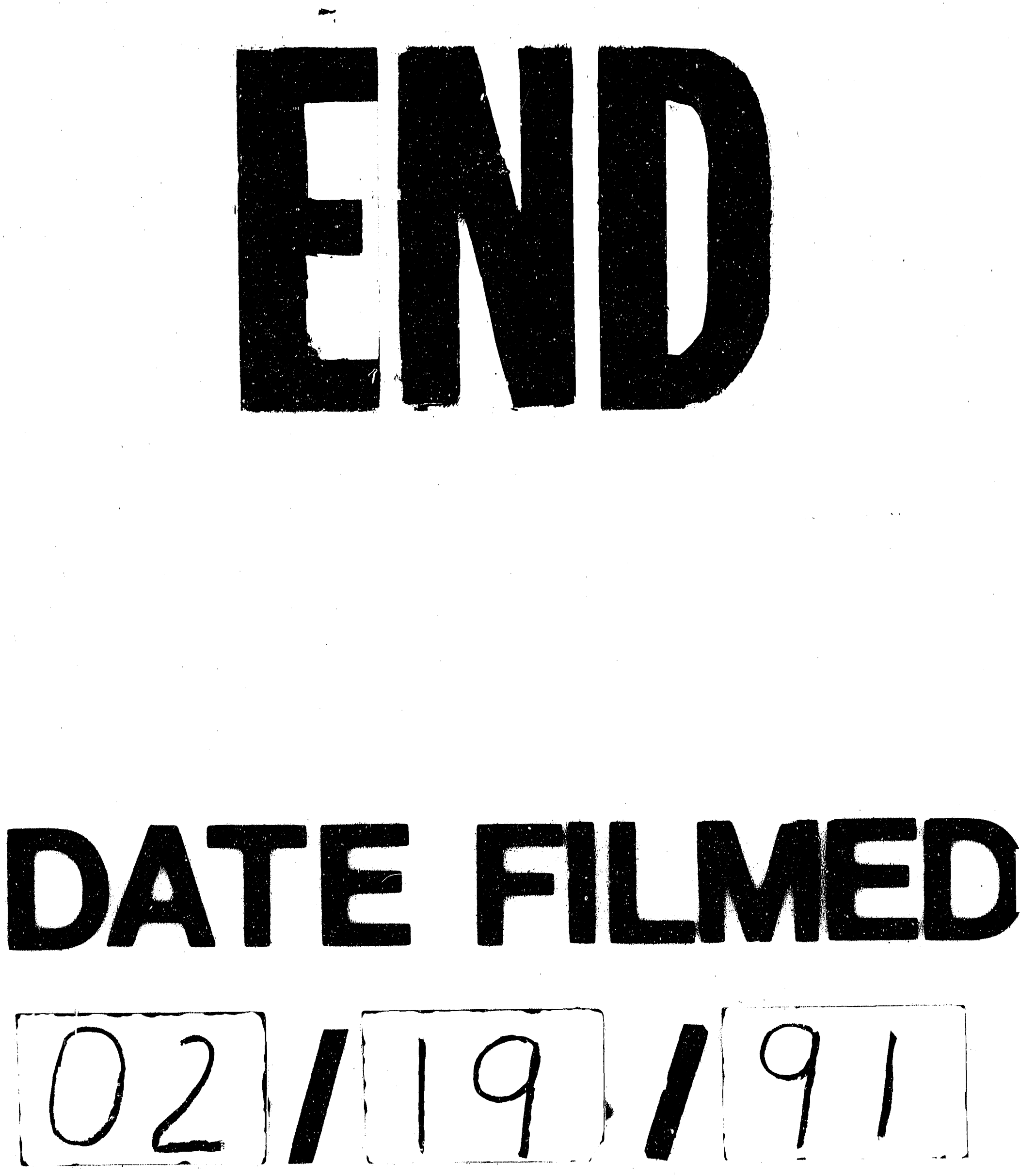
